SILESIAN UNIVERSITY OF TECHNOLOGY SCIENTIFIC PAPERS

\title{
ORGANIZATION AND MANAGEMENT
}

Scientific paper no. 150

MODERNITY OF INDUSTRY AND SCIENCES

Edited by

Jan PYKA

Radoslaw WOLNIAK

Bożena SKOTNICKA-ZASADZIEŃ 
Kolegium redakcyjne

REDAKTOR NACZELNY - Prof. dr hab. inż. Andrzej BUCHACZ

REDAKTOR DZIAŁU - Prof. dr hab. inż. Radosław WOLNIAK

Druk z materiałów przygotowanych przez autorów

Redakcja Wydawnictwa nie odpowiada za stronę językową i treść artykułów

Wydano za zgodą

Rektora Politechniki Śląskiej

ISSN 1641-3466

(C) Copyright by

Wydawnictwo Politechniki Śląskiej

Gliwice 2021

\section{WYDAWNICTWO POLITECHNIKI ŚLĄSKIEJ}

ul. Akademicka 5, 44-100 Gliwice

tel. (32) 237-13-81, faks (32) 237-15-02

www.wydawnictwopolitechniki.pl

Sprzedaż i Marketing

tel. (32) 237-18-48

wydawnictwo_mark@polsl.pl 


\section{CONTENTS}

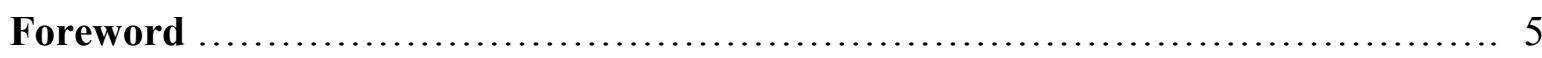

1. Pawel BELCH - Management of a transport company during the Covid-19

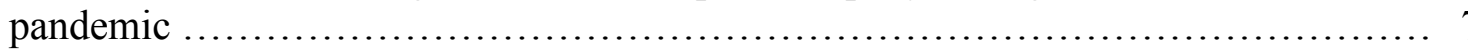

2. Agnieszka DZIUBIŃSKA - Is acting on emerging markets environment a challenge of the unknown? The answer from complexity theory perspective $\ldots \ldots \ldots \ldots \ldots \ldots \ldots \ldots$. 17

3. Adam JANISZEWSKI - Organizational responses to sustainable development challenges - conditions \& consequences

4. Szymon JOPKIEWICZ, Agata JOPKIEWICZ - Innovations in the dimension of communication in health sector and the perspective of Society 5.0

5. Kamil KARSKI - Selected applications of the blockchain network in the Economy 4.0

6. Izabela KONIECZNA - Features of the offer in the distribution area. Comparative analysis on the example of dairy cooperatives in the Małopolskie and Świętokrzyskie voivodeships

7. Teresa KRAŚNICKA - Innovation of Polish family and non-family businesses

8. Agnieszka KRAWCZYK-SOLTYS - Professional competencies in shaping the organizational competences of Polish Emergency Medical Units in the light of survey research

9. Agnieszka KUŚ - Inefficiency in spectrum auctions - empirical evidence

10. Adrianna MASTALERZ-KODZIS - Quantitative analysis of the economic potential on the example of the Upper Silesian Metropolis

11. Rafal MATWIEJCZUK - The premises of the evolution and development of firm competences in strategic management

12. Monika MIŚKIEWICZ-NAWROCKA - The application of Czekanowski diagram to assess the financial situation of non-financial enterprises in Poland in the years $2010-2020$

13. Elżbieta PAWLOWSKA, Pawel WITKOWSKI, Paulina TRYBUS -

Mediation as an innovative dispute resolution tool based on the example of public organizations

14. Iwona PISZ - Impact Covid-19 pandemic on implementation Industry 4.0 in enterprises and supply chains

15. Ewa POŚPIECH - Comparison of profits of effective portfolios with non-effective portfolios taking into account the fuzzy approach

16. Agnieszka PUTO - Opinions of Polish students on the need for the transition to distance learning when facing the global pandemic Covid-19

17. Marlena SMUDA-KOCOŃ - Framework of contradictions shaping bank management: a conceptual paper 
18. Dorota SOBOL, Aleksandra PIETRZAK - Effectiveness evaluation of the communication process with employees on the example of the Kaufland Poland branch

19. Izabela STEINEROWSKA-STREB - Internationalization of Polish enterprises. A comparative analysis of family and non-family businesses

20. Pawel SZEWCZYK - Mangement of blockchain based digital assets in industry and services

21. Dobrochna SZTAJERSKA, Marcin BOGDAŃSKI - Improvement of maintenance process in a coal mine - case study

22. Piotr TWOREK, Józef MYRCZEK - Risk management in construction enterprises in Śląskie and Małopolskie voivodships in Poland

23. Roman TYLŻANOWSKI - Creativity as the main determinant of implementing frugal innovations in enterprises

24. Jerzy WACCHOL - Global environment as a factor of changes in organization and modern management concepts

25. Marta WIĄCEK - The impact of relations with stakeholders on change management, innovation and competitiveness of the organization on the example of the current economic situation of enterprises in Poland

26. Dariusz WYRWA - Research methods and techniques applied during preparation of regional innovation strategies of Polish regions

27. Katarzyna ZEUG-ŻEBRO - Spatial modeling of investment activity of enterprises in service sector

28. Katarzyna $\dot{\mathbf{Z}} \mathbf{A K}$ - Implementation of the green governance concept and green management practices in corporations of EBRD regions - selected issues 


\section{FOREWORD}

Presented number of Silesian University of Technology. Scientific Papers. Organization and Management Series concentrate on various aspects of contemporary management. The number contains results of researches of scientist from various Polish Universities. The number consists of 28 papers.

The papers presented in the number concentrate on many topics connected with organization and management. Authors in his papers concentrate problems connected with: logistic, the impact of pandemic COVID-19 on various aspects of management, marketing, Industry 4.0 and Society 5.0, innovativeness in business activities, human resources management, methods and tools of management, international management and environmental management.

Jan Pyka

Radostaw Wolniak

Bożena Skotnicka-Zasadzień 



\title{
MANAGEMENT OF A TRANSPORT COMPANY DURING THE COVID-19 PANDEMIC
}

\author{
Paweł BEŁCH \\ Rzeszow University of Technology, Faculty of Management, Department of Management Systems \\ and Logistics, Poland; p.belch@prz.edu.pl, ORCID: 0000-0003-0818-5284
}

\begin{abstract}
Purpose: The end of the first quarter of 2020 is the beginning of a new, difficult time in the functioning of transport companies, as well as the entire Polish and world economy. The appearance of Covid-19 (SARS-CoV-2) resulted in a number of market restrictions and a sharp decline in transport orders. Enterprises had to change the way they were managed and operated, had to adapt to a different economic reality in order to continue to prosper. The aim of the article is to define the essence of managing a transport company in the new market and economic conditions that appeared during the Covid-19 pandemic.
\end{abstract}

Design/methodology/approach: The research procedure included review of polish and foreign literature, analysis of legal acts, questionnaire research, analysis of the content of internal documents of transport companies, method of analysis and synthesis, case study, methods of inductive and deductive reasoning. The article presents the results of scientific research on the impact of Covid-19 on the management and decisions made in a transport company.

Findings: The high level of impact of the Covid-19 pandemic on the management of a transport company has been demonstrated. The factor that most influenced the management and decisions of transport companies is the decline or fear of a decline in contracts for transport services. Transport companies are afraid of the further negative effects of the pandemic, and therefore do not want to take out investment loans in order to develop the company. The article discusses the activities of transport companies and the management of a transport company in crisis conditions.

Research limitations/implications: The article presents a survey carried out in Polish transport companies from the Podkarpackie and Lubelskie voivodships. Therefore, the research results concern the area of south-eastern Poland.

Practical implications: The results of the research may be helpful for managers of transport companies (management decisions made) in order to limit the negative impact of the Covid-19 pandemic on their business activities.

Originality/value: The presented research and conclusions provide practical guidance to managers about what decisions and actions can improve the economic condition of their transport companies in the difficult period of the Covid-19 pandemic, based on the example of the analyzed transport companies.

Keywords: business management, transport company, Covid-19 pandemic, crisis.

Category of the paper: research paper. 


\section{Introduction}

Business management is a set of decisions and activities, very complex and difficult, which is to ensure the proper functioning of the enterprise and generate profit from its activities. A transport company provides services that consist of the commercial transport of people or goods. Transport is one of the most important industries that has a significant contribution to the development of the economy of each country, including Poland. Carriers support the operation of industry and the manufacturing sector, they also increase the level of Gross Domestic Product (GDP). The dynamic development of the TSL (Transport - Forwarding Logistics) industry, which has taken place in recent years, has been very limited since March 2020. The reason for this slowdown is the emergence of the global Covid-19 epidemic (SARS-CoV-2). The restrictions and restrictions introduced in order to fight the coronavirus resulted in a significant decrease in demand for the transport services provided. In this difficult period for entrepreneurs, the management of a transport company gained particular importance. Managers of transport companies had to modify the current and strategic management of the enterprise and adapt it to the new economic conditions. The actions taken were necessary and necessary, they were aimed at restructuring the enterprise, reducing operating costs and reducing expenses. Transport companies had to start to function more efficiently and more efficiently to continue to generate income and prosper in the market, to survive this very difficult period in their history, which it is not known when it will realistically end. The proper management of a transport company is a very difficult task for any manager, especially in this new and uncertain time of the Covid-19 epidemic.

\section{Activities of transport companies}

Transport as a branch of the national economy has a significant impact on its development, in every segment of material production and services. All types of economic activities are related to transport, by transporting people to specific destinations, distribution of products and services, as well as raw materials and materials necessary for the production. Therefore, it contributes to the generation of national income, influencing the dynamics of the production development of enterprises and guaranteeing the implementation of trade in goods (Bełch, 2019). Transport activity is a broad concept, covering many activities thanks to which the cargo will reach from the place of origin to its destination. It is difficult to imagine the world economy, especially in the period of its globalization, without the dense network of transport routes and connections that allow producers, exporters and importers to freely conclude contracts, regardless of where the goods are located and where their future owner is. Those regions of the 
world that do not have roads and transport points cannot take part in international trade and industrial cooperation. Commercial transport activity consists in the provision of transport services, i.e. the paid transport of people or goods and the provision of additional services directly related to it (Neider, 2015). The importance of transport in the economy is constantly growing. This is due to processes such as: specialization and division of labor, competition in the market, pressure to reduce costs, economies of scale of production, mass consumption, development of cooperation, striving to improve customer service and shortening the life cycle of products (Długosz, 2009).

Running a transport company is a challenge that comes with a lot of planning and proper logistics, especially when it comes to international transport. A modern transport company has to cope with many modern tasks. They result from the variety of services provided and the need to regulate the level of prices for these services. However, the greatest importance is attached to ensuring the quality of transport services. This is related to the known paradox between the choice of quality and the price of activities in the transport sector (Gołembska, 2020). A transport company should implement modern equipment and means of transport into its activities. It is a requirement of increasing competition and the rapid development of digitization and robotics in connection with the next industrial revolution, which is referred to as "Industry 4.0". This has a large impact on the ongoing changes in the global economic system, including transport (Strandhagen et al., 2017). The use of intelligent technologies allows for the design of new and more efficient transport processes, products and services (Lee et al., 2015; Hirsch-Kreinsen, 2016). One of the basic factors that determine transport accessibility is also a modern transport infrastructure (Dijkstra, Annoni, Kozovska, 2011).

Each company must define its position on the market of transport services against the competition, and above all (Rosa, 2013; Marecki, Wieloch, 2008):

- identify competitors and assess their strength and threat which they pose or may pose to a given company in the future,

- determine what situation on the market (in the economy) will favor the expansion of other entities.

The transport services market is a comprehensively analyzed and complex issue. It is shaped by the relations between supply and demand, taking into account a specific price level. The transport company must constantly adapt its activities to changing environmental conditions. It should constantly research and analyze the market on which it is located, both in relation to the changes taking place there, and to the relationship of the transport services market with the environment. 


\section{Management of a transport company in crisis conditions}

The year 2020 brought with it many new, unforeseen events related to the emergence of the global Covid-19 pandemic. It is a very hard and difficult period for the world economy, as well as for individual countries and enterprises. The Covid-19 virus not only stopped the development of transport companies, but also prevented their current functioning for several months. In order to survive, transport companies had to learn to function in the new, difficult reality, managers had to learn to manage a transport company in a crisis.

Crisis management is the process of planning and taking actions aimed at reducing the risk associated with the emergence of a crisis or crisis, taking control of the crisis and returning to the pre-crisis state (Grocki, 2020). Of course, the course of the crisis caused by Covid-19 was not significantly influenced by the individual company, but proper management should minimize the negative impact of the crisis on the functioning of the company. The content of the elements of the crisis management model determines the area of crisis management. It mainly concerns such elements as: goal, idea, methods, participants, area (Langinvainio, 2006). K. Fearn-Banks (2007) defines crisis management as a process that minimizes the risk and the degree of uncertainty associated with the occurrence of an adverse event, and thus allows for increasing control over activities related to the fate of the enterprise. New business planning should include a response plan to known events, but you should also be prepared for events whose size and nature cannot be assessed in advance. Changes in the company are also required by the way the team works, which prepares decisions during crisis situations. The management team must have the ability to achieve situational awareness and flexibly select task modules to new crisis conditions (Skomra, 2020). In the case of Covid-19, the situation of transport companies has become very tough and their future uncertain. State authorities, in order to limit the spread of the epidemic, introduced a number of severe restrictions, as a result of which, inter alia, schools, state offices, restaurants, state borders were closed, mass events were canceled, and contact between people was limited to a minimum. This resulted in a significant decrease in demand for transport services. It was possible to observe the occurrence of the logical correlation which is the most difficult to detect. It is the interdependence between the various types of critical infrastructure and between it and the administration. They interact with each other without any physical, digital or geographic connection (Rinaldi, Peerenboom, $\&$ Kelly, 2001). Logical correlations are the most difficult to detect and therefore are often not taken into account at the stage of risk assessment and response planning. Another example of this correlation is the 2009 epidemic of influenza A (H1N1) in Mexico, where restrictions on the spread of the epidemic were not as expected (Lee et al., 2010; Chowell et al., 2011). By managing a transport company in a market economy, the owner strives to achieve certain goals. One of the primary goals is profit, which should exist not only on paper but also on hand. In order to be able to earn a profit, it is necessary to take care of, among others o systematic reduction of operating costs of own business (Sikorski, 2008). Managing a transport company in crisis conditions is a set of activities and decisions, non-standard and uncertain, that are taken 
by a manager in particularly difficult economic conditions and market environment. That is why reasonable and effective management of a transport company, in the conditions of crisis and with constantly growing competition, is so important in the context of the current operation and achievement of the set business goals.

\section{Covid-19 and management of a transport company - the results of empirical research}

In order to determine the impact of the Covid-19 pandemic on the management of a transport company, surveys were carried out in Polish enterprises from the Podkarpackie and Lubelskie voivodships that conduct transport activities. The project of empirical research aimed at the implementation of the assumed goal of the article and the verification of the formulated hypothesis required the use of various research instruments. Therefore, a questionnaire and a case study were used. The first stage is a pilot study that was conducted on the basis of a questionnaire survey on a sample of 6 companies. Thanks to this study, the research tool was verified and methodological information was obtained that improved the course of the research process. The next stage included questionnaire research, which was essential for identifying the research areas in the author's area of interest. The questionnaires were completed in the period August-September 2020 by decision-makers in the surveyed transport companies (owner, president, director - CEO, manager), who deal with management on a daily basis. Questionnaires with cover letters were sent to 64 companies. The group (research sample) was selected in a non-random, purposeful manner. Finally, completed questionnaires were obtained from 19 companies, which gives a response rate of $29.7 \%$. The most important research results are presented in Figures 1 and 2 and Table 1.

In the first part of the survey, respondents answered the general question: "What is the level of impact of the Covid-19 pandemic on the management of your transport company"?

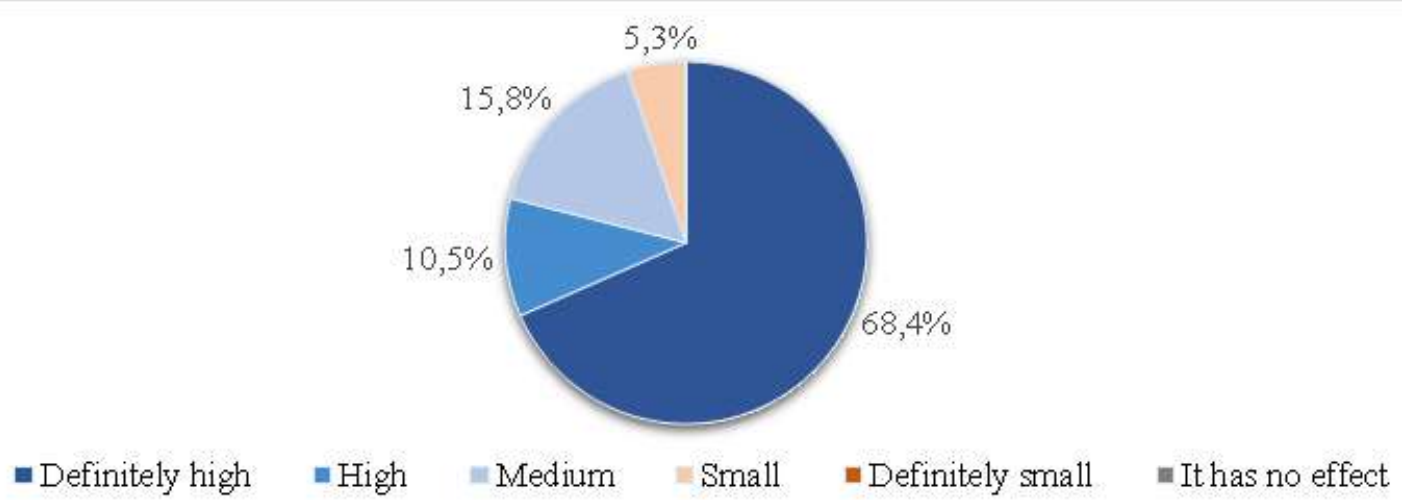

Figure 1. The level of Covid-19 impact on the management of a transportation company. Source: own study. 
$68.4 \%$ of the surveyed companies assess the level of the impact of the Covid-19 pandemic on the management of their transport company as definitely high (Figure 1), 10.5\% indicate the level of this impact as high, another $15.8 \%$ of the respondents described the level of the impact as medium, while only $5.3 \%$ ( 1 enterprise) believe that it is small. There was no answer about a definitely small level, as well as the respondents did not answer about the lack of the described impact. It follows that in total as many as $78.9 \%$ - 15 out of 19 surveyed enterprises perceive a high level of Covid-19 impact on the management of their transport company. The responses presented show that Covid-19 has a very large impact on the management of transport enterprises, it has a strong influence on them.

The next figure (Figure 2) presents the 4 most frequently indicated factors related to the Covid-19 pandemic situation, which, according to the respondents, had the greatest impact on the management and decisions (operational, tactical, strategic) in the surveyed transport companies.

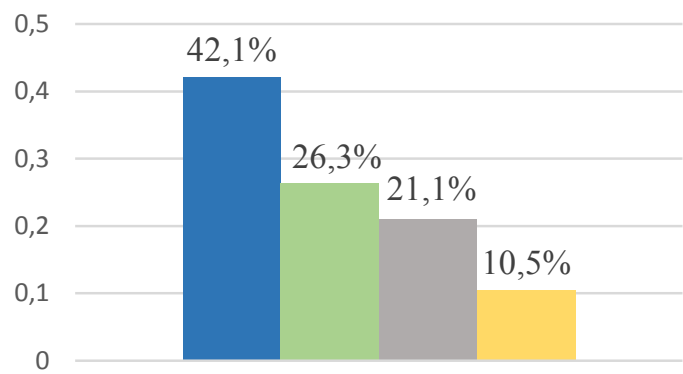

\footnotetext{
Decline or fear of a decline in transportation contracts

Losing customers to competing companies

Fear of reducing employment (dismissal of employees)

The risk of moving experienced employees (drivers) to another enterprise
}

Figure 2. Factors related to the situation of the Covid-19 pandemic that most influenced the management and decisions made in a transport company. Source: own study.

According to the opinion of respondents (Figure 2), the factor related to the Covid-19 pandemic situation that had the greatest impact on the management and decisions made in their transport company was the decline or fear of a decline in contracts for transport services (42.1\% of responses out of four with the greatest weight).

Below (Table 1) there are management decisions taken in the surveyed companies in order to limit the negative impact of the Covid-19 pandemic on their transport activities (in the period: March-August 2020). 
Table 1.

Management decisions taken to reduce the negative impact of the Covid-19 pandemic on transport activities

\begin{tabular}{|c|c|c|}
\hline Management decisions & $\begin{array}{l}\text { Number of } \\
\text { enterprises } \\
\text { (out of } 19 \\
\text { surveyed) } \\
\end{array}$ & Percentage \\
\hline $\begin{array}{l}\text { Ongoing familiarization with reliable sources of information about Covid-19, } \\
\text { i.e. governmental reports and relevant institutions, e.g. the Chief Sanitary } \\
\text { Inspector }\end{array}$ & 19 & $100 \%$ \\
\hline Obtaining funds from the government program "Anti-crisis shield" & 19 & $100 \%$ \\
\hline $\begin{array}{l}\text { Optimization (reduction) of operating costs, price negotiations with suppliers, } \\
\text { changing suppliers of goods and services, incl. cheaper fuel and spare parts for } \\
\text { vehicles, lower utility charges (change of operator), reduction of necessary } \\
\text { personnel and office expenses }\end{array}$ & 19 & $100 \%$ \\
\hline The strategy of continuous acquisition of new customers & 19 & $100 \%$ \\
\hline A more detailed (in-depth) analysis of the financial situation of contractors & 18 & $94,7 \%$ \\
\hline Suspension of investment plans, enterprise development & 17 & $89,5 \%$ \\
\hline $\begin{array}{l}\text { Increasing the group of service subcontractors and business contacts (greater } \\
\text { choice) }\end{array}$ & 16 & $84,2 \%$ \\
\hline Lowering prices for provided transport services & 16 & $84,2 \%$ \\
\hline Introducing remote work and similar forms of work for some employees & 14 & $73,7 \%$ \\
\hline Lowering the salary of employees & 14 & $73,7 \%$ \\
\hline Shortening the deferred payment deadline for provided transport services & 12 & $63,2 \%$ \\
\hline Reduction of employment (layoffs of drivers) & 10 & $52,6 \%$ \\
\hline Taking a working capital loan for current business activity & 7 & $36,8 \%$ \\
\hline Appointment of the anti-crisis staff in the company during the pandemic & 7 & $36,8 \%$ \\
\hline Taking a short-term loan in the current account & 5 & $26,3 \%$ \\
\hline Sale of trucks and other fixed assets in order to obtain additional funds & 5 & $26,3 \%$ \\
\hline Obtaining external funds from local and European funds & 5 & $26,3 \%$ \\
\hline Using the help of external managers & 3 & $15,8 \%$ \\
\hline $\begin{array}{l}\text { Advertising of transport services in the press, local television, } \\
\text { on billboards and leaflets }\end{array}$ & 2 & $10,5 \%$ \\
\hline Taking out an investment loan & 1 & $5,3 \%$ \\
\hline
\end{tabular}

Source: own study.

In all surveyed companies (100\%) decisions were made that concerned the current access to reliable sources of information about Covid-19, optimization (reduction) of operating costs, price negotiations with suppliers, obtaining funds from the government program "Anti-crisis shield", as well as a strategy of continuous acquisition of new customers (to support the declining demand for transport services). Only in one surveyed transport company a decision was made to take out an investment loan, which indicates that enterprises are afraid of an uncertain economic future and decided to suspend investments until the situation on the transport market improves.

\section{Summary}

Managing a transport company during the Covid-19 pandemic is a great challenge for managers, which they have to cope with in this difficult and uncertain time, if they want to 
continue to function in the transport market, generate income, or even invest and develop their business in the future. The work of managers is associated with making a large number of decisions that relate to current operations, planning and appropriate logistics, especially in international transport. Transport is a sector of the economy that is currently undergoing major changes. The Covid-19 pandemic, digital evolution, the coming green deal, legislative changes. All these elements will have a key impact on what transport will look like in the coming years. An important element securing the transport activity is diversification. The time of the Covid-19 pandemic has shown that focusing on one branch of transport is not always a good strategy in business. The freezing of the economy to fight the coronavirus has exposed transport companies to losses. Therefore, they often have to analyze their profitability, balance the currently conducted processes related to acquiring new freight and start building "financial pillows" that will allow them to maintain financial liquidity.

\section{References}

1. Bełch, P. (2019). Transport drogowy materiałów niebezpiecznych w obliczu „szarej strefy” na przykładzie przedsiębiorstwa handlowego z sektora paliw płynnych. Gospodarka Materiałowa i Logistyka, Vol. 1, pp. 16-21.

2. Chowell, G., Echevarría-Zuno, S., Viboud, C., Simonsen, L., Tamerius, J. (2011). Characterizing the Epidemiology of the 2009 influenza A/H1N1 Pandemic in Mexico. PLoS Med., Vol. 8, Iss. 5.

3. Dijkstra, L., Annoni, P., Kozovska, K. (2011). A New Regional Competitiveness Index: Theory, Methods and Findings. European Union Regional Policy, Vol. 2, pp. 3-26.

4. Długosz, J. (2009). Systemy transportowe, transport intermodalny. In: D. Kisperska-Moroń, and S. Krzyżaniak (Eds.), Logistyka. Biblioteka Logistyka (pp. 275-286). Poznań: Instytut Logistyki i Magazynowania.

5. Fearn-Banks, K. (2007). Crisis communications: A casebook approach. London: Routledge.

6. Gołembska, E., and Gołembski, M. (2020). Transport w logistyce. Warszawa: CeDeWu.

7. Grocki, R. (2020). Zarzadzanie kryzysowe. Warszawa: Difin.

8. Hirsch-Kreinsen, H. (2016). Digitization of industrial work: development paths and prospects. Journal for Labour Market Research, Vol. 49, Iss. 1. pp. 1-14.

9. Langinvainio, M. (2006). A Dozen Interpretations of Civilian Crisis Management. In: S. Korhonen, and J. Sumuvuori (Eds.), From Conflicts to Development (pp. 34-57). Jyväskylä: GKO. 
10. Lee, B.Y., Brown, S.T., Cooley, P., Potter M.A. (2010). Simulating School Closure Strategies to Mitigate an Influenza Epidemic. Journal of Public Health Management and Practice, Vol. 16, Iss. 3. pp. 252-261.

11. Lee, J., Bagheri B., Kao, H.A. (2015). A cyber-physical systems architecture for Industry 4.0 - based manufacturing systems. Manufacturing Letters, Vol. 3, pp. 18-23.

12. Marecki, K., Wieloch, M. (2008). Biznesplan. Elementy planowania działalności rozwojowej. Warszawa: SGH.

13. Neider, J. (2019). Transport międzynarodowy. Warszawa: PWE.

14. Rinaldi, S.M., Peerenboom, J.P., Kelly, T.K. (2001). Identifying, understanding, and analyzing critical infrastructure interdependencies. IEEE Control Systems Magazine, Vol. 21, Iss. 6. pp. 11-25.

15. Rosa, G. (2013). Konkurencja na rynku ustug transportowych. Warszawa: C.H. Beck.

16. Sikorski, P.M. (2008). Spedycja w praktyce - wiek XXI. Warszawa: PWT.

17. Skomra, W. (2020). Nowe oblicze zarządzania ryzykiem jako konsekwencja rosnącej zmienności otoczenia. In: G. Gierszewska (Ed.), Zarzadzanie w przedsiębiorstwie N.0. Droga do przyszłości (pp. 214-234). Warszawa: Politechnika Warszawska.

18. Strandhagen, J., Alfnes, E., Strandhagen, J.O., Vallandingham, L. (2017). The fit of Industry 4.0 applications in manufacturing logistics: a multiple case study. Advances in Manufacturing, Vol. 5, pp. 344-358. 



\title{
IS ACTING ON EMERGING MARKETS ENVIRONMENT \\ A CHALLENGE OF THE UNKNOWN? THE ANSWER FROM COMPLEXITY THEORY PERSPECTIVE
}

\author{
Agnieszka DZIUBIŃSKA \\ University of Economics in Katowice, Department of Enterprise Management, 1 Maja 50, 40-287 Katowice, \\ Poland; agnieszka.dziubinska@ue.katowice.pl, ORCID: 0000-0003-4385-1123
}

Purpose: The contemporary environment imposes tensions, which result in growing unpredictability, on companies. This makes it difficult to rely on traditional forms of organization and strategies based on the rational decision-making model. The aim of the author's own research was to identify the ways of adaptation of enterprises to the conditions of emerging markets, which are defined as a business environment of high uncertainty.

Design/methodology/approach: A single case study was used in the research. The enterprise selected for the research is a good example of the studied phenomenon, which also made convenient access to data in longitudinal studies possible. The obtained results were confronted with the literature on the subject in the field of CAS.

Findings: The case of the enterprise selected for the study belongs to a group of independent SMEs that can compete against the largest players in the industry. The results of the study indicated that it was possible due to similar mechanisms existing on various levels of the analysis. These include making decisions based on the patterns derived from personal experience; high adaptability resulting from the required diversity, which, at the same time, makes effectiveness more important than efficiency; lack of a clear strategy, and instead the ability to deal with initial conditions and monitoring the emergence of patterns; openness to experimentation, and individual assessments and measures.

Research limitations/implications: The limitations of the obtained results may result from a limited test sample.

Originality/value: The theoretical perspective adopted in the research - CAS and the empirical dimension - emerging markets, constitute a relatively little explored alternative to research conducted in their mainstream. The obtained research results may be of interest to representatives of science and practice, especially with regard to the current crisis caused by the Covid-19 pandemic.

Keywords: unpredictability, emerging markets, CAS.

Category of the paper: Research paper. 


\section{Introduction}

The diverse business environment conditionings created by the global economic system have influence on the diversity of forms of business organisations and their strategies (Jones, 2019). For at least few decades, emerging markets have been an interesting and ambiguous strategic challenge on the competitive world map $^{1}$. One of the reasons for this is the fact that, together with the development of global economy, the relationships with entities on emerging markets have become common in virtually every industry (Ghemawat, and Jones, 2017). On the one hand, they create a potential for traditional sources of cost advantages, but also for very large, and therefore attractive, markets. On the other hand, however, these markets are associated with high uncertainty. The reason for that is the lack of institutions appropriate for mature markets, whose task is "to reduce uncertainty by establishing stable (yet not necessarily efficient) structures within human interactions" (North, 1990, p. 5). In general sense, institutions are "socially created constraints which give a structure to social interactions" (North, 1990, p.3). Taking this research perspective, Khanna and Palepu (2010, p. 6) defined the emerging market as a place where the buyer and the seller cannot do business easily. Such an approach towards emerging markets allows us to look at them more through the prism of properties they are characterised by than with regard to the geographical dimension with which they are most frequently identified. This perspective seems to be interesting from the point of view of crises and the accompanying uncertainty which the entities present on the so-called mature markets have experienced in the recent years, such as, for example, the consequences of Brexit or the latest events related to the Sars-Cov-2 pandemic.

In the literature on the subject, the belief that they are on a development path that brings them closer to the model corresponding to mature markets is a common denominator of the vast majority of results obtained from the studies on emerging markets. However, emerging markets may be looked at in another way. Although, so far, this aspect has been less explored than mainstream studies, the scale of opportunities effectively seized by enterprises that come from "peripheral regions" can no longer be considered marginal. The successes of enterprises from emerging markets achieved thanks to a diversity of forms and high dynamics of development have become an inspiration for the author's own studies.

The objective of the studies whose results are presented in this article, was to identify ways in which enterprises that operate in emerging markets conditions handle uncertainty. The publications that address the issue of surprising strategies and organisational forms of enterprises from emerging markets contain analyses conducted from the point of view of

\footnotetext{
${ }^{1}$ The term "emerging markets" itself is considered to have been popularised in the 1980s. Currently, such terms as emerging economies, emerging markets, middle income countries happen to be used interchangeably. "Emerging markets" replaced previously used terms such as "the second-world countries" or even "the thirdworld countries." These are countries of low income, high growth rate, which use liberalisation as their basic growth generator (Hoskisson et al., 2000).
} 
traditional ways of competing, and concern mainly the largest enterprises. The complexity theories (Rokita, and Dziubińska, 2016) create a new perspective within this scope, and the assumptions resulting from this appear particularly promising with regard to emerging markets. Therefore, this theoretical perspective has been adopted in the author's own studies.

The structure of the article is composed of the following parts. First, the idea of complex adaptive systems (CAS) and selected issues related to their dynamics were presented. Then, on this basis, the components of complexity in the actions of an enterprise from an emerging market purposefully selected for the studies were identified. The obtained results made it possible to attempt to determine the characteristics of enterprises that are of key significance within this scope, which were later confronted with the literature on the subject. The summary of the results obtained in this way in terms of the characteristics of enterprises that handle the challenges of the environment characterised by high uncertainty is the last part of the article.

\section{Organisation as CAS in the environment of emerging markets}

The issue of new forms and routines emerging from simple mechanisms as building blocks raised in the author's own studies falls within the area appropriate for the complexity theory (Holland, 1998; Gellman, 2002; Hazy, Backström, 2013). CAS constitute the basic unit of analysis in the complexity science. CAS are networks of interactions similar to neural networks between independent agents who are connected with one another by dynamic cooperation, e.g. in reaching common objectives, satisfying common needs or representing a common point of view. Hedlund (1994, p. 82) described similar structures as temporary groups of people and units. CAS are natural for social systems (e.g., Homans, 1950; Roy, 1954). The property of CAS is that they are able to learn, solve problems creatively and adapt quickly (Carly, and Hill, 2001' Carly, and Lee, 1998; Goodwin, 1994; Levy, 1992; Rokita, and Dziubińska, 2016).

There are a few different approaches towards defining CAS. One of them is the reference to constraints. Referring to what has already been mentioned in the introduction, these constraints may be identified with the rules in force on the market that regulate behavior of agents (Dziubińska, 2017). These "rules of the game" consist of formal rules (laws, regulations) and informal constraints (customs, norms, culture). On mature markets, properly functioning rules specify the possible behavior of agents. Therefore, a relatively low risk that consists in the fact that undertaken interactions between participants of the system will lead to foreseeable results, is a characteristic feature of mature markets. Accordingly, from this point of view, poor security of transactions, communication, partner transparency on emerging markets gives room for opportunistic behavior and increases uncertainty (Khanna, and Palepu, 2010, pp. 41-51). 
In a situation where agents are not bound by the rules, there are also no repetitive patterns, and foreseeable results cannot be expected. The behavior of the whole system is then characterized by randomness, or to put it differently, chaos. In the practice of social systems, chaos is always a temporary state. A practical example of such a state of the market can be a crisis resulting from the collapse of previously binding economic structures or time of deeper political and social transformation. Emerging from the state of chaos towards an orderly system, for example, by imposing draconian strict rules, or towards systems in which emergence plays a significant role.

Therefore, the third state of the system is also possible, in which the rules (e.g., by their less formal nature) limit the behavior of agents to a lesser extent than it is in orderly systems, whereas agents modify these rules as a result of interactions occurring during the time. Agents and system constraints - rules co-evolve.

Dooley (2006) describes CAS as aggregates of interacting agents who evolve according to three basic principles: the order emerges in the opposite way to the pre-defined one, the history of the system is irreversible, the future of the system is often unpredictable. Due to the randomness present in the system, and because of the fact that dynamics of complex systems may be highly sensitive to small disturbances (Lorenz, 1993), CAS correspond more to the metaphor of an organic ecosystem than to the metaphor of a machine. The change in CAS appears in unexpected places and is non-linear, and the history of the system is irreversible, i.e., a return to the initial conditions is not possible.

CAS create fundamentally different conditions for activities of the agents. In particular, one of the basic differences between a complex system and a complicated system is worth emphasizing. If a system can be described on the basis of its individual constituents, even if their number is huge, it is then complicated. If interactions between the constituents of the system and interactions between the system and environment are of such nature that the system as a whole cannot be fully understood by a simple analysis of its constituents, it is then complex (Cilliers, 1998). CAS are unique and extraordinary in their ability to adapt to changes of the environment in a quick and creative manner. CAS increase their ability to adapt to environmental problems or internal needs through diversification of their behavior and strategies (Holland, 1995; McKelvey, 2008). Such diversity, in view of complexity, is understood as an increase in internal complexity (number and level of interdependence, heterogeneousness of skills and points of view within CAS, number of CAS and tension) up to a level that is reached by competitors or above (level of necessary Ashby variety 1963). By increasing their complexity, which has already been mentioned above, CAS increase their ability to process data (Lewin, 1992), solve problems (Levy, 1992), learn (Carley, and Hill, 2001; Levy, 1992) and change creatively (Marion, 1999). These are the properties that seem to be desirable in the conditions of high uncertainty of the environment. 


\section{Methodology of the author's own studies and case study}

The research procedure has been subordinated to the assumptions of the qualitative approach that is aimed at building a theory (Eisenhadrt, 1989; Yin, 2009). To be more precise, a single-time case study was applied. With regard to its mode of operation, the company that has been selected for the study constitutes a very good example of the studied phenomenon. The company was able to achieve success in spite of lack of traditional sources of advantage. Moreover, cooperation with this company enabled the author to gain an exceptionally convenient access to data that are relatively difficult to obtain (Yin, 2009; Eisenhardt, and Graebner, 2007).

The company in its current form appeared on the Polish market in 2014, however, the history of its brand reaches the year 1933. Before 2014, the company had been located in Silesia, and after the second world war it operated as an industrial state-owned enterprise. In 1991, the company transformed into a Sole-shareholder Company of the State Treasury. In 1998, its shares were included in the National Investment Fund program. In 2004, the controlling interest was purchased by an Italian investor who incorporated the company as a branch to its international structure. In 2014, the company was taken over by a Polish entrepreneur who concentrated on the activity in the mining industry, in the field of control hydraulics. In 2018, company X was ranked, inter alia, among the Brilliants of Polish Economy (in Polish: Brylanty Polskiej Gospodarki). In 2019, the company was developing dynamically in the area of project execution. Company X (the name was encoded for the purposes of publication of the results) is located on the Polish market, but it also conducts international activity. The spatial extent of the study included three selected markets which the company operates on, i.e., Poland, China and Russia. The study was of longitudinal nature and encompassed the years 2014-2019.

The data came from a few sources: in-depth direct interviews and direct observation. The interviews (lasting from one to two hours) were conducted with employees with relevant knowledge at all organizational levels. The data were collected until saturation was reached, i.e., when subsequent information did not cause an increase in knowledge about the described phenomena. The collected data were subject to triangulation by cross-checking against annual reports, company's internal documents, statements published by company $\mathrm{X}$ and its partners (domestic and foreign). The data analysis was conducted using a constant comparative method to extract and refine categories from notes and documents. The data were coded by only one person which may constitute a certain constraint. However, the summarized data and initial results were reinterpreted by the respondents. In the last stage of the analysis, the obtained categories were confronted with a list of basic complexity ingredients in entrepreneurial activities according to the suggestion developed by McKelvey (2016). 


\section{Results of studies and their interpretation Company $X$ as CAS}

The industry of mining equipment manufacturers where company $\mathrm{X}$ operates is a typical example of a mature industry. One of the characteristic symptoms of this state is that after the wave of consolidations and acquisitions on the market, a very limited number of, mostly large, companies remained on the market. Their basic advantage is ability to provide holistic solutions within sets of devices. Furthermore, the companies have at their disposal traditional sources of advantages such as high level of concentration of capital and global reach. At this point it is worth noting the competitive situation created by the sector itself. On the one hand, for a long time, the economies of many countries have been indicating high demand for energy. On the other hand, the vision of limited natural resources and increasing pressure on the part of the natural environment result in the fact that specific ways of diverting from obtaining energy from fossil fuel combustion more and more frequently appear in political declarations of the most important state officials. These factors and the very dynamic economic growth, especially of the largest economies defined as emerging markets (including BRIC) made them become one of the most significant markets for the manufacturers of mining equipment. It is interesting that small and medium-sized European companies performed surprisingly well on these markets. Having at their disposal advanced technological solutions, they were able to compete successfully with global rivals. It should also be emphasized that very often competition with the largest companies required cooperation of many small, independent entities that were only able to provide the client with the whole complex of devices together.

The presented context makes it possible to outline strategic challenges faced by small and medium-sized companies competing internationally. From the point of view of the addressed issue, the basis for the success of these companies can be, in a synthetic manner, summarized in the following way: in the face of challenges that are impossible to predict in advance resulting from the unknown environment of emerging markets, and lack of efficient control over the whole project by independent entities, the companies had to deal with the emerging situation in an adaptive way, based on their abilities to learn and creative thinking. The case of company $\mathrm{X}$, deliberately selected for the studies, is among these companies. Unlike its partners, company $\mathrm{X}$ did not have distinctive technical key competences. As a small company, it also had at its disposal limited opportunities within the scope of expert management systems. The part of the project provided by company $\mathrm{X}$ constituted an element which was rather easy to obtain. However, company $\mathrm{X}$ could effectively exploit its resources thanks to the strengths such as relationship skills and experience in operations on both mature and emerging markets. These skills proved their worth in practice. As other studies suggest, the group of small and medium-sized, highly adapted companies is not homogeneous. In particular, the stronger the technical dimension of key competences, the lower the tendency to adapt to unique local conditionings compared to the most open cases of companies (Dziubińska, 2015). 
The detailed characteristics of company X, i.e., its strong embedding in interactions with its partners, relatively ambiguous boundaries resulting from various (formal and not formally confirmed) forms of cooperation, strong reliance on experience (frequently non-formalized) or a development path shaped depending on the emerging events, justify the conviction that this is an example of a company that represents the CAS metaphor. With regard to the constraints imposed by the objective of the article specified in the introduction, particular attention will be paid to the aspect of CAS, i.e., basic complexity ingredients in entrepreneurial activities of company X. The most important of them are presented in table 1.

Table 1.

Dynamics of development of company X as CAS

\begin{tabular}{|c|c|}
\hline $\begin{array}{l}\text { "Constituents" of } \\
\text { complexity }\end{array}$ & Examples from the practice of the enterprise \\
\hline Adaptive pressure & Declining sector; competition on the part of global enterprises \\
\hline Dissipative structure & $\begin{array}{l}\text { Solving tensions / problems in cooperation between companies providing various } \\
\text { technical parts of the system; supporting the development of activities on the foreign } \\
\text { emerging market of companies from mature markets }\end{array}$ \\
\hline $\begin{array}{l}\text { Regions of emergence } \\
\text { (between the first and } \\
\text { second critical value) }\end{array}$ & $\begin{array}{l}\text { Lack of strict rules / procedures; overlapping and unspecified strictly in advance scopes } \\
\text { of responsibility; limited formal tools supporting decision-making processes - key } \\
\text { interpretation in a given context }\end{array}$ \\
\hline $\begin{array}{l}\text { Tiny initiating events } \\
\text { (catalysts) }\end{array}$ & Ideas for development inspired by the events resulting from daily contacts \\
\hline Links & $\begin{array}{l}\text { Diversified character of the bond - strong bonds based on trust and translating to } \\
\text { efficiency in mutual actions and weaker bonds (lower frequency and familiarity) which } \\
\text { made it possible to open new development paths (industries, markets, products) in the } \\
\text { long run. }\end{array}$ \\
\hline Path dependence & $\begin{array}{l}\text { Experience, next to "tiny initiating events" as one of the key factors shaping the } \\
\text { trajectory of the company's development }\end{array}$ \\
\hline Constraints & $\begin{array}{l}\text { Values (constraints free from the context) and conditionings resulting from particular } \\
\text { projects (context-sensitive constraints) }\end{array}$ \\
\hline Co-evolution & $\begin{array}{l}\text { Modifications of the modes of operation, modifications of products under the influence } \\
\text { of experiences from foreign markets }\end{array}$ \\
\hline Non-linearity & $\begin{array}{l}\text { Exploitation of developed solutions in new circumstances (market environment, } \\
\text { projects, experiments in new industries) }\end{array}$ \\
\hline
\end{tabular}

Own work with the use of McKelvey (2016), pp. 55-56.

Self-organization was a crucial mechanism present in the actions of the companies cooperating with one another as well as inside company $\mathrm{X}$. When unforeseen problems occurred, the employees could enjoy great freedom in searching for solutions (freedom of decision and applied measures). Although, in general, the mechanism worked well, it also generated other problems, for example, connected with the fact that due to its small size company $\mathrm{X}$ had at its disposal a limited number of employees, which means that there were limits to its competences. It could also be noticed that long-term tensions in case of growing problems favored a decrease in internal motivation of employees.

Acknowledging the key role of interaction and indicated mechanisms leading to selforganization perhaps reveals the most significant difference between traditional global, companies and the group of small and medium-sized companies that compete with them and assume a specific configuration depending on a given project. It is related to the so-called 
context-sensitive constraints which are inseparably accompanied by CAS and fundamentally differ from systems that are subject to reduction (Juarrero, 1999) ${ }^{2}$. Context-sensitive constraints (linkages and catalysts) work as bottom-up constraints on the system through its own past experiences and environment. It justifies the statement that CAS cover the initial conditions which accompanied their establishment, and that their origin and trajectories limit future development and evolution. High sensitivity to initial conditions and historically conditioned dynamic processes is a property of CAS. Thanks to them, the systems are able to self-organize and develop on path-dependence basis. Prigogine even claimed that systems "carry their history on their backs" meaning that the internal structure reflects their history. This property of CAS has its consequences for the opportunity to get to know and understand such organizations as the example of company X (by a researcher or another participant of the competitive market game). This is because no explanation here is possible without taking into consideration the trajectory and context of company's development in which it is embedded. It is not possible to determine here to what extent (perhaps seemingly unordered for an external observer) structure and actions of company $\mathrm{X}$ are a result of experiences in cooperation within the framework of groups of companies being established (seemingly ad hoc), and to what extent of the origin and long-term activity on emerging markets. However, the fundamentals of the complexity theory make it possible to notice an interesting, different from the one represented by traditional enterprises, model of adaptation to operating in the environment of high unpredictability. What is more, the long-standing presence of company $\mathrm{X}$ on the market proves that it can be at least as effective as traditional forms and strategies of competition.

\section{Conclusions: selected adaptive characteristics of companies operating in the conditions of high uncertainty}

The conditionings of the environment, which correspond to complex systems, create operating conditions of an organization that are fundamentally different from the ones that are characteristic for the structured systems. One of the most significant challenges for business organizations in this respect is uncertainty. The use of the CAS metaphor in the interpreting the results of the author's own studies has made it possible to distinguish a few characteristics of enterprises that have the ability to handle uncertainty in a different way than traditional enterprises.

\footnotetext{
${ }^{2}$ First order context-dependent constraints such as non-linear interactions, positive feedback and catalysts make units strongly co-dependent through the change of their marginal probabilities (probabilities of particular elements differ due to the fact that they occur in specific relationships).
} 
The conditions of high uncertainty do not make it possible to determine precise objectives in the long term, and to draw up a strategy that would specify detailed steps which are supposed to properly close the gap between the current state and the ideal future one (Komańda, 2011). The theory on the subject of CAS made it possible to notice an interesting alternative in the modes of actions of cooperating independent companies which company $\mathrm{X}$ belonged to. The companies did not operate within the framework of one stable structure. Instead, they organized themselves around a common objective which was prompt project execution and handled the emerging circumstances "on an ongoing basis" as well as the experience models emerging on this basis. Those patterns emerging from experiences which were positively assessed were maintained, while those ones which could have negatively influenced the results were disrupted. Especially in the latter case capturing signals quickly constituted a key ability. The mechanisms occurred on the level of the group of cooperating companies as well as within company X. Additionally, it should be emphasized that all the projects and results obtained within their framework in company X were assessed individually. In case of certain activities, high risk or low economic advantages was accepted at the price of gaining valuable experience. These are practical examples which can illustrate the thesis that Holling (1976) formulated about "optimization of failure costs", i.e., the system experiencing small periodic "minifailures" that do not threaten the survival (identity) of the system since they prevent the evolution of inflexibility. With regard to business activity, it should be emphasized that high adaptiveness based on creativity and learning means that efficiency is frequently achieved at the price of lower effectiveness. In other words, adaptability is possible thanks to a certain scope of lack of effectiveness.

Other significant issues that require attention are leadership and decision making. Unpredictability creates circumstances which make it impossible to make decisions based on assumptions resulting from a rational model of decision-making processes (Courtney, Kirkland, and Viguerie, 1997; Jędralska, 2010). In return, such companies as the case of company X, rely on models created through the accumulation of practical experience which are constantly confronted with emerging events. In such cases, the greater the diversity, the greater the ability to generate an appropriate response (McKelvey, and Boisot, 2010). The diversity of experience is also valuable on the level of the teams created, since uncertainty results in the fact that managing an organization on the basis of predetermined rules has its constraints. Tn alternative, confirmed by the practice of company $\mathrm{X}$, is to create a team which, thanks to self-organization, is able to cope with solving problems on its own. 


\section{Summary and directions of further studies}

The article addresses the issue of how to adapt companies in conditions of uncertainty. In the author's own studies, the environment of emerging markets has become their empirical expression. The CAS theory was used as a theoretical context for the considerations. This is a perspective which makes it possible to open a new direction of studies in the field of organization theory and strategic management. These two contexts of studies made it possible to attempt to identify the adaptive properties of an organization from the perspective which was not sufficiently explored in the mainstream studies. The presented results of the studies are a step towards a better categorization of terms that help to describe the effective actions of an organization in the conditions defined as unknown. This seems to be significant as traditional literature may not provide a sufficiently satisfactory basis for making decisions, and as a result, actions. The presented conclusions are a part of broader studies on the adaptation of an organization and seem to confirm the attractiveness of the open research path. This conviction is reinforced by the noticeable results of recent events which have shaped the economic reality of enterprises.

\section{References}

1. Ashby, R. (1963). Wstęp do cybernetyki. Warszawa: PWN.

2. Carley, K., and Hill, V. (2001). Structural change and learning within organizations. In: A. Lomi and E.R. Larsen (Eds.), Dynamics of organizational societies (pp. 63-92). Cambridge: AAAI/MIT Press.

3. Carley, K., and Lee, J.S. (1998). Dynamic organizations: Organizational adaptation in a changing environment. Advances in Strategic Management: A Research Annual, 15, pp-pp. 269-297.

4. Cilliers, P. (1998). Complexity and postmodernism: Understanding complex systems. London: Routledge.

5. Courtney, H., Kirkland, J., and Viguerie, P. (1997). Strategy Under Uncertainty. Harvard Business Review, 75(6), Nov.-Dec., pp. 67-79.

6. Dooley, K.J. (1996). Complex adaptive systems: A nominal definition. The chaos network, 8(1), pp. 2-3.

7. Dziubińska, A. (2015). An evolutionary approach to understanding adjustment of MNCs in a complex environment. Problemy Zarzadzania, 13/1(2), pp. 183-199.

8. Dziubińska, A. (2017). Innowacja instytucjonalna w warunkach transformacji otoczenia. Studia i Materiaty, 2/2017(24), cz. 1, pp. 48-59. 
9. Eisenhardt, K.M. (1989). Building theories from case study research. Academy of Management Review, 14(4), pp. 532-550.

10. Eisenhardt, K.M., and Graebner, M.E. (2007). Theory building from cases: opportunities and challenges. Academy of Management Journal, 50(1), pp. 25-32.

11. Gell-Mann, M. (2002). What is complexity. In: A.Q. Curzio and M. Fortis (Eds.), Complexity and Industrial Clusters: Dynamics and Models in Theory and Practice (pp. 13-24). Heidelberg: Physica-Verlag.

12. Ghemawat, P., and Jones, G. (2017). Globalization in Historical Perspective. In: P. Ghemawat (Ed.), The Laws of Globalization and Business Applications (pp. 56-81). Cambridge: Cambridge University Press.

13. Goodwin, B. (1994). How the leopard changed its spots: The evolution of complexity. New York: Charles Scribner's Sons.

14. Hazy, J.K. and Backström, T. (2013). Human Interaction Dynamics (HID): Foundations, definitions, and directions. Emergence: Complexity \& Organization, 15(4), pp. 91-124.

15. Hedlund, G. (1994). A model of knowledge management and the N-form corporation. Strategic Management Journal, 15(Special Issue), pp. 73-90.

16. Holland, J.H. (1995). Hidden order. Reading: Addison-Wesley Publishing Company.

17. Holland, J.H. (1998). Emergence: From Chaos To Order. Addison-Wesley.

18. Holling, C.S. (1976). Resilience and stability of ecosystems. In: E. Jantsch, and C.H. Waddington (Eds.), Evolution and Consciousness: Human Systems in Transition (pp. 73-92). Reading: Addison-Wesley.

19. Homans, G.C. (1950). The human group. New York: Harcourt, Brace and World.

20. Hoskisson, R.E., Eden L., Lau, C.M., and Wright, M. (2000). Strategy in Emerging Economies. Academy of Management Journal, 43, pp. 249-266.

21. Jędralska, K. (2010). Kontekst niepewności w procesie zarzadzania strategicznego. In: K. Jędralska (Ed.), Zarządzanie niepewnościa (pp. 9-28). Katowice: Wydawnictwo UE.

22. Jones, G. (2019) International Business and Emerging Markets in Historical Perspective. In: R. Grosse and K.E. Meyer (Eds.), The Oxford Handbook of Management in Emerging Markets (pp. 55-76). Oxford: Oxford University Press.

23. Juarrero, A. (1999). Dynamics in action: intentional behavior as a complex system. MIT Press Cambridge.

24. Khanna, T., and Palepu, K.G. (2010). Winning in Emerging Markets: A Road Map for Strategy and Execution. Boston: Harvard Business Press.

25. Komańda, M. (2011). Między wiedzą a niewiedzą: droga ku przewadze organizacyjnej. In: K. Hajduk (Ed.), Sustainability odpowiedzia na kryzys ekonomiczny. Nowe koncepcje przedsiębiorstwa przyszłości (pp. 258-263). Warszawa: Instytut Organizacji i Zarządzania w Przemyśle ORGMASZ.

26. Levy, S. (1992). Artificial life: The quest for new creation. New York: Random House.

27. Lorenz, E. (1993). The essence of chaos. Seattle: University of Washington Press. 
28. Marion, R. (1999). The edge of organization: Chaos and complexity theories of formal social organizations. Newbury Park: Sage.

29. Mc Kelvey, B., and Boisot, M. (2010). Redefining strategic foresight" "fast" and "far" sight via complexity science. In: L.A. Costanzo, and R.B. MacKay (Eds.), Handbook of Research on Strteagy and Foresight (pp. 15-47). Cheltenham/Northampton: Edward Elgar.

30. McKelvey, B. (2008). Emergent strategy via Complexity Leadership: Using complexity science and adaptive tension to build distributed intelligence. In: M. Uhl-Bien and R. Marion (Eds.), Complexity and leadership volume I: Conceptual foundations (pp. 225-267). Charlotte: Information Age Publishing.

31. McKelvey, B. (2016) Complexity Ingredients Required For Entrepreneurial Success. Entrepreneurship Research Journal Entrepreneurship Research Journal, 6(1), pp. 53-73.

32. North, D.C. (1990). Institutions, Institutional Change and Economic Performance. Cambridge: Cambridge University Press.

33. Rokita, J., and Dziubińska, A. (2016). Systemy złożone w zarządzaniu. Katowice: Wydawnictwo Uniwersytetu Ekonomicznego.

34. Roy, D. (1954). Efficiency and 'the fix': Informal intergroup relations in a piecework machine shop. American Journal of Sociology, 60, pp. 255-266.

35. Yin, R.K. (2009). Case studies: design and methods. Thousand Oaks: Sage Publications. 


\title{
ORGANIZATIONAL RESPONSES TO SUSTAINABLE DEVELOPMENT CHALLENGES - CONDITIONS \& CONSEQUENCES
}

\author{
Adam JANISZEWSKI \\ University of Economics in Katowice; adam.janiszewski@ue.katowice.pl, ORCID: 0000-0003-4730-5410
}

\begin{abstract}
Purpose: The aim of the paper is to discuss assumptions that stand behind the idea that, in order to analyze a way in which organizations are willing to respond to environmental challenges, it is necessary to consider how the diffusion of knowledge related to sustainable management practices can impact on decision making dependent on managers' cognitive frames. The analysis is focused on the sensemaking process initiated by a necessity to make a decision on whether to engage in a sustainability project involving steps to be made to protect natural environment. The attention is paid to its possible realization dependent on cognitive frames used by decision makers. This way of analysis allows for better understanding of factors which may hinder enterprises from implementing sustainability idea. In the paper current literature related to the topic is reviewed and next selected issues considered as critical for understanding the matter are described and discussed.
\end{abstract}

Design/methodology/approach: Theoretical analysis is conducted and the key assumptions of critical realism related to ontological and epistemological dimensions are implemented. The importance of abductive way of thinking is outlined.

Findings: In general, it is argued that managers who are more likely to accept paradoxical nature of challenges related to the implementation of sustainability tools should find it more useful to follow multidimensional paths through which they may reach stakeholders. It is also presented that in order to show how decisions as to implement the sustainability idea can be made, it is necessary to take into account consequences that are to arise from the fact that attitudes towards sustainability management are influenced by historical conditions. Because of the wide array of actors who may contribute to the successful implementation of the sustainability idea, it is predicted that different cognitive approaches should be used. The arguments that are provided appear to also prove that it is useful to consider deeply relations among sensemaking process and cognitive frames used by managers.

Originality/value: The paper includes an authorial analysis in which conclusions are inferred based on hitherto conducted research and formulated research propositions related to sensemaking process, cognitive aspects of making decisions as well as to issues of building legitimacy in the light of environmental challenges which modern enterprises need to deal with. The analysis can provide decision makers with some new insights as to why they make decisions as they used to, which next should allow them to change their habits.

Keywords: sensemaking, cognitive frame, sustainable development, decision making.

Category of the paper: conceptual. 


\section{Introduction}

It is argued that "sensemaking" is especially important for managers who are faced with a change that entails severe modifications in a way their interactions with the world around them take place. When being interpreted, communicated and implemented change requires that managers actually "struggle for meaning" (Lüscher and Lewis, 2008, p. 221). The paper aims at considering the content of the sensemaking process in the hypothetical situation of making decision on how to face challenges of sustainable development and to undertake a sustainability project involving implementation of one of the many sustainability tools like e. g. sustainable supply chain management or sustainability network (Johnson, 2015, p. 278). To make the analysis more meaningful there is a differentiation introduced between decision makers who follow a business case frame and these who follow a paradoxical frame. The most important relations that are to be considered are outlined in the Figure 1.

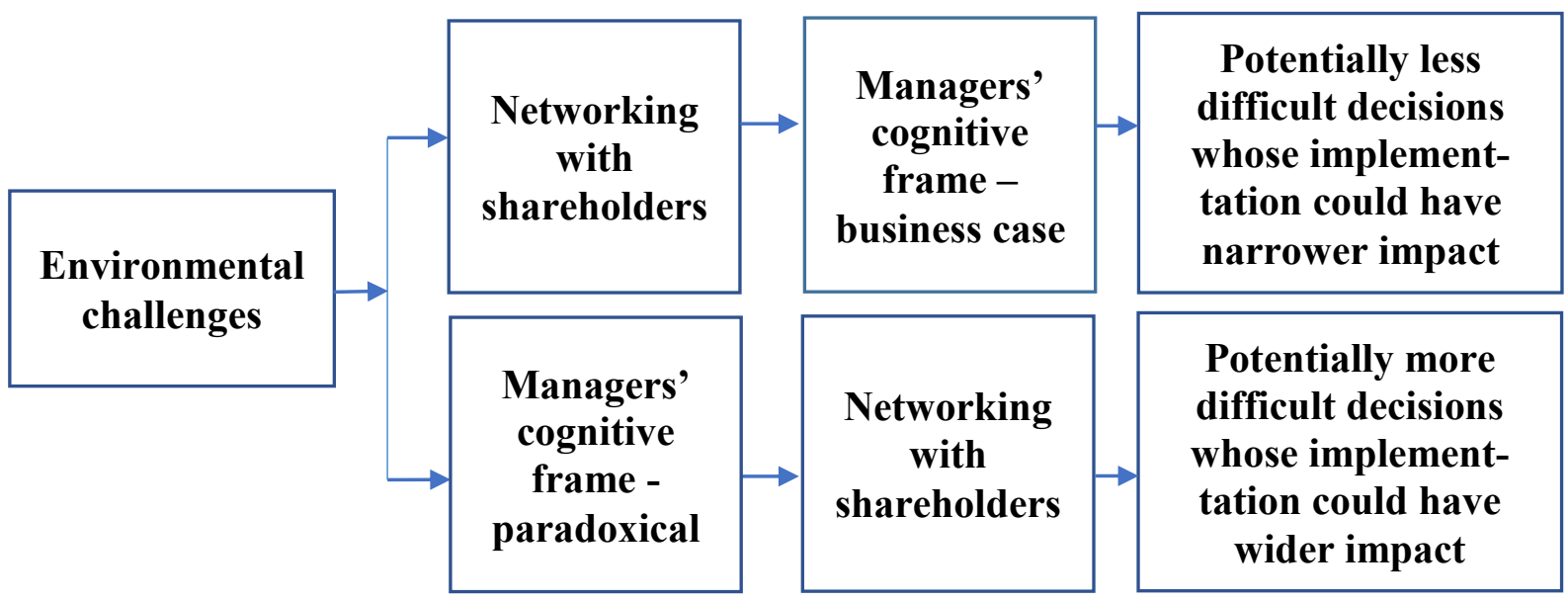

Figure 1. Conceptual framework. Source: Author's own elaboration based on Delbridge and Edwards (2013); Hahn et al. (2015); Hörisch, Johnson and Schaltegger (2015).

As we can see there is the assumption that a way in which managers are to respond to the environmental challenges is determined to some extent by their cognitive frame as well as is impacted by network structures within which they used to cooperate. There is also one distinction proposed which shows that managers with a paradoxical cognitive frame are believed to recognize what relations between structures and actions are whereas managers with a business case frame may tend to "read action from structure"1 (Delbridge and Edwards, 2013, p. 933). What it means is that depending on the type of an adopted cognitive frame some managers are more prone to follow ways of thinking stemming from given conditions while others appear to be more likely to resist and to search for their own solutions. It is to be added that when conducting analysis based on the assumptions of critical realism the attention should be paid to Delbridge and Edwards' stance. They proposed that in order to show how historical conditions influence undertaken actions it is an idea to treat analytically structures and actions as separate. Otherwise the analysis could focus only the process of responding to external 
institutional pressures that would be to occur in a very predictable way. Then it also becomes more visible how participants' reflexivity is to moderate actions that they perform. Taking into considerations many logics (they can be understood as ways in which goals are conceptualized - Hahn et al., 2015, p. 35) causes participants' reflexive process to not be fixed. It is claimed that an ability to be reflexive is to be determined by many factors like experiences from the past, social environment as well as to be impacted by individual features and views (Delbridge and Edwards, 2013, pp. 928-929). Critical realism argues that although social structures are believed to exist partially independent of human activity or human knowledge about them, they are also believed to be dependent on "people's conceptions of what they are doing in their activity" (Al-Amoudi and Willmott, 2011, p. 31; Bhaskar, 1998) ${ }^{2}$. Consequently, when admitting this partial independent existence of structures, it is to take into account and to incorporate into the analysis the aspect of how meaningful concepts are dependent on given discursive order (Al-Amoudi and Willmott, 2011, p. 36) ${ }^{3}$. Because networks which are to be built by managers with a paradoxical cognitive frame are believed to be comprised of more differentiated entities they should allow managers to come closer to the full realization of sustainable development concept which is understood in this paper as inclusive, connected, equitable, prudent and secure human development (Gladwin, Kennelly, and Krause, 1995) ${ }^{4}$. It is worth reminding that Gladwin, Kennelly and Krause (1995) posed the question about stakeholder models, that was whether they should be extended in such a way to be temporally and spatially inclusive to a greater extent (Gladwin, Kennelly, and Krause, 1995, p. 898; Starik, 1995). The questions that are to be considered refer to networking with stakeholders as these networks can be considered as being channels through which both diffusion and dissemination of practices as well as knowledge related to them can occur. What is to be emphasized, the way in which it happens is also aided by a key element of legitimacy, that is the process of theorization. It allows for existing norms and practices to be abstracted into some generalized categories. The theorization results in that diffusion and dissemination of practices become taken-for-granted as time goes by (Suddaby, Bitektine, and Haack, 2017, pp. 460-461). Here, it appears to that there are two factors that should make researchers paying even more attention to how business firms try to implement sustainability idea. Firstly, it is argued that currently it is the task for civil society actors and private actors (including here business firms) to define standards of behavior in order for sustainable development to flourish (Scherer, Palazzo, and Seidl, 2013, p. 260; e.g. Mena, and Palazzo, 2012). Secondly, the level of engagement of these actors with sustainability idea is expected to grow because social sensitivity to unsustainable business practices is to pursue its growing (Scherer, Palazzo, and Seidl, 2013, p. 260). That is why organizational responses, their consequences and reasons that lead to the way in which organizations respond to the arising challenges should be taken into account. 


\section{Theoretical background}

According to Weick sensemaking is related to putting an effort into the creation of order and understanding which should be coherent. This process is directed by a structure of assumptions, roles and boundaries which can be used until some kinds of shocks and surprises start showing that hitherto used structures should be abandoned (Lüscher, and Lewis, 2008, p. 222; Weick, 1995). This process, in general, is viewed as being comprised of three phases, that is scanning phase, interpretation phase and responding phase (Hahn et al., 2015, p. 24).

The action research on how managers face with changes in the company conducted by Lüscher and Lewis (2008) allowed these authors to go through the process which they understood as a process of sensemaking that occurred in a collaborative manner. There were few phases described. The first one was the mess and it was followed by the problem formulation and next by the facing dilemma. The last two stages were the paradox and the workable certainty. From the point of view of the analysis performed in this paper it should be emphasized that during each of these phases different kind of questions are considered as being helpful because they allow a group to move on in the process (Lüscher, and Lewis, 2008, pp. 221-227). At the beginning of this process it is important to allow managers to set the boundaries for exploration by selecting aspects of the issue being under consideration they should be interested in. Then by asking intricate questions referring to expectations, or initial goals, a logic which managers appear to follow at the time could surface. Next phase involves bounding what managers have already known in such a way that a reflection should be possible (Lüscher, and Lewis, 2008, p. 228; Ackoff, 1978). Having problems formulated individuals are actually saying that they are prepared to make necessary steps in order to find a solution. Then so called linear questions are expected to appear. They are connected to managers' concerns or factors that have an impact on the issue to be resolved. This is the time when realizing all oversimplifications in how the issue is stated, managers come to conclusions that they are not able to simply make use of problem solving logic as well as they see that still some key elements (including other perspectives and connections) are not taken into account (Lüscher, and Lewis, 2008, p. 229). Next during dilemma phase managers are expected to ask so called circular questions (Lüscher, and Lewis, 2008, p. 229; Tomm, 1987). As a result, they should get to know both opinions and feelings of their subordinates or executives. Here managers are to overcome a "sense of paralysis" (Lüscher, and Lewis, 2008, p. 229; Smith, and Berg, 1987), which may appear when they have to deal with the solutions that all have some advantages and disadvantages and actually there is a lack of a clear reason why one solution may be treated as being better in comparison to the other one (Lüscher, and Lewis, 2008, p. 229). Next phase is the one in which managers may realize that the tensions which they are considering actually have paradoxical nature. In order to understand how a paradox can be perceived it is useful to refer to Smith and Lewis's (2011) view on the issue. 
They distinguish three kinds of tensions, that is a paradox, a dilemma and dialectic tensions ${ }^{5}$. Paradox is defined by them as "contradictory yet interrelated elements that exist simultaneously and persist over time" (Smith, and Lewis, 2011, p. 386). When considering elements linked to each other by paradoxical relations, one can see that formal logic encourages "either/or" thinking. However, from the point of view of the whole system it is possible to notice synergies among these elements as they are just interrelated (Smith, and Lewis, 2011, p. 386; Cameron, and Quinn, 1988). It is important to notice that distinctions among these three terms are rather fluent ones, because it is possible that they overlap. It happens e.g. when because of interrelatedness of elements contradictions among them are to appear again and again so that dilemma can not be resolved once and for all. In case of synthesis, because it favors one element over the other in a gradual way, it is the case that main characteristics of contradictory elements are to be retained when new synthesis emerge. Due to the fact that here differences among elements tend to be neglected, the integration that happens is to last only temporary (Smith, and Lewis, 2011, pp. 386-387). Paradoxical nature implies that opposing solutions are interwoven, so that any choice can not resolve the tension (Lüscher, and Lewis, 2008, p. 229; Lewis, 2000). Reflexive questions should then help managers examine implications which are not obvious at once (Lüscher, and Lewis, 2008, p. 229; Tomm, 1987). These questions can refer to the results of undertaken approaches as well as to ways in which responsibilities are defined, which is why double-loop learning can be considered as a consequence of posing them (Lüscher, and Lewis, 2008, p. 229; Argyris, 1993). This is also the moment in which "either/or" approach is replaced

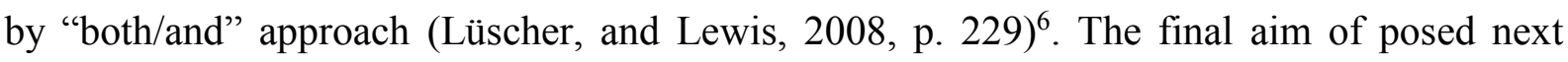
interventive questions and deeper explorations is to reach so called workable certainty. Being aware that the process of sensemaking is constant, managers should be able to act in a way that is to correspond to the situation in which they are faced with tensions on a regular basis. It is to be added that during the last phase questions as to why one thinks that proposed solutions are actually to work well can appear (Lüscher, and Lewis, 2008, p. 230).

Describing managers' behavior during the responding phase of the sensemaking process Hahn et al. (2015, p. 31) argue that managers are expected to act in a way that depends on their stance. In general, it is understood as a kind of attitude toward a problem managers are faced with and it is based on their rationalizations (Hahn et al., 2015, p. 31). What is important from the point of view of the analysis in this paper is that when analyzing sustainability issues it is helpful to perceive what one does or what one does not do in the light of stances which people may have. For example, a concentration on activities and solutions is believed to be specific for pragmatic stance. Those who take it are to avoid to debate current situation. But others are more willing to approach the topic of sustainability development in a more philosophical way. Then there are possible different views on e.g. whether the natural environment is only a resource needed to achieve higher life quality or whether it is reasonable to consider human beings as having privileged position among other species (Byrch et al., 2009, p. 2). 
It is worth paying attention to the fact that managers' cognitive frames have an impact on what these stances are to be like. Cognitive frames are expected to lead to responses by shaping meanings and filtering bits of information which managers are to absorb (Hahn et al., 2015, p. 18; Porac, and Thomas, 2002; Weick, 1995). In general, Hahn et al. (2015, p. 31) propose to distinguish two kinds of frames - a business case frame and a paradoxical frame. Business case frames that are expected to result in a pragmatic stance involve considering primarily economic objectives, exploiting opportunities as well as subordinating environmental and social issues to economic ones. What is more, managers with a business case frame may consider sustainability issues actually as totally positive or totally negative, so that they think about them in a univalent way. On the one hand, they may focus on narrow ranges of possible responses. This is because the complexity of information is reduced (Hahn et al., 2015, p. 23; e.g. Levinthal, and Rerup, 2006). On the other hand, due to the fact that they actually attempt to exploit existing routines the responses which they are to propose should be quite workable (Hahn et al., 2015, p. 19). Following alignment logic, these managers are believed to gather detailed information, which should allow for understanding cause-and-effect relationships (Hahn et al., 2015, p. 28; Sharma et al., 1999). Paradoxical frames that are expected to result in a prudence stance involve taking into account ambivalent interpretations of sustainability issues. This is because economic as well as social and environmental issues are considered as being equally important. These managers are to check more information sources due to this high level of diversity (Hahn et al., 2015, p. 25; Beyer et al., 1997). As a result, it can be argued that responses that are analyzed by managers directed by paradoxical frames allow for more comprehensive answers. Nonetheless, due to the fact that the level of considered risk when responding in this way is greater these managers respond more carefully and in a rather slow manner (Hahn et al., 2015 , p. 19). Having only a moderate sense of control over sustainability issues, these managers at the same time do not have a need to see "immediate financial implications" (Hahn et al., 2015, p. 26; Byrch et al., 2007). It appears also reasonable to assume that they can be aware that evaluators of their activities, would they be individuals or collectives, are diverse, so that their judgments and motives are to be diverse as well even if they are under the impact of strong institutional pressures (Suddaby, Bitektine, and Haack, 2017, p. 466; Bitektine, and Haack, 2015).

It can be claimed that efforts put into the environment protection and taking care of the natural environment and its inhabitants may often require that one needs to be focused on wider range of issues requiring integrated transdisciplinary knowledge for sustainable human - nature balance (Shrivastava, Ivanaj, and Persson, 2013, pp. 238-239). In the light of hitherto considerations it appears to be reasonable to argue that managers with a paradoxical frame find it more useful to treat problems from transdisciplinary point of view. The challenge is that it demands that people are ready to overcome their fear of unknown in order to achieve more than it is possible by making use of the classical analytical approach (Shrivastava, Ivanaj, and Persson, 2013, p. 239). However, it is not to be said that cognitive frames of a given type are 
generally more useful than other ones (Hahn et al., 2015, p. 35). As they are different their simultaneous use appears to be required to meet demands that stem from tensions resulting from paradoxical specificity of many challenges that modern organizations have to deal with when following requirements of sustainable development.

\section{Methods and results}

In the paper the author pays primary attention to the consequences arising from the process of responding to sustainability challenges. The process is believed to be influenced by cognitive frames that are mobilized by managers when going through sensemaking process. As the assumption is that there two kinds of these frames, that is business case one and paradoxical one, it appears that the analysis conducted on how individual decision makers can impact network cooperation allows the author to outline the most important, however not necessary always visible at once, consequences of the fact that enterprises currently are operating in the global environment that is not only fragmented or dynamic, but there are many sustainability demands that often can be contradictory (Scherer, Palazzo, and Seidl, 2013, p. 261). Hence, in order to achieve the main goal of this paper the analysis is conducted whose main assumptions are included in table 1 . Based on selected foreign scientific papers the process of sensemaking is investigated in a hypothetical situation of making decision on whether to take part in network project aimed at dealing with challenges of sustainable development. Based on the literature focused mainly on legitimacy management there are also considered answers which, based on described assumptions, could potentially be proposed by managers with different cognitive frames. It should be explained that predicted ways in which different managers are expected to approach the problem correspond to some extent to strategies and approaches proposed by literature (e.g. Scherer, Palazzo, and Seidl (2013) - strategies of adaptation, manipulation as well as moral reasoning together with both approaches to cope with possibilities to implement different strategies - one best way, contingency, paradox - and ways of creation of suitable conditions - structural solutions, contextual solutions as well as solutions based on reflective capacities; Suchman (1995) - strategies of building pragmatic legitimacy, moral legitimacy as well as cognitive legitimacy; Suddaby, Bitektine and Haack (2017) strategies of conforming, decoupling as well as performing/learning in case of legitimacy considered as property; Tost (2011) - approaches to the process of legitimation analyzed from the point of view of institutional theory and social psychology). However, it is not argued that proposed reactions follow strictly these described strategies. They are actually to combine some chosen elements from them all. 
Table 1.

Impact of managerial cognitive frames on sensemaking - proposed relations

\begin{tabular}{|c|c|c|c|c|}
\hline $\begin{array}{l}\text { Cogni- } \\
\text { tive } \\
\text { frame }\end{array}$ & $\begin{array}{l}\text { Phase of } \\
\text { sensemaking } \\
\text { process } \\
\text { during orga- } \\
\text { nizational } \\
\text { change } \\
\end{array}$ & $\begin{array}{l}\text { Pro- } \\
\text { posed } \\
\text { main } \\
\text { issues to } \\
\text { be consi- } \\
\text { dered } \\
\end{array}$ & $\begin{array}{l}\text { Possible questions } \\
\text { (related to networking } \\
\text { with stakeholders) }\end{array}$ & $\begin{array}{l}\text { Possible approaches } \\
\text { to the problem }\end{array}$ \\
\hline $\begin{array}{l}\text { Business } \\
\text { case }\end{array}$ & \multirow[t]{2}{*}{ Mess } & \multirow[t]{2}{*}{$\begin{array}{l}\text { Connec- } \\
\text { tivity }\end{array}$} & $\begin{array}{l}\text { How can network relations be } \\
\text { maintained to prevent } \\
\text { stakeholders from leaving the } \\
\text { network and at the same time } \\
\text { to enable flow of a legiti- } \\
\text { macy-building information } \\
\text { throughout the network? }\end{array}$ & $\begin{array}{l}\text { Pragmatic approach with the } \\
\text { attention paid to beneficial } \\
\text { exchanges, however, there appear } \\
\text { to be a probability that } \\
\text { an approach similar to decoupling } \\
\text { may emerge. }\end{array}$ \\
\hline $\begin{array}{l}\text { Parado- } \\
\text { xical }\end{array}$ & & & $\begin{array}{l}\text { How can an adequate network } \\
\text { structure comprised of } \\
\text { enterprises and organizations } \\
\text { from different fields be built? } \\
\text { What kind of motivations can } \\
\text { participants have? }\end{array}$ & $\begin{array}{l}\text { An approach similar to moral } \\
\text { reasoning with the attention being } \\
\text { paid to encouraging participation } \\
\text { of different entities and to } \\
\text { promoting awareness as to their } \\
\text { influence on final results, a risk } \\
\text { can emerge that too many } \\
\text { companies would take part in it. }\end{array}$ \\
\hline $\begin{array}{l}\text { Business } \\
\text { case }\end{array}$ & \multirow{2}{*}{$\begin{array}{l}\text { Problem } \\
\text { formulation }\end{array}$} & \multirow[t]{2}{*}{ Equity } & $\begin{array}{l}\text { Which kind of requirements } \\
\text { regarding costs to be incurred } \\
\text { can prevail when realizing the } \\
\text { project? }\end{array}$ & $\begin{array}{l}\text { Search for the best solutions taking } \\
\text { into account criteria related to the } \\
\text { efficiency of the company and to } \\
\text { the possible extent related to the } \\
\text { efficiency of the whole network }\end{array}$ \\
\hline $\begin{array}{l}\text { Parado- } \\
\text { xical }\end{array}$ & & & $\begin{array}{l}\text { Whether can the pressure to } \\
\text { exchange knowledge when } \\
\text { operating within diversified } \\
\text { network be diminished due to } \\
\text { changes in foundational rules } \\
\text { that members are to abide by } \\
\text { when exchanging resources? }\end{array}$ & $\begin{array}{l}\text { A challenge it would be to set } \\
\text { standards of cooperation in order } \\
\text { to create suitable conditions to } \\
\text { improve activities and at the same } \\
\text { time to not induce too much } \\
\text { pressure that could force partners } \\
\text { to exchange knowledge even if } \\
\text { they see it as inequitable. }\end{array}$ \\
\hline $\begin{array}{l}\text { Business } \\
\text { case }\end{array}$ & \multirow[t]{2}{*}{$\begin{array}{l}\text { Dilemma } \\
\text { consideration }\end{array}$} & \multirow[t]{2}{*}{ Prudence } & $\begin{array}{l}\text { Whether members of the } \\
\text { network can be afraid of } \\
\text { suffering financial losses as a } \\
\text { result of realizing common } \\
\text { projects due to the lack of } \\
\text { conditions that could allow all } \\
\text { members to improve their } \\
\text { efficiency? }\end{array}$ & $\begin{array}{l}\text { Some engagement in preparing } \\
\text { ideas on how it could be resolved, } \\
\text { tendencies to justify why the } \\
\text { things are the way they are }\end{array}$ \\
\hline $\begin{array}{l}\text { Parado- } \\
\text { xical }\end{array}$ & & & $\begin{array}{l}\text { How can trust be created } \\
\text { when there are a lot of } \\
\text { dimensions of cooperation } \\
\text { among members from } \\
\text { different fields that are } \\
\text { difficult for others to make } \\
\text { them realize? }\end{array}$ & $\begin{array}{l}\text { Both following the idea of } \\
\text { "either/or" methods of making a } \\
\text { choice and taking into account that } \\
\text { being taken for granted can occur } \\
\text { only when nobody tells about it, } \\
\text { could lead to that the existence of } \\
\text { some dimensions of cooperation is } \\
\text { not to be articulated }\end{array}$ \\
\hline
\end{tabular}


Cont. table 1 .

\begin{tabular}{|c|c|c|c|c|}
\hline $\begin{array}{l}\text { Business } \\
\text { case }\end{array}$ & \multirow[t]{2}{*}{$\begin{array}{l}\text { Paradox } \\
\text { approached }\end{array}$} & \multirow[t]{2}{*}{ Security } & $\begin{array}{l}\text { Which are the } \\
\text { consequences of } \\
\text { multilateral anxieties } \\
\text { concerned with a lack } \\
\text { of financial } \\
\text { advantages? }\end{array}$ & $\begin{array}{l}\text { If external conditions are to be suitable } \\
\text { then it is assumed to be possible that } \\
\text { stance "both/and" instead of "either/or" be } \\
\text { taken; when searching for advantages to be } \\
\text { derived from the cooperation, } \\
\text { non-financial opportunities could be } \\
\text { included }\end{array}$ \\
\hline $\begin{array}{l}\text { Parado- } \\
\text { xical }\end{array}$ & & & $\begin{array}{l}\text { Which are the } \\
\text { consequences of } \\
\text { multilateral anxieties } \\
\text { resulting from the } \\
\text { fear of losing } \\
\text { different kind of } \\
\text { resources? }\end{array}$ & $\begin{array}{l}\text { The first possibility is related to } \\
\text { approaching the paradox which involves } \\
\text { looking for ways to operate effectively in } \\
\text { different fields, and the second approach is } \\
\text { related to a risk of the emergence of } \\
\text { manipulation as a problem can be seen as } \\
\text { being impossible to be overcome }\end{array}$ \\
\hline $\begin{array}{l}\text { Business } \\
\text { case }\end{array}$ & \multirow[t]{2}{*}{$\begin{array}{l}\text { Workable } \\
\text { certainty }\end{array}$} & \multirow[t]{2}{*}{$\begin{array}{l}\text { Inclusi- } \\
\text { veness }\end{array}$} & \multirow{2}{*}{$\begin{array}{l}\text { Can proposed steps to } \\
\text { be made really be } \\
\text { considered as the } \\
\text { solution to the } \\
\text { problem if there are } \\
\text { still unresolved } \\
\text { contradictions? }\end{array}$} & $\begin{array}{l}\text { Claims indicating on the necessity to } \\
\text { follow proposed solutions because of legal } \\
\text { and economic issues (e. g. the avoidance } \\
\text { of having to pay financial penalties due to } \\
\text { the fact of not abiding by the } \\
\text { environmental law) would appear } \\
\text { probable; the possibilities for the creation } \\
\text { of the external environment are rather not } \\
\text { visible, entities may be assessed as } \\
\text { legitimated by others if they promote their } \\
\text { material interest }\end{array}$ \\
\hline $\begin{array}{l}\text { Parado- } \\
\text { xical }\end{array}$ & & & & $\begin{array}{l}\text { Considered consequences of proposed } \\
\text { solutions (in terms of their short and long } \\
\text { time possible impact as well as from the } \\
\text { point of view of spatial impacts) should } \\
\text { focus on possibilities of gathering } \\
\text { resources which are to be used when } \\
\text { implementing projects in the future in } \\
\text { other networks; entities may be assessed as } \\
\text { legitimated to the extent in which they } \\
\text { communicate that, as a result of their } \\
\text { membership in the network, members can } \\
\text { gain respect and status; hence, they want to } \\
\text { create the external environment actively }\end{array}$ \\
\hline
\end{tabular}

Source: Author's own elaboration based on Gladwin, Kennelly and Krause (2015), Scherer, Palazzo and Seidl (2013); Suchman (1995); Suddaby, Bitektine and Haack (2017) and Tost (2011).

Further analysis is not focused on drawing conclusions on whether decision makers should decide on one or more of these strategies that next could be implemented. It is thought to show what kind of issues decision makers are likely to perceive and in which direction their perception is supposed to be shaped by cognitive frames that impact on how information related to sustainability issues is processed. It should also be explained that the assumption is here that being focused on sustainability projects managers need also plunge into considerations of more general aspects (in table 1 these are proposed main issues to be considered during each phase of the sensemaking process that refer to dimensions mentioned by Gladwin, Kennelly and Krause, 2015) and their point of view on them is to influence how they approach issues crucial to cooperation with others. 


\section{Discussion}

In table 1 first main issue to be considered is underlied by the assumption that managers with a paradoxical cognitive frame may appear to be more open towards claims that are constituents of the dimension of connectivity. Hence, their assumed attitude towards network cooperation is to involve searching for partners from different fields. They should understand that only if global problems are to be perceived as connectivity dimension assumes, that is as systemically interconnected and interdependent, can members of the network face with economic, social and environmental challenges (Gladwin, Kennelly, and Krause, 1995, p. 879). That is why they are to be more willing to undertake cooperation with actors representing social field, environmental field as well as economic field. What is also important is to notice that it can not be sufficient to focus only on environmental issues when implementing sustainability idea. When it happens like this Gladwin, Kennelly and Krause (2015, p. 879) argue it is a threat that only trivial results be produce. Taking it all into account it can be seen why these managers are expected to focus firstly on ensuring appropriate network structure. An approach to the problem which they are likely to implement may in some way be similar to moral reasoning discussed by Scherer, Palazzo and Seidl (2013). It means that they would actively engage in discussions with network participants to make it possible that they become aware of their roles and next they can fulfill their tasks. In this way managers with a paradoxical frame are expected to be more knowledgeable about sources of their motivation. The question to investigate is how this knowledge can contribute to shaping appropriate discursive practices. In case of managers with a business case frame it appears to be reasonable to assume that following their clear assessments of positiveness and negativity (e g. related to values and facts - Gladwin, Kennelly, and Krause, 2015, p. 885; Wilber, 1995) to some extent they may omit the complex interlinkages among the issues to be resolved when implementing sustainability project. That is why it is postulated that the question to be posed by them would relate to maintaining effective network structure with regard to the ease with which knowledge can flow. It may appear to be similar to claims represented by technocentric paradigm which sees the value of the world as only monetarily quantifiable (Gladwin, Kennelly, and Krause, 2015, p. 882). It means that it can be expected that decision makers are to follow partially what Suchman (1995) described as pragmatic legitimacy as well as what Suddaby et al. (2017) called decoupling. Being focused on ensuring economic advantages could lead to that a risk emerges that insufficient activities within other fields would be only commented in a exaggerated way. This is because it may be noticed that the problems related to dynamic complexity and interrelationships among different elements (including ecosystem degradation) demands systemic thinking about individuals and units responsible for these connections. Without considerations of these issues it is simpler to focus mainly on economic aspects 
(Gladwin, Kennelly, and Krause, 2015, p. 895). But the problem may arise when external pressures become intensified in other fields. ${ }^{7}$

At the general level issues related to the dimension of equity are concerning the distribution of resources (Gladwin, Kennelly, and Krause, 1995, p. 879). It has been noted that ideas related to sustainability may turn out to be difficult to being operationalized like e. g. levels of waste emissions on the one hand and natural assimilative capacity on the other hand (Gladwin, Kennelly, and Krause, 1995, p. 891). The view that is also criticized by Gladwin, Kennelly and Krause (1995) is that sustainability tools (or tools of "greening" as it is directly stated by them) like e. g. life-cycle analysis are focused on instrumental or process objectives too much. At the same time they emphasize that managers need to be informed about how far away there still are from achieving ultimate goals (Gladwin, Kennelly, and Krause, 1995, pp. 899-900). Due to the fact that levels of the use of different kind of materials and connected to them emissions may be difficult to specify it may be that managers with a business case frame find it easier to adopt measures simply determined by financial considerations and in this way a call to an action in their problem formulation may be well visible. Having had network created managers with a business case frame may also find it less complicated to implement the project as the data related to how to share profits resulting from the projects are relatively easy to transfer. As a result, the high level of engagement of stakeholders appears to be more probable as the chances to derive advantages from the network cooperation with regard to ways of rendering services, selling goods would be more visible. It may be noticed that showing legitimacy with regard to technical dominance is specific for pragmatic strategy of legitimacy building as interpreted by Suddaby et al. (2017). However, the threat that partners would have difficulties to meet demands as to cost-effective requirements can be exposed. Especially, it is to happen when discursive practices would turn out to cause implicitly participants to match ecological solutions with the only cost effective ones. They could focus on it because as technocentric paradigms claim each time externalities arise from market failures they are not to be internalized until it is cost effective (Gladwin, Kennelly, and Krause, 1995, p. 884). For managers with a paradoxical frame it may turn out to be more difficult to specify the problem, especially when they would try to communicate with different groups in their whole network using the language adequate to the group. Because of these difficulties and uncertainties as to how should suitable behavior be like, then a risk may emerge that hitherto recognized patterns of behavior (related e.g. to categories like "green identity" immersed in the discursive practices approaching somehow radical view of ecocentrism) are likely to dominate. This way of behavior could be to some extent (especially with regard to social or symbolic dimension) similar to the one described by Suddaby as conforming (2017). If these managers were closer to the stand represented by technocentrism they would not pay sufficient attention to this aspect at the end. If these managers were closer to the stand represented by ecocentrism then pragmatic action could turn out to be even more difficult, because here worldview of ecocentrism means that all legitimate interests should be taken into account (Gladwin, 
Kennelly, and Krause, 2015, p. 889). Recognizing as the sustaincentrism sees it that all human values are dependent on a healthy context comprised of ecological, social and economic dimension (Gladwin, Kennelly, and Krause, 1995, p. 895) is to outline the interpretive doubts even more (Gladwin, Kennelly, and Krause, 1995, p. 894). Awareness as to the necessity of introducing policy instruments and economics incentives is to create special requirements directed towards more active participation of local authorities as well as towards social and political institutions (Gladwin, Kennelly, and Krause, 1995, p. 893). The problem of embracing possible goals and interests of all engaged entities would be strengthened.

The prudence dimension of sustainable development requires that due to the constrains like complex dynamics in ecological and social systems (Gladwin, Kennelly, and Krause, 1995, p. 879; Costanza et al., 1993) people maintain cautious attitude as well as they should be prepared for constant surprise (Gladwin, Kennelly, and Krause, 1995, p. 879; Ludwig, Hilbron, and Walters, 1993). When facing with dilemma managers with a paradoxical frame are supposed to consider firstly how to create trust so much needed when there are many different entities operating as network members. It has been proved (e.g. Capaldo, 2007) that there are some solutions which when having been implemented within the network should allow entities to work together until they finish due to the end of the project. But what is more, these managers may still be aware that besides reasons like many entities belonging to different groups there are other reasons why cooperation may cause partners to be anxious about it. These reasons could turn out to be impossible to become visible. Even if these managers were to start talking about them, it could turn out to be unreasonable because for their project to be regarded as taken-for-granted it would be better not to engage too much in justifying it (Suchman, 1995). Here the task of finding one solution to solve the problem once and for all is turn out to be impossible and it could lead managers to the final feeling of an absurdity of the whole situation related to organizational change (Hahn et. al., 2015). If these managers were to follow sustaincentrism assumptions, they should have a belief that both knowledge possessed by human beings as well as institutions created by them are all able to reveal these limits and thresholds that they are looking for (Gladwin, Kennelly, and Krause, 1995, p. 895). Taking into account the context of sustainability projects it could happen that they would rest assure that in the long-term they are not to break any rules threatening the cooperation. In case of managers with a business case frame the dilemma involves noticing that network members may be afraid of financial losses and it may be difficult to ensure every member that in short time space (again it is the assumption which is connected to technocentric worldview - Gladwin, Kennelly, and Krause, 1995, p. 883) conditions under which members cooperate in a network actually could be considered as sufficient to operate efficiently. Until project is to be profitable these managers are assumed not to ignore the risk that the project may turn out to be a failure, however, irreversible changes as to the list of the members of a project are not to be avoided. It would simply be impossible that every participant could derive enough advantages from the cooperation. 
The security dimension of sustainable development in general terms require that decision makers take action to ensure that people could live in a safe and healthy way having lives of a good quality. Needless to say, there are many demands which have to be met in order for it to be fulfilled, e. g. reciprocity, transparency or accountability (Gladwin, Kennelly, and Krause, 1995, p. 880; Veiderman, 1994) as well as taking care of such processes as self-organization (Gladwin, Kennelly, and Krause, 1995, p. 880; Norton, 1991). In the phase when paradox should be approached it is to be noticed that managers with a business case frame who are focused on economic aspects could become irritated that tensions, resulting from the uncertainty determined by the risk of possible financial failure, can not be solved once and for all. Even if given solution would be implemented with success (financial primarily) it might happen that as time goes by this solution would turn out to be obsolete and would cause members of the network to incur losses. In spite of this risk it would be unreasonable to resign from assumed project. This is because as a result of its realization it is possible at least to build suitable competences in order to be able to implement technologies of next generations. As these managers are assumed to see the reality as positive or negative only, this phase can be actually never approached by them. It is more possible that they would consider the issue from the point of view of separated time intervals (similarly to the so called structural separation that is an approach to the matching different strategies described by Scherer, Palazzo, and Seidl, 2013). That is why steps made by them should look like being reasonable and rational rather in short-time interval. In case of managers with a paradoxical frame who are not to avoid considering analyzed circumstances as complex two scenarios appear to be possible. Firstly, taking into account three fields (that is economic, social and environmental) in which results achieved may stem from following seemingly opposed paths, it is reasonable to argue that these managers would understand the necessity to balance undertaken actions. Consequently, they may be more willing to take into consideration that environmental issues may result in an inflow of new inhabitants possessing high qualifications, which may allow in long time frame to achieve additional goals in two other fields. However, it may require that not only does each individual make a decision on what steps could contribute to sustainability, but also different levels of management are willing to consider issues even if they should be solved by managers at lower levels. Hence, reflexive capacities as described by Scherer, Palazzo, and Seidl (2013) would be required. In long-time horizon these managers are expected to build enterprise that thanks to improving its competences should achieve some level of excellence. Otherwise when being more aware of the structures that are built in network created due to the project realization these managers may start to manipulate (e.g. as tertius gaudens broker - Obstfeld, 2005). It could especially occur when it is quite visible for members of the network that it is not possible to accept the level of the complexity of encountered problems. Then ways in which some pieces of information are transferred when being modified could contribute to lowering tensions. Eventually it could turn out that in the long term frame it would 
be more profitable for such organization to separate and connect members of different networks depending on the specificities of the task.

In case of the phase of the workable certainty the question which both managers with a business case frame as well as managers with a paradoxical frame are expected to pose is actually the same and relates to whether given solution actually works. The dimension of the general view on sustainable development to which attitude stood by managers would be of greater importance is inclusiveness. It relates to that sustainability should include both social and ecological efficiency as well as it emphasizes that taking into account human dimension of sustainability means that it is necessary to recognize "driving forces" of "anthropogenic global environmental change" like technological changes or political and economic institutions (Gladwin, Kennelly, and Krause, 1995, p. 878; Stern, Young, and Druckman, 1992). When trying to consider consequences of possible managers' views related to this dimension for sustainability project, the issue to be discussed is which kind of explanations may be taken into account to pursue the engagement in it. Even if some members of the network would be disadvantaged in some way or be forced to leave the network, the whole project from the point of view of managers with business case frame may appear to fulfill its role as e. g. it allows other members to avoid suffering losses or to derive benefits. Each time these managers can actually justify solutions in relation to conditions under which they are implemented. If the external environment changes, then it is not the problem on the part of those who undertake activities, only the one related to the external environment. Due to the fact of being more sensitive to the issue of network structure managers with a paradoxical frame are likely to pay attention to that this kind of failure is also possible as a result of the inappropriate network structure and the rules of behavior that result from it. For example, it may happen when some important entities are unrepresented or overrepresented. That is why in this case it is more probable that managers would focus on the issue of inviting other entities (or encouraging them to leave on the contrary) as they are expected to how they can shape correct environment in order to possess resource base which is to be suitable regarding current conditions.

\section{Conclusions}

In this paper it has been proved that when analyzing how organizations can respond to sustainable development challenges it is necessary to consider managerial cognitive frames. This is because they are to shape channels through which knowledge related to sustainable management practices flows as well as its content. Adapting proposition presented by Gladwin, Kennelly, and Krause (1995) it has been assumed that main dimensions through which individuals are to think about sustainable development cover connectivity, equity, prudence, security as well as inclusiveness. The topic is to be considered as important from the point of 
view of management theory because as Gladwin, Kennelly and Krause (1995) argue by disassociating organizations and biosphere as well as human communities from each other, management theories may encourage even implicitly to behave in a way that finally can lead to the destruction of natural and social systems (Gladwin, Kennelly, and Krause, 1995, p. 896). Shrivastava, Ivanaj and Persson make a claim in favor of innovations to be introduced in products, services as well as in environment friendly production and logistics systems or human resources management and business models that should be focused on sustainability and possibilities of value creation together with stakeholders (Shrivastava, Ivanaj, and Persson, 2013, p. 232; e.g. Boons, and Lüdeke-Freund, 2012). In general, sustainability causes enterprises to be obligated to formulate and next to achieve simultaneously goals that cover social, economic and environmental issues (Hahn et al., 2015, p. 20; e.g. Gao, and Bansal, 2013). In the literature it is argued that worldviews could be a factor that influences how people can assess these dimensions (Gladwin, Kennelly, and Krause, 1995). Assuming that worldviews can have an impact on how managers are to make decisions related to their engagement in cooperation with other entities to realize sustainable projects, in the paper it is proposed to take into account managerial frames (Hahn et al., 2015) as well. These frames are factors that are believed to modify ways in which managers think actually about both sustainability development in general and implementation of their projects. As it has been argued in the paper managers with a business case frame are expected to be both limited in scope due to favoring incremental adaptations and swift due to economic pressure (Hahn et al., 2015, p. 32; Slawinski, and Bansal, 2012). Having to assess and to integrate a greater diversity of aspects that may turn out to be competing with each other, managers with a paradoxical frame need to spend more time on making decisions on in their opinion unique issues (Hahn et al., 2015, p. 32: Slawinski, and Bansal, 2012). Descried differences when being match to challenges of sustainable development appear to have a great impact on how enterprises may cooperate in networks and as a consequence on final results. The task for managers is actually to make use of different experiences. The issue which is worth emphasizing is that the attention paid to possible relations among cognitive frames and ways in which individuals may come to realize how social structures within which they operate can impact their decision. That is the direction of analysis stemming from the assumption of critical realism related to epistemological relativism and the fact that our knowledge is to be limited by historical conditions. In order to take it into account as well as to not being indifferent toward the issue of human reflexive capacity, it is advisable to maintain analytical separation between structures and actions. In the paper it has been assumed that paradoxical cognitive frames can be a factor that may to some extent contribute to this kind of ability to perceive the world in this way. Again, although considerations of theoretical implications of presented ideas appear to be promising research avenue for the future, the above-mentioned propositions need to be further investigated empirically. Here it could be difficult to claim whether e. g. in case of being focused only on economics aspects at the same time an individual could have views that are to be in favor of some kind of 
superiority of human to nature that is considered as specific in case of technocentrism worldview (Gladwin, Kennelly, and Krause, 1995, p. 882). Similarly, in case of managers with a paradoxical frame it is to be checked whether they actually would like to agree with the statement according to which there is an inextricable link between human activities and natural systems (Gladwin, Kennelly and Krause, 2015, p. 890). The issue could also be how we should interpret some ideas related to these worldviews (as e. g. trickle-down benefits) in the context of network cooperation (Gladwin, Kennelly and Krause, 1995, p. 884). The limitations of the above-mentioned analysis result from the fact that the considerations are connected to the hypothetical situation so that the postulates presented here are to be treated primarily as proposals to be investigated. Conducting theoretical analysis of the problem may appear to be simplified due to the lack of empirical data, however, the fact that two types of frames described in the paper are to some extent contradictory to each other help the author to outline possible differences based on results of researches discussed in literature. Finally it is to notice that the theoretical analysis of how different cognitive frames can impact on a process of making decisions on sustainability challenges could make it more visible why some phenomenon may occur when partners are to cooperate in networks also due to using the description of sensemaking process. Here it is important to remember that proposed phases of this process follow research conducted within different context of decision making (Lüscher, and Lewis, 2008). At the same time both research conducted by Lüscher, and Lewis (2008) and hypothetical decision on sustainable project discussed in this paper entail organizational changes that is why the decision to refer to this description has been made. It enabled the author to show how managers with different cognitive frames may come to their conclusions by posing different questions that reflect their ways of thinking, which is here believed to be one of decisive factors about future process of implementation proposed solutions.

\section{References}

1. Al-Amoudi, I., Willmott, H. (2011). Where constructionism and critical realism converge: interrogating the domain of epistemological relativism. Organization Studies, vol. 32, no. 1, pp. 27-46.

2. Byrch, Ch., Kearins, K., Milne, M.J., Morgan, R.K. (2009). Sustainable Development: What does it really mean? University of Auckland Business Review, vol. 11(1), pp. 1-7.

3. Capaldo, A. (2007). Network structure and innovation: The leveraging of a dual network as a distinctive relational capability. Strategic Management Journal, vol. 28(6), pp. 585-608. 
4. Delbridge, R., Edwards, T. (2013). Inhabiting institutions: critical realist refinements to understanding institutional complexity and change. Organization Studies, vol. 34(7), pp. 927-947.

5. Gladwin, T.N., Kennelly, J.J., Krause, T.-S. (1995). Shifting paradigms for sustainable development: implications for management theory and research. Academy of Management Review, vol. 20, no. 4, pp. 874-907.

6. Greenwood, R., Raynard, M., Kodeih, F., Micelotta, E.R., Lounsbury M. (2011). Institutional complexity and organizational responses. The Academy of Management Annals, vol. 5, no. 1, pp. 317-371.

7. Hahn, T., Preuss, L., Pinkse, J., Figge, F. (2015). Cognitive frames in corporate sustainability: managerial sensemaking with paradoxical and business case frames. Academy of Management Review, vol. 4015, no. 1, pp. 18-42.

8. Johnson, M.P. (2015). Sustainability management and small and medium-sized enterprises: managers' awareness and implementation of innovative tools. Corporate Social Responsibility and Environmental Management, vol. 22, pp. 271-285.

9. Lüscher, L.S., Lewis, M.W. (2008). Organizational change and managerial sensemaking: working through paradox. Academy of Management Journal, vol. 51, no. 2, pp. 221-240.

10. Obstfeld, D. (2005). Social networks, the tertius iungens orientation, and involvement in innovation. Administrative Science Quarterly, vol. 50(1), pp. 100-130.

11. Scherer, A.G., Palazzo, G., Seidl, D. (2013). Managing legitimacy in complex and heterogeneous environments: sustainable development in a globalized world. Journal of Management Studies, vol. 50, no. 2. doi: 10.1111/joms.12014.

12. Shrivastava, P., Ivanaj, S., Persson, S. (2013). Transdisciplinary study of sustainable enterprise. Business Strategy and the Environment, vol. 22, p. 230-244. doi:10.1002/ bse. 1773 .

13. Suchman, M.C. (1995). Managing legitimacy: strategic and institutional approaches. Academy of Management Review, vol. 20, no. 3, pp. 571-610.

14. Suddaby, R., Bitektine, A., Haack, P. (2017). Legitimacy. Academy of Management Annals, vol. 11, no. 1, pp. 451-478, doi: 10.5465/annals.2015.0101.

15. Tost, L.P. (2011). An integrative model of legitiacy judgments. Academy of Management Review, vol. 36, no. 4, pp. 686-710, doi: 10.5465/amr.2010.0227.

16. Turner, J.H. (2008). Struktura teorii socjologicznej. Warszawa: PWN. 


\section{Footnotes}

${ }^{1}$ Social structures can be understood as configurations of rules (normative and interpretive rules) and resources (allocation and authority resources) that are used based on foundational organizational rules to create and recreate different types of social relations both in time and in space. Social relations allow for shaping institutions and dependent on which kind of rules and resources are of primary importance it is possible to say about different institutional orders, e. g. political or economic (Turner, 2008, p. 576-577).

${ }^{2}$ Put it differently, it may be said that given thing (or a state or an idea) is to exist before it is discovered. However, when others are to accumulate knowledge about it as a result of this discovery, it is believed that this knowledge is to contribute to a change of this given thing (or a state or an idea). What is important, this change is believed to occur not only because of this knowledge but also due to many other factors like e. g. social environment (Al-Amoudi, and Willmott, 2011, p. 32).

${ }^{3}$ It means that categories by which people describe the world are to obtain their meaningfulness primarily because they are used within given set of discursive practices (like e. g. a discourse of environmental debate). They cause that these categories are grasped (like e. g. "environmental activist" or "grey consumer"). Then the task is to investigate these practices which allow categories to be hegemonic (Al-Amoudi, and Willmott, 2011, p. 36). It can be assumed that such categories refer to given aspects of existing state of affairs, however, it should not be assumed that these categories are more useful than others (e. g. "environmentally aware person" or "customer increasingly interested in green issues") without considering the contexts in which they are used (Al-Amoudi, and Willmott, 2011, p. 31; Bhaskar, 1986).

${ }^{4}$ However controversial it may appear to be, Gladwin, Kennelly and Krause (2015) chose these criteria to compare with each other three worldviews (these are ecocentrism, technocentrism as well as sustaincentrism) at the same time arguing that it is not useful to refer to such validity claims as truthfulness, rightness or aesthetic to evaluate alternate worldviews, because these worldviews should not be assessed as being right or wrong (Gladwin, Kennelly, and Krause, 2015, p. 881). As they aimed at "coherent persuasiveness" (Gladwin, Kennelly, and Krause, 2015, p. 881) and due to the fact that there is no neutral algorithm which would be to prove the correctness of an alternative paradigm (in case of checking which of the worldviews entail paradigmatic assumptions that are more likely to allow for sustainable development when being put into practice) (Gladwin, Kennelly, and Krause, 2015, p. 882; Kuhn, 1970) their stance has been accepted be scientific community.

${ }^{5}$ In case of dilemma, some advantages and disadvantages of each of the alternatives taken into consideration can be emphasized (Smith, and Lewis, 2011, p. 386; McGrath, 1982). In order to resolve the dilemma it is simply needed to choose one option whose advantages outweigh, so that the issue is approached from a "either/or" perspective (Smith, and Lewis, 2011, p. 387; Cameron, and Quinn, 1988). In case of dialectic tension, which is when ongoing process of resolving tensions occurs, the integration is a tool to resolve them. (Smith, and Lewis, 2011, p. 386-387).

${ }^{6}$ To have these problems explained more accurately, it can be noticed that needs for exploration and exploitation (March, 1991) when considered as dilemma cause managers to separate exploration and exploitation on temporal or spatial basis (Smith, and Lewis, 2011, p. 388). Considering the tension between exploration and exploitation as dialectic entails identifying emerging synergies that are to take place when new ideas, skills, and strategies are integrated along with the old ones (Smith, and Lewis, 2011, p. 388; Bledow et al., 2009; Farjoun, 2010). Taking a view on organizations as ambidextrous ones mean that paradox approach is adopted. Here it is emphasized that in order to support organizational learning both exploitation and exploration need to take place simultaneously as they reinforce one another (Smith, and Lewis, 2011, p. 388; e.g. O'Reilly, and Tushman; He and Wong, 2004).

${ }^{7}$ It is to be added that the way in which cognitive frames influence decision making process can be moderated by different factors. However, in this paper these issues are not analyzed in detail. Here it can only be noticed that the organizational identity is one of these factors. It can be considered as a set of attributes that make one organization distinguishable from the other one (Greenwood et al., 2011, p. 347; e.g. King et al., 2010). In general, the stronger the identity is, the more probable it can be that the organization will be ignoring external requirements (Greenwood et al., 2011, p. 348; Gioia and Thomas, 1996; Miliken, 1990). 


\title{
INNOVATIONS IN THE DIMENSION OF COMMUNICATION IN HEALTH SECTOR AND THE PERSPECTIVE OF SOCIETY 5.0
}

\author{
Szymon JOPKIEWICZ ${ }^{*}$, Agata JOPKIEWICZ ${ }^{2}$ \\ ${ }^{1}$ Jan Kochanowski University, Faculty of Law and Social Science, Department of Management; \\ szymon.jopkiewicz@ujk.edu.pl, ORCID: 0000-0001-5289-6820 \\ ${ }^{2}$ Jan Kochanowski University, Faculty of Pedagogy and Psychology, Institute of Adult Education; \\ agata.jopkiewicz@ujk.edu.pl, ORCID: 0000-0003-2198-2069 \\ * Correspondence author
}

Purpose: The aim of the article is to present the perceptions of ICT in times of the development of Society 5.0 in the awareness of beneficiaries of the healthcare system, and outlining the prospects of applying these solutions in the health sector.

Design/methodology/approach: The research was conducted in Świętokrzyskie Voivodeship. The questionnaire was used to survey people using primary healthcare services.

Findings: The respondents identified the importance of various forms of using ICT by primary healthcare entities, specifying their preferred information communication channel. The greatest number of indications, nearly $92 \%$ of the respondents, chose a direct contact with the doctor as important or very important.

Originality/value: The health sector in Poland, as well as in other countries of the EU, has been the subject of constant changes though they are not clearly visible for the general public. Technological progress and the related innovations in the field of communication are an opportunity to improve the information flow between the doctor and patient. Moreover, they facilitate gaining knowledge and thus constitute an important dimension in the process of learning in the perspective of Society 5.0 development. New ICT channels may be an important method for the health sector to find ways of reducing the costs of patient service.

Keywords: health sector, ICT, Society 5.0.

\section{Introduction}

The impact of modern technology on the healthcare system has become increasingly important in recent years. The health sector in Poland, as well as in other countries of the EU, has been the subject of constant changes though they are not clearly visible for the general public. Technological progress and the related innovations in the field of communication are an opportunity to improve the information flow between the doctor and patient. Moreover, 
they facilitate gaining knowledge and thus constitute an important dimension in the process of learning in the perspective of Society 5.0 development.

Functioning of healthcare sector in Poland and in other EU countries is the result of many political and economic conditions taking place over time. The economic conditions are important as the changes in healthcare create a wide variety of organizational and financial forms (Świder, 2004) connected by a common information network.

Society 5.0 is the idea of a modern, future-oriented and human-centred society, in which the unity of the real and virtual world is realised through technologies, e.g. Artificial Intelligence, Internet of Things, robotics or Big Data. According to this concept, the aim of the society will be to create a reality in which services will be provided to everyone at any time and place, regardless of the region, age, gender, language, i.e. without limitations, with the simultaneous economic growth and prosperity and overcoming social challenges, thus contributing to the prosperity of global society (du Val, 2019). Society 5.0 is more precisely described in the Japanese approach, which promotes a model of inter-human relations focused on an individual (human-centric society), where the economic progress serves to solve social problems through the system and technologies which integrate virtual and physical space. It is, therefore, the society which is characterised by a higher level of integration, in which interrelated realities - the digital one and the real one - facilitate embedding virtual space in the real world. Such society can be called super-intelligent or creative. It is the subsequent, fifth stage in the evolution of societies, following the hunting society, agricultural society, industrial society or information society that we have nowadays (Tworóg, Mieczkowski, 2019).

Building and maintaining an effective healthcare system is not easy and can be influenced by the following aspects: ageing society, constant mobility of people, low effectiveness of financial resources from public funds spent on health services. What is more, the problem of cost intensity of the new medical technologies is growing. These issues lead to the conclusion that new ways of implementing innovative solutions must be searched for, which will provide for effective distribution of financial means and improve information flow, and thus the control over the functioning of the whole healthcare system in Society 5.0.

Therefore, the use of ICT is of key importance to improve the quality of services offered in health sector. The widespread introduction of information-communication technologies will provide cost-effective care, among others, based on models of data management such as Big Data or Data Mining. Although in some cases the approach is used frequently, in the global scale digital tools are still rare, which results from the fact that implementing ICT in healthcare is a process, not a single action. The long term nature of changes allows both the medical personnel and patients to adapt to developing needs and new challenges (Batko, 2017). The difficulties which can be encountered while implementing innovative solutions include, primarily, the limited access to technologies, problems of integrating them with the work of medical personnel and concerns related to privacy and data security. The obstacles are being overcome, but not quickly enough. Therefore, new information-communication technologies 
creating intelligent solutions for sectors of economy and functioning organisations can be an alternative in addressing the needs of the developing Society 5.0. ICT can provide high quality of services, giving an opportunity to build a cost-effective system of healthcare.

Acknowledging that scientific discoveries and innovations are intermediary forces connecting different sectors, countries and regions, their cooperation should contribute to achieving the goals of sustainable development. Parallel assumptions constitute the basis of the European idea of Responsible Research \& Innovation (RRI), which emphasises that research and innovation should take into consideration complex reality and respond to its demands. The challenges facing the Old Continent were outlined in the Europe 2020 strategy, and include, among others, such areas as health, demographic changes and prosperity; food, agriculture, forestry and water; safe, clean and efficient energy; smart, ecological, integrated transport; climate, environment and natural resources (du Val, 2019). Realising the idea of Society 5.0, the above mentioned activities should concern all countries, all the regions in them, regardless of their GDP, so as to equalize living standards and access to highly-qualified services.

Therefore, the aim of the article is to present the perceptions of ICT in times of the development of Society 5.0 in the awareness of potential beneficiaries of the healthcare system, and outlining the prospects of applying these solutions in the health sector.

\section{Technological Innovations and Health - the Role of Information Flow in the Perspective of Society 5.0.}

Global trends and recommendations of WHO and national health organisations leave no doubt that digitalisation of healthcare is the only right procedure, especially in the context of Society 5.0. According to WHO, e-health is the only way to overcome the limitations of a traditional healthcare system which constitute the so-called health system challenges (HSC). The World Health Organisation points to three main challenges of healthcare (Chojnacki, Chromiec, 2019):

1. Insufficient resources, both human and material, which can be overcome by creating programs for optimising certain activities to be performed without human intervention (e.g. administrative matters).

2. Lack of data or access to data, which can be counteracted by using automatic recording of diagnostic tests results, creating an electronic platform of medical documentation, as well as creating medical data registers.

3. Deficiencies in monitoring patients' condition, follow-ups which could be realised e.g. by using applications connected to medical devices to monitor automatically patients' health or patient empowerment. 
Information-communication technologies are a driving force of economic, scientific and technological development (Watanabe et al., 2015), and an important source of competitive advantages (Iniesta-Bonillo et al., 2013). Their functioning in terms of support for specific sectors of economy is varied and changes over time.

Currently ICT is one of the most dynamically developing sectors of economy, its implementation on the level of enterprises and skilful use of related technologies are one of the most important stimuli influencing the increase of productivity (Venturini, 2015) and vitalising the economy. The diffusion of information and knowledge connected with applying ICT in sectors of economy is accelerated when the networks of cooperating units are geographically concentrated, therefore the need to use ICT systems and increase cooperation between them (Juchniewicz, Grzybowska, 2010). The above mentioned situation takes place in the health sector, where the ongoing process of marketisation, and the related dynamic development of technologies have improved task coordination and control over the distribution of public funds. Moreover, the effective use of technologies in healthcare sector allows for receiving up-to-date information about the beneficiaries of the system, which can affect the quality of services offered and reduce the costs of patient service.

The development of ICT has been gradually changing practically every aspect of social life (Rattle 2010), starting from business transactions, everyday routine, lifestyle and ending with politics or economics. Consequently, new aspects emerge and deserve attention: e-economy, e-democracy, e-education, e-trade, e-business, e-banking, e-taxes and e-health (Çilan, 2009).

Changes that are brought by the ICT revolution and globalisation trigger a discussion in areas related to health and information flow which facilitate learning process in organisations and societies:

- demographic changes in developed and developing countries. Currently, there are approximately 7 billion people in the world (Social, Digital and Mobile Worldwide, 2012). The UN estimates indicate that by the year 2053 there will be over 9 billion people on Earth. This will happen due to increasing improvement of the quality of healthcare, and more precisely technological development in that area, more effective disease control and global economic development (Friedman, 2008).

- increased financial burdening of the state budget with the cost of healthcare (Gartner, 2009), which is the challenge even for the richest countries in the world (Roper et al., 2011).

ICT may be an element of improvement and reducing the expenses on healthcare systems, however much will depend on the level of its implementation and costs which can be paid by the stakeholders of the service relation. There are three levels of ICT services for communication and knowledge exchange: 
1. Links and networks: email, telecommunication infrastructure, cables, satellites.

2. Public information and communication: government information, crucial information for the community, public broadband network.

3. Information and communication connected with healthcare (von Dijk, 2006).

Referring to healthcare, it is indicated that an important argument for the use of modern technologies in this segment is obtaining accurate information about a patient, sharing knowledge, educating patients, and thus the process of learning an organisation in interaction with the environment. Moreover, ICT usage allows for reducing the costs of medical services. This matter is of crucial importance especially in relation to Polish healthcare system (Andreassen, 2012), where one can observe a constant increase of costs of a single patient's service, connected with low reimbursement from the National Health Fund (Narodowy Fundusz Zdrowia NFZ) in relation to the growing number of long-living pensioners - the main beneficiaries of the system. Therefore, it is reasonable to search for reduction in at least part of the costs generated by the healthcare system. Obtaining complete and fast information about a patient, knowledge exchange - interactive process of learning through the use of information technologies.

The above mentioned areas open a perspective of improving the flow of information, triggering the process of learning, the beneficiary of which becomes a health sector unit, obtaining up-to-date knowledge and the possibility of reaction, which facilitates the process of treatment, and additionally engages the patient to consciously build knowledge about his/her health condition.

\section{E-Health in the Dimension of Information-Communication Technologies in the Health Sector}

The term e-health can be interpreted as the use of ICT in all activities that relate to the healthcare sector (Dąbrowska, 2009) and refers to health information portals, electronic records, telemedicine services, personal portable communication devices (Andreassen, 2012) and many other ICT tools used in preventive actions, diagnosing, treatment or monitoring health condition (Dąbrowska, 2009). Generally speaking, e-health is applying ICT in the healthcare sector (Pawar et al., 2012). New information communication technologies are important not only in terms of improving the quality of patient service, but also bring certain economic benefits. They mean better compliance with the doctor's recommendations: the number of ordered diagnostic and specialistic tests, frequency of visits or the length of hospitalisation and the overall duration of treatment (Charles et al., 2000). In times of problems with the public health service functioning and lack of access to certain services, the fact of reducing costs of patient care thanks to effective communication through ICT seems invaluable. 
E-health covers several healthcare and information technology services, e.g. (Dąbrowska, 2009):

- electronic medical records which facilitate the exchange of patient data between healthcare entities (general practitioners, specialists, hospital teams and pharmacists);

- telemedicine covering all sorts of tests and measurements which do not require a patient's visit to a specialist;

- medicine based on scientific evidence which includes a system providing information on the proper treatment for a certain patient's condition;

- consumer healthcare information technology which allows for the access to information on certain issues from the area of medicine;

- healthcare knowledge management - specialistic access to medical information;

- virtual healthcare teams which include healthcare professionals who pass on information about patients through digital devices.

\section{Materials and Methods}

The research was conducted in Świętokrzyskie Voivodeship, which belongs to the so-called eastern wall i.e. the region with the lowest share in GDP $(2.3 \%$ according to the Central Statistical Office data of 2018). The questionnaire was used to survey people using primary healthcare services (POZ). The group under study was diversified in terms of the place of residence (small towns and cities with more than 100,000 inhabitants), with nearly half of the respondents being the residents of urban areas and the rest from rural areas, age (50-59 years old), as well as gender - women constituted $70.14 \%$ and men nearly $30.00 \%$ of the respondents, and education - people with higher education accounted for $13 \%$, while $64 \%$ had secondary education. People with primary or vocational education constituted a little over $22 \%$. The most numerous group were women with secondary education $-67 \%$ of the respondents, whereas men with the same education accounted for $57 \%$ of the respondents.

\section{Results}

The respondents identified the importance of various forms of using ICT by primary healthcare entities (POZ), specifying their preferred information communication channel the telephone, the Internet, direct contact with medical personnel. The greatest number of indications, nearly $92 \%$ of the respondents, chose a direct contact with the doctor as important or very important. The category of tele-advice with the use of a telephone was chosen by just 
over $66 \%$ of the respondents. Whereas online contact was indicated as important by $27 \%$ of the people under study, which may come as a surprise in times of digitalisation of the health sector, the more so that the category of online contacts with a health sector unit was picked up by nearly $40 \%$. In turn, the category of contact with other patients through ICT tools was crucial for every fourth of the respondents, which may prove that a number of patients need additional information and/or a "group support". C to C communication is the arena for exchanging patients' knowledge and experiences important from the perspective of their dilemmas.

Table 1.

Forms of communication in service relations of the health sector entities (\%)

\begin{tabular}{|l|c|c|c|c|c|}
\hline \multicolumn{1}{|c|}{ Opinion } & $\begin{array}{c}\text { Totally } \\
\text { unimportant }\end{array}$ & $\begin{array}{c}\text { Rather } \\
\text { unimportant }\end{array}$ & $\begin{array}{c}\text { Neither } \\
\text { important nor } \\
\text { unimportant }\end{array}$ & $\begin{array}{c}\text { Quite } \\
\text { important }\end{array}$ & $\begin{array}{c}\text { Very } \\
\text { important }\end{array}$ \\
\hline direct contact with the doctor & 0,72 & 3,23 & 3,94 & 38,35 & 53,76 \\
\hline $\begin{array}{l}\text { tele-advice from the doctor with } \\
\text { the use of a telephone }\end{array}$ & 3,23 & 12,19 & 18,28 & 46,24 & 20,07 \\
\hline online contact with the doctor & 16,85 & 25,45 & 30,47 & 22,22 & 5,02 \\
\hline $\begin{array}{l}\text { online contact with the medical } \\
\text { entity }\end{array}$ & 11,11 & 18,64 & 31,54 & 30,47 & 8,24 \\
\hline $\begin{array}{l}\text { contact with other patients with } \\
\text { the use of ICT (C to C) }\end{array}$ & 21,15 & 26,88 & 27,96 & 18,28 & 5,73 \\
\hline
\end{tabular}

Source: Authors' study.

\section{Summary}

The idea of Society 5.0 which assumes the development of economy in cooperation between physical and digital environment realised though technologies may encounter certain barriers resulting from region-specific features, customs, habits and mentality, as well as the level of education in local communities in terms of access to and operating ICT devices. Therefore, despite the EU directives, governments, international organisations e.g. WHO, on the local level still the prevailing role in the preferred by patients forms of interaction may be given to the direct contact with the doctor, being the core of the service and the guarantee of quality and safety of the health service. Slightly different results in this matter were obtained in research carried out by the Future Health Index (FHI) in 2019 which indicate that $36 \%$ of patients are willing to undergo remote medial consultations in situations where the direct contact with the doctor is not necessary (2019 FHI Report), and 85\% of patients prefer to make appointments online, which differs from the indications obtained from the survey by $30-50 \%$. Such discrepancy can be explained, inter alia, by the lack of certainty or patients' trust as to the safety of collected data, and/or low awareness concerning the advantages of implementing ICT tools in the health sector. 
A significant role in increasing patients' awareness and encouraging them to use digital tools may by played by medical personnel who by recommendations can educate and provide knowledge on the use of ICT. In other words, the communication process leads to learning in service interactions, as a result of which the new value is created in the form of up-to-date knowledge. Thus, it will be necessary to share information about data security and benefits resulting from digital solutions for patients offered by health institutions.

It is worth noticing the role of digital interactive ITC media which, though unable to eliminate the direct contact, as it is indispensable, may create its valuable supplement. It may refer to activities like registration, additional information or consultation via a telephone or ICT. Introducing new interpersonal means of communication for patients may be a significant convenience, and for the health sector an important method of searching for ways of reducing the costs of patient service. Moreover, the development of digital media creates a chance to expand the activities connected with disease prevention. It is also another opportunity to reduce the high costs of health service in Poland.

\section{Conclusion}

1. The surveyed group identifies effective forms of communication with service providers with new ICT technologies, the role of institutions and their personnel will be to improve the ways of communication preferred by patients, which may favour the development of the idea of Society 5.0 in the health services sector.

2. Although the dominant method in the communication between a patient, doctor and personnel is still the direct contact, the respondents (aged 50-59) begin to notice the significant role of digital ICT media.

3. New ICT channels may be an important method for the health sector to find ways of reducing the costs of patient service. Moreover, their advancement creates an opportunity for learning processes which are essential in times of Society 5.0 development. 


\section{References}

1. Andreassen, H. (2012). ICT and patient roles; contradictions in e-health policy. Health Policy and Technology, Vol. 1, Iss. 2, pp. 88-89.

2. Batko, K. (2017). Możliwości wykorzystania systemów analitycznych w usprawnianiu opieki zdrowotnej. Zeszyty Naukowe Uniwersytetu Ekonomicznego w Katowicach. Uniwersytet Ekonomiczny w Katowicach. nr 316, p. 45.

3. Charles, C., Gafin, A., Whelan, T. (2000). How to improve communication between doctor and patients. British Medical Journal, Vol. 320, pp. 1220-1221.

4. Chojnacki, M., Chromiec, Z. at al. (2019). Pokłady cyfrowego bogactwa w stużbie pacjentom, czyli o wykorzystaniu potencjału danych $w$ sektorze ochrony zdrowia. Raport Alumnów Projektu „Liderzy Ochrony Zdrowia” Fundacji im. Lesława A. Pagi, p. 83.

5. Çilan, Ç.A., Bolat, B.A., Coşkun, E. (2009). Analyzing digital divide within and between member and candidate countries of European Union. Government Information Quarterly, Vol. 26, Iss. 1, p. 98.

6. Dąbrowska, A. (2009). Charakterystyka wybranych e-usług na polskim rynku. In: A. Dąbrowska, M. Jakoś-Kresło, A. Wódkowski (eds.), E-usługi a społeczeństwo informacyjne (pp. 96-98). Warszawa: Difin.

7. du Vall, M. (2019). Super inteligentne społeczeństwo skoncentrowane na ludziach, czyli o idei Społeczeństwa 5.0 słów kilka. Państwo i Społeczeństwo, nr 2, pp. 11-31.

8. eHealth for a Healthier Europe! - opportunities for a better use of healthcare resources (2009). Gartner, p. 7.

9. Friedman, T.L. (2008). Hot, Flat and Crowded. Why We Need a Green Revolution And How It Can Renew America. New York: Farrar, Stratus and Giroux, pp. 27-28.

10. Iniesta-Bonillo, M.A., Sanchez-Fernandez, R., Schlesinger, W. (2013). Investigating factors that influence on ICT usage in higher education: a descriptive analysis. International Review on Public and Nonprofit Marketing, Vol. 10, Iss. 2, pp. 163-164.

11. Juchniewicz, M., Grzybowska, B. (2010). Innowacyjność mikroprzedsiębiorstw w Polsce. Warszawa: PARP, pp. 36-37.

12. Pawar, P., Jones, V., van Beijnum, F., Hermenes, H. (2012). A framework for the comparison of mobile patient monitoring systems. Journal of Biomedical Informatics, Vol. 45, Iss. 3, p. 544.

13. Rattle, R. (2010). Computing Our Way to Paradise? The Role of Internet and Communication Technologies in Sustainable Consumption and Globalization. LanhamNew York-Toronto-Plymouth: Altamira Press, p. 1.

14. Roper, A.T., Cunningham, S.W., Porter, A.L., Mason, T.W., Rossini, F.A., Banks, J. (2011). Forecasting and Management of Technology. Hoboken: John Wiley \& Sons, p. 11. 
15. Social, Digital and Mobile Worldwide. The Key Numbers for Each Region Around the Globe. We Are Social, January 2012, p. 2.

16. Świder, P. (2004). Skuteczność a system finansowania ochrony zdrowia w krajach Unii Europejskiej - porównania. Problemy Zarządzania, Ochrona zdrowia, No. 4(6), p. 7.

17. Tworóg, J., Mieczkowski, P. (2019). Krótka opowieść o gospodarce 5.0, czyli jak żyć i funkcjonować w dobie gospodarki 4.0 i sieci $5 G$. Warszawa: Krajowa Izba Gospodarcza Elektroniki i Telekomunikacji, Fundacja DigitalPoland, p. 28.

18. Venturini, F. (2015). The modern drivers of productivity. Research Policy, Vol. 44, Iss. 2, pp. 359-361.

19. von Dijk, J. (2006). The Network Society. Social Aspects of New Media. London-Thousand Oaks-New Delhi: SAGE Publications, pp. 254-255.

20. Watanabe, Ch., Naveed, K., Zhao, W. (2015). New Paradigm of ICT productivity Increasing role of un-captured GDP and growing anger consumers. Technology in Society, Vol. 41, p. 29. 


\title{
SELECTED APPLICATIONS OF THE BLOCKCHAIN NETWORK IN THE ECONOMY 4.0
}

\author{
Kamil KARSKI \\ Lima Reklama, Rybnik; karskikamil@gmail.com
}

Purpose: The paper focuses on a trial of defining the assumptions of the fourth industrial revolution and presenting selected applications of modern Blockchain technology. The aim of this article is to draw attention to the growing importance of modern technologies having a significant impact on the development of the world economy and to show the opportunities of their potential introduction to the market.

Design/methodology/approach: The article is both theoretical and empirical. Literature research allowed to determine main pillars that Industry 4.0 is based on. From among them, the invention was selected, which has a wide range of impact both on the production environment and on the society.

Findings: The article shows the essence of new technologies in the Industry 4.0 and the selected applications of one of them. The article defines the impact of new technologies on economic development and provides a general research of new technologies in new World Economics.

Research limitations/implications: Blockchain network is a dynamically developing technology that can be, used in many different areas of life, unfortunately it is still in its infancy and its implementation is very slow.

Practical implications: One of the applications of the Blockchain network is the implementation to production systems that make order management more flexible and guarantee non-failure production which is also encrypted.

Social implications: Blockchain technology could redefine how people are using public services as daily bases.

Originality/value: The article contains description of new technology in modern economics. The article may be useful for researchers working on that subject and or the practitioners trying develop production or services using such invention for their clients.

Keywords: Blockchain, Industry 4.0, Smart factory, Data protection, Financial Service.

Category of the paper: Research paper. 


\section{Introduction}

Nowadays most enterprises face great difficulties which have a considerable impact on their continued existence on the market. A strong competitive environment, switching production processes according to changing consumer demands, the accuracy of effective decisions, or the speed of processing data accruing from the market - are the main, but not the only challenges faced by organizations. The aforementioned aspects affect an increasingly complex production system that provides huge amounts of data. It turns out that a company is not able to manage such a large amount of knowledge due to the lack of tools and platforms that are necessary for mutual cooperation of all areas of the company's activity. To remedy it, a concept was developed, that would combine knowledge, simulation, learning and optimization to improve modern production systems.

The concept of Industry 4.0 was coined at the industrial technology fair in Hanover 2011 (German - Industrie 4.0). Considerations had begun on what the changes would involve, when they would take place and what their effect would be. During the technological event, it turned out that in fact the fourth industrial revolution has already commenced and humanity is currently dealing with it. Taking into account other breakthroughs that lasted for decades and were limited to industry only, the fourth revolution can be described as a holistic one, as it covers almost every area of human life.

The first revolution began around 1760 and lasted until roughly 1840 . There had been a shift from using muscle strength to using mechanical force. The development started with the construction of the railway and the invention of the steam engine, which lead to the introduction of mechanical production. The popularization of the steam drive made the production not only more efficient, but also much faster. Due to the use of rail transport, the distribution time of goods thus produced was significantly shortened (Schwab, 2018).

The second industrial revolution, which dates back to the turn of the 19th and 20th centuries, enabled mass production - that began with the introduction of a production line and electricity (Iwański, Gracel, 2016).

The third industrial revolution took place in the 1960s. It is commonly referred to as the computer or digital revolution. Successively, significant improvements were made: in the semiconductor industry - the invention of transistors (Issacson, 2016) and large operating systems such as BSD. In the following years, personal computers and the Internet began to appear. The communication technology involved satellite TV and cellular connections, and Toyota developed a modern production and logistics model Just In Time (Czyżewski et al., 2017).

Industry 4.0 marks the fourth industrial revolution. It can be described as Economy 4.0. It brings together technology and value chain organization (Hermann et al., 2015). It is assumed that this revolution means a vision of smart factories based on intelligent cyber-physical 
systems. The implementation of this idea will allow for the development of intelligent, autonomous production systems, capable of self-configuration, self-control and self-repair. The main pillars on which this revolution is based are (Erboz, 2017):

- Big Data and Analytics,

- Autonomous Robots,

- Simulation,

- Industrial Internet of Things (IIoT),

- Computing Cloud,

- Horizontal and Vertical System Integration,

- Additive Manufacturing (3d printing),

- Cyber Security,

- Augmented Reality.

The author decided to describe a selected issue from a wide spectrum of the phenomena accompanying the fourth industrial revolution, which is the use of Blockchain network in a smart factory.

\begin{tabular}{|l|l|l|l|}
\hline Industry 1.0 & Industry 2.0 & Industry 3.0 & Industry 4.0 \\
\hline & & & \\
\hline Steam Engine & Electricity & Computers & Big Data, IIOT, AI \\
\hline
\end{tabular}

Figure 1. Industrial Revolutions. Source: own work.

\section{Characteristics of Blockchain network}

The emergence of distributed ledger technology (DLT) - blockchain networks, can be compared to the internet revolution. The main assumption of distributed registers is to move away from centrally managed information to its encryption at each member of the data exchange system. It is also associated with the risk of interference in its structures by users, who might try to falsify the results of calculations in individual blocks that store data (Walch, 2017). 
The year 2008 is considered to be the launch of the Blockchain network. For more than 12 years after this invention, there has been a strong link between the decentralized data registry and the creation of the Bitcoin cryptocurrency. The assumptions of this network were developed in the so-called Nakamoto Manifesto. It was probably created by one person or a group of anonymous cryptographers (Nakamoto, 2008). Since then, the interest in this technology and the potential use of this network for applications other than the world of finance and cryptocurrencies has increased rapidly. In turn, another version of the block system - Etherum - was proposed by 19-year-old Vitalik Buterin (Wood, 2014). In its implementation, the so-called Smart Contracts could be used. Contrary to the Bitcoin cryptocurrency, the Etherum network enables a much faster information exchange, which is 14-15 seconds, respectively, where the average Bitcoin exchange time is about 10 minutes (Kumar, Tripathi, 2019).

In the original Buterin project, there was a message, similar to Nakamoto's, that an opensource, global, decentralized register of contracts, transfers of property rights and the possibility of settling transactions should be created, on a principle that works like in the Bitcoin cryptocurrency case. Financial and technology industry companies such as Microsoft, Intel, Toyota, Credit Suisse, saw great opportunities using Etherum for their purposes, because it was programmable, while Bitcoin did not include this functionality (Petković, 2017).

To understand how the Blockchain network works, the following diagram was used (Hassan, Jain, Chandna, 2017):

\section{HOW A BLOCKCHAIN WORKS}

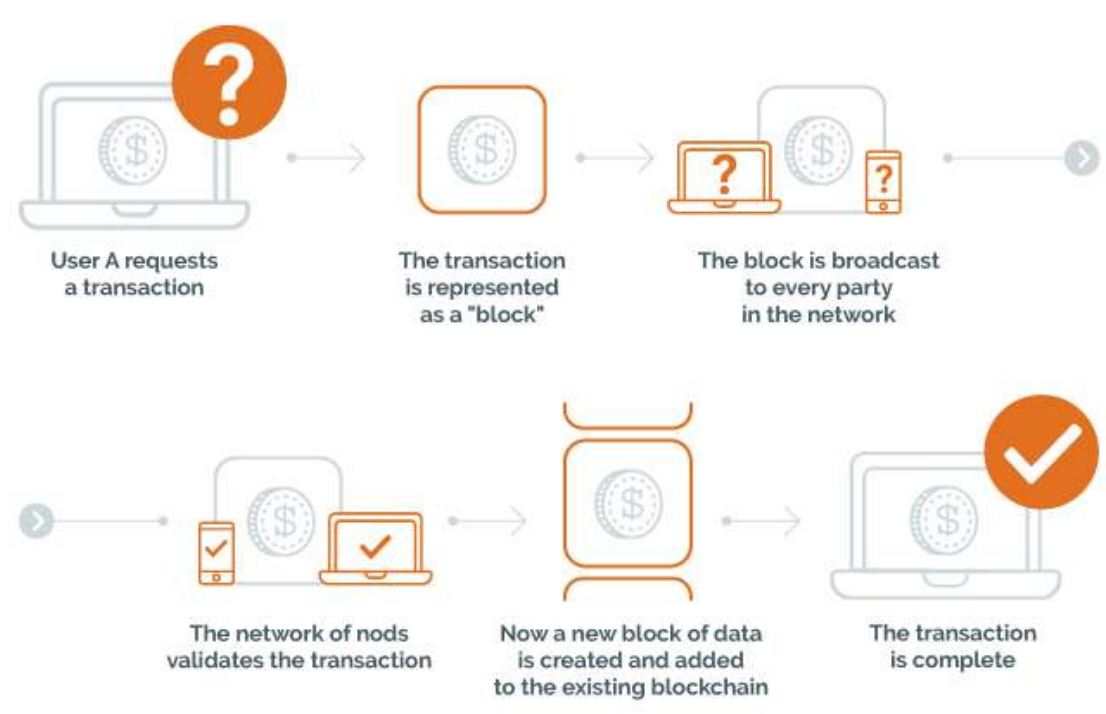

Figure 2. How blockchain technology works, from: "Blockchain, Cryptocurrency And Bitcoin" by N. Hassan, N. Jain, Chandna V.K., Copyright 2018 by JECRC Foundation. 
- In order to send or receive a bitcoin or to send any information, the user must make a transaction that is distributed to each participant in the network. Cryptographic algorithms add a record in the ledger for each user.

- Complex mathematical algorithms add the transaction to the public digital ledger. There is only one ledger and it is updated at the same time for each network participant, which guarantees durability and correctness of the operation. The network of nodes then validates the transaction.

- A new block transaction is added chronologically to the main Blockchain. No previous operation can be changed or deleted. Hence, it is difficult to counterfeit, because the transactions are cryptographically encrypted throughout the procedure, but remain publicly

- The operation is complete.

Initially, Bitcoin's Blockchain did not have a large size, but in later years, with the increase in the number of transactions, the size of the ledger increased significantly and in 2014 it exceeded 20 gigabytes. The amount of energy needed to maintain the network exceeded Ireland's energy demand (O'Dwyer, Mallone, 2014).

From the very beginning of the implementation of Blockchain technology and its use in the creation of digital currencies, it has become clear that cryptocurrencies are only a pretext to create innovative solutions. Big Data analysts, engineers and IT specialists have proposed the implementation of Blockchain technology for contract registration, voting during political elections, writing notarial deeds, placing orders or any other official documents.

The hash function is used to create blocks, which enables the transfer of data or large data sets. In computer science, this is often referred to as a hash (character string). Its task is to create a new string with a fixed, pre-programmed value, which is encoded to an unreadable form from any sequence of characters, e.g. passwords, texts or computer files. The most important advantages of the hash function are (Foroglou, Tsilidou, 2015):

- Unidirectionality and irreversibility - the created hash is one of a kind. It is very easy for a processor to compute a dataset hash, but it is not possible for such a process to go the other way. Having a hash created, there is no contingency to recover the original data.

- Overlap tolerance - two different datasets will not produce the same hash.

- Time stamping - both single operations or entire blocks are synchronized between all network participants.

Individual transactions are hashed separately to ensure the integrity of the transaction registry. The particular users avail themselves of their own key, which is not certified and that reflects the assumptions about the decentralization and anonymity of this system. 


\section{Selected applications of Blockchain network}

The fourth industrial revolution is represented by many components that interpenetrate and form a coherent whole. Each concept has a greater or lesser impact on human life. Blockchain is an example of innovation in Economy 4.0, which, in the author's opinion, penetrates technical, social and financial spheres, or - in the near future - will find its application in genetics.

\subsection{Financial system}

The financial system is a system of interacting financial institutions, capital markets and other elements of the financial system infrastructure. It is the part of the economic system which enables the provision of services that allow the circulation of purchasing power in the economy. The main features and functions of the financial system can be distinguished (Pietrzak, Polański, Woźniak 2012):

- Monetary - provides the non-financial entities with money and enables its circulation in the economy.

- Capital-redistributive - enables the flow of free funds from those entities that command them to those who need them.

- Controlling - regulates cash flows, in particular over the funds invested, borrowed and redistributed in the past.

The last function is the most important in modern economy, as it ensures the verification of financial flows and guarantees the stability of the entire financial order. An inseparable element of this system is the task of eliminating the risk in the form of imposing restrictions and rules of conduct on market participants. The current infrastructure consists of a large number of participants whose task is to process and record cash transactions, exchange of securities, derivatives and others. Processing institutions may at any time indicate the owner of the assets and the parties that have been trading.

The operation of the financial system to date has been working for nearly a century, but the ossifying structures did not allow smaller entities to decide about the future of the financial world, and also prevented the implementation of new revolutionary innovations.

Bitcoin, as the first cryptocurrency in history, is treated by the media as a future-oriented settlement system between members and as so called digital gold. Unfortunately, as noted by the author of this paper, despite many advantages that Bitcoin has, it is still a tool that is difficult to use (a small error during the transaction is enough and the funds will be irretrievably lost because the operations are irreversible) and very susceptible to speculation. These disadvantages do not allow Bitcoin to be considered a reliable means of payment. According to the creator's or creators' assumptions, the number of coins is limited to 21 million and their mining will take place in the next few years (Satoshi, 2008). 
Such limited supply makes Bitcoin a tool resistant to hyperinflation, unlike empty fiat money, the unlimited printing of which increases the debt of many countries. The financial system must settle its reckonings with the central unit of account, and therefore a third participant in the transaction must be present. In case of private entities, it is a banking system, while financial institutions simultaneously settle their own operations, using special units called clearing houses. Each of the centers has dozens of departments that deal with a single element of the accounting chain, that ultimately leads to validation of the transaction. In Polish banking system, an example of a clearing house that executes payment orders between banks is Krajowa Izba Rozliczeniowa S.A. (National Clearing House), established in 1992, which was established on the initiative of the Polish Banks Association, 16 largest banks and the National Bank of Poland (Marciniak-Neider, 2011).

Blockchain enables a replacement of all types of transactions, i.e. operations in securities, trading in receivables, funds and contracts (Mainelli, Milne, 2016).

\subsection{Smart factories}

The world of finance is certainly the place where Blockchain technology will find the widest application. In addition to banking, Blockchain can be successfully used in smart factory management and cyber-security.

A smart factory is defined as a plant that is designed to come to the aid of the employed human resources and machines in order to achieve more efficient production realizations. It is based on elements of the Industrial Internet of Things (IIoT), cyber-physical systems as well as artificial intelligence (AI). As a result, it will lead to the fact that a given plant will be "intelligent" enough to repair machines and devices on its own, to control the production process and to make corrections along with changes in the order. Using the resources of a smart factory will enable the production of individualized goods in accordance with the criteria presented by a particular customer. This will take place as part of mass production, so the time to deliver the order will not differ from that in case of large-scale production.

Enterprises that will implement Blockchain network technologies in their smart factories will reduce costs resulting from errors in orders. They will be able to avoid the use of defective materials from suppliers who suddenly changed their sub-contractors (Angrish, Hasan, Starly, 2018).

Having access to his Blockchain, the client is able to track the production process on an ongoing basis and make corrections, which he deems appropriate. Thanks to this transparency in production, the ordering party can be sure that their individualized order will not be subject to production faults resulting from human factor errors. Also, in case of external factors, e.g. natural disasters, the entire order is easy to recreate for the participants of this private Blockchain network. 


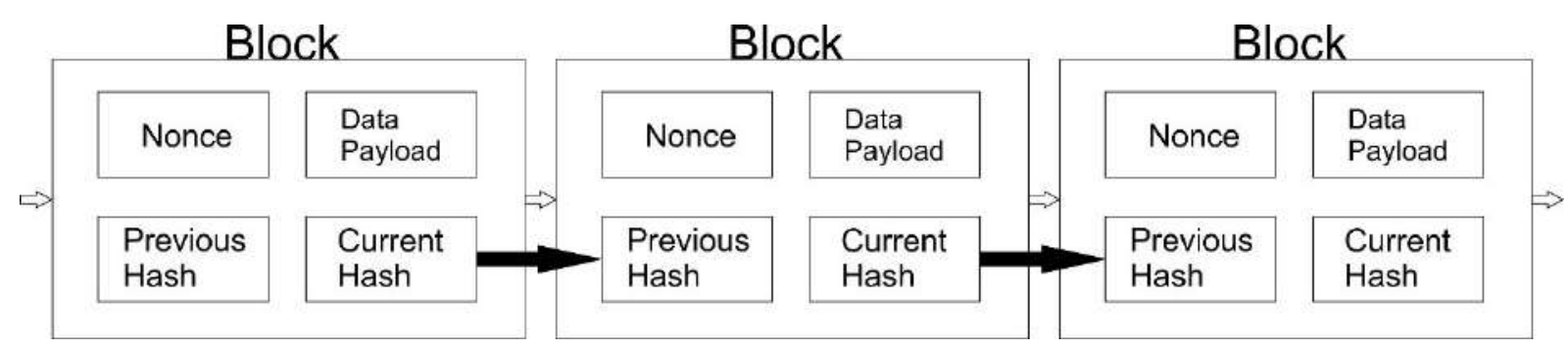

Figure 3. Schemat wprowadzania kolejnych danych do zlecenia w sieci Blockchain. Source: own work.

This proposed solution will fully automate the order processing. The smart factory itself, in the initial period of its existence, will be supervised by highly qualified personnel. Soon, with further expansion of the tools and platforms of the fourth industrial revolution, the human factor will be completely eliminated and will be replaced by the Industrial Internet of Things (IIoT) and Artificial Intelligence (AI). The next generation of smart factories created in this way will be completely automated. The cyber-physical system will itself determine how many prefabricates it needs for production (using the Japanese Just-In-Time method), will send a notification to the customer about the progress in production, will organize logistics and distribution of the product to the customer by means of autonomous self-propelled vehicles or drones to the recipient, who may also turn out to be ... a smart factory.

For the customer, the benefits resulting from the implementation of the Blockchain network are undeniable. Also, companies that implement this invention will not only save material resources, finances and time, but also significantly improve their cyber-security.

The factories of the future will be particularly vulnerable to data theft and industrial espionage. Many companies will change their production model to additive manufacturing 3D printing (Sturm et al., 2017). This type of production only requires a physical 3D printer and a digital object, which will make the production faster and cheaper. The listed advantages are a potential field for criminal activity from the hackers' point of view. The stolen design can easily be used to produce replacements, leaving the company with a loss of sales revenues and putting consumers at risk of using non-genuine parts. Another risk may be sabotage by manipulating the design by adding some internal flaws that are difficult to detect. From the outside, the product will not differ from the prototype, while the internal structure, slightly changed parameters or a different material may contribute to the creation of huge losses for the attacked company.

\subsection{E-voting}

Observing the political situation in Belarus (August 2020) due to the presidential elections and the resulting riots, it is justified to work on the electronic voting system and to implement it for general use.

One of the ways in which the Blockchain network is used, that inspires the most trust among citizens, is political elections. Blockchain provides information on the course of voting, which is verified by the multilateral cooperation of thousands of computers and a publicly available digital code. 
The above-mentioned features significantly increase the trust between citizens and the government, as the voter's personal data and the right to privacy are subject to special protection, and additionally, they promote greater involvement in exercising their electoral rights. Younger voters will be more likely to vote online via mobile devices than the traditional way, waiting in long queues to get a ballot paper and select their candidate.

Blockchain architecture secures every vote in a cryptographic manner, and the collection of election results takes place in a decentralized manner. There is no need to wait for the official announcement of the results by the central election commission, which receives the results from local election commissions. The main problem with this solution is still the slow verification of each operation, but in the future this problem will be solved.

The following conditions must be met to recognize a modern voting method as meeting the requirements of a democratic and law-abiding state (Curran, 2018):

- Publicly verifiable - each person involved in the elections can monitor the voting process on an ongoing basis and confirm the results of the election.

- Transparent - Blockchain architecture enables transparent voting supervision.

- Reliable and consistent - the election results should be the same for every verification unit, and the network itself should be resistant to hacking attacks.

- Ensuring anonymity - the ballot card cannot be assigned to the voter, but the voters can verify their votes.

- Third party controlled.

\section{Summary}

- A breakthrough Blockchain technology started a revolution, as it did with the computer revolution and the invention of the Internet. The fourth revolution proceeds more violently and much faster than the previous ones, it covers all spheres of human life.

- Blockchain architecture, which has an enormous potential, will find applications in many areas of the economy and social life, including:

- The world of finance and cryptocurrencies.

○ Production technology.

○ Political elections.

- Supply chain management.

- Power engineering.

○ Digital offices. 
Without a shadow of a doubt, the use of Blockchain technology increases the efficiency of business operations and improves the quality of life of citizens. The greatest advantages of this invention are decentralization and network security. Combined with other elements that make up the fourth industrial revolution, the companies planning to build smart factories will make a significant leap in competition with their competitors.

Financial institutions are closely watching the development of Blockchain technology and how it affects the behavior of participants. It offers individual users the speed of operation and low transaction costs, and through its decentralization, it will additionally guarantee anonymity and privacy. The world's financiers are not in favor of humanity settling massively through Blockchain, as they would lose their profits and control over the flow of funds and financial market participants. The biggest inconvenience, when conducting a transaction, is the risk of a mistake in sending the funds, as the transactions are inherently irreversible and there is no trusted third party to control the flow.

Citizens of a country that implement the architecture of dispersed blocks into its administration and public life will gain tools that will allow them to deal with many official matters without leaving their home. All government services, i.e. taxes, contributions, notarial deeds, land registers, will be publicly verifiable and transparent, and the political elections conducted will be scattered, undeniable, and most importantly, every citizen will be able to verify the voting results.

While Blockchain technology offers many benefits to society, its widespread use is still in its infancy as it is a complex code and a non-intuitive environment. The interface is still much more complicated and unclear than the ones of banking platforms or the Internet. Another issue is the lack of trust of people in unknown technologies and inventions.

The paper presents only selected examples of the applications of this technology, it is not yet widely known and used, but its enormous potential means that there will be more and more practical adhibitions.

The fourth industrial revolution offers many inventions and facilities for mankind, but one has to bear in mind that technological evolution is much faster than social evolution. It must be remembered that in highly developed countries there are still people who, for various reasons, have been socially and digitally excluded. Not everyone will be the beneficiary of the fourth revolution, because there are still regions in the world where the products of the second revolution (i.e. electrification) have not yet occurred, so it is even less possible to present Economy 4.0 inventions to these societies. 


\section{References}

1. Angrish, A., Hasan, M., Starly, B. (2018 June 18-22). A Case Study for Blockchain in Manufacturing: "FabRec": A Prototype for Peer-to-Peer Network of Manufacturing Nodes. $46^{\text {th }}$ SME North American Manufacturing Research Conference, USA. DOI: 10.1016/j.promfg.2018.07.154.

2. Curran, K. (2018). E-voting on Blockchain. The Journal of British Blockchain Assocation, vol. 1. Available at: https://jbba.scholasticahq.com/article/4451-e-voting-on-theblockchain, 24.08.2020, DOI: 10.31585/jbba-1-2-(3)2018.

3. Czyżewski, A., Grzegorczyk, W., Kozłowski, A., Bodnari, E., Krzemiński, B. (2017). Gospodarka 4.0 Czas zmiany dla biznesu. Warszawa: PKN Orlen.

4. Erboz, G. (2017 June 1-2). How To Define Industry 4.0: Main Pillars Of Industry 4.0. Managerial Trends In The Development Of Enterprises In Globalization Era. Slovakia.

5. Foroglou, G., Tsilidou, A.-L. (2015 May 14). Further Applications of The Blockchain. $12^{\text {th }}$ Student Conference on Managerial Science and Technology, Greece.

6. Hassan, N., Jain, N., Chandna, V.K. (2018 April 6-7). Blockchain, Cryptocurrency and Bitcoin. International Journal of Computer Engineering and Applications. Indonesia.

7. Herman, M., Pentek, T., Otto, B. (2015). Design Principles for Industrie 4.0 Scenarios: A Literature Review, No. 01. Dortmund: Technische Universitat. DOI: 10.13140/ RG.2.2.29269.22248.

8. Issacon, W. (2016). Innowatorzy. Kraków: Insignis, p. 187-188.

9. Iwański, T., Gracel, J.,(2016). Przemysł 4.0 Rewolucja już tu jest. Co o niej wiesz? Kraków: Astor, p. 6.

10. Kumar, R., Tripathi, R. (2019 November 15-17). Implementation of Distributed File Storage and Access Framework using IPFS and Blockchain. 2019 Fifth International Conference on Image Information Processing (ICIIP). India

11. Mainelli, M., Milne, A. (2016). The Impact and Potential of Blockchain on The Securities Transaction Lifecycle. SWIFT Institute Working Paper No. 2015-007. Available at SSRN: https://ssrn.com/abstract=2777404, 23.08.2020.

12. Marciniak-Neider, D. (2011). Rozliczenia Międzynarodowe. Warszawa, PWE.

13. Nakamoto, S. (2008). Bitcoin: Peer-to-peer Electronic Cash System. Retrieved: https://www.bitcoin.org, 21.08.2020.

14. O’Dwyer, K.J., Mallone, D. (2014 June 26-27). Bitcoin Mining And Its Energy Foot Print. $25^{\text {th }}$ IET Irish Signals \& System Conference 2014 \& 2014 China-Ireland International Conference On Information And Communications Technologies. Ireland. DOI: 10.1049/CP.2014.0699. 
15. Petković, B. (2017). 10 Companies And Businesses That Accept Etherum. Retrieved: https://www.insidermonkey.com/blog/10-companies-and-businesses-that-acceptethereum-599996/, 22.08.2020.

16. Pietrzak, B., Polański, Z., Woźniak, B. (2012). System finansowy w Polsce. Warszawa: PWN, p. 18-19.

17. Schwab, K. (2018). Czwarta Rewolucja Przemysłowa. Warszawa: Wydawnictwo Studio Emka, p. 22-23, 62-63.

18. Sturm, L.D. et al. (2017). Cyber-physical vulnerabilities in additive manufacturing systems: A case study attack on the .STL file with human subjects. Journal of Manufacturing Systems, Vol. 44, Part 1, p. 154-164. DOI: 10.1016/j.jmsy.2017.05.007.

19. Walch, A. (2017). Should Public Blockchains Serve as Financial Market Infrastructures? Handbook of Digital Banking and Internet Finance, Vol. 2. Amsterdam: Elsevier.

20. Wood, G. (2014). Etherum: A secure Decentralized Generalised Transaction Ledger. Etherum project yellow paper, 151, p. 1-32. 


\title{
FEATURES OF THE OFFER IN THE DISTRIBUTION AREA. COMPARATIVE ANALYSIS ON THE EXAMPLE OF DAIRY COOPERATIVES IN THE MALOPOLSKIE AND ŚWIĘTOKRZYSKIE VOIVODESHIPS
}

\author{
Izabela KONIECZNA \\ Jan Kochanowski University in Kielce, Faculty of Law and Social Sciences, Department of Management; \\ irud@interia.pl, ORCID: 0000-0002-3632-3245
}

Purpose: The first purpose of this article is to identify and compare the validity of features of the offer for the customer in the area of distribution from the point of view of dairy cooperatives from Poland from the Świętokrzyskie and Małopolskie provinces, which are adjacent to each other.

Design/methodology/approach: Direct interviews using a questionnaire survey were conducted among representatives of cooperatives representing $41 \%$ of the population, which resulted from the willingness to participate in the survey.

Findings: The analysis of the research results, taking into account the mean for all customers, show that the indicated features of the offer for the customer in the distribution area were considered by cooperatives from both provinces as very important (there was only one feature that was not indicated by all cooperatives).

Originality/value: The comparison of the validity of features of the offer for the customer in the area of distribution of selected cooperatives from two different voivodeships.

Keywords: Distribution, value creation, features of the offer, cooperatives.

Category of the paper: Research paper, case study.

\section{Introduction}

The main distribution's goal is to transfer finite goods from production to purchase and consumption (Burda, 2012). Distribution involves taking steps to deliver the product, along with the ownership (in the case of sale) or the right to use the product (in the case of lease), from the place of manufacture to the final buyer (Kłeczek, 1992). This transfer implies a series of specific activities, among others there can be distinguished the location of the outlets, the establishment of the ways to supply goods, the creation of the system for the goods' transfer, handling, transportation and insurance as well as the usage of certain methods to exhibit, present 
and sell the goods (Burda, 2012). It is known that the main functions of distribution logistics are the following 1) definition of consumer demand and its satisfaction; 2) establishment of economic relations on the supply of goods, rendering of services to consumers; 3) building an organizational scheme of distribution channels; 4) accumulation, sorting and arrangement of stocks of the finished products; 5) transportation of the finished products, returnable containers; 6) consolidation and dispersal of goods; 7) choice of the rational forms of physical distribution and trade organization; 8) maintaining quality standards of the finished products and logistics services; 9) monitoring and information support of the distribution (Lukinykh, Lukinykh, 2015).

The key role that distribution plays is satisfying a firm's customer and achieving a profit for the firm (Burnett, 2010, p. 282). Especially since the volume of sales revenues is largely influenced by the distribution policy, under which decisions are made to choose the sales route and outlets (e.g. the choice of own branches, sales agents or completely independent sales plants) and decisions about distributing products in a network of possible outlets (degree of distribution, network density, etc.) (Sierpińska, Jachna, 2007). The market analysis needs to identify who the customer is and what criteria they use to judge a product offering (Drummond et al., 2008). This allows an organization to understand the needs of the customer, and identifying changing trends in consumer behavior may begin to signal potential market developments and opportunities (Drummond et al., 2008). It is possible when the distribution network is efficiently managed (Blythe, 2005). The design of the distribution network is influenced by the marketing policy of the manufacturer (Große-Brockhoff, Klumpp, Krome, 2011), especially since the larger and more geographically dispersed is the market, the greater is the need to use the services of intermediaries due to the high costs associated with directly serving numerous customers (Altkorn, 2004). In this case goods come down the channel and information goes up (Blythe, 2005), because producers rarely directly deliver products to final consumers instead they are just one segment in whole distribution channel (Vučemilović, 2015). There are three levels of distribution intensity: intensive distribution (when the manufacturer offers end buyers a certain type of product through as many merchants as possible in a specific geographic area), selective distribution (when the manufacturer offers end buyers a certain type of product through selected commercial intermediaries in a specific geographic area), exclusive distribution (when the manufacturer offers end buyers a specific type of product through one selected commercial broker in a specific geographic area) (Kłeczek, 1992). The choice of participants in the distribution channel is considered as one of the critical decisions for the manufacturer. The basic factors to be considered when making a decision are: 1. funding and credit strength, 2. the power of promotion and sales of the distributor, 3. ability to maintain stocks and storage locations, and 4. principles of management (Krawczyk, 2000). Therefore company will conduct profitable business only if all companies involved in distribution channel are profitable (Vučemilović, 2015). Deciding, which is the best distribution strategy for a particular product of a company can make an enormous impact on the success of 
that company (Lourenço, 2005), especially since distribution channel can also be a way of achieving advantage in relation to competition (Vučemilović 2015).

Therefore, the purpose of this article is to identify and compare the validity of features of the offer for the customer in the area of distribution from the point of view of dairy cooperatives from Poland from the Świętokrzyskie and Małopolskie provinces, which are adjacent to each other.

\section{Methods}

The subject of the research carried out among representatives of dairy cooperatives from the Świętokrzyskie and Małopolskie provinces was an assessment of the validity of the offer's features in the distribution area. There was used purposeful selection of the sample. Direct interviews using a questionnaire survey were conducted among representatives of cooperatives representing $41 \%$ of the population, which resulted from the willingness to participate in the survey. Respondents had to indicate which features of the offer are important for different customers' groups: consumers, enterprises - users (gastronomy), wholesalers, independent retail grocery stores, large and local shopping chains, agents involved in the food trade, other dairies and other institutional buyers. They had to assess such features/elements of the offer as: differentiation of the distribution method, ensuring easy access to the product on the market, ensuring a convenient time to purchase the product, ensuring a convenient place to purchase the product, the ability to purchase products via the internet, product delivery time, timely deliveries, frequency of deliveries, flexibility of delivery in terms of time, size, range and delivery method, reliability of deliveries in terms of time, quantity and quality of delivered products, completeness of deliveries - compliance of delivery with the order, the possibility of quick communication between the buyer and the bidder (eg on-line). The assessment was made on a scale of 1 to 5 , where 5 meant that the offer feature is extremely important, 4 - important, 3 - quite important, 2 - little important, and 1 - completely unimportant. If the cooperative was not able to assess or did not have specific clients, 0 was inserted - not applicable. The research results are presented in Table 1 and 2. Additionally, these results are enhanced by the analysis of the financial ratios, which are shown in Table 3. 


\section{Results}

Table 1 shows that there are no agents involved in the food trade, other dairies and other institutional buyers among the cooperatives from both provinces customers. Additionally, among customers of cooperatives from Świętokrzyskie Province there are no independent grocery stores and large retail chains.

Table 1.

The validity of features of the offer for the customer in the distribution area for different types of customers

\begin{tabular}{|c|c|c|c|c|c|c|c|c|c|c|c|}
\hline \multirow{2}{*}{\multicolumn{3}{|c|}{ Features/elements of the offer }} & \multirow{3}{*}{ 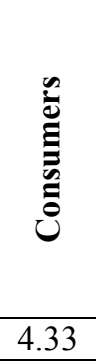 } & \multirow{3}{*}{ 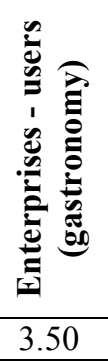 } & \multirow{3}{*}{ 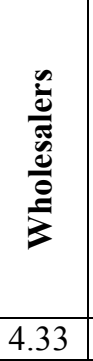 } & \multirow{3}{*}{ 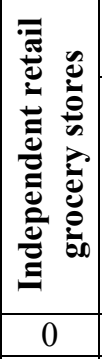 } & \multicolumn{2}{|c|}{$\begin{array}{c}\text { Shopping } \\
\text { chains }\end{array}$} & \multirow{2}{*}{ 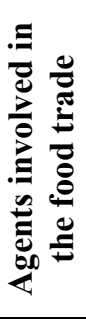 } & \multirow{3}{*}{ 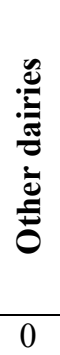 } & \multirow{3}{*}{ 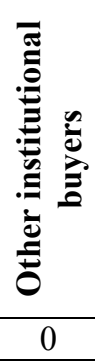 } \\
\hline & & & & & & & 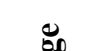 & $\equiv$ & & & \\
\hline \multirow{6}{*}{$\begin{array}{l}\text { Differentiation of } \\
\text { the distribution } \\
\text { method }\end{array}$} & \multirow{3}{*}{ Ś } & Mean & & & & & 0 & 4.33 & 0 & & \\
\hline & & Standard deviation & 0.577 & 0.707 & 0.577 & 0 & 0 & 0.577 & 0 & 0 & 0 \\
\hline & & Median & 4 & 4 & 4 & 0 & 0 & 4 & 0 & 0 & 0 \\
\hline & \multirow{3}{*}{$\mathrm{M}$} & Mean & 4.25 & 4.00 & 4.00 & 5.00 & 4.00 & 4.25 & 0 & 0 & 0 \\
\hline & & Standard deviation & 0.500 & 0.816 & 0.816 & 0.000 & 0.000 & 0.957 & 0 & 0 & 0 \\
\hline & & Median & 4 & 4 & 4 & 5 & 4 & 5 & 0 & 0 & 0 \\
\hline \multirow{6}{*}{$\begin{array}{l}\text { Ensuring easy } \\
\text { access to the } \\
\text { product on the } \\
\text { market }\end{array}$} & \multirow{3}{*}{$\dot{S}$} & Mean & 4.33 & 4.50 & 4.33 & 0 & 0 & 4.00 & 0 & 0 & 0 \\
\hline & & Standard deviation & 0.577 & 0.707 & 1.155 & 0 & 0 & 0.000 & 0 & 0 & 0 \\
\hline & & Median & 4 & 5 & 5 & 0 & 0 & 4 & 0 & 0 & 0 \\
\hline & \multirow{3}{*}{$\mathrm{M}$} & Mean & 4.50 & 4.50 & 4.00 & 4.00 & 4.00 & 3.50 & 0 & 0 & 0 \\
\hline & & Standard deviation & 0.577 & 0.577 & 0.816 & 0.000 & 0.000 & 0.577 & 0 & 0 & 0 \\
\hline & & Median & 5 & 5 & 4 & 4 & 4 & 4 & 0 & 0 & 0 \\
\hline \multirow{6}{*}{$\begin{array}{l}\text { Ensuring a } \\
\text { convenient time to } \\
\text { purchase the } \\
\text { product }\end{array}$} & \multirow{3}{*}{$\dot{S}$} & Mean & 4.00 & 5.00 & 4.00 & 0 & 0 & 4.33 & 0 & 0 & 0 \\
\hline & & Standard deviation & 0.000 & 0.000 & 0.000 & 0 & 0 & 0.577 & 0 & 0 & 0 \\
\hline & & Median & 4 & 5 & 4 & 0 & 0 & 4 & 0 & 0 & 0 \\
\hline & \multirow{3}{*}{$\mathrm{M}$} & Mean & 4.00 & 4.50 & 3.75 & 4.00 & 4.00 & 3.75 & 0 & 0 & 0 \\
\hline & & Standard deviation & 0.816 & 1.000 & 0.500 & 0.000 & 0.000 & 1.258 & 0 & 0 & 0 \\
\hline & & Median & 4 & 5 & 4 & 4 & 4 & 4 & 0 & 0 & 0 \\
\hline \multirow{6}{*}{$\begin{array}{l}\text { Ensuring a } \\
\text { convenient place } \\
\text { to purchase the } \\
\text { product }\end{array}$} & \multirow{3}{*}{$\dot{S}$} & Mean & 4.33 & 5.00 & 3.33 & 0 & 0 & 4.33 & 0 & 0 & 0 \\
\hline & & Standard deviation & 0.577 & 0.000 & 0.577 & 0 & 0 & 0.577 & 0 & 0 & 0 \\
\hline & & Median & 4 & 5 & 3 & 0 & 0 & 4 & 0 & 0 & 0 \\
\hline & \multirow{3}{*}{$\mathrm{M}$} & Mean & 4.25 & 4.00 & 4.50 & 4.00 & 3.00 & 3.75 & 0 & 0 & 0 \\
\hline & & Standard deviation & 0.500 & 0.000 & 0.577 & 0.000 & 0.000 & 0.957 & 0 & 0 & 0 \\
\hline & & Median & 4 & 4 & 5 & 4 & 3 & 4 & 0 & 0 & 0 \\
\hline \multirow{6}{*}{$\begin{array}{l}\text { The ability to } \\
\text { purchase products } \\
\text { via the Internet }\end{array}$} & \multirow{3}{*}{$\dot{S}$} & Mean & 4.00 & 4.50 & 3.67 & 0 & 0 & 4.00 & 0 & 0 & 0 \\
\hline & & Standard deviation & 0.000 & 0.707 & 0.577 & 0 & 0 & 0.000 & 0 & 0 & 0 \\
\hline & & Median & 4 & 5 & 4 & 0 & 0 & 4 & 0 & 0 & 0 \\
\hline & \multirow{3}{*}{$\mathrm{M}$} & Mean & 4.50 & 4.25 & 4.50 & 5.00 & 2.00 & 3.75 & 0 & 0 & 0 \\
\hline & & Standard deviation & 0.577 & 0.500 & 0.577 & 0.000 & 0.000 & 1.258 & 0 & 0 & 0 \\
\hline & & Median & 5 & 4 & 5 & 5 & 2 & 4 & 0 & 0 & 0 \\
\hline & & Mean & 4.33 & 4.00 & 4.00 & 0 & 0 & 4.00 & 0 & 0 & 0 \\
\hline & Ś & Standard deviation & 0.577 & 0.000 & 0.000 & 0 & 0 & 1.000 & 0 & 0 & 0 \\
\hline Product delivery & & Median & 4 & 4 & 4 & 0 & 0 & 4 & 0 & 0 & 0 \\
\hline time & & Mean & 4.00 & 4.25 & 4.00 & 4.00 & 4.00 & 4.00 & 0 & 0 & 0 \\
\hline & $\mathrm{M}$ & Standard deviation & 0.816 & 0.500 & 0.816 & 0.000 & 0.000 & 0.816 & 0 & 0 & 0 \\
\hline & & Median & 4 & 4 & 4 & 4 & 4 & 4 & 0 & 0 & 0 \\
\hline
\end{tabular}


Cont. Table 1.

\begin{tabular}{|c|c|c|c|c|c|c|c|c|c|c|c|}
\hline \multirow{6}{*}{ Timely deliveries } & & Mean & 4.33 & 4.50 & 4.67 & 0 & 0 & 3.67 & 0 & 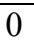 & 0 \\
\hline & $\dot{S}$ & Standard deviation & 0.577 & 0.707 & 0.577 & 0 & 0 & 1.528 & 0 & 0 & 0 \\
\hline & & Median & 4 & 5 & 5 & 0 & 0 & 4 & 0 & 0 & 0 \\
\hline & & Mean & 4.25 & 3.50 & 3.75 & 4.00 & 4.00 & 4.00 & 0 & 0 & 0 \\
\hline & $\mathrm{M}$ & Standard deviation & 0.500 & 0.577 & 1.258 & 0.000 & 0.000 & 0.000 & 0 & 0 & 0 \\
\hline & & Median & 4 & 4 & 4 & 4 & 4 & 4 & 0 & 0 & 0 \\
\hline \multirow{6}{*}{$\begin{array}{l}\text { Frequency of } \\
\text { deliveries }\end{array}$} & & Mean & 4.33 & 4.00 & 4.33 & 0 & 0 & 4.00 & 0 & 0 & 0 \\
\hline & $\dot{S}$ & Standard deviation & 0.577 & 0.000 & 0.577 & 0 & 0 & 0.000 & 0 & 0 & 0 \\
\hline & & Median & 4 & 4 & 4 & 0 & 0 & 4 & 0 & 0 & 0 \\
\hline & & Mean & 4.25 & 4.50 & 4.00 & 4.00 & 4.00 & 4.25 & 0 & 0 & 0 \\
\hline & $\mathrm{M}$ & Standard deviation & 0.957 & 0.577 & 0.000 & 0.000 & 0.000 & 0.500 & 0 & 0 & 0 \\
\hline & & Median & 5 & 5 & 4 & 4 & 4 & 4 & 0 & 0 & 0 \\
\hline \multirow{6}{*}{$\begin{array}{l}\text { Flexibility of } \\
\text { delivery in terms } \\
\text { of time, size, } \\
\text { range and delivery } \\
\text { method }\end{array}$} & & Mean & 4.33 & 3.50 & 3.67 & 0 & 0 & 4.67 & 0 & 0 & 0 \\
\hline & Ś & Standard deviation & 0.577 & 0.707 & 0.577 & 0 & 0 & 0.577 & 0 & 0 & 0 \\
\hline & & Median & 4 & 4 & 4 & 0 & 0 & 5 & 0 & J & 0 \\
\hline & & Mean & 4.00 & 4.50 & 4.25 & 5.00 & 5.00 & 4.25 & 0 & 0 & 0 \\
\hline & $\mathrm{M}$ & Standard deviation & 0.816 & 0.577 & 0.500 & 0.000 & 0.000 & 0.500 & 0 & 0 & 0 \\
\hline & & Median & 4 & 5 & 4 & 5 & 5 & 4 & 0 & 0 & 0 \\
\hline \multirow{6}{*}{$\begin{array}{l}\text { Reliability of } \\
\text { deliveries in terms } \\
\text { of time, quantity } \\
\text { and quality of } \\
\text { delivered products }\end{array}$} & & Mean & 4.00 & 4.00 & 4.00 & 0 & 0 & 3.67 & 0 & 0 & 0 \\
\hline & Ś & Standard deviation & 0.000 & 0.000 & 1.000 & 0 & 0 & 0.577 & 0 & 0 & 0 \\
\hline & & Median & 4 & 4 & 4 & 0 & 0 & 4 & 0 & 0 & 0 \\
\hline & & Mean & 4.00 & 3.50 & 3.25 & 4.00 & 3.00 & 3.75 & 0 & 0 & 0 \\
\hline & $\mathrm{M}$ & Standard deviation & 0.816 & 0.577 & 0.500 & 0.000 & 0.000 & 0.500 & 0 & 0 & 0 \\
\hline & & Median & 4 & 4 & 3 & 4 & 3 & 4 & 0 & 0 & 0 \\
\hline \multirow{6}{*}{$\begin{array}{l}\text { Completeness of } \\
\text { deliveries - } \\
\text { compliance of } \\
\text { delivery with the } \\
\text { order }\end{array}$} & & Mean & 4.00 & 4.50 & 3.67 & 0 & 0 & 4.67 & 0 & 0 & 0 \\
\hline & S & Standard deviation & 0.000 & 0.707 & 0.577 & 0 & 0 & 0.577 & 0 & 0 & 0 \\
\hline & & Median & 4 & 5 & 4 & 0 & 0 & 5 & 0 & 0 & 0 \\
\hline & & Mean & 3.75 & 4.00 & 3.25 & 4.00 & 4.00 & 3.50 & 0 & 0 & 0 \\
\hline & $\mathrm{M}$ & Standard deviation & 0.957 & 0.816 & 0.957 & 0.000 & 0.000 & 0.577 & 0 & 0 & 0 \\
\hline & & Median & 4 & 4 & 4 & 4 & 4 & 4 & 0 & 0 & 0 \\
\hline \multirow{6}{*}{\begin{tabular}{|l|} 
The possibility of \\
quick \\
communication \\
between the buyer \\
and the bidder \\
(eg. on-line)
\end{tabular}} & & Mean & 0 & 0 & 0 & 0 & 0 & 0 & 0 & 0 & 0 \\
\hline & $\dot{S}$ & Standard deviation & 0 & 0 & 0 & 0 & 0 & 0 & 0 & 0 & 0 \\
\hline & & Median & 0 & 0 & 0 & 0 & 0 & 0 & 0 & 0 & 0 \\
\hline & & Mean & 0 & 0 & 0 & 0 & 0 & 0 & 0 & 0 & 0 \\
\hline & $\mathrm{M}$ & Standard deviation & 0 & 0 & 0 & 0 & 0 & 0 & 0 & 0 & 0 \\
\hline & & Median & 0 & 0 & 0 & 0 & 0 & 0 & 0 & 0 & 0 \\
\hline
\end{tabular}

Scale: $1-5$, where 5 - extremely important, 4 - very important, 3 - quite important, 2 - little important, 1 - completely unimportant, 0 - not applicable. Ś - Świętokrzyskie Province; M - Małopolskie Province.

Source: own work and (Konieczna, 2014).

Table 2.

The validity of features of the offer for the customer in the distribution area for all customers - an average rating

\begin{tabular}{|l|c|c|}
\hline \multicolumn{1}{|c|}{ Features/elements of the offer } & $\begin{array}{c}\text { Świętokrzyskie } \\
\text { Province }\end{array}$ & $\begin{array}{c}\text { Malopolskie } \\
\text { Province }\end{array}$ \\
\hline Differentiation of the distribution method & 4.12 & 4.25 \\
\hline Ensuring easy access to the product on the market & 4.29 & 4.08 \\
\hline Ensuring a convenient time to purchase the product & 4.33 & 4.00 \\
\hline Ensuring a convenient place to purchase the product & 4.25 & 3.92 \\
\hline The ability to purchase products via the Internet & 4.04 & 4.00 \\
\hline Product delivery time & 4.08 & 4.04 \\
\hline Timely deliveries & 4.29 & 3.92 \\
\hline Frequency of deliveries & 4.17 & 4.17 \\
\hline
\end{tabular}


Cont. table 2.

\begin{tabular}{|l|c|c|}
\hline Flexibility of delivery in terms of time, size, range and delivery method & 4.04 & 4.50 \\
\hline $\begin{array}{l}\text { Reliability of deliveries in terms of time, quantity and quality of delivered } \\
\text { products }\end{array}$ & 3.92 & 3.58 \\
\hline Completeness of deliveries - compliance of delivery with the order & 4.21 & 3.75 \\
\hline $\begin{array}{l}\text { The possibility of quick communication between the buyer and the bidder } \\
\text { (eg on-line) }\end{array}$ & 0 & 0 \\
\hline An average rating for the validity of features of the offer & $\mathbf{4 . 1 6}$ & $\mathbf{4 . 0 2}$ \\
\hline
\end{tabular}

Scale: 1-5, where 5 - extremely important, 4 - very important, 3 - quite important, 2 - little important, 1 - completely unimportant, 0 - not applicable.

Source: own work.

When analyzing the table 1 it is clear that:

- Differentiation of the distribution method is extremely important for independent retail grocery stores (mean rating is 5.00) according to cooperatives from Małopolskie Province. It is very important for consumers, wholesalers, small shopping chains, and for enterprises - users (gastronomy) (mean rating is in the range from 3.50 to 4.33) in the opinion of cooperatives from both provinces. According to cooperatives from Małopolskie Province it is also very important for large shopping chains (mean rating is 4.00).

- Ensuring easy access to the product on the market is extremely important for enterprises - users (gastronomy) according to cooperatives from both provinces, and for consumers in opinion of cooperatives from Małopolskie Province (mean rating is 4.50). It is very important for wholesalers and small shopping chains (mean rating is in the range from 3.50 to 4.33 ) in the opinion of cooperatives from both provinces. It is also very important for consumers according to cooperatives from Świętokrzyskie Province (mean rating is 4.33), for large shopping chains and for independent retail grocery stores (mean rating is 4.00) from Małopolskie Province.

- Ensuring a convenient time to purchase the product is extremely important for enterprises - users (gastronomy) (mean rating is in the range from 4.50 to 5.00) and very important for consumers, wholesalers and small shopping chains (mean rating is in the range from 3.75 to 4.33 ) in the opinion of cooperatives from both provinces. It is also very important for independent retail grocery stores, and large shopping chains (mean rating is 4.00) according to cooperatives from Małopolskie Province.

- Ensuring a convenient place to purchase the product is extremely important for enterprises - users (gastronomy) (mean rating is 5.00) according to cooperatives from Świętokrzyskie Province, and for wholesalers (mean rating is 4.50) in the opinion of cooperatives from Małopolskie Province. It is very important for consumers and small shopping chains (mean rating is in the range from 3.75 to 4.33 ) according to cooperatives from both provinces, and for independent retail grocery stores, and enterprises - users (gastronomy) (mean rating is 4.00) in the opinion of cooperatives from Małopolskie Province. It is also quite important for wholesalers (mean rating is 3.33) according to cooperatives from Świętokrzyskie Province, and for large shopping chains (mean rating is 4.00) in the opinion of cooperatives from Małopolskie Province. 
- The ability to purchase products via the Internet is extremely important for independent retail grocery stores (mean rating is 5.00), consumers, and wholesalers according to cooperatives from Małopolskie Province, and for enterprises - users (gastronomy) (mean rating is 4.50) in the opinion of cooperatives from Świętokrzyskie Province. It is very important for small shopping chains (mean rating is in the range from 3.75 to 4.00) according to cooperatives from both provinces. It is also very important for enterprises - users (gastronomy) (mean rating is 4.25) in the opinion of cooperatives from Małopolskie Province, for consumers (mean rating is 4.00), and for wholesalers (mean rating is 3.67) according to cooperatives from Świętokrzyskie Province. On the other hand it is little important for large shopping chains (mean rating is 2.00).

- Product delivery time is very important for consumers (mean rating is in the range from 4.00 to 4.33 ), enterprises - users (gastronomy) (mean rating is in the range from 4.00 to 4.25), wholesalers and for small shopping chains (mean rating is 4.00) according to cooperatives from both provinces. In the opinion of cooperatives from Małopolskie Province it is also very important for independent retail grocery stores, and large shopping chains (mean rating is 4.00 ).

- Timely deliveries are extremely important for wholesalers (mean rating is 4.67), and for enterprises - users (gastronomy) (mean rating is 4.50) in the opinion of cooperatives from Świętokrzyskie Province. They are very important for consumers (mean rating is in the range from 4.25 to 4.33 ), and for small shopping chains (mean rating is in the range from 4.67 to 4.00 ) according to cooperatives from both provinces. They are also very important for independent retail grocery stores, and large shopping chains (mean rating is 4.00) in the opinion of cooperatives from Małopolskie Province.

- Frequency of deliveries is extremely important for enterprises - users (gastronomy) (mean rating is 4.50) in the opinion of cooperatives from Małopolskie Province. It is very important for consumers (mean rating is in the range from 4.25 to 4.33 ), wholesalers (mean rating is in the range from 4.00 to 4.33 ), and for small shopping chains (mean rating is in the range from 4.00 to 4.25 ) according to cooperatives from both provinces. It is also very important for enterprises - users (gastronomy) (mean rating is 4.00) according to cooperatives from Świętokrzyskie Province. In the opinion of cooperatives from Małopolskie Province it is also very important for independent retail grocery stores, and large shopping chains (mean rating is 4.00).

- Flexibility of delivery in terms of time, size, range and delivery method is considered as extremely important for independent retail grocery stores, large shopping chains (mean rating is 5.00), and enterprises - users (gastronomy) (mean rating is 4.50) according to cooperatives from Małopolskie Province. It is also extremely important for small shopping chains (mean rating is 4.67) in the opinion of cooperatives from Świętokrzyskie Province. In the opinion of cooperatives from both provinces it is also very important for consumers (mean rating is in the range from 4.00 to 4.33 ) and 
wholesalers (mean rating is in the range from 3.67 to 4.25 ). This element of the offer is also very important for enterprises - users (gastronomy) (mean rating is 3.50) according to cooperatives from Świętokrzyskie Province, and for small shopping chains (mean rating is 4.25) in the opinion of cooperatives from Małopolskie Province.

- Reliability of deliveries in terms of time, quantity and quality of delivered products is very important for consumers, enterprises - users (gastronomy), and small shopping chains (mean rating is in the range from 3.67 to 4.00 ) according to cooperatives from both provinces. It is also very important for wholesalers in the opinion of cooperatives from Świętokrzyskie Province, and for large shopping chains according to cooperatives from Małopolskie Province (mean rating is 4.00). As quite important this element is considered to be for wholesalers (mean rating is 3.25), and large shopping chains (mean rating is 3.00) in the opinion of cooperatives from Małopolskie Province.

- Completeness of deliveries - compliance of delivery with the order is considered as extremely important for enterprises - users (gastronomy), and small shopping chains (mean rating is in the range from 4.50 to 4.67 ) in the opinion of cooperatives from Świętokrzyskie Province. It is very important for consumers according to cooperatives from both provinces (mean rating is in the range from 3.75 to 4.00 ). This feature of the offer is also very important for wholesalers in the opinion of cooperatives from Świętokrzyskie Province, for enterprises - users (gastronomy), large shopping chains, and independent retail grocery stores (mean rating is in the range from 4.50 to 4.67) according to cooperatives from Małopolskie Province. It is also little important for wholesalers in the opinion of cooperatives from Małopolskie Province (mean rating is $3.25)$.

- The possibility of quick communication between the buyer and the bidder (eg on-line) is not applicable for cooperatives from both provinces.

The analysis of table 1 also shows that:

- For consumers extremely important are ensuring easy access to the product on the market, and the ability to purchase products via the Internet according to cooperatives from Małopolskie Province (mean rating is 4.50). In the same time these features of the offer are very important for consumers in the opinion of cooperatives from Świętokrzyskie Province (mean rating is in the range from 4.00 to 4.33). According to cooperatives from both provinces very important are: differentiation of the distribution method, ensuring a convenient time to purchase the product, ensuring a convenient place to purchase the product, product delivery time, timely deliveries, frequency of deliveries, flexibility of delivery in terms of time, size, range and delivery method, reliability of deliveries in terms of time, quantity and quality of delivered products, and the possibility of quick communication between the buyer and the bidder (eg on-line) (mean rating is in the range from 3.75 to 4.33 ). 
- For enterprises - users (gastronomy) extremely important are ensuring easy access to the product on the market, ensuring a convenient time to purchase the product according to cooperatives from both provinces (mean rating is in the range from 4.50 to 5.00). In opinion of the cooperatives from Świętokrzyskie province extremely important are also ensuring a convenient place to purchase the product, the ability to purchase products via the Internet, timely deliveries, and completeness of deliveries - compliance of delivery with the order whereas cooperatives from Małopolskie Province claim that extremely important are frequency of deliveries, and flexibility of delivery in terms of time, size, range and delivery method (mean rating is in the range from 4.50 to 5.00). Very important for this kind of clients are differentiation of the distribution method, product delivery time, and reliability of deliveries in terms of time, quantity and quality of delivered products in the opinion of cooperatives from both provinces (mean rating is in the range from 3.50 to 4.00 ). According to cooperatives from Świętokrzyskie Province very important are also frequency of deliveries, and flexibility of delivery in terms of time, size, range and delivery method, while in the opinion of cooperatives from Małopolskie Province very important are ensuring a convenient place to purchase the product, the ability to purchase products via the Internet, timely deliveries, and completeness of deliveries - compliance of delivery with the order (mean rating is in the range from 3.50 to 4.25 ).

- For wholesalers extremely important are ensuring a convenient place to purchase the product, and the ability to purchase products via the Internet in the opinion of cooperatives from Małopolskie Province (mean rating is 4.50), while according to cooperatives from Świętokrzyskie Province these are timely deliveries (mean rating is 4.67). As claim cooperatives from both provinces very important for wholesalers are differentiation of the distribution method, ensuring easy access to the product on the market, ensuring a convenient time to purchase the product, product delivery time, frequency of deliveries, and flexibility of delivery in terms of time, size, range and delivery method (mean rating is in the range from 3.67 to 4.33 ). In the same time according to cooperatives from Świętokrzyskie Province very important are the ability to purchase products via the Internet, reliability of deliveries in terms of time, quantity and quality of delivered products, and completeness of deliveries - compliance of delivery with the order (mean rating is in the range from 3.67 to 4.00). On the other hand very important are timely deliveries in the opinion of cooperatives from Małopolskie Province (mean rating is 3.75). As quite important is considered by cooperatives from Świętokrzyskie Province the ensuring a convenient place to purchase the product (mean rating is 3.33) and for cooperatives from Małopolskie Province the reliability of deliveries in terms of time, quantity and quality of delivered products, and completeness of deliveries - compliance of delivery with the order (mean rating is 3.25). 
- For independent retail grocery stores extremely important are differentiation of the distribution method, the ability to purchase products via the Internet, and flexibility of delivery in terms of time, size, range and delivery method in the opinion of cooperatives from Małopolskie Province (mean rating is 5.00). Other features of the offer are considered as very important according to cooperatives from Małopolskie Province (mean rating is 4.00). Cooperatives from Świętokrzyskie Province do not have such customers.

- For large shopping chains extremely important is the flexibility of delivery in terms of time, size, range and delivery method in the opinion of cooperatives from Małopolskie Province (mean rating is 5.00). Cooperatives from Małopolskie Province also claim that for large shopping chains very important are differentiation of the distribution method, ensuring easy access to the product on the market, ensuring a convenient time to purchase the product, ensuring a convenient place to purchase the product, product delivery time, timely deliveries, frequency of deliveries, and completeness of deliveries - compliance of delivery with the order (mean rating is 4.00 ), while quite important are ensuring a convenient place to purchase the product, and reliability of deliveries in terms of time, quantity and quality of delivered products (mean rating is 3.00). According to these cooperatives little important is the ability to purchase products via the Internet (mean rating is 2.00). Cooperatives from Świętokrzyskie Province do not have such customers.

- For small shopping chains extremely important are the flexibility of delivery in terms of time, size, range and delivery method, and completeness of deliveries - compliance of delivery with the order according to cooperatives from Świętokrzyskie Province (mean rating is 4.67), whereas these features of the offer in the opinion of cooperatives from Małopolskie Province are very important (mean rating is in the range from 3.50 to 4.25). Cooperatives from both provinces claim that very important for small shopping chains are other features of the offer (mean rating is in the range from 3.67 to 4.33 ).

\section{Summary}

Distribution enables to expand the value for customer by the service. The analysis of the research results, taking into account the mean for all customers, shows that the indicated features of the offer for the customer in the distribution area were considered by cooperatives from both provinces as very important (there was only one feature that was not indicated by all cooperatives). However they differ in assessment. The highest is assessed the flexibility of delivery in terms of time, size, range and delivery method (the mean assessment of the importance of a feature is 4.27), than differentiation of the distribution method, and ensuring 
easy access to the product on the market (the mean assessment of the importance of the features is 4.19), ensuring a convenient time to purchase the product, frequency of deliveries (the mean assessment of the importance of the features is 4.17), timely deliveries (the mean assessment of the importance of a feature is 4.11), ensuring a convenient place to purchase the product (the mean assessment of the importance of a feature is 4.09), product delivery time (the mean assessment of the importance of a feature is 4.06), and the ability to purchase products via the Internet (the mean assessment of the importance of a feature is 4.02). The lowest are assessed completeness of deliveries - compliance of delivery with the order (the mean assessment of the importance of a feature is 3.98), and reliability of deliveries in terms of time, quantity and quality of delivered products (the mean assessment of the importance of a feature is 3.92). When taking into account analyzed provinces separately different features of the offer are assessed the highest. According to cooperatives from Świętokrzyskie Province the most important for consumers is ensuring a convenient time to purchase the product (the mean assessment of the importance of a feature is 4.33), and for cooperatives from Małopolskie Province is the flexibility of delivery in terms of time, size, range and delivery method (the mean assessment of the importance of a feature is 4.50). In the same time cooperatives from both provinces agree in assessment of the least important feature for consumers, which is the reliability of deliveries in terms of time, quantity and quality of delivered products. The mean assessment of the importance of this feature is 3.92 in the opinion of cooperatives from Świętokrzyskie Province and 3.58 according to cooperatives from Małopolskie Province. In assessing other features of the offer both provinces differ. Research result also show that cooperatives from Małopolskie Province rather lower assessed the validity of the features of the offer for their customers than cooperatives from Świętokrzyskie Province despite these provinces adjacent to each other.

\section{References}

1. Altkorn, J. (2004). Podstawy marketingu. Kraków: Instytut Marketingu.

2. Blythe, J. (2005). Essentials of Marketing. Harlow: Prentice Hall.

3. Burda, A., (2012). Redefining the Role of Distribution and its Relationship with Production. Economy, Commerce and Tourism Series, Vol. IX, pp. 80-92.

4. Burnett, J. (2008). Core Concepts of Marketing. Zurich: Global Text Project.

5. Drummond, G., Ensor, J., Ashford, R. (2008). Strategic Marketing: Planning and Control. Oxford: Butterworth-Heinemann.

6. Ehmke, C., Fulton, J., Lusk, J. (2007). Marketing's Four P's: First Steps for New Entrepreneurs. Purdue Extension: Knowledge to Go. Purdue University, No. EC-730, pp. 1-12. 
7. Große-Brockhoff, M., Klumpp, M., Krome, D. (2011). Logistics capacity management A theoretical review and applications to outbound logistics. Essen: Institut für Logistik- \& Dienstleistungsmanagement der FOM Hochschule für Oekonomie \& Management.

8. Kłeczek, R. (1992). Marketing. Jak to się robi. Wrocław: Zakład Narodowy im. Ossolińskich.

9. Konieczna, I. (2014). Ważność cech oferty dla klienta w obszarze dystrybucji z punktu widzenia spółdzielni mleczarskich $\mathrm{z}$ województwa świętokrzyskiego. Logistyka, No. 6 , pp. 14354-14364.

10. Krawczyk, S. (2000). Logistyka w zarządzaniu marketingiem. Wrocław: Wydawnictwo Akademii Ekonomicznej.

11. Lourenço, H.R. (2005). Logistics Management. An Opportunity for Metaheuristics. In: C. Rego, B. Alidaee (Eds.), Metaheuristic Optimization via Memory and Evolution Tabu Search and Scatter Search. Series: Operations Research/Computer Science Interfaces Series, Vol. 30, pp. 329-356.

12. Lukinykh, Lukinykh (2015). Algorithm for the Procurement and Inventory Management in the Distribution Supply Chain. Business Logistics in Modern Management - Proceedings of The $15^{\text {th }}$ International Scientific Conference. Osijek: JOSIP Juraj Strossmayer University of Osijek, pp. 79-91.

13. Sierpińska, M., Jachna, T. (2007). Ocena przedsiębiorstwa wedtug standardów światowych. Warszawa: PWN.

14. Vučemilović, V. (2015). Distribution Channels of Major Construction Materials. Business Logistics in Modern Management - Proceedings of The $15^{\text {th }}$ International Scientific Conference. Osijek: JOSIP Juraj Strossmayer University Of Osijek, pp. 131-141. 


\title{
INNOVATION OF POLISH FAMILY AND NON-FAMILY BUSINESSES
}

\author{
Teresa KRAŚNICKA \\ University of Economics in Katowice; teresa.krasnicka@ue.katowice.pl, ORCID: 0000-0002-6862-2901
}

Purpose: The study aimed to identify differences in the level of innovation of the two types of firms - family (FB) and non-family (NFB) - and understand how the expectations of the management and/or business owners vary regarding the impact of innovations on business performance.

Design/methodology/approach: Research questions were formulated based on the review of the findings of the surveys that compared innovation in family and non-family firms worldwide. Then, empirical research was conducted in 334 family and non-family firms in Poland.

Findings: The findings do not confirm significant differences in the level of product innovation between FB and NFB. On the other hand, they point to a higher level of innovation measured with the number of process innovations in NFB. Research shows that firms rate the degree to which the expectations of innovation effects were fulfilled relatively low in both types of firms. Research limitations/implications: The applied measurement of the level of innovation according to the number of implemented innovations does not take into account their qualitative aspect, whether they are radical or incremental. The survey (questionnaire and interview) was based solely on the number of innovations declared as implemented by the respondents.

Practical implications: The survey findings should inspire managers of family and non-family firms to analyze both the expected effects of the implementation of a particular type of innovation and to assess its actual outcomes.

Social implications: Studies show that FB are not less innovative when it comes to implementing new or modified products and services. This contradicts both the opinions and some research results about the conservatism of FB or their stronger orientation towards family goals at the expense of a firm's growth.

Originality/value: This comparative study on FB and NFB innovation fills a gap in the area where knowledge concerning this issue is still scarce in Poland.

Keywords: family business, non family business, innovation, product innovation, business process innovation.

Category of the paper: Research paper. 


\section{Introduction}

Interest both in business innovation and in family businesses (FB) as opposed to non-family businesses (NFB) is fully justified by the importance of both issues. Innovation is one of the key factors in the competitiveness of enterprises and economies, while family businesses, according to all estimates, dominate in the structure of entities running economic activity practically in most countries. Simultaneously, the existing knowledge on FB points to their certain characteristics that distinguish them from businesses that are not family-owned, nor is the family involved in management. Therefore, family businesses attract unwavering interest of researchers, who undertake to explore various aspects of their operations (De Massis and Foss, 2018; Neubaum, 2018). Also in Poland, FB come under increasingly extensive scientific investigation, including research on their innovation, but research gaps still exist, which encourages further examination. Knowledge concenring differences in innovation of FB compared to NFB is still limited. The question about the existence of these differences and their underlying causes is still open, as studies conducted in different countries do not provide a conclusive answer, and in Poland the deficit of research into this issue is particularly evident. Therefore, the article aims to present the results of the survey which are to enrich the knowledge on innovation of family and non-family businesses, measured with the number of different types of innovations implemented in the last three years. The following research questions were formulated:

1. is the level of innovation in family businesses lower than the one in non-family businesses, as may be concluded from some studies conducted worldwide?

2. do such variables as the size of a firm, its business profile and its age cause differences in the level of innovation?

3. do managers/business owners differ in their assessment of the effectiveness of the innovations implemented - were their expectations concerning improved business performance fulfilled?

\section{Characteristics of family businesses}

Family businesses are the subject of intensive research with primary focus on identifying family influence, family involvement in the business and its management - on business performance and other aspects of business operations. This need for research is manifested not only in family business journals (such as Family Business Review), but also in special issues of peer-reviewed journals on entrepreneurship. Similarly, Polish scientific periodicals dedicate 
whole issues to family business studies ${ }^{1}$. On the one hand, studies on family businesses stem from their role in the economy and, on the other hand, from their unique nature. FB are attributed a number of characteristic features such as:

- family management of the business, which, in consequence, creates unique bonds and interdependencies between family members and the business; this can generate problems in terms of equal treatment of employees who are not family members,

- succession based on a chosen strategy, the aim of which is to maintain continuity of family management of the business,

- aspiration to remain independent,

- orientation towards financial and non-financial goals,

- a variety of goals pursued by family members working in the firm integrated into the business (making a decent living, developing a career path, the opportunity to fulfil higher-level needs, such as prestige and self-actualization),

- capital of the business in the hands of the family (one or more),

- financing initial growth with family-owned capital, such as owners' property, newly acquired property through marriage, etc. (cf. Sułkowski and Marjański, 2009; Safin, 2007).

An important research direction involves comparative analyses of FB vs. NFB, concerning selected issues, for example, the level of innovation (Ahluwalia, Mahto, and Walsh, 2017). These studies are based on the assumption that FB differ from NFB to a significant extent, hence the need to define the former and identify the characteristics distinguishing them from other entities forming the structure of the economy. Literature offers no single definition of FB and researchers tend to adopt definitions that correspond to the objectives of a study, its context, etc. There is universal agreement that it difficult to make a clear distinction between FB and NFB and awareness that such a dichotomous approach can certainly lead to errors in qualification, as pointed out by researchers in this area (e.g. Steeger and Hoffmann, 2016). According to Habbershon and Williams (1999), FB are unique bundles of resources and capabilities which result from interactions between the family and the firm. Generally, however, researchers tend to use such criteria as the family's majority ownership, family management and control of the business, and, as Klein points out (2000), failure to meet one of these criteria must be compensated by the others. The criterion frequently adopted for classifying a firm as FB is only majority ownership or self-identification by the founder and/or manager (cf. Steeger and Hoffmann, 2016). Polish authors also recognize a variety of criteria as constitutive of FB, stressing that the most frequent ones include ownership, control over the firm (as a consequence

\footnotetext{
${ }^{1}$ One example is the journal „Przedsiębiorczość i Zarządzanie”, which publishes entire issues dedicated to family businesses. In 2016, 2017 and 2018, three-part publications were released, which were dedicated to family businesses in Poland and other countries.
} 
of ownership), and management (cf. Surdej and Wach, 2010) $)^{2}$. Moreover, FB research often adopts such a definition that corresponds to the needs of a particular research project (cf. Steinerowska-Streb, 2015). Although knowledge about FB has grown significantly (De Massis and Foss, 2018), it is still difficult to define these firms in an unequivocal manner and a variety of issues are yet not clearly addressed, for example, innovation.

\section{Current state of research on innovation in family businesses}

Attempts at defining the key concept of innovation, especially in terms of innovation measurement, still reveal significant differences, which - in the research context - relate mainly to research objectives and other methodological assumptions. Literature provides numerous reviews concerning the definition of the concept and its typologies, authored both by Polish (Pichlak, 2012) and foreign researchers (De Massis, Frattini and Lichtenthaler, 2013). Enterprise innovation is understood as a firm's ability and willingness to create new solutions, adapt the existing ones, and pursue their implementation. The construct is of multidimensional nature, in its fullest form - three-dimensional, embracing not only an organization's willingness to generate (or adapt) innovations, but also its ability and readiness to take risks related to the implementation of new solutions (Pichlak, 2012, pp. 35-36). Research on business innovation uses a variety of measures, such as innovation expenditure, the number of patents, and the number of innovations implemented in a particular period of time (for example, three years).

Based on the extant research, the determinants of FB innovation activity and related processes appear to be extremely complex. The family's impact on the firm owned may be positive or negative. On the one hand, researchers point to the long-term orientation of family businesses, owned and managed by family members, which may encourage investing in innovation, despite the risk involved. As a result, innovation can become an important factor ensuring the survival of the firm and its transfer to the next generation (Jaskiewicz, Combs and Rau, 2015). Other studies, on the other hand, emphasize a kind of conservatism of family businesses and caution in making decisions carrying relatively high risk. Undoubtedly, decisions concerning the implementation of innovations, especially technological ones, involve such risk. This conservatism has many causes and results from the desire to pass on the firm to the next generation and achieve not only economic but also non-economic goals. This increases the fear of both technological (especially with new products or technologies) and financial failure. These circumstances translate into relatively low R\&D expenditure and the avoidance of technologically advanced innovations, which are characterized by a relatively higher risk of

\footnotetext{
${ }^{2}$ Surdej and Wach (2010) present a wide review of family business definitions based on different criteria.
} 
failure. Some studies confirm the low innovativeness of family businesses (Matzler, et al., 2015). Furthermore, Bendig, et al. (2020) point out not only the depth of family involvement in business as an important determinant of FB innovation activity, but also the nature of innovations implemented by FB - whether they are technological inventions or market innovations.

At the same time, FB are observed to manifest a variety of strengths in the context of undertaking innovation activity. It is emphasized that family members running FB can make better, more rational use of the limited resources they have, especially financial resources allocated to innovation (De Massis et al., 2018). Duran et al. (2016) formulated the principle of FB performance in this regard as: "doing more with less". Furthermore, some researchers argue that FB can make more effective use of extensive knowledge, often accumulated over several generations, concerning products, formulas, technologies, but also market knowledge and close customer relationships (Bendig et al., 2020).

Studies are also conducted on the tension between capacity to engage in R\&D activity and reluctance to invest in it. Family business researchers describe this phenomenon as "willingness-ability paradox" (De Massis et al., 2015). Some studies confirm that if this scepticism of family members can be overcome, FB can be more effective in innovation activity than NFB, assuming similar expenditure (Duran et al., 2016). The "willingness-ability paradox" is examined from different points of view, as its significance may vary depending on the type of innovation under consideration (Bendig et al., 2020). Studies are undertaken to explain its underlying causes. Rondi et al. (2019), for example, propose the concept of family business innovation posture, which embraces two factors - risk-taking propensity and tradition attachment - and can account for the diversity of family attitudes to innovation. The above review shows that research on the impact of broadly understood family involvement in business (assessed using various measures) on innovation, its effects and, finally, FB performance does not provide a conclusive answer. Similarly, studies conducted in our country do not provide an unequivocal answer to the question on how family involvement affects FB performance (cf. Kraśnicka, Ingram, and Głód, 2019). The results of the surveys on FB innovation to date are also inconclusive when comparing family firms with non-family firms. Therefore, the comparative trend presents both the results that identify FB as less innovative than nonfamily businesses and those that provide empirical evidence of their higher innovativeness compared to NFB. This current of research is based on empirically verified theories explaining relationships between family involvement in FB management and innovative activity, measured in particular, on the one hand, with investment expenditure on innovation and, on the other hand, with the results expressed as the number of innovations implemented, patents obtained, etc. Therefore, the comparison of FB and NFB innovation takes into account these numerous differences that may occur between the two types of firms, relating to the factors determining 
the level of innovative activity and its effects. Differences in investment expenditure on innovation and knowledge resources may have a positive impact on the relevance of innovations (measured with the number of market-relevant product announcements), but a negative influence on a firm's number of inventions (measured with the number of patents) (Bendig et al., 2020). Firms may also vary in terms of social capital as a determinant of innovation (Chrisman et al., 2015). Literature also presents research results showing that family firms are more innovative than non-family firms (Kammerlander and van Essen, 2017). N. Kammerlander and M. van Essen collected all available publications and research papers that addressed innovation in $\mathrm{FB}$ and $\mathrm{NFB}$, in particular those relating to investment in innovation (measured with $R \& D$ expenditure) and its effectiveness expressed with new products, patents and patent citations. The publications embraced 108 empirical studies conducted in 42 countries in the years 1981-2012. Meta-analysis yielded the following results: family firms invest less in innovation than other (public and private) firms that are not family owned. On average, FB have a lower R\&D budget than other firms of similar size, but at the same time FB are more efficient in terms of innovation processes (every dollar invested in R\&D makes a greater return measured with the number of patents, the number of new products, or revenues generated by new products). Based on the results, N. Kammerlander and M. van Essen (2017) concluded that FB had a higher level of innovation than other firms. Other researchers also conducted comparative studies of FB and NFB innovation (Classen et al. 2014). Their study in Germany revealed significant differences between family and nonfamily small and medium-sized businesses at every stage of the innovation process. In the sample, non-family SMEs were more likely to invest in innovation than family firms of the same size. In terms of innovation performance, however, it turned out that family SMEs were at least as effective as non-family SMEs in product innovation and on average more effective than non-family SMEs in process innovation. Moreover, these results confirm the view that family SMEs strive to maximize the probability of long-term survival by choosing positive but less intensive innovation investments compared to non-family SMEs (Classen et al., 2014).

The above review of research results concerning, in particular, the comparison of FB and NFB innovation, shows that its analysis - due to high complexity - is difficult, which is related to its numerous determinants, especially in FB. The research results so far provide various answers to the question concerning the level of innovation in FB compared to the one in NFB. Undoubtedly, the differences in the evaluation of innovation in these two types of firms may also stem from different methods of measuring it used in research as well as independent variables the influence of which on innovation is examined. 


\section{Research method}

In the light of the existing research gap concerning FB innovation compared to NFB innovation in Poland, the following research questions were formulated:

1. is the level of innovation in family businesses lower than the one in non-family businesses, as may be concluded from some studies conducted worldwide?

2. do such variables as the size of a firm, its business profile and its age cause differentiation in the level of innovation?

3. do managers/business owners differ in their assessment of the effectiveness of the innovations implemented - were their expectations concerning improved business performance fulfilled?

The key methodological procedure in this study is the selection of criteria to distinguish family businesses from other firms, which is difficult, especially in the case of micro, small and medium-sized firms, as FB are mostly firms classified as SMEs. As indicated above, various operational definitions of FB are adopted for the purposes of research. Family businesses are defined as those that employ at least two family members and the family is the majority owner of the firm (Naldi et al., 2013; Reay, Jaskiewicz, and Hinings, 2015). The definition that is often used for research purposes includes ownership and/or management with the intention of developing and pursuing a business vision by a dominant coalition of members of one family (or several families) to make the firm sustainable across future generations of the family (or families) (Chua, Chrisman and Sharma, 1999, p. 25). Taking into account this large variety of adopted criteria as well as their number (cf. Roessl, Fink, and Kraus, 2010) ${ }^{3}$, this study assumed that FB are firms in which family members directly manage the business (they are members of the board) and have a share of ownership ensuring control over the business ( $20 \%$ and more). Additionally, it was assumed that at least one other family member participates in the activities of the business.

As indicated above, different indicators are used to measure innovation. These may include innovation expenditure, $R \& D$ expenditure, or the number of patents, although these indicators are considered of little use in the examination of firms among which micro and small businesses dominate (Ahluvalia, Mahto and Walsh, 2017) and others are used, for example, the number of innovations implemented in a certain time period (e.g., De Massis et al., 2013). Such measures are also suggested in the Oslo Manual, both in the third (2008) and fourth editions (2018). The fourth edition of the Oslo Manual (2018) distinguished only two main types of business innovation: product innovation (understood as the implementation of a new or improved product or service) and business process innovation (understood as new or improved processes, concerning one or more functions of the firm, which are significantly different from those previously implemented in the firm). Business process innovations include new or improved

\footnotetext{
${ }^{3}$ Roessl, Fink and Kraus (2010) adopted as many as five criteria for identifying family businesses.
} 
processes for manufacturing (service provision), distribution and logistics, marketing and sales, information and communication, and administration and management. The importance of innovation concerning management processes, methods and structures, the so-called management innovation, was long emphasized (Kraśnicka, Głód and Wronka-Pośpiech, 2016), which was reflected in the fourth edition of the Oslo Manual (2018). For the purposes of the survey presented here, the definitions of product and process innovations were adopted in accordance with the Oslo methodology. Based on its principles, the following measures of innovation were applied:

- the number of product (or service) innovations implemented in the last three years;

- the number of business process innovations, including the number of innovations in:

1. manufacturing processes;

2. logistics and distribution;

3. marketing and sales;

4. information and communication;

5. administration and management - implemented in the last 3 year.

To fulfill the aims the purposeful sampling based on the following criteria was used. The invitation to participate in the research was sent to 600 companies in all 16 provinces of Poland ${ }^{4}$. In the sample's selection, the familiness criterion was taken into account so that the sample had equal numbers of family and non-family enterprises. Besides, the selection of the sample took into account the criteria of the size and profile of activity, so that all categories of enterprises by size (based on the number of employees) and selected four business profiles (trading, service, manufacturing, mixed) were equally represented in the sample. Ultimately, the invitation to participate in the research was accepted by 343 companies, and 334 companies were qualified for the analysis (mainly due to incomplete answers, etc.).

The survey was carried out partly with a questionnaire interview, conducted by an interviewer, and partly with a survey questionnaire. The questionnaire contained, among other things, two special questions concerning the subjective opinion of the respondent on to what extent the implemented innovations (product and process innovations separately) fulfilled the expectations of the management and/or owners of the firm in terms of imporved business performance (sales and/or profit). A 5-point Likert scale was used for this subjective assessment of innovation effects.

Descriptive statistics, including averages and standard deviation, were used to analyze the results.

\footnotetext{
${ }^{4}$ The survey was carried out by a specialized unit - the Center for Research and Knowledge Transfer at the University of Economics in Katowice. The Center uses its own databases of firms.
} 


\section{Population characteristics of the respondent firms}

The survey covered 334 firms, divided into family (164 FB) and non-family (170 NFB) businesses. In terms of core activity, the population was slightly dominated by service providers (35\%) and firms with a mixed business profile (31\%). In terms of size, measured with the number of employees, small businesses (with up to 49 employees) were the most numerous and accounted for more than $48 \%$ of the total number of respondents. The second largest group included microfirms, which made up $14 \%$ of the entire sample. In terms of age, on the other hand, the largest group was the firms operating for 11 to 20 years (over 39\%), while the least numerous group included the firms existing for over 30 years $(14 \%)$.

As for differences between family and non-family firms according to these three characteristics, they are generally insignificant, although they did occur in several cases. In terms of core activity, slightly more NFB were service providers (66 NFB to 51 FB); on the other hand, more FB specialized in manufacturing (48 to 25). When the size is taken into account, only very large firms - employing over 500 people - were predominantly non-family owned (16 to 6). The analysis of the two populations of firms based on their age reveals that only the first "age" category - up to 10 years of operation - was strongly dominated by NFB (49 to 25). Table 1 presents detailed data concerning, among others, the structure of the respondent population of firms.

\section{Table 1.}

Innovation and the evaluation of its effects by profile, size and age of respondent firms

\begin{tabular}{|c|c|c|c|c|c|c|c|c|c|c|c|c|}
\hline \multirow[t]{2}{*}{ 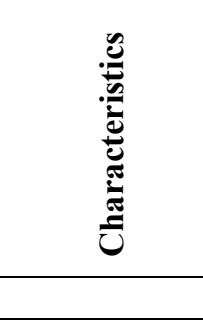 } & \multirow[t]{2}{*}{ 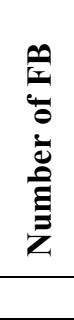 } & \multirow[t]{2}{*}{$\frac{\infty}{e^{\circ}}$} & \multirow[t]{2}{*}{ 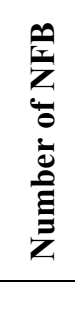 } & \multirow[t]{2}{*}{$\begin{array}{l}\frac{D}{Z} \\
\partial^{\circ}\end{array}$} & \multicolumn{2}{|c|}{ 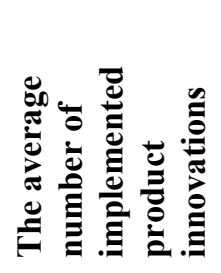 } & \multicolumn{2}{|c|}{ 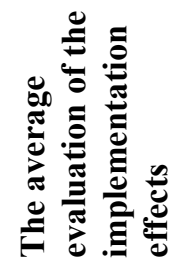 } & \multicolumn{2}{|c|}{ 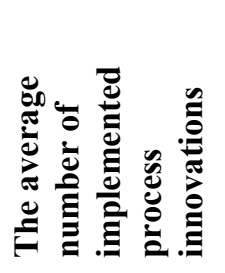 } & \multicolumn{2}{|c|}{ 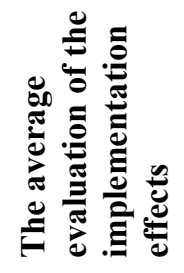 } \\
\hline & & & & & FB & NFB & FB & NFB & FB & NFB & FB & NFB \\
\hline 1. Profile: & 164 & 100 & 170 & 100 & 3.6 & 3.3 & 2.6 & 2.5 & 19.7 & 21.2 & 2.9 & 2.96 \\
\hline /1/Trading & 18 & 11 & 22 & 13 & 2.25 & 2.0 & 2.55 & 2.41 & 14.3 & 14.70 & 2.69 & 2.95 \\
\hline /2/Service & 51 & 31 & 66 & 39 & 2.96 & 3.23 & 2.75 & 2.46 & 16.79 & 21.84 & 2.85 & 2.87 \\
\hline $\begin{array}{l}\text { /3/Manu- } \\
\text { facturing }\end{array}$ & 48 & 29 & 25 & 15 & 3.98 & 4.6 & 2.47 & 2.67 & 22.53 & 30.26 & 3.12 & 3.29 \\
\hline /4/Mixed & 47 & 29 & 57 & 34 & 4.51 & 3.27 & 2.5 & 2.42 & 21.94 & 18.94 & 2.92 & 2.92 \\
\hline $\begin{array}{l}2 . \text { Size by } \\
\text { the number of } \\
\text { workers }\end{array}$ & 164 & 100 & 170 & 100 & 3.63 & 3.29 & 2.57 & 2.47 & 19.68 & 21.18 & 2.91 & 2.96 \\
\hline Up to 9 & 26 & 16 & 21 & 12 & 1.87 & 2.69 & 2.32 & 2.29 & 12.48 & 12.1 & 2.52 & 2.5 \\
\hline $10-49$ & 75 & 46 & 87 & 51. & 3.03 & 2.83 & 2.48 & 2.40 & 17.33 & 17.84 & 2.87 & 2.93 \\
\hline $50-99$ & 24 & 15 & 17 & 10 & 3.19 & 3.76 & 2.7 & 2.53 & 17.10 & 26.53 & 2.92 & 2.9 \\
\hline $100-249$ & 19 & 12 & 17 & 10 & 4.76 & 2.94 & 2.69 & 2.47 & 22.26 & 22.44 & 3.15 & 2.96 \\
\hline $250-499$ & 14 & 9 & 12 & 7 & 6.32 & 5.71 & 2.83 & 3 & 37.07 & 35.75 & 3.5 & 3.55 \\
\hline 500 and more & 6 & 4 & 16 & 9 & 10.5 & 4.59 & 3 & 2.6 & 41.75 & 33.34 & 3.5 & 3.31 \\
\hline
\end{tabular}


Cont. table 1

\begin{tabular}{|l|l|r|l|r|r|r|r|r|r|r|r|r|}
\hline 3. Age & $\mathbf{1 6 4}$ & $\mathbf{1 0 0}$ & $\mathbf{1 7 0}$ & $\mathbf{1 0 0}$ & $\mathbf{3 . 6 2 5}$ & $\mathbf{3 . 2 9}$ & $\mathbf{2 . 5 6}$ & $\mathbf{2 . 4 7}$ & $\mathbf{1 9 . 6 8}$ & $\mathbf{2 1 . 1 8}$ & $\mathbf{2 . 9 3}$ & $\mathbf{2 . 9 6}$ \\
\hline Up to 10 years & 25 & 15 & 49 & 29 & 3.62 & 2.91 & 2.67 & 2.53 & 14.8 & 17.58 & 2.88 & 2.84 \\
\hline 11-20 years & 65 & 40 & 67 & 39 & 3.72 & 3.41 & 2.52 & 2.44 & 19.97 & 20.36 & 2.96 & 2.96 \\
\hline 21-30 years & 47 & 29 & 33 & 19 & 3.6 & 3.55 & 2.58 & 2.45 & 22.51 & 23.77 & 2.9 & 3.07 \\
\hline $\begin{array}{l}\text { More than 30 } \\
\text { years }\end{array}$ & 27 & 16 & 21 & 12 & 3.44 & 3.36 & 2.57 & 2.5 & 18.56 & 28.14 & 2.97 & 3.05 \\
\hline
\end{tabular}

Source: own elaboration.

\section{Presentation of the results}

In line with the objectives of the study, we first analyzed the level of innovation of family and non-family firms, measured with the number of both product and business process innovations, implemented in the last three years. Based on the results (Table 1), it can be concluded that innovation in the two groups of firms is at a similar level and amounts, on average, to 3.6 product innovations per FB and 3.3 per NFB. The innovation index shows a slightly greater difference for process innovations, as it amounts to 19.7 in FB and 21.2 in NFB.

Table 2 shows that a higher percentage of FB than NFB did not implement any product innovations $-17 \%$ of FB to $11 \%$ of NFB. The largest number of respondents implemented between two and five product innovations in the past three years, 53\% of FB and slightly more NFB $-57 \%$.

Table 2.

Quantitative characteristics of product innovations implemented in family and non-family firms

\begin{tabular}{|l|r|r|r|r|}
\hline The number of implemented innovations & The number of FB & \% FB & The number of NFB & \% NFB \\
\hline No implementation & 28 & $17 \%$ & 18 & $11 \%$ \\
\hline 1 & 27 & $16 \%$ & 32 & $19 \%$ \\
\hline 2 & 30 & $18 \%$ & 42 & $25 \%$ \\
\hline $3-5$ & 57 & $35 \%$ & 54 & $32 \%$ \\
\hline $6-10$ & 10 & $6 \%$ & 20 & $12 \%$ \\
\hline $11-20$ & 9 & $5 \%$ & 3 & $2 \%$ \\
\hline More than 20 & 3 & $2 \%$ & 1 & $1 \%$ \\
\hline
\end{tabular}

Source: own elaboration.

In the case of business process innovations implemented in FB (Table 3), the lowest percentage $-10.4 \%$ - did not implement marketing innovations, while the highest $(25 \%)-$ did not implement administration and management innovations. A similar pattern was confirmed for NFB. Most FB (46-53\%) implemented two to five process innovations; only in the case of information and communication innovations the largest percentage of firms (43\%) implemented one or two. A similar result was obtained for NFB, where, too, the largest number of firms (41-49\%) implemented two to five innovations, except for administration and 
management innovations. In this case, the largest number of firms (44\%) implemented one or two innovations of this type.

The analysis of the research results taking into account the three selected characteristics of FB and NFB revealed that in trading and service firms the adopted product innovation indicator was lower than the average (Table 1). Moreover, this innovation indicator was higher than its average value in firms with a manufacturing and mixed profile, with the highest values reported for NFB with a manufacturing profile (4.6) and FB with a mixed profile (4.5). Slightly greater variation in the level of product innovation was found in firms of different sizes, both FB and NFB. Among FB, large firms (with 250-499 employees) and those employing 100-249 employees achieved higher (than average) product innovation indicators. Interestingly, the highest number of implemented innovations (10.5) was declared by FB respondents, representing the six largest firms, employing 500 and more workers.

\section{Table 3.}

Quantitative characteristics of business process innovations implemented in family and nonfamily firms

\begin{tabular}{|l|r|r|r|r|r|r|r|r|r|r|}
\hline $\begin{array}{l}\text { The number } \\
\text { of implemented } \\
\text { innovations }\end{array}$ & FB/MP & FB/L & FB/MS & FB/IC & FB/AM & $\begin{array}{l}\text { NFB } \\
\text { MP }\end{array}$ & $\begin{array}{l}\text { NFB } \\
\text { L }\end{array}$ & $\begin{array}{l}\text { NFB } \\
\text { MS }\end{array}$ & $\begin{array}{l}\text { NFB } \\
\text { IC }\end{array}$ & $\begin{array}{l}\text { NFB } \\
\text { AM }\end{array}$ \\
\hline No implementation & 23 & 25 & 17 & 16 & 41 & 22 & 30 & 16 & 19 & 31 \\
\hline 1 & 31 & 21 & 21 & 35 & 28 & 34 & 24 & 26 & 30 & 40 \\
\hline 2 & 30 & 55 & 49 & 36 & 41 & 32 & 55 & 41 & 33 & 35 \\
\hline $3-5$ & 56 & 32 & 34 & 31 & 34 & 51 & 29 & 35 & 37 & 32 \\
\hline $6-10$ & 17 & 24 & 26 & 20 & 15 & 17 & 20 & 30 & 26 & 16 \\
\hline $11-20$ & 4 & 5 & 6 & 13 & 2 & 12 & 10 & 19 & 20 & 13 \\
\hline More than 20 & 3 & 2 & 11 & 13 & 3 & 2 & 2 & 3 & 5 & 3 \\
\hline $\begin{array}{l}\text { The total number } \\
\text { of firms that } \\
\text { implemented } \\
\text { innovations }\end{array}$ & 141 & 139 & 147 & 148 & 123 & 148 & 140 & 154 & 151 & 139 \\
\hline
\end{tabular}

Description: MP - manufacturing process innovations; L - logistics and distribution innovations;

MS - marketing and sales innovations; IC - information and communication innovations; AM - administration and management innovations.

Source: own elaboration.

Similarly, higher (than average) product innovation indicators per firm were established for large NFB (more than 250 workers). Some differences in FB and NFB innovation, measured with the number of business process innovations, were revealed. In FB, the indicator was above the average in firms operating in the manufacturing sector and with a mixed profile. In addition, it increased with the size of the firm. Similar patterns were observed for NFB, i.e. the highest innovation indicator in manufacturing firms and an increase in the indicator corresponding to a higher firm's size. The lowest process innovation indicator was established for microfirms, both FB and NFB. The final characteristic of firms - their age - also differentiates the level of innovation of the respondent firms: in NFB, it increases with age. In FB, firms existing up to 10 years had the lowest rate, while those existing for 21-30 years - the highest. 
The survey also examined the subjective evaluation of the effects of the implementation of innovations by the management in FB and NFB (opinions on to what extent the innovations fulfilled the expectations of the management and/or owners of the firm to improve business performance - sales and/or profit). First, the analysis of the data in Table 1 reveals no significant differences in such opinions in FB and NFB. Second, the average (expressed on a 5-point scale) did not exceed 3.0, which means that the respondents declared that the implementation of the innovations did not meet (either "fully" -5 or "to a significant extent" -4 ) the expectations of the management/owners to improve business performance or were not able to determine the actual effects of the implemented innovations. The mean for product innovations in the entire sample was 2.5 (on a 5-point scale), while for business process innovations it was slightly higher and stood at 2.9 (Table 4).

Table 4.

Descriptive statistics for the entire sample of firms $(N=334)$

\begin{tabular}{|l|c|c|c|c|}
\hline \multicolumn{1}{|c|}{ Variable } & Minimum & Maximum & Mean & $\begin{array}{c}\text { Standard } \\
\text { deviation }\end{array}$ \\
\hline $\begin{array}{l}\text { 1. The evaluation of the effects of the } \\
\text { implementation of product innovations } *\end{array}$ & 1.00 & 4.00 & 2.5 & .61 \\
\hline $\begin{array}{l}\text { 2. The evaluation of the effects of the } \\
\text { implementation of business process innovations }\end{array}$ & 1.00 & 5.00 & 2.9 & .83 \\
\hline
\end{tabular}

* the number of valid responses: 288 .

Source: own elaboration.

Regardless of a business profile, size and age, the mean was at a similar level for product innovations in both FB and NFB and it is low -2.6 for FB and 2.5 for NFB. On the other hand, in the case of business process innovations, the average evaluation of the effects of these innovations for all FB and NFB was slightly higher (but does not exceed "3"). The average evaluation of the effects of process innovations was more varied according to the respondents' characteristics and in some cases exceeded the value of "3". Both in FB and NFB with a manufacturing profile, the values stood at 3.1 and 3.3, while, for example, the respective values for large firms (with 250-499 employees) were 3.5 and 3.5. It is also notable that the differences in the evaluation of the effects of implemented innovations, both product and business process related, were small, as indicated by the value of standard deviation (the smaller its value, the closer the opinions are to the mean) (see Table 4).

\section{Discussion}

The most important conclusions from the survey amount to the following: First, no significant differences in the level of innovation measured according to the Oslo methodology standards (Oslo Manual, 2018), i.e. with the number of product innovations, 
were identified in the sample. Some variation was observed in the number of business process innovations in the last three years - NFB implemented more such innovations. The research results indicate that the characteristics of family businesses are not evidently reflected in the level of their innovation (especially product innovation) - compared to non-family businesses. The results of studies conducted around the world, reviewed in the first part of the article, do not conclusively answer the question whether familiness significantly determines innovation of family businesses, giving rise to differences with non-family businesses in this respect. Although the results of the survey on innovation of Polish FB and NFB do not provide an unequivocal answer to the question posed, neither do they contradict the results of other studies (Classen et al., 2014; Kammerlander, and van Essen, 2017), especially those that point to certain FB characteristics that have a positive or negative impact on innovation. The impact of negative characteristics that may affect innovation can be compensated with the characteristics that have a positive influence on FB innovation. The analysis of the research results should also address the question whether this absence of differences with regard to product innovations may be the result of the measurement method applied. Innovation research - as discussed in the introduction - uses a variety of measures, often broken down into input (e.g. innovation expenditure, R\&D expenditure) and output (e.g. sales of new products). Moreover, the study did not apply the division of innovations into two important categories: radical and incremental, so we do not have any knowledge about the qualitative aspects of innovations implemented in the respondent firms. We also have to remember about paradoxes so characteristic of FB. Researchers emphasize that family businesses are inherently characterized by paradoxes that are manifested in tensions between the desire to preserve tradition and the need to make changes, between the expected standard of living for the family and the growth of the firm, or between the founder's wish to retain control and the successor's aspiration of autonomy, which can both hinder and foster innovation, affecting the level of FB innovation (Ingram et al., 2016).

Second, the characteristics such as a business profile and age have little impact on the differences in the level of innovation in FB and NFB, measured with the number of product innovations. A higher innovation indicator was observed in manufacturing firms and firms conducting mixed activity. In addition, greater differences were identified with respect to business process innovations - as compared to product innovations. The survey confirms that the size of firms is the factor which positively influences their innovation, which - in the case of Poland - is confirmed by the data of Statistics Poland and the reports published by the Polish Agency for Enterprise Development.

Third, the subjective opinions on the extent to which the implementation of innovations fulfilled the expectations of the management/owners of improved business performance (sales and/or profit) turned out to be very "averaged" and relatively low, as the averages did not exceed 3.0 (at low values of standard deviation, i.e. low response variation from the average). This question indirectly concerned the relationship between innovation and firm performance, 
otherwise confirmed as positive by studies into the links between innovation and performance, regardless of what performance measures are used (Rosenbusch, Brinckmann and Bausch, 2011). However, some studies show that, for example, the character of the sector may decide whether a product innovation will have a positive impact on a firm's growth or not (cf. Fuetsch and Suess-Reyes, 2017). Moreover, some research results do not confirm the positive impact of selected innovations (e.g. a new market entry) on family business performance (Alberti and Pizzurno, 2013).The subjective opinions on whether innovations fulfilled the expectations of management/owners may indirectly reflect rather moderate motivation to implement the innovations, ultimately determining the number (and type) of innovations implemented by a firm, which, according to research, is not high. Additionally, poor opinions may result from the lack of precise knowledge of the respondents about the effects of the innovations implemented in their firm, which prompted a "hard to say" answer. Lack of knowledge may be caused by lack of in-depth analyses accompanying the implementations, especially in the case of product innovations, hence the opinions may only be intuitive. Business process innovations may be more difficult to evaluate as fulfilling the expectations or not for other reasons, too. The effects of some implementations are frequently "observed" only after they accumulated, which may be related to a number of additional conditions, or it takes more time, going beyond the research horizon, for these effects to occur ${ }^{5}$. Low opinions expressed by the respondents with regard to the expected impact of innovations on improved business performance may also be a result of excessive, perhaps unrealistic expectations in this respect, and may even point to irregularities in the process of innovation development and implementation. It seems particularly difficult to explain why management/owners expressed such low opinions concerning the fulfillment of their expectations of improved business performance as a result of innovation implementations, especially that the number of such implementations is relatively low: on average one innovation per firm per year. Moreover, the opinions in FB are only marginally higher than in NFB, which may contradict the idea that the former engage in innovation activity with great caution, making the most efficient use of their resources (Duran et al., 2016; De Massis et al., 2018). Generally, the implementation of any type of innovation can generate effects over a longer period of time, going beyond the time horizon of the study.

\section{Summary}

This comparative study on FB and NFB innovation fills a gap in the area where knowledge concerning this issue is still scarce in Poland. It did not reveal any significant differences in the level of product innovation of the respondent firms, although innovation was expected to be

\footnotetext{
${ }^{5}$ For example, the purchase of modern software for one area of a firm's operations will bring the expected benefits if The implementation of IT solutions will also embrace other interconnected processes.
} 
lower in FB, as some world studies argue. FB turned out to be less innovative in terms of process innovation. Although family firms have a number of strengths that can potentially foster innovation, studies comparing FB and NFB innovation do not provide conclusive results, which implies that FB may be both more and less innovative (De Massis et al., 2015; Fuetsch, and Suess-Reyes, 2017) or such differences may not exist at all. Family businesses have to face a number of contradictions and paradoxes resulting from the combination of two separate systems: family and business, which are driven by different logics. These contradictions can complicate innovation processes and contribute to their complexity, different degrees of family commitment and different effects. Further comparative research should therefore be pursued, but it should use other measures of innovation and innovation should be divided into at least two additional categories: radical and incremental. It also seems necessary to complement quantitative surveys with qualitative studies.

The study confirms a relatively low level of innovation of the respondent firms (especially product innovations) and, according to the respondents' opinions, the expectations of management and/or owners regarding the impact of innovations on improved business performance fail to be fulfilled. These poor opinions of innovation effects are a cause for concern for a number of reasons, but mainly because they may discourage innovation activity. Certainly, the results in this area inspire continued exploration of innovation activity of firms, especially relating to the organization of the innovation process and the analysis and measurement of its effectiveness: do firms evaluate the effectiveness of innovations they implemented and how do they do it?

What implications could such research have for practice - for FB managers/owners and politicians? Studies show that FB are not less innovative when it comes to implementing new or modified products and services. This contradicts both the opinions and some research results about the conservatism of FB or their stronger orientation towards family goals at the expense of a firm's growth. It seems that the results concerning the poor opinions on the expected effects of implemented innovations should encourage entrepreneurs to reflect on the problem, analyze the expected effects of a particular type of innovation as well as carefully assess the results actually achieved - including the impact of the time factor.

\section{Acknowledgements}

The author wishes to thank Prof. Tomasz Ingram for his contribution to the analysis of the empirical research results. 


\section{References}

1. Ahluwalia, S., Mahto, R.V., and Walsh, S.T. (2017). Innovation in small firms: Does family vs. non-family matter? Journal of Small Business Strategy, 27(3), 39-49.

2. Alberti, F.G., and Pizzurno, E. (2013). Technology, innovation and performance in family firms. International Journal of Entrepreneurship and Innovation Management, 17(1-3), 142-161. https://doi.org/10.1504/IJEIM.2013.055253.

3. Bendig, D., Foege, J.N., Endriß, S., and Brettel, M. (2020). The Effect of Family Involvement on Innovation Outcomes: The Moderating Role of Board Social Capital. Journal of Product Innovation Management, 37(3), 249-272. https://doi.org/10.1111/ jpim. 12522 .

4. Chrisman, J.J., Chua, J.H., De Massis, A., Frattini, F., and Wright, M. (2015). The ability and willingness paradox in family firm innovation. Journal of Product Innovation Management, 32(3), 310-318. https://doi.org/10.1111/jpim.12207.

5. Chua, J.H., Chrisman, J.J., and Sharma, P. (1999). Defining the family business by behavior. Entrepreneurship theory and practice, 23(4), 19-39. https://doi.org/ $10.1177 \% 2 \mathrm{~F} 104225879902300402$.

6. Classen, N., Carree, M., Van Gils, A., and Peters, B. (2014). Innovation in family and nonfamily SMEs: an exploratory analysis. Small Business Economics, 42(3), 595-609. https://doi.org/10.1007/s11187-013-9490-z.

7. De Massis, A., \& Foss, N.J. (2018). Advancing family business research: The promise of microfoundations. Family Business Review, 31(4), 386-396. doi:10.1177/ 0894486518803422.

8. De Massis, A., and Foss, N.J. (2018). Advancing family business research: The promise of microfoundations. Family Business Review, 31(4), 386-396. https://doi.org/ $10.1177 \% 2 F 0894486518803422$.

9. De Massis, A., Audretsch, D., Uhlaner, L., and Kammerlander, N. (2018). Innovation with Limited Resources: Management Lessons from the German Mittelstand. Journal of Product Innovation Management, 35(1), 125-146. https://doi.org/10.1111/jpim.12373.

10. De Massis, A., Di Minin, A., and Frattini, F. (2015). Family-Driven Innovation: Resolving the Paradox in Family Firms. California Management Review, 58(1), 5-19. https://doi.org/10.1525\%2Fcmr.2015.58.1.5.

11. De Massis, A., Frattini, F., and Lichtenthaler, U. (2013). Research on technological innovation in family firms: Present debates and future directions. Family Business Review, 26(1), 10-31. https://doi.org/10.1177\%2F0894486512466258.

12. Duran, P., Kammerlander, N., van Essen, M., and Zellweger, T. (2016). Doing more with less: Innovation input and output in family firms. Academy of Management Journal, 59(4), 1224-64. https://doi.org/10.5465/amj.2014.0424. 
13. Fuetsch, E., and Suess-Reyes, J. (2017). Research on innovation in family businesses: are we building an ivory tower? Journal of Family Business Management. 7(1), 44-92. https://doi.org/10.1108/JFBM-02-2016-0003.

14. Habbershon, T.G., and Williams, M.L. (1999). A resource-based framework for assessing the strategic advantages of family firms. Family Business Review, 12(1), 1-25. doi:10.1111/j.1741-6248.1999.00001.x.

15. Ingram, A.E., Lewis, M.W., Barton, S., and Gartner, W.B. (2016). Paradoxes and innovation in family firms: The role of paradoxical thinking. Entrepreneurship Theory and Practice, 40(1), 161-176. https://doi.org/10.1111\%2Fetap.12113.

16. Jaskiewicz, P., Combs, J.G., and Rau, S.B. (2015). Entrepreneurial legacy: Toward a theory of how some family firms nurture transgenerational entrepreneurship. Journal of Business Venturing, 30(1), 29-49. https://doi.org/10.1016/j.jbusvent.2014.07.001.

17. Kammerlander, N., and van Essen, M. (2017). Family firms are more innovative than other companies. Harvard Business Review, January 25.

18. Klein, S.B. (2000). Family business in Germany: significance and structure. Family Business Review, 13(3), 157-182.

19. Kraśnicka, T., and Głód, G. (2018). Związki pomiędzy innowacyjnością a wynikami firm rodzinnych. Przedsiębiorczość i Zarządzanie, 19(6), cz. 2, Konkurencyjność wspótczesnych przedsiębiorstw-modele, koncepcje i uwarunkowania), 309-323.

20. Kraśnicka, T., Głód, W., Wronka-Pośpiech, M. (2018). Management innovation, proinnovation organisational culture and enterprise performance: testing the mediation effect. Review of Managerial Science, 12(3), 737-769.

21. Kraśnicka, T., Ingram, T., Głód, G. (2019). Rodzinność polskich przedsiębiorstwstymulator czy przeszkoda innowacyjności. Przegląd Organizacji, 7, 22-31.

22. Kraśnicka, T., Steinerowska-Streb, I. (2019). Family involvement, and innovation of family enterprises. Organization \& Management, Zeszyty Naukowe Politechniki Ślaskiej, Sería: Organizacja i Zarzadzanie,136, 289-303.

23. Matzler, K., Veider, V., Hautz, J., and Stadler, Ch. (2015). The Impact of Family Ownership, Management, and Governance on Innovation. Journal of Product Innovation Management, 32(3), 319-333. https://doi.org/10.1111/jpim.12202.

24. Naldi, L., Cennamo, C., Corbetta, G., and Gomez-Mejia, L. (2013). Preserving socioemotional wealth in family firms: Asset or liability? The moderating role of business context. Entrepreneurship Theory and Practice, 37(6), 1341-1360. https://doi.org/ 10.1111\%2Fetap. 12069.

25. Neubaum, D. (2018). Family business research: Roads travelled and the search for unworn paths. Family Business Review, 31, 259-270. https://doi.org/ $10.1177 \% 2 \mathrm{~F} 0894486518792948$. 
26. OECD Publishing (2018). Oslo Manual 2018: Guidelines for collecting, reporting and using data on innovation. Organisation for Economic Co-operation and Development OECD.

27. Pichlak, M. (2012). Uwarunkowania innowacyjności organizacji. Studium teoretyczne $i$ wyniki badań empirycznych. Warszawa: Difin.

28. Podręcznik Oslo (2008). Zasady gromadzenia $i$ interpretacji danych dotyczacych innowacji. OECD, EUROSTAT, 2005. Warszawa: Ministerstwo Nauki i Szkolnictwa Wyższego, Departament Strategii i Rozwoju Nauki.

29. Reay, T., Jaskiewicz, P., \& Hinings, C.R. (2015). How family, business, and community logics shape family firm behavior and "rules of the game" in an organizational field. Family Business Review, 28(4), 292-311. https://doi.org/10.1177\%2F0894486515577513.

30. Roessl, D., Fink, M., and Kraus, S. (2010). Are family firms fit for innovation? Towards an agenda for empirical research. International Journal of Entrepreneurial Venturing, 2(3-4), 366-380. https://doi.org/10.1504/IJEV.2010.037118.

31. Rondi, E., De Massis, A., and Kotlar, J. (2019). Unlocking innovation potential: A typology of family business innovation postures and the critical role of the family system. Journal of Family Business Strategy, 10(4), 100236. https://doi.org/10.1016/j.jfbs.2017.12.001.

32. Rosenbusch, N., Brinckmann, J., and Bausch, A. (2011). Is innovation always beneficial? A meta-analysis of the relationship between innovation and performance in SMEs. Journal of Business Venturing, 26(4), 441-457. https://doi.org/10.1016/j.jbusvent.2009.12.002.

33. Safin, K. (2007). Przedsiębiorstwa rodzinne - istota i zachowania strategiczne. Wrocław: Wydawnictwo AE.

34. Steeger, J.H., and Hoffmann, M. (2016). Innovation and family firms: ability and willingness and German SMEs. Journal of Family Business Management. 6(3), 251-269. https://doi.org/10.1108/JFBM-09-2015-0036.

35. Steinerowska-Streb, I. (2015). Bariery finansowe w działalności polskich przedsiębiorstw rodzinnych. In: B. Piasecki, A. Marjański (eds.), Przedsiębiorczość i Zarządzanie. Firmy rodzinne - doświadczenia i perspektywy zarzadzania, tom XVI, zeszyt 7, część II, 351-369.

36. Sułkowski, Ł., and Marjański, A. (2009). Firmy rodzinne, jak osiagnać sukces w sztafecie pokoleń. Warszawa: Wydawnictwo Poltex.

37. Surdej, A., and Wach, K. (2010). Przedsiębiorstwa rodzinne wobec sukcesji. Warszawa: Difin. 


\title{
PROFESSIONAL COMPETENCIES IN SHAPING THE ORGANIZATIONAL COMPETENCES OF POLISH EMERGENCY MEDICAL UNITS IN THE LIGHT OF SURVEY RESEARCH
}

\author{
Agnieszka KRAWCZYK-SOŁTYS \\ Opole University, Faculty of Economics; akrawczyk.soltys@uni.opole.pl, ORCID: 0000-0003-1575-3497
}

\begin{abstract}
Purpose: The aim of the article is to identify the current level of professional competencies and to determine the extent to which individual professional competencies affect the organizational competences of Emergency Medical Units in the areas of marketing (recognizing the patient's needs), quality (level of medical services) and logistics (provision of medical services in the right place and time).
\end{abstract}

Design/methodology/approach: The model of professional competencies of medical staff employed in Polish EMU establishes eight domains. To achieve superior organizational performance is very important to identify which set of professional competencies is required to gain their strategic goals. The research was carried out in 2018 in Emergency Medical Units in six voivodships. 135 respondents took part in the survey.

Findings: As a result of the research, it is determined that the highest level among the professional competencies presented in the model is characterized by transportation competencies. Among managerial competencies, the following have the greatest impact on the organizational competences of Emergency Medical Units: in the area of quality - transportation competencies, while in the areas of marketing and logistics - transportation, therapeutics and assessment and diagnostics competencies.

Practical implications: Nowadays health systems are being confronted with rapidly increasing demand generated by the COVID-19 outbreak. A well-organized and prepared health system has the capacity to maintain equitable access to essential service delivery throughout an emergency, limiting direct mortality and avoiding increased indirect mortality.

Originality/value: An integration professional competencies of medical personnel of Emergency Medical Units with its organizational competences especially relevant in pandemic time.

Keywords: Emergency Medical Units, organizational competences, professional competencies.

Category of the paper: research paper. 


\section{Introduction}

The predominant objective of Emergency Medical Units, correspondingly to the Polish health policy, is to provide patients with compelling healthcare by implementing an emergency medical service which takes into consideration the expectations and values of patients. The aim depends on suitable professional competencies of the personnel hired in these units, managerial competencies controlling these organizations, as well as managerial competences.

Contemporary medical entities operate in a very turbulent environment, and are shaped by the influence of factors which relate to both distal and near surroundings (mainly due to underfunding, lack of liquidation, performing a social mission resulting from the nature of these units, etc.). These factors contribute to an increase in the requirements for medical entities, including emergency medical units. They include, in particular: patient orientation and needs, high quality of medical services provided and the optimization of the functioning of these organizations within the budget. The knowledge and competences of the personnel employed in these organizations are therefore becoming increasingly important because more and more needs are identified to facilitate the transfer of research solutions to clinical and management practice and the development of policy and legal solutions in this field, which should ultimately translate into better satisfaction for the needs of patients, as well as increasing the competitiveness of these units (Krawczyk-Sołtys, 2018).

Nowadays health systems are being confronted with rapidly increasing demand generated by the COVID-19 outbreak. A well-organized and prepared health system has the capacity to maintain equitable access to essential service delivery throughout an emergency, limiting direct mortality and avoiding increased indirect mortality. Hence, there is so important to integrate professional competencies of medical personnel of Emergency Medical Units EMU with its organizational competences.

The issue of professional competencies was promoted by D. McClelland (Mc Clelland, 1973), one of the founders of the Hay McBer, who theorized that in the aspect of foreseeing the future efficiency of people's work, not their intelligence but instead their competencies should be examined.

The precursor of resource approach, E.T. Penrose (Penrose, 1959), was the leader in noticing organizational competences, stressing that in order to gain a competitive advantage, not only are the organization's resources crucial, but primarily - the skills to use them in processes.

Competency identification systems need to identify both - personal (professional and managerial) competencies and organizational competences (Boam, and Sparrow, 1992).

The competences of healthcare organizations may be acquired from different kinds of knowledge. Some of them rely on "know-how" - practical forms of knowledge obtained through incremental advancements to medical services and processes, another - on "know- 
why" - theoretical forms of comprehending that allows the creation of new kinds of services and processes. Different healthcare organizations competences come from diverse levels of activity: some are determined broadly from the capabilities of these entities to create and provide definite types of medical services, another is implied to come from the abilities to plan and organize resources in new and powerful ways, others mostly rely on the potential of managers to build up new strategies for creating organizational value.

This article focuses on the identification of common professional competencies of medical personnel within Emergency Medical Units (EMU), as well as the significantly shaped competences of such organizations in order to determine the extent to which individual professional competencies affect the organizational competences of these entities in the areas of marketing (recognizing the patient's needs), quality (the level of medical services) and logistics (a provision of medical services in the right place. The proposed lists of managerial and professional competencies were created and are based on the analysis of healthcare competencies models - the study of the literature - and the author of this papers observations of the analyzed entities.

The article assumes that competencies are a conglomerate of abilities consisting of: knowledge, education, experience, other predispositions and personality traits. These competencies are used and developed in the process of providing medical services in order to achieve results consistent with the strategic intentions of emergency medical units (KrawczykSołtys, 2018a).

\section{A model overview of professional competencies in health care}

Team for Research on Hospital Management "Avicenna" of the Jagiellonian University on the grounds of research established 13 competencies of medical staff, which were split into three classes of interpersonal and social competencies, i.e. threshold, desirable and expected competences: communication, defiance to stress, empathy, assertiveness, optimism, availability, responsibility, regularity, accuracy, openness, creativity, perseverance, willingness and catalyst to permanently boost knowledge and skills (Kęsy, 2013).

Threshold competencies comprise of communication skills. Furthermore, the ability to create a directive so as not to provoke the imbalance of information between the staff and the patient in an empathetic manner is crucial for medical workers. This group also consists of regularity (which is not only a ground for development at work, but also in the face of medical knowledge, permanent learning) and openness (aiming to reduce the distance between the patient and the staff). Competencies, practicality and promoting the achievement of duties for medical employees cover responsibility and assertiveness and concentrate on the skill to argue, explain the diagnosis and set up the treatment process, etc. Another advantageous competence 
is resistance to stress, optimism and accuracy. The continuing competencies are presented in the expected group, which are not crucially at the positions of medical employees, but undoubtedly boost the character of work.

R.M. Epstein and E.M. Hundert (Epstein, and Hundert, 2002) characterized the professional competencies of medical staff as the repeated and skillful use of communication, knowledge, professional skills, scientific understanding, emotions, qualities, and reflection in everyday practice for the benefits of the individual and the community being dealt with. Professional competencies are framed and based on a groundwork of elemental clinical skills, scientific knowledge, and principled advancement. They cover a cognitive role (acquiring and adopting knowledge), a centralizing function (accounting biomedical and psychosocial statistics when it comes to clinical reasoning), and principled function (the eagerness, patience, emotional awareness). Enumerated competencies are progressive, temporary, and context-vulnerable and are believed to rely on the mode of the mind. This comprehension of competencies is comparable to the thorough typology of competencies often quoted in the literature presented by G. Cheetham and G. Chivers (Cheetham, and Chivers, 1996, 1998): cognitive competencies, functional competencies, personal (behavioral) competencies, ethical competencies, and metacompetencies (applied with the possibility to deal with ambivalence).

Another proposition is five clusters of competencies for coordinated/integrated health services (Langings, and Borgermans, 2015):

1. patient advocacy - ability to promote patients' right to ensure the best quality of care and empowering patients to become active participants of their health;

2. effective communication - ability to establish quickly a rapport with patients and their family members in an empathetic and sensitive manner incorporating the patients' perceived and declared culture;

3. team work - ability to function effectively as a member of an inter-professional team which includes providers, patients and family members in a way that reflects an understanding of a team dynamics and group/team processes in building productive working relationships and that is focused on health outcomes;

4. people-centred care - ability to create conditions for providing coordinated/integrated services focused on the patients and their families' needs, values and preferences along with a continuum of care and over the life-course;

5. continuous learning - ability to demonstrate reflective practice, based on the best available evidence and to assess and continually improve the services delivered as an individual provider and as a member of an inter-professional team.

These provide a foundation for evaluating the performance of the medical staff. These clusters are fundamental to achieving care that is appropriate, evidence-based, personalized, population-focused, comprehensive, accessible, coordinated and continuous. 
A set of simple, core competencies is proposed that medical staff should possess:

- provide patient-centered care-identify, respect, and care about patients' differences, values, preferences, and expressed needs; relieve pain and suffering; coordinate continuous care; listen, inform clearly, communicate and educate patients; share decision making and management; continuously advocate disease prevention, wellness, and promotion of healthy lifestyles, including a focus on the health of the population;

- work in interdisciplinary teams - cooperate, collaborate, communicate, and integrate care in teams to ensure that the care is continuous and reliable;

- employ evidence-based practice - integrate best research with clinical expertise and patient values for optimum care, and participate in learning and research activities to a feasible extent;

- apply quality improvement-identify errors and hazards in care; understand and implement basic safety design principles, such as standardization and simplification; continually understand and measure quality of care in terms of structure, process, and outcomes in relation to patient and community needs; design and test interventions to change processes and systems of care, with the objective of improving quality;

- utilize informatics-communicate, manage knowledge, mitigate error, and support decision making using information technology.

Significant work undertaken by researchers and experts in this competency area reveals the specific skills required by today's medical staff to be more responsive to patient's needs (Halpern et al., 2001; Committee on Quality of Health Care in America, Institute of Medicine, 2001; Lewin et al., 2001; Mead and Bower, 2000; O'Neil, 1998; Stewart, 2001): share power and responsibility with patients and caregivers; communicate with patients in a shared and fully open manner; take into account patients' individuality, emotional needs, values, and life issues; implement strategies to reach out to those who can take care of themselves, include strategies of care which support the broader community, enhance prevention and promote health.

\section{An identification of the level of professional competencies in Emergency Medical Units and the degree of their impact on organizational competences - research results}

The research was conducted in the second and third quarters of 2018 in emergency medical units in the following regions: Śląskie, Mazowieckie, Opolskie, Warmińsko-Mazurskie, Lubelskie and Dolnośląskie. 135 respondents took part in the survey.

The selection of the research sample was random. The research sample included respondents from two regions characterized by the largest number of emergency medical teams (Mazowieckie - 193 and Śląskie - 116) and Warmińsko-Mazurskie region, where there is the 
largest indicator of the number of teams per 100,000 residents - 5.4 (average in Poland was 4) (Pomoc doraźna..., 2018).

According to the assumptions of healthcare marketing (Bober, Majchrzak-Lepczyk, 2015) in the sphere of marketing it is necessary to focus on the processes of providing medical services that determine the pro-quality needs of consumers and the implementation of tools and techniques shaping their repetitive quality. Among the key dimensions of the quality of services provided by emergency medical services, reference was made to substantive and psychosociological dimensions (Lisiecka-Biełanowicz, 2016). In the sphere of logistics, reference was mainly made to shaping, controlling and controlling supply and service processes implemented as part of actions aimed at saving people's health and life (Bartczak, 2015).

Respondents assessed the current level of professional competencies and the degree to which they affect organizational competencies in the areas of marketing (recognition of patient needs), quality (level of medical services rendered) and logistics (provision of medical services in the right place at the right time) (Krawczyk -Sołtys, 2018b).

The respondents were determined using a five-level Likert scale of the current level of professional competencies of medical staff then they were determined by the impact level of these competencies on organizational competences in three fields in five-level Likert scale marketing (perceiving patient's needs), quality (of implemented medical services) and logistics (arrangement of medical services both at the right time and place).

\subsection{An identification of the level of professional competencies in Emergency Medical Units}

The study presented that the highest rated professional competencies were Transportation Competencies $(4,30)$. The following were: firstly, preparing ambulance for service $(4,49)$, secondly, driving ambulance or emergency response vehicle $(4,23)$, thirdly, transferring patient to air ambulance $(4,14)$ fourthly, transporting patient in air ambulance $(3,94)$.

The next researched area were Therapeutics Competencies $(4,18)$. The results presented data in the following order of significance: preparing oxygen delivery devices $(4,54)$, delivering oxygen and administering manual ventilation $(4,44)$, utilizing ventilation equipment $(4,23)$, immobilizing actual and suspected fractures $(4,20)$, maintaining patency of upper airway and trachea $(4,10)$, administering medications $(4,07)$, providing basic care for soft tissue injuries $(4,05)$, implementing measures to maintain hemodynamic stability $(3,77)$.

Then, as far as the study is concerned the respondents referred to the level of Professional Responsibilities Competencies (4,11). The figures show as follows: functioning as a professional $(4,13)$, participating in continuing education and professional development $(3,77)$, possessing an understanding of the medicolegal aspects of the profession $(4,19)$, recognizing and complying with relevant Polish legislation $(4,01)$, functioning effectively in a team environment $(4,22)$, making decisions effectively $(4,10)$, managing scenes with actual or potential forensic implications $(4,34)$. 
In sequence, Assessment and Diagnostics Competencies have been established $(4,06)$. The results are presented as regards: conducting triage in a multiple-patient incident $(4,01)$, obtaining patient history $(4,08)$, conducting complete physical assessment demonstrating appropriate use of inspection $(3,92)$, palpation and percussion $(4,57)$, assessing vital signs, utilizing diagnostic tests $(3,74)$.

Another observation finds that respondents indicated Communication Competencies $(3,94)$. In regards to: practicing effective oral $(4,04)$ and written $(3,91)$ communication skills, practicing effective non-verbal communication skills $(3,84)$ and practicing effective interpersonal relations $(3,98)$.

The analysis of respondents in question pinpointed Communication Competencies $(3,94)$ : practicing effective oral $(4,04)$ and written $(3,91)$ communication skills, practicing effective non-verbal communication skills $(3,84)$ and practicing effective interpersonal relations $(3,98)$.

This paragraph presents the results of interpretation of respondents who pointed Integration Competencies $(3,86)$ : utilizing differential diagnosis skills, decision-making skills and psychomotor skills in providing care to patients $(3,85)$, providing care to meet the needs of unique patient groups $(3,83)$, conducting ongoing assessments and provide care $(3,89)$.

It is paramount to stress that according to the respondents opinion Health Promotion and Public Safety Competencies $(3,72)$ are of the lowest level. Therefore presenting the components present as follows: integrating professional practice into community care $(3,43)$, contributing to public safety through collaboration with other emergency response agencies $(4,09)$, participating in the management of a chemical, biological, radiological, nuclear and explosive incident $(3,66)$.

\subsection{An identification of the impact level of professional competencies on organizational competences of Emergency Medical Units in the area of marketing}

Examination of key points in this section highlights the highest rated professional competencies which were Transportation Competencies $(4,07)$. For the sake of clarity, preparing ambulance for service $(4,21)$, driving ambulance or emergency response vehicle $(4,14)$, transferring patient to air ambulance $(4,04)$ and transporting patient in air ambulance $(3,88)$.

In the next area as regards Therapeutics Competencies $(4,04)$ the following statistic results are presented: maintaining patency of upper airway and trachea $(3,95)$, preparing oxygen delivery devices $(4,26)$, delivering oxygen and administering manual ventilation $(4,22)$, utilizing ventilation equipment $(4,11)$, implementing measures to maintain hemodynamic stability $(3,76)$, providing basic care for soft tissue injuries $(4,01)$, immobilizing actual and suspected fractures $(4,08)$, administering medications $(3,94)$.

If one takes into consideration the importance of Assessment and Diagnostics Competencies $(4,04)$ : then the following data concerns: conducting triage in a multiple-patient incident $(4,06)$, obtaining patient history $(4,07)$, conducting complete physical assessment demonstrating 
appropriate use of inspection $(3,94)$, palpation and percussion $(4,32)$, assessing vital signs, utilizing diagnostic tests $(3,80)$.

Then the respondents pointed to the level of distinction regarding Professional Responsibilities Competencies $(3,95)$. As regards the numbers, findings concern: functioning as a professional $(4,16)$, participating in continuing education and professional development $(3,72)$, possessing an understanding of the medicolegal aspects of the profession $(3,95)$, recognizing and complying with relevant Polish legislation $(3,84)$, functioning effectively in a team environment $(4,06)$, making decisions effectively $(3,99)$, managing scenes with actual or potential forensic implications $(3,91)$.

Next, respondents enumerations indicated Communication Competencies (3,90). The figures show as follows: practicing effective oral $(3,94)$ and written $(3,67)$ communication skills, practicing effective non-verbal communication skills $(3,97)$ and practicing effective interpersonal relations $(4,03)$.

The analysis of respondents in question pinpointed Integration Competencies $(3,88)$. The results present the following: utilizing differential diagnosis skills, decision-making skills and psychomotor skills in providing care to patients $(3,90)$, providing care to meet the needs of unique patient groups $(3,85)$, conducting ongoing assessments and provide care $(3,89)$.

Then, as far as the study is concerned the respondents referred to the level of Health and Safety Competencies $(3,78)$ : maintaining good physical and mental health $(3,63)$, practicing safe lifting and moving techniques $(3,74)$ and creating and maintaining a safe work environment $(3,96)$.

In the last section of the analysis, the study reveals that of the lowest level - in respondents opinion - are Health Promotion and Public Safety Competencies $(3,75)$. In regards to: integrating professional practice into community care $(3,55)$, contributing to public safety through collaboration with other emergency response agencies $(4,00)$, participating in the management of a chemical, biological, radiological, nuclear and explosive incident $(3,71)$.

\subsection{An identification of the impact level of professional competencies on organizational competences of Emergency Medical Units in the area of quality}

This section presents the results of the highest rated professional competencies $(4,16)$ which were: Transportation Competencies, Therapeutics Competencies and Assessment and Diagnostics Competencies.

It is important to emphasise that among Transportation Competencies the following were pointed out: firstly - preparing ambulance for service $(4,46)$, secondly - driving ambulance or emergency response vehicle $(4,25)$, thirdly - transferring patient to air ambulance $(4,11)$ and fourthly - transporting patient in air ambulance $(3,83)$.

Amid Therapeutics Competencies it is important to emphasise such data: maintaining patency of upper airway and trachea $(4,15)$, preparing oxygen delivery devices $(4,37)$, delivering oxygen and administering manual ventilation $(4,24)$, utilizing ventilation equipment 
$(4,24)$, implementing measures to maintain hemodynamic stability $(3,90)$, providing basic care for soft tissue injuries $(4,04)$, immobilizing actual and suspected fractures $(4,20)$, administering medications $(4,12)$.

At this stage, the analysis focuses on Assessment and Diagnostics Competencies which were supported by: conducting triage in a multiple-patient incident $(4,22)$, obtaining patient history $(4,19)$, conducting complete physical assessment demonstrating appropriate use of inspection $(4,10)$, palpation and percussion $(4,47)$, assessing vital signs, utilizing diagnostic tests $(3,81)$.

Another respondents examination of key points in this section highlights Professional Responsibilities Competencies (4,13). The results are presented as regards: functioning as a professional $(4,21)$, participating in continuing education and professional development $(3,83)$, possessing an understanding of the medicolegal aspects of the profession $(4,18)$, recognizing and complying with relevant Polish legislation $(4,10)$, functioning effectively in a team environment $(4,29)$, making decisions effectively $(4,19)$, managing scenes with actual or potential forensic implications $(4,13)$.

The analysis of this part aims to present respondents indication to Communication Competencies $(4,09)$. They are as follows: practicing effective oral $(4,07)$ and written $(4,01)$ communication skills, practicing effective non-verbal communication skills $(4,10)$ and practicing effective interpersonal relations $(4,16)$.

On the basis of respondents observation, the level of Health and Safety Competencies was described $(3,98)$ : maintaining good physical and mental health $(3,72)$, practicing safe lifting and moving techniques $(4,00)$ and creating and maintaining a safe work environment $(4,21)$.

In sequence, the statistics describe respondents answers in relation to Integration Competencies $(3,94)$. The figures show as follows: utilizing differential diagnosis skills, decision-making skills and psychomotor skills in providing care to patients $(3,88)$, providing care to meet the needs of unique patient groups $(3,97)$, conducting ongoing assessments and provide care $(3,97)$.

All in all, according to respondents the lowest level refers to Health Promotion and Public Safety Competencies $(3,80)$. They concern: integrating professional practice into community care $(3,37)$, contributing to public safety through collaboration with other emergency response agencies $(4,17)$, participating in the management of a chemical, biological, radiological, nuclear and explosive incident $(3,86)$.

\subsection{An identification of the impact level of professional competencies on organizational competences of Emergency Medical Units in the area of logistic}

The data shown in this section points out that the highest rated professional competencies, is namely Transportation Competencies $(4,30)$. They are in order of significance as follows: preparing ambulance for service $(4,45)$, driving ambulance or emergency response vehicle 
$(4,37)$, transferring patient to air ambulance $(4,23)$ and transporting patient in air ambulance $(4,16)$.

For the sake of clarity it is essential to point out that respondents referred to the level of Professional Responsibilities Competencies $(3,93)$. They were enumerated as follows: functioning as a professional $(4,01)$, participating in continuing education and professional development $(3,56)$, possessing an understanding of the medicolegal aspects of the profession $(3,94)$, recognizing and complying with relevant Polish legislation $(3,88)$, functioning effectively in a team environment $(3,99)$, making decisions effectively $(4,05)$, managing scenes with actual or potential forensic implications $(4,04)$.

Next, the examination of key points in this paragraph concerns Assessment and Diagnostics Competencies $(3,92)$. Hence, the results are presented as follows: conducting triage in a multiple-patient incident $(4,11)$, obtaining patient history $(3,89)$, conducting complete physical assessment demonstrating appropriate use of inspection $(3,83)$, palpation and percussion $(4,15)$, assessing vital signs, utilizing diagnostic tests $(3,62)$.

As regards Therapeutics Competencies $(3,88)$ it is observed that they include: maintaining patency of upper airway and trachea $(3,88)$, preparing oxygen delivery devices $(4,05)$, delivering oxygen and administering manual ventilation $(3,98)$, utilizing ventilation equipment $(3,93)$, implementing measures to maintain hemodynamic stability $(3,65)$, providing basic care for soft tissue injuries $(3,74)$, immobilizing actual and suspected fractures $(3,96)$, administering medications $(3,82)$.

Then, the respondents determined the level of Health and Safety Competencies $(3,77)$. The content refers to: maintaining good physical and mental health $(3,59)$, practicing safe lifting and moving techniques $(3,78)$ and creating and maintaining a safe work environment $(3,95)$.

This section focuses on the respondents indication of Communication Competencies $(3,76)$. They are: practicing effective oral $(3,84)$ and written $(3,59)$ communication skills, practicing effective non-verbal communication skills $(3,74)$ and practicing effective interpersonal relations $(3,88)$.

In sequence, the analysis of respondents answers highlighted the influence of Integration Competencies $(3,74)$. In regard to: utilizing differential diagnosis skills, decision-making skills and psychomotor skills in providing care to patients $(3,69)$, providing care to meet the needs of unique patient groups $(3,79)$, conducting ongoing assessments and provide care $(3,73)$.

The analysis focused on, in the respondents opinion, the lowest level of Health Promotion and Public Safety Competencies $(3,62)$. This section enumerates: integrating professional practice into community care $(3,26)$, contributing to public safety through collaboration with other emergency response agencies $(3,94)$, participating in the management of a chemical, biological, radiological, nuclear and explosive incident $(3,66)$.

As a matter of fact, the most significantly shaping organizational competences of Emergency Medical Units in all areas were Transportation Competencies. They are as follows: in marketing area $(4,07)$, in quality area $(4,16)$ and in logistic area $(4,30)$. In quality area the 
same indications - 4,16 - have been obtained amongst both Assessment and Diagnostics Competencies and Therapeutics Competencies.

Then, the data shows that:

- in marketing area respondents distinguished in the order of significance: Assessment and Diagnostics Competencies and Therapeutics Competencies $(4,04)$, Professional Responsibilities Competencies (3,95), Communication Competencies (3,90), Integration Competencies $(3,88)$, Health and Safety Competencies $(3,78)$ and Health Promotion and Public Safety Competencies $(3,75)$;

- in quality area respondents highlighted the influence of the following: Professional Responsibilities Competencies (4,13), Communication Competencies (4,09), Health and Safety Competencies (3,98), Integration Competencies $(3,94)$ and Health Promotion and Public Safety Competencies $(3,80)$;

- in logistics area as far as the study is concerned the respondents referred to: Professional Responsibilities Competencies (3,93), Assessment and Diagnostics Competencies $(3,92)$, Therapeutics Competencies $(3,88)$, Health and Safety Competencies $(3,77)$, Communication Competencies (3,76), and Health Promotion and Public Safety Competencies $(3,62)$.

\section{Conclusions and Further Research}

The significance of competencies issues and their importance in the management of healthcare organizations, including emergency medical units, is widely emphasized in the literature on the subject. (Liang et al., 2018, Leggat et al., 2011; Bartram et al., 2012; Clark, Armit, 2010; Richtie, Yen, 2013). The importance of the impact of professional competencies on organizational competences in health care is also pointed out (Lustri, Miura, Takahashi, 2007; Yang et al., 2006; Wickramasinghe, De Zoyza, 2011).

The accomplishments of such organizations (on top of the systems and processes that determine them) stem from the bodies who are linked with the process, the competence they separately and together have to possess, and the behaviour they must employ (individually and interactively) to implement the process - their competencies (Krawczyk-Sołtys, 2019).

The specific understanding of competencies in services, mainly professional services (in general public named human based) which emergency medical services are a part of, is pinpointed by S.G. Hein and C.D. Riegel (Hein, and Riegel, 2012). Correspondingly to the final effect of empirical research J.A. Chapman and G. Lovell (Chapman, and Lovell, 2006) have stated that the competence groundwork in professional services inclines the key skills and approaches necessary to grant the service. 
Evidence demonstrates that attempts concentrated on merging medical personnel knowledge and skills to community needs means potential deficits and maldistribution of the medical personnel, escalates productivity, work comfort, enrollment and confinement and, in a long term, supports to enhance the quality of care. The process of combining their professional competencies to patient requirements engages a lot more than only attaining this personnel that has general knowledge and skills to perform more efficiently and effectively. To some extent it means making certain that the medical personnel is capable of implementing these knowledge and skills into practice i.e. build up competencies or to intensify organizational competences of medical units.

The examination of professional competencies of Medical Emergency Units employees is to regulate presently possessed and achievable by the staff competencies crucial for effective, and quality decent accomplishment of aims and responsibilities. The competence test ought to be executed with a clear indication and explanation of individual competencies components, principally: knowledge, skills and attitudes.

Amongst the most crucial defining the bottom line competences of Medical Emergency Units one can determine precursors competencies, for which the impetus of the acquisition process is the following the recent technologies and solutions used in the provision of emergency medical services and mainstream competencies regulated by observing the organization's needs.

Healthcare organizations with core competences can somewhat determine the environments (i.e. creating new opportunities) in which they act and challenge and that is the reason why they are more likely to gain aimed outcomes (Eden, Ackermann, 2010).

The issue of competencies and their importance in the management of healthcare organizations, including emergency medical units, is attracting an increasing interest. It is especially evident in pandemic time. Therefore, it seems necessary to conduct empirical and literature research in this area, which will enrich scientific knowledge, rationalize research methodology, as well as allow to formulate recommendations for practice.

\section{References}

1. Bartczak, K. (2015). Logistyka w systemie ratownictwa medycznego w Polsce. Logistyka, 5, pp. 7241-7249.

2. Bartram, T., Casimir, G., Djurkovic, N., Leggat, S., and Stanton, P. (2012). Do perceived high performance work systems influence the relationships between emotional labor, burnout and intention to leave? A study of Australian nurses. Journal of Advanced Nursing, 68(7), pp. 1567-1578. 
3. Boam, R., and Sparrow, P.R. (eds.) (1992). Designing and Achieving Competency. A Competency Based Approach to Developing People and Organizations. London: McGraw-Hill.

4. Bober, B., Majchrzak-Lepczyk, J. (2015). Rola oraz zadania marketingu w procesie świadczenia usług w szpitalach publicznych. Handel Wewnętrzny, 5(358), pp. 62-80.

5. Chapman, J.A., and Lovell, G. (2006). The competency model of hospitality service: Why it doesn't deliver. International Journal of Contemporary Hospitality Management, 18(1), pp. 78-88.

6. Cheetham, G., and Chivers, G. (1996). Towards a holistic model of professional competence. Journal of European Industrial Training, 20(5), pp. 20-30.

7. Cheetham G., and Chivers, G. (1998). The reflective (and competent) practitioner: a model of professional competence which seeks to harmonize the reflective practitioner and competence-based approaches. Journal of European Industrial Training, 22(7), pp. 267276.

8. Clark, J., and Armit, K. (2010). Leadership competency for doctors: a framework. Leadership in Health Services, 23(2), pp. 115-129.

9. Committee on Quality of Health Care in America, Institute of Medicine (2001). Crossing the Quality Chasm: A New Health System for the 21st Century. Washington, DC: National Academy Press.

10.Eden, C., and Ackermann, F. (2010). Competences, Distinctive Competences, and Core Competences. In: R. Sanchez, A. Heene (eds.), A Focused Issue on Identifying, Building and Linking Competences. Research in Competence-Based Management, 5. Bingley: Emerald Group Publishing Ltd.

11. Epstein, R.M., and Hundert, E. (2002). Defining and Assessing Professional Competence. JAMA, 287(2), pp. 226-235.

12.Halpern, R., Lee M.Y., Boulter P.R., and Phillips R.R. (2001). A synthesis of nine major reports on physicians competencies for the emerging practice environment. Academic Medicine, 76(6), pp. 606-15.

13. Hein, S.G., and Riegel, C.D. (2012). Human Resource and Organizational Management Content in the Hospitality Curriculum: How the Professionals View It. Journal of Human Resources in Hospitality \& Tourism, 11(2). pp. 165-181.

14. Kęsy, M. (2013). Kształtowanie kompetencji menedżerskich personelu medycznego w szpitalach. Kraków: Wydawnictwo Uniwersytetu Jagiellońskiego.

15. Krawczyk-Sołtys, A. (2018a). Modelowanie kompetencji w jednostkach ratownictwa medycznego - założenia wstępne. In: M. Tutko, M. Wronka-Pośpiech (eds.), Nauki o zarzadzaniu $w$ odmiennych kontekstach badawczych (pp. 105-116). Kraków: Wydawnictwo Uniwersytetu Jagiellońskiego. 
16. Krawczyk-Sołtys, A. (2018b). Personal Competencies Enhancing Organizational Competences Of Emergency Medical Units In Poland - Empirical Research. Conference Proceedings Of The 2nd International Scientific Conference Development And Administration Of Border Areas Of The Czech Republic And Poland Support For Sustainable Development, E. Ardielli (ed.). Ostrava, pp. 125-134.

17. Krawczyk-Sołtys, A. (2019). Professional and managerial competencies enhancing organizational competences of emergency medical units. Zeszyty Naukowe Politechniki Śląskiej, 136, pp. 305-322.

18. Langings, M., and Borgermans, L. (2015). Strengthening a competent health workforce for the provision of coordinated/integrated health services. Working Document. Copenhagen: World Health Organization.

19. Leggat, S.G., Balding, C., and Anderson, J.A. (2011). Empowering health-care managers in Australia: an action learning approach. Health Services Management Research, 24(4), pp. 196-202.

20. Liang, Z., Howard, P.F., Leggat, S., and Bartram, T. (2018). Development and validation of health service management competencies. Journal of Health Organization and Management, 32(2), pp. 157-175.

21.Lewin, S.A., Skea, Z.C., Entwistle, V., Zwarenstein, M., and Dick, J. (2001). Interventions for providers to promote a patient-centred approach in clinical consultations (Cochrane Review). Cochrane Database System Review, 4: CD003267.

22.Lisiecka-Biełanowicz, M. (2016). Zarzadzanie jakościa relacji w organizacjach ochrony zdrowia. Warszawa: Difin.

23. Lustri, D., Miura, I., and Takahashi, S. (2007). Knowledge Management Model: Practical Application for Competency Development. The Learning Organization, 14(2), pp. 186-202.

24. McClelland, D. (1973). Testing for Competence Rather Than for "Intelligence". American Psychologist, 28, pp. 1-14.

25. Mead, N., and Bower, P. (2000). Patient-centredness: A conceptual framework and review of the empirical literature. Social Science Medicine, 51(7), pp. 1087-110.

26. O'Neil, E.H. and the Pew Health Professions Commission (1998). Recreating health professional practice for a new century - The fourth report of the PEW health professions Commission. San Francisco, CA: Pew Health Professions Commission.

27. Penrose, E.T. (1959). The Theory of the Growth of the Firm. New York: John Wiley \& Sons.

28. Pomoc doraźna i ratownictwo medyczne (2018). Warszawa: Główny Urząd Statystyczny, https://stat.gov.pl, 20.01.2019. 
29. Ritchie, D., and Yen, M. (2013). Health services management development: what formal knowledge should support the skills and experience required? Australian Health Review, 37(2), pp. 189-193.

30.Stewart, M. (2001). Towards a global definition of patient centered care. British Medical Journal, 322(7284), pp. 444-45.

31. Wickramasinghe, V., and De Zoyza, N. (2011). Managerial competency requirements that enhance organizational competences: A study of a Sri Lanka telecom organization. The International Journal of Human Resource Management, 22(14), pp. 2981-3000.

32. Yang, B.C., Wu, B.E., Shu, P.G., and Yang, M.H. (2006). On establishing the core competency identifying model: A value-activity and process oriented approach. Industrial Management \& Data Systems, 106(1), pp. 60-80. 



\title{
INEFFICIENCY IN SPECTRUM AUCTIONS - EMPIRICAL EVIDENCE
}

\author{
Agnieszka KUŚ \\ Pope John Paul II State School of Higher Education in Biała Podlaska, Faculty of Economic Sciences; \\ a.kus@dydaktyka.pswbp.pl, ORCID: 0000-0002-6258-6823
}

\begin{abstract}
Purpose: The spectrum is scarce recourses, so it is very important to allocate it in a way to maximize the economic and social returns to the countries` economies. Economists agree that the best way to allocate rare resources are auctions. Despite their good properties, in some environments, they can create inefficiency. We describe some potential sources of inefficiency in spectrum auctions and some negative effects of inefficient spectrum allocation. We also discuss how the government through appropriate spectrum policy and auction designing can promote efficient spectrum allocation.
\end{abstract}

Design/methodology/approach: The paper is based on the literature on the spectrum auction and public documents published by national spectrum authorities. Theoretical discussions are supported by case studies of real world spectrum auctions. Much attention has been paid to the case of the Polish 4G auction.

Findings: Extremely high reserve prices or rigorous approach to promoting entry could lead to price distortions, misallocation or even unsold spectrum which harm both competition and consumers. The case of the Polish $4 \mathrm{G}$ auction confirms that gaps in the detailed auction rules may lead to significant delays in frequency allocation and increase the risk of an ineffective auction outcome.

Practical implications: In the light of our findings, it is important that the rules of the auction in the $3.6 \mathrm{GHz}$ band currently planned in Poland should allow the regulator to control the pace of the auction and take into account the risk of inefficient outcome associated with passive bids. Originality/value: The discussions made in this paper could help policy makers in Poland and other countries in spectrum auction designing.

Keywords: spectrum auction, inefficiency, Polish 4G auction, spectrum policy, auction design.

Category of the paper: Case study.

\section{Introduction}

Auctions are now a common way of spectrum assigning in both developed and emerging countries. Before auctions, licenses were most often allocated through comparative selection 
procedures (called beauty contests) or lotteries (which were popular especially in the US) ${ }^{1}$. One of the reasons for resigning from beauty contests was that they ran too slowly and raised concerns about objectivity. In turns, lotteries encouraged the participation of bidders without the prime objective to acquire and use spectrum but rather to resell them at much higher prices, which harmed the public interest. Auctions save time needed for comparative hearings and are more transparent than administrative procedures (McMillan, 1994). The auction rules are relatively simple and clearly defined. Moreover, they must be accepted by each participant before the auction, which reduces the risk of challenging the final result.

Auctions leave spectrum valuation to operators who, unlike spectrum regulators, have more information about the market situation and can better estimate the real value of a license. They express this information in their bids, which increases the chances of obtaining a license by the most competitive operators. By introducing market mechanisms into the assignment process, auctions are generally more efficient than administrative procedures. A well designed spectrum auction "can maximise societal benefits of a scarce resource and ensure that economic rent is obtained by the public rather than shareholders" (OECD, 2000, p. 4).

Despite many advantages, auctions also have some weaknesses. The success of the auction largely depends on how it was designed. In particular, the auction rules have been adapted to the specific market situation in which they will be applied. There is evidence that auctions, in some circumstances, may lead to distorted outcomes resulting in inefficiency (GSMA, 2014; Earle, and Sosa, 2013).

The aim of this paper is to present potential sources and negative effects of inefficiency at spectrum auctions and discuss how the government (spectrum regulators) through appropriate spectrum policy and auction designing can promote efficient spectrum allocation. We start by determining what efficiency means in relation to spectrum assignment. In section 3 we discuss some sources and possible negative effects of inefficiency in spectrum auctions. Theoretical discussions are supported by the examples of actual spectrum auctions. Potential inefficiency during the Polish 4G auction was discussed in section 4. Section 5 concludes.

\section{The efficiency of spectrum auctions}

At the early stage of using spectrum auctions, one of the basic criteria for evaluating the efficiency was revenue, and the successful auctions were considered those that ended with high prices. An example may be the series of European UMTS auctions from the years 2000-2001.

\footnotetext{
1 In Europe, administrative procedures based on the comparative assessment of applications against a predetermined set of criteria were the primary form of licensing until 2000. In 2000-2001, a series of European auctions for third-generation mobile licenses took place which contributed to the spread of spectrum auctions in Europe (See: Cave, Webb, 2013).
} 
Then the auction in the UK obtained high prices of $4.31 \$ / \mathrm{MHz} /$ pop was considered a success, while the auction in the Netherlands where the prices were several times lower - a failure. The fact that the auction in the Netherlands allowed for the distribution of $355 \mathrm{MHz}$ of spectrum, much more than in any other European UMTS auction was often ignored. The approach of ranking the auction based on the revenue alone often contradicts the original reason why administrative procedures and lotteries were dropped in favour of competitive bidding. This reason was that competitive bidding probably allocated licenses to companies that could use them in the most productive way ignored (Hazlett et al., 2012).

The fast technological development and a significant increase in the demand for mobile services made spectrum a scarce resource and gained its value. The efficiency of using this rare resource began to gain more and more importance, often putting the auction revenues in the background. Nowadays, economists often point out that focusing on revenue maximization is short-sighted and does not benefit the economy in the long run. Instead of maximizing revenues, the main goal of the government should be efficiency and competition in the market, which in the long run will bring the government more benefits, lead to better and cheaper services (Cramton, 2013; Cramton et al., 2011). Recently governments also paying more and more attention to the effectiveness of spectrum allocation. The efficiency of using the spectrum was one of the common goals during the European $5 \mathrm{G}$ auctions so far. For instance, in UK Ofcom in the "Statement Award of the 2.3 and $3.4 \mathrm{GHz}$ spectrum bands" defines its purpose as follows: „In light of our duties, our objective is to design the auction in a way that enables the allocation of the spectrum to those bidders most likely to put it to the most efficient use and deliver the highest possible value to society. In so doing, we consider that it should be designed in a manner that promotes competition. We consider that this should fulfil our duty to secure the optimal use of the spectrum and enable us to achieve our wider policy objective that everyone in the UK can enjoy fast and reliable mobile broadband services" (Ofcom, 2017, p. 15).

There are many approaches to the concept of efficiency in microeconomic. One of the basic ones is connected with efficient allocation which means mechanisms ensuring that the goods sold go to the bidders who value the item the most (Maskin, 2003). This approach is in line with the seller's revenue maximization concept but is not always appropriate for spectrum auctions. Spectrum, as a scarce resource and of great importance for the economy, should be distributed in a way that ensures the greatest social welfare. Assigning a license to the operator who values it the most does not always agree with this purpose. An example would be the monopolist that probably values the licenses the most, because in his valuation it takes into account future profits related to the exclusion of rivals, thus maintaining its monopolistic position in the market. However, it would be better for consumer and generally for social welfare if the new entrant obtains a license as this would improve competition, which in the future is likely to result in lower retail prices and more innovative services (Cramton et al., 2011; van Damme, 2002). Thus, the efficiency in spectrum assignment should be considered as an assigning spectrum to those participants, which could generate the greatest economic value for society 
(Zehle, 2019). This will be of direct public benefit because it will ensure that consumers and businesses can all realize the greatest available value from using the frequencies.

As Hazlett and Munoz pointed: "to maximize consumer welfare, spectrum allocation should avoid being distracted by side issues like government license revenues" (Hazlett et al., 2012, p. 95). Focusing on revenue is therefore the wrong approach. It can lead to many distortions of auction results that are inconsistent with social welfare. In the next section we will discuss some sources and possible effects of inefficiency in spectrum auctions, based on examples of real spectrum auctions.

\section{The inefficient outcomes on spectrum auctions - evidence from actual auctions}

While market mechanisms are generally the most efficient way to distribute spectrum, they may not, under certain circumstances, lead to an outcome that maximizes social welfare such as incomplete allocation or inefficient spectrum use (Rosston, Steinberg, 1997). The main source of ineffectiveness in spectrum auctions are problems related to the market structure, especially asymmetry between participants and the related distortions of competition. Unequal opportunities between participants harm both the competition at the auction and the competition on the post-auction market. The common asymmetry in telecommunication markets is the asymmetry between incumbent and smaller operators. The incumbents have a stronger market position: apart from the customer base, they also have some spectrum resources and infrastructure, which lowers the costs of network deployment and implementation of new services and increases the chance of winning a license. In addition, the incumbent has a greater incentive to win a license because. in the event of failure, he may lose not only the chance for new customers but also the existing ones.

Regulators have a number of instruments to level the playing field and promote competition. The evidence confirms that these instruments should be used with caution because, if used improperly, they may be a source of inefficiency and led to the failure of the auction. In the following, we will discuss examples of auctions where inappropriate policy choices led to some auction distortion.

\subsection{Spectrum aggregation limits}

Excessive spectrum concentration in the hands of one or a small group of operators and the existing barriers of entry may have negative effects on the market. It weakens the competitive pressure from market participants, creates a field for tacit coordination and increases the risk of higher detail prices (Cave, Webb, 2013). Spectrum aggregation limits are a common tool used by authorities around the world to prevent these unfavourable occurrences. These restrictions 
may apply to the amount of spectrum that the operator can get at the auction or may refer to the operator's total resources in a given band, including those he had before the auction ${ }^{2}$. Another form could be to reserve a license for new entrants or existing small operators.

Although aggregation limits in many cases were effective (for example, during the UMTS auction in the UK they allowed a new player (Three) to enter the market, which improved competition in the English mobile services market and speeded the implementation of new technologies in the UK), there is evidence that, if used incorrectly, an aggressive policy to promote new market entry may lead to resource misallocation and many other distortions of results or its inefficient use (Earle, and Sosa, 2013).

An example could be the Dutch $2.6 \mathrm{GHz}$ auction in 2010. The auction offered $190 \mathrm{MHz}$ spectrum divided into 13 paired 2x5MHz blocks (FDD), 10 unpaired 5MHz blocks (TDD) and additionally two $5 \mathrm{MHz}$ guard blocks. In order to promote the new entry, the regulator implemented strict spectrum limits that applied to the general resources of operators in the $900 \mathrm{MHz}, 1800 \mathrm{MHz}$ and $2.1 \mathrm{GHz}$ bands, which significantly limited the possibilities of incumbent operators. As a result of applied restrictions, new entrants were able to bid up to $50 \mathrm{MHz}$ TDD and 2x20 MHz FDD, while one of the incumbents (T Mobile) was limited to one $2 \times 5 \mathrm{MHz}$ block (Marsden et al., 2010). Due to the very restrictive spectrum caps imposed on the incumbent operators, there was insufficient demand for unpaired blocks, which resulted in $55 \mathrm{MHz}$ remaining unsold generating economic losses related to the delay in accessing to improved service.

Another example is the Canadian $600 \mathrm{MHz}$ band auction in 2019. There were $70 \mathrm{MHz}$ band ( 7 blocks of paired spectrum $2 \times 5 \mathrm{MHz}$ ) available in 16 service areas. During this auction, the regulator did not introduce restrictions concerning the amount of spectrum that each participant can purchase at the auction, but in order to encourage competition, 3 blocks in each service area have been reserved for "facilities-based providers" who are defined as "not national incumbent service providers, and that are actively providing commercial telecommunications services to the general public in the license area of interest" (ISED, 2018). While the 3 existing incumbent operators (Bell, Telus, and Rogers) were excluded from bidding on reserved blocks, other participants were allowed to bid on all blocks (both, set aside and not set aside) what advantaged them significantly. Such an unfavourable for incumbent set-asides design led to 8 blocks in six regions remaining unsold despite the fact that there was excess demand from open bidders. Set-asides in conjunction with combinatorial clock auction (CCA) format resulted in some other non-competitive and unfavourable for consumers outcomes of the Canadian auction. The first is excessively concentrated ownership: in many regions, two delivers have acquired all available spectrum. The second problem was a huge difference in the prices paid by incumbents and "facilities-based providers" (Ostrowsky, 2019).

\footnotetext{
${ }^{2}$ This type of restriction was commonly used during European auctions of digital dividend and often applied to general resources of operators in sub-1-GHz band (Cave, Webb, 2013).
} 
Set-aside constraints were also a problem during the Canadian Advanced Wireless Spectrum (AWS) auction in the $2 \mathrm{GHz}$ band in 2008 . With the aim of introducing the fourth national wireless provider, almost half of the $105 \mathrm{MHz}$ spectrum available at the auction was reserved for new entrants and smaller regional providers. In this case (as in 2019), the auction rules strongly favoured new non-incumbent as they were eligible to bid on all blocks, while incumbent operators were allowed to submit bids only for not set-asides blocks. All available spectrum was sold during this auction, however other problems arose. The set-aside spectrum was purchased by 5 participants: 3 new entrants (PublicMobile, Wind, Mobilicity) and two regional players (Videotron and EastLink), but only the latter two participants successfully implemented services using the acquired frequencies. After the 5-year lock-up period, PublicMobile sold the licenses to the incumbent Telus, Mobilicity filed for bankruptcy and Wind became insolvent after "its Europeanbased financial backer, VimpelCom, wrote off its \$768-million investment in the start-up" (Masse, and Beaudry, 2014, p. 30). The attempt to introduce a national provider remained unsuccessful (did not lead to a permanent entry into the market) and was costly for the society. The set-aside blocks were sold at a discount of about $30 \%$ compared with the blocks open to bidding by all operators. According to CIBC World Markets, this amounted to a \$617-million subsidy for new entrants (Masse, and Beaudry, 2014). Despite such a high subsidy, the set-aside spectrum was not used effectively.

A similar situation took place during the UMTS auction in Germany in 2000. The auction included $120 \mathrm{MHz}$ of spectrum divided into twelve 2 x $5 \mathrm{MHz}$ lots, but each bidder could buy only from 2 to 3 blocks. The available spectrum went to 4 incumbent operators and two new participants (MobilCom and Group 3G) who withdrew from the market shortly after the auction and did not use the acquired spectrum. The 3G group filed for bankruptcy in 2002, while MobilCom returned its license to the German regulator in 2003 (Earle, and Sosa, 2013). The remaining spectrum was only sold in 2010 during the $4 \mathrm{G}$ auction causing 10 years delays in allocating $3 \mathrm{G}$ bands.

Economists do not agree on the reasons for the failure of the German auction. According to Early and Sosa, the policy limiting the ability to bid for individual players contributed to the loss to consumers of access to improved mobile services (Earle, and Sosa, 2013). Cramton, on the other hand, argues that the result of the German auction cannot be regarded as a confirmation of the failure of spectrum limits, explaining that the spectrum limits at this auction were not binding and incumbents were not constrained by the limits (Cramton, 2013b).

In our opinion, perhaps spectrum limits were not the only reason for the inefficient spectrum allocation in Germany, but the fact that the participants acquired spectrum below the limits does not proof that set-asides had no effect (were not binding) and didn't matter to the auction failure. The incumbents initially reported their demand for 3 blocks, which indicates that they were interested in 3 or even more number of blocks, so spectrum cups could limit their actual requirements. The fact that they finally got only 2 blocks could result from this, that the prices reached a level higher than their value of the third block. In such a situation rational players 
(as probably were incumbents) resigned from bidding in order to avoid the winner's curse. Moreover, a policy promoting a new entry encouraged entities that otherwise might not have decided to participate, sparked their enthusiasm which probably led to overbid their values of licenses. All of this indirectly contributed to the fact that, similarly to Canada, the spectrum went to operators who did not have sufficient funds to use them effectively.

\subsection{Reserve prices}

The reserve price is the minimum price at which the regulatory authority agrees to sell licenses. It is a measure that allows the government to achieve a certain level of revenue from selling licenses. In the case of competitive auctions, the starting price will probably be irrelevant to the final prices. Nevertheless, in a situation where, for example, due to onerous coverage obligations, the government expects limited competition in the auction, reserve price may be a way to provide a country with an economic rent that reflects its value.

Setting reserve prices is not an easy decision as each choice comes with some risk. Low minimum prices increase the risk of collusion to acquire spectrum at a low price. Moreover, in the case of weak competition, it exposes the government to low revenues and the need to sell the license at a price below its social value, which harms consumers. On the other hand, too high reserve price may discourage new entrants, which reduces the competition and increases the chances of unsold lots (Mochon, and Saez, 2017).

Too high minimum prices are often the cause of unsuccessful auctions, where all or part of the spectrum remains unsold, generating losses for the public. An example can be the multiband auction in India in 2016. This was multiband auction included $700 \mathrm{MHz}, 850 \mathrm{Mhz}$, $900 \mathrm{MHz}, 1800 \mathrm{MHz}, 2100 \mathrm{Mhz}, 2300 \mathrm{MHz}$ and $2500 \mathrm{MHz}$ ranges. Due to high reserve prices, $60 \%$ of the offered spectrum remained unsold and the revenue from the auction amounted to only $11.6 \%$ of the total sum of minimum prices. ${ }^{3}$ Among the bands that did not find buyers, there was all an extremely important and valuable for operators $700 \mathrm{MHz}$ band, which is the most suitable for ensuring coverage in rural areas. The fact that this band was lying fallow for several years has damaged the Indian telecommunications market and deprived consumers of the possibility of access to better quality services. According to analysts from Coleago Consulting, this result could have been avoided and the government was informed about it before the auction. Obtaining significant revenue was, however, the goal of the Indian government, which, despite warnings about excessive asking prices and wrong methodology of setting them, decided not to change the established auction rules (Zehle, 2019).

High reserve prices also resulted in unsold licenses at the 2013 Australia 4G auction. The asking prices at this auction were extremely high, especially for the $700 \mathrm{MHz}$ band, for which prices were set at $\$ 1.36 / \mathrm{MHz} /$ pop. This was 186 percent of the average price paid at

\footnotetext{
${ }^{3}$ According to Coleago Consulting the reserve prices for all spectrum available in the auction were over twice the annual industry revenue (Zehle, 2019).
} 
other auctions for the spectrum from the digital dividend. Extremely high minimum prices led to the fact that $30 \mathrm{MHz}$ of the $90 \mathrm{MHz}$ offered in the $700 \mathrm{MHz}$ band remained unsold. According to Coleago Consulting, it generated losses due to unsold licenses of several billion USD. Another damage to the market was distorted competition resulting from the fact that one of the operators (Vodafone) did not obtain a license in this band until 2017, when this band was again put up for sale (Australian spectrum auction failure, 2013).

\subsection{Coverage obligations}

Formulas Coverage obligations are one of the instruments used by the regulatory authority to achieve goals regarding the scope and development of the network. They could be considered as some indirect form of financing network development (Webb, 2010). When defining obligations, policymakers are faced with a trade-off between coverage improvement and revenues. This is due to the fact that potential licensees include their offers costs related to the fulfilment of obligations, so they will be willing to pay less for a license on which certain obligations are imposed. The difference between what an operator is willing to pay for a license without obligation and a license with obligation can therefore be seen as a loss of revenue for the government or the amount that the government contributes to supporting the implementation of broadband coverage (GSMA, and Frontier Economic, 2015).

Generally, coverage obligations can have many positive effects on the market. They support the efficient use of spectrum and encourage competition in the development of network infrastructure, which in turn may translate into a competition between operators and lower prices of mobile services (Eylert, 2005). However, if they are too restrictive, going beyond consumer demand, they can harm the market and consumers. The example could be UMTS auctions in Sweden and Norway. In both countries, the regulator has implemented very stringent rollout obligations ( $80 \%$ of population in Norway and $99.98 \%$ in Sweden). The operators asked for a change them, arguing this with the difficult market situation. However, the regulator decided not to relax originally established obligations, which resulted in the withdrawal of foreign participants (newcomers) from the auctions, and reduced competition during the auction (Eylert, 2005). ${ }^{4}$

The extensive obligations imposed on all auction winners can also lead to costly and inefficient duplication of infrastructure, especially in economically unprofitable rural areas. To avoid this type of inefficiency, regulators could use a number of preventive instruments:

- the Italian regulator, during the $20185 \mathrm{G}$ auction for the $700 \mathrm{MHz}$ band, in addition to the individual coverage obligations for each winner, also specified more restrictive but collective obligations to cover rural areas and main transport routes with $5 \mathrm{G}$;

\footnotetext{
${ }^{4}$ The way to avoid entry barriers is relaxing obligations for new entrants. Such a solution was used by the German BNetzA during the last C-band auctions in 2019, which encouraged new entrant to participate in the auction making the auction more competitive.
} 
- during the German auction in the $3.6 \mathrm{GHz}$ band, the coverage and roll-out requirements were extremely exacting compared to this type of auction in other European countries. The regulator's concept, however, was to ensure good coverage through the cooperation agreements between operators. The auction rules encouraged (but did not oblige) operators to cooperate at the service level, e.g. infrastructure sharing and roaming. The key factor promoting cooperation was the fact that the obligations performed with other spectrum holders under cooperation agreements were included as the obligations of each of them;

- one of the $800 \mathrm{MHz}$ licenses in Sweden included an obligation to provide mobile broadband internet in locations where there is currently no access to other forms of broadband internet, so only one operator (who got this license) was obligated to fulfil coverage obligations in unprofitable areas (GSMA, 2016).

Another, less intrusive way to provide coverage is to make publicly available data on the coverage of operators in a given region. Such information allows consumers to make aware decisions about choosing an operator with better services and also encourages others to improve their network as not lose customers. In this way, an appropriate information policy could encourage the improvement of the coverage without government intervention and could often be a sufficient driving force behind the availability of mobile services from auctions as it enhances competition (Webb, 2010). Such a less intrusive approach was adopted at the UK C-band frequency auction in 2018 Ofcom did not implement any coverage obligations during the $3.4 \mathrm{GHz}$ auction, arguing that "market mechanisms should promote spectrum efficiency and be more effective than regulatory interventions in this respect" (Ofcom, 2014, p. 83).

\section{Potential inefficiency during the Polish LTE action}

Auction rules, like other tools of regulatory policy discussed in Section 3, can also be a potential source of inefficiency. An auction that encourages speculative behaviour and/or strategic bidding increases the risk of inefficient outcome and does not maximize social welfare. To ensure efficiency, the auction rules shouldn't favour specific bidders and outcomes, but allow everyone to compete on equal terms. An example of how shortcomings in the auction design may generate the risk of an undesirable outcome will be discussed in the case of the Polish LTE auction.

The Polish regulator (UKE), for the sale of 5 blocks $2 \times 5 \mathrm{MHz}$ in the $800 \mathrm{MHz}$ band and 14 blocks $2 \times 5 \mathrm{MHz}$ in the $2.6 \mathrm{GHz}$ band, applied the rules of the successfully used worldwide simultaneous multiple-round auction (SMRA). This format gives many possibilities of modification, which allows for adapting the auction rules to specific market circumstances. 
The case of the Polish auction shows, however, that even a seemingly small modification auction rules may, in certain circumstances, lead to a lot of distortion and increases the risk of inefficient spectrum allocation.

\subsection{The lack of control over the speed of the auction}

Radio frequencies are a scarce resource of great importance to the economy, therefore it is important to make it available to operators on time. Any delay in spectrum assigning is associated with economic losses related to the inability of using them. In this context, apart from the timely release of spectrum, it is also important that the spectrum allocation process is quick and efficient. For this to happen, the auction rules should allow the regulator to control the pace of the auction and give the ability to bring the auction to the end if necessary ${ }^{5}$. The Polish auction rules did not include sufficient instruments for the regulator to control the pace of the auction. The bid increments were small (ranging from 1 to $5 \%$ ) and only the players decided which one to choose - the auctioneer could not change them. The participants used this favourable auction rule and almost always chose the minimum increment amount of $1 \%$. This led to a very long bidding process, which could not be stopped under the primary auction rules. The Polish auction rules originally included the same ending rule that has been used in SMRAs in many other countries: the auction was supposed to end only after a round that no license received a new bid (Milgrom, 2000). Unfortunately, this rule, combined with the low bid increments and the lack of tools for the regulator to speed up the auction, led to unexpected delays. The bidding lasted 8 months $^{6}$, which resulted in inefficiency related to the delay in the allocation of valuable resources ${ }^{7}$.

\subsection{Changes in ending rules}

The long bidding and high prices of spectrum which significantly exceeding the prices reached in similar auctions in other countries, forced the government, fearing the negative effects of high retail prices, to change the ending rules. These rules assumed that if SMRA did not end within 512 rounds, a final round of sealed bids would be announced. In this round, participants could submit bids without financial limit, but only for blocks they had active bids in the last round of SMRA (i.e. round 512). These rules created an uneven playing field in the sealed final round. They advantaged these players who in round 512 submitted bids for blocks, which had no excess demand, as this guaranteed them to receive the spectrum without having

\footnotetext{
5 The importance of controlling the pace of the auction was convinced by the German regulator BNetzA during the $5 \mathrm{G}$ auction in 2019. This auction lasted 497 rounds and only an increase in the rate increase six times led to its end.

${ }^{6}$ The entire allocation procedure, including the process of consulting the auction rules and explaining the auction documentation took over 2 years.

${ }^{7}$ A detailed analysis of the Polish LTE auction can be found in the article of A. Kuś (see: Kuś, 2020).
} 
to raise the price in the round of sealed bids ${ }^{8}$. Such rules encourage strategic bidding and increase the risk of disturbing the characteristic for SMRA the process of the prices discovering.

Two operators, Orange and $\mathrm{P} 4$, took advantage of the gaps in changed auction rules. In round 512, they made bids for blocks without excess demand, which allowed them to get spectrum without raising the price in the sealed round 513. The prices of three blocks acquired by Orange and P4 (Orange bought 2 blocks, and P4 bought one block) were substantially lower than the prices of the other two blocks for which the operators had to compete in the last round. Thus, the process of market prices discovering taking place during competitive bidding was disturbed and the auction led to the fact that identical licenses were sold at significantly different prices (final prices of blocks in the $800 \mathrm{MHz}$ band varied up to $40 \%$ ).

Another potential source of inefficiency during the Polish $4 \mathrm{G}$ auction was related to the fact that the bids were not binding - the participant could drop out from the auctioned blocks after the auction if, for example, he considered that the amount he was offered was too high. The only cost was the loss of the wadium which was too low to prevent frivolous offers. Although the regulator required the participants to pay deposits it did not constitute sufficient protection against speculative bidding, as deposits were refunded to each participant after the auction (even to those who give up the license). One of the participants - NetNet took advantage of this opportunity and after the final round in which it made the highest bid for a single block in the $800 \mathrm{MHz}$ band, he resigned from the license. It generated a high risk of further delays in spectrum allocation and the risk of spectrum to be unsold.

\subsection{Passive bids}

The next potential source of the Polish auction distortion is the rather unusual way of defining valid bids. The auction regulations assumed to define two types of valid bids: active and passive. The active bid in a given round was the bid submitted in the previous round or the bid that in the previous round was the highest bid for one of the blocks (i.e. was the standing high bid). The introduction of active bids resulted from the characteristic of SMRA activity rule. Each participant to maintain the right to bid had to actively participate in the auction from the beginning. The lack of activity resulted in a partial or total (depending on the undertaken actions) loss of the possibility of bidding at a later stage of the auction. Having an active bid allowed the player to continue bidding. Passive bid (in round $n$ ) was a valid bid submitted in the round preceding the previous round (i.e. round n-2) or in earlier rounds, which wasn't standing high bid and for which the participant did not perform any activity, i.e. did not increase its amount or did not switch it to another block. In other words, if a participant stopped actively bidding on a given block (and did not withdraw an offer by moving it to another block),

\footnotetext{
${ }^{8}$ At that time, the excess demand in the $800 \mathrm{MHz}$ band was two blocks, therefore, the overdemand in the $800 \mathrm{MHz}$ band could be placed on one or two different blocks. In the first case, this would mean that in the final 513 sealed round 3 buyers will compete for one block, while the remaining 4 blocks will be awarded to those participants who placed the highest bids on them in round 512 (the situation what in last rounds there will be no demand for some block was rather unlikely because players could not withdraw their standing high bids).
} 
this offer became the so-called passive bid. The lack of activity and switching to a passive bid on a given block resulted in the loss of eligibility points, and thus the bidding rights at the current level. However, in a situation where the player whose bid in this block was standing high bid withdrawn from the auction or was disqualified, then the next bid in the ranking became standing high bid (even when it was a passive bid). Switching to passive bids, in certain circumstances, gave buyers a chance to stand "in the game" despite the lack of activity in bidding. Thus, such a solution was more advantageous for the player than the withdrawal from the auction, as it gave the opportunity to win a license even when much earlier, at much lower prices, they give up from active bidding.

The motivation for introducing passive bids was most likely to reduce the risk of unsold licenses in the event of a winner's withdrawal. However, such rules, combined with the aforementioned non-binding nature of bids and the lack of safeguards guaranteeing the credibility of bidding created a huge field for manipulation and speculative behaviour. They encouraged the frivolous players, who could make their bids passive in the early stage of the auction, hoping that in the event of winner's resignation or disqualification, it would give a chance to acquire the spectrum at an abnormally low price.

In fact, the pessimistic scenario did not come true. NetNet's bid was not the only bid submitted for this A1 block in the last round of SMRA (see Table 1). After his resignation, this block went to T Mobile (player D), who agreed to accept the abandoned block for the price of PLN 2.022 billion (EUR 478 million) that he offered in the 513 round. Taking into account the existing auction rules, the result could be much more unfavourable. If player D did not decide to take the license at the price he offered, then block A1 would go to the buyer F. The price that he would have to pay for this block would be PLN 357 million (EUR 84 million) and would be almost 6 times lower than the price, which was declared by player B and about 4,5 lower than the average price of the remaining blocks (A2-A5) in the $800 \mathrm{MHz}$ band.

Table 1.

The final phase of bidding on Block A1 during the Polish LTE auction

\begin{tabular}{|c|c|c|c|c|c|c|c|}
\hline \multirow[b]{2}{*}{ Round } & \multirow[b]{2}{*}{$\begin{array}{l}\text { Bidding } \\
\text { format }\end{array}$} & \multicolumn{3}{|c|}{ Active bids } & \multicolumn{3}{|c|}{ Passive bids } \\
\hline & & Bidders & $\begin{array}{l}\text { Ammount } \\
\text { (mln PLN) }\end{array}$ & $\begin{array}{l}\text { Ammount } \\
\text { (mln EUR) }\end{array}$ & Bidders & $\begin{array}{l}\text { Ammount } \\
\text { (mln PLN) }\end{array}$ & $\begin{array}{l}\text { Ammount } \\
\text { (mln EUR) }\end{array}$ \\
\hline 510 & SMRA & B & 1481 & 350 & $\begin{array}{l}\mathrm{F} \\
\mathrm{A}\end{array}$ & $\begin{array}{l}357 \\
353\end{array}$ & $\begin{array}{l}84 \\
83\end{array}$ \\
\hline 511 & SMRA & B & 1481 & 350 & $\begin{array}{l}\mathrm{F} \\
\mathrm{A}\end{array}$ & $\begin{array}{l}357 \\
353 \\
\end{array}$ & $\begin{array}{l}84 \\
83\end{array}$ \\
\hline 512 & SMRA & $\begin{array}{l}\text { D } \\
\text { B }\end{array}$ & $\begin{array}{l}1496 \\
1481\end{array}$ & $\begin{array}{l}354 \\
350\end{array}$ & $\begin{array}{l}\mathrm{F} \\
\mathrm{A}\end{array}$ & $\begin{array}{l}357 \\
353\end{array}$ & $\begin{array}{l}84 \\
83 \\
\end{array}$ \\
\hline 513 & Sealed bid & $\begin{array}{l}\text { B } \\
\mathrm{D}\end{array}$ & $\begin{array}{ll}\mathbf{2} \mathbf{0 5 3} \\
2022 \\
\end{array}$ & $\begin{array}{l}485 \\
478\end{array}$ & $\begin{array}{l}\mathrm{F} \\
\mathrm{A}\end{array}$ & $\begin{array}{l}357 \\
353 \\
\end{array}$ & $\begin{array}{l}84 \\
83 \\
\end{array}$ \\
\hline
\end{tabular}

Source: Own elaboration based on data from the Office of Electronic Communications (UKE) ${ }^{9}$.

\footnotetext{
${ }^{9}$ The bidding of the last phase of auction described in this part was based on data from the UKE of the detailed course of the auction. Bidders' identities have been encoded in these data and marked with the symbols A-F; therefore, these symbols were used in this paper.
} 
A similar risk would arise if the total surplus of demand in the $800 \mathrm{MHz}$ band (which from round 66 was 2 blocks) was distributed in such a way that in round 512 the buyer's B offer would be the only bid on block A1. Then, according to the changed ending rules, player B would be the only player able to bid in the final round 513. In case of his resignation, player $F$ would receive block A1 at an extremely low price, causing losses in the efficiency.

\section{Conclusions}

The structure of the competition in the selection process and the provision of a sufficient amount of spectrum on time is one of the most important elements of auction designing (Hazlett et al., 2012). According to the report "The Cost of Spectrum Auction Distortions. Review of spectrum auction policies and economic assessment of the impact of inefficient outcomes" delays in spectrum allocation lead to permanent economic losses and do not maximize social welfare. A particularly unfavourable situation occurs when the spectrum, e.g. due to incorrect decisions of regulatory policy, remains unused for a long time. The social losses on this account often exceed the revenues that the government can get from selling the remaining spectrum at an additional auction (GSMA, Frontier Economic, 2015).

Ensuring competition is also extremely important for achieving economic efficiency. An auction, where there are barriers to entry is unlikely to be effective. Regulatory authorities have a number of tools to promote competition both at the auction and on the post-auction market. The goal of these instruments should not, however, be to raise revenue, as such an approach is often contrary to the pro-efficiency goals (Cramton et al., 2011). Extremely high reserve prices or rigorous approach to promoting entry could interfere with the auction process and lead to price distortions, misallocation or even unsold spectrum which harm both competition and consumers. This is confirmed by the empirical examples discussed in this paper.

The case of the Polish 4G auction confirms that gaps in the auction rules may lead to significant delays in frequency allocation and increase the risk of an ineffective auction outcome. Our findings, especially those concerning the control over the speed of the auction and the risk associated with passive bids, should be considered when designing the rules of currently planned in Poland auction on $3.6 \mathrm{GHz}$ band. 


\section{References}

1. Australian spectrum auction failure. Available online http://www.coleago.com/australianspectrum-auction-failure/, 07.10.2020.

2. Cave, M., and Webb, W. (2013). Spectrum Limits and Auction Revenue: the European Experience. Retrieved from https://ecfsapi.fcc.gov/file/7520934210.pdf, 12.10.2020.

3. Cramton, P. (2013a). Spectrum Auction Design. Review of Industrial Organization, Vol. 42, Iss. 2, 161-190.

4. Cramton, P. (2013b). The rationale for spectrum limits and their impact on auction outcomes. Retrieved from http://www.cramton.umd.edu/papers2010-2014/cramtonspectrum-limits-ex-parte.pdf, 2.10.2020.

5. Cramton, P., Kwerel, E., Rosston, G. and Skrzypacz, A. (2011). Using spectrum auctions to enhance competition in wireless services. Journal of Law and Economics, Vol. 54, 197-188.

6. Earle, R. and Sosa, D.W. (2013). Spectrum auctions around the world: An assessment of international experiences with auction restrictions. Analysis Group. Retrieved from https://www.analysisgroup.com/globalassets/insights/publishing/2013_earle_sosa_spectru mauctionsworldwide.pdf, 20.09.2020.

7. Eylert, B. (2002). The Mobile Multimedia Business. Requirements and Solutions. Hoboken: John Wiley \& Sons.

8. GSMA, Coleago Consulting (2014). The Cost of Spectrum Auction Distortions. Review of spectrum auction policies and economic assessment of the impact of inefficient outcomes. Retrieved from https://www.gsma.com/spectrum/wp-content/uploads/2014/11/The-Costof-Spectrum-Auction-Distortions.-GSMA-Coleago-report.-Nov14.pdf, 26.04.2020.

9. GSMA, Frontier Economic (2015). Benefits of network competition and complementary policies to promote mobile broadband coverage. Retrieved from https://www.gsma.com/mobilefordevelopment/wp-content/uploads/2015/02/Benefits-ofnetwork-competition-and-complementary-policies-to-promote-mobile-broadbandcoverage-Report.pdf, 03.07.2020.

10. GSMA (2016). Best practice in mobile spectrum licensing. Retrieved from https://www.gsma.com/spectrum/wp-content/uploads/2016/11/spec_best_practice_ ENG.pdf, 5.09.2020.

11. Hazlett, T., Munoz, R.E., and Avanzini, D.B. (2012). What Really Matters in Spectrum Allocation Design. Northwestern Journal of Technology and Intellectual Property, Vol. 10, Iss. 3, 93-123.

12. ISED, Technical, Policy and Licensing Framework for Spectrum in the $600 \mathrm{MHz}$ Band. Retrieved from http://www.ic.gc.ca/eic/site/smt-gst.nsf/eng/sf11374.html, 15.10.2020. 
13. Kuś, A. (2020). Polish experience from first-ever spectrum auction. Telecommunication Policy, Vol. 44 Iss. 7, 1-11.

14. Marsden, R., Sexton, E., and Siong, A. (2010). Fixed or flexible? A survey of $2.6 \mathrm{GHz}$ spectrum awards. DotEcon Discussion Paper, Iss. 10/01. Retrieved from https://www.dotecon.com/assets/images/dp1001.pdf, 19.02.2020.

15. Maskin, E. (2003). Auctions and Efficiency. In: M. Dewatripont, L. Hansen, and S. Turnovsky (Eds.), Advances in Economic Theory (invited lectures from the 8th World Congress of the Econometric Society) (pp. 1-24). Cambridge: Cambridge University Press.

16. Masse, M., Beaudry, P. (2014). The State of Competition in Canada's Telecommunications Industry. Montreal: Montreal Economic Institute.

17. McMillan, J. (1994). Selling Spectrum Rights. Journal of Economic Perspectives, Vol. 8, Iss. 3, 145-162.

18. Milgrom, P. (2000). Putting auction theory to work: The simultaneous ascending auction. Journal of Political Economy, Vol. 108, Iss. 21, 245-272.

19. Mochon, A., Saez, Y. (2017). A Review of Radio Spectrum Combinatorial Clock Auctions. Telecommunications Policy, Vol. 41, Iss. 5-6, 303-324.

20. OECD (2001). Spectrum allocation: Auctions and comparative selection procedures. Economic Arguments. Report Working Party on Telecommunication and Information Services Policies DSTI/ICCP/TISP(2000)12/FINAL. Retrieved from https://www.oecd.org/sti/broadband/27125982.pdf, 18.12.2019.

21. Ofcom (2014). Public Sector Spectrum Release (PSSR) - Award of the $2.3 \mathrm{GHz}$ and $3.4 \mathrm{GHz}$ bands - Consultation document. Retrieved from https://www.ofcom.org.uk/ __data/assets/pdf_file/0025/78055/Public_Sector_Spectrum_Release_2-3_and_34_ghz_award.pdf, 17.07.2020.

22. Ofcom (2017). Award of the 2.3 and $3.4 \mathrm{GHz}$ spectrum band. Competition issues and Auction Regulations. Retrieved from https://www.ofcom.org.uk/_data/assets/pdf_file/ 0022/103819/Statement-Award-of-the-2.3-and-3.4-GHz-spectrum-bands-Competitionissues-and-auction-regulations.pdf, 17.07.2020.

23. Ostrowsky, M. (2019). Comments on the Outcomes and Design Issues in the 2019 Canadian Auction of Spectrum Licenses in the $600 \mathrm{MHz}$ Band. Retrieved from https://www.ic.gc.ca/eic/site/smt-gst.nsf/vwapj/SLPB-002-19-TELUS-Attachment3.pdf/ \$FILE/SLPB-002-19-TELUS-Attachment3.pdf, 18.10.2020.

24. Rosston, G.L., Steinberg, J.S. (1997). Using Market-Based Spectrum Policy to Promote the Public Interest. Federal Communications Law Journal, Vol. 50, Iss. 1, 87-116.

25. Van Damme, E. (2002). The European UMTS-Auctions. European Economic Review, Vol. 46, 846-869. 
26. Webb, W. (2010). Being Mobile: Future Wireless Technologies and Applications. Cambridge: Cambridge University.

27. Zehle, S. (2019). Sustainable spectrum pricing. Fostering the deployment of $5 G$ through appropriate spectrum pricing. Retrieved from http://www.coleago.com/wpcontent/uploads/2019/07/Sustainable-Spectrum-Pricing-Coleago-June-2019-1.pdf, 18.09.2020. 


\title{
QUANTITATIVE ANALYSIS OF THE ECONOMIC POTENTIAL ON THE EXAMPLE OF THE UPPER SILESIAN METROPOLIS
}

\author{
Adrianna MASTALERZ-KODZIS \\ University of Economics in Katowice, Department of Statistics, Econometrics and Mathematics; \\ Adrianna.Mastalerz-Kodzis@ue.katowice.pl, ORCID: 0000-0001-9099-3576
}

\begin{abstract}
Purpose: The aim of the article is to show the modified method of calculating the economic potential on the example of territorial units of the Upper Silesian Metropolis.

Design/methodology/approach: Economic potential is a measure of a region's strength compared to other regions. In economics, potential is a substitute for socio-economic development. The methodology of calculating the modified economic potential of territorial units was discussed in the first part of the article, and an empirical example is presented in the second part.
\end{abstract}

Findings: As a result of the research, strong regions were identified and the self-potential of the regions and their surroundings were compared.

Research limitations/implications: The proposed modified method of potentials can be used for a comparative analysis of any territorial units. The metric that is used to measure the distance between territorial units is important.

Practical implications: On the basis of the presented method, any regions or countries can be compared in terms of socio-economic development.

Social implications: The method makes it possible to compare the socio-economic development of regions in terms of income and population.

Originality/value: The article compares selected communes of the Silesian Voivodeship in terms of income, population and socio-economic development. A modified measure of economic potential was used.

Keywords: economic potential, territorial unit potential, socio-economic development.

Category of the paper: Research paper.

\section{Introduction}

Potential is defined in economics as a resource of abilities, opportunities or performance that can be assigned to a given territorial unit or organization. In 1970, G. Dutton introduced the concept of income and population potential and their quotient, which became the equivalent of a measure of socio-economic development (Dutton, 1970). However, the potential of the 
organization, enterprise and region, area - a territorial unit - is a multidimensional concept, as it depends on many different, often interdependent factors. The potential determines the capabilities of an individual on the basis of the abilities, competences and skills of a given organization, and measures the ability to use these resources and the resources of the environment.

According to the spatial model of the potential, the possibilities of a territorial unit (region, voivodeship, district or community) depend on the condition of the unit itself, but also on the unit's location in the space under consideration and on the adopted distance metric. It can be a geographic space where the distance between units is measured as the Euclidean distance between the geographic coordinates of the distinguished points, you can also consider road distance (shortest, fastest), consider the availability of connections between units. An interesting approach is also to consider a metric as an economic quantity. Among others, in the works of (Suchecki, 2010, 2012) there is a discussion on the use of the potential and potential quotient method in deliberations in the field of spatial econometrics (Paelinck and Klaassen, 1982; Rich, 1980; Sen and Smith, 1995; Mastalerz-Kodzis, 2018).

The aim of the work is to present an example of the empirical application of the spatial method of economic potential for territorial units of the Upper Silesia Metropolis (GZM Metropolis of Upper Silesia and Zagłębie). The first part discusses the methodology of calculating the economic potential of territorial units, the second one presents an empirical example. The article ends with a summary.

\section{Economic potential of regions}

Sustainable economic development of the state and territorial units is the goal of the activities of state and local authorities. A proper diagnosis of the actual state, examination of the dependencies, relations between territorial units and their economic and social characteristics is the foundation for further activities aimed at improving the quality of life of the population and achieving the intended pace of economic growth (Biernacki, 2006; Stiglitz, 2012).

One of the measures of the development possibilities of territorial units is the economic potential. The analysis of the values of historical economic variables, including potential, changes in time and space, provides information on the direction and strength of changes in the economy for individual territorial units, and allows for taking actions to prevent negative trends. Numerous works in the field of regional research indicate the increased importance of location in economic research (Krugman, 1991; Giri, 2004; Arbia, 2006; Paelinck and Klaassen, 1983; Krugman, 1991; Pooler, 1987; Rich, 1980; Suchecki, 2012; Combes, Mayer, Thisse 2006; Geis, Mur, and Zoller, 2004). 
The economic potential of territorial units is a multidimensional concept. Its size includes, among others, the number and structure of the population, the level of income and professional activity of inhabitants, the development of the local labour market. The economic potential largely determines the development of a territorial unit, implies economic changes, and stimulates investments. The economic potential is positively correlated with the measure of socio-economic development, the increase in potential increases the quality of life of the inhabitants and increases public safety.

The methodology of determining the potential of regions can be found, among others, in the works of: Dutton, 1970; Sen and Smith, 1995; Zeliaś, 1991; Chojnicki, 1966. An important element of the method of calculating this measure is the selection of an appropriate measure of the distance between territorial units (selection of the metric).

Potential models analyse the impact of all territorial units on a given unit. Then the potential can be interpreted as a force, intensity of the impact of all regions of the territorial division system on the selected region. A given region may have a small own potential, but it may be located in close proximity to strong regions, in a favourable territorial location, then its potential is increased.

The literature distinguishes between spatial models of income potential, population and location (Suchecki, 2012; Pooler, 1987). Population potential is a substitute for socio-economic phenomena, and income potential is treated as a measure of the availability of economic activity.

The 21 st century is the time when the coal-based economy is being abandoned and replaced with ecological energy sources. For Poland, Silesia is a region abundant in coal deposits, therefore the upcoming transformation processes will be most noticeable in this region. Changing the structure of the industry is inevitable, the problem is to achieve it over time. Therefore, there is a need to diagnose the current state of the economy and create new economic zones that will activate professionally young people and people previously working in the mining and mining sector. Therefore, the measurement of the potential and strength of individual regions in the process of change is of particular importance. Therefore, in the empirical example in point 2.2, it was decided to calculate the potential for territorial units belonging to the GZE Metropolis.

\section{Methodology of calculating the potential of regions}

In physics, a potential is an auxiliary quantity that describes a physical field. The field of physical quantities is a set of functions characterizing points in space and other parameters (e.g. time). For a given system of physical units $(k, m=1, \ldots, n ; n$ - any natural number), 
for example, a partial potential $P_{k m}$ is used to analyse the interactions of units. For any two units, it is determined in accordance with the formula (1):

$P_{k m}=\alpha_{0} \frac{M_{k} M_{m}}{d_{k m}}$

The value of the partial potential is interpreted as the amount of energy between units $k$ and $m$ per unit mass, $M_{k}, M_{m}$ is the mass of the units, $d_{k m}$ the distance between the units, and $\alpha_{0}$ is a parameter.

On the basis of the definition of partial potential, the concept of the potential of a territorial unit is constructed. It is assumed that the territorial division system consists of n objects - spatial units $(n \in N)$. The potential of each individual is dependent on all other individuals, but to a different extent. The model of the potential of the $k$-th spatial unit in a given time unit (in a year, quarter, month) is written in the formula (2):

$P_{k}=\alpha_{0} \sum_{\substack{m=1 \\ m \neq k}}^{n} \frac{M_{m}^{\alpha_{1, m}} W_{m}^{\alpha_{2, m}}}{d_{k m}^{\beta}}$

where:

$M_{k}$ - the mass of $k$-th unit,

$W_{k}$ - the weight of the mass of $k$-th unit,

$\alpha_{0}, \alpha_{1, m}, \alpha_{2, m}$ - structural parameters of the model,

$\beta$ - distance parameter, other symbols as above.

The components of the above formula may have an economic interpretation. For example, the mass of a unit may be production volume, GDP, population, employment, foreign trade turnover, investment volume. The weight of the mass of a given spatial unit may be the occupational structure of the population, age, gender, income, and the size of investments per capita. The weights can be taken arbitrarily or calculated on the basis of statistical data. The distance metric between units is, for example, temporal, physical, Euclidean, and economic. Model parameters are determined using the least squares method.

The explained variable $V_{k}$ is interpreted as the total magnitude of the impact on the $k$-th spatial unit, and the total potential of the $k$-th unit is the sum of the partial potentials of all units of the system. The economic potential can be interpreted as the intensity of the impact of all regions of the system on a selected region. The potential is the sum of two components: own potential and the potential of the surrounding. The geographical location has a significant impact on the value of the potential of the surroundings. In economics, the following spatial models of potential can be mentioned: income, population, location (the region's accessibility to residents of other regions). The income potential is a function of the income generated in 
a given region and in other regions, while the population potential is interpreted as the accessibility of a given region to the population of other regions.

The following designations are adopted:

$P P_{k}$ - total potential of the population in the $k$-th region,

$I P_{k}$ - total income potential in $k$-th region,

$Q P_{k}$ - quotient of potentials in the $k$-th region (economic potential),

$G D P_{k}$ - GDP in the $k$-th region,

$P_{k}$ - population in $k$-th region,

$d_{k m}$ - distance between regions $k$ and $m$.

The total potential of the population and the total income potential are defined as the sum of their own and the environment's potentials (formulas (3) and (4)):

$$
\begin{aligned}
& P P_{k}=P_{k}+\sum_{\substack{m=1 \\
m \neq k}}^{n} \frac{P_{m}}{d_{k m}}, \\
& I P_{k}=G D P_{k}+\sum_{\substack{m=1 \\
m \neq k}}^{n} \frac{G D P_{m}}{d_{k m}} .
\end{aligned}
$$

However, the quotient of the potential for the $k$-th region is given by the formula (5):

$$
Q P_{k}=\frac{I P_{k}}{P P_{k}}
$$

Potential is a measure of the spatial accessibility of a region, it determines the intensity of the impact between regions, taking into account economic values and distances between regions. In formulas (3) and (4), it is divided by the distance between the units, because the greater the distance, the smaller the influence on the analysed characteristics.

\section{Analysis of the economic potential of municipalities of the Upper Silesia Metropolis (GZM)}

GZM was established on July 1, 2017, the implementation of its tasks began on January 1, 2018. It is located in the Silesian Voivodeship, covers 41 communes, including 13 cities with district status and 13 communes with city status (Figure 1). The metropolis is inhabited by over 2 million people, but the population of the metropolis has been decreasing since 1989 . 
The analysis of demographic and economic characteristics over time for municipalities included in the Metropolis is interesting and important for economic reasons and sociological.

The functioning of the territorial units of the Metropolis largely depends on the development of industry in the region. One of the dominant industries in Silesia is mining. However, due to climate change and European Union directives, the structure of industry, and thus employment in the region, must change. This change will cause numerous social problems, changes in the labour market and changes in the income of the population.

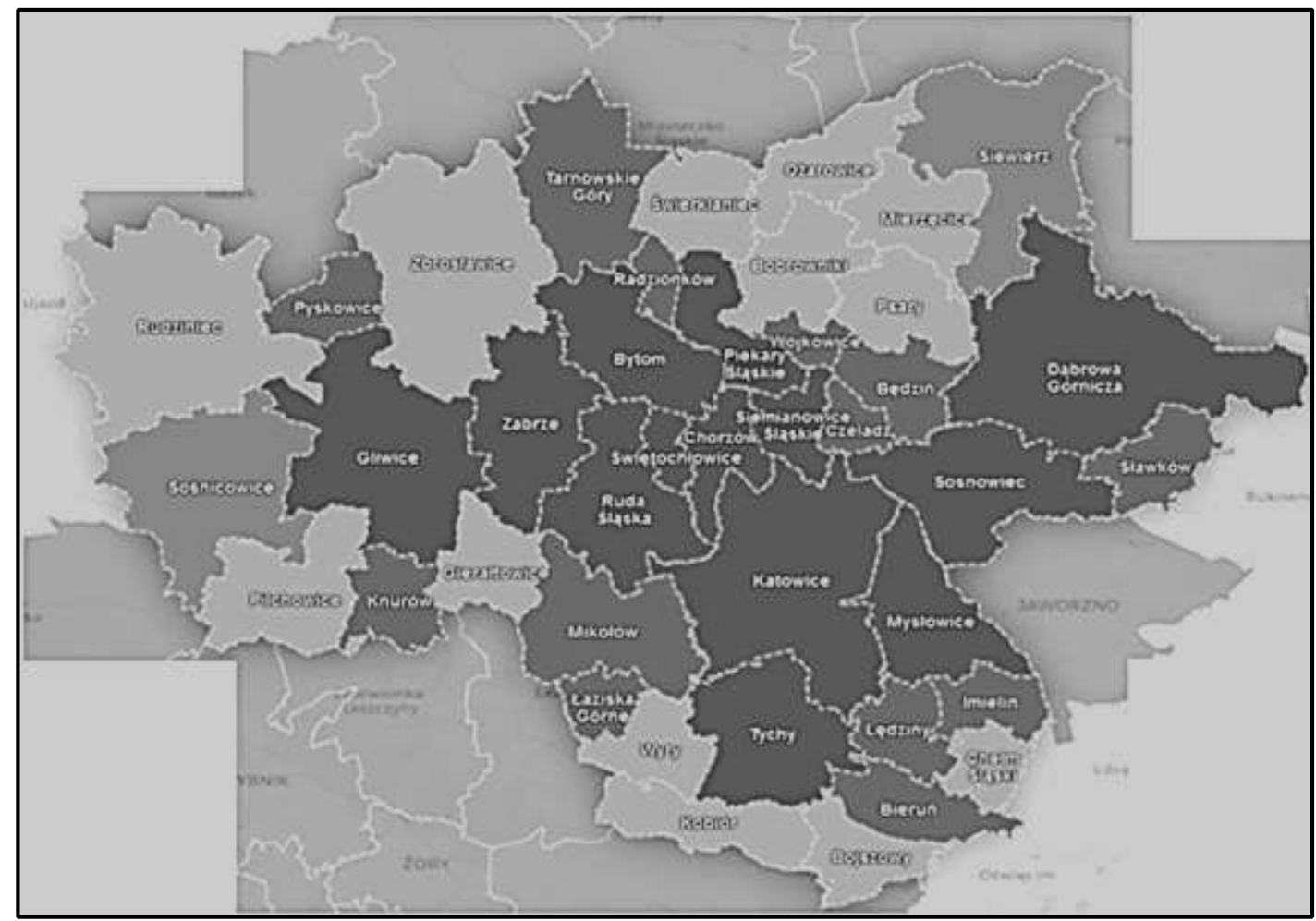

Figure 1. Metropolis of GZM. Adapted from: http://infogzm.metropoliagzm.pl.

Based on the data obtained from the Central Statistical Office, the economic potential of territorial units included in the Metropolis GZM was determined. The data on the population and incomes of municipalities (as a substitute for GDP) for 2018 were used for empirical research. The Euclidean distance was the metric. On the basis of the data, the economic potential of the municipalities included in the Metropolis was calculated. The results are presented in Figure 2. The highest potential was recorded for the cities: Gliwice, Katowice, Dąbrowa Górnicza, Tychy and Chorzów. These cities are the most developed in terms of socioeconomic.

Then, the values of $Q P_{k} / g_{k}$ for municipalities of the Metropolis were determined, where $g_{k}$ is the quotient of $I_{k} / P_{k}$. The values are shown in Figure 3. Fourteen regions have a measure value of less than 1 . This proves their strong position compared to other regions. It can be written that they are little dependent on other territorial units. The remaining 27 municipalities have a $Q P_{k} / g_{k}$ value greater than 1 . 
However, attention should be paid to the method of determining the measures and the metric used. In the process of determining the economic potential, for example for voivodships, the distances between voivodships are large, therefore they have a significant impact on the potential values. The smaller the territorial units, the smaller the distances between them, which implies a smaller influence of the value $d_{k m}$ on the value of the potential. From the point of view of the inhabitants, the accessibility of a region that is significantly distant is lower than that of a region closer to us (for example, taking into account the daily commuting to work or schools). The distance parameter for small areas is less important.

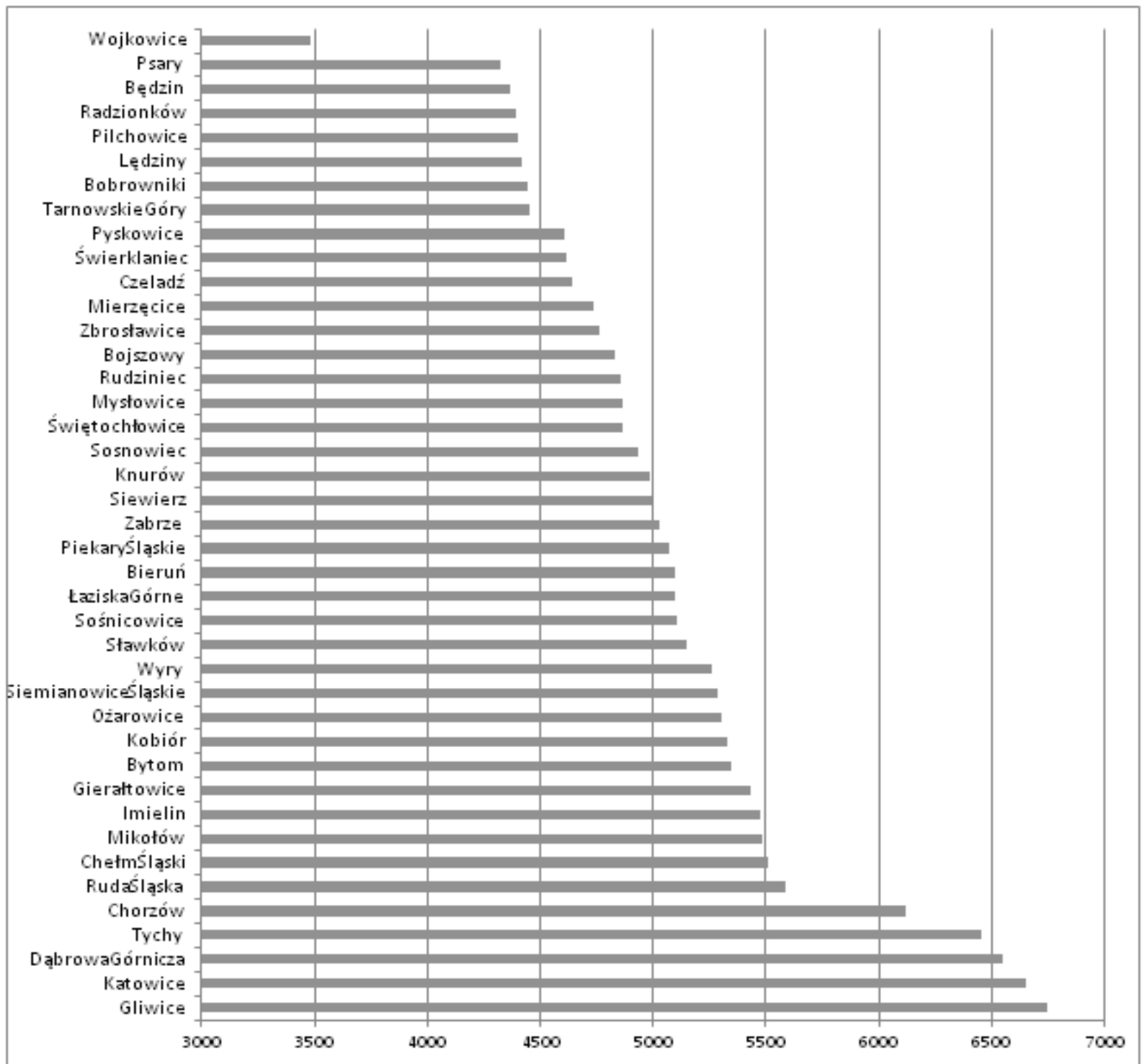

Figure 2. Economic potential $Q P_{k}$ of communes included in the Metropolis GZM.

The analysis of demographic and economic characteristics for the communes of the Metropolis GZM allows for the following conclusions:

- Population potential allows to identify communes with a large population in a given commune and in its immediate vicinity. The components of this potential are the own potential of the population (population of a given territorial unit) and the potential of the 
surrounding population. The potential of the population may be useful in land development planning, designating special economic zones, and planning economic activities.

- The income potential indicates units that are strong in terms of GDP, income from a given source, or their substitute. Rich communes can plan new investments, modernize infrastructure and invest.

- The quotient of potentials determined as the quotient of income potential and population allows to answer the question to what extent a given territorial unit depends on the environment, it indicates strong regions, highly developed socially and economically, and less developed regions.

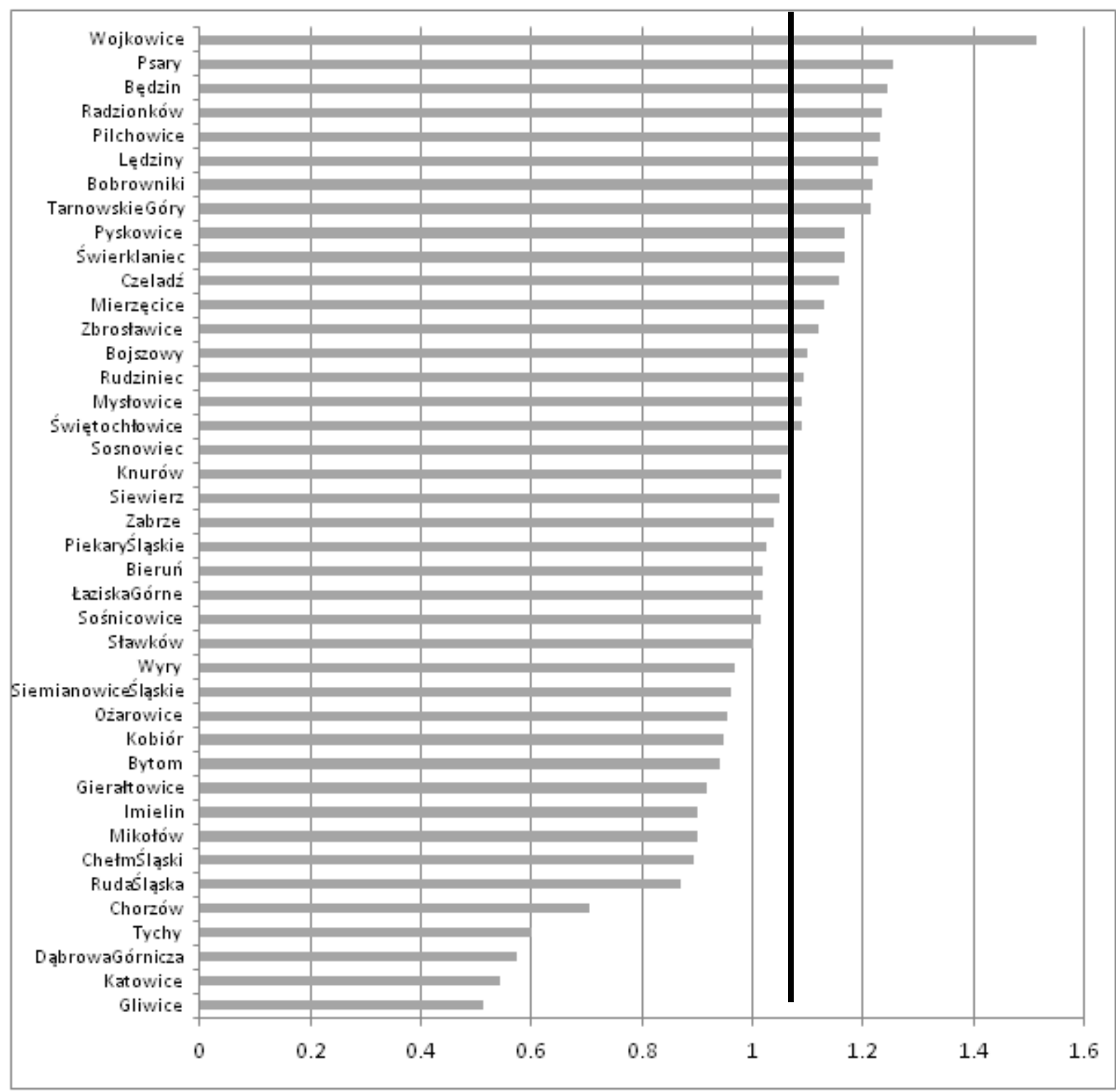

Figure 3. Values of the $Q P_{k} / g_{i k}$ measure for the territorial units included in the Metropolis GZM.

In the Silesian Voivodeship, a decreasing number of people has been observed for over 30 years. It is worth paying attention to the fact that cities with the greatest economic potential are also depopulating. However, there is a correlation between the value of the economic potential and the pace of population decline. Cities with high economic potential (Gliwice, 
Tychy, Chorzów) are depopulating slowly. Due to the small distances between the regions, the population of the Metropolis settles in small towns or communes on the outskirts of large agglomerations without any problems with getting there.

\section{Summary}

In the article, on the basis of statistical data, the values of the economic potential for 41 communes included in the Metropolis GZM were determined. Strong communes, characterized by a high level of socio-economic development, and weak ones, largely dependent on the economic environment, were selected.

A question can be asked about the direction of changes in the economic and social spheres that will be subject to municipalities in the era of decreasing population of Silesia, including the Metropolis. The low rate of population growth, the movement of people from large agglomerations to small towns and communes certainly affects the economic potential of the regions.

Potential as a quantitative measure, can serve as a measure of socio-economic development, and can also be an auxiliary element in the decision-making process at the local management level. The quotient of potentials can therefore be a useful tool supporting economic decisionmaking and shaping the development strategies of cities and regions.

The method of potentials is used in regional analyses at the level of states, regions and even territorial units and communes. It influences efficient management in the economic sphere, it allows, for example, to effectively use the population's resources and the economic potential of regions. In this article, on the basis of the proposed method of the economic potential of the organization, an attempt was made to determine the possibility of the organization functioning in a specific economic environment. The use of any metric in the analysis process allows for great application possibilities of the proposed methodology, but also requires further empirical and simulation analyses. However, it seems that the proposed approach is interesting and has a wide field of application. 


\section{References}

1. Arbia, G. (2006). Spatial econometrics. Berlin: Springer.

2. Biernacki, M. (2006). Kilka uwag o pomiarze dobrobytu społecznego. Mathematical economics, $n r$ 3(10). Wrocław: Wydawnictwo Uniwersytetu Ekonomicznego we Wrocławiu.

3. Chojnicki, Z. (1966). Zastosowanie modeli grawitacji i potencjału w badaniach przestrzenno-ekonomicznych. KPZK PAN, $n r 14$.

4. Combes, P.P, Mayer, T., Thissem J.F. (2006). Economie Geographique. Economica. Paris.

5. Dutton, G. (1970). Macroscopic Aspects of Metropolita Evolution. Harvard Papers in Theoretical Geography. Geography of Income Series, no. 1.

6. Geis, A., Mur, J., Zoller, H. (2004). Spatial Econometrics and Spatial Statistics. New York: Palgrave Macmillan.

7. Giri, C.N. (2004). Multivariate Statistical Analysis. USA: Marcel Dekker.

8. Krugman, P.R. (1991). Geography and Trade. Cambridge, Massachusetts: The MIT Press.

9. Mastalerz-Kodzis, A. (2018). Dynamiczne modele specjalne Nowej Ekonomii Geograficznej. Wydawnictwo Uniwersytetu Ekonomicznego w Katowicach.

10. Paelinck, J.H.P., and Klaassen, L.H. (1983). Ekonometria przestrzenna. Warszawa: PWN.

11. Pooler, J. (1987). Measuring Geographical Accessibility: A Review of Current Approaches and Problems in the Use of Population Potentials. Geoforum, no. 3(18), pp. 269-289.

12. Rich, D.C. (1980). Potential Models in Human Geography. Concepts and Techniques in Modern Geography. Geo Abstracts, No. 26.

13. Sen, A., Smith, T. (1995). Gravity Models of Spatial Interaction Behavior. BerlinHeidelberg: Springer-Verlag.

14. Stiglitz, J.E. (2012). Macroeconomics Fluctuations, Inequality and Human Development. Journal of Human Development and Capabilities, 13(1), pp 31-58.

15. Suchecki, B. (ed.) (2010). Ekonometria przestrzenna. Metody i modele analizy danych przestrzennych. Warszawa: Wydawnictwo C.H. Beck.

16. Suchecki, B. (ed.) (2012). Ekonometria przestrzenna II. Modele zaawansowane. Warszawa: Wydawnictwo C.H. Beck.

17. www.bdl.stat.gov.pl.

18. www.infogzm.metropoliagzm.pl.

19. www.stat.gov.pl.

20. Zeliaś, A. (ed.) (1991). Ekonometria Przestrzenna. Warszawa: PWE. 


\title{
THE PREMISES OF THE EVOLUTION AND DEVELOPMENT OF FIRM COMPETENCES IN STRATEGIC MANAGEMENT
}

\author{
Rafał MATWIEJCZUK \\ University of Opole, Institute of Management and Quality Studies, Chair of Logistics and Marketing, Opole, \\ Poland; rmatwiejczuk@uni.opole.pl, ORCID: 0000-0001-8638-3273
}

\begin{abstract}
Purpose: The aim of the article is to identify the premises of the evolution and development of firm competences in strategic management.

Design/methodology/approach: The article indicates the key role of competences in strategic management. An extensive literature review and an identification approach were used.

Findings: Competences may significantly affect the achievement of the expected market and economic outcomes, as well as building a long-term competitive advantage of a firm.

Practical implications: The results of the research presented in the article show the significant importance of the firm competences in strategic management and business practice.

Originality/value: The most important conditions for the development of the firm competences in the field of strategic management were presented. The article is addressed both to researchers as well as managers and other business practitioners.
\end{abstract}

Keywords: competences, strategic potentials, strategic management.

Category of the paper: Conceptual paper.

\section{Introduction}

The strategic potentials of a firm, which comprise resources, capabilities and competences, play a significant role in strategic management. The abovementioned potentials contribute to the expected market as well as economic outcomes achievement by a firm. The particular importance in achieving such outcomes is assigned to the firm competences. Competences are often perceived as the most important strategic potentials in achieving the expected outcomes and building firm competitive advantage. The aim of the article is to identify the premises of the evolution and development of firm competences in strategic management. 


\section{The nature of the term "competences"}

In the recent years, in the area of business management, especially in strategic management, one may notice the growing importance of the so-called strategic potentials of the firm (Day, and Wensley, 1988; Christensen, 1996; Day, 1994; Foss, 1996; Knudsen, 1996). Strategic potentials, which include the resources, capabilities and competences of the firm, are the factors affecting the achievement of the expected market outcomes (customer satisfaction, customer loyalty, market share) as well as economic outcomes (profit, profitability, return on invested capital) by the firm.

The expected outcomes are the result of undertaking and implementing the planned tasks by the firm, both at the strategic as well as the operational level, in accordance with the structure of the adopted goals and the firm capabilities, as well as taking into account the market, competitive and macroeconomic conditions. Such outcomes, related to the achievement of planned results, may constitute the basis for the firm success. In a situation where the market and economic outcomes achieved by the firm are more favorable than those achieved by the competitors, strategic potentials may lead to the creation of a competitive advantage of the firm.

Among the strategic potentials considered in the context of achieving the expected market and economic outomes by the firm, as well as gaining and maintaining a long-term competitive advantage, the key importance is assigned to the firm competences.

The notion as well as the concept of the firm competence has not been always clearly defined so far. Apart from the differences in the definitions of the "competences" term, there is a noticeable difference in the interchangeable use of the term "competences" and related terms and concepts such as "key competences", "core competences", "distinctive competences", "critical competences", etc. There are also situations in which the authors equate the term/concept of competences with other terms/concepts, especially with capabilities, dynamic capabilities, resources or assets (Hamel, and Prahalad, 1994; Leonard-Barton, 1995; Drejer, 1996, 2002; Chiesa, and Manzini, 2000; Spanos, and Prastacos, 2004), and even suggestions in which the significance of differences between these terms/concepts is questioned (Barney, and Clark, 2007).

In striving to explain the nature and essence of the competences, one may notice some symptoms of tautology. For example, O. Williamson (1999) draws attention to the occasional attempts to define or describe key competences as the competences that are key, without further defining and/or explaining their specific characteristics, which further exacerbates the terminological ambiguity in relation to this notion/concept. Sometimes there are also some symptoms of identifying or reducing the notion/concept of competences to narrower notions/concepts, e.g. to the so-called routine activities carried out by the firm (Teece, Pisano, and Shuen, 1997). An overview of the definitions of competences is presented in table 1. 
Table 1.

Definitions of the term "competence"

\begin{tabular}{|c|c|}
\hline $\begin{array}{c}\text { Author/Authors } \\
\text { (year) }\end{array}$ & Definition \\
\hline $\begin{array}{l}\text { R.E. Boyatzis } \\
(1982)\end{array}$ & $\begin{array}{l}\text { Competences are the features of persons that enable/lead to the effective and/or } \\
\text { distinctive performance of specific tasks }\end{array}$ \\
\hline $\begin{array}{l}\text { R. Hall } \\
(1992)\end{array}$ & $\begin{array}{l}\text { Competences are the knowledge of employees and other stakeholders of the firm as } \\
\text { well as shared capabilities that make up the organizational culture }\end{array}$ \\
\hline $\begin{array}{l}\text { V. Chiesa, } \\
\text { M. Barbeschi } \\
(1994)\end{array}$ & $\begin{array}{l}\text { Competences can be defined as a unique combination of knowledge, skills and } \\
\text { technologies leading to the production of a series of profitable innovations }\end{array}$ \\
\hline $\begin{array}{l}\text { D. Turner, } \\
\text { M. Crawford } \\
(1994)\end{array}$ & $\begin{array}{l}\text { Competences reflect combinations of skills, knowledge and behavior, widespread both } \\
\text { within the firm as well as among individual employees, based on systems, processes } \\
\text { and structures occurring in the firm }\end{array}$ \\
\hline $\begin{array}{l}\text { N.J. Foss } \\
(1996)\end{array}$ & $\begin{array}{c}\text { Competences constitute - usually idiosyncratic - knowledge capital that allows its } \\
\text { owner to carry out activities and solve problems in a specific way and usually perform } \\
\text { it more effectively than others }\end{array}$ \\
\hline $\begin{array}{l}\text { R. Sanchez, } \\
\text { A. Heene, } \\
\text { H. Thomas } \\
\quad(1996)\end{array}$ & $\begin{array}{l}\text { Competences are the capabilities leading to ensure the coordinated use of resources, } \\
\text { which are the prerequisite for achieving the goals set by the firm }\end{array}$ \\
\hline $\begin{array}{l}\text { B. Eriksen, } \\
\text { N. Foss } \\
(1997)\end{array}$ & $\begin{array}{l}\text { Competences can be defined as the unique knowledge of the firm related to the } \\
\text { processes of effective development, production and marketing of properly defined } \\
\text { products and services, concerning in particular the organization and management of } \\
\text { these processes }\end{array}$ \\
\hline $\begin{array}{l}\text { M. Javidan } \\
\text { (1998) }\end{array}$ & $\begin{array}{l}\text { Competences are the result of a cross-functional integration and coordination of } \\
\text { capabilities related to activities and resources implemented and used in the firm scale } \\
\text { as well as in the entire value chain scale }\end{array}$ \\
\hline $\begin{array}{l}\text { The Concise } \\
\text { Oxford Dictionary } \\
\text { of Current English } \\
(2002)\end{array}$ & $\begin{array}{l}\text { Competences are the capabilities to perform a given task, which are the characteristic } \\
\text { features for a given person }\end{array}$ \\
\hline $\begin{array}{l}\text { J. Mills, } \\
\text { K. Platts, } \\
\text { M. Bourne, } \\
\text { H. Richards } \\
\quad(2002)\end{array}$ & $\begin{array}{l}\text { Competences are the capabilities to perform specific tasks and activities, which may be } \\
\text { strong (high) or weak (low) in relation to a given firm. A firm has strong (high) } \\
\text { competences when it is able to achieve more favorable outcomes than competitors in } \\
\text { terms of the customer value creation. The firm has weak (low) competences when it is } \\
\text { not able to achieve more beneficial outcomes than its competitors in terms of the } \\
\text { customer value creation }\end{array}$ \\
\hline $\begin{array}{l}\text { J.D. Brazell, } \\
\text { T.M. Devinney, } \\
\text { D. Midgley } \\
(2005)\end{array}$ & $\begin{array}{l}\text { Competences can be defined as the complex combination of assets, resources and } \\
\text { processes that enable firms to meet customer needs }\end{array}$ \\
\hline $\begin{array}{l}\text { T.J. Lehtonen } \\
\quad(2005)\end{array}$ & $\begin{array}{l}\text { Competences are persistent capabilities that are or may be of strategic importance in } \\
\text { the firm's efforts to achieve success, taking into account the current and future } \\
\text { conditions of competition }\end{array}$ \\
\hline $\begin{array}{l}\text { S. Ray, } \\
\text { K. Ramakrishnan } \\
\quad(2006)\end{array}$ & $\begin{array}{l}\text { Competences can be defined as a combination of resources possessed by a firm in the } \\
\text { form and quantity securing its operations, the integration of which - thanks to } \\
\text { appropriate management processes as well as routine activities - leads to the } \\
\text { achievement of the firm's goals }\end{array}$ \\
\hline $\begin{array}{l}\text { G. Guallino, } \\
\text { F. Prevot } \\
(2008)\end{array}$ & $\begin{array}{c}\text { Competences are a set of resources possessed by a firm, related to the performance of } \\
\text { activities leading to the achievement of the assumed goals, through the development of } \\
\text { adequate capabilities to perform tasks }\end{array}$ \\
\hline
\end{tabular}

Source: Based on: Bove, Harmsen and Grunert, 2000; Boyatzis, 1982; Brazell, Devinney, and Midgley, 2005; Chiesa, and Barbeschi, 1994; Foss, 1996; Guallino and Prevot, 2008; Hall, 1992; Javidan, 1998; Lehtonen, 2005; Mills et al., 2002; Moore, Cheng, and Dainty, 2002; Ray, and Ramakrishnan, 2006; Sanchez, Heene, and Thomas, 1996; Turner, and Crawford, 1994. 
The definitions of competences presented above indicate the considerable variation in the views of individual authors, which is not without influence on the terminological ambiguity regarding the nature of competences.

In the opinion of some authors, competences are only the characteristics of people who can/are able to perform specific tasks or activities in the way that is expected from them. Other authors reduce the term of competences to knowledge, or possibly to knowledge and capabilities, which are the distinguishing features not only of people, but of the firms as well. Still, the other authors take the view that competences are resources and/or capabilities used by individuals and/or firms to achieve the set goals. The authors who believe that competences are the results of the integration of resources (including knowledge) and capabilities, which create the premises for achieving the expected market and economic outcomes by a firm, move relatively the furthest in their interpretations.

\section{The roots of the "competences" term}

The term "competences", or more precisely, "distinctive competences", was introduced in 1957 by P. Selznick, by "embedding" the issue of competences in the area of sociology (Selznick, 1957; Eden, and Ackermann, 2010). In the area of management, and more specifically, the area of strategic management, the term "competences" was firstly used by I.H. Ansoff and K.R. Andrews (Ansoff, 1965; Andrews, 1971; Eriksen, and Mikkelsen, 1996). J.T. Mahoney and J.R. Pandian (Mahoney, and Pandian, 1992) emphasize that the competences, especially those introduced by P. Selznick, and then developed by I.H. Ansoff and K.R. Andrews, i.e. distinctive competences, have evolved towards constantly gaining importance strategic potentials of the firm, playing a significant role in its value chain as well as affecting the competitiveness of the firm, including, in particular, the possibilities of achieving and sustaining the firm competitive advantage.

The term "competence" comes from the Latin word "competere", which means "appropriate" (Nordhaug, and Grønhaug, 1994). Bearing in mind the sociological origin of this term, as well as taking into account the individual skills of people enabling the performance of tasks assigned to them in accordance with the adopted goals (guidelines), the original perception of the term "competences" was reduced to the characteristics of a person who was able to effectively and efficiently carry out the assigned tasks and, consequently, achieve the set goals.

After being "transferred" to the area of management, the term of competences has gained a number of, often significantly different, definitions and interpretations. A. Collin draws attention to the variety of approaches appearing in the studies devoted to the essence and significance of competences in management (Collin, 1989). In his opinion, the diversified use of "competences" term not only significantly complicates the explanation of their nature, 
but also influences the recognition of the possibility of using competences in the efforts of the firms to achieve the expected outcomes. As A. Collin points, on the one hand, the key role of competences as factors affecting the achievement of the expected market and economic outcomes by a firm has been emphasized for a long time, but on the other hand, for many years of evolution and development of the "competences" term, relatively little attention has been paid to the very essence of this notion, methods of its precise definition, or directions of its development.

In this paper it was assumed that the firm competences are the long-term capabilities concerning the using of the resources involved in the implementation of the goals and tasks set by the firm, leading to the achievement of the expected market and economic outcomes by a firm as well as to the creation of its competitive advantage. The basis for the development of competences understood in this way is the integration and coordination of the firm resources and capabilities, also taking into account the knowledge as the very specific as well as significant type of resources (Matwiejczuk, 2014).

O. Nordhaug and K. Grønhaug (Nordhaug, and Grønhaug, 1994) emphasize that in the case of the competences one can speak of their progressive and - at the same time - diversified and multidimensional impact on various aspects and processes concerning business management. This is related not only to different ways of perceiving and interpreting competences, but also to different, although sometimes - at least to some extent - complementary sources and directions of the firm competences development.

\section{Conditions for the development of the firm competences in strategic management}

According to O. Nordhaug and K. Grønhaug (Nordhaug, and Grønhaug, 1994), in the process of the competences development in the context of business management, two basic issues should be highlighted.

Firstly, when speaking about the firm competences in the context of business management, the managerial features and/or properties of competences are often emphasized, concerning the conditions, possibilities and ways of using them for more effective and efficient business management. From the point of view of the competences development, this trend also extends to the psychological and sociological foundations of building and forming the firm competences, which support the achievement of firm goals.

Secondly, taking into account the evolution and development of the contemporary management, it can be said that the competences have permanently "entered" one of its most important areas, which is strategic management. Within the area of strategic management the concepts as "core competences", "key competences", "dominant competences", "distinctive 
competences", "critical competences" or "metacompetences" came to be considered as the the mostly significant.

R. Durand and B.V. Quelin, as well as M. Hülsmann and Ch. Wycisk emphasize that along with the development of various management concepts that are based on the use of competences leading to the achievement of the goals set by a firm, competences are more and more often associated with integrated ("aggregated") sets of capabilities, enabling efficient and effective implementation, both operational and strategic processes and activities that affect the forming of the firm competitiveness, as well as creating a competitive advantage by a firm (Durand, and Quelin, 2000; Hülsmann, and Wycisk, 2008).

In the recent years, more and more attention has been paid to the fact that competences are one of the most important and valuable strategic potentials of a firm, which should not only be permanently developed, but also protected from the competitors. Competences may be a significant determinant of creating a long-term competitive advantage of a firm.

The issue of the competences as the strategic potentials of a firm that have a significant importance for the creation of the firm competitive advantage has been more and more often "included" in one of the contemporary trends in strategic management, referred to as the "Resource-Based View (RBV)". Without going deeper into the assumptions and areas of the $\mathrm{RBV}$ concept, it is worth noting that competences are currently perceived as the key strategic potentials of the firm, which include integrated sets of capabilities that enable the use of the firm resources in creating a long-term competitive advantage.

It can be said that in the recent years there has been a noticeable shift of the "center of gravity" from broadly understood firm resources (material, non-material, financial, personal) towards the firm competences, which "constitute" unique - compared to the competitors compositions of resources and capabilities, affecting the achievement of the expected market and economic outcomes, and - as a result - the firm success as well as the sustainable, long-term competitive advantage by a firm. Therefore, the issue of competences requires further in-depth research, concerning not only the integration of resources and capabilities on which competences are "embedded", but also the forming and development of business models based on the strategic potentials of the firm.

\section{Conclusion and further research}

The article presented the premises of the evolution and development of the firm competences, "embedded" in the area of strategic management. The firm competences play a very important role in strategic management. Competences may significantly affect the achievement of the expected market and economic outcomes by a firm, as well as building a long-term competitive advantage of a firm. 
The issue of the firm competences undoubtedly deserves further research. In particular, it is worth focusing the future research on the determinants and circumstances of shaping and developing business models based on the firm success potentials, including - in particular the firm competences.

\section{References}

1. Andrews, K.R. (1971). The Concept of Corporate Strategy. Homewood, Ill: Irwin.

2. Ansoff, I.H. (1965). Corporate Strategy: An Analytic Approach to Business Policy for Growth and Expansion. New York: McGraw-Hill.

3. Barney, J.B., and Clark, D.N. (2007). Resource-Based Theory. Creating and Sustaining Competitive Advantage. New York: Oxford University Press Inc.

4. Bove, K., Harmsen, H., and Grunert, K.G. (2000). The Link Between Competencies and Company Success in Danish Manufacturing Companies. In: R. Sanchez, and A. Heene (Eds.), Research in Competence-Based Management. Advances in Applied Business Strategy, Vol. 6, Part C (pp. 23-43). Stamford, CT: JAI Press Inc.

5. Boyatzis, R.E. (1982). The Competent Manager - A Model for Effective Performance. New York: John Wiley \& Sons.

6. Brazell, J.D., Devinney, T.M., and Midgley, D. (2005). Relating Customer Value to Strategic Competence: A Discrete Choice Measurement Approach. In: R. Sanchez, and J. Freiling (Eds.), A Focused Issue on the Marketing Process in Organizational Competence. Research in Competence-Based Management, Vol. 1 (pp. 15-45). Oxford: Elsevier Ltd.

7. Chiesa, V., and Barbeschi, M. (1994). Technology Strategy in Competence-Based Competition. In: G. Hamel, A. Heene (Eds.), Competence-Based Competition (pp. 293314). Chichester: John Wiley and Sons.

8. Chiesa, V., and Manzini, R. (2000). Diversification Strategies and Competence-Based Competition: Suggestions from Three Case Studies. In: R. Sanchez, and A. Heene (Eds.), Research in Competence-Based Management. Advances in Applied Business Strategy, Vol. 6, Part C (pp. 45-66). Stamford, CT: JAI Press Inc.

9. Christensen, J.F. (1996). Analysing the Technology Base of the Firm. A Multi-dimensional Resource and Competence Perspective. In: N.J. Foss, Ch. Knudsen (Eds.), Towards a Competence Theory of the Firm (pp. 111-132). London: Routledge.

10. Collin, A. (1989). Managers' Competence: Rhetoric, Reality and Research. Personnel Review, Vol. 18, No. 6, pp. 20-25.

11. Day, G.S. (1994). The Capabilities of Market-Driven Organizations. Journal of Marketing, Vol. 58, No. 4, pp. 37-52. 
12. Day, G.S. and Wensley, R. (1988). Assessing Advantage: A Framework of Diagnosing Competitive Superiority. Journal of Marketing, Vol. 52, No. 2, pp. 1-20.

13. Drejer, A. (1996). Integration of Business Strategy and Competence Development. Ph.D. Thesis. Aalborg: Department of Production, Aalborg University.

14. Drejer, A. (2002). Strategic Management and Core Competencies. Theory and Application. Westport, CT: Quorum Books.

15. Durand, R., and Quelin, B.V. (2000). Linking Competencies, Sustainable Competitive Advantage, and Performance: An Empirical Investigation. In: R. Sanchez, and A. Heene (Eds.), Research in Competence-Based Management. Advances in Applied Business Strategy”, Vol. 6, Part C (pp. 97-123). Stamford, CT: JAI Press Inc.

16. Eden, C., and Ackermann, F. (2010). Competences, Distinctive Competences, and Core Competences. In: R. Sanchez, and A. Heene (Eds.), A Focused Issue on Identifying, Building, and Linking Competences. Research in Competence-Based Management, Vol. 5 (pp. 3-33). Bingley: Emerald Group Publishing Ltd.

17. Eriksen, B., and Mikkelsen, J. (1996). Competitive Advantage and the Concept of Core Competence. In: N.J. Foss, Ch. Knudsen (Eds.), Towards a Competence Theory of the Firm (pp. 54-74). Routledge: London.

18. Foss, N.J. (1996). Introduction. The Emerging Competence Perspective. In: N.J. Foss, Ch. Knudsen (Eds.), Towards a Competence Theory of the Firm (pp. 1-12). LondonNew York: Routledge.

19. Guallino, G., and Prevot, F. (2008). Competence-Building through Organizational Recognition or Frequency of Use: Case Study of the Lafarge Group's Development of Competence in Managing Post-Merger Cultural Integration. In: R. Martens, A. Heene, and R. Sanchez (Eds.), Competence Building and Leveraging in Interorganizational Relations. Advances in Applied Business Strategy, Vol. 11 (pp. 63-92). Oxford: Elsevier Ltd.

20. Hall, R. (1992). The Strategic Analysis of Intangible Resources. Strategic Management Journal, Vol. 13, No. 2, pp. 135-144.

21. Hamel, G., and Prahalad C.K. (1994). Competing for the Future. Cambridge, MA: Harvard Business School Press.

22. Hülsmann, M., and Wycisk, Ch. (2008). The Role of Flexibility in Strategic CompetenceManagement - Contributions of the Concept of Self-Organization. In: R. Sanchez (Ed.), A Focused Issue on Fundamental Issues in Competence Theory Development. Research in Competence-Based Management, Vol. 4 (pp. 259-279). Bingley: Emerald Group Publishing Ltd.

23. Javidan, M. (1998). Core Competence: What Does it Mean in Practice? Long Range Planning, Vol. 31, No. 1, pp. 60-71.

24. Knudsen, Ch. (1996). The Competence Perspective. A Historical View. In: N.J. Foss, Ch. Knudsen (eds.), Towards a Competence Theory of the Firm (pp. 13-37). Routledge: London. 
25. Lehtonen, T.J. (2005). Building Strategic HRM Practices within the Competence-Based View: Introducing A CBM-Based Strategic HRM Framework. In: R. Sanchez, and A. Heene (Eds.), Competence Perspectives on Resources, Stakeholders and Renewal. Advances in Applied Business Strategy, Vol. 9 (pp. 129-145). Oxford: Elsevier Ltd.

26. Leonard-Barton, D. (1995). Wellsprings of Knowledge: Building and Sustaining the Sources of Innovation. Boston, MA: Harvard Business School Press.

27. Mahoney, J.T. and Pandian, J.R. (1992). The Resource-Based View within the Conversation of Strategic Management. Strategic Management Journal, Vol. 13, No. 5, pp. 363-380.

28. Matwiejczuk, R. (2014). Kompetencje logistyki w tworzeniu przewagi konkurencyjnej przedsiębiorstwa. Opole: Wydawnictwo Uniwersytetu Opolskiego.

29. Mills, J., Platts, K., Bourne, M., and Richards, H. (2002). Strategy and Performance. Competing through Competences. Cambridge: Cambridge University Press.

30. Moore, D.R., Cheng, M.I. and Dainty, A.R.J. (2002). Competence, Competency and Competencies: Performance Assessment in Organizations. Work Study, Vol. 51, No. 6, pp. 314-319.

31. Nordhaug, O., and Grønhaug, K. (1994). Competences as Resources in Firms. The International Journal of Human Resource Management, Vol. 5, No. 1, February, pp. 89-106.

32. Ray, S., and Ramakrishnan, K. (2006). Resources, Competences and Capabilities Conundrum: A Back-To-Basics Call. Decision, Vol. 33, No. 2, pp. 4-15.

33. Sanchez, R., Heene, A., and Thomas, H. (1996). Towards the Theory and Practice of Competence-Based Competition. In: R. Sanchez, A. Heene, and H. Thomas (Eds.), Dynamics of Competence-Based Competition: Theory and Practice in the New Strategic Management (pp. 1-35). London: Elsevier.

34. Selznick, P. (1957). Leadership in Administration: A Sociological Interpretation. New York: Harper and Row.

35. Spanos, Y.E. and Prastacos, G. (2004). Understanding Organizational Capabilities: Towards a Conceptual Framework. Journal of Knowledge Management, Vol. 8, No. 3, pp. 31-43.

36. Teece, D.J., Pisano, G. and Shuen, A. (1997). Dynamic Capabilities and Strategic Management. Strategic Management Journal, Vol. 18, No. 7, pp. 509-533.

37. Turner, D., and Crawford, M. (1994). Managing Current and Future Competitive Performance: The Role of Competence. In: G. Hamel, A. Heene (Eds.), Competence-Based Competition (pp. 241-263). Chichester: John Wiley and Sons.

38. Williamson, O.E. (1999). Strategy Research: Governance and Competence Perspectives. Strategic Management Journal, Vol. 20, No. 12, pp. 1087-1108. 



\title{
THE APPLICATION OF CZEKANOWSKI DIAGRAM TO ASSESS THE FINANCIAL SITUATION OF NON-FINANCIAL ENTERPRISES IN POLAND IN THE YEARS 2010-2020
}

\author{
Monika MIŚKIEWICZ-NAWROCKA \\ University of Economics in Katowice; monika.miskiewicz@ue.katowice.pl, ORCID: 0000-0002-2766-1322
}

Purpose: The changing financial situation of enterprises under the influence of various political, economic, social, etc. decisions is the cause of interest of many researchers. The aim of the research is to assess the financial situation of non-financial enterprises in Polish voivodships, taking into account the division into the private sector and the public sector in 2010-2020, and an attempt to classify the analyzed voivodeships into separate classes.

Design/methodology/approach: Czekanowski's method was used to achieve the goal, which allows for the comparison of the examined objects in terms of the analyzed phenomenon. The visualization of this method is an ordered Czekanowski diagram, on the basis of which it is possible to group objects and observe whether their geographic location influences the results of grouping.

Findings: The conducted analysis made it possible to group voivodeships in terms of the financial situation of enterprises, both for the public and private sectors. In the analyzed period, among the voivodships of Poland, several groups of similar voivodships can be distinguished in terms of the financial situation of enterprises. A voivodship was also selected, which differs from the rest of the voivodships - it is characterized by a lack of similarity in terms of the considered features, both in the whole analyzed period. It was also shown that the lockdown resulting from the SARS-CoV-2 pandemic had a significant impact on the financial results of Polish enterprises in the first half of 2020.

Research limitations/implications: Using the MaCzek computer program to construct Czekanowski's diagrams, in some cases isolating similar objects in an unambiguous manner was difficult and hindered interpretation.

Originality/value: Showing that the application of Czekanowski's method to the analysis of the financial situation of public and private sector enterprises in Poland is possible and allows for the assessment of the similarity of voivodeships. The article and the application of the method is useful for entrepreneurs and investors.

Keywords: diagram of Czekanowski, net financial result, enterprices, public sector, private sector.

Category of the paper: research paper. 


\section{Introduction}

The main source of information for the assessment of the financial situation of enterprises are its financial statements. Information contained therein is very important for stakeholders when making rational decisions (eg. investment, cooperation) affecting the company. The reports are prepared in accordance with the International Financial Reporting Standards or the Accounting Act and contain integrated information on the financial results of business entities, i.e. profits achieved, revenues, costs incurred, amounts of budget liabilities or short and long-term receivables.

The basic elements of the financial statements are the balance sheet, profit and loss account, and cash flow statement. The balance sheet informs about the assets of the enterprise and the sources of its financing. The profit and loss account informs about the revenues, operating costs and financial results achieved in a given period. The cash flow statement is information about the cash flows from operating, investing and financing activities. (Wędzki, 2009) The basic tool for assessing the company's situation is the ratio analysis, which can be divided into a preliminary analysis of the financial statements (the structure of the balance sheet of the income statement and the cash flow statement, the structure of equity capital of the enterprise), the analysis of financial liquidity (from the static, income and structural point of view), and debt analysis. (level of debt and debt service capacity), business efficiency analysis (working capital cycle, cash conversion cycle, and its components), profitability analysis (sales profitability, equity and assets ratios) (Wędzki, 2009; Czekaj, Dresler, 2005).

The company's financial situation is a strong indicator of changes taking place in the company. There is a strong positive correlation between financial indicators and the investment decisions made (Kolegowicz, Krzemiński, 2019). However, the preparation of an opinion on the state of the enterprise, adequate to the current state of affairs, requires the extension of the scope of research, which cannot be limited only to the financial statements (Hamrol, 2013). The assessment of the company's financial situation should be carried out in time and space, that is, take into account internal and external conditions in the environment of the assessed enterprise. The internal conditions include the selection of appropriate tools (e.g. financial analysis) that enable the analysis of changes taking place in the enterprise and drawing correct conclusions. On the other hand, external conditions relate to the functioning of the enterprise against its environment, assessment of the strengths and weaknesses of the enterprise related to its resources, as well as opportunities and threats in its environment. As noted by M. Hamrol, the subject of the analysis should also be the relationships at the level of the industry in which the enterprise operates and the phenomena occurring in its closer and more distant environment (Hamrol, 2013). Also the results obtained by Szymańska and Jegers show a strong influence on the capital structure of both the environment and the factors generated by the sector in which the activity is conducted (Szymańska, Jegers, 2014). 
Research conducted for many years confirms that the socio-economic situation in Poland is improving every year, however, the disproportions in the level of development of voivodships remain high. The analyzes of the socio-economic development in voivodships in the voivodships in 1996-2017 carried out by A. Malina showed the existence of significant disproportions in development between the eastern and western parts of Poland, and the widening of the distance between the voivodeship with the highest and the lowest level of development. The voivodships located in western and central Poland (Mazowieckie and Wielkopolskie) are among the most developing voivodships (Malina, 2020). Similar conclusions can be drawn from the analysis carried out in the study by D. Michon (2017), where the voivodeships of the western and central (Mazowieckie) parts of the country were also identified as developing better.

The aim of the study is to determine the similarity of the financial situation of non-financial enterprises, as well as to examine whether the similarity of the taken into account financial indicators of enterprises in the analyzed voivodeships is related to their geographical location and mutual distance. An additional aim of the study is to check how the lockdown resulting from the ARS-CoV-2 pandemic influenced the financial results of Polish enterprises in the first half of 2020.

The Czekanowski diagram was used to group voivodeships in terms of the financial situation of enterprises. Such grouping will allow the voivodships to be divided into groups characterized by a high degree of mutual similarity.

The research used statistical data from the Central Statistical Office in 2010, 2019 and 2020. Due to the study of the effects of the pandemic on the financial situation of enterprises, data for the first half of each of the years mentioned were taken into account. The free MaCzek 3.3.44 program by Piotr Jaskulski and Arkadiusz Sołtysiak, available at http://www.antropologia.uw.edu.pl/MaCzek/maczek.html was used to present the results (access: 20/09/2020).

\section{The financial situation of non-financial enterprises in Poland}

Fig. 1-2 shows the financial results of Polish non-financial enterprises, taking into account the net profit and net loss for the first half of 2000-2020 for the private and public sectors. 


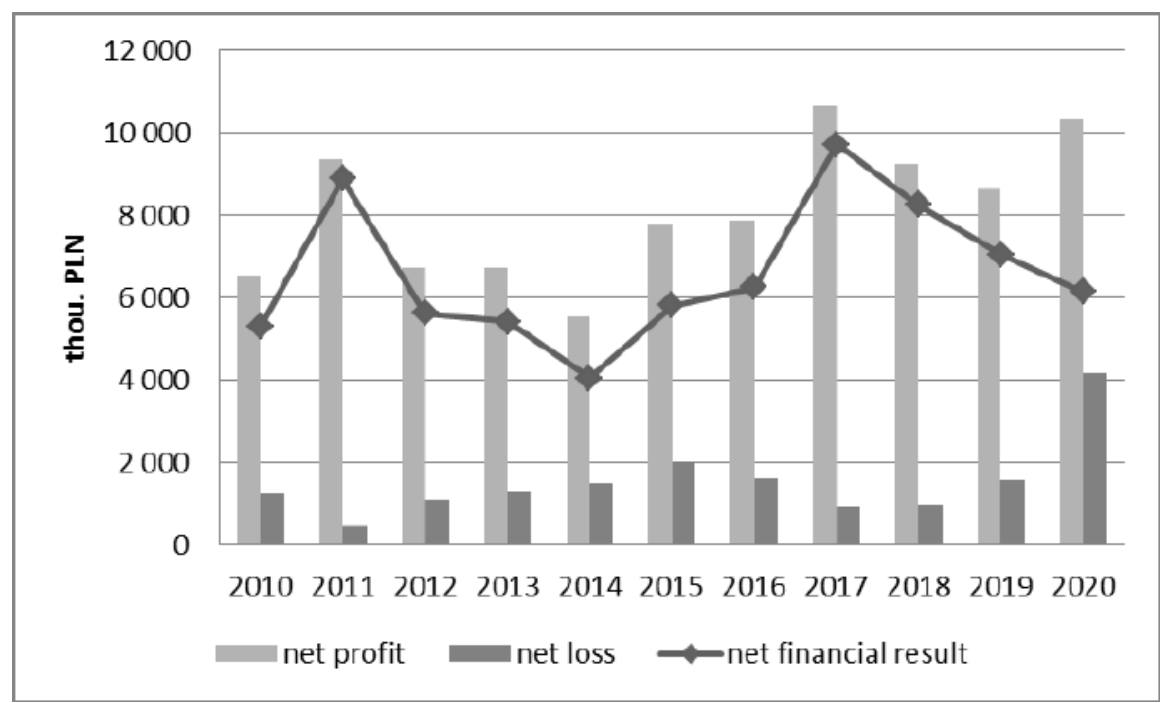

Figure 1. Net financial result, net profit and net loss of public sector non-financial enterprises in Poland for the first half of 2010-2020.

Based on the data in Figure 1, it can be seen that the highest average values of the net financial result, and also the average net profit for public sector enterprises for the first half of the year, were obtained in 2017 and 2011. Additionally, the lowest average net loss was recorded in 2011. On the other hand, the lowest average financial result was observed in the first half of 2014. Analyzing the above chart, one can also notice the impact of the pandemic on the financial result of enterprises in the first half of 2020. Despite one of the highest average net profit values in 2020, the average net loss is several times higher than in the previous years, which results in a much lower average financial result than in 2017-2019.

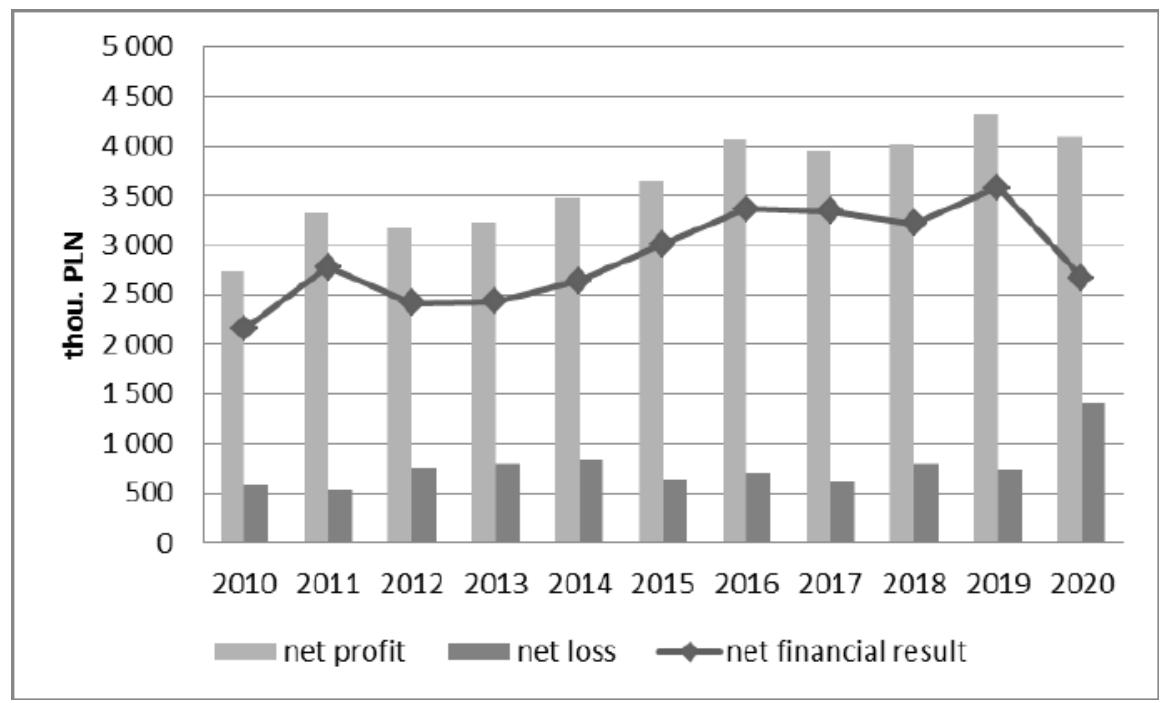

Figure 2. Net financial result, net profit and net loss of private sector non-financial enterprises in Poland for the first half of 2010-2020.

Financial data on private sector enterprises (Fig. 2) are characterized by lower values of the analyzed indicators per 1 enterprise than the indicators of public sector enterprises. The average financial result as well as the net profit reaches the highest value in the first half of 2019 . We observe the lowest average financial result in the first half of 2010. Similarly to the public 
sector enterprises, the lowest average net loss was recorded in 2011. On the other hand, in 2020 the average net loss is several times higher than in previous years, with one of the highest average net profit, which, similarly to the public sector, results in a much lower average financial result than in previous years.

Fig. 3-4 presents the average net financial result of enterprises in individual voivodeships in 2010, 2019 and 2020. The results obtained by public sector enterprises are higher than those of private sector enterprises. When analyzing the public sector (Fig. 3), it can be observed that the highest values of the average net financial result were obtained for the Mazowieckie voivodship, which despite the restrictions related to the pandemic in 2020 achieved almost $50 \%$ higher average net financial result than in 2010-2019. Among the voivodships where enterprises improved the average net financial result in the first half of 2020, the Kujawskopomorskie, Zachodniopomorskie, Warmińsko-mazurskie and Podkarpackie voivodeships can be mentioned. On the other hand, enterprises from the Śląskie and Pomorskie voivodeships recorded a net loss significantly exceeding the average net profit, which resulted in a negative net financial result. In addition, Śląskie also recorded a negative average net financial result in 2014 and 2015, and Pomorskie in 2010.
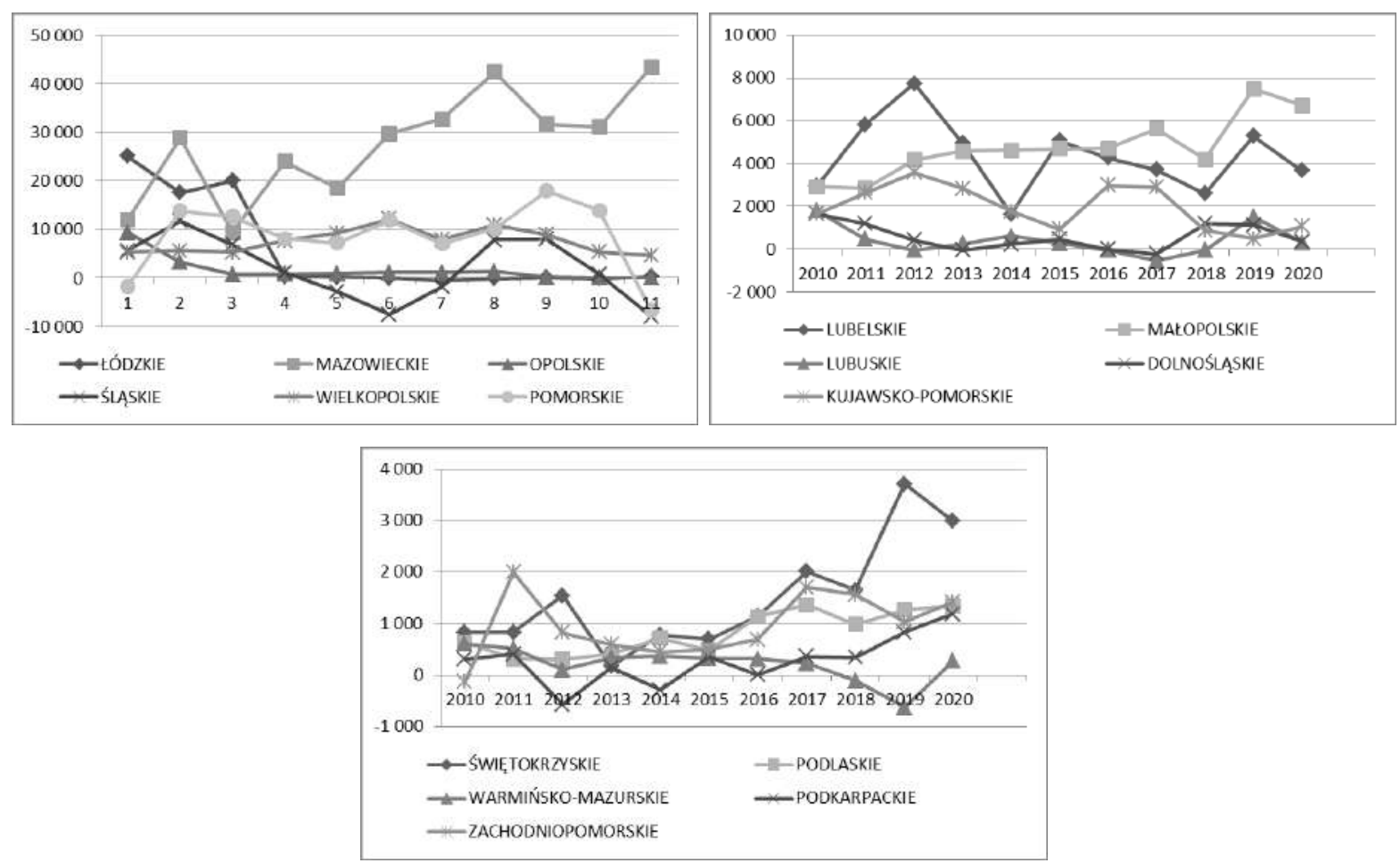

Figure 3. Net financial result of non-financial enterprises of the public sector in voivodships for the first half of the year 2010-2020. 

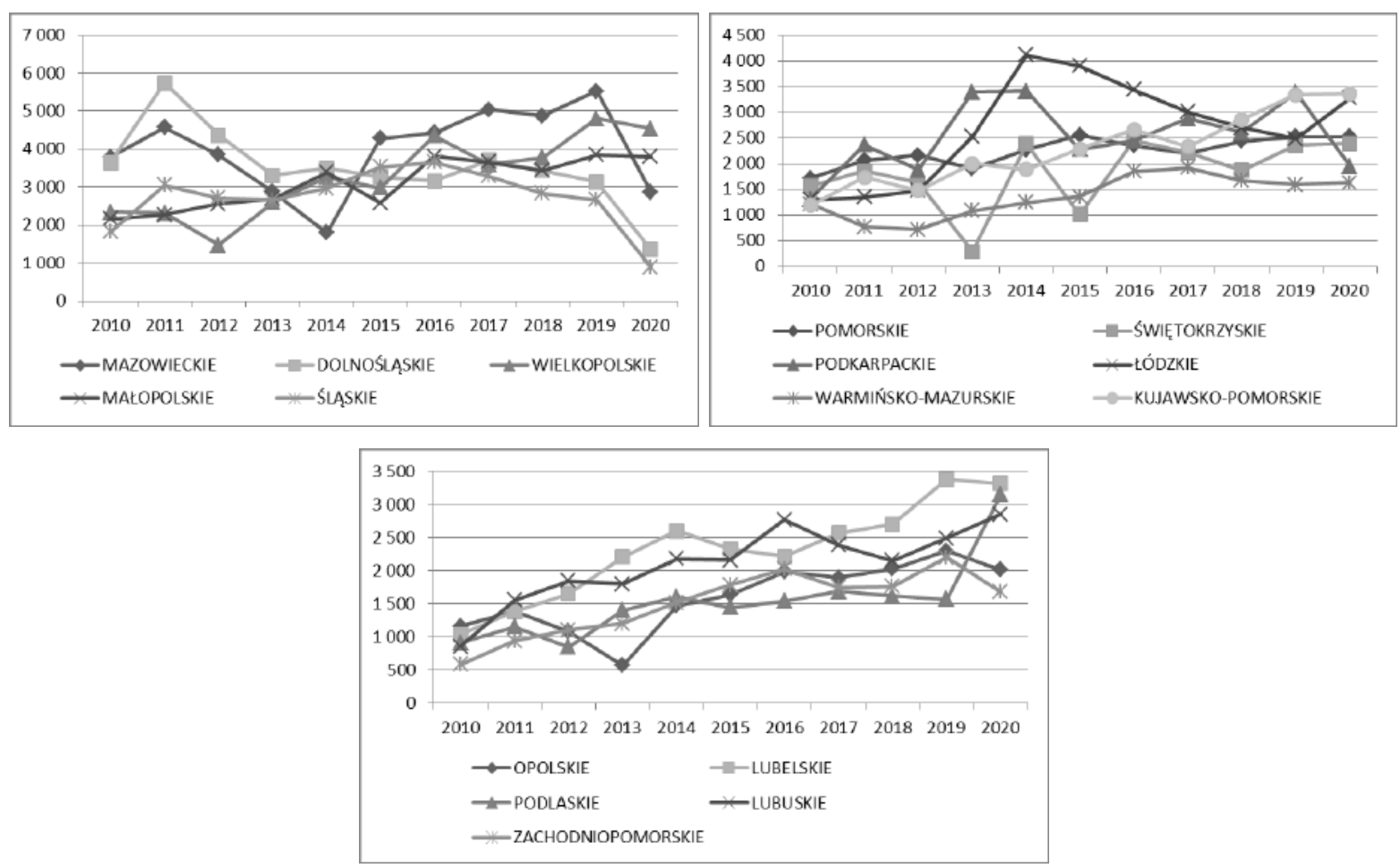

Figure 4. Net financial result of non-financial enterprises of the private sector in voivodships for the first half of the year 2010-2020.

Enterprises of the private sector (Fig. 4) are characterized by positive values of the net financial result, and for the Opolskie, Lubelskie, Lubuskie, Podlaskie and Zachodniopomorskie voivodeships a clearly upward trend can be observed. In the Podlaskie voivodeship in the first half of 2020, enterprises achieved a financial result more than twice as high as in 2019. The highest result was recorded for the Dolnośląskie voivodeship in 2011, and then for the Łódzkie Voivodeship in 2014, but in the following years we observe a downward trend in these voivodeships. As in the public sector, the highest values of the net financial result since 2015 were obtained for enterprises from Mazowieckie voivodship, which for the private sector obtained half the result. Among the voivodeships where enterprises also achieved a much lower net financial result compared to the first half of 2019, we have Podkarpackie, Dolnośląskie and Śląskie, while in the Łódzkie and Lubuskie voivodeships enterprises improved this result in the first half of 2020.

\section{The Czekanowski's diagram}

The creation of Czekanowski's diagram (Czekanowski, 1913) is one of the oldest taxonomic methods that allows to determine the relationships between objects and to visualize the relationships and similarities between them. The diagram is a visualization of the distance matrix between these objects. The objects most similar to each other are closest to the main 
diagonal of the distance matrix. The farther from the main diagonal the objects are less similar to each other (Jaskulski, Sołtysiak, 2004; Sołtysiak, Jaskulski, 1999).

The diagram is drawn according to the following stages (Heffner, Gibas, 2007):

- defining the data matrix,

- standardization or unitization of variables,

- selection of the measure of similarity,

- estimation of taxonomic distance matrices,

- determination of the minimum and maximum value in the taxonomic distance matrix,

- estimation of class intervals for taxonomic distances based on the determined empirical variability area,

- developing a disordered Czekanowski diagram,

- organizing Czekanowski's diagram,

- interpretation of obtained results.

Standardization of variables can be performed according to the formula (Dziechciarz, 2012):

$z_{i j}=\frac{x_{i j}-\bar{x}_{j}}{S_{j}}$,

where:

$z_{i j}$ - standardized variable $x_{j}$ for the $i$-th object,

$x_{i j}$ - variable $x_{j}$ for the $i$-th object,

$\bar{x}_{j}$ - arithmetic mean of the variable $x_{j}$,

$S_{j}$ - standard deviation of the variable $x_{j}$.

However, the similarity distance matrix is determined using the Euclidean metric.

\section{The empirical research}

The subject of the study were Polish voivodeships in 2010, 2019 and 2020. The study took into account over 17 thousand. enterprises from both the public sector (2010 - 1512 enterprises, 2019 - 1354 enterprises, 2020 - 1355 enterprises) and the private sector (2010 - 15707 enterprises, 2019 - 15650 enterprises, 2020 - 15764 enterprises). The data used in the analysis concerned the financial situation of all enterprises employing more than 49 people who are required to submit financial reports. The considered indicators describe the financial situation of enterprises in the analyzed voivodeships in a multilateral manner. The financial ratios were for the first half of 2010, 2019 and 2020. 
In the first stage of the research, a set of diagnostic variables was defined, eliminating the variables that are too strongly correlated with each other. Table 1 presents a set of diagnostic features taken into account in the study, taking into account the division into stimulants (S) and destimulants (D). The selection of the following measures resulted from the analysis of the factors determining the changes taking place. From among the 15 initially considered measures, due to the high degree of correlation with other variables, the following was abandoned: gross turnover profitability index, net turnover profitability index, short-term receivables, short-term investments, short-term liabilities, current assets, inventories.

\section{Table 1.}

The set of diagnostic features

\begin{tabular}{|l|l|c|}
\hline Symbol & Name & Stimulant/Destimulant \\
\hline X1 & Net profit [thou. PLN/company] & S \\
\hline X2 & Net loss [thou. PLN/enterprise] & D \\
\hline X3 & $\begin{array}{l}\text { Share of the number of enterprises with a net profit in the total number } \\
\text { of enterprises [\%] }\end{array}$ & $\mathrm{S}$ \\
\hline X4 & Cost level indicator [\%] & $\mathrm{D}$ \\
\hline X5 & Gross sales profitability indicator [\%] & $\mathrm{S}$ \\
\hline X6 & First degree financial liquidity indicator [\%] & $\mathrm{S}$ \\
\hline X7 & Second degree financial liquidity indicator [\%] & $\mathrm{S}$ \\
\hline
\end{tabular}

Then the destimulants were replaced with stimulants according to the formula (Lipieta et al., 2000):

$$
D \rightarrow S=x_{j, \max }-x_{j}
$$

In the next stage of the study, voivodeships were grouped in terms of the similarity of their financial situation of enterprises using the Czekanowski diagram. Czekanowski's diagrams for the tested objects are presented in Figs. 5-10. Individual lines and columns of the diagram correspond to the subsequent voivodeships. The larger the symbol at the intersection of the row and column, the greater the similarity of voivodships in terms of the examined features. The most similar objects are closest to the main diagonal, while the further from the main diagonal, the less similar objects in terms of the examined features.

On the basis of the diagrams created (Figs. 5-10), it can be seen that voivodships form groups of objects that are most similar to each other. However, it should be noted that in some cases the division is not clear and some voivodships can be assigned to two groups. 


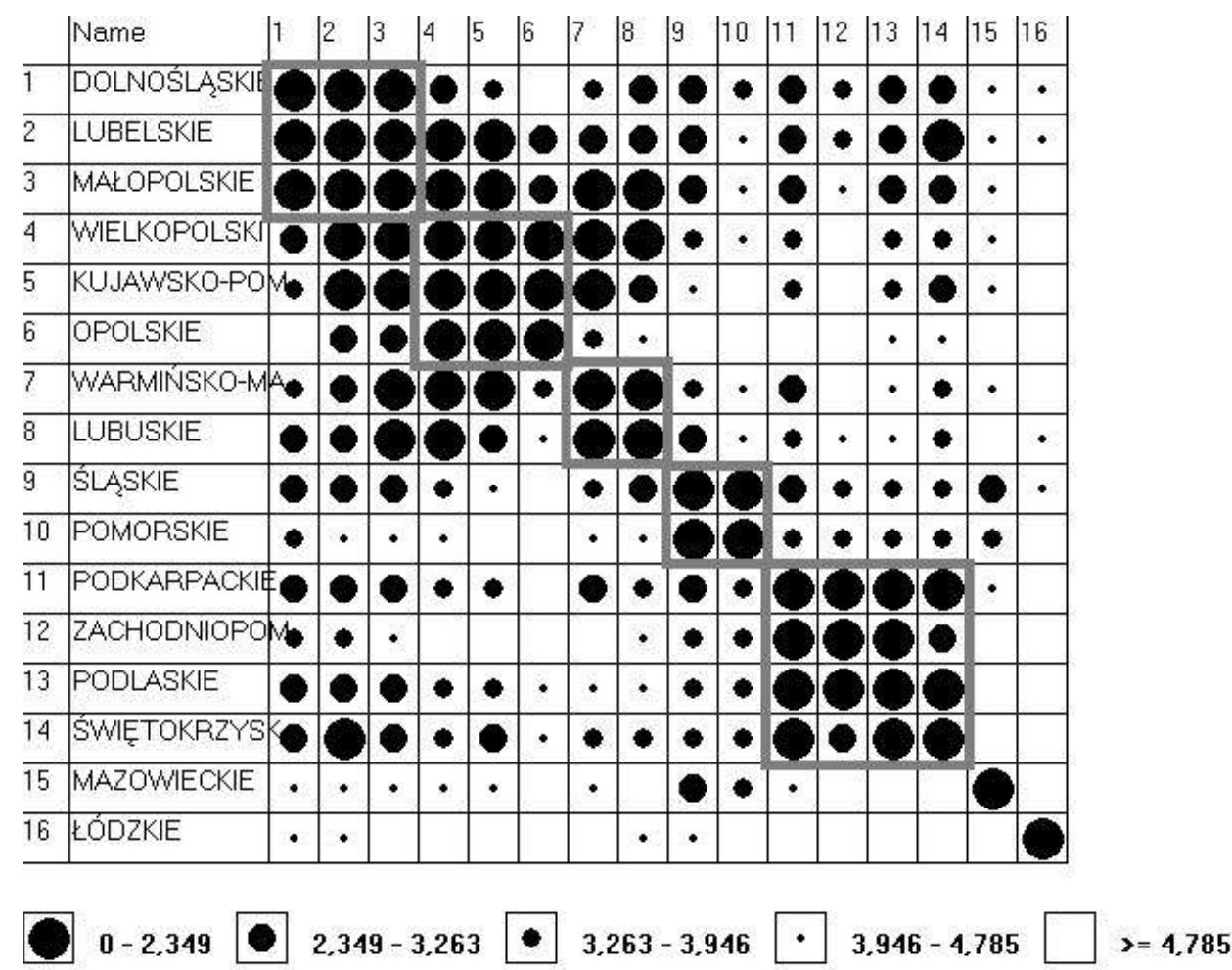

Figure 5. An orderly diagram of Czekanowski for public sector enterprises in 2010.

When analyzing the division of voivodships according to the financial situation of public sector enterprises in 2010 (Fig. 5), five groups of the most similar objects can be distinguished:

- group I: Dolnośląskie, Lubelskie, Małopolskie,

- group II: Wielkopolskie, Kujawsko-Pomorskie, Opolskie,

- group III: Warmińsko-Mazurskie, Lubuskie,

- group IV: Ślaskie, Pomorskie,

- group V: Podkarpackie, Zachodniopomorskie, Podlaskie, Świętokrzyskie.

Mazowieckie and Łódzkie voivodships do not form any groups.

The voivodships belonging to group I were characterized by the highest gross profitability ratio of public sector enterprises. The voivodeships in group II have achieved the highest 1 st and 2nd degree financial liquidity ratios with the lowest cost ratio for almost all voivodships. Group III consists of voivodships where enterprises achieved the lowest net losses with the highest share of the number of enterprises reporting net profit in the total number of enterprises. Group IV included voivodships with enterprises with the highest values: net profit and net loss. The voivodships from group $\mathrm{V}$ were characterized by the highest values of the cost level index with the lowest gross sales profitability index and the lowest share of the number of enterprises reporting net profit. 


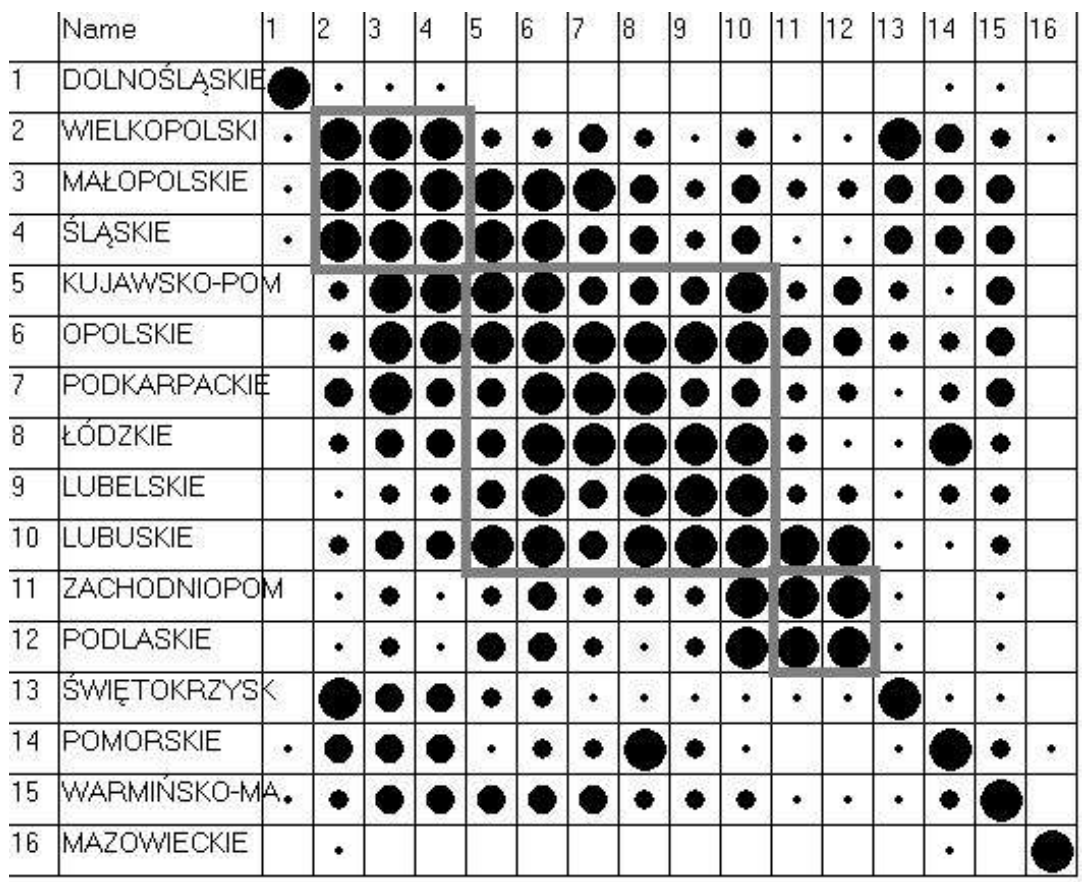

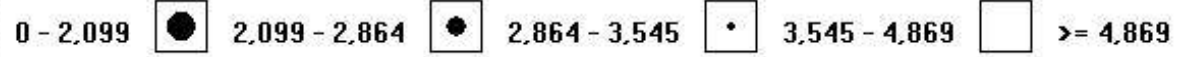

Figure 6. An orderly diagram of Czekanowski for private sector enterprises in 2010.

In the case of the private sector, in 2010 (Fig. 6), we can also distinguish three groups of the most similar voivodships in terms of the financial situation of enterprises. These are:

- group I: Wielkopolskie, Małopolskie, Śląskie,

- group II: Kujawsko-Pomorskie, Opolskie, Podkarpackie, Łódzkie, Lubelskie, Lubuskie,

- group III: Zachodniopomorskie, Podlaskie.

Dolnośląskie, Świętokrzyskie, Pomorskie, Warmińsko-Mazurskie and Mazowieckie voivodships do not form any groups.

In the private sector in 2010 , the voivodships belonging to group I were characterized by the highest level of net profit of enterprises and the highest share of the number of enterprises reporting a net profit in the total number of enterprises. Group II included voivodeships with the lowest share of the number of enterprises reporting a net profit in the total number of enterprises. On the other hand, the voivodships belonging to group III included those for which the cost level index was the highest with the lowest values: net profit, gross sales profitability index and 2nd degree financial liquidity index. 


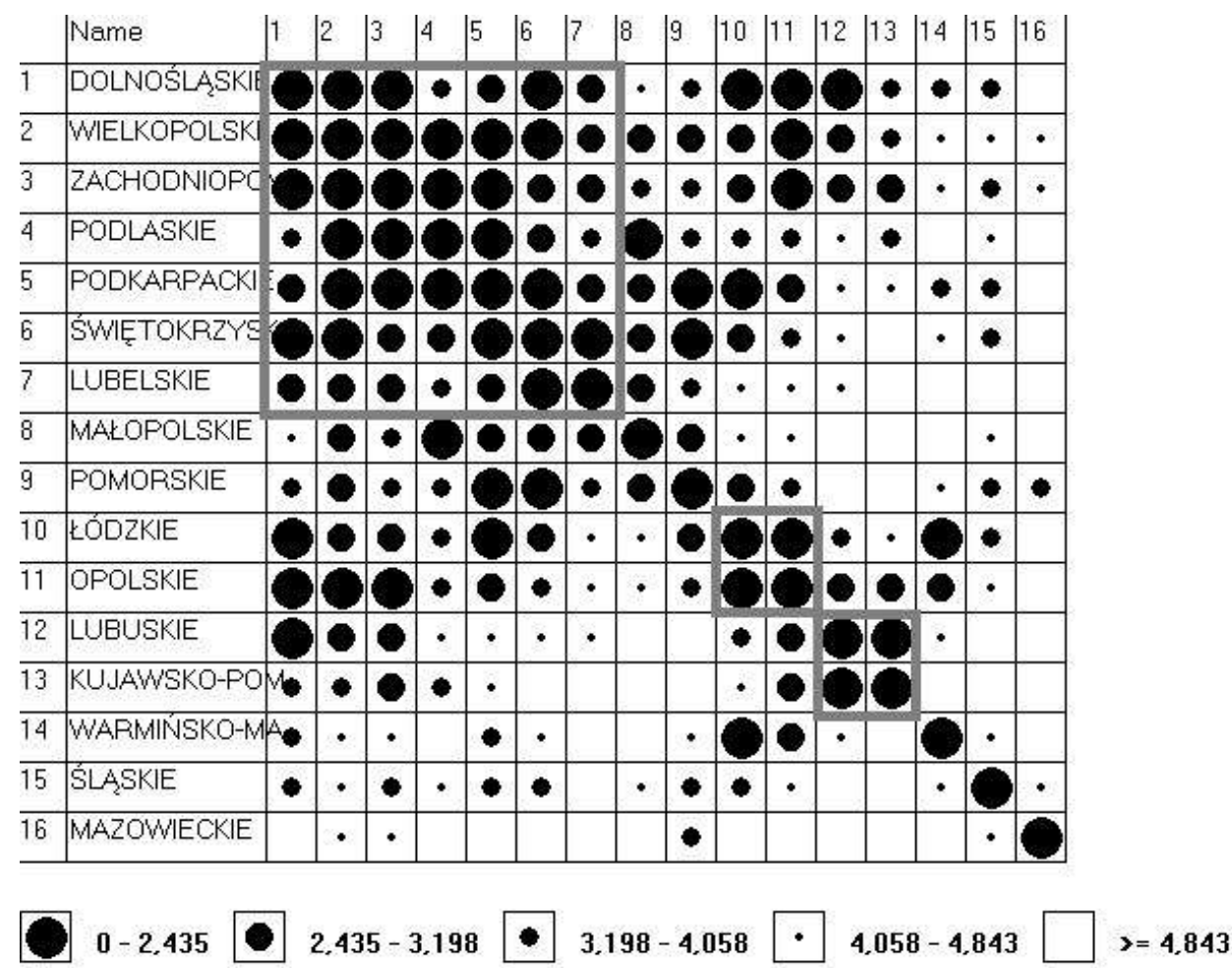

Figure 7. An orderly diagram of Czekanowski for public sector enterprises in 2019.

Based on the data contained in Figure 7, three groups of the most similar voivodeships were distinguished in terms of the financial situation of public sector enterprises in 2019. The following groups include, respectively:

- group I: Dolnośląskie, Wielkopolskie, Zachodniopomorskie, Podlaskie, Podkarpackie, Świętokrzyskie, Lubelskie,

- group II: Łódź, Opolskie,

- group III: Lubuskie, Kujawsko-Pomorskie.

The remaining Małopolskie, Pomorskie, Warmińsko-Mazurskie, Śląskie and Mazowieckie voivodships do not form any groups.

The voivodeships belonging to group I have the highest gross sales profitability ratio of public sector enterprises in 2019. with the lowest values of net loss and 2nd degree financial liquidity. The second group includes voivodeships for which the highest values achieved net profit and the cost level index, with the lowest values of the gross sales profitability index of enterprises. On the other hand, the voivodeships with the highest values of 1 st and 2 nd degree financial liquidity ratios belonged to group III. 


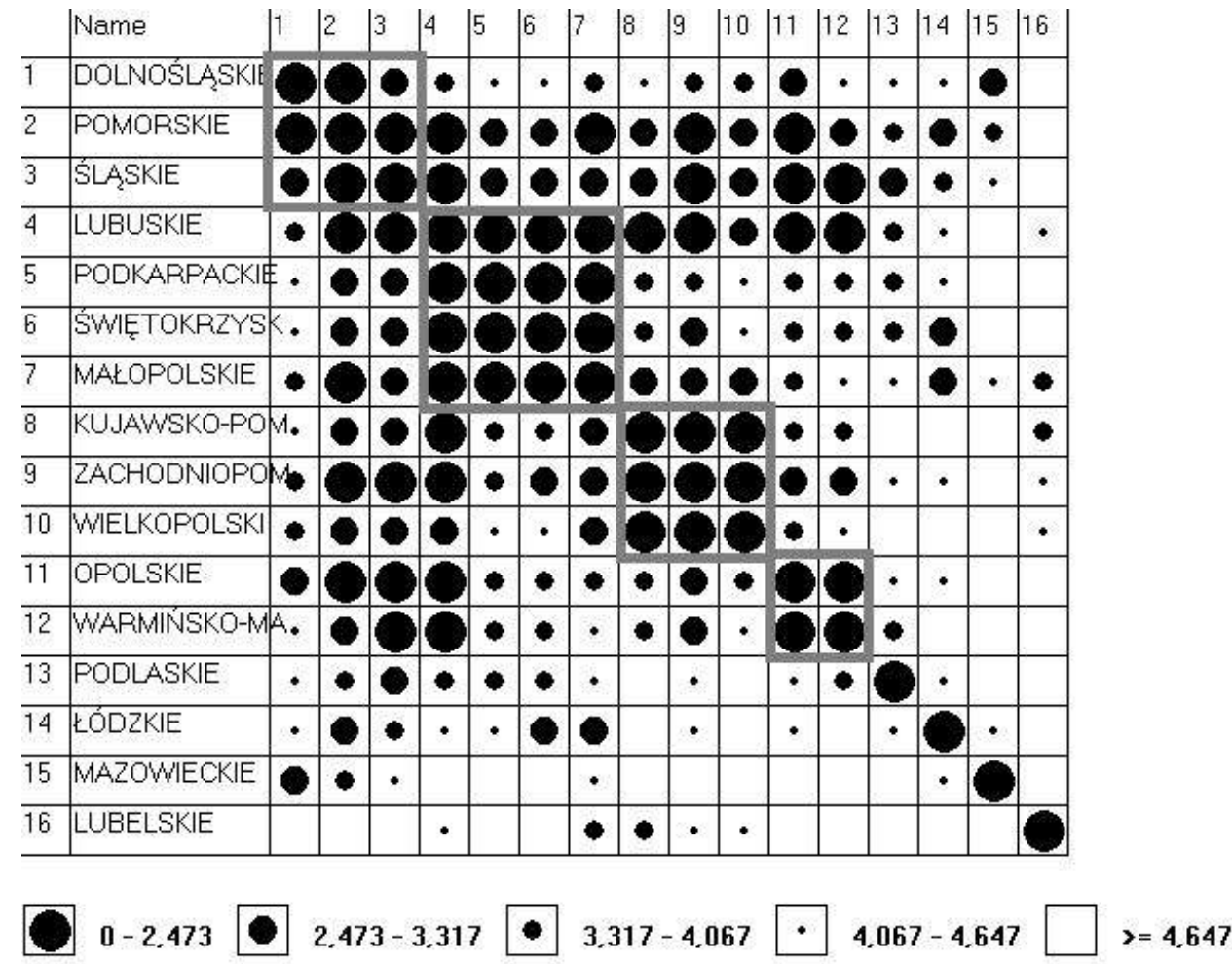

Figure 8. An orderly diagram of Czekanowski for private sector enterprises in 2019.

In the case of the private sector in 2019 (Fig. 8), four groups of the most similar voivodships can be distinguished in terms of the financial situation of enterprises. These are:

- group I: Dolnośląskie, Pomorskie, Śląskie,

- group II: Lubuskie, Podkarpackie, Świętokrzyskie, Małopolskie,

- group III: Kujawsko-pomorskie, Zachodniopomorskie, Wielkopolskie,

- group IV: Opolskie, Warmińsko-mazurskie.

As in the case of the public sector, the remaining voivodships do not form any groups.

When analyzing the private sector (Fig. 8), it can be seen that the voivodeships belonging to group I are characterized by the highest net loss of enterprises. The second group includes voivodeships for which enterprises achieved the highest values for the 1st and 2nd degree financial liquidity ratios and the lowest levels of net loss for almost all voivodships. The voivodeships belonging to group III are characterized by the highest values of gross sales profitability ratios with the lowest 2 nd degree financial liquidity ratios. On the other hand, group IV was made up of voivodships for which the share of the number of enterprises reporting net profit in the total number is the lowest. 


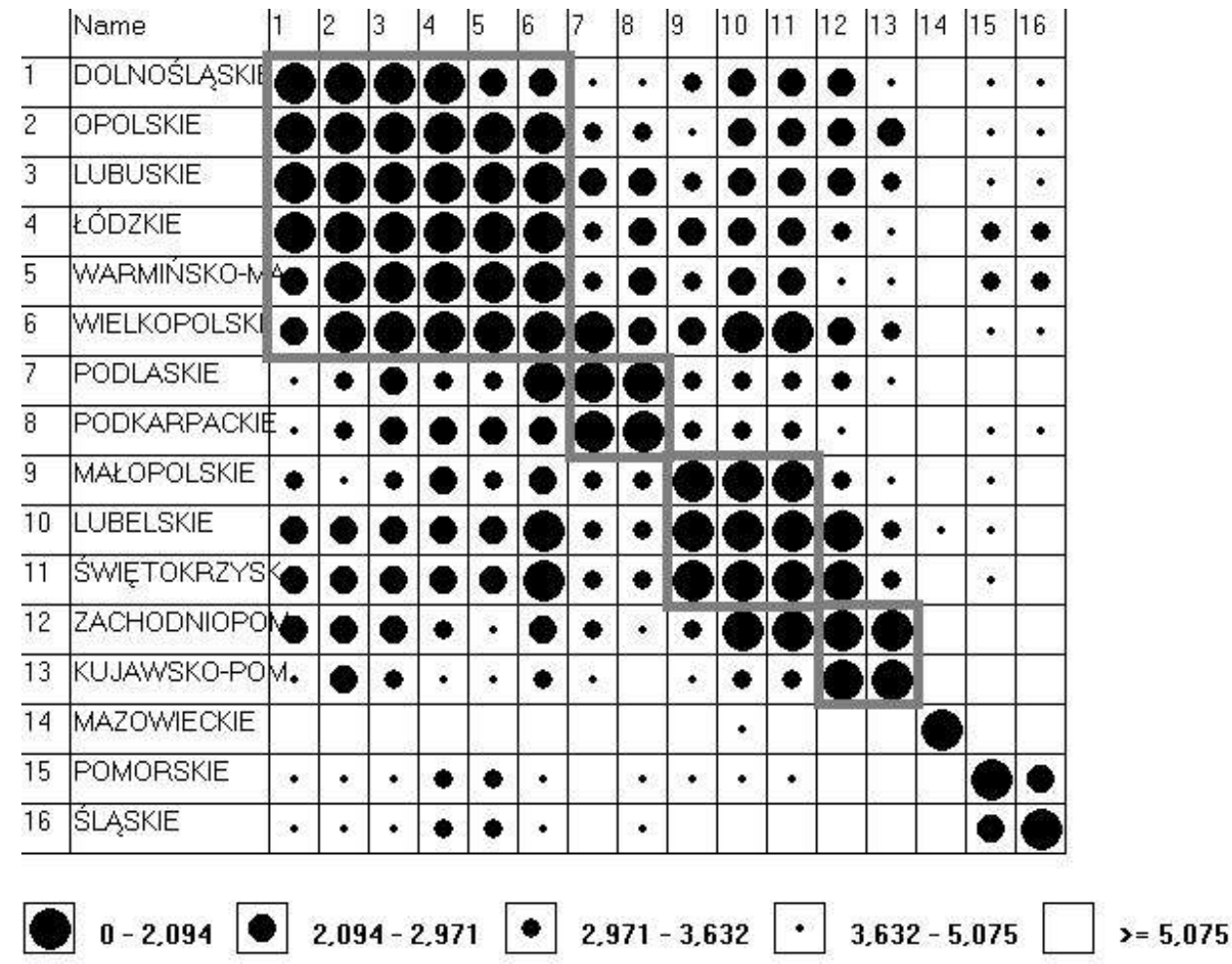

Figure 9. The orderly diagram of Czekanowski for public sector enterprises in 2020.

For public sector enterprises in 2020 (Fig. 9), four groups of the most similar voivodships can be distinguished:

- group I: Dolnośląskie, Opolskie, Lubuskie, Łódzkie, Warmińsko-Mazurskie, Wielkopolskie,

- group II: Podlaskie, Podkarpackie,

- group III: Małopolskie, Lubelskie, Świętokrzyskie,

- group IV: Zachodniopomorskie, Kujawsko-Pomorskie.

Mazowieckie, Pomorskie and Śląskie voivodships do not form any groups.

On the basis of the above diagram (Fig. 9) it can be seen that the voivodeships belonging to group I are characterized by the highest cost level index, with the lowest gross sales profitability index and the lowest net profit for almost all voivodships. The second group includes voivodships for which enterprises achieved the highest shares of the number of enterprises reporting net profit in the total number of enterprises, with the lowest values of net loss. The voivodeships belonging to group III are characterized by the highest values of gross sales profitability indexes with the lowest cost level indexes. On the other hand, group IV included voivodeships with the highest values of 1 st and 2 nd degree financial liquidity ratios. 


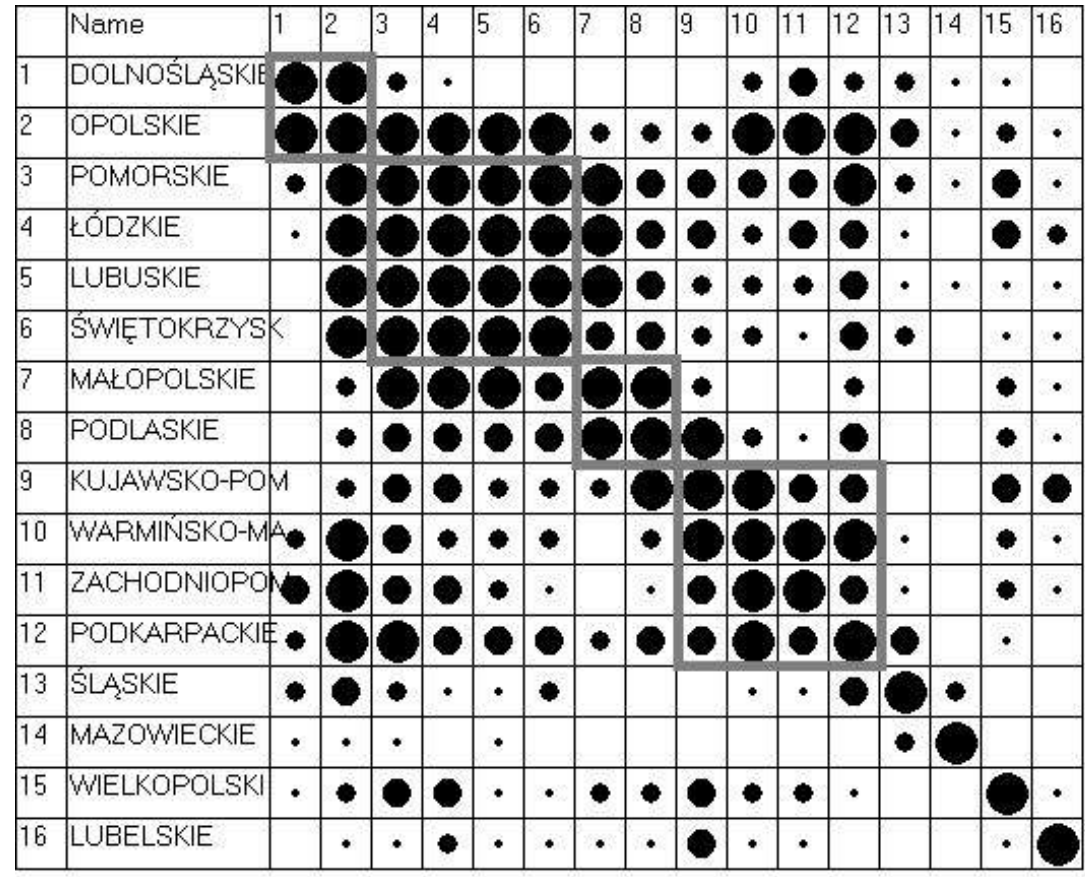

$0-2.71$

$2,71-3.193$

$3,193-3,873$

$3,873-4,674$

Figure 10. The orderly diagram of Czekanowski for private sector enterprises in 2020.

When analyzing the division of voivodships according to the financial situation of private sector enterprises in 2020 (Fig. 10), four groups of the most similar objects were distinguished:

- group I: Dolnośląskie, Opolskie,

- group II: Pomorskie, Lódzkie, Lubuskie, Świętokrzyskie,

- group III: Małopolskie, Podlaskie,

- group IV: Kujawsko-Pomorskie, Warmińsko-Mazurskie, Zachodniopomorskie, Podkarpackie.

The remaining Śląskie, Mazowieckie, Lubelskie and Wielkopolskie voivodships do not form any groups.

The voivodeships belonging to group I are characterized by the highest cost level ratio of private sector enterprises in 2020, with the lowest shares of the number of enterprises reporting net profit in the total number of enterprises. The second group includes voivodeships with enterprises with the highest value of 1 st and 2 nd degree financial liquidity ratios. Group III includes voivodeships for which enterprises achieved 2 nd degree financial liquidity ratios. However, the voivodeships with the lowest net profit belonged to group IV.

When analyzing the diagrams concerning public sector enterprises (Fig. 5, 7, 9), it can be noticed that voivodships changed their affiliation to similarity groups. The exception is Dolnośląskie, which in each of the analyzed periods was in the first group, and Mazowieckie, which never belonged to any group. Podkarpackie and Podlaskie voivodships are very similar in terms of the financial situation of enterprises in the public sector throughout the entire period. 
The remaining voivodships in each of the analyzed periods showed similarities to different voivodships.

For the private sector (Fig. 6, 8, 10) it can also be noticed that voivodships changed their affiliation to similarity groups. A great similarity between voivodships in terms of the financial situation of enterprises, which persisted throughout all the analyzed years, was noted in Lubuskie, Łódzkie and Świętokrzyskie.

Comparing diagrams 5 and 6 , it can be noticed that in 2010, both for the public sector and the private sector, almost all voivodeships were assigned to different groups due to the financial situation of enterprises. The exception is Kujawsko-Pomorskie and Opolskie, which are very similar in terms of the financial situation of enterprises both for the public sector and the private sector. In 2019, such a strong similarity between the financial situation of public and private sector enterprises was noted for the Podkarpackie and Świętokrzyskie voivodships. In 2020, however, we can observe such a similarity for the Dolnośląskie and Opolskie regions as well as for the Kujawsko-pomorskie and Zachodniopomorskie regions.

\section{Conclusion}

In the analyzed period, among the voivodships of Poland, several groups of similar voivodships can be distinguished in terms of the financial situation of enterprises. When analyzing the financial results of public sector enterprises, such groups include Podkarpackie and Podlaskie, which belong to the so-called the eastern wall and are relatively close geographically.

For the private sector, such a group consists of the Lubuskie, Łódzkie and Świętokrzyskie voivodships. The Łódzkie and Świętokrzyskie voivodeships are neighbour to each other, and the Lubuskie voivodship is quite close geographically to the Łódzkie.

In all considered cases, the Mazowieckie Voivodeship differs from the rest of the voivodships in terms of the financial situation of enterprises. It is not similar in terms of the considered features for both public and private sector enterprises.

When analyzing the financial results of non-financial enterprises in the selected period, it can be noticed that the disproportions between the western and eastern parts of the country are slowly blurring. For the public sector, the financial situation of enterprises in the Lubelskie is similar to the financial situation of enterprises from the western and central voivodeships of the country. However, the Podkarpackie and Podlaskie voivodeships still stand out from the rest, with the lowest financial results of enterprises in the public sector. On the other hand, for the private sector, the distance between the voivodships of eastern Poland and other voivodships is decreasing The exceptions are the Mazowieckie and Wielkopolskie Voivodeships, which are in the best situation in the private sector in terms of financial results. 
The financial indicators of enterprises for the first half of 2020 show the impact of the pandemic on the financial situation of enterprises in the first half of 2020. Despite one of the highest values of net profit in 2020, the value of net loss achieved by public sector enterprises is several times higher than in previous years. Private sector enterprises are in a similar situation, in 2020 the net loss is several times higher than in previous years, with one of the highest net profit values.

\section{References}

1. Czekaj, J., Dresler, Z. (2005). Zarzadzanie finansami przedsiębiorstw. Podstawy teorii. Warszawa: PWN.

2. Czekanowski, J. (1913). Zarys metod statystycznych w zastosowaniu do antropologii. Prace Naukowego Towarzystwa Warszawskiego, 5. Warszawa.

3. Dziechciarz, J. (2012). Ekonometria. Metody, przykłady, zadania. WUE, Wrocław.

4. Hamrol, M. (2013). Niedoceniane aspekty badania sprawozdania finansowego przedsiębiorstwa. Finanse, Rynki Finansowe, Ubezpieczenia, nr 59, pp. 123-132.

5. Heffner, K., Gibas, P. (2007). Analiza ekonomiczno-przestrzenna. Katowice: WUE.

6. http://www.antropologia.uw.edu.pl/MaCzek/maczek.html, 20.09.2020.

7. Jaskulski, P., Sołtysiak, A. (2004). Diagram Czekanowskiego: pomysł, historia, zastosowania. Prace Naukowe AE we Wroctawiu. Taksonomia, t. 11, nr. 1022. Klasyfikacja $i$ analiza danych - teoria i zastosowania, pp. 374-383.

8. Kolegowicz, K., Krzemiński, P. (2019). The influence of financial condition on investment decisions in enterprises in Poland. Scentific Paper of Silesian University of Technology, Organization and Management Series, No. 136, pp. 243-255.

9. Lipieta, A., Malina, A., Papież, M., Pawełek, B., Wanat, S., Zeliaś, A. (2000). Taksonomiczna analiza przestrzennego zróżnicowania poziomu życia $w$ Polsce $w$ ujęciu dynamicznym. Kraków: AE.

10. Malina, A. (2020). Analiza przestrzennego zróżnicowania poziomu rozwoju społecznogospodarczego województw Polski w latach 2005-2017. Nierówności Społeczne a Wzrost Gospodarczy, $n r$ 61(1/2020), pp. 138-155.

11. Michoń, D. (2017). Zróżnicowanie rozwoju społeczno-gospodarczego województw ze względu na realizację celów polityki spójności. Wiadomości Statystyczne, No. 12(679), pp. 80-94.

12. Sołtysiak, A., Jaskulski, P. (1999). Czekanowski's Diagram. A Method of Multidimensional Clustering. New Techniques for Old Times. CAA 98. Computer Applications and Quantitative Methods in Archaeology. Proceedings of the 26th 
Conference, Barcelona, March 1998, J.A. Barceló, I. Briz, A. Vila (eds.). BAR International Series, 757. Oxford, pp. 175-184.

13. Szymańska, A., Jegers, M. (2014). The Structure of Capital and Revenue in Social Enterprises. Ekonomia Społeczna, No. 1, pp. 51-68.

14. Wędzki, D. (2009), Analiza finansowa sprawozdania finansowego. Tom 1. Sprawozdanie finansowe. Kraków: Wolters Kluwer Polska. 



\title{
MEDIATION AS AN INNOVATIVE DISPUTE RESOLUTION TOOL BASED ON THE EXAMPLE OF PUBLIC ORGANIZATIONS
}

\author{
Elżbieta PAWŁOWSKA ${ }^{1 *}$, Paweł WITKOWSKI ${ }^{2}$, Paulina TRYBUS $^{3}$ \\ ${ }^{1}$ Silesian University of Technology, Faculty of Organization and Management, Institute of Management, \\ Administration and Logistics; elzbieta.pawlowska@polsl.pl, ORCID: 0000-0001-6863-5430 \\ ${ }^{2}$ Silesian University of Technology, Faculty of Organization and Management, Institute of Management, \\ Administration and Logistics; paweł.witkowski@polsl.pl, ORCID: 0000-0001-9158-9751 \\ ${ }^{3}$ University of Silesia, Faculty of Law and Administration; paulina.hanisz@gmail.com, \\ ORCID: 0000-0002-9386-278X \\ * Correspondence author
}

Purpose: The objective of this article is to identify the context of developing mediation in public administration and also to demonstrate its role in problem-solving in that area. On those grounds, the authors attempted at answering the study question: Is the mediation tool widely used in the public administration area and does it facilitate dispute resolution?

Design/methodology/approach: To look for evidence enabling to answer the study question, the case study method was used as it was appropriate for the analysis of qualitative phenomena (Grzegorczyk, 2015). Case study enables to formulate conclusions concerning the causes and results of the actual studied phenomenon course. The study undertaken by the Authors is an individual case study where the authors used various techniques and tools for data collection and analysis, i.e. participant observation, document analysis and Internet sources.

Findings: Currently, a growing number of proceedings in administration bodies and administrative courts can be observed, but the role of mediation in their resolution is still negligible. An undoubted problem of the administrative mediation is the absence of trust of the public administration bodies, courts and the general public in this conflict resolution form. This is why it is necessary to introduce legislative amendments, educate in this area and promote it.

Originality/value: The presented analysis is important as it indicates the role of administrative mediation and the importance of its popularization.

Keywords: administrative mediations, settlement, conflict.

Category of the paper: research paper. 


\section{Introduction}

Public organizations were created to provide services for the society. This means their basic function is to satisfy collective public needs using public resources and services. As emphasized by B. Kożuch, a public organization is a complex whole with features characteristic of all organizations, but with a specific system of objectives and values. Moreover, it is distinguished by a peculiar internal bond and specific relations with the external environment (Kożuch, 2004). Cooperation of the public organizations with the broadly-taken environment and also shaping the appropriate relations is difficult, as some of them are governed by the applicable legal system, while the other are of a versatile and multi-dimensional nature and depend on the actual or prospective stakeholders, and also on changing forms of cooperation (Sojkin, 2018). Any disputable matters between them may refer both to the conflict of interests between the parties and to the conflict of social interest and the party's interest (Mediacja..., 2019).

Mediation may constitute an innovative approach to solving the emerging disputes. This tool has not been used so far in the administrative practice. According to the definition, broadly taken innovations are valuable, innovative ideas (Krawczyk, 2012). It should be stressed that innovativeness is no longer characteristic solely of the private sector, but innovations are more and more appreciated in the public sector, though they are not well studied (Innovations in the public sector in the European Union states). Importantly, mediations may take the burden off the administrative bodies and courts, minimize the costs of administrative and court proceedings, and also contribute to speeding them up. Mediation is employed not only for the disputable interests of the parties, but also when there is a negotiation standstill, compensation or deadlock (Sołtysiak, 2012). Using the mediation tool in the public sphere is an alternative to the formalized and domineering proceedings. Mediation in the public administration reduces the risk of initiating the review or court and administrative proceedings by the dissatisfied party. A key component of using mediation as the dispute resolution method in the administrative proceedings is the significant simplification of the procedure course. What is more, the administrative settlement shortens the proceedings. This is why it is important to indicate the role of mediation in the resolution of disputes concerning the public sector and everyday problems of citizens and to verify if this tool contributes to the faster dispute resolution and satisfaction of the parties. 


\section{Mediation as the dispute resolution tool}

Mediation is a voluntary, confidential and non-formalized out-of-court procedure enabling to reach a settlement and issue an administrative decision or court order accepted by the parties to the dispute. It enables to go beyond a purely legal conflict resolution which is not always satisfactory. Reference works contain numerous definitions of mediation which are not identical. This results e.g. from the fact that this problem is dealt with by many authors from various sectors. The table below presents selected definitions of mediation proposed by different authors.

Table 1.

Mediation definitions

\begin{tabular}{|c|c|}
\hline Author & Definition \\
\hline M. Tabernacka & $\begin{array}{l}\text { "Mediation is a process aimed at reaching a settlement both with respect to the } \\
\text { dispute, and also in the deadlock or standstill during negotiations. Mediation may } \\
\text { contribute also to establishing contacts between the parties" (Tabernacka, 2009). }\end{array}$ \\
\hline D. Peters & $\begin{array}{l}\text { "Mediation can be understood as assisted negotiations, while the latter constitute the } \\
\text { most popular procedure in building legal relations and resolving disputes" } \\
\text { (Pieckowski, 2015). }\end{array}$ \\
\hline E. Jastrzębska & $\begin{array}{l}\text { "Mediation is an amicable dispute resolution method. It appeared relatively recently } \\
\text { in the Polish law. The potential of this procedural instrument has not been used fully. } \\
\text { At present, a case may be sent to mediation in all the most important } \\
\text { court proceedings types, including civil, family, business, administrative and related } \\
\text { to the minors. This method was first used in criminal proceedings" } \\
\text { (http://www.stowarzyszeniefidesetratio.pl/kwartalnik.html). }\end{array}$ \\
\hline $\begin{array}{l}\text { Directive of the } \\
\text { European Parliament } \\
\text { and of the Council }\end{array}$ & $\begin{array}{l}\text { "Mediation means a structured process, however named or referred to, whereby two } \\
\text { or more parties to a dispute attempt by themselves, on a voluntary basis, to reach } \\
\text { an agreement on the settlement of their dispute with the assistance of a mediator. } \\
\text { This process may be initiated by the parties or suggested or ordered by a court or } \\
\text { prescribed by the law of a Member State. It includes mediation conducted by a judge } \\
\text { who is not responsible for any judicial proceedings concerning the dispute in } \\
\text { question. It excludes attempts made by the court or the judge seised to settle a dispute } \\
\text { in the course of judicial proceedings concerning the dispute in question" (Directive } \\
\text { of the European Parliament and of the Council } 2008 / 52 / E C, 2008 \text { ). }\end{array}$ \\
\hline E. Bieńkowska & $\begin{array}{l}\text { "Mediation is an attempt at reaching an amicable resolution of a criminal conflict, } \\
\text { satisfactory for both parties, by means of voluntary negotiations with the } \\
\text { participation of a third party, neutral towards the parties and their conflict, } \\
\text { i.e. the mediator who supports the course of the negotiations, mitigates any emerging } \\
\text { tension and helps, without imposing any solution related to the developed settlement" } \\
\text { (Bieńkowska, 2011). }\end{array}$ \\
\hline P. Sołtysiak & $\begin{array}{l}\text { "Mediation is an amicable procedure when a third party attempts at the reconciliation } \\
\text { of the parties' standings, mitigating the tension between them and creating conditions } \\
\text { to find a solution acceptable for everyone" (http://dlibra.bg.ajd.czest.pl:8080/ } \\
\text { Content/1549/Gubernaculum_02_6-9.pdf). }\end{array}$ \\
\hline W. Kopaliński & $\begin{array}{l}\text { "Mediation is an intermediation in the dispute to reach an agreement" (Morgała, } \\
\text { 2014). }\end{array}$ \\
\hline $\begin{array}{l}\text { K. Bargiel- } \\
\text { Matusiewicz }\end{array}$ & $\begin{array}{l}\text { "Mediation (from Latin mediatio) is a voluntary and confidential process of reaching } \\
\text { the dispute resolution, carried out in the presence of a neutral person, or the mediator" } \\
\text { (Bargiel-Matusiewicz, 2014). }\end{array}$ \\
\hline $\begin{array}{l}\text { Słownik języka } \\
\text { polskiego (Polish } \\
\text { dictionary) }\end{array}$ & $\begin{array}{l}\text { "Mediation is the help in dispute resolution to facilitate reaching the settlement by } \\
\text { the parties" (https://sjp.pwn.pl/). }\end{array}$ \\
\hline
\end{tabular}

Source: own work. 
Based on the above list of mediation definitions, it can be inferred the mediation process participants are the conflicted parties and also an impartial mediator who is neutral vis-a-vis them and the dispute subject. According to A. Cisek, the source of mediation is the dispute which the parties want to resolve and thus ask a third party, neutral towards the process participants. This third party is to support them when reaching a voluntary settlement which will be satisfactory for the parties to the dispute (Binsztok, 2015). Consequently, a factor required to start the mediation process is the existence of a conflict between the parties and for the mediation procedure to take place it is necessary to ensure the presence of a third party, namely a mediator.

\section{Mediation in administrative procedure}

On 1 June 2017, the Act of 7 April 2017 amending the Code of Administrative Procedure and some other acts (Journal of Laws 2017, item 935.) introduced regulations amending the said code (The Act of 14 June 1960 Code of Administrative Procedure, i.e. of 20 December 2019, Journal of Laws 2020, item 256 as amended, hereinafter CAP) and bringing provisions on the mediation instrument in the administrative procedure domain.

The new regulations enable to carry out mediation in the course of the administrative procedure. It adds provisions concerning the rules of the administrative procedure and introducing the concept of the tacit resolution. The provisions concerning mediation (Article 96a-96n) introduced in the CAP are included in chapter 5a, called "Mediation".

The new provisions are introduced to reduce the duration of a given case, facilitate the procedure and reduce the number of cassation decisions and promote citizens' trust towards the public authorities. Mediation is of a transformatory nature and becomes a factor shaping the administration culture (Kocot-Łaszczyca et al., 2018). Mediation in the administrative procedure may be carried out at the request of a party or ex officio. A prerequisite for mediation is the participants' consent for it. It is, first and foremost, a measure which is to enable to consider and explain factual and legal circumstances. Mediation may result in the adoption of arrangements concerning the case resolution by the participants which, in turn, may result in reaching the settlement or issuing a decision considering the said arrangements (Kmiecik, 2019).

Two mediation types can be distinguished, i.e. horizontal mediations with the dispute between at least two parties, and vertical mediations with the dispute between one or more parties and the administration body. 
According to Article 96a CAP, mediation may be carried out whenever the case nature allows. Mediation participants may be the body running the procedure and one or more parties to the procedure. Mediation introduced to the administrative procedure is used also in cases when:

- there are multiple parties,

- it is possible to reach the settlement,

- a legal remedy was brought against the decision issued in the first instance,

- competences are exercised when they are acknowledged by the administration body,

- there is some preliminary problem (the need to agree the decision wording with another administration body),

- the body intends to issue a decision detrimental for the addressee and may expect an appeal.

The introduced amendments to the Code of Administrative Procedure extended and modified Article 13 thereof which contains the rule that the public administration bodies in cases the nature of which allows that - strive to resolve any disputes amicably and determine the rights and obligations being the subject of the procedure in cases within their competence, including but not limited to by the following actions:

1) inducing parties to reach a settlement in cases where the participants have disputable interests;

2) required to carry out mediation.

They are also obliged to undertake any activities reasonable at a given stage of the procedure which enable to carry out mediation or reach a settlement, including but not limited to providing explanation on the possibilities and benefits of the amicable case resolution.

The mediation principle in the above-mentioned Article of the Code does not include limitations concerning the multiple parties to the procedure and does not indicate the existence of the disputable interests of those parties as a prerequisite. Particular attention is deserved by the fact that the prerequisite for initiating mediation is the existence of disputable matters and not of the disputable interests of the parties. Disputable matters are the aspects where the procedure participants do not share the same opinion. Those aspects, however, are important for the determination of the rights and obligations of the participants of a given case. If mediation results in any arrangements concerning case resolution within the applicable law, the administration body is obliged to resolve it according to such arrangements (if no settlement is reached).

It should be stressed also that before the said amendments were introduced (before 1 June 2017) there were no provisions in the administrative law which would refer to carrying out mediation within the administrative procedure. There was solely a regulation enabling the parties with disputable interest to reach the administrative settlement. 
A certain exception was Article 47(2) of the Act of 13 October 1995 Hunting Law (At present, i.e. as at 20 December 2019, Journal of Laws 2020, item 67 as amended). The above provision stated, by 29 June 2027, that when there is a dispute between the owner or holder of land and the lessee or administrator of the hunting district concerning the value of the compensation for losses, the parties could contact the communal body competent based on the loss location for mediation to reach the amicable dispute resolution. However, that was not an administrative, but a civil dispute. The provision provided for the transfer of competences to carry out mediation to the communal bodies. A body competent to carry out mediation in this respect was a voit, mayor or president of the town/city, or another authorized body. At present, the resolution of such disputes is governed in detail in the Hunting Law. The decision-making competences in this respect are held e.g. by the forest manager, and this procedure in any non-regulated aspects is subject to the provisions of the Code of Administrative Procedure, including in relation to mediation.

A similar situation took place when carrying out mediations before the voivodeship inspector of the Trade Inspection. Until 9 January 2017, mediation in this respect was carried out pursuant to Article 36 of the Act of 15 December 2000 on the Trade Inspection (Consolidated text of 19 July 2019, Journal of Laws 2019, item 1668 as amended) which was in force at that time, and the forms of cooperation in the mediation process were determined by $\S 2$ of the Regulation of the Council of Ministers of 5 March 2002 on the method of cooperation of the Trade Inspection bodies with the poviat (municipal) ombudsman for consumers' affairs, government and local government administration bodies, inspection bodies and nongovernmental organizations representing the consumers' interests. The mediation between a consumer and an entrepreneur was to promote the social sense of the legal transaction security and, consequently, contribute to the development of the civic society idea. Reaching the dispute resolution by the parties themselves in the course of mediation improves their relations permanently.

Currently, the Act on the Trade Inspection states that if this is supported by the nature of the case, the voivodeship inspector initiates measures aimed at the out-of-court resolution of the civil law dispute between a consumer and an entrepreneur by means of:

1) promoting the reconciliation of both parties' standings to resolve the dispute by the parties thereto or

2) presenting a proposed dispute resolution to the parties.

The Trade Inspection as the public administration body is authorized to carry out procedures related to the out-of-court resolution of consumer disputes.

In the recent legislative activity, the legislator tries to differentiate between the administrative law and civil law disputes. The new regulations introduced to the Code of Administrative procedure as at 1 June 2017 enable to carry out mediation procedure in administrative law proceedings. They determine the subjective and objective scope and the course of mediation. It seems that amending CAP the legislators indicated the direction and 
operation method of the modern public administration which is less domineering and more amicable.

\section{Public organization characteristics}

Identifying public organizations, it is important to define the term "administration" first to understand the origin of the public organizations in a broader context. In the most general approach, administration is any organized activity aimed at achieving specific objectives. It is a permanent, purposeful and planned activity (Ochendowski, 2013). Administration can be understood also as the governing activity of the authorities carried out pursuant to the acts to satisfy the collective and individual needs of the citizens (Zimmerman, 2008). It means identified activity structured formally, organizationally and in terms of competences (Hausner, 2005). To ensure it is fully an organizational activity, it should be carried out by a bureaucratic system, comprising a broad range of problems of social significance, and should be governed appropriately in the general legal standards (Hausner, 2005). Currently, the public administration in European states has an organizational, enforcement and operational function. To perform such functions, more and more extended structures are created, i.e. the public administration system (Hausner, 2005).

Public administration provides public services which may be analyzed in a narrow and a broader sense. Public services in the narrow sense are connected directly with the public goods category. In the broader sense, on the other hand, they cover the whole range of services which are provided in the public interest and which the state can have influence on by its financial or organizational instruments. This comprises services performed directly by the public administration and also by other entities which the public authorities are responsible for (System monitorowania..., 2019, p. 8). Considering the public tasks in those two aspects, it is possible to distinguish tasks satisfying directly repeatable, typical social needs in the narrow approach. However, in the broad approach those may be tasks satisfying all the needs, even the indirect ones (Noworól, 2016).

As mentioned above, public services are provided e.g. by public organizations acting in the public interest in line with the social and political criteria. They constitute an open system, are subject to external influences and their paramount task is to react to the society needs and to satisfy them on the best level possible (Sternal, 2004). The subject of the public organizations' operations is very broad and versatile. Examples of the areas dealt with by the public sector organizations include activities ensuring the sovereignty of the country and legal order, activities protecting the ownership and freedoms of individuals, tasks concerning land management, infrastructure management, environment protection, health care, education, culture, sports, social services or administrative services (Kożuch, 2007). The objectives of 
public organizations are complex, often not defined clearly, and sometimes even non-viable as they need to meet many different requirements at the same time. The objectives are a peculiar link between the interested parties, top managers and employees of the organization (Hatch, 2002).

The most important properties of public organizations include (Kożuch, 2004):

- creation by people or by founding members,

- combination of the basic creative factor, i.e. people, with the material, technical and property measures,

- purpose orientation (implementation of individual and collective objectives of the participants and the ones stipulated in the founding act, pursuit of the social mission),

- having an internal structure, i.e. the set of organizational rules, work distribution,

- having a common management body (coordinating control system created to plan, organize, check and motivate),

- deliberate conduct (the ability to determine and possibly change the objectives and the methods to achieve them independently),

- equifinality (the ability to achieve the same end objectives with different initial conditions and different resources),

- the ability to consolidate the activity patterns (creating conditions promoting institutionalization, i.e. the identification in space, economy, law and formalizing the objectives and functions) (Golinowski, 2005),

- cooperation with the surrounding environment in terms of exchanging any goods, information,

- $\quad$ self-organization ability, i.e. increasing the capacity.

Based thereon, it can be stated the public nature is an essential attribute of public organizations.

Comparing public organizations to non-public ones, it can be noticed the former have a more formalized nature than the private-sector ones (this is connected with the inability to take a risk and with the decision-making process where highly formalized procedures are present). The decision-making process is based on the legal regulations and all conduct of a public organization employees is described by legal standards (Golinowski, 2005). Public sector organizations have values and missions targeted towards the public good and satisfaction of the public interest. Public organizations, contrary to the commercial ones, are responsible towards the citizens using the provided goods or services as they affect the quality of human life directly by providing them. The public institution responsibility is determined by the legal regulations (Kożuch, 2004). This specific system of values and the social mission fulfilled are the key value of public organizations. 


\section{Mediation in public administration - case study}

For the study, one of the qualitative scientific research methods was selected, i.e. a case study. The case study is empirical reasoning concerning the phenomenon in its natural context, particularly when the boundary between the case and its context cannot be drawn beyond any doubt (Yin, 2013). Case study is deemed to be an attractive problem-solving method in reference works. Here, the qualitative studies ensure empirical, in depth insight in the structure of the case of the administrative body's inactivity. In the studies described, the study question was formulated as follows: is the mediation tool widely used in the public administration area and does it facilitate dispute resolution?

The research process started from the analysis of the cases connected with mediation carried out in public organizations in the Voivodeship Administrative Court in Gliwice which was selected on purpose. The studies enable to claim that only one case connected with administrative mediations was examined in the years 2015-2019 in the Silesian Voivodeship (Judgment of the provincial administrative court in Gliwice, reference number IV SAB/G1 111/15, 2015). This case was related to the administration body inactivity. See its outline below.

Legal counsel A. B., acting in the name of the Nursing Home for Adults in B, in a communication of 5 February 2015, applied for disclosing public information to the Emergency Medical Services in K. In the said application, he applied for providing information if the entity has a procedure concerning the rules of transporting patients with an ambulance, including the "S" type one. If such a procedure existed, its disclosure was requested, and if no such a procedure was developed, a request was made to get a written explanation of the rules in force for transporting patients with an ambulance, including in the " $\mathrm{S}$ " type one, and to name the people who carried out the intervention on 3 January 2015 and 28 January 2015 in the Nursing Home for Adults, hereinafter referred to as the NHA, in B. Next, in a communication dated 10 August 2015, the legal counsel acting in the name of the NHA in B, lodged a complaint with the Voivodeship Administrative Court in Gliwice, concerning the inactivity of the Director of the Emergency Medical Services in K., requesting to have the application for disclosing the public information investigated, stating such an inactivity took place with a gross violation of the applicable law and having the legal costs reimbursed. In that complaint, it was stressed an application to have the public information disclosed was made on 5 February 2015 and the information was not received by the time when the complaint was made.

In response to the complaint, the Director of the Emergency Medical Services in K. applied for the mediation proceedings in this case.

The representative of the NHA in B. considered this proposal unacceptable and stressed it was a Court task at that stage to decide if the administrative body stays inactive, but the Voivodeship Administrative Court in Gliwice appointed the mediation meeting and obliged the parties to the proceedings to send their representatives authorized to make declarations of intent 
to that meeting. On the appointed date, the representative of the Emergency Medical Services in K. came with a relevant Power of Attorney, while the representative of the complainant came with no relevant Power of Attorney and thus the proceedings could not take place. The case was sent for the investigation in a simplified procedure. The Voivodeship Administrative Court in Gliwice checked the legality of activities undertaken by the public administration body which revealed the criteria for considering the lodged complaint concerning the administrative body's inactivity were fulfilled in principle.

After the detailed analysis of all the administrative files submitted was completed, the adjudication panel in the said case decided this inactivity did not take place with a gross violation of the law.

The Voivodeship Administrative Court in Gliwice, having examined, in a simplified procedure on 4 November 2015, the case resulting from the complaint of the Nursing Home for Adults in B. concerning the inactivity of the Director of the Voivodeship Emergency Medical Services in K. with respect to disclosing public information:

1) obliged the Director of the Voivodeship Emergency Medical Services in K. to investigate the application of the complainant within 14 days after the files were submitted;

2) decided the body's inactivity did not take place with the gross violation of the law;

3) decided the Director of the Voivodeship Emergency Medical Services in K. should pay the amount of PLN [...] to reimburse the costs of the court procedure.

The court expressed also its disapproval of the conduct of the Nursing Home representative as they displayed poor knowledge of legal regulations and no respect for the Court in this procedure.

Poor knowledge of legal regulations was evidenced when the complaint was lodged with the administrative court as the professional representative should know such a complaint is to be placed by the agency of the administration body. What is more, the representative in their communication presented arguments against mediation which ignored the wording of the Law of procedure in administrative courts and the possibility to carry out mediation ex officio provided in them.

The disrespect for the Court was proved by directing a representative to the mediation meeting with no relevant empowerment to make binding declarations of intent in the complainant's name, though both parties were instructed in that aspect.

The court expressed a view that the mediation procedure was conducted at the body's request and did not lead to a settlement due to the absence of the Power of Attorney to make declarations of intent by one party. Consequently, the case was sent to the examination in a simplified procedure and a decision considering the complaint was issued.

Based on the analysis carried out, it may be claimed the mediation tool in the public administration and administrative court area is not popular, as corroborated by the number of cases sent for mediation by the court in the Silesian Voivodeship. Answering the question if using the mediation tool in dispute resolution contributes to their faster completion, it can be 
declared with full confidence this is the case when mediation is effected. This is evidenced by shorter duration of the mediation procedure when compared to the time when the court meeting, hearing is appointed and when possible cassation proceedings take place in the Supreme Administrative Court.

\section{Conclusions and recommendations}

Administrative mediations are an innovative dispute resolution tool which stands a chance of gaining popularity in the public sector. It enables to develop a settlement fast and efficiently with relatively small resources used for that purpose. At present, mediation is used successfully in other areas of law, i.e. mediation in business law, civil law, employee affairs, and also family or criminal law. In those areas, mediation is used in the whole territory of Poland and this form of procedures is more and more popular.

In the public sector, the introduction of new provisions to the Code of Administrative Procedure governs mediation in the area of law and administrative procedure so this instrument needs not be governed in other acts where the conflict between parties to the administrative procedure or between a party and the body took place. It can be declared new regulations in the administrative law area make it possible to use the mediation instrument in public organizations where the body may both initiate and participate in the mediation. An important success factor when using this tool is the absence of any adverse consequences brought about by terminating the mediation by its participants. Moreover, the mediation procedure is a less expensive alternative to the court proceedings.

Unfortunately, mediation is not highly popular yet in administrative procedures and in administrative court proceedings. At present, in the analyzed period, mediation proceedings were carried out only once in the Silesian Voivodeship by the Voivodeship Administrative Court in Gliwice, but this may change thanks to the widely advocated idea of dealing with any disputes and such a way of dispute resolution means no domineering measures are required towards the citizens.

To make this institution popular in the public institutions sector, it would be important to introduce exemption from the mediation procedure costs to the CAP provisions. Such a possibility exists in the court procedure, but CAP has not provided for exemption from the costs in the mediation proceedings. Also, the public administrative bodies' orientation toward promoting the mediation instrument to increase the awareness of both the society and the public institution employees in this respect is important.

To conclude, mediation is an innovative tool with numerous advantages. This solution is undoubtedly a beneficial alternative particularly to court proceedings resulting from appeals against administrative decisions. As the public administration has only recently received legal 
grounds to employ mediation in administrative procedure, mediation is not fully used yet. It should be stated that thanks to its positive aspects, mediation is likely to become a broadly used tool in the future.

\section{References}

1. Bargiel-Matusiewicz, K. (2014). Negocjacje i Mediacje. Warsaw: PWE, 95.

2. Bieńkowska, E. (2011). Mediacja w sprawach karnych, Mediacje w Polskim Systemie Prawa. Warsaw: Ministry of Justice, 4.

3. Binsztok, A. (2015). Mediacje gospodarcze. Wrocław: Wydawnictwo MARINA, p. 26.

4. Consolidated text of 19 July 2019, Journal of Laws 2019, item 1668 as amended.

5. Directive of the European Parliament and of the Council 2008/52/EC of 21 May 2008 on certain aspects of mediation in civil and commercial matters. Official Journal EU L (2008).

6. Golinowski, J. (2005). Dylematy wizerunku instytucji publicznej. Warsaw: Aspra, 78-86.

7. Grzegorczyk, W. (2015). Studium przypadku jako metoda badawcza i dydaktyczna $\mathrm{w}$ naukach o zarządzaniu. In: Wybrane problemy zarządzania $i$ finansów. Studia przypadków. Łódź: Wydawnictwo Uniwersytetu Łódzkiego, 9-16.

8. Hatch, M.J. (2002). Teoria organizacji. Warsaw: PWN, 129-131.

9. Hausner, J. (2005). Administracja publiczna. Warsaw: PWN, 13-25.

10. http://dlibra.bg.ajd.czest.pl:8080/Content/1549/Gubernaculum_02_6-9.pdf, 20.06.2018.

11. http://www.stowarzyszeniefidesetratio.pl/kwartalnik.html, 20.06.2018.

12. https://sjp.pwn.pl/, 20.06.2018.

13. Journal of Laws (2017). Item 935.

14. Journal of Laws (2020). At present, i.e. as at 20 December 2019, item 67 as amended.

15. Judgment of the provincial administrative court in Gliwice, reference number IV SAB/G1 111/15, 2015. Retrieved from http://orzeczenia.nsa.gov.pl, 07.07.2020.

16. Kmiecik, Z.R. (2019). Postępowanie administracyjne, postępowanie egzekucyjne w administracji i postepowanie sadowoadministracyjne. Warsaw: Wolters Kluwer Polska, 161.

17. Kocot-Łaszczyca, A., and Łaszczyca, G. (2018). Mediacja w ogólnym postępowaniu administracyjnym, Warsaw: Wolters Kluwer Polska, 15-16.

18. Kożuch, B. (2004). Zarzadzanie publiczne. W teorii i praktyce polskich organizacji. Warsaw: Placet, 83-99.

19. Kożuch, B. (2007). Nauka o organizacji. Warsaw: CeDeWu, 79.

20. Krawczyk, M. (2012). Finansowanie działalności. For more information on the definition of innovation and innovativeness. Finansowanie działalności innowacyjnej MSP. Łódź: UŁ, 52. 
21. Mediacja w postępowaniu administracyjnym. Podręcznik dla pracowników administracji publicznej przygotowany we wspótpracy Ministerstwa Przedsiębiorczości i Technologii z Centrum Mediacji Gospodarczej przy Krajowej Izbie Radców Prawnych (2019). Retrieved from www.gov.pl/web/rozwoj/mediacja-w-postepowaniu-administracyjnym, 07.07.2020, 4 .

22. Morgała, S. (2014). Mediacja - nowa przestrzeń zarządzania konfliktem wyzwania, strategie, rozwiazania. Warsaw: Faculty of Law and Administration of the University of Warsaw, 98.

23. Noworól, A. (2016). Obszary zarządzania publicznego. Cracow: Monografie i Studia Instytutu Spraw Publicznych Uniwersytetu Jagiellońskiego, 27.

24. Ochendowski, E. (2013). Administracja publiczna. Torun: Towarzystwo Naukowe Organizacji i Kierowania, 21-203.

25. Pieckowski, S. (2015). Mediacje gospodarcze. Warsaw: Difin, 27-28.

26. Sojkin, B., and Michalak, S. (2018). Kształtowanie relacji i ich wartości dla interesariuszy przez instytucje naukowo-badawcza, no. 27, iss. 1, 40.

27. Sołtysiak, P. (2012). Mediacja jako alternatywna metoda rozwiązywania sporów. Zeszyty Naukowe Instytutu Administracji Akademii im. Jana Dtugosza w Czestochowie, no. 2(6), Częstochowa: Gubernaculum et Administratio, 28.

28. Sternal, M. (2004). Sektor prywatny, sektor publiczny. Zarzadzanie w kulturze, no. 5, 57.

29. System monitorowania usług publicznych. Koncepcja wykonawcza (2019).

30. Tabernacka, M. (2009). Negocjacje i mediacje w sferze publicznej. Warsaw: Oficyna a Wolters Kulwer business, 29-30.

31. The Act of 14 June 1960 Code of Administrative Procedure, i.e. of 20 December 2019, Journal of Laws (2020), item 256 as amended, hereinafter CAP.

32. Yin, R.K. (2013). Case study research: Design and methods. Sage publications, 10.

33. Zimmerman, J. (2008). Prawo administracyjne. Warsaw: Oficyna a Wolters Kluwer business, 25-29. 



\title{
IMPACT COVID-19 PANDEMIC ON IMPLEMENTATION INDUSTRY 4.0 IN ENTERPRISES AND SUPPLY CHAINS
}

\author{
Iwona PISZ
}

The University of Opole, Faculty of Economics, Institute of Management and Quality Sciences; ipisz@uni.opole.pl, ORCID: 0000-0001-6079-3178

\begin{abstract}
Purpose: The aim of this study is to discuss the impact COVID-19 pandemic on implementation 4.0 technologies in enterprises and supply chains.

Design/methodology/approach: The study performs review of literature to identify key aspects of Industry 4.0, the COVID-19 pandemic in the economy.

Findings: The paper explained the changes in the functioning of enterprises and supply chains and their transformation towards Industry 4.0. The authors defined the impact of the COVID-19 pandemic in the context of applying technology trends of the Industry 4.0 by enterprises and supply chains. We claim that in the enterprises and supply chains will be the need to invest in new technologies for the long term and implement new infrastructures. The COVID-19 pandemic is likely to help us push the accelerator pedal on Industry 4.0 in the industries, especially manufacturing industry.

Originality/value: The study is one of the analysis of the relationships between enterprises and supply chains in the framework of Industry 4.0 and the aspects the COVID-19 pandemic in creating value chain. The study can be addressed to project managers and supply chains managers responded for implementation technologies of Industry 4.0.
\end{abstract}

Keywords: Industry 4.0, COVID-19 pandemic, digitalization, enterprise, industry, management, supply chain.

Category of the paper: research paper.

\section{Introduction}

As we can see, nowadays changes in the global world are becoming faster and more unpredictable. Enterprises, especially small and medium sized enterprises have to react very quickly to challenges and opportunities of the business world. The industries, including the automotive industry, manufacturing industry, are being pummeled by the COVID-19 pandemic at a time when it already has enough challenges to deal with in the form of digital transformation as a consequent of the Industry 4.0 concept. 
On the one hand the world is gripped by the Covid-19 pandemic since December 2019 in China and since February in Europe and the rest of the world. The global economy will take a massive hit from the impact of the COVID-19 pandemic this year and the next years. The COVID-19 pandemic is hitting many enterprises and supply chains, harder than the 2008 financial crisis. We can suppose that it will take longer to recover from the losses they sustain. The economic slump will affect all regions and countries. Every manufacturer is impacted by this crisis in some way and for many this poses an existential threat. The industries in Europe and in the United States will be hit even harder than in China. In those countries we expect the weeks of lockdown and the further measures to protect the health of the population to cause GDP to plummet by 5.2\% (Europe) and 5.4\% (USA) in 2020. Although we do expect the global economy to grow again in 2021, even in China, Europe and the United States, this growth will not be sufficient to offset the losses of 2020 (Roland Berger, 2020).

Table 1.

COVID-19: some industries impacted similarly to the global financial crisis

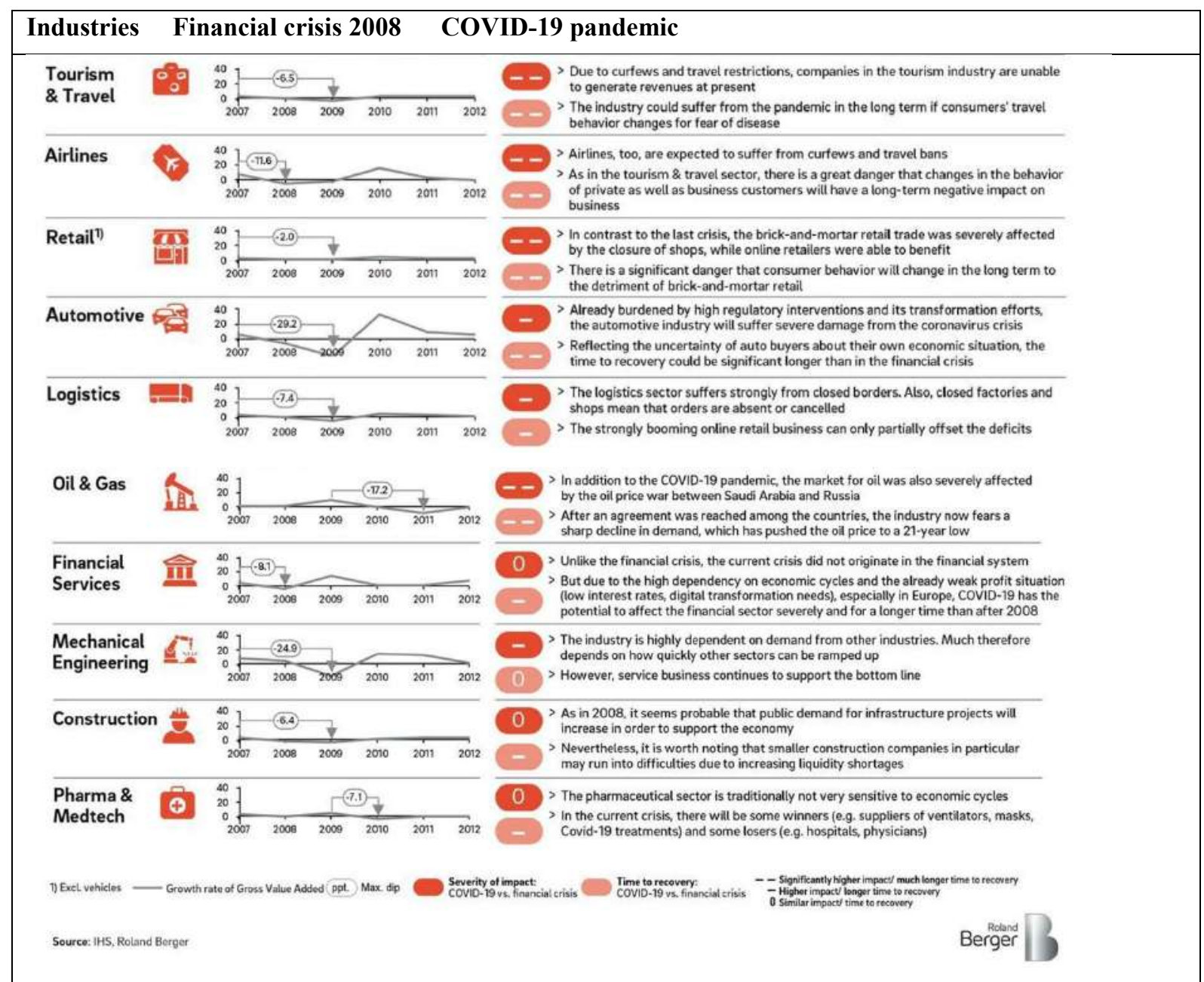

Adapted from: "Latest update of our corona economic impact series" by Roland Berger, 2020. 
On the other hand the 4.0 concept is becoming more and more popular nowadays (Kumar et al., 2019) in manufacturing practice. The appearance of the Fourth Industry Revolution is a consequence of the dynamically changing business environment and constantly growing customer requirements. Currently, flexibility and response to changing market needs in real time are becoming increasingly important. This is why enterprises strive to adapt production processes in such a way that it is possible to produce individualized products at a time when there is a real demand for them. Industry 4.0 opens up new opportunities for creating added value for the customer and stimulating technological and process innovation, which allows for increased competitiveness.

Prior to the crisis generated by COVID-19 pandemic, Industry 4.0 was an area of great interest to many manufacturers in the world, especially in Europe. It was an exciting topic with huge potential benefits and was widely regarded as a 'positive' and future thinking topic. Today, many of enterprises, especially manufacturing enterprises are focused on the here and now because of the COVID-19 pandemic. Some manufacturers have ceased production completely, some have seen greatly reduced demand and others have seen a huge increase in demand. Additionally, we can observed that the global supply chains are experiencing a level of disruption that has never been seen before. The focus for many manufacturers now is survival first and foremost and beyond that, damage limitation.

We consider following problem: given is a manufacturing enterprise and its supply chain, which is focused on implementation the concept of Industry 4.0 prior to the crisis generate by the COVID-19 pandemic. The key business drivers of Industry 4.0 prior to the crisis were focused on competitive advantage, cost reduction, productivity, sustainability and innovation. We are looking an answer for the following question: does the enterprise engagement in implementation the concept of Industry 4.0 change because of the COVID-19 pandemic? Can the Covid-19 pandemic accelerate implementation the concept Industry 4.0?

\section{Literature review}

Industry 4.0 describes the increasing digitization of the entire value chain and the resulting interconnection of people, objects and systems through real time data exchange. The 4.0 concept is a result of some processes, for example: internationalization, information technology development and also hyper competition. Dynamic development of manufacturing Industry 4.0 is observed since 2011, when the main idea of Industry 4.0 was published for the first time (Kagermann et al., 2011). In the same year it became a strategic initiative of the German government and was included in the "High-Tech Strategy 2020 Action Plan". In the literature, the term Industry 4.0 is often referred to as the Fourth Industrial Revolution (Kagermann et al., 2013) (Figure 1). Additionally, in the literature we can found such terms: 
"factories of the future", "smart factory", "intelligent manufacturing" (in Europe), "Industrial Internet" (in USA) and "Internet+" (in China) (Mrugalska, and Wyrwicka, 2017).

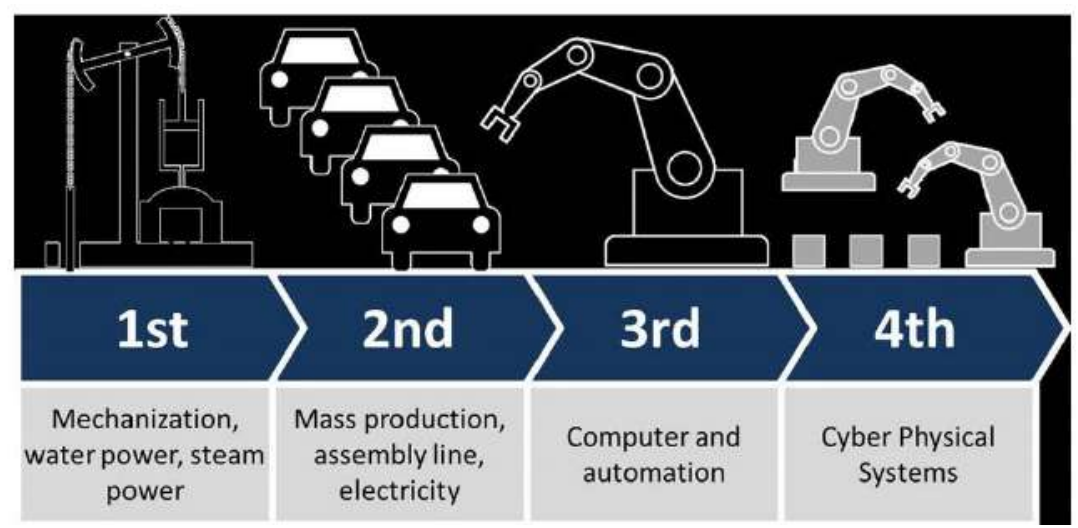

Figure 1. The four major industrial stages. Adapted from: "Examining COVID-19's Impact on Industry 4.0. Is Coronavirus Triggering Industry 5.0?" by C. McMahon. Copyright 2020 by KEYPOINT INTELLIGENCE.

The growing interest in the concept of Industry 4.0 has resulted in the growing number of papers and reports dedicated to this concept. Industry 4.0 was a top priority for many organizations, research centers and universities before the financial crisis. The majority of experts in the academia believe that the Industry 4.0 term itself is unclear, and manufacturing firms are facing difficulties when it comes to understanding this phenomenon, and identifying the steps required for the transition toward Industry 4.0. Based on the systematic review of Industry 4.0 literature we can state that a number of definitions are being created, but none has yet been established as the generally accepted one. Some scholars such as Gilchrist (2016), Liao et al. (2017), Santos et al. (2017), Ustundag and Cevikcan (2017) and Vogel-Heuser and Hess (2016) believe that Industry 4.0 can be defined based on its design principles and technology trends. One of the definition presented in the literature based on design principles and technology trends of Industry 4.0 is proposed by Ghobakhloo (2018). He defines Industry 4.0 as an integrative system of value creation that is comprised of 12 design principles and 14 technology trends (Figure 2).

The concept of Industry 4.0 (or Smart Industry) has become its element. This revolution is connected with the following three phenomena (Paprocki, 2016):

- universal digitization and ensuring constant communication between people, people with devices, and devices among themselves,

- increasing the implemented innovations of subversive character (disruptive innovations), allowing for a stepwise increase in the efficiency of the socioeconomic system,

- the development of machines capable of autonomous functioning through the use of artificial intelligence. 


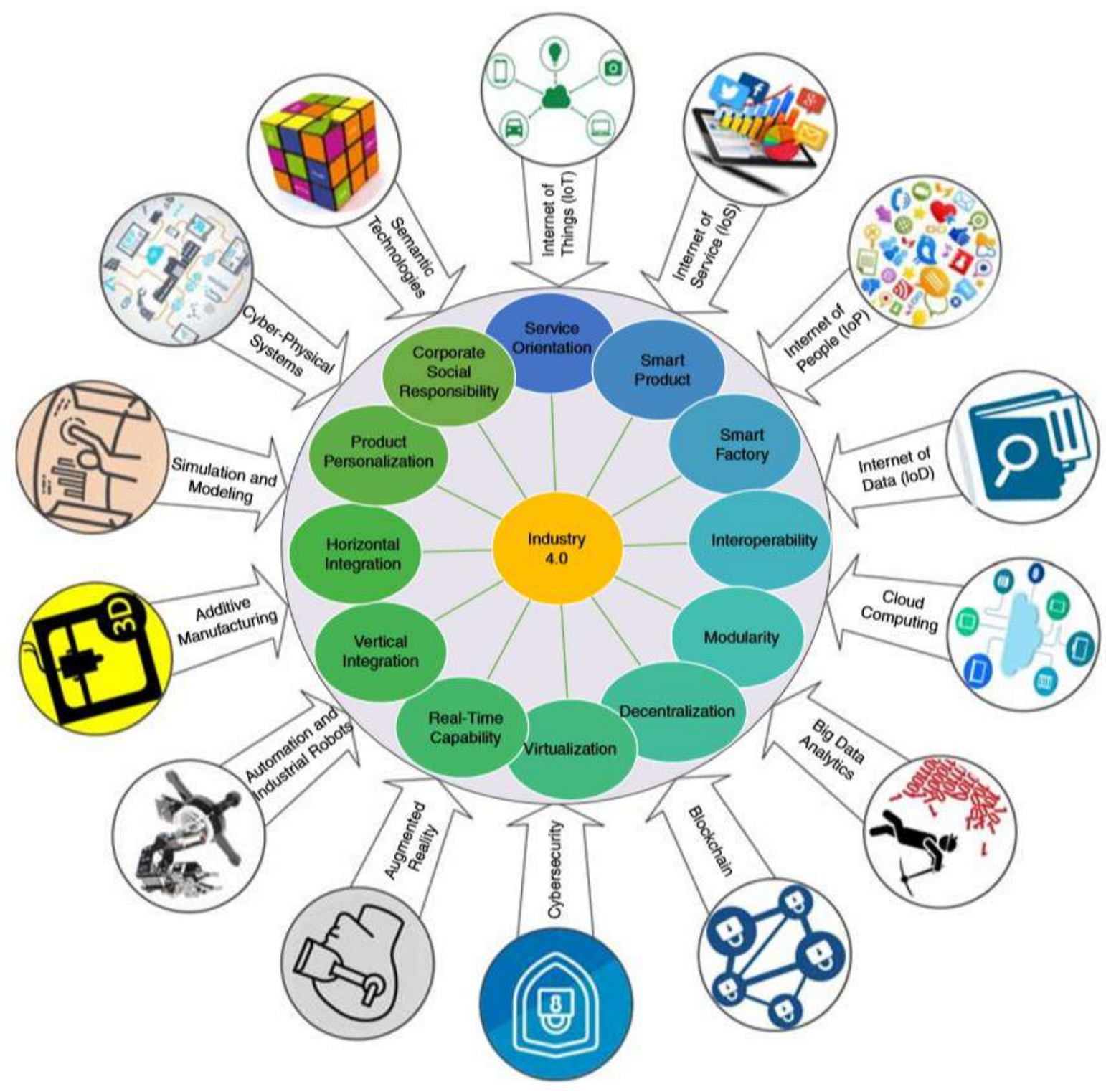

Figure 2. Key design principles and technology trends of Industry 4.0. Adapted from: "The future of manufacturing industry: a strategic roadmap toward Industry 4.0" by M. Ghobakhloo. Copyright 2018 by Emerald.

The concept of Industry 4.0 means the connection of production machines in the real world with the virtual world of the Internet and information technology. People, machines, and IT systems automatically exchange information during the course of production - within the factory and within various IT systems operating in an enterprise. Industry 4.0 covers the entire value chain: from ordering and delivering components for on-going production to shipping goods to customers and after-sales services (Figure 3 ).

The concept of Industry 4.0 is presented as an emerging structure in which manufacturing and logistics systems in the form of a Cyber-Physical Production System (CPPS) intensively use the globally available information and communications network for an extensively automated exchange of information and in which the production and business processes are matched (Bahrin et al., 2016; Lars, 2016). In production management, Industry 4.0 is very responsive and adaptive to customer demands. Fulfilling individual customer needs is the main 
objective of Industry 4.0 (Neugebauer et al., 2016). The need for Industry 4.0 in production management is to convert regular machines to self-aware and self-learning machines to improve their overall performance and maintenance management with the surrounding interaction (Lee et al., 2014). The significant efficiency of Industry 4.0 can be obtained mainly through the consequent digital integration and intelligentization of manufacturing processes (Zhou, 2013). As we know, integration needs to take place on the horizontal axis (across all participants in the entire value-chain) and on the vertical axis (across all organizational levels). Fully integrated and networked factories, machines, and products then need to act in intelligent and partly autonomous ways that require minimal manual interventions. By converting the analog data in Industry 4.0 into digital data, the information available in this productivity chain can be used by all players from any location and at any time. On this basis, production and sales processes can be optimized.

Enterprises have two pathways ahead of Industry 4.0 in the area of production management (i.e., users of Industry 4.0 or providers of Industry 4.0). Users are those who primitively try to implement CPS-based solutions in various departments, whereas providers are the ones who provide these solutions to other companies (Kagermann, 2013).

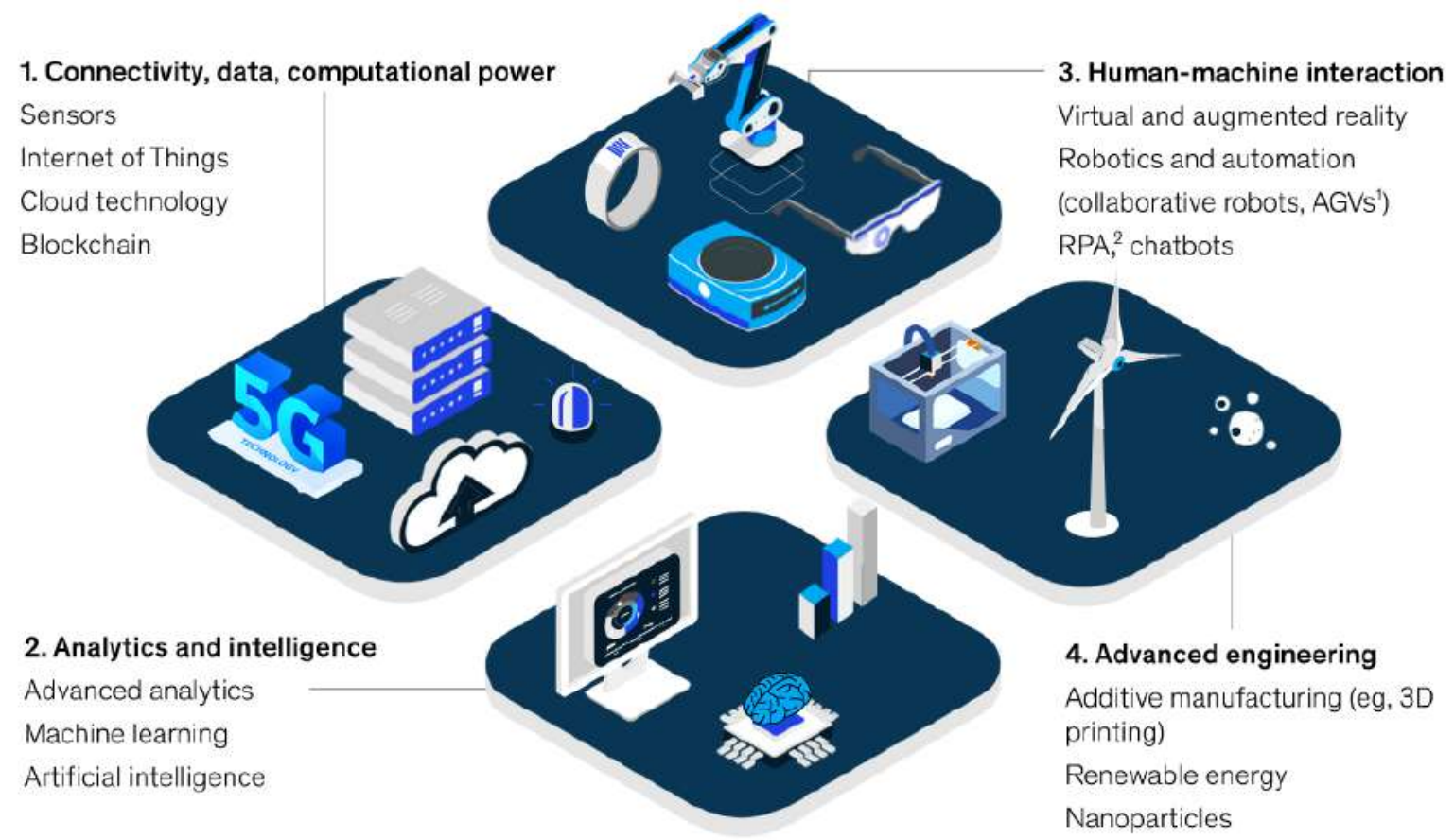

Figure 3. The core technologies of the Industry 4.0. Adopted from: "Industry 4.0: Reimagining manufacturing operations after COVID-19" by Agrawal M., Eloot K., Mancini M., Patel A., Copyright 2020 by McKinsey. 


\section{The coronovirus COVID-19 versus The Industry 4.0}

As it was mentioned, the initial outbreak of coronavirus COVID-19 appeared in China in the end of 2019 year. However, the outbreak has grown into a global pandemic and has cut global supply chains. On March 11, 2020, the World Health Organization formally declared COVID-19 a pandemic, underscoring the precipitous global uncertainty that had plunged lives and livelihoods into a still-unfolding crisis (McKinsey, 2020). Currently worldwide confirmed 33137748 cases and 998372 deaths (Coronavirus COVID-19 Global Cases by the Center for Systems Science and Engineering (CSSE) at Johns Hopkins University (JHU)). The coronavirus COVID-19 is affecting 213 countries and territories around the world (Figure 4).

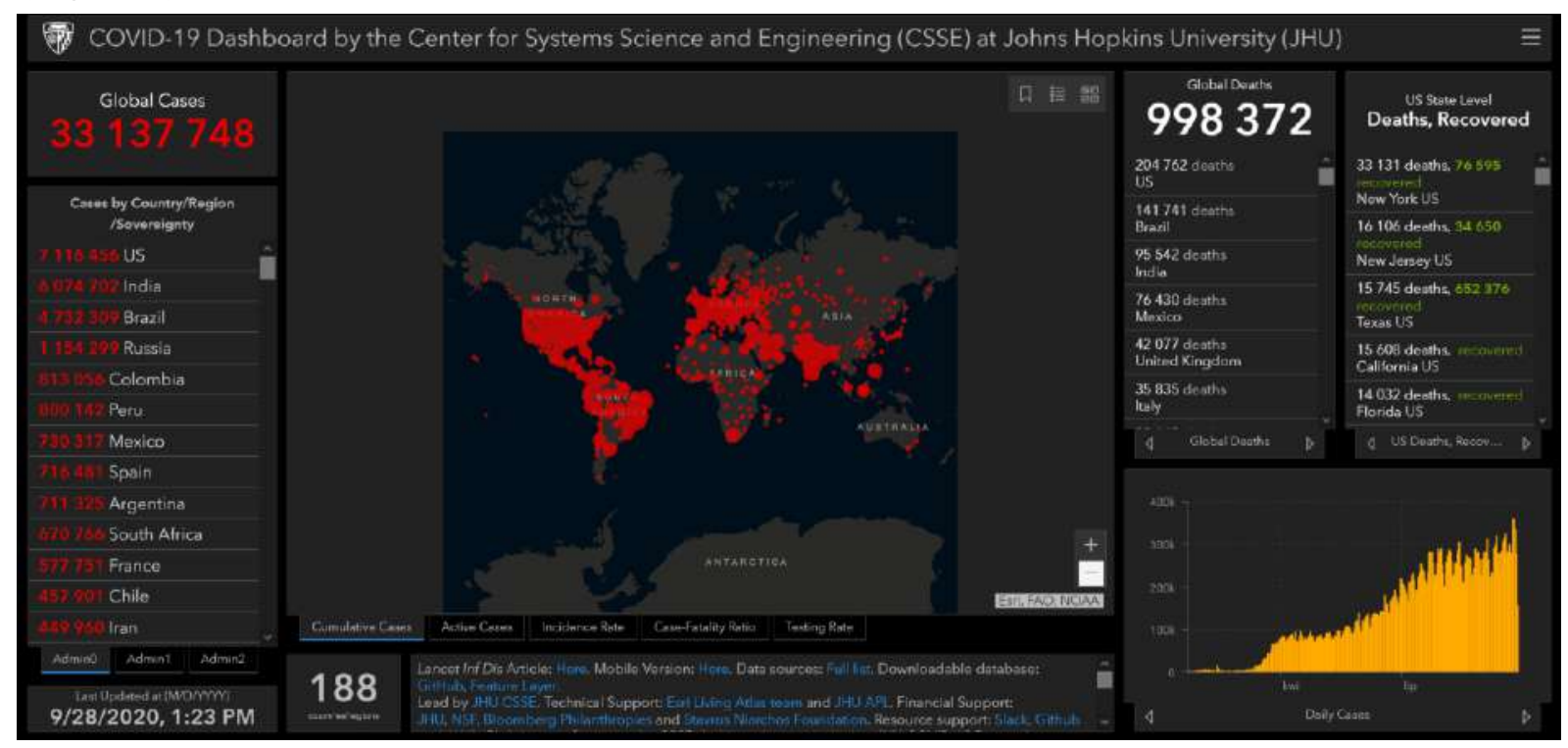

Figure 4. COVID-19 Dashboard by the Center for Systems Science and Engineering (CSSE) at Johns Hopkins University (JHU), Adopted from: https://www.arcgis.com/apps/opsdashboard/index.html \#/bda7594740fd40299423467b48e9ecf6, 28.09.2020.

As we can imagine, for some manufacturers, the digital transformation (the concept of Industry 4.0) might have always been in the pipeline. Now, it seems that the implementation of this concept has been be fast-tracked as a result of the restrictions the COVID-19 pandemic has brought. Manufacturers will have been forced to abandon their traditional processes and to transform the processes and applied new principles and technology trends according to Industry 4.0. As we can observed supply chains and manufacturing leaders before the pandemic were forced to implement new technologies. We can formulate a research questions: How will manufacturing and its supply chains look after the COVID-19 pandemic?

Many meetings, congresses, and exhibitions had to be canceled as a result of restrictive measures. This pandemic poses several major threats to economy stability and enterprises. COVID-19 has affected production, inbound and outbound logistics - logistics systems in many enterprises, and additionally many supply chains, for example public food distribution systems 
in many countries. For example, schools closing under India's national lockdown resulted in suspension of school feeding programs - one of the country's largest safety nets. School closures are also depriving many poor U.S. children of publicly provided meals. Farmers and other suppliers have found difficulty finding market outlets to replace institutional outlets such as restaurants and schools, resulting in substantial wastage of milk and other nutrient-rich foods. Other safety nets are also affected, including community nutrition programs for pregnant women and lactating mothers.

Restrictions on working work travel and the current lockdown of the COVID-19 pandemic have seen a transition for many workers in manufacturing enterprises to remote working, with this being made possible by video conferencing platforms. The remote working can be done by management staff, the top and middle staff. Since the beginning of the pandemic, company sources have reported a 70 per cent increase in the use of Facebook Messenger's video call function, and in just one record day, applications like Skype, Zoom, WhatsApp and Google Hangouts received approximately 600,000 downloads, according to the New York Times. We have also seen more online sharing and multiple editing of documents on services such as SharePoint and Google Docs. The future of work has changed. Work-from-home arrangements are a viable strategy for many businesses and that this is likely to be true even after the crisis is over. Remote working may well become more of the norm, and businesses could reduce the volume of office spaces needed and spend more money on new technology (Diver, 2020).

The enterprises and the global supply chains are experiencing a level of disruption that has never been seen before. Some manufacturers have ceased production completely, some have seen greatly reduced demand and others have seen a huge increase in demand. Every manufacturer is impacted by this crisis in some way and for many this poses an existential threat.

Based on the latest report done by McKinsey we can state that the auto industry is one of the world's largest and has been devastated by the pandemic: sales may drop by 20 to 30 percent in 2020. The profits of this industry will fall by $\$ 100$ billion. But automakers can respond. One example: software-subscription services, which enable people to pay for programs that unlock features from heated seating to full self-driving capabilities, allow dealerships to develop a better relationship with consumers while offering drivers additional flexibility and customization (Agrawal et al., 2020).

The business drivers of the Industry 4.0 pre-crisis were focused on: competitive advantage, cost reduction, time reduction, materials reduction, waste reduction, productivity creasing, sustainability and innovation. The goal was to make well run businesses run better. From one side the focus for many manufacturers now is survival first and foremost and then beyond that, damage limitation. We can observe many of companies are focused on the here and now. Many companies are moving to work remotely, the world industry is facing big problems due to delayed responses and unusable production capacities due to production stoppage and transport, especially in automotive enterprises. 


\section{The role of The Industry 4.0 in the perspective of the pandemic}

The COVID-19 has the impact on implementation the concept of the Industry 4.0 in the area of production management in enterprises and global supply chains. The changes can be observed in research and development, designing, inventory management, service, and customer care. From the other side the pandemic transforms the design, manufacture, operation, and service of products and production systems. Manufacturing is transformed from single automated cells to fully integrated automated facilities that can communicate with one another and boost flexibility, speed, productivity, and quality.

This raises a few challenging problems dedicated to manufacturing and the concept of Industry 4.0. We believe that the Industry 4.0 is relevant topic for manufacturers. This concept is not only as relevant as it was before the pandemic. But how we can observe it is actually far more relevant for enterprises and supply chains.

In a production system, the nine pillars of Industry 4.0 will transform isolated and optimized cell production into a fully integrated, automated, and optimized production flow. This will lead to greater efficiency and changes in traditional production relationships among suppliers, producers, and customers as well as between human and machine. In Industry 4.0, these transformation, sensors, machines, work pieces, and IT systems will be connected along the value chain beyond a single enterprise. These connected systems (also referred to as CyberPhysical Systems) can interact with one another using standard Internet-based protocols and analyze data to predict failure, configure themselves, and adapt to changes. Industry 4.0 will make it possible to gather and analyze data across machines, enabling faster, more flexible, and more efficient processes to produce higher-quality goods at reduced costs. This in turn will increase manufacturing productivity, shift economics, foster industrial growth, and modify the profile of the workforce, ultimately changing the competitiveness of companies and regions (Rüßmann et al., 2015). Industry 4.0 aims at the construction of an open and smart manufacturing platform for industrial-networked information application (Bahrin et al., 2016). Real-time data monitoring (tracking the statuses and positions of products as well as holding the instructions to control production processes) are the main needs of Industry 4.0 (AlmadaLobo, 2015).

The COVID-19 pandemic has precipitated profound changes across the globe, accelerating the shift towards digital transformation and radically impacting workflow in global supply chains and in enterprises gathered in supply chains. The Industry 4.0 enable last-minute changes to production and deliver the ability to respond flexibly to disruptions in enterprises and supply chains. It is very important in the perspective the pandemic. The COVID-19 pandemic has already highlighted the possible uses and benefits of the components of Industry 4.0, especially virtual reality. It may be the dawn of a new digital reality. 
The Industry 4.0 should has a different role in the time of the pandemic. It should help to make sure that more companies survive, shorten the recovery phase and help return businesses to normal operations as soon as possible, provide the platform to develop new, more resilient businesses in the medium to long term. These can be achieved because many of the capabilities it offers could have greatly reduced the impact of this crisis on citizens, enterprises, supply chains.

In this content we can observe: real-time visibility into the availability of raw materials, finished goods, WIP, people and assets, use of Artificial Intelligence and Machine Learning to constantly reassess and re-plan activities, Robotic Process Automation to support non-value add labor intensive activities, the use of mobile technology, Augmented Reality and Virtual Reality to enable workers to perform tasks they were not trained for more easily. This could have assisted with skills shortages due to self-isolation or repurposing of manufacturing. The same technologies together with digital twins and remote support from OEM's would improve availability of assets. The same technologies could also have enabled more remote working and virtual working to help with the issue of lockdown and social distancing. Additionally, 3D printing of spare parts that were stuck in the supply chains. Use of AGV's, autonomous electric vehicles and drones to again reduce the reliance on people and to further assist with social distancing. In the pandemic time which is full of the risk and uncertainty, the enterprises and supply chains have on open access to technologies that can help employees, companies, communities, and governments continue to move forward to better future.

As we can observe many manufacturing plants and premium logistics warehouses in China have already adopted Industry 4.0 and Logistics 4.0, respectively. Given the impact the COVID-19 outbreak has had on manufacturing and supply chains within the country, we do expect many more factories and logistics warehouses to follow and implement Industry 4.0 and Logistics 4.0 technology and systems, respectively in other countries. By doing this, manufacturing and supply chains will be able to better ensure that goods and products make their way from production facilities to customers in the most efficient manner under any situation and at any time.

We claim that in the manufacturing industry will be the need to invest in new technologies for the long term and implement new infrastructures. The COVID-19 pandemic is likely to help us push the accelerator pedal on Industry 4.0 in the industries, including manufacturing industry. In due to the pandemic the goal for all manufacturers will be to implement Industry 4.0 as soon as possible and at the lowest cost. In defining the operating model for this implementation the enterprises will factor in lessons learned from the global crisis of COVID-19 and try to build a more resilient and agile business. We believe that the key finding will be that the systems and processes in place were not fit for purpose. It is too early to say for certain, but it seems clear from events unfolding before us that one of the major weaknesses is a lack of real time visibility across the business. Visibility that is essential to support critical business decision. 


\section{Results}

Based on the results of research papers and surveys of manufacturers we can state that the enterprises and supply chains should be much more digital in the future, as is already evident in the immediate response to the crisis. We can observed that industry leaders are leveraging Industry 4.0 solutions. Fast 40 percent have implemented a nerve-center, or control-tower, approach to increase end-to-end supply-chain transparency, and around a quarter are fasttracking automation programs to stem worker shortages arising from the COVID-19 pandemic. Industry 4.0 which includes connectivity, advanced analytics, automation, and advancedmanufacturing technologies - was gaining momentum before the COVID-19 pandemic, helping companies transform their operations in everything from production efficiency to product customization, with improvements in speed to market, service effectiveness, and new-business model creation.

As we can observe the role of Industry 4.0 becomes even more critical in the backdrop of a crisis such as the COVID-19 pandemic. Players utilizing digital solutions are better-positioned to weather the storm, having moved faster and further than their peers during the crisis. A recent McKinsey survey of manufacturing and supply chain professionals found that 93 percent plan to focus on resilience of their supply chain, and 90 percent plan to invest in talent for digitization (Agrawal et al., 2020).

To thrive in today's marketplace, the enterprise especially small and medium-sized enterprise must continuously strive to improve its position relative to its competitors in a business environment characterised by increased competition, a need for developing better products at reduced cost, and reduced time to market. This enterprise should seek rapid, flexible and cost-minimised solutions in the development and manufacture of products. Achieving the speed of response that is needed in today's global markets is firmly rooted in the internal and external flexibility a company can rely when responding to disturbances in its operating environment. The success of an enterprise results from the skillful use of processes, principles, rules of conduct and resources in response to opportunities and risks that arise, among these non-standard project-based orders. Therefore, the transformation of business conduct and the differentiation between routine tasks and tasks that are unique (project-based orders treated as projects) in a production system become necessary. It is main stream of the Industry 4.0 concept.

Therefore, it is interesting to analyze the Industry 4.0 idea acceptance within SMEs. The Industry 4.0, is currently widely described in the scientific literature and popular term used in the business world. The Industry 4.0 determines changes in production - from mass production to personalized production (customization) - which make the production processes more flexible and provide the means to meet the individual needs of different customers more effectively (Figure 5). 

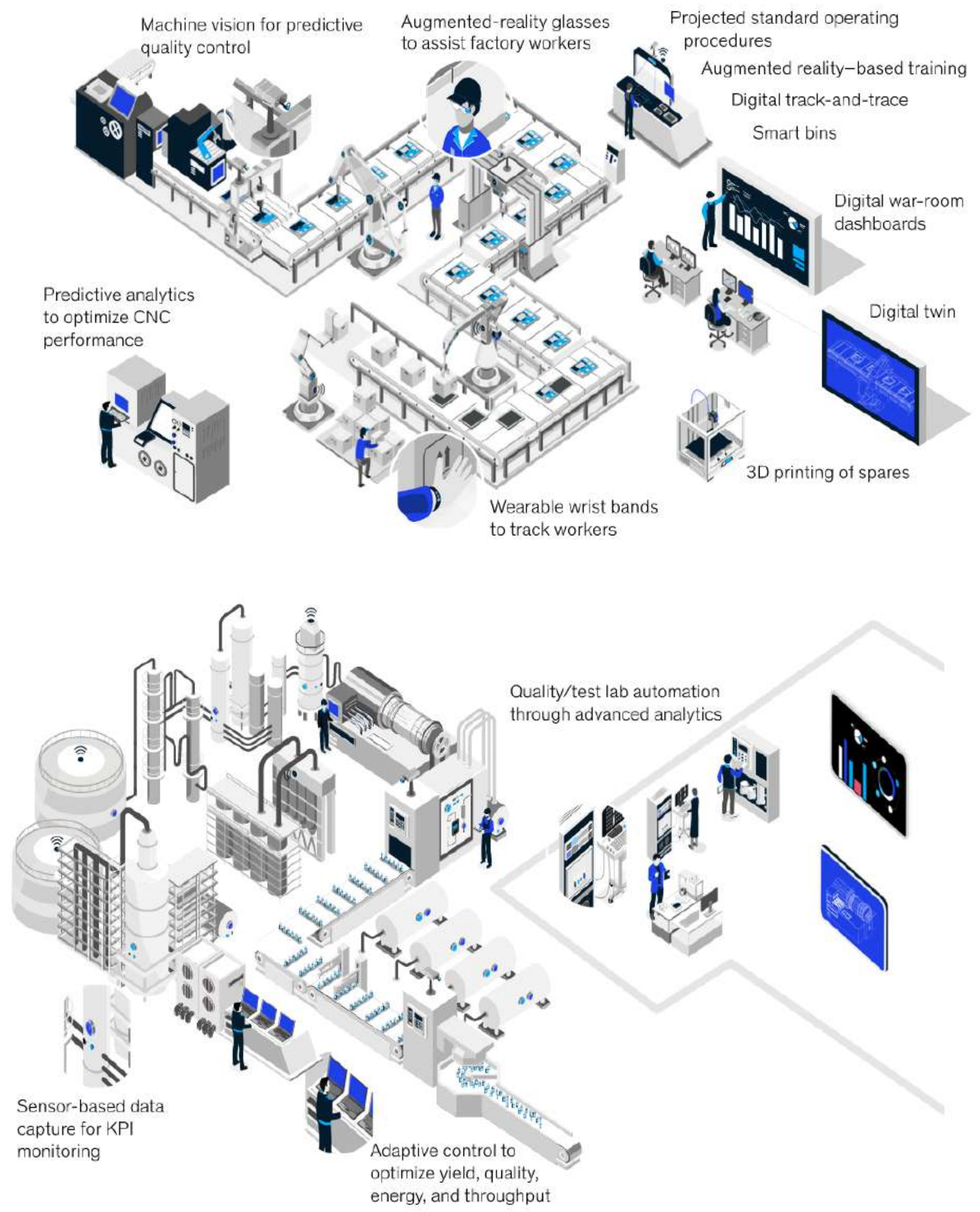

Figure 5. The process of manufacturing 4.0 in the smart factory. Adopted from: "Industry 4.0: Reimagining manufacturing operations after COVID-19" by Agrawal M., Eloot K., Mancini M., Patel A., Copyright 2020 by McKinsey.

The crucial role in the supply chain is played by small and medium enterprises as their level of digitalization impacts on ability to compete by smart supply chain idea. 


\section{Summary}

The COVID-19 outbreak is a complex crisis made up of multiple trigger points - health, policy, the economy in the world. Its impact on the enterprises and the supply chains is observed in the context of Industry 4.0. Enterprises can deploy digital solutions beyond the four walls of a manufacturing plant, reaching across the end-to-end value chain to address planning (and replanning) challenges related to disruptions at suppliers or production plants, operational challenges in managing workplace health risks, and delivery challenges posed at transportation modes or in warehouses, and it is more needed than before the crisis. A core element of manufacturing and supply-chain operations - planning - has traditionally been conducted in silos, with demand forecasting, supply planning, production planning, logistics planning, and sales and operations planning (S\&OP) all handled by separate teams. Interrupted global trade flows and value chains have forced companies to break the silos to improve end-to-end visibility. As a result, the potential impact from optimized planning is more evident. But it also requires a more sophisticated analytical approach, and collaboration across multiple functions and stakeholders (McKinsey, 2020).

The manufacturing disruptions from the COVID-19 pandemic stem from many sources, ranging from safe-distancing measures and staggered worker attendance to restricted migrantlabor movement within and between countries. Digital technologies can help mitigate the effects in multiple ways, boosting employee safety, operational efficiency, asset productivity, and product quality. In most companies, and especially in SMEs, data collection is manual, using pen and paper or basic spreadsheets. The process is prone to errors and inaccuracies, which are naturally exacerbated during the stress of a crisis. Digital solutions allow manufacturers to automate data collection by adding sensors or directly tapping into machines' programmable logic controllers (PLCs) to collect data and display it on live dashboards (McKinsey, 2020).

Supervisors can then monitor factory performance remotely and in real time. They can deploy interventions when needed, conduct effective performance-management meetings, adapt daily plans to meet customer demands, and to improve labor productivity as well as operational efficiency - all remotely. In addition, process automation and physical automation or robotics can supplement labor capacity. In some instances, "brownfield" automation of existing operations has become a more attractive way to manage worker shortages and minimize potential business losses due to unmet orders. At one industrial manufacturing company, robots are now delivering raw materials and semi-finished goods to different production lines - helping the production team cope with a reduced workforce while preventing close contact between production and material-handling employees (McKinsey, 2020). 
The COVID-19 crises reduced availability of transportation modes while introducing added complexities, such as new requirements for packaging and for safe, last-mile contactless delivery. In this context, digital and analytics solutions can increase visibility of both demand and supply for logistics services, improving real-time performance (McKinsey, 2020).

\section{References}

1. Agrawal, M., Eloot, K., Mancini, M., Patel, A, (2020). Industry 4.0: Reimagining manufacturing operations after COVID-19. McKinsey, Retrieved from https://www.mckinsey.com/business-functions/operations/our-insights/industry-40reimagining-manufacturing-operations-after-covid-19\#, 29.10.2020.

2. Almada-Lobo, F. (2015). The Industry 4.0 revolution and the future of Manufacturing Execution Systems (MES). Journal of Innovation Management JIM, Vol. 3, Iss. 4, pp. 16-21.

3. Bahrin, M.A.K, Othman, M.F., Azli, N.H.N., Talib, M.F. (2016). Industry 4.0: A Review on Industrial Automation and Robotic. Jurnal Teknologi, 78: 6-13, pp. 1137-143.

4. CSSE (2020). COVID-19 Dashboard by the Center for Systems Science and Engineering (CSSE) at Johns Hopkins University (JHU). Retrieved from: https://www.arcgis.com/apps/ opsdashboard/index.html\#/bda7594740fd40299423467b48e9ecf6, 28.09.2020.

5. Dabrowska-Hoffa, P., Grzybowska, K. (2020). Simulation modeling of the sustainable supply chain. Sustainability, 12, 6007. doi: 10.3390/su12156007.

6. Diver, C. (2020). Coronavirus: How is COVID-19 accelerating the uptake of Industry 4.0? Manchester: Manchester Metropolitan University.

7. Ghobakhloo, M. (2018). The future of manufacturing industry: a strategic roadmap toward Industry 4.0. Journal of Manufacturing Technology Management, June, doi: 10.1108/ JMTM-02-2018-0057.

8. Ghobakhloo, M. (2018). The future of manufacturing industry: a strategic roadmap toward Industry 4.0. Journal of Manufacturing Technology Management, doi: 10.1108/JMTM-022018-0057.

9. Gilchrist, A. (2016). Industry 4.0: The Industrial Internet of Things. Heidelberg: Springer.

10. Kagermann, H., Lukas, W., Wahlster, W. (2011). Industrie 4.0 - Mitdem Internet er Dinge auf dem Wegzur 4. Industriellen Revolution [Industry 4.0: with the Internet of Things towards 4th industrial revolution]. VDI Nachrichte, retrieved from http://www.vdinachrichten.com/artike1/Industrie-4-0-Mit-dem-Internet-derDinge-auf-dem-Weg-zur-4industriellen-Revolution/52570/1, 11.09.2020. 
11. Kagermann, H., Wahlster, W., Helbig, J. (2013). Recommendations for implementing the strategic initiative INDUSTRIE 4.0. Final report of the Industrie 4.0 Working Group. Frankfurt am Main: Acatech.

12. Kagermann, H., Wahlster, W., Helbig, J., Hellinger, A., Stumpf, V., Kobsda, C. (2013). Umsetzungsempfehlungen für das Zukunftsprojekt Industrie 4.0 - Abschlussbericht des Arbeitskreises Industrie 4.0 [Implementation recommendations for the future project Industry 4.0 - final report of the Industry 4.0 working group], Berlin.

13. Kumar, K., Zindani, D., Davim J.P. (2019). Digital Manufacturing and Assembly Systems in Industry 4.0. Boca Raton: CRC Press.

14. Lars, A. et al. (2016). German Standardization Roadmap: Industry 4.0. Version 2. Berlin: DIN e.V.

15. Lee, J., Kao, H.A., Yang, S. (2014). Service innovation and smart analytics for Industry 4.0 and big data environment. Product Services Systems and Value Creation. Proceedings of the 6th CIRP Conference on Industrial Product-Service Systems. Procedia CIRP 16, pp. 3-8.

16. Liao, Y., Deschamps, F., de Freitas Rocha Loures, F., Ramos, L.F. (2017). Past, present and future of Industry 4.0 - a systematic literature review and research agenda proposal. International Journal of Production Research, Vol. 55, Iss. 12, pp. 3609-3629, doi: 10.1080/00207543.2017.1308576.

17. Liao, Y., Deschamps, F., Loures, E.d.F.R., and Ramos, L.F.P. (2017). Past, present and future of Industry 4.0-a systematic literature review and research agenda proposal. International Journal of Production Research, Vol. 55, No. 12, pp. 3609-3629.

18. McKinsey (2020). The path to the next normal Leading with resolve through the coronavirus pandemic. McKinsey Publishing.

19. McMahon, C. (2020, April 20). Examining COVID-19's Impact on Industry 4.0. Is Coronavirus Triggering Industry 5.0? Retrieved from: https://www.keypointintelligence. com/news/editors-desk/2020/april/examining-covid-19-s-impact-on-industry-40/.

20. Miśkiewicz, R., Wolniak, R. (2020). Practical Application of the Industry 4.0 Concept in a steel company. Sustainability, 12, 5776, doi: 10.3390/su12145776.

21. Mrugalska, B., Wyrwicka, M.K. (2017). Towards Lean Production in Industry 4.0. Procedia Engineering, vol. 182, pp. 466-473, doi: 10.1016/j.proeng.2017.03.135.

22. Neugebauer, R., Hippmann, S., Leis, M., Landherr, M. (2016). Industrie 4.0 - From the perspective of applied research. 49th CIRP conference on Manufacturing systems (CIRPCMS 2016), 2-7.

23. Paprocki, W. (2016). Koncepcja Przemysł 4.0 i jej zastosowanie w warunkach gospodarki cyfrowej. In: J. Gajewski, W. Paprocki, J. Pieregud (eds.), Cyfryzacja gospodarki i społeczeństwa - szanse i wyzwania dla sektorów infrastrukturalnych. Gdańsk: Publikacja Europejskiego Kongresu Finansowego, Instytut Badań nad Gospodarką Rynkową, Gdańska Akademia Rynkowa. 
24. Roland Berger (2020, 24 April). Latest update of our corona economic impact series. Retrieved from: https://www.rolandberger.com/it/Point-of-View/Point-of-View-Details 65664.html, 11.09.2020.

25. Rüßmann, M., Lorenz, M., Gerbert, P., Waldner, M., Justus, J., Engel, P., Harnisch, M. (2015). Industry 4.0: The Future of Productivity and Growth in Manufacturing Industries. The Boston Consulting Group.

26. Santos, C., Mehrsai, A., Barros, A., Araújo, M. and Ares, E. (2017), Towards Industry 4.0: an overview of European strategic roadmaps. Procedia Manufacturing, Vol. 13, No. 1, pp. 972-979.

27. Ustundag, A., Cevikcan, E. (2017). Industry 4.0: Managing the Digital Transformation. Heidelberg: Springer.

28. Vogel-Heuser, B., Hess, D. (2016). Guest editorial Industry 4.0 - prerequisites and visions. IEEE Transactions on Automation Science and Engineering, Vol. 13, No. 2, pp. 411-413.

29. Zhou, J. (2013). Digitalization and intelligentization of manufacturing industry. Adv. Manuf., Vol. 1, Iss. 1, pp. 1-7. 


\title{
COMPARISON OF PROFITS OF EFFECTIVE PORTFOLIOS WITH NON-EFFECTIVE PORTFOLIOS TAKING INTO ACCOUNT THE FUZZY APPROACH
}

\author{
Ewa POŚPIECH \\ Economic University in Katowice; posp@ue.katowice.pl, ORCID: 0000-0001-5015-8875
}

Purpose: The aim of the article is to compare the results of the constructed effective portfolios and non-effective portfolios build on the basis of the value of the indicator constituting a synthetic assessment of decision variants.

Design/methodology/approach: The article uses the multi-criteria TOPSIS method in the standard and fuzzy approach. It was used to evaluate listed companies that were examined in terms of selected fundamental and market characteristics. Taking into account the fuzzy method made it possible to treat the values of criteria from three years as triangular fuzzy numbers, and the values of the measure on the basis of which the ranking was created were also used to build non-effective portfolios.

Findings: A multi-criteria evaluation of selected listed companies was performed and, on the basis of the obtained rankings, the sets constituting the basis for the construction of effective and non-effective portfolios were selected. The designated effective portfolios (after pre-selection using the FTOPSIS method) were in most cases more profitable than the market portfolio, while the non-effective portfolios, using TOPSIS as the pre-selection method, were (with one exception) more profitable than the effective portfolios.

Research limitations/implications: It was not possible to unequivocally recommend the approach used, although the results appear promising.

Practical implications: Taking into account the proposed approach, one can methodically build more profitable and more attractive portfolios.

Originality/value: Non-standard approach to criteria assessments and the use of metacriterion values to determine the portfolio structure. The considerations may be of interest to stock market investors.

Keywords: Effective portfolios, fuzzy TOPSIS, multi-criteria problem, non-effective portfolios.

Category of the paper: Research paper. 


\section{Introduction}

Various methods are used to build equity portfolios. When a long-term portfolio is constructed, fundamental analysis is often used to assess the company and its economic environment. Such an assessment is made on the basis of many indicators characterizing the studied areas. The multitude of available indicators may make the analysis of the issue difficult, so it is worth approaching the problem in a methodical manner: selecting the most important factors describing the company's condition, and then applying the method of ordering objects assessed through the prism of these factors. Such a possibility is provided by the use of multicriteria methods that allow for the ordering of objects assessed in terms of many criteria. The conducted analysis makes it possible to identify companies with the most preferred features by the decision-maker, and based on the obtained set, a portfolio can be built. One of the options for selecting a portfolio is to designate effective portfolios consisting in solving optimization tasks in which, at a given rate of return, the portfolio risk is minimized or, at a given risk level, the portfolio's rate of return is maximized (Jajuga, and Jajuga, 2015). The research made it possible to designate effective portfolios that minimize the portfolio risk, compare them with the results of the market portfolio and, using a non-standard concept, construct non-effective portfolios.

The aim of the article is to compare the results of the constructed effective portfolios and non-effective portfolios built on the basis of the value of the indicator constituting a synthetic assessment of decision variants, as well as a recommendation of the approaches used. The research hypothesis states that the obtained non-effective portfolios may be more profitable for the investor than the effective and market portfolios.

\section{Research methodology}

In the research, to assess the economic and financial situation of companies, the multicriteria TOPSIS method was used in two versions: standard and fuzzy. This method is widely used in a variety of problems and its end result is a ranking of objects. It is possible to distinguish several variants of the method, so it can be used, for example, for variables presented in the form of crisp values, fuzzy numbers, interval numbers, linguistic data and others. The TOPSIS method has also found applications in supporting portfolio selection (Chen, and Hung, 2009; Ece, and Uludag, 2017; Kazemi et al., 2014; Liu, et al., 2012; Nguyen, and Gordon-Brown, 2012; Raei, and Bahrani Jahromi, 2012). The considerations presented in this study are a continuation of previous research in which, by proposing various approaches, 
ways to generate profitable, attractive portfolios for the investor are looked for (Pośpiech, 2017a, 2017b, 2018; Pośpiech, and Mastalerz-Kodzis, 2015, 2016).

In the article, as in previous works, the starting point is the selection of the initial set of companies, assessment of their economic and financial situation (using the TOPSIS methods, where the role of evaluation criteria play chosen fundamental and market indicators), building the ranking and selecting the set constituting the basis for portfolio construction. The ranking was built using the TOPSIS and FTOPSIS methods. Data from three years were taken into account for selected indicators (Tarczyński, 2002). Using the standard version of the method, the mean value for the studied years was determined, while in the case of the fuzzy version, the data from three years were represented as triangular fuzzy numbers $\widetilde{a}_{i}^{(k)}=\left(l_{i k}, m_{i k}, u_{i k}\right)$, where: $k$-specifies the criterion number, $l_{k}$ - the smallest value of the criterion assessment for the company from selected years, $m_{k}$ - the middle value of the criterion assessment for the company from chosen years, $u_{k}$ - the highest value of the criterion assessment for the company from considered years.

The procedure of determining the multi-criteria ranking using TOPSIS methods can be found in many works, including (Hwang, and Yoon, 1981; Jahanshahloo, et al., 2006; Lai, et al., 1994; Roszkowska, and Wachowicz, 2013; Trzaskalik, 2014). Generally, it includes building a decision matrix, its normalization, determination of ideal and non-ideal solutions, calculation of object distances from these points and the relative distance $S_{i}$, on the basis of which the ranking is constructed (the higher the value, the higher the position in the ranking).

Four fundamental and market indicators were selected as evaluation criteria (Leszczyński, 2004; Tarczyński, 2001, 2002; Trzaskalik, 2006; Tyran, 2001):

- return of assets ROA (net income/average total assets),

- return of equity ROE (net income/shareholder equity),

- P/BV (price-book value),

- P/E (price-earnings ratio).

Each of the above criteria was found to be of equal importance and the maximization of each of them was assumed.

As the analyzes are a continuation of previous research, the base set of companies includes those that made up the WIG20 index in December 2017, while the data for the indicators come from 2015-2017. After applying multi-criteria methods and obtaining rankings, effective portfolios were determined using the classic Markowitz approach (Markowitz, 1952), in which the portfolio variance was minimized at a given rate of return (the average of positive rates of return of companies forming WIG20 was taken into account). Then, based on the values of the relative distance $S_{i}$, non-effective portfolios were built (Pośpiech, 2020a), and their results were compared with the effective portfolios and the market portfolio represented by the WIG20 index. 


\section{Results of empirical analysis}

The use of selected multi-criteria methods made it possible to obtain the rankings presented in Table 1.

Table 1.

Values of the $S_{i}$ indicator and rankings according to method of pre-selection

\begin{tabular}{|c|c|c|c|c|}
\hline \multirow{3}{*}{ Ranking } & \multicolumn{4}{|c|}{$S_{i}$ according to the methods } \\
\hline & \multicolumn{2}{|c|}{ TOPSIS } & \multicolumn{2}{|c|}{ FTOPSIS } \\
\hline & Company & $S_{i}$ & Company & $S_{i}$ \\
\hline 1 & $\mathrm{CCC}$ & 0.968 & $\mathrm{CCC}$ & 0.792 \\
\hline 2 & LPP & 0.856 & LPP & 0.686 \\
\hline 3 & EUR & 0.724 & PKN & 0.617 \\
\hline 4 & PKN & 0.723 & EUR & 0.586 \\
\hline 5 & PZU & 0.663 & PZU & 0.574 \\
\hline 6 & CPS & 0.644 & CPS & 0.538 \\
\hline 7 & PGN & 0.643 & PGN & 0.534 \\
\hline 8 & LTS & 0.630 & BZW & 0.531 \\
\hline 9 & BZW & 0.627 & PEO & 0.523 \\
\hline 10 & PEO & 0.619 & $\mathrm{PKO}$ & 0.510 \\
\hline 11 & $\mathrm{ACP}$ & 0.607 & MBK & 0.509 \\
\hline 12 & PKO & 0.604 & $\mathrm{ACP}$ & 0.506 \\
\hline 13 & MBK & 0.602 & LTS & 0.506 \\
\hline 14 & ENG & 0.600 & ALR & 0.503 \\
\hline 15 & ALR & 0.577 & ENG & 0.497 \\
\hline 16 & PGE & 0.576 & PGE & 0.443 \\
\hline 17 & OPL & 0.476 & TPE & 0.417 \\
\hline 18 & JSW & 0.473 & JSW & 0.381 \\
\hline 19 & $\mathrm{KGH}$ & 0.416 & OPL & 0.377 \\
\hline 20 & TPE & 0.241 & $\mathrm{KGH}$ & 0.290 \\
\hline
\end{tabular}

Adapted from: "The Risk of Multi-Criteria Portfolios Taking into Account the Fuzzy Approach" by E. Pośpiech, 2018.

According to research, in order to significantly reduce the unsystematic risk, the portfolio should contain from 10 to 15 instruments (Mayo, 2014). That is why, in the research, portfolios were constructed from sets containing ten to fifteen companies. The companies occupying the highest positions in the ranking were taken into account. Table 2 shows the sets of companies selected after the initial selection using TOPSIS and FTOPSIS methods.

Table 2.

The sets of companies - the basis of portfolio selection

\begin{tabular}{|l|c|c|c|c|c|c|}
\hline \multirow{3}{*}{ Methods } & \multicolumn{6}{|c|}{ Sets of companies } \\
\cline { 2 - 7 } & \multirow{2}{*}{$n=10$} & \multicolumn{4}{|c|}{$\begin{array}{r}\text { Companies successively attached to the previous group } \\
\text { in order to obtain a given number set }\end{array}$} \\
\cline { 2 - 8 } & $\begin{array}{l}\text { CCC, LPP, EUR, PKN, PZU, CPS, } \\
\text { PGN, LTS, BWZ, PEO }\end{array}$ & ACP & PKO & MBK & ENG & ALR \\
\hline FTOPSIS & $\begin{array}{c}\text { CCC, LPP, EUR, PKN, PZU, CPS, } \\
\text { PGN, PKO, BWZ, PEO }\end{array}$ & MBK & ACP & LTS & ALR & ENG \\
\hline
\end{tabular}

Source: Own study based on the data from the websites: www.bankier.pl, www.gpw.pl, http://infostrefa.com/infostrefa/pl/archiwum. 
Table 3 presents the designations of the effective portfolios generated during the research.

Table 3.

Designations of constructed effective portfolios

\begin{tabular}{|l|c|c|c|c|c|c|}
\hline \multirow{2}{*}{ Methods } & \multicolumn{6}{|c|}{ Designation of the portfolio depending on the pre-selection method and the size of the set } \\
\cline { 2 - 7 } & $n=10$ & $n=11$ & $n=12$ & $n=13$ & $n=14$ & $n=15$ \\
\hline TOPSIS & $\mathrm{P} 1$ & $\mathrm{P} 3$ & $\mathrm{P} 5$ & $\mathrm{P} 7$ & $\mathrm{P} 9$ & $\mathrm{P} 11$ \\
\hline FTOPSIS & $\mathrm{P} 2$ & $\mathrm{P} 4$ & $\mathrm{P} 6$ & $\mathrm{P} 8$ & $\mathrm{P} 10$ & $\mathrm{P} 12$ \\
\hline
\end{tabular}

Source: Own study.

Twelve portfolios were built (for 03/01/2018), with P7 = P8 and P11 = P12. It was examined how the performance of the portfolios developed in comparison to the market portfolio (marked as PM) throughout the next year (2018). The results are presented in Figures 1-6.

\section{Profits/losses of portfolios}

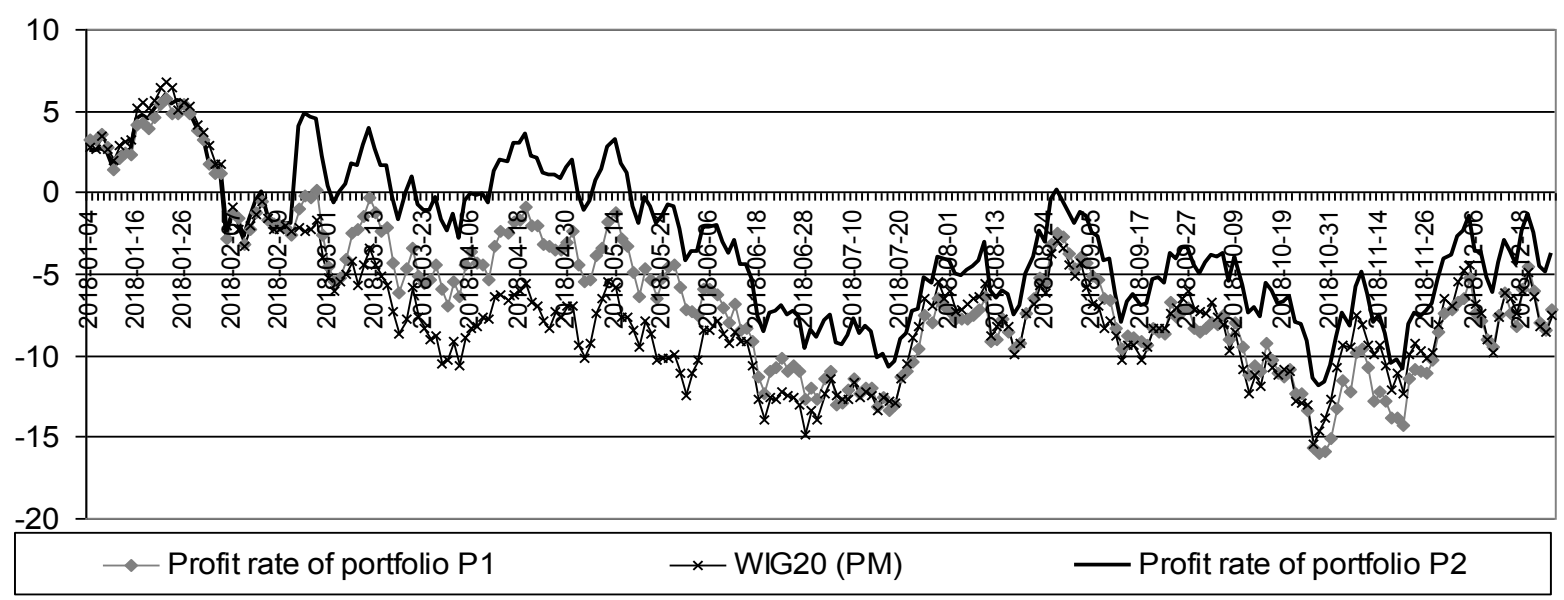

Figure 1. Profits/losses of portfolios P1, P2 $(n=10)$ and PM. Source: Own study based on the data from the websites: www.bankier.pl, www.gpw.pl, http://infostrefa.com/infostrefa/pl/archiwum.

Profits/losses of portfolios

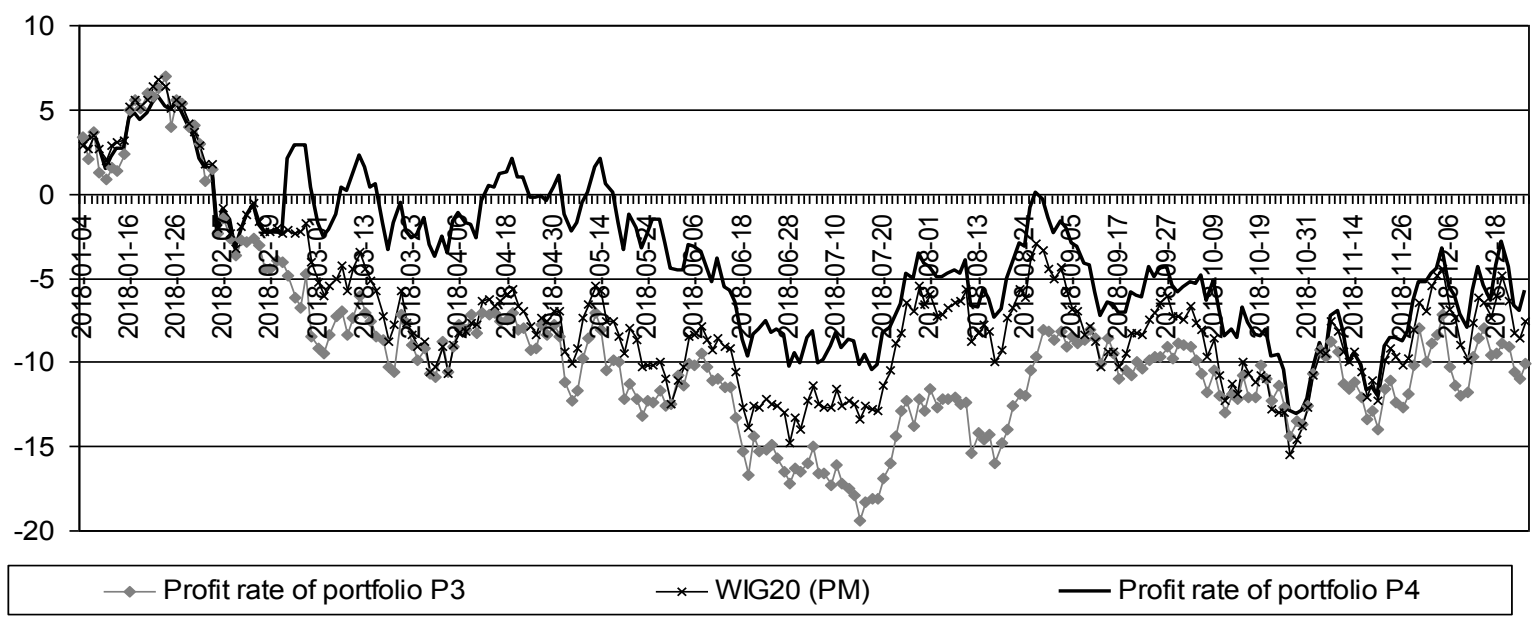

Figure 2. Profits/losses of portfolios P3, P4 $(n=11)$ and PM. Source: Own study based on the data from the websites: www.bankier.pl, www.gpw.pl, http://infostrefa.com/infostrefa/pl/archiwum. 
Profits/losses of portfolios

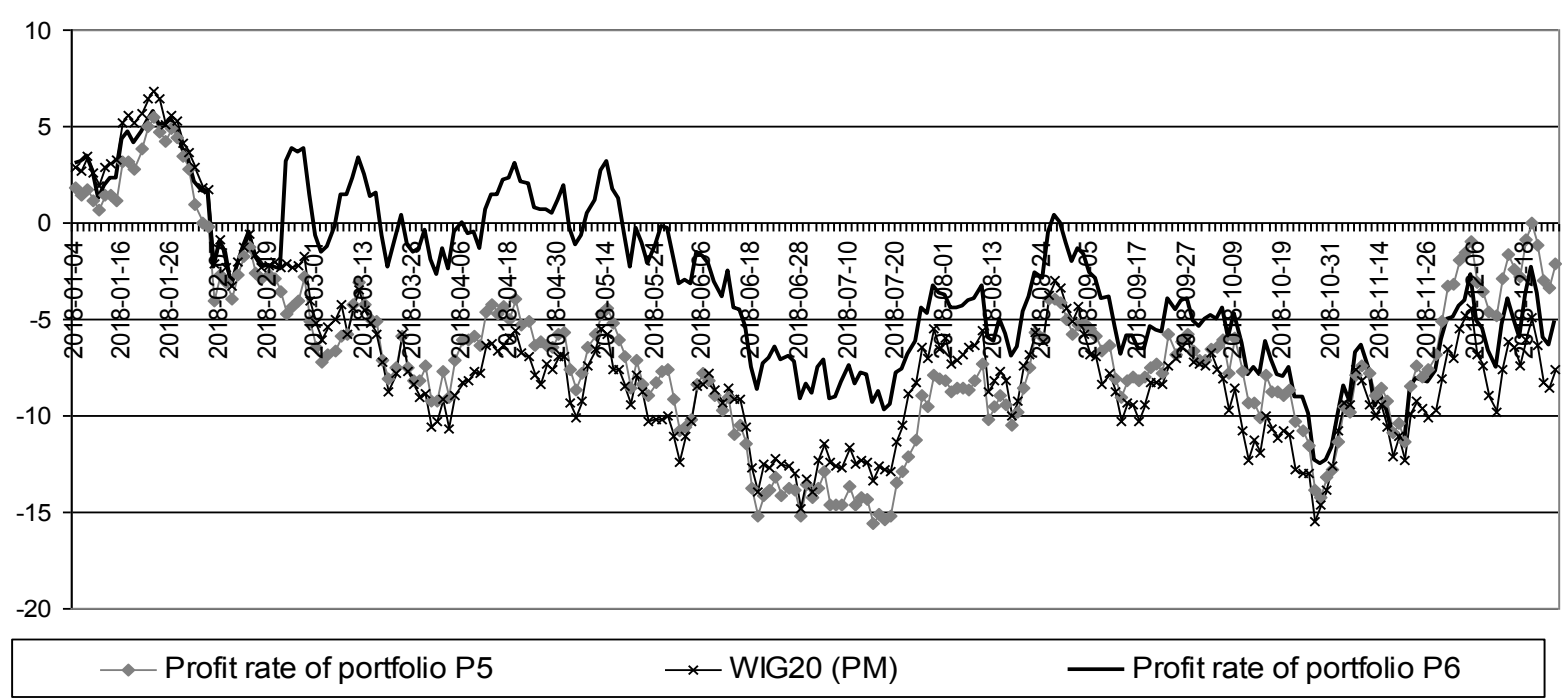

Figure 3. Profits/losses of portfolios P5, P6 $(n=12)$ and PM. Source: Own study based on the data from the websites: www.bankier.pl, www.gpw.pl, http://infostrefa.com/infostrefa/pl/archiwum.

Profits/losses of portfolios

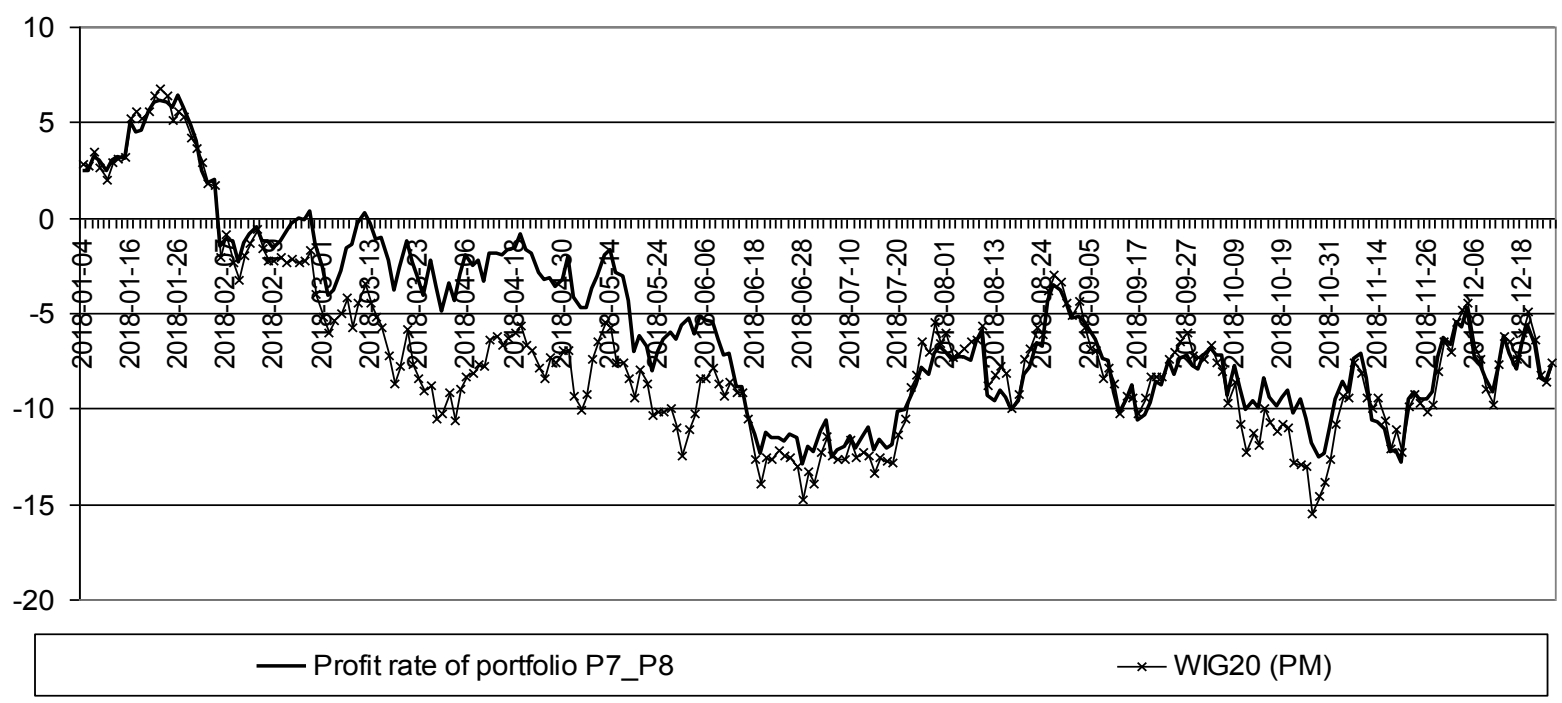

Figure 4. Profits/losses of portfolios P7 = P8 $(n=13)$ and PM. Source: Own study based on the data from the websites: www.bankier.pl, www.gpw.pl, http://infostrefa.com/infostrefa/pl/archiwum. 
Profits/losses of portfolios

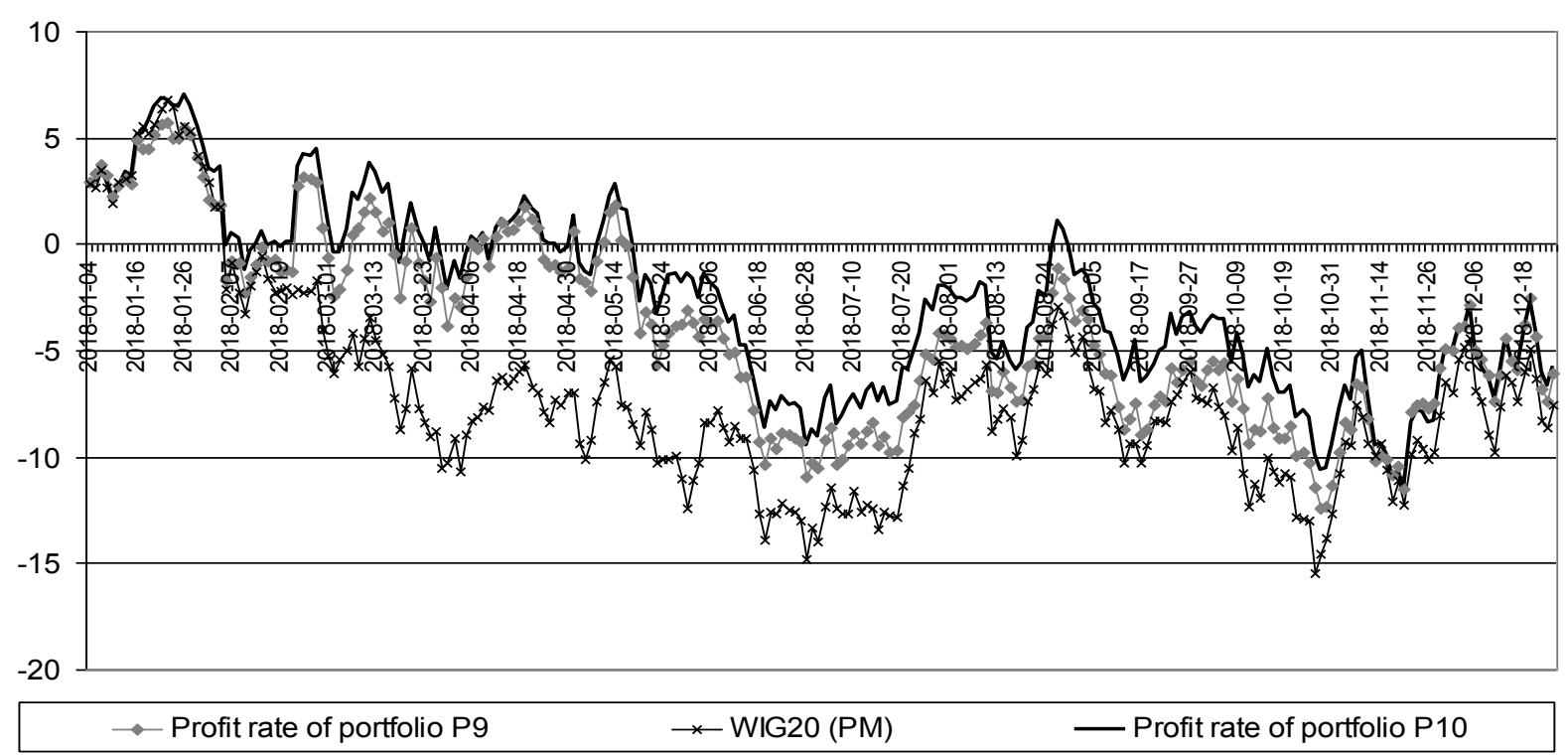

Figure 5. Profits/losses of portfolios P9, P10 $(n=14)$ and PM. Source: Own study based on the data from the websites: www.bankier.pl, www.gpw.pl, http://infostrefa.com/infostrefa/pl/archiwum.

Profits/losses of portfolios

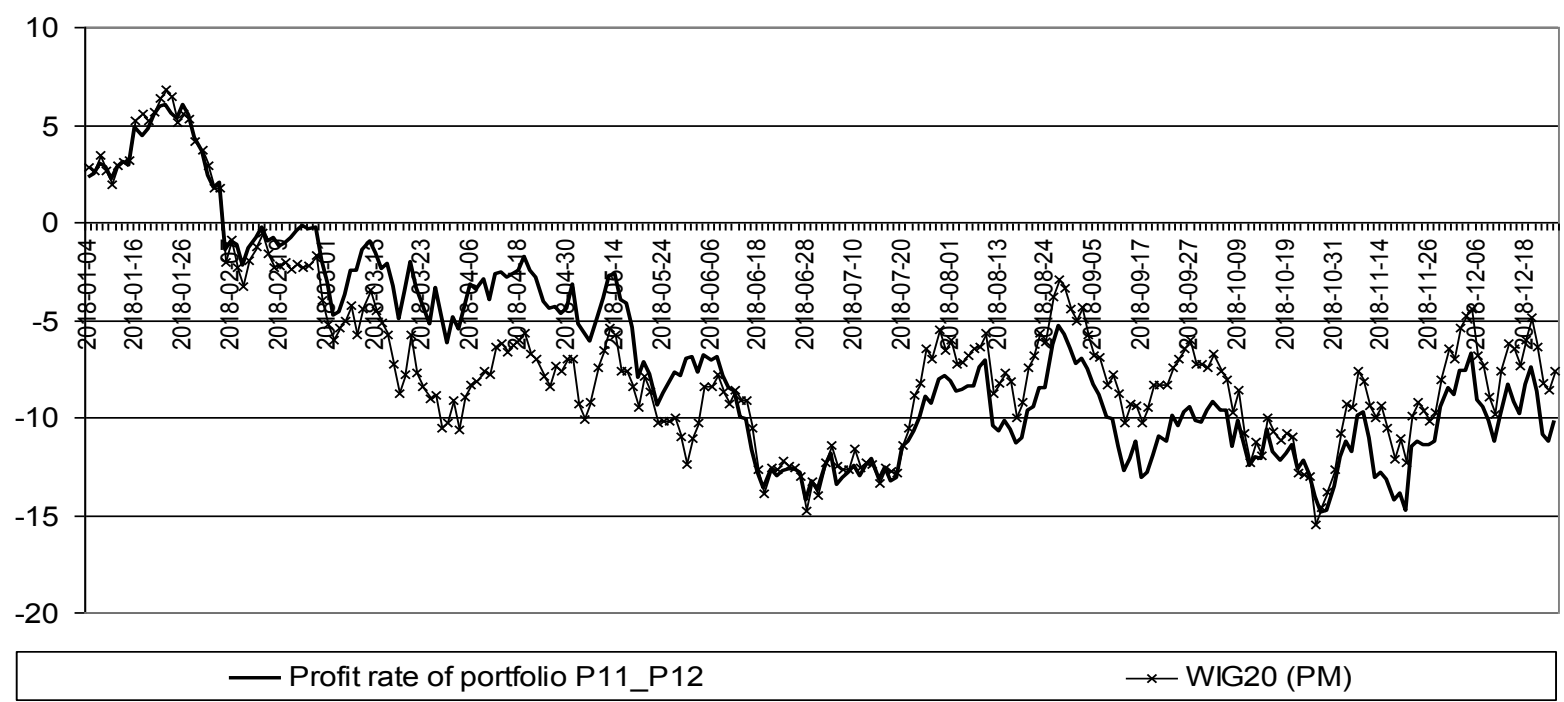

Figure 6. Profits/losses of portfolios P11 = P12 $(n=15)$ and PM. Source: Own study based on the data from the websites: www.bankier.pl, www.gpw.pl, http://infostrefa.com/infostrefa/pl/archiwum.

Conclusions for the effective portfolios:

- $n=10$ - almost throughout the entire period, the P1 portfolio records similar or better results than the market portfolio, the $\mathrm{P} 2$ portfolio recorded definitely the best results (until May it records even several percent profits);

- $n=11$ - the P3 portfolio in the first half of 2018 records comparable results with PM, then slightly worse, the $\mathrm{P} 4$ portfolio again records better results than the other two throughout the entire period; 
- $n=12$ - the P5 portfolio and the market portfolio PM are comparable, the P6 portfolio shows better results until the end of October 2018;

- $n=13-$ the P7 and P8 portfolios are identical, and for the longer period of 2018 they record no worse results than the market portfolio;

- $n=14$ - in the first half of 2018, the P10 portfolio records no worse results than P9 and definitely better than PM, in the second half of the year the differences between the portfolios results are smaller, but P10 usually records lower losses;

- $n=15-\mathrm{P} 11$ and P12 portfolios are the same - until the end of May 2018 they record comparable profits or lower losses than PM, while in the later period the PM portfolio performs no worse than the effective portfolios.

The presented results show that better results (higher profits or lower losses) are recorded by effective portfolios from the population selected using the FTOPSIS method, however, the observed losses, especially in the second half of the analyzed year, may suggest the need to reconstruct the portfolio after 5-6 months after its construction, which it will certainly improve its results (Pośpiech, 2020b).

The question is, if with the approach used, it is possible to obtain portfolios with better performance. The concept of building (non-effective) portfolios emerged, the structure of which was determined on the basis of the value of the relative distance measure $S_{i}$ - the value of the ratio in relation to the sum values of all ratios included in the portfolio is the share of the stock in the portfolio (Pośpiech, 2020a). The results of portfolios constructed in this way are shown in Figures 7-12 (portfolio designations are similar to those in Table 3 with the annotation "nef"). Additionally, they were compared with the effective portfolios that obtained the best results.

Profits/losses of portfolios

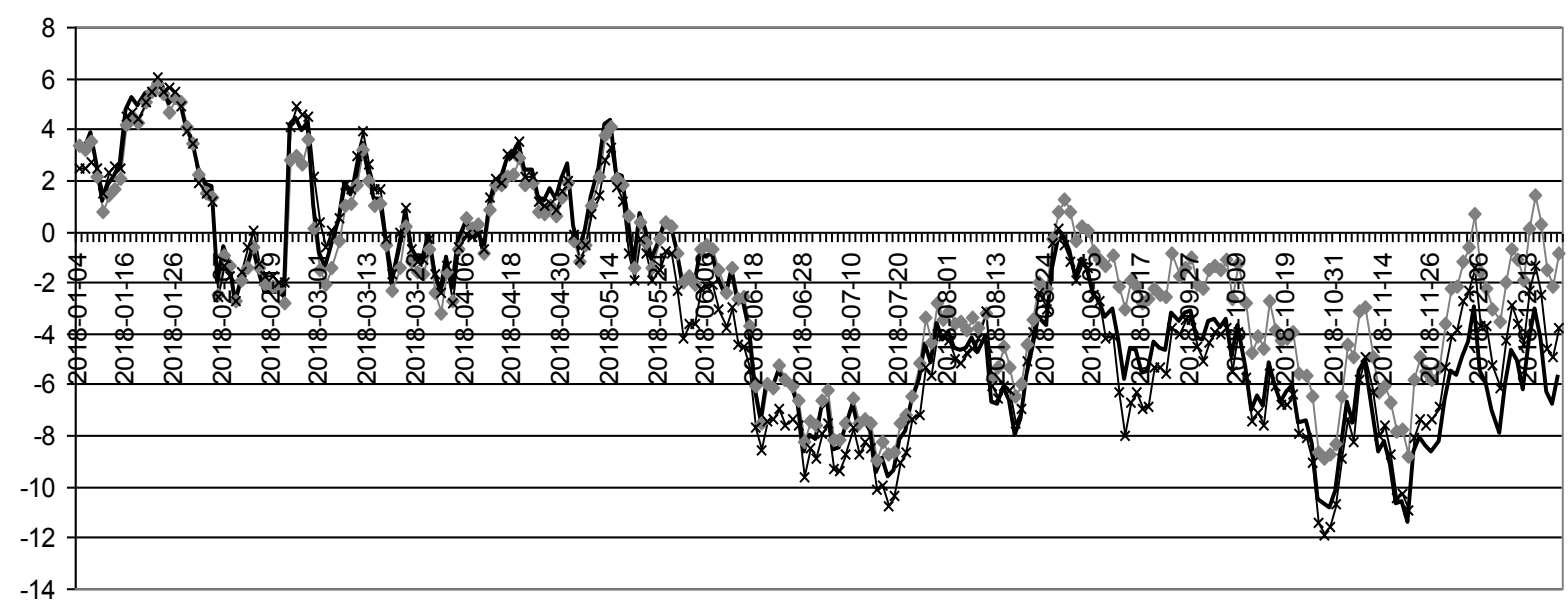

$\rightarrow-$ Profit rate of portfolio P1nef $\quad$ - Profit rate of portfolio P2nef $\quad \rightarrow$ Profit rate of portfolio P2

Figure 7. Profits/losses of portfolios P1nef, P2nef $(n=10)$ and P2. Source: Own study based on the data from the websites: www.bankier.pl, www.gpw.pl, http://infostrefa.com/infostrefa/pl/archiwum. 


\section{Profits/losses of portfolios}

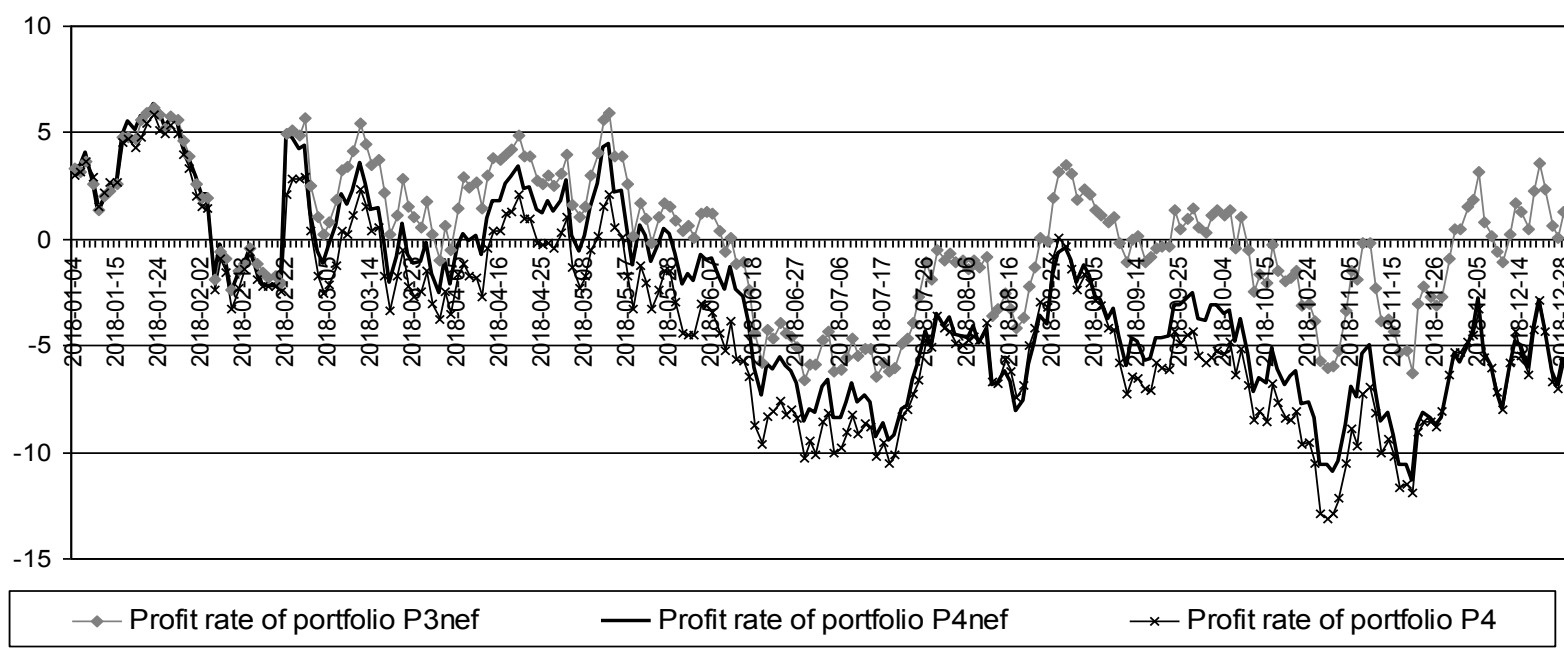

Figure 8. Profits/losses of portfolios P3nef, P4nef $(n=11)$ and P4. Source: Own study based on the data from the websites: www.bankier.pl, www.gpw.pl, http://infostrefa.com/infostrefa/pl/archiwum.

\section{Profits/losses of portfolios}

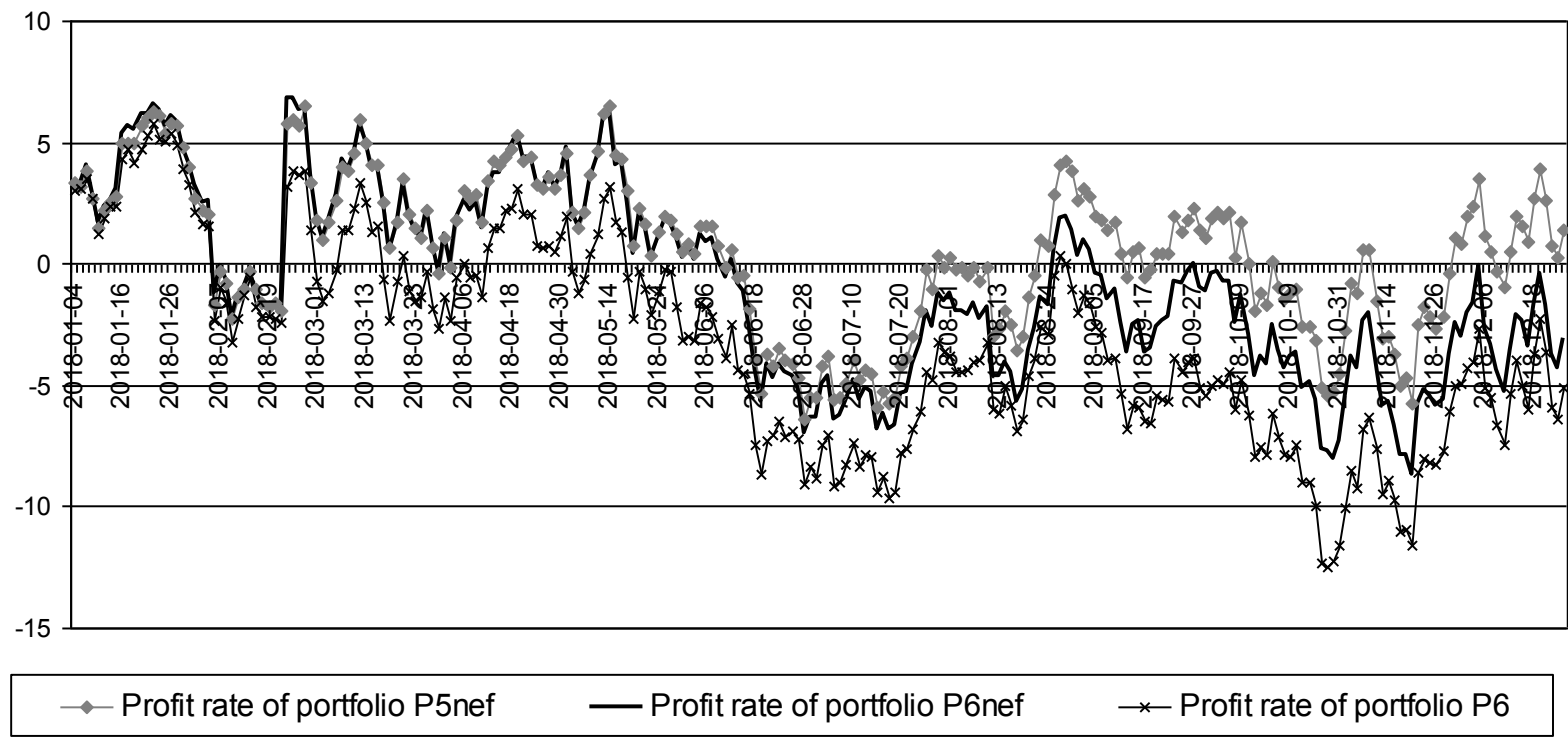

Figure 9. Profits/losses of portfolios P5nef, P6nef $(n=12)$ and P6. Source: Own study based on the data from the websites: www.bankier.pl, www.gpw.pl, http://infostrefa.com/infostrefa/pl/archiwum. 


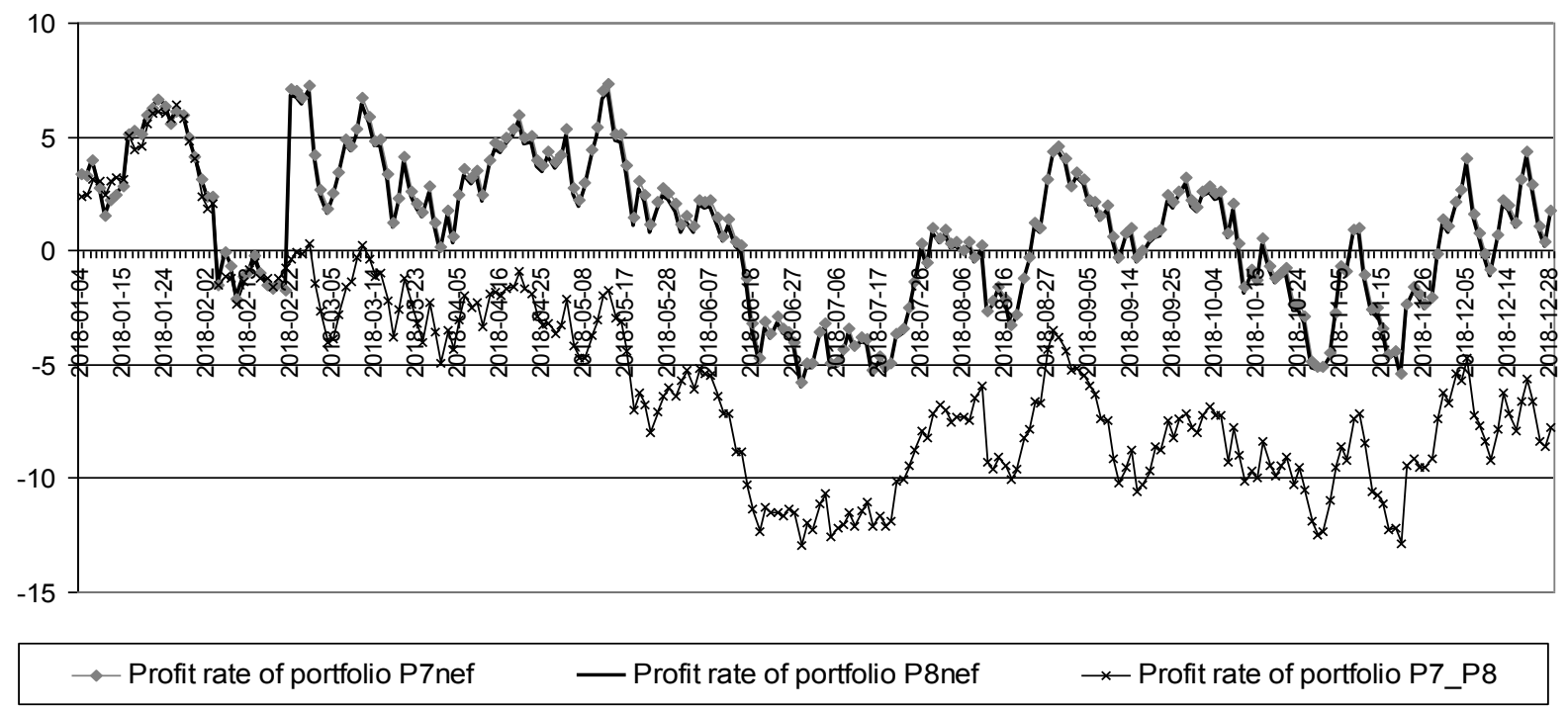

Figure 10. Profits/losses of portfolios P7nef, P8nef $(n=13)$ and P8. Source: Own study based on the data from the websites: www.bankier.pl, www.gpw.pl, http://infostrefa.com/infostrefa/pl/archiwum.

Profits/losses of portfolios

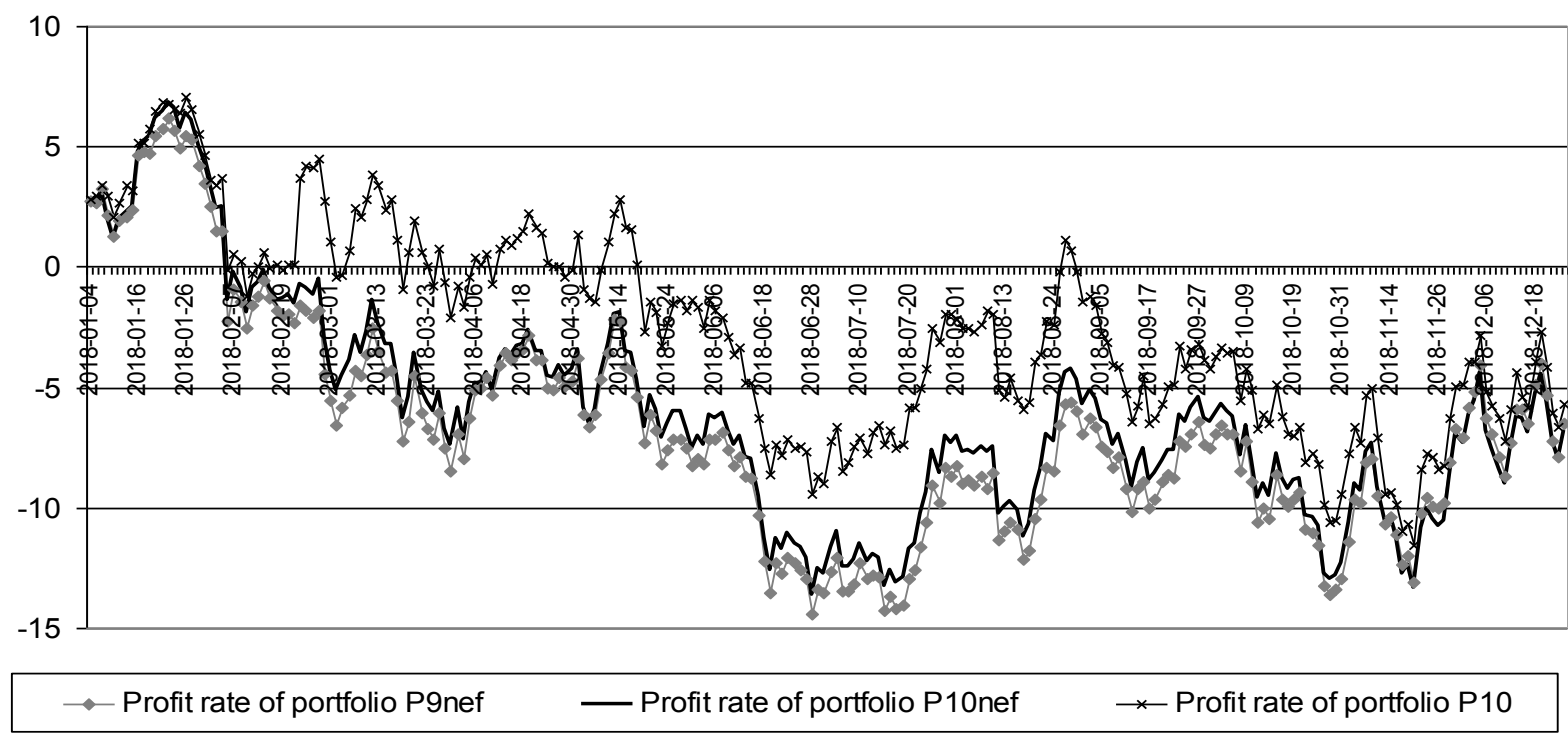

Figure 11. Profits/losses of portfolios P9nef, P10nef $(n=14)$ and P10. Source: Own study based on the data from the websites: www.bankier.pl, www.gpw.pl, http://infostrefa.com/infostrefa/pl/archiwum. 
Profits/losses of portfolios

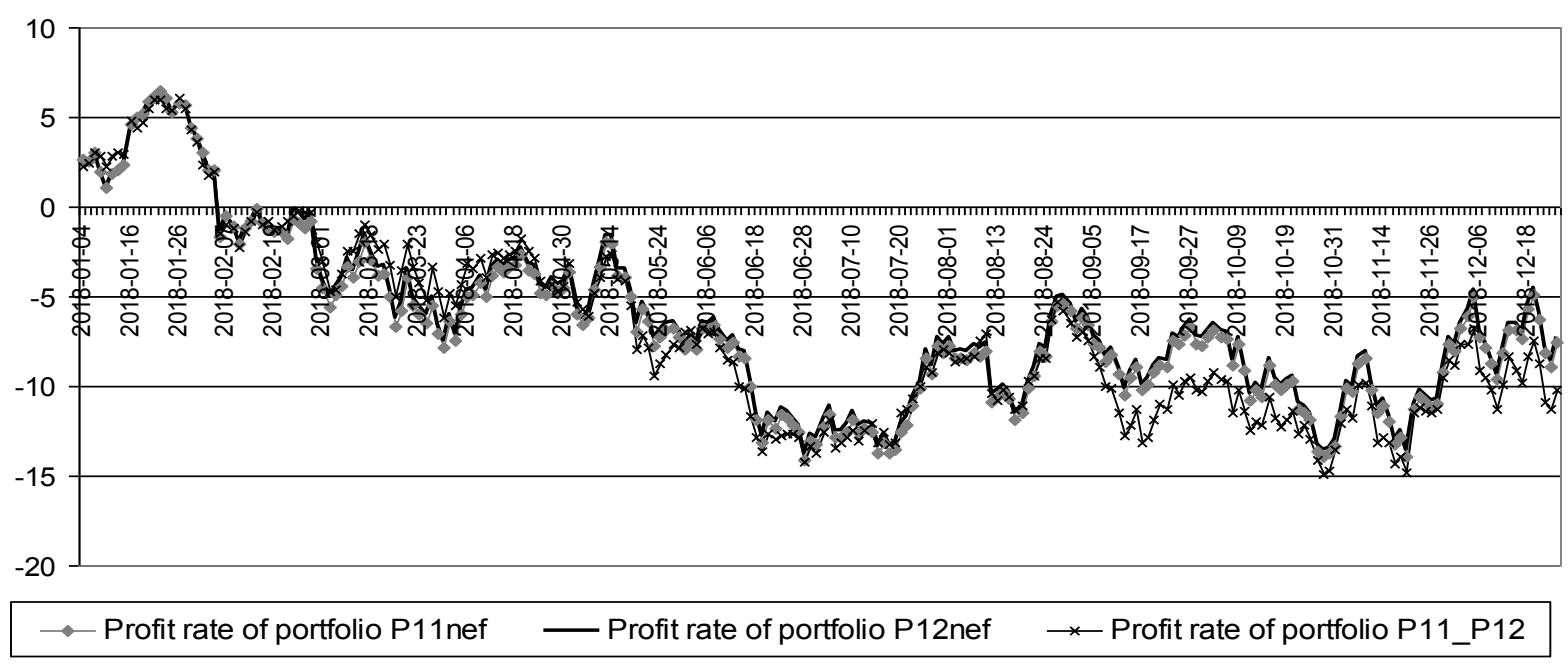

Figure 12. Profits/losses of portfolios P11nef, P12nef $(n=15)$ and P12. Source: Own study based on the data from the websites: www.bankier.pl, www.gpw.pl, http://infostrefa.com/infostrefa/pl/archiwum.

Conclusions for non-effective portfolios:

- $n=10$ - until the end of August 2018, all portfolios recorded similar results, since September, the P1nef portfolio recorded better results (mainly lower losses);

- $n=11$ - the P4nef portfolio outperformed the P4 throughout the year, but the P3nef portfolio was the best;

- $n=12$ - throughout 2018, the non-effective portfolios P5nef and P6nef recorded better results (mostly profits) than P6, in the first half of the year the results of non-effective portfolios were comparable, while in the second half of the year the best results were achieved by the P5nef portfolio;

- $n=13$ - non-effective portfolios record similar results, and definitely better than P8 (most of them record profits throughout the period);

- $n=14$ - non-effective portfolios record similar results, but this time P10 has better results;

- $n=15-$ all three portfolios record comparable results, a little bit better are the noneffective ones.

\section{Summary}

The conducted analyzes showed that effective portfolios generated from the sets selected as a result of the preliminary multi-criteria procedure most often record better results compared to the market portfolio (higher profits or lower losses). This regularity is visible especially in the 
first half of 2018, which means that after this period, the portfolio structure should be modified. The best in this comparison is the portfolio selected after the companies selection made using the FTOPSIS method. The obtained effective portfolios mainly recorded little gains or losses, therefore the concept of using the relative distance values obtained under the multi-criteria procedure to determine the portfolio structure was developed. The non-effective portfolios constructed on their basis, in most of the considered cases, recorded better results (much smaller losses or significantly higher profits) - the only exception was the portfolio consisting of 14 shares. Moreover, using the proposed concept, the portfolios selected on the basis of $S_{i}$ values obtained by the TOPSIS method had better or at least not worse results.

The analyses showed once again that the ordering of companies using the FTOPSIS method and building effective portfolios on this basis enables generating of portfolios with better results than the market portfolio. However, non-effective portfolios constructed on the basis of $S_{i}$ value may generate even better results - this time the portfolios obtained using the standard TOPSIS method as a pre-selection method are more attractive. Although the results are not unequivocal, they seem promising, and there are many indications that the proposed portfolio selection concept may actually enable the generation of attractive portfolios. Nevertheless, the presented idea requires further research.

\section{References}

1. Chen, C.T., and Hung, W.Z. (2009). A New Decision-Making Method for Stock Portfolio Selection Based on Computing with Linguistic Assessment. Journal of Applied Mathematics and Decision Science. doi: http://dx.doi.org/10.1155/2009/897024.

2. Ece, O., and Uludag, A.S. (2017). Applicability of Fuzzy TOPSIS Method in Optimal Portfolio Selection and an Application in BIST. International Journal of Economics and Finance, 9(10), 107-127. doi: https://doi.org/10.5539/ijef.v9n10p107.

3. http://infostrefa.com/infostrefa/pl/archiwum, 15.09.2020.

4. Hwang, C. L., and Yoon, K. (1981). Multiple Attribute Decision Making: Methods and Application. Berlin: Springer Verlag.

5. Jahanshahloo, G.R., Hosseinzadeh Lotfi, F., and Izadikhah, M. (2006). Extension of the TOPSIS Method for Decision-making Problems with Fuzzy Data. Applied Mathematics and Computation, 181(2), 1544-1551. doi: http://dx.doi.org/10.1016/j.amc.2006.02.057.

6. Jajuga, K., and Jajuga, K. (2015). Inwestycje - Instrumenty finansowe. Aktywa niefinansowe. Ryzyko finansowe. Inżynieria finansowa. Warszawa: PWN.

7. Kazemi, A., Sarrafha, K., and Bedel, M. (2014). A hybrid fuzzy decision making method for a portfolio selection: A case study of Tehran Stock Exchange. International Journal of 
Industrial and Systems Engineering, 18(3), 335-354. doi: http://dx.doi.org/10.1504/ IJISE.2014.065537.

8. Lai, Y.J., Liu, T.Y., and Hwang C.L. (1994). TOPSIS for MODM. European Journal of Operational Research, 76(3), 486-500. doi: http://dx.doi.org/10.1016/0377-2217(94) 90282-8.

9. Leszczyński, Z. (2004). Analiza ekonomiczno-finansowa spółki. Warszawa: PWE.

10. Liu, Y.J., Zhang, W.G., and Xu, W.J. (2012). Fuzzy multi-period portfolio selection optimization models using multiple criteria. Automatica, 48(12), 3042-3053. doi: http://dx.doi.org/10.1016/j.automatica.2012.08.036.

11. Markowitz, H.M. (1952). Portfolio selection. Journal of Finance, 7(1), 77-91. doi: http://dx.doi.org/10.2307/2975974.

12. Mayo, H.B. (2014). Inwestycje. Warszawa: PWN.

13. Nguyen, T.T., and Gordon-Brown, L.N. (2012). Fuzzy Numbers and MCDM Methods for Portfolio Optimization. International Journal of Computer, Electrical, Automation, Control and Information Engineering, 6(12), 1593-1605.

14. Pośpiech, E. (2017a). Multi-criteria fuzzy modelling in the issue of portfolio selection. In: M. Čulik (ed.), Financial Management of Firms and Financial Institutions 2017. Proceeding (Part III) (pp. 700-707). Ostrava: VŠB-TU.

15. Pośpiech, E. (2017b). Rozmyte modelowanie we wspomaganiu decyzji inwestycyjnych. Organizacja i Zarzadzanie, 113, 375-384.

16. Pośpiech, E. (2018). The Risk of Multi-Criteria Portfolios Taking into Account the Fuzzy Approach. In: M. Čulík (ed.), Managing and Modelling of Financial Risks. 9th International Scientific Conference - Proceedings (Part 2) (pp. 411-418). Ostrava: VŠB-TU.

17. Pośpiech, E. (2020a). Modelowanie nieostre $w$ wielokryterialnym wspomaganiu decyzji inwestycyjnych. Katowice: Wydawnictwo Uniwersytetu Ekonomicznego.

18. Pośpiech, E. (2020b). The Multi-criteria Fuzzy Approach to Building and Evaluating Effective Portfolios. Organizacja i Zarzadzanie, 144, 397-407.

19. Pośpiech, E., and Mastalerz-Kodzis, A. (2015). Wybór metody wielokryterialnej do wspomagania decyzji inwestycyjnych. Organizacja i Zarządzanie, 86, 379-388.

20. Pośpiech, E., and Mastalerz-Kodzis, A. (2016). Zastosowanie metody TOPSIS w ujęciu rozmytym do selekcji walorów giełdowych. Organizacja i Zarządzanie, 96, 395-404.

21. Raei, R., Bahrani Jahromi, M. (2012). Portfolio optimization using a hybrid of fuzzy ANP, VIKOR and TOPSIS. Management Science Letters, 2, 2473-2484. doi: http://dx.doi.org/ 10.5267/j.ms1.2012.07.019.

22. Roszkowska, E., Wachowicz, T. (2013). Metoda TOPSIS i jej rozszerzenia - stadium metodologiczne. In: T. Trzaskalik (ed.), Analiza wielokryterialna. Wybrane zagadnienia (pp. 11-40). Katowice: Uniwersytet Ekonomiczny.

23. Sprawozdania finansowe rozważanych spólek z lat 2015-2017. Retrieved from: http://www.money.pl/gielda/spolki-gpw/, 15.09.2020. 
24. Tarczyński, W. (2001). Rynki kapitałowe. Metody ilościowe. Warszawa: Polska Agencja Wydawnicza PLACET.

25. Tarczyński, W. (2002). Fundamentalny portfel papierów wartościowych. Warszawa: PWE.

26. Trzaskalik, T. (ed.) (2006). Metody wielokryterialne na polskim rynku finansowym. Warszawa: PWE.

27. Trzaskalik, T. (ed.) (2014). Wielokryterialne wspomaganie decyzji. Warszawa: PWE.

28. Tyran, M.R. (2001). Wskaźniki finansowe. Kraków: Oficyna Ekonomiczna.

29. www.bankier.pl, 15.09.2020.

30. www.gpw.pl, 15.09.2020. 


\title{
OPINIONS OF POLISH STUDENTS ON THE NEED FOR THE TRANSITION TO DISTANCE LEARNING WHEN FACING THE GLOBAL PANDEMIC COVID-19
}

\author{
Agnieszka PUTO \\ Technical University of Czestochowa; agnieszka.puto@pcz.pl, ORCID: 0000-0002-1947-0753
}

Purpose: The objective of the article is to present the condition of Polish universities and trends occurring in distance learning and e-learning. The results of the research conducted among students of Polish universities (N-2226), who were forced to the transition to distance learning from day to day, are presented in the article. Using well-known statistical measures, the correlations between the selected factors have been indicated. The research results on the correlations between the following variables have been presented - the opinions on the need for the transition to distance learning during the pandemic and:

- gender,

- age,

- taking up employment in addition to studying,

- an opportunity to study in a separate room.

Design/methodology/approach: For the research purposes, a well-known Internet Survey Panel was utilized, which was used to create and manage the surveys as well as to collect the results. The bivariate analysis was used, the objective of which was to determine the empirical relationship between the selected variables. In the research, among others, the following were used: Chi-Square Test for Independence, Phi-Square Test for Independence, Spearman's rank correlation test. For the data with the responses specified on the ordinal scale in the correlation analysis, Spearman's rank correlation coefficient was used.

Findings: The change in the teaching method which has been experienced in relation to the global pandemic may prove to be a breakthrough and give rise to changes in student education so as to educate the future staff of Industry 4.0 using distance learning. Increasing students' involvement in the learning process may help them acquire competences useful in their professional life more effectively.

Keywords: academic e-learning, distance learning, student, skills, stress, Industry 4.0.

Category of the paper: empirical. 


\section{Introduction}

On 2 March 2020 the Sejm of the Republic of Poland, passed a special law concerning specific solutions related to the prevention, counteraction and eradication of COVID-19, other infectious diseases and crisis situations caused by them. Originally, COVID-19 became the epidemic in Wuhan, China. Unfortunately, it spread rapidly and became an international issue (Anjorin, 2020; Burke, 2020; Phelan et al., 2020). Bill Gates called it the pandemic of the $21^{\text {st }}$ century (Gates, 2020). This unprecedented situation forced the governments of the countries to distance the society, including university students.

Higher education is facing a number of challenges nowadays, including quality, high costs, demographic decline, student diversity. On the threshold of the global pandemic associated with coronavirus disease COVID-19, Polish universities additionally have faced the need to modify their forms of education. The ban on physical contact have forced universities and students to move to work in the virtual environment, using distance learning, including e-learning.

The objective of the article is to present the condition of Polish universities and trends occurring in distance learning and e-learning. The results of the research conducted among students of Polish universities (N-2226), who were forced to the transition to distance learning from day to day, are presented in the article. Using well-known statistical measures, the correlations between the selected factors have been indicated. The research results on the correlations between the following variables have been presented - the opinions on the need for the transition to distance learning during the pandemic and:

- gender,

- age,

- taking up employment in addition to studying,

- an opportunity to study in a separate room.

It is worth pinpointing that the conducted research may become the contribution to further research in the context of Industry 4.0. Will the experience gained allow students for more effective development in the future professional life? Experiences associated with the sudden need for the transition to distance learning may enable an improvement in distance-learning courses and their adjustment to the needs of users. They are also a type of preparation to a remote form of education which is increasingly preferred by enterprises, particularly the ones aspiring to be Factories 4.0. 


\section{The condition of higher education in Poland at the end of 2018}

In Poland, there are 392 universities, including130 public ones and 262 non-public ones, including 15 run by religious organizations. As of 31 December 2018, there were 1230.3 thousand students at universities, i.e. by 61.6 thousand fewer compared to the previous year, including $73.3 \%$ at public universities. In the academic year of $2017 / 18$ the graduation diploma was awarded to 327.7 thousand graduates, i.e. by $15.4 \%$ less than in 2017 . The structure of students and graduates of Polish universities is presented in Figure 1.

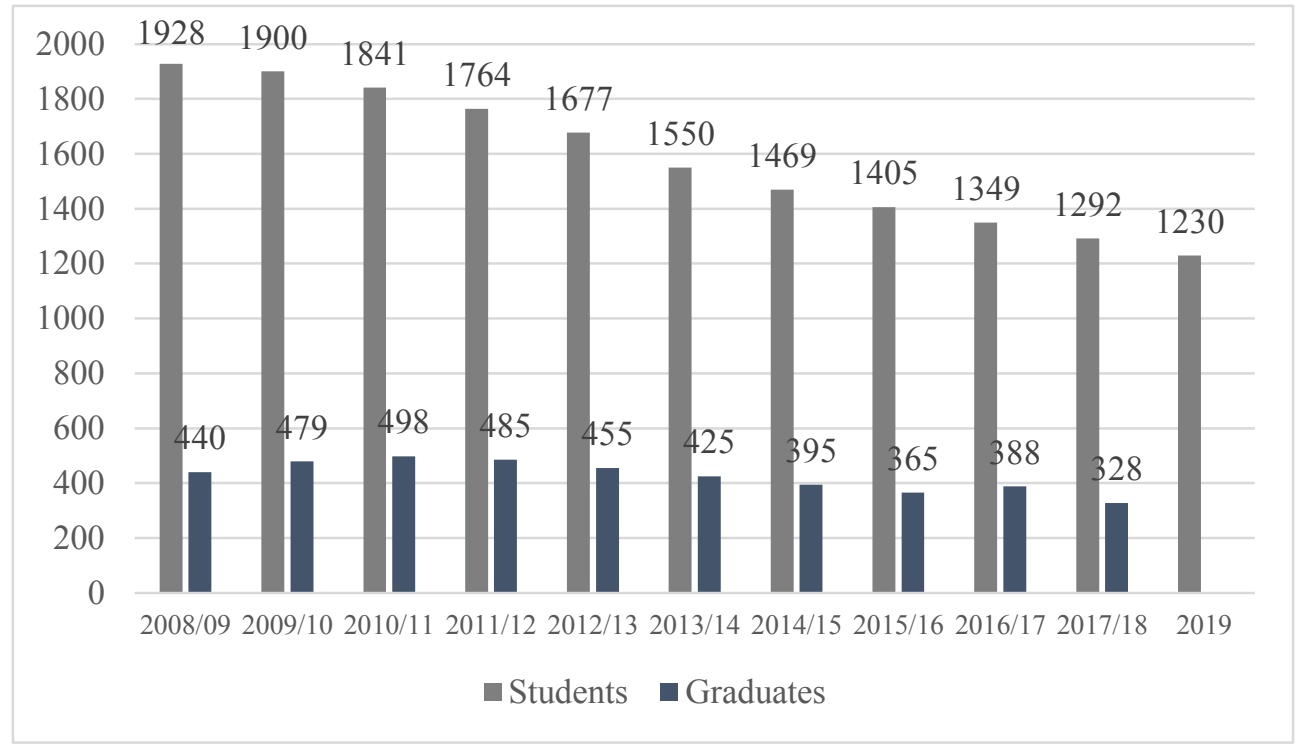

Figure 1. Students and graduates of universities in thousands (including foreigners). Central Statistical Office, 2019.

Over the last 10 years the number of students has decreased steadily, from 1927.8 thousand in the academic year of 2008/2009 to 1230.3 thousand in the academic year of 2018/2019. The largest number of graduates -497.5 thousand people - was recorded in the academic year of 2010/2011. Since then, the decrease in the number of graduates has been observed, to 327.7 thousand people in the academic year of 2017/2018. In the academic year of 2018/2019 women amounted to $58.0 \%$ of students. There were 809.3 thousand people registered for fulltime courses, i.e. $65.8 \%$ of students, whereas, 4210 thousand people for part-time courses. Nearly $64.0 \%$ of people (787.2 thousand) chose the first cycle degree programs. There were $24.1 \%$ of students in the second cycle degree programs, and $11.6 \%$ in the long-cycle Master's degree programs.

Table 1.

The number of students in Poland in 2018 in total

\begin{tabular}{|c|c|c|c|}
\hline Total & Including women & $\mathrm{A}$ & Foreigners out of the total number \\
\hline & Full-time & Part-time c & \\
\hline 1230254 & 713451 & 809259 & 420995 \\
\hline
\end{tabular}

Source: Central Statistical Office. 
Among the most frequently selected groups of courses, there were: Business, administration and law, where there were $22.0 \%$ of all the students, Technology, industry, construction (respectively 17.2\%), Social sciences, journalism and information and Health and social care (11.5\% each). 78.3 thousand foreigners, including 40.1 thousand women planned to study in Poland for at least one academic year, i.e. by $7.6 \%$ more than in the previous academic year. Most foreigners came from European countries, whereas the most numerous group was people from Ukraine (39.2 thousand, i.e. 50.1\% of all foreigners). The subsequent groups, in terms of the number, were students from Belarus (7.3 thousand - 9.3\%) and from India (3.6 thousand $4.6 \%)$. Full-time courses were taken up by 68.1 thousand foreigners $(87.0 \%)$.

\section{E-learning in Poland}

E-learning is becoming an increasingly popular form of educating students, increasing their qualifications and skills. The use of this method may considerably improve e-learning management, increase the quality of teaching individual subjects as well as the whole process of university education, reduce the costs of educating students, and also strengthen competitive advantage of the university in the education market (Jelonek, Dunay, Illes, p. 122). In a number of publications, technical and technological conditions of e-learning are pinpointed. Such a view is presented by the following definition: "e-learning is the use of electronic media for a variety of learning purposes that range from add-on functions in conventional classrooms to full substitution for the face-to-face meetings by online encounters" (Guri-Rosenblit, 2005).In Polish higher education, for several years, a trend has been observed associated with searching for new forms of using technology to support traditional academic teaching, which in turn would allow for an increase in students' involvement in the process of learning, which in turn would help them to acquire competences that are useful not only immediately after leaving the university but also in their professional life. E-learning provides opportunities which cannot be provided by traditional training. Some of the most important advantages of this form of education are primarily mobility, flexibility and interactivity. An opportunity to take part in the course, without leaving the desk, at any time convenient for oneself, is certainly an inestimable value. For employers, all of this also translates into a lower cost of implementation of this type of training. Therefore, there is no need to rent conference rooms, there is no need to arrive at the designated place and provide accommodation and board. An additional advantage of e-learning is the fact that the student or the employer is trained individually. Therefore, it depends on them how much time they will devote to training so as to complete it with a positive result. Thus, they are not dependent on the other participants of the course or the lecturer/trainer themselves. Materials and presentations can be browsed at any mobile devices at any time convenient for them. The presented material can be referred to at 
any time and the entire training can be repeated or its individual parts. This is definitely one of the main advantages of e-learning. Therefore, online education may provide educational space, allowing students to access educational opportunities, while continuing to fulfill their various work and family responsibilities (O'Shea, Stone, and Delahunty, 2015). E-learning relates to the whole of the processes associated with teaching and learning in the environment of and by means of modern information technologies, in particular the Internet. In terms of the educational approach, e-learning is a method of teaching, education supported by digital technologies. This aspect is also pinpointed by the following definition: "e-learning is the use of new multimedia technologies and the Internet to improve the quality of learning by facilitating access to resources and services, as well as remote exchange and collaboration" (Alonso et al., 2005).

Lederman (2020) rightly stated that, due to the COVID-19 crisis, teachers and students have found themselves in a situation in which they have felt compelled to adopt the digital academic experience as the summum bonum of the online teaching process. It is worth pinpointing that COVID-19 (EdSource, 2020) caused an enduring threat to our high school institutions and day by day exacerbated the teaching-learning.

\subsection{The results of own research on the opinion of Polish students in relation to the need for the transition to distance learning}

The research was conducted in the period of May-June 2020. It included a group of Polish students. The main objective of the research was to examine the opinion of Polish students on the need for the transition to distance learning during the pandemic of COVID-19. The survey questionnaire consisted of 36 questions, the questions using the Likert scale were used, both open and close-ended ones. The main objective of the research was to examine the mood of Polish students in relation to the need for the transition to distance learning. In the article, some of the survey research was presented. In the article, the results of the research into the correlations between the following variables were presented - the opinions on the need for the transition to distance learning and:

- gender,

- age,

- taking up employment in addition to studying,

- an opportunity to study in a separate room.

For the research purposes, a well-known Internet Survey Panel was utilized, which was used to create and manage the surveys as well as to collect the results. The bivariate analysis was used, the objective of which was to determine the empirical relationship between the selected variables. In the research, among others, the following were used: Chi-Square Test for Independence, Phi-Square Test for Independence, Spearman's rank correlation test. For the data with the responses specified on the ordinal scale in the correlation analysis, Spearman's rank correlation coefficient was used. Each time the value of the received coefficient was tested for 
its significance. Only statistically significant ones at the level of $\alpha=0.05$ were interpreted. For the data determined on the nominal scale in the correlation analysis, the $\chi 2$ measure and $\varphi-$ Youl's correlation coefficient were used. The value of the $\chi^{2}$ coefficient was tested for significance, and in the case of the data for which the number of cells was less than 5, Yates' correction was used.

\subsection{Characteristics of the surveyed respondents}

2226 students from Poland took part in the research. The questionnaire was sent to the university authorities, secretary's offices of individual scientific bodies, representatives of scientific circles. Most of the respondents who participated in the research were women (52\%). These were predominantly young people aged 21-25 (79\%). Most people were doing full-time $(82 \%)$ Master's courses (49\%). Nearly half of the people did not take up any gainful employment so far (41\% responded: "I do not work in addition to studying) - compare: Table 2.

Table 2.

The structure of the respondents $(N-2226)$

\begin{tabular}{|c|c|c|}
\hline Categories of the division & Specification & Percentage of the respondents \\
\hline \multirow{2}{*}{ Gender } & Female & $52 \%$ \\
\hline & Male & $48 \%$ \\
\hline \multirow{5}{*}{ Age } & Under 20 & $10 \%$ \\
\hline & $21-25$ & $79 \%$ \\
\hline & $26-30$ & $7 \%$ \\
\hline & $31-40$ & $3 \%$ \\
\hline & $41-50$ & $1 \%$ \\
\hline \multirow{2}{*}{ Type of studies } & Full-time & $82 \%$ \\
\hline & Part-time & $18 \%$ \\
\hline \multirow{3}{*}{ Degree of studies } & Bachelor's & $27 \%$ \\
\hline & Master's & $49 \%$ \\
\hline & Engineering & $24 \%$ \\
\hline \multirow{4}{*}{$\begin{array}{l}\text { Do you work in addition to } \\
\text { studying? }\end{array}$} & No & $41 \%$ \\
\hline & Yes, full-time & $34 \%$ \\
\hline & Yes, part-time & $1 \%$ \\
\hline & Yes, occasionally & $24 \%$ \\
\hline \multirow{2}{*}{$\begin{array}{l}\text { Do you have an opportunity to } \\
\text { study in a separate room? }\end{array}$} & Yes & $83 \%$ \\
\hline & No & $17 \%$ \\
\hline \multirow{3}{*}{$\begin{array}{l}\text { Do you have a connection that } \\
\text { allows you to learn via the Internet } \\
\text { without interruption? }\end{array}$} & Yes & $63 \%$ \\
\hline & No & $12 \%$ \\
\hline & Others & $25 \%$ \\
\hline \multirow{3}{*}{$\begin{array}{l}\text { Do you have the hardware and } \\
\text { software sufficient to learn via the } \\
\text { Internet without interruption? }\end{array}$} & Yes & $74 \%$ \\
\hline & No & $6 \%$ \\
\hline & Others & 20 \\
\hline
\end{tabular}

Source: The author's own research.

The condition of the Polish student's equipment is at a satisfactory level. $83 \%$ of the respondents had an opportunity to learn in a separate room, $63 \%$ of the respondents had a connection allowing them to learn via the Internet without interruption, and $74 \%$ of the respondents had the hardware and software sufficient for distance learning. Formulas should be 
aligned to the left. Each formula should have its number written in an Arabic numeral in parentheses (placed in line with the formula), aligned to the right edge of the page. For easier formatting, it is recommended to enter the formula in a table with invisible borders.

\subsection{The analysis of the research results}

The author of the research asked the students to express their opinions on a few aspects associated with distance learning. Nearly half (49\%) stated that they definitely had to deal with everything by themselves, which resulted in stress about the lack of time ( $44 \%$ - definitely yes) and the new situation (29\% - definitely yes). For a large part of the respondents, home conditions were not favorable ones (30\% - definitely yes), which was partially related to household chores (28\% - definitely yes) - compare Table 3.

Table 3.

The opinion of Polish students on the need for the transition to distance learning during the pandemic $(N-2226)$

\begin{tabular}{|l|c|c|c|c|c|}
\hline Specification & $\begin{array}{c}\text { I definitely } \\
\text { disagree }\end{array}$ & $\begin{array}{c}\text { I rather } \\
\text { disagree }\end{array}$ & $\begin{array}{c}\text { I have no } \\
\text { opinion }\end{array}$ & $\begin{array}{c}\text { I rather } \\
\text { agree }\end{array}$ & $\begin{array}{c}\text { I definitely } \\
\text { agree }\end{array}$ \\
\hline $\begin{array}{l}\text { I have an opportunity to acquire new } \\
\text { competences }\end{array}$ & $20 \%$ & $25 \%$ & $21 \%$ & $23 \%$ & $11 \%$ \\
\hline I'm getting to know new IT tools & $14 \%$ & $17 \%$ & $16 \%$ & $32 \%$ & $22 \%$ \\
\hline I'm learning time management & $20 \%$ & $20 \%$ & $17 \%$ & $25 \%$ & $19 \%$ \\
\hline $\begin{array}{l}\text { I'm learning to prioritize the tasks } \\
\text { entrusted, I first choose the most } \\
\text { important things to do and postpone the } \\
\text { less important ones }\end{array}$ & $14 \%$ & $14 \%$ & $15 \%$ & $31 \%$ & $26 \%$ \\
\hline I need to handle everything by myself & $5 \%$ & $10 \%$ & $11 \%$ & $26 \%$ & $49 \%$ \\
\hline I'm stressed about the lack of time & $11 \%$ & $12 \%$ & $13 \%$ & $20 \%$ & $44 \%$ \\
\hline $\begin{array}{l}\text { I do not have sufficient skills to handle } \\
\text { distance learning tools }\end{array}$ & $43 \%$ & $24 \%$ & $14 \%$ & $12 \%$ & $8 \%$ \\
\hline $\begin{array}{l}\text { I have a problem with the hardware } \\
\text { (a computer, a printer) }\end{array}$ & $37 \%$ & $22 \%$ & $13 \%$ & $17 \%$ & $11 \%$ \\
\hline I have no access to high-speed Internet & $36 \%$ & $18 \%$ & $14 \%$ & $17 \%$ & $15 \%$ \\
\hline I am stressed about the new situation & $21 \%$ & $13 \%$ & $15 \%$ & $22 \%$ & $29 \%$ \\
\hline $\begin{array}{l}\text { Family responsibilities make my } \\
\text { learning difficult }\end{array}$ & $18 \%$ & $16 \%$ & $15 \%$ & $23 \%$ & $28 \%$ \\
\hline $\begin{array}{l}\text { Home conditions are not favorable for } \\
\text { studying }\end{array}$ & $21 \%$ & $14 \%$ & $16 \%$ & $20 \%$ & $30 \%$ \\
\hline
\end{tabular}

Source: The author's own research.

In the first place, the hypothesis was formulated that the gender and age of students have an impact on the perception of factors associated with the need for the transition to distance learning during the pandemic (Table 4 and 5). 
Table 4.

The values of coefficients of the correlation between the responses on the need for the transition to distance learning during the pandemic and gender

\begin{tabular}{|c|c|c|c|}
\hline \multirow{2}{*}{ Response } & \multicolumn{3}{|c|}{ Coefficient } \\
\hline & Chi & Phi & p \\
\hline I have an opportunity to acquire new competences & 0.005 & 0.049 & 0.824 \\
\hline I'm getting to know new IT tools & -0.103 & 20.079 & 0.000 \\
\hline I'm learning time management & -0.078 & 11.267 & 0.001 \\
\hline $\begin{array}{l}\text { I'm learning to prioritize the tasks entrusted, I first choose the } \\
\text { most important things to do and postpone the less important ones }\end{array}$ & -0.033 & 2.043 & 0.153 \\
\hline I need to handle everything by myself & -0.071 & 9.895 & 0.002 \\
\hline I'm stressed about the lack of time & -0.067 & 8.534 & 0.003 \\
\hline I do not have sufficient skills to handle distance learning tools & -0.071 & 9.628 & 0.002 \\
\hline I have a problem with the hardware & -0.079 & 11.922 & 0.001 \\
\hline I have no access to high-speed Internet & -0.015 & 0.452 & 0.501 \\
\hline I'm stressed about the new situation & -0.130 & 32.052 & 0.000 \\
\hline Family responsibilities make my learning difficult & -0.011 & 0.223 & 0.636 \\
\hline Home conditions are not favorable for studying & -0.020 & 0.725 & 0.394 \\
\hline
\end{tabular}

Source: The author's own research.

As indicated by the statistical analyses carried out, there is no evidence of the statistically significant correlation between gender and an opportunity to acquire new competences in relation to the transition to distance learning during the pandemic.

\section{Table 5.}

The values of coefficients of the correlation between the responses on the need for the transition to distance learning during the pandemic and age

\begin{tabular}{|c|c|c|c|}
\hline \multirow{2}{*}{ Response } & \multicolumn{3}{|c|}{ Coefficient } \\
\hline & $\mathbf{R}$ & $\mathbf{t}(\mathbf{N}-2)$ & $\mathbf{p}$ \\
\hline I have an opportunity to acquire new competences & 0.009 & 0.433 & 0.665 \\
\hline I'm getting to know new IT tools & -0.029 & -1.385 & 0.166 \\
\hline I'm learning time management & -0.003 & -0.120 & 0.904 \\
\hline $\begin{array}{l}\text { I'm learning to prioritize the tasks entrusted, I first choose the } \\
\text { most important things to do and postpone the less important ones }\end{array}$ & -0.018 & -0.862 & 0.389 \\
\hline I need to handle everything by myself & -0.033 & -1.539 & 0.124 \\
\hline I'm stressed about the lack of time & -0.083 & -3.938 & 0.000 \\
\hline I do not have sufficient skills to handle distance learning tools & -0.089 & -4.226 & 0.000 \\
\hline I have a problem with the hardware & -0.064 & -3.027 & 0.002 \\
\hline I have no access to high-speed Internet & -0.073 & -3.429 & 0.001 \\
\hline I'm stressed about the new situation & -0.097 & -4.574 & 0.000 \\
\hline Family responsibilities make my learning difficult & 0.019 & 0.913 & 0.361 \\
\hline Home conditions are not favorable for studying & -0.002 & -0.104 & 0.917 \\
\hline
\end{tabular}

Source: The author's own research.

The results of the statistical research did not confirm the existence of the statistically significant correlation between age and an opportunity to acquire new competences in relation to the transition to distance learning during the pandemic. Subsequently, it was examined whether the entrepreneurship of students manifesting itself in taking up employment in the course of studies was favorable for handling the new situation (Table 6). 
Table 6.

The values of coefficients of the correlation between the responses on the need for the transition to distance learning during the pandemic and taking up employment in addition to studying

\begin{tabular}{|l|l|l|l|}
\hline \multicolumn{1}{|c|}{ Response } & \multicolumn{2}{c|}{ Coefficient } \\
\cline { 2 - 4 } & \multicolumn{1}{|c|}{$\mathbf{R}$} & \multicolumn{1}{c|}{ t(N-2) } & \multicolumn{1}{c|}{ p } \\
\hline I have an opportunity to acquire new competences & -0.077 & -3.631 & 0.000 \\
\hline I'm getting to know new IT tools & -0.097 & -4.580 & 0.000 \\
\hline I'm learning time management & -0.044 & -2.054 & 0.040 \\
\hline $\begin{array}{l}\text { I'm learning to prioritize the tasks entrusted, I first choose the } \\
\text { most important things to do and postpone the less important ones }\end{array}$ & -0.062 & -2.924 & 0.003 \\
\hline I need to handle everything by myself & 0.054 & 2.567 & 0.010 \\
\hline I'm stressed about the lack of time & -0.028 & -1.319 & 0.187 \\
\hline I do not have sufficient skills to handle distance learning tools & 0.030 & 1.403 & 0.161 \\
\hline I have a problem with the hardware & 0.019 & 0.876 & 0.381 \\
\hline I have no access to high-speed Internet & -0.031 & -1.469 & 0.142 \\
\hline I'm stressed about the new situation & -0.079 & -3.756 & 0.000 \\
\hline Family responsibilities make my learning difficult & 0.109 & 5.179 & 0.000 \\
\hline Home conditions are not favorable for studying & 0.063 & 2.966 & 0.003 \\
\hline
\end{tabular}

Source: The author's own research.

There is a statistically significant negative correlation between taking up employment in addition to studying and learning time management, at the level of -0.44 . The people employed indicate learning time management more rarely - they must have acquired these skills earlier in connection with the fulfillment of different tasks simultaneously. Another hypothesis related to home conditions in which students were to study. It was assumed that students with an opportunity to study in a separate room more favorably accept the new situation related to the need for studying at home (Table 7).

Table 7.

The values of coefficients of the correlation between the responses on the need for the transition to distance learning during the pandemic and an opportunity to study in a separate room

\begin{tabular}{|c|c|c|c|}
\hline \multirow{2}{*}{ Response } & \multicolumn{3}{|c|}{ Coefficient } \\
\hline & Chi & Phi & p \\
\hline I have an opportunity to acquire new competences & -0.087 & 13.381 & 0.000 \\
\hline I'm getting to know new IT tools & -0.126 & 29.967 & 0.000 \\
\hline I'm learning time management & -0.094 & 16.181 & 0.000 \\
\hline $\begin{array}{l}\text { I'm learning to prioritize the tasks entrusted, I first choose the } \\
\text { most important things to do and postpone the less important ones }\end{array}$ & -0.096 & 17.626 & 0.000 \\
\hline I need to handle everything by myself & 0.026 & 1.379 & 0.240 \\
\hline I'm stressed about the lack of time & 0.079 & 11.993 & 0.001 \\
\hline I do not have sufficient skills to handle distance learning tools & 0.090 & 15.386 & 0.000 \\
\hline I have a problem with the hardware & 0.155 & 46.755 & 0.000 \\
\hline I have no access to high-speed Internet & 0.117 & 26.451 & 0.000 \\
\hline I'm stressed about the new situation & 0.094 & 16.793 & 0.000 \\
\hline Family responsibilities make my learning difficult & 0.170 & 54.777 & 0.000 \\
\hline Home conditions are not favorable for learning & 0.194 & 70.245 & 0.000 \\
\hline
\end{tabular}

Source: The author's own research.

The results of the statistical analysis indicated that there is a statistically significant positive correlation between being stressed about the new situation and an opportunity to study in a separate room at the level of 0.094 . People not having a separate room assess the level of stress resulting from the new situation significantly higher. 


\section{Conclusion}

The results of the research indicate that gender and age are not significant in terms of the approach to distance learning. Home conditions in which the students study and entrepreneurial actions they have taken so far turn out to be significant. Not having a separate room to study results in higher stress related to studying. In turn, people combining professional work with studying handle time management better. Undoubtedly, distance learning is a modern form of education which is inscribed in the Industry 4.0 methods of educating staff. The concept assumes that in 10-15 years a significant part of industrial production will be carried out by smart digitized factories in which the product and process mechatronization will dominate, achieved due to saturation with automation devices, robotic production lines, remote control systems - carried out using IT and Internet tools (Saniuk, Saniuk, 2017, pp. 12-15). Changes in production processes will only be possible if adequate human capital is guaranteed. New areas, still not defined today, will require new competences and new specialists. The pace of changes may be high, therefore, the changes to the profession, subsequent retraining, the need for constant further training will be necessary. All of this causes that distance learning, which has been experienced globally, plays the key role in preparing students to act in the face of the upcoming fourth industrial revolution. In Industry 4.0, a natural thing will be to include the activities directed to training in staff development programs, using the resources stored on computers and activities performed in the network. This results from the fact that ICT significantly enables the transfer of knowledge, not only by more effective exchange of data but, most of all, due to unique methods for their presentation. Therefore, the change in the teaching method which has been experienced in relation to the global pandemic may prove to be a breakthrough and give rise to changes in student education so as to educate the future staff of Industry 4.0 using distance learning. Increasing students' involvement in the learning process may help them acquire competences useful in their professional life more effectively. You can also use abbreviated notation, when in the paper we already mention a given author, report or legal act, e.g. Smith (2017).

\section{References}

1. Alonso, F., López, G., Manrique, D., Viñes, J.M. (2005). An instructional model for webbased e-learning education with a blended learning process approach. British Journal of Educational Technology, 36(2).

2. Anjorin, A.A. (2020). The coronavirus disease 2019 (COVID-19) pandemic: A review and an update on cases in Africa. Asian Pacific Journal of Tropical Medicine, 13(5), p. 199. 
3. Burke, R.M. (2020). Active monitoring of persons exposed to patients with confirmed COVID-19-United States, January-February 2020. MMWR. Morbidity and Mortality Weekly Report, 69(9), pp. 245-246.

4. Central Statistical Office (2019). Szkolnictwo wyższe w roku akademickim 2018/2019, https://stat.gov.pl/obszary-tematyczne/edukacja/edukacja/szkolnictwo-wyzsze-w-rokuakademickim-20182019-wyniki-wstepne,8,6.html, 01.09.2020.

5. EdSource (2020). Coronavirus: Highlighting strategies for student success. Retrieved from https://edsource.org/topic/coronavirus.

6. Eze, S.C., Chinedu-Eze, V. C., \& Bello, A.O. (2018). The utilisation of e-learning facilities in the educational delivery system of Nigeria: a study of M-University. International Journal of Educational Technology in Higher Education, 15(1), p. 34.

7. Grabara, J. (2013). Sustainable Logistics Management. Sibiu Editura Universitatii "Lucian Blaga" din Sibiu.

8. Gates, B. (2020). Responding to Covid-19-a once-in-a-century pandemic? New England Journal of Medicine, 382(18), pp. 1677-1679.

9. Guri-Rosenblit, S. (2005). Distance education and e-learning: Not the same thing. Higher Education, 49(4).

10. Jelonek, D., Dunay, A., Illes, B.C. (2017). Academic e-learning management with e-learning scorecard. Polish Journal Of Management Studies, 16(2), p. 122.

11. Lederman, D. (2020). Will shift to remote teaching be boon or bane for inline learning? Inside Higher Ed., March 18.

12. O'Shea, Stone, and Delahunty (2015). I 'feel' like I am at university even though I am online. Exploring how students narrate their engagement with higher education institutions in an online learning environment. Distance Education, 36. DOI: 10.1080/ 01587919.2015.1019970.

13. Phelan, A.L., Katz R., \& Gostin L.O. (2020). The novel coronavirus originating in Wuhan, China: challenges for global health governance. Jama, 323(8), pp. 709-710.

14. Saniuk, S., Saniuk, A. (2017). Analiza sytuacji polskich przedsiębiorstw w sieciach przemysłowych w dobie Industry 4.0. Management Sciences, Nauki o Zarządzaniu, 2(31), Wrocław: Uniwersytet Ekonomiczny, pp. 12-15.

15. Zheng, Y., Ma, Y., Zhang, J. et al. (2020). COVID-19 and the cardiovascular system. Nat. Rev. Cardiol., 17, 259-260, DOI: 10.1038/s41569-020-0360-5. 



\title{
FRAMEWORK OF CONTRADICTIONS SHAPING BANK MANAGEMENT: A CONCEPTUAL PAPER
}

\author{
Marlena SMUDA-KOCOŃ \\ University of Economics in Katowice; marlena.smuda-kocon@ue.katowice.pl, ORCID: 0000-0003-0468-5708
}

Purpose: The paper is an attempt to enter the discussion in the subject literature on elucidating problems in the non-systemic approach to managing the bank as an organization. The purpose of the paper is to identify the contradictions within which banks are managed, and which are aggravated in contingency situations. Due to the sensitive matter of the services they provide, banks are institutions that require special attention particularly now, when the COVID situation is radically testing management quality.

Design/methodology/approach: The paper is the result of a literature review.

Findings: The epistemological studies conducted have culminated in a framework of contradictory determinants shaping bank management during fast-paced changes in market conditions. The theoretical construct proposed may be a point of departure for empirical verification and further analytic work on the capacity of banks to reconcile the antinomies identified in the paper.

Originality/value: The study makes it possible for managers to fill the knowledge gap with respect to areas and implications of the identified contradictions. Awareness of their existence and, as a result, management that supports processes for responding to a volatile environment is particularly useful in crisis situations. The proposed theoretical concept may be applied to identify antinomies or their lack in other areas of management research for various organization types.

Keywords: contradictions, bank management.

Category of the paper: Conceptual paper.

\section{Introduction}

As organizations, banks do not form a homogenous group. Neither does a general theory of bank management exist. Moreover, a review of the literature indicates that research on this topic is developing in different directions (liquidity, bank value, capital and risk management to name only some). In practice, the various ways of managing banks are influenced by numerous 
exogenous and endogenous factors. These determinants mean that bank management has a rapidly changing and complex nature.

At the same time, a review of the literature shows that scholars have deemed contradictions or paradoxes in management to be an important topic and are making efforts to define these terms and analyze their many dimensions. Contradictions such as those between the categories of cooperation and competition (Brandenburger \& Nalebuff, 1996; RazaUllah, Bengtsson, $\&$ Kock, 2014), stability and change (Farjoun, 2010), profit and goal (Jay, 2013), or innovation and utility (Miron-Spektor, Erez, \& Naveh, 2011) are only some of them.

Previous studies on identified contradictions in organization management have, however, primarily been focused on an aggregated level of analysis (Schad et al., 2017). From the perspective of findings from the subject literature, the topic of contradictions within which banks are managed are a research subject that requires a separate theoretical approach. There is a lack of studies that concentrate on the specific nature of financial institutions. This paper attempts to fill this research gap by putting the previous cognitive findings, which are the result of literature reviews, side by side with the reality of managing a bank in a volatile environment. The purpose of the paper is to identify the contradictions within which banks are managed, and which are aggravated in contingency situations.

Scholars (Bennett, and Lemoine, 2014; Mack et al., 2016) indicate that in conditions of volatility, uncertainty, complexity and ambiguity (a so-called VUCA world) conventional management requires constant verification. Economic practice also proves that managers are forced to look for solutions that will allow them to preserve continuity of operations also in new, often crisis situations (economic fluctuations, stock market collapse, pandemics and consequences of economic lockdowns). All these factors impact the degree of complexity involved in processes of managing a modern bank. In consequence, the awareness that contradictions exist in the management of the special organization that is a bank, and their proper leveraging, is currently gaining particular importance.

\section{Literature review}

As Choudhry (2018) notes, different aspects of banking have a highly varying nature, but regardless of whether the discussion concerns commercial or investment banking, the common goal of all banking operations is management that allows return on capital and appreciation of the banking business.

As Capiga (2010, pp. 16-17) indicates, irrespective of whether bank management is defined as a process, a system or a model, it always involves such specific features as: levels, functions, subject and orientation of management (Figure 1). 


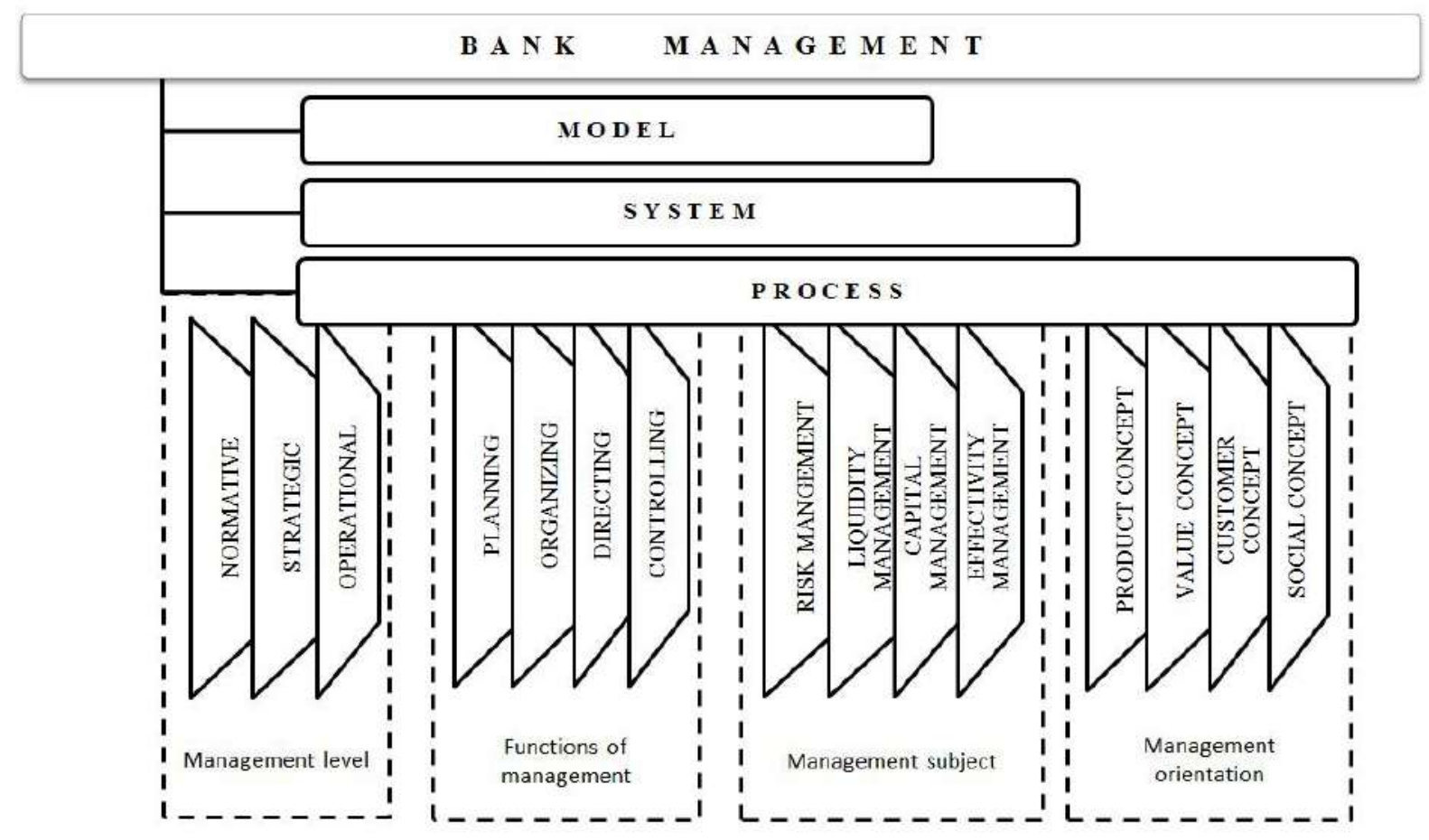

Figure 1. Bank management as process, system and model. Adapted from: Capiga M. (2010), Zarządzanie bankiem. PWN, Warszawa, pp. 16-17.

Even without delving into deeper analysis of the definitions proposed in the subject literature, it is clear that bank management is a complicated topic. Its level of complexity is increased by the fact that a bank is an organization that is simultaneously open and closed, modern and conservative, innovative and similar to others (Bakalarczyk, 2014) and thus requires rather special and constantly improved solutions that nevertheless remain linked to tradition (Bakalarczyk, 2013). Contradictions are an inherent element of these institutions' functioning.

The subject literature suggests that the existence of paradoxes should be used to build theories of management (Poole at al., 1989). Bloodgood (2010) perceives the need to manage contradictions and paradoxes from the perspective of their usefulness in organizational learning. Leclercq-Vandelannoitte (2013), meanwhile, indicates that integrating contradictions and paradoxes in change management is conducive to organizational development.

Antinomies in management and guidelines for effective operation were discussed already by Kotarbiński (1957) and Zieleniewski (1981). However, it is impossible to disagree with Lichtarski that amid the increasing dynamics and unpredictability of the environment their role is growing (Lichtarski, 2016).

A review of the subject literature indicates that the topic of contradictions in management has been analyzed in the context of entrepreneurship (Bratnicki, 2004), the decision-making and human capital management (Waldman et al., 2019), project management (Lichtarski, 2016), and strategic management processes. At the same time, Senge (1990) has written about tension, while other authors point to the existence of dilemmas in management (Hampden- 
Turne, and Trompenaars, 2000), dualisms or antinomies (Lichtarski, 2016). With respect to strategic management, paradoxes are also mentioned (De Wit, Meyer, 2007; Mesjasz, 2016). As regards the banking sector, researchers usually point out the existence of paradoxes in the area of risk management (Lim et al., 2016). While the topic of contradictions in enterprise management is nothing new, as it is rooted in philosophy (Oleksyn, 2013), academic studies investigate antinomies in bank management only fragmentarily.

For the purposes of this study it is assumed that contradictions in management are states of tension between logically justified elements that may be mutually exclusive. Therefore, decision-makers are faced with dilemmas (choice between $\mathrm{X}$ and $\mathrm{Y}$ ), have to deal with paradoxes (choice of $\mathrm{X}$ and $\mathrm{Y}$ ) or dialectics (if $\mathrm{X}$ and $\mathrm{Y}$ then $\mathrm{Z}$ ). A dialectic view of organizations is described among others by Nonaka (2002), while Cohen (1998) and Lewis (2000) talk of the nature of paradoxes inherent in the functioning of each organization.

The organization and management process may be treated as a sequence of choices between: flexibility and formalism, centralization and decentralization, an exploitation and an exploration-based approach, increasing activity and minimising interventions, an individual approach and routine action, increasing organization complexity and efforts to simplify (Smith, Lewis, 2011). According to De Witt and Meyer's (2007) concept, it is contradictions such as profitability vs. responsibility, logic vs. creativity, control vs. chaos and globalization vs. regionalization that form the basis for creating organizational strategy. Mechiche (2019) indicates three main areas of contradictions in business: leadership, strategy, and management and organizational paradoxes.

Contradictory theoretical assumptions and practical recommendations undoubtedly become fundamental principles of management in a complex world (Drucker, 1995). Furthermore, processes occurring in a volatile environment cause the rapid obsoleting of knowledge held. It becomes necessary to acquire knowledge on innovative management, and as Taleb (2020) indicates, the ability to mitigate unpredictability of phenomena and conquer chaos is gaining key importance. As a result, today it is banks that are the most serious challenge for managers. Faced with such high uncertainty they should revise their business strategies, also taking into account factors of an antinomic nature. Thus, in a further part of the paper selected contradictions of bank management have been identified and presented. 


\section{Result - framework of contradictions in management as a theoretical construct}

As a result of the literature review, contradictory determinants of bank management have been distinguished. Their significance is reinforced by the exogenous turbulence of the present epidemic. This turbulence, scholars suggest (Amankwah-Amoah et al., 2020), goes beyond past experience and knowledge due to its unpredictability and complexity.

The first antinomy is a consequence of the need to consider the legal environment, both local and international, in real solutions to bank management problems. It is not possible to apply the rules of the free market game to bank operations. Relaxing the principle of being guided in bank operations not by economics only brought disastrous economic consequences in the long term: the speculation bubble effect (Mukherjee, 2019). The rules of the bank "market game" are regulated by law and by special institutions established for that purpose (e.g. central bank, supervisory commissions). Although there is the contemporary bitcoin experiment, bitcoin trading is regulated by a law instituted by the interested parties themselves (and not by the legislature or government). In their decisions, bank management boards must take into account social and political responsibility. Particularly after the last financial crisis, much is being said about paying attention to certain bank products and services (e.g., mortgages), establishment of bank holdings in place of investment banks and the need to develop new analytical measures for the effects of bank operations (Koch, and McDonald, 2010). It has even been suggested that a new paradigm should be devised for bank management, according to which banks should build public confidence (Koch, and McDonald, 2010).

The consequences of such an orientation for bank managers' decisions also include the requirement of management procedure transparency and efforts to guarantee relatively high social responsibility of decision-makers for the economic risk taken. The modern bank is an almost ideal example of the systemic nature of economic relationships in the supra-regional dimension. The fall of a small, regional bank leads to serious problems and causes reactions on many different markets and on a far larger scale than the region in which the bank's customers are situated. A small bank does not mean small management problems, as is the case for a manufacturing micro-business. This is why guarantee funds whose purpose is to protect the system from catastrophe are created and national governments undertake rescue actions, generating public debt (very visible particularly during the current pandemic). Having a global and a systemic nature, which are features of the modern financial markets, must be recognized as important to bank management. Taking this into account means that on the one hand banks must comply with universal principles and grow similar (mimetics, emulation), and on the other they have their separate institutional logic (Lawrynowicz, 2013) and have to build a brand- and product-based competitive advantage (Piocha, and Radlińska, 2008). In banks, similarities to others and differences are visible for instance in structural solutions (Flejterski, 1999) and products (Grzegorczyk, 2001). 
Second, the bank's products and business itself are becoming increasingly complex. Banks have links with insurance and leasing companies. They are entities that create so-called financial engineering and mixed (e.g., private-public) capital. Complexity, intangibility and high pace of changes in bank products and services lead to special challenges with respect to employee skills, operation flexibility, monitoring competitor activity, innovation, but also data protection and loyalty to the institution and the customer. Hundreds of regulations impact bank activity not only externally, but also internally in the case of regulations created for the needs of management, particularly in times of economic turbulence. They should all be coherent and solve any contradictions. Fluent operation within the field of legal provisions, control, the market and internal processes are a key competence for bank executives (Gup, 1995). At the same time, being institutions that require public confidence, banks are obliged to protect access to information and to money itself, while meeting process transparency and disclosure requirements. Thus, another dilemma that decision-makers have is reconciling the transparency requirement with the need to ensure security of information and funds.

A central position in the bank's assets seems to be held by capital. Until recently, the financial capital of a bank played the key role. It is the raison d'être of the bank as an institution. Undeniably, in every financial institution it is primarily money that counts. Consequently, banks in particular are assessed through the lens of financial indicators and financial assets held. On the other hand, however, particularly after the crisis of the first decade of the 21 st century, other constituents of the organization's total capital are also considered to be important. As many authors indicate, banks are institutions in which intellectual capital plays an equally important role to financial capital (Nosowski, 2013). Because of problems with the valuation of banks' financial assets and of risk, as well as unfair practices of measurement institutes, relational, organizational and human capital have also caught decision-makers' attention. The great importance of assessing intellectual capital in banks is related to the intangible nature of banking services. Potential customers judge a bank based on the quality of services it provides, which are a function of the knowledge, competence and skills of the bank's employees. The question in economically unstable times is, to what extent will decision-makers be willing to invest in intellectual capital, and to what extent will normalizing the financial situation be the priority. It is commonly said that it is necessary to replace the authoritarian and control-driven management style by participatory management, a focus on entrepreneurship and opportunity-taking. Independence favors seizing opportunities as they appear, but is also related to higher risk.

Banks are undoubtedly entities that focus primarily on the performance of commercial goals. In the current pandemic situation, their role also includes distribution of special aid programmes, carried out in cooperation with state institutions. The present extraordinary circumstances force the banking sector to undertake above-standard action. Meeting the challenges set by the present requires flexibility while maintaining a stable capital position and liquidity. On the one hand, the inevitable changes in the area of digitalization of bank activity require adequate means for implementing investments. On the other, however, the dynamic 
increase in safety regulations may cause innovation to slow - a phenomenon that can also in itself be a source of risk. It is the management that ultimately decides whether to seize the opportunities that appear, or conversely to adopt a conservative, cautious attitude for uncertain times. Many more of these kinds of antinomies may be cited (Oleksyn, 2013). Only some of them are included in Figure 2, but the list remains open.
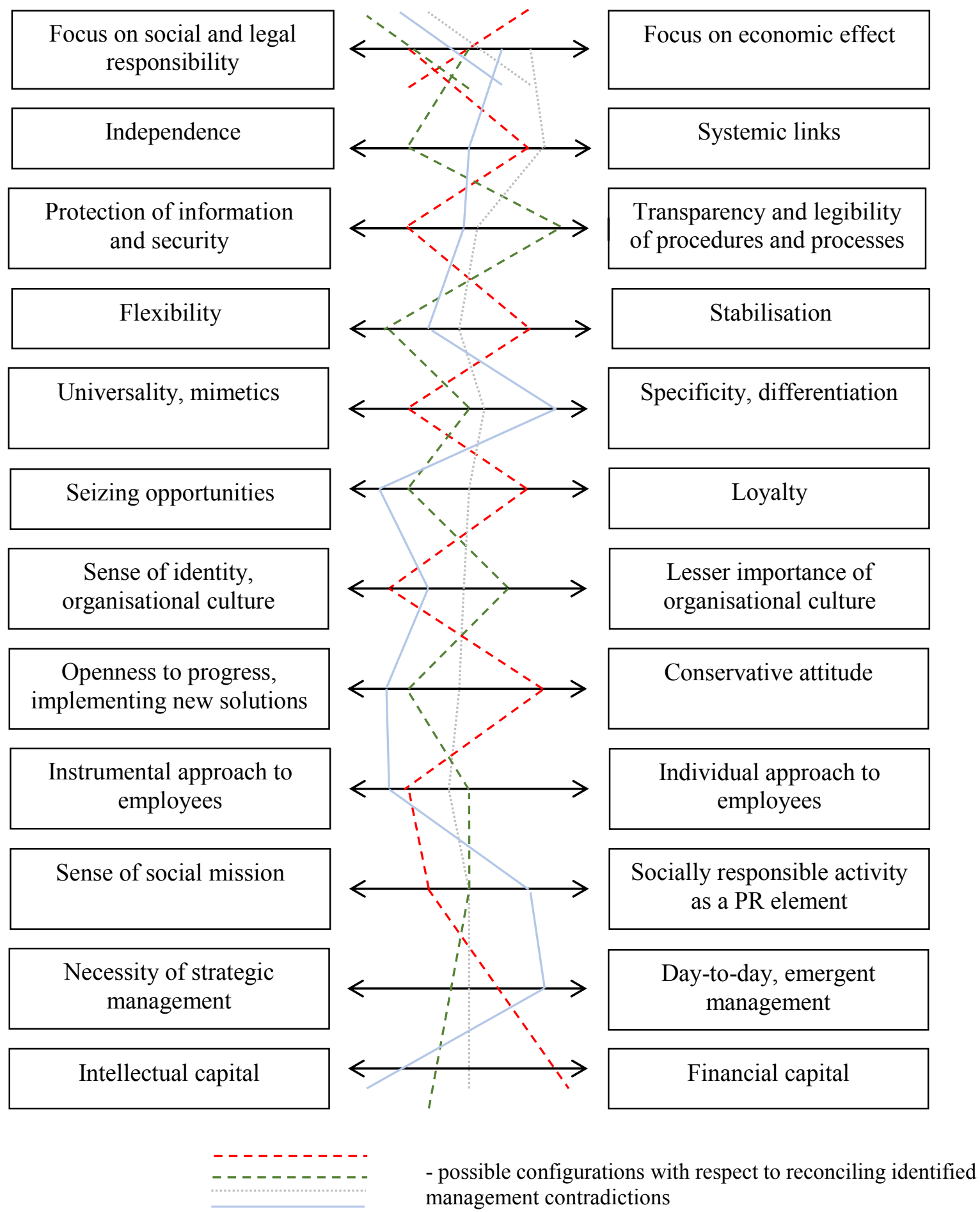

Figure 2. Framework of contradictions shaping bank management. Own compilation. 
The issue of creating a positive image by banks also remains to be addressed. On the one hand, banks have been taking socially responsible action from the start of the pandemic, but on the other, in contingencies the planning of protective measures (redundancies, changes in the credit portfolio, etc.) becomes inevitable. The factors determining which solutions will be adopted doubtless include bank size, its scope of activity and finally the level of decision makers' awareness. Contradictions may also emerge in the attitudes of executive staff. On the one hand some are visionary leaders, while on the other administration-driven leaders are mentioned (Bratnicki, 2002, pp. 98).

Importantly, the management may adopt solutions that are mid-way between the indicated extreme situations. This makes the number of possible configurations unlimited, and establishing what course they will take is particularly interesting in various turbulent conditions.

It seems interesting to establish how these configurations take shape in the case of individual banks during financial turbulence (example of the 2008-2010 crisis) or unforeseen upheavals due to the current pandemic. The management may strive to establish a state of balance between the identified incompatible areas of activity by adopting intermediary, compromise-based solutions. The existence of contradicting guidelines does not mean that in every instance, one solution has to be chosen in a dichotomous manner (Lichtarski, 2016). Bank managers often have to reconcile the identified contradictions. Thus standardization of certain actions must coexist with the possibility of undertaking atypical projects and solving problems unconventionally (Kousholt, 2007). Intellectual capital should be supported by the appropriate material capital, and focus on economic effect should not preclude socially responsible operations. It may be expected that depending on the external and internal determinants present, the point of gravity will move towards one extreme.

All the above determinants, but also many more specific ones (e.g. macro: those related to ideology, fashion; mezzo: to the political system, economic opportunities, development of information technologies, openness to capital flow; micro: to individuals and situations) mean that bank management is quite dynamic and requires a constant search for original and innovative solutions.

\section{Discussion}

In management we encounter various contradictions, and only selected examples have been presented above. Many of the principles of management fall somewhere between the extremes of categories like change management - stabilization, control - autonomy, permanence flexibility. 
It should be noted that the proposed theoretical concept assumes a number of generalizations and may be treated as a point of departure for building other expanded variants. On the other hand, the high level of generality makes it possible to successively verify the topic and allows the observed antinomies to be described in more detail depending on the features of the organization studied. The high, negative pace of changes in the environment emphasizes the necessity of detecting and further analyzing them. The conditions present in the environment of modern organizations, which may lead to the intensification of the observed contradictions, support the need for even simplified studies. At the same time, in a period where much focus is placed on sustainable development, it should be considered whether it is harmony that is the most important measure of success, or rather the ability to deal with clashing forces (Bratnicki, 2002, p. 84).

\section{Summary}

The article uses the achievements of modern strategic management to identify contradictions in bank management. The priority for banks is to satisfy the demands placed on them by the COVID situation. Moreover, establishing and verifying which areas of bank management and their related contradictions are the most important in assessing a financial institution is not only a theoretical contribution, but also has practical implications. The structure of the research tool proposed in the paper may be the starting point for empirical verification and further analytic work on the capacity of banks to reconcile the antinomies identified in the paper. Analysis of banks' management operations and practices is a challenge for future research. Identifying whether and how far, according to the banks' judgement, regulatory pressure impedes innovation, or whether and how far the necessity of maintaining security standards in periods of turbulence in the environment hampers digital transformation and processes of technological and personal change has a key importance for future bank functioning. It becomes relevant to investigate whether and to what extent, under conditions of uncertainty and volatility of the environment, managers attempt to reconcile the identified contradictions and how effective any compromise-based solutions are. The proposed framework of contradictions opens a new research perspective for analyzing banks. 


\section{References}

1. Amankwah-Amoah, J., Khan, Z., Wood, G. (2020). COVID-19and business failures: The paradoxes of experience, scale and scope for theory and practice. European Management Journal, pp. 1-5. doi: 10.1016/j.emj.2020.09.002.

2. Bakalarczyk, S. (2013). Modern bank management. Lap Lambert Academic Publishing.

3. Bakalarczyk, S. (2014). Innovation Management by Banks. Warszawa: Difin.

4. Bennett, N., and Lemione, G.J. (2014). What a difference a word makes: Understanding threats to performance in a VUCA world. Business Horizons, pp. 1-7. doi:10.2139/ ssrn. 2406676.

5. Bloodgood, J.M., and Chae, B. (2010). Organizational paradoxes: dynamic shifting and integrative management. Management Decision, Vol. 48 No. 1, pp. 85-104. https://doi.org/10.1108 / 00251741011014472.

6. Brandenburger, A.M., Nalebuff, B.J. (1996). Co-opetition. New York: Doubleday.

7. Bratnicki, M. (2004). Organizational Enterpreneurshipscape: Contradictions, Processes, Dimensions, Forms and Questions. Dabrowa Gornicza: Academy of Business in Dabrowa Gornicza.

8. Capiga, M. (2010). Zarzadzanie bankiem. Warszawa: PWN.

9. Choudhry, M. (2018). An introduction to banking principles, strategy and risk management. Wiley: Chichester West Sussex.

10. Drucker, P.F. (1995). Zarządzanie w czasach burzliwych. Kraków: Wydawnictwo Akademii Ekonomiczne.

11. Eisenhardt, K.M., and Martin, J.A. (2000). Dynamic capabilities: What are they? Strategic Management Journal, Vol. 21, pp. 1105-1121.

12. Farjoun, M. (2010). Beyond dualism: Stability and change as a duality. Academy of Management Review, 35(2), pp. 202-225.

13. Flejterski, S. (1999). Różnicowanie struktur we współczesnej bankowości. Szczecin: WNUS.

14. Flejterski, S. (2012). Niestabilne equailibrium: w poszukiwaniu nowego paradygmatu w bankowości. In: I. Pyka and J. Cichorska (Eds.), Finanse $w$ niestabilnym otoczeniu dylematy $i$ wyzwania: bankowość (pp. 39-46). Katowice: Wydawnictwo Uniwersytetu Ekonomicznego.

15. Grzegorczyk, W. (2001). Produkty bankowe. Rozwój i sprzedaż. Warszawa: Biblioteka Menedżera i Bankowca.

16. Gup, B.E. (1995). The Bank Director's Handbook: The Board Member's Guide to Banking \& Bank Management, Hardcover: Irwin Professional Publishing.

17. Hampden-Turner, C., Trompenaars, A. (2000). Building cross-cultural competence: how to create wealth from conflicting values. Chichest: Wiley. 
18. Jay, J. (2013). Navigating paradox as mechanisms of change and innovation in hybrid organizations. Academy of Management Journal, 56(1), pp. 137-159.

19. Koch, T.W., MacDonald, S.S. (2010). Bank Management. Mason: Sounth Wester Cengage Learning.

20. Kotarbiński, T. (1957). Wybór pism, t. 1: Myśli o działaniu. Warszawa: PWN.

21. Kousholt, B. (2007). Project Management - Theory and Pracitice. Copenhagen: Narayana Press.

22. Ławrynowicz, W. (2013). Tożsamość organizacyjna banków spółdzielczych w Polsce. Ujęcie instytucjonalne. Warszawa: Poltext.

23. Leclercq-Vandelannoitte, A. (2013), Contradiction as a medium and outcome of organizational change: a Foucauldian reading. Journal of Organizational Change Management, Vol. 26, $n r$ 3, pp. 556-572, https://doi.org/10.1108/09534811311328579.

24. Lewis, M.W. (2000). Exploring Paradox: Toward a More Comprehensive Guide. Academy of Management Review, 25(4), pp. 760-776. doi: 10.5465/AMR.2000.3707712.

25. Lichtarski, J.M. (2016). Antynomie w zarządzaniu projektami. Prace Naukowe Uniwersytetu Ekonomiczne we Wrocławiu, nr 421, pp. 346-359.

26. Lim, Ch.Y., Woods, M., Humphrey, Ch., Seow, J.L. (2016). The paradoxes of risk management in the banking sector. The British Accounting Review, Vol. 49, pp. 75-90, https://doi.org/10.1016/j.bar.2016.09.002.

27. Luhmann, N. (1995). The paradoxy of observing system, Cultural Critique, No. 31, The Politics of Systems and Environments, Part II, pp. 37-55. Minneapolis: University of Minnesota Press.

28. Mack, O., Khare, A., Kramer, A., Burgartz, Th. (2016). Managing in a VUCA World. Cham Heidelberg: Springer.

29. Mechiche, M. (2019). Paradoxes of Business: Towards A Practice Model to Attend to Paradox Tensions in Organizations and Develop the Leaders of Tomorrow. International Journal of Applied Research in Management and Economics, 2(1), pp. 45-50.

30. Mesjasz, Cz. (2016). Paradoksy w systemowej teorii zarządzania. Prace Naukowe Uniwersytetu Ekonomicznego we Wrocławiu, nr 421, pp. 397-417.

31. Meyer, R., De Vit, B. (2007). Strategy Synthesis: Resoving Strategy Paradoxes to Create Competitive Advantage. Cengage Learning EMEA.

32. Miron-Spektor, E., Gino, F., \& Argote, L. (2011). Paradoxical frames and creative sparks: Enhancing individual creativity through conflict and integration. Organizational Behavior and Human Decision Processes, 116(2), pp. 229-240.

33. Mukherjee, S. (2019). Existence of Speculative Bubbles for the US at Times of Two Major Financial Crises in the Recent Past: An Econometric Check of BitCoin Prices. In: U. Hacioglu (Ed.), Blockchain Economics and Financial Market Innovation (pp. 475486). Springer. 
34. Nosowski, A. (2013). Modelowanie zorientowane biznesowo a kapitał intelektualny banku. Zarzadzanie i Finanse, $n r$ 2, pp. 406-417.

35. Oleksyn, T. (2013). Różne filozofie zarządzania. In: T. Oleksyn (Eds.), Filozofia a zarzadzanie (pp. 63-66). Warszawa: Wolters Kluwer.

36. Piocha, S., Radlińska, K. (2008). Konkurencja i konkurencyjność sektora banków komercyjnych. Zeszyty Naukowe Wydziału Nauk Ekonomicznych Politechniki Koszalińskiej, nr 12, pp. 119-132.

37. Poole, M.S., van de Ven, A.H. (1989). Using Paradox to Build Management and Organization Theories. The Academy of Management Review, Vol. 14, No. 4, pp. 562-578.

38. Raza-Ullah, T., Bengtsson, M., Kock, S. (2014). The coopetition paradox and tension in coopetition at multiple levels. Industrial Marketing Management, 43(2), pp. 189-198.

39. Schad, J., Lewis, M.W., Raisch, S., Smith, W.K. (2017). Paradox Research in Management Science: Looking Back to Move Forward. Academy of Management Annals, Vol. 10, No. 1, https://doi.org/10.5465/19416520.2016.1162422.

40. Senge, P.M. (1990). Piąta dyscyplina. Warszawa: PWN.

41. Smith, W.K., Lewis, M.W. (2011). Toward a Theory of Paradox: A Dynamic Equilibrium Model of Organizing. Academy of Management Review, 36(2), pp. 381-403. doi: 10.5465/ AMR.2011.59330958.

42. Taleb, N.N. (2020). Antykruchość: jak żyć w świecie, którego nie rozumiemy. Poznań: Wydawnictwo Zysk i S-ka.

43. Waldman, D.A., Putnam, L.L., Miron-Spektor, E., Siegel, D. (2019). The role of paradox theory in decision making and management research. Organizational Behavior and Human Decision Processes, Vol. 155, pp. 1-6.

44. Wit, B., Meyer, R. (2010). Strategy Synthesis: Resolving Strategy Paradoxes to Create Competitive Advantage. Cengage Learning EMEA.

45. Zieleniewski, J. (1981). Organizacja i zarządzanie. Warszawa: PWN. 


\title{
EFFECTIVENESS EVALUATION OF THE COMMUNICATION PROCESS WITH EMPLOYEES ON THE EXAMPLE OF THE KAUFLAND POLAND BRANCH
}

\author{
Dorota SOBOL ${ }^{1 *}$, Aleksandra PIETRZAK ${ }^{2}$ \\ ${ }^{1}$ University of Warma and Mazury in Olsztyn, Faculty of Economic Sciences; dorota.sobol@uwm.edu.pl, \\ ORCID: 0000-0002-2514-9560 \\ ${ }^{2}$ University of Warma and Mazury in Olsztyn, Faculty of Economic Sciences; pietrzakola1@wp.pl \\ * Correspondence author
}

Purpose: The main purpose of the research was to analyze and evaluate the effectiveness of the communication process with employees on the example of the Kaufland Polska branch located in the Mazowieckie Voivodeship. A complementary goal was to identify the most important managerial tasks and skills in this area.

Design/methodology/approach: The article presents a theoretical approach to internal communication based on the literature, while the own research allowed for the analysis and evaluation of this process. The survey method was used, in which the research technique was used in the form of an interview according to the developed questionnaire.

Findings: Communication between the manager and employees is two-way and there is feedback, both sides show commitment and show an open attitude to make the process effective. Employees assessed the current internal communication process and the functions performed by the manager in this process very positively, however, they are also able to notice shortcomings related to communication.

Research limitations/implications: The study was conducted among all employees of only one branch of Kaufland Polska. An additional limitation was the epidemiological situation in Poland caused by covid-19, which made it impossible to apply an additional research method - a participant observation method that would enrich the results obtained in the main study.

Practical implications: In order to improve the internal communication process, the manager should encourage employees to express their opinions and suggestions on topics related to their job position, team communication or observed problems. It is important that the manager cares about the quality and continuous improvement of the communication process and his own interpersonal skills, so that there are as few communication barriers as possible.

Originality/value: The communication process should be tailored to the specificity of the organization. It is completely different in a small enterprise than in a large hypermarket chain, where there are teams of employees in various positions, working in shifts, often with customers present and under time pressure. The obtained research results made it possible to assess the current internal communication process, and the application of the formulated guidelines will certainly improve the communication process and increase employee involvement, and ultimately the quality of service and customer satisfaction. 
Keywords: manager, internal communication process.

Category of the paper: research paper.

\section{Introduction}

Internal communication is a pillar of a strong organization and is perceived as an important factor contributing to the development of the organization (Meyer, 2014). Practice shows that most of the problems in the organization are the result of improper communication. It is not surprising that there is a constant interest in this subject. Nowadays, in the 'information age', which surprises with the amount and speed of information and the development of communication tools, effective communication does not lose its importance and topicality. It is the foundation of the success of each group (Penc, 2001). Currently, it is said that communication is the engine of all changes, and its benefits will be achieved much faster (Quirke, 2011; Kożusznik, 2011).

Effective communication takes place when the flow of information takes place in the right form and time, and the messages are received in accordance with the intention of the sender and produce the intended effect. In order for communication to run smoothly and effectively, there must be feedback between the participants in the process.

The communication process depends on many factors and should be tailored to the specifics of the organization. It is completely different in a small enterprise than in a large hypermarket chain, where there are teams of employees in various positions, working in shifts, often in the presence of customers.

The priority of all employees is to satisfy each client every day. The implementation of the business goal and assumptions is the result of the effort and commitment of the entire team. Daily interactions and relations between a manager and employees are an integral part of the work performed at individual positions, therefore the quality of communication determines the quality of work results. It also indicates the daily challenges of the manager to unite the staff and achieve mutual success.

The article presents the theoretical approach to internal communication based on the literature on the subject, while the own research allowed for the analysis and evaluation of this process on example of the Kaufland Polska branch. 


\section{Internal communication - theoretical approach}

Communication can be seen as a 'strategic path' (Scandelius, and Cohen, 2016; Birim, 2016) in the processes of the organization's relationship with the environment (external communication) and interactions with staff (internal communication). Both types of communication should be integrated with each other. However, internal communication is one of the fundamental axes of business activities, as it constitutes the central system of all processes of the organization (Martinez, and Fernandez, 2018). For the organization to function, the tasks of individual units and teams must be carried out in a coordinated, efficient and effective manner, and the necessary harmonization of these activities would not be possible without internal communication (Yeomans, and FitzPatrick, 2017). M. Welch and P.R. Jackson (2007, p. 193) define it as 'communication between the strategic managers of the organization and its internal stakeholders, aimed at promoting involvement in the organization, a sense of belonging, awareness of a changing environment and understanding of its evolving goals'. In a metaphorical way, internal communication is defined as the bloodstream of the organization. In other terms, internal communication is a systematic process of information processing and distribution (Verčič et. al., 2012) and take place in two directions: vertically and horizontally.

Vertical communication takes place between people at different levels in the business hierarchy and can go up and down, and the criterion for applying this classification relates to the place where the initiatives come from. Downstream communication is initiated from the top management and penetrates the various levels of the organization, stopping at executive employees, and consists in communicating what is important (mission) and valued (principles) (Cornelissen, 2012). The main task is to advise, educate and instruct, inform, direct, evaluate employees and transfer the goals and tasks that are necessary for the efficient operation of the organization. It is obvious that communication is filtered, constantly modernized and held at certain levels, because each manager individually decides what information needs to be provided to employees (Kożuch, 2001). It is important for employees to receive information without delay, in a form that is useful and acceptable to them (Welch, 2012 for: Verghese, 2017), which will enable them to correctly read management's expectations and effectively perform their duties at individual work positions (Atambo, and Momanyi, 2016).

Upward communication is the transfer of information on the progress of work at lower levels to higher levels in the business hierarchy. D. Tourish and P.J. Robson (2006) emphasizes that critical upstream communication is valuable to the organization as it provides a potential safeguard against unrealistic views from senior management. In addition to feedback on the duties performed, employees should be able to communicate upwards their ideas, their own perceptions of the work environment or express opinions on plans and suggestions that may contribute to improving the profitability and efficiency of the organization (Cornelissen, 2012). 
Sharing ideas, information and opinions related to work (feedback) has been recognized as a factor stimulating employee engagement (Ruck et al., 2017). Thus, a two-way process of vertical communication can be an opportunity for employees and managers to exchange views on problems occurring in the organization, as well as participate in decision-making, by enabling employees to express their opinions on specific topics (Wilkinson et al., 2004).

Horizontal communication occurs between members of a given team, groups, departments. The most important task of this communication is the development of a natural channel of organizational coordination and elimination of problems that slow down the information provided indirectly from the common superior (Kożuch, 2001). Usually, the development of horizontal communication proves an increase in the maturity of employees who, without waiting for orders in advance, show initiative themselves, activity and creativity as well as the ability to cooperate effectively (Oleksyn, 2001).

The process of communication in the organization follows a specific model (Figure 1). Typically, in this process there is feedback between the sender and the receiver of the message, which enables a better understanding of the message and sometimes also its modification. So far, no model of internal communication has been created that would be effective in every organization. However, it should be consistent with the value system and business philosophy, as well as optimally suited to the specificity and resources of a specific entity and adapted to changing environmental conditions.

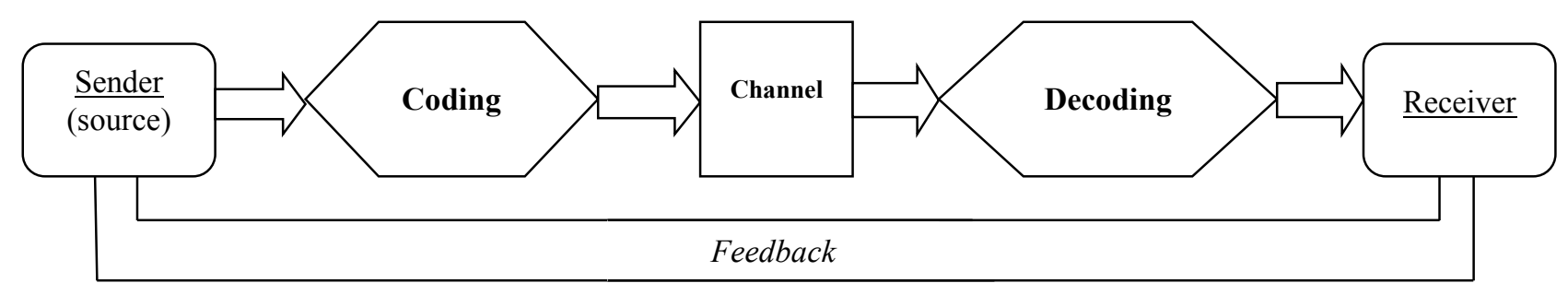

Figure 1. Model of the communication process in the organization. Adapted from: „Sztuka kierowania” by T. Oleksyn. 2001, p. 207.

In organizations, communication can be formal and informal. In the first case, communication is carried out in accordance with a hierarchical structure, division of duties, responsibilities, decision-making powers and through official information flow channels used to transmit messages. A wide range of information exchange within the organization can be in writing or orally, among others. through: e-mail, computer network, internal normative acts, information bulletins, notice boards, meetings, employee opinion polls, etc. (Oleksyn, 2001). In the process of internal communication, the use of digital solutions and tools is becoming more and more common. Information provided in this form reaches employees on time or in real time (Martinez, and Fernandez, 2018). One of the newer communication trends within the organization is presenting employees with a task in the form of a video. The idea is to replace too long emails or articles that are targeted at all employees with a short video. Research shows that over $70 \%$ of employees are more likely to watch corporate video than read long e-mail. 
As a result, employees are better able to understand the message (Tarnowski). On the other hand, social networks allow employees to quickly transfer information and provide an extensive form of dialogue. This form is characterized primarily by range, accessibility, intuitiveness in use and constantly growing usability. This area of communication is constantly evolving. It is considered an increasingly innovative way of communicating with employees in the organization (Smoląg, and Ślusarczyk, 2018). In addition, the situation caused by covid-19 and the epidemiological threat forced the reorganization of the work of many organizations, which is why the above solutions and applications, such as MS Teams, Zoom, have been widely used for ongoing contact with employees.

On the other hand, informal communication is substitute and consists in transmitting, receiving and agreeing information, behavior and actions, regardless of the defined channels and forms of information flow in the formal communication process. In this case, it is difficult to predict when and to whom the message will be addressed, as well as whether it will reach and be properly received at all (Kożuch, 2001). From the organizational level, the consequences of informal communication may be positive (e.g. reducing the information gap among employees), but also negative (e.g. leakage of information covered by a trade secret, gossip, inability to express an opinion on a given topic, anxiety among employees). Usually, the less good formal communication there is, the more informal, not always positive, communication (Oleksyn, 2001).

It is worth adding that the process of communication also has an interpersonal dimension, which consists in sending and receiving information between the sender and the recipient, causing specific effects and types of feedback. Communication in the organization can be factual, instrumental and emotional. In order for communication to be effective, it is worth building it on a level that will allow the manager to communicate during subsequent conversations. Each emotion or intention will affect the quality of the interlocutor's relationship level, or the lack of it (Kozyra, 2019). Thus, the goal of effective internal communication is also to build mutual trust between communication participants, and to increase the degree of acceptance and friendship (Waters et al., 2013).

Communication undoubtedly covers and applies to all members of a given organization, therefore it is important to determine the way of cooperation within the organization and to indicate the most important communication roles and tasks at individual levels of the organizational structure.

As D.H. Holt noticed, 'managers work on the system, contractors work on the system. Managers are responsible for creating, shaping and modifying the system in such a way that all people working in it can act in the most effective way to achieve the goals of the organization' (Bolesta-Kukułka, 2003, p. 22). Thus, managers as creators of success organizations, define work processes (including the internal communication process) and decide on the way of using the organization's resources to achieve its goals. Therefore, as J. George emphasizes, 'managers of all levels should be good communicators' (Slijepčević et al., 2018, p. 329). The task of the 
communicator is to activate employees to two-way communication to ensure the possibility of dialogue (e.g. through face-to-face discussions, online meetings, joint analysis of topics highlighted on internal blogs, surveys). Employees should be able to express their opinions and share ideas that are aimed at improving or introducing change (Ruck et al., 2017). Employee involvement allows managers to get a complete picture of a specific problem and enrich the decision-making process with new solutions (Robson, and Tourish, 2005).

On the other hand, the target recipients of internal communication are all employees of the organization perceived as internal stakeholders or 'ambassadors of the organization' who can best represent the values of the organization and influence the formation of its reputation in business (Slijepčević et al. 2018).

In any organization, both managers and employees need appropriate systems and means of communication, as well as appropriate communication skills related to the way messages are communicated and information circulated. Effective communication is the foundation of the success of any group, and the success of the communication process is its continuous improvement (Penc, 2010).

According to P. Jaworowicz, M. Jaworowicz (2017) and J. Penc (2010), effective communication in a modern organization consists mainly of the following elements:

- clearly stated intention of the sender;

- an appropriately selected form of communication using the language of the recipient;

- a convincing and motivating message;

- matching the type of recipient;

- making sure that the message was received and understood by the recipient;

- observing the recipient's reaction, especially when the employee's favor is expected;

- holding a reply message when necessary.

To sum up, it can be assumed that internal communication is a comprehensive process that includes various ways of employee interaction within the organization (Cornelissen, 2012). Its importance is emphasized by both theoreticians and practitioners. Effective internal communication is a prerequisite for achieving motivation and job satisfaction, employee engagement, productivity growth and, as a result, solid business performance of the organization (Meyer, 2014; Ruck et al., 2017; Slijepčević et al., 2018; Potocki et al., 2011; Verčič et al., 2012). Additionally, effective communication can reduce uncertainty and gossip, serve as a catalyst for change, and contribute to community awareness, knowledge sharing and trust building among members of the organization (Verghese, 2017). On the other hand, dysfunctions in the internal communication process are detrimental to managers, employees and the organization as a whole - they can lead to poor performance, strained interpersonal relationships, poor service, and dissatisfied customers (Atambo, and Momanyi, 2016). 
In order to fully use the potential of the organization, it is necessary to simultaneously involve employees and managers in improving the internal communication process. The challenge of today's leaders-managers is to build bilateral, trust-based relationships with employees in order to improve the efficiency of the organization (Yeomans, and FitzPatrick, 2017), and in a broader perspective, customer satisfaction, which is 'the only path to true enterprise development' (Reichheld, 2006, p. 118).

\section{Methodology of the conducted research and characteristics of the respondents}

The main purpose of the research was to analyze and evaluate the effectiveness of the communication process with employees of the Kaufland Polska branch located in the Mazowieckie Voivodeship. The Kaufland hypermarket chain belongs to the German Schwarz group and sells food and everyday items. Kaufland hypermarkets operate in European countries, including in Germany, the Czech Republic, Slovakia and Croatia. Kaufland in Poland has been present since 2001. As of January 2020, there are 213 Kaufland stores in Poland, which employ 15,000 people (Kaufland.pl/...).

The subject of the study was a branch of the Kaufland hypermarket chain operating in the Mazowieckie Voivodeship since 2010. Throughout the period of operation, the store has been constantly strengthening its position on the market, and customers are already convinced of the quality of services and product offer. Efficiency and maintenance on the market is proof of modern management of the company, consistent with the fundamental values of the company, such as: efficiency, dynamics and fair play as well as management principles, which are an obligation towards employees. The head of the department attaches great importance to ensuring the timely execution of tasks at a high level. One of the main factors influencing the efficiency of the store is undoubtedly communication with employees.

An empirical study, aimed at obtaining primary data, was carried out among all employees of the Kaufland Polska branch located in the Mazowieckie Voivodeship. The results were supplemented by a telephone interview with the head of this department. In order to ensure complete anonymity of respondents, the exact location of the enterprise is not disclosed.

The survey method was used, in which the research technique was used in the form of an interview according to the developed questionnaire. The study was conducted in April 2020. Due to the ongoing epidemiological threat in Poland and the risk of the spread of the coronavirus, the study was conducted in the form of an online survey, lasted 7 days and proceeded smoothly. 
All employees completed the survey correctly, which means 100\% feedback. Analyzing the gender structure of the respondents, the enterprise employs significantly more women $(85 \%)$ than men $(15 \%)$, which may be related to the dominant share of women employed in administrative and customer service positions in commercial enterprises. The largest number of respondents indicated up to 50 thousand as their place of residence. residents $(57 \%), 37 \%$ of the respondents indicated that they live in the countryside, and $7 \%$ of the respondents live in a city with more than 100,000 . residents. This means that more than half of the respondents live and work in the same city, the rest commute to work from neighboring towns. Taking into account the age of the respondents, it can be noticed that most people are in the age range from 31 to $40(46 \%)$, then in the age range from 41 to $50(30 \%)$ and currently there are no employees under the age of 20.

Table 1.

Characteristics of the respondents

\begin{tabular}{|c|c|c|c|}
\hline & & Share in numbers & Percentage \\
\hline \multirow[t]{2}{*}{ Sex } & Woman & 63 & $15 \%$ \\
\hline & Man & 11 & $85 \%$ \\
\hline \multirow[t]{4}{*}{ Age } & $20-30$ years & 15 & $20 \%$ \\
\hline & $31-40$ years & 34 & $46 \%$ \\
\hline & $41-50$ years & 22 & $30 \%$ \\
\hline & 51 years and older & 3 & $4 \%$ \\
\hline \multirow{3}{*}{$\begin{array}{l}\text { Place of } \\
\text { residence }\end{array}$} & Village & 27 & $36 \%$ \\
\hline & Town up to 50.000 inhabitants & 42 & $57 \%$ \\
\hline & Town up to 100.000 inhabitants & 5 & $7 \%$ \\
\hline \multirow[t]{4}{*}{ Seniority } & up to 1 year & - & - \\
\hline & from 2 to 5 years & 17 & $23 \%$ \\
\hline & from 6 to 10 years & 29 & $39 \%$ \\
\hline & over 10 years & 28 & $38 \%$ \\
\hline \multirow{4}{*}{$\begin{array}{c}\text { Current } \\
\text { workplace }\end{array}$} & $1^{\text {st }}$ workplace & 11 & $14 \%$ \\
\hline & $2^{\text {nd }}$ workplace & 27 & $37 \%$ \\
\hline & $3^{\text {rd }}$ workplace & 27 & $37 \%$ \\
\hline & $4^{\text {th }}$ and more & 9 & $12 \%$ \\
\hline
\end{tabular}

Source: own study based on research.

Most of the employed are people with 6 to 10 years of work experience, such an answer was given by $39 \%$ of the respondents. Slightly fewer people answered that their work experience exceeds 10 years (38\%). On the other hand, the lowest number of people indicated that they had a professional experience of 2 to 5 years $(23 \%)$. It can be observed that for the majority of respondents the current workplace is the second or third place of employment such an answer was given by a total of $74 \%$ of the respondents. The youngest staff admitted that Kaufland is their first place of employment. On the basis of the answers obtained, it can be concluded that the percentage of respondents has been employed in the enterprise almost from the beginning of its 10 -year operation, the team consists mainly of employees with many years of professional experience. 


\section{Characteristics of the communication process with employees}

The internal communication process in the Kaufland Polska branch is formalized. The efficient flow of information and action begins with the manager. The manager provides the employees with all necessary messages on an ongoing basis and in person, which allows to avoid distortions and misunderstandings. $\mathrm{He}$ is aware that an informed employee is an appreciated employee who is more committed to achieving the company's goal. Systematic sharing of work-related information is fundamental to building mutual trust and commitment across the group. The success of communication with employees is not attack and criticism, but effective information, consultation and careful listening to their opinions. The course of the conversation largely depends on him, he is responsible for maintaining the appropriate tone of the conversation and providing the necessary information as well as the quality and continuity of the conversation.

Each message that is to be sent to employees is carefully thought out in advance and built in such a way that it is fully understood by each employee. However, in the event of additional queries and difficulties - especially in the case of new, complex tasks - the manager is available to help and support. According to the manager, the best and most convenient form of communication with the team is a direct meeting. Then he is able to notice how the employee accepted the task, or if he has any doubts. The employee can ask questions and the manager answers immediately. The store staff is located in one facility, so the best form of communication is a face-to-face meeting. In a situation where the employee is outside the facility, the manager chooses the telephone form of contact. On the other hand, he provides general information by e-mail, which he himself receives by e-mail. Guidelines for new, complex procedures and with a lot of detailed information are provided in writing because he is confident that the employee can always remember what he is obliged to do. He communicates current tasks orally during a meeting with the team and divides activities for each employee.

The manager knows the skills and disposition of his employees, which makes it easier for him to assign individual and group tasks. In the latter case, the team can work more effectively, without disputes, and employees are more willing to share knowledge. Based on his own observations of team relations and the quality of internal communication, he decides whether there is a need to organize a communication meeting.

The manager describes his relations with employees as good, but usually does not give the opportunity to comment on assigned tasks in order to avoid unnecessary chaos in the team. Tries to rationally assign tasks, taking into account the character and predispositions of employees. He tries to consult decisions about the team with employees. Although it is demanding, it cares for a friendly working atmosphere, as it affects the satisfaction and efficiency of everyone's work. In his opinion, the ability to assign tasks and good communication between the leader and the team is the key to the company's success. 
The interview with the manager made it possible to characterize the communication process in the surveyed company and to compare its responses with the responses of employees, which are presented later in the article $^{1}$.

\section{The results of the survey}

The main purpose of the manager's communication with employees, indicated by the respondents, is assigning and discussing the task ( $77 \%$ and $70 \%$ of responses, respectively) and checking the progress of work (57\%). The following answers were given in the following places: gaining opinions on a given topic, motivating and evaluating conversation, solving problems of the organization. All the above answers were selected by $5 \%$ of the respondents.

Employees positively assessed the effectiveness of the current internal communication process. More than half of the respondents stated that the messages conveyed by the manager are fully understandable. If necessary, employees can count on a detailed explanation of the message. Usually, such inquiries concern the clarification of new, complex or higher difficulty tasks. Respondents' responses also indicate that the manager often allows employees to ask questions (Figure 2). Such an attitude proves the willingness to explore the subject and the commitment of employees' forces to the most effective implementation of the activity.

The relationship between the supervisor and the subordinate was assessed as good by the respondents, employees are aware that they can ask questions and openly talk to the manager, but usually they are not able to comment on the assigned tasks.

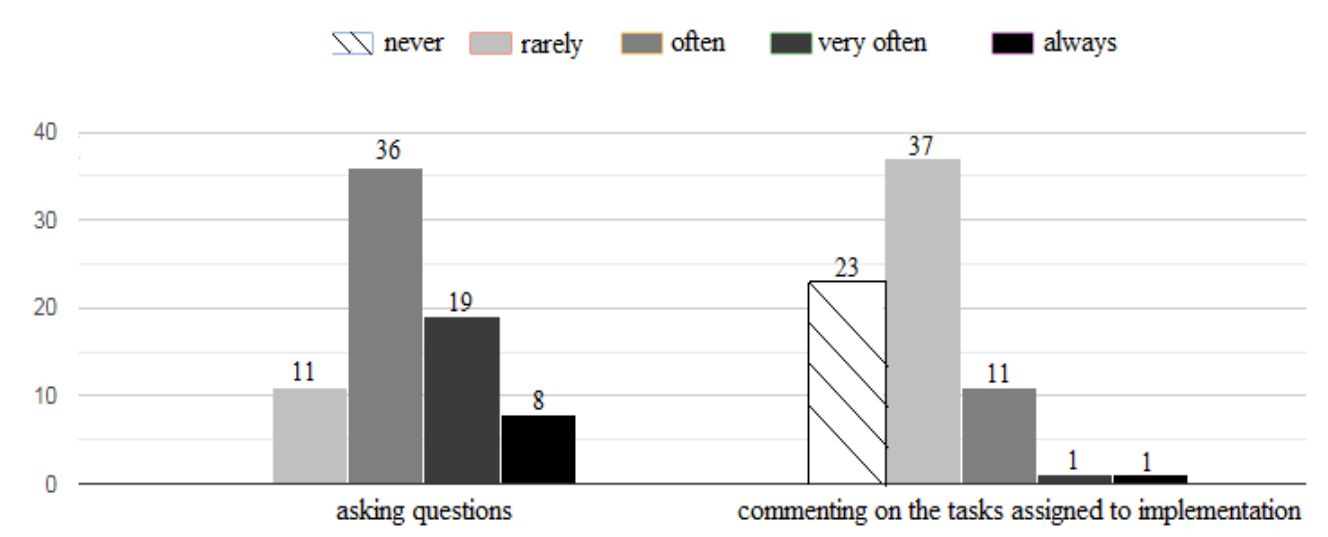

Figure 2. Possibility to ask questions and comment on assigned tasks to be performed. Source: own study based on research.

\footnotetext{
${ }^{1}$ This part presents selected results of the empirical study conducted by A. Pietrzak for the thesis prepared under supervision of D. Sobol, PhD at the Faculty of Economic Sciences, University of Warmia and Mazury in Olsztyn.
} 
Employees also assessed the effectiveness of various forms of communication used by the manager in the internal communication process (Figure 3). The highest-rated form of information transfer is oral and written. The respondents assessed their effectiveness in relation to the rest very highly - the importance index exceeds 0.75 Verbally conveying the message gives the possibility of immediate reaction and obtaining an answer in case of doubts. They justify the high assessment of the effectiveness of the written form of transferring information by the open possibility of returning to a given document, especially when it concerns a more complex procedure of task implementation. They are sure that nothing has been missed.

On the other hand, the most highly rated form of communication is the oral form $\left(w_{i}=0.89\right)$. This is due to the fact that it is the fastest form of communication of the action, but also in case of doubts, the fastest way to get a response from the manager (feedback), which allows you to start a conversation and maintain a positive relationship between the interlocutors. The effectiveness of telephone contact and digital forms (video call, communicator) of communication of activities was also rated high (the importance index is about 0.7 ). It should be emphasized that during the research, the use of digital forms was relatively new and resulted from the necessity (limiting direct interpersonal caused by covid-19), however, significantly improved the process of communication between the manager and the staff during the period of restrictions related to the epidemiological state in Poland.

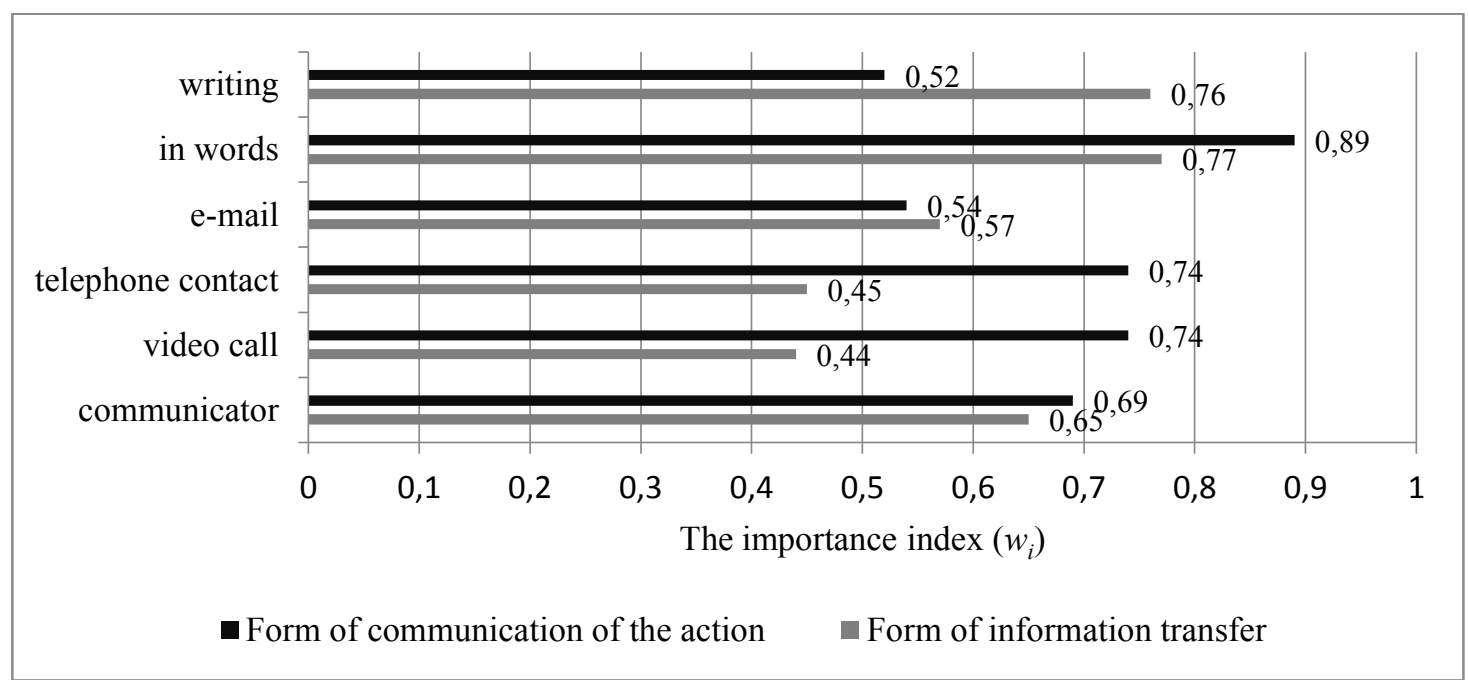

Explanation:

The importance (influence) index $\left(w_{i}\right)$ of the effectiveness of forms of information transfer and activities in the opinion of employees participating in the study was calculated as a weighted arithmetic mean as per the following notes on the Likert scale from 1 to 5, where: 5 - very effective, 1 - ineffective. The importance index is a number between 0 and 1, whereas: index $\mathrm{w}=0$ - ineffective form; $0<\mathrm{w} \leq 0,5$ - neutral form; $0,51 \leq \mathrm{w}<1-$ very effective form; $\mathrm{w}=1-$ ineffective form. The index corresponds to the idea proposed by W. Karaszewski and S. Sudoł (1997, pp. 17-18).

Figure 3. Assessment of the effectiveness of forms of information transfer and activities. Source: own study based on research. 
Analyzing the research results, it can be concluded that the communication process in a company takes place mainly at the emotional level of interpersonal communication (37 responses). During the conversation, the interlocutors can express their views, values and emotions, which will affect the level of the interlocutor's relationship or the lack of it. The participants of the conversation are then very involved in the communication process, they also learn a different point of view of a given topic. However, in certain situations, the exchange of information and opinions devoid of emotions takes place ( 27 responses), and sporadically communication is limited only to one-way communication (10 responses). It is worth adding that during direct conversations with the supervisor, employees pay close attention to the way of non-verbal communication: tone and strength of expression (42\%) and the manager's facial expressions and body posture (31\%), and then the content and style of expression ( $15 \%$ and $12 \%$ respectively).

Interesting results are also provided by employees' opinions on the most important tasks and managerial skills in the process of effective communication in the Kauflan Polska branch. The obtained answers made it possible to create a profile of an effective manager in the process of communicating with employees (Table 2).

Table 2.

Manager's profile in the process of effective communication with employees

\begin{tabular}{|c|c|c|}
\hline Managerial tasks & Skills & Traits and attitudes \\
\hline 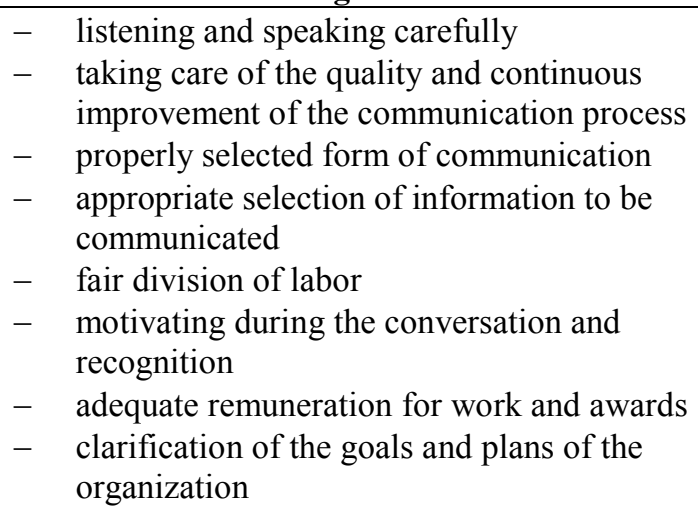 & $\begin{array}{ll}- & \text { communicate } \\
& \text { intelligible messages } \\
- & \text { listening carefully } \\
- & \text { conflict resolution } \\
- & \text { making decisions } \\
- & \text { motivating } \\
- & \text { negotiation }\end{array}$ & $\begin{array}{ll}- & \text { personal culture } \\
- & \text { honesty } \\
- & \text { empathy } \\
- & \text { oppenness to } \\
& \text { opinion } \\
- & \text { sincerity } \\
- & \text { sense od humor } \\
- & \text { kindness } \\
- & \text { firmness }\end{array}$ \\
\hline
\end{tabular}

Source: own study based on research.

Analyzing the answers to the question 'what does an effective manager provide employees in the communication process?' it can be generally concluded that the expectations of employees relate to the key roles and boil down to the effective implementation of the most important tasks of the manager in the process of creating the company's success. In the supplementary question, most of the respondents indicated that the most important task of a manager in the process of effective communication is listening carefully to all employees and speaking clearly (76\%). Immediately after that, the respondents indicated the care for the quality and continuous improvement of the communication process $(61 \%)$ and the appropriately selected form of communication (55\%). However, they admit that the manager rarely organizes meetings concerning the issues of internal communication. 
Useful skills in the process of effective communication are primarily: communicating messages to employees in an understandable way, but also listening carefully and solving problems and conflicts in order to prevent unnecessary chaos from destroying the prevailing atmosphere at work (e.g. as a result of being uninformed, gossiping). It is also important that employees feel that they can turn to the manager for guidance or help in solving a problem, even one that has occurred unexpectedly. The respondents perceive the manager as a rational decision maker. Depending on the specificity of the problem, the manager makes decisions on his own (17 responses), supports the decision-making process through consultations with the first-level management (48 responses), and also with employees (17 responses). In rare cases, the manager uses the help of experts. Employee participation in decision-making processes is a positive phenomenon of two-way communication, which certainly strengthens their sense of belonging and recognition.

The manager's qualities and attitudes that influence building lasting, trust-based relationships with subordinates, and thus the quality and level of communication, are: personal culture, honesty, empathy and openness. It is important to treat team members with respect, avoid favoritism, and be able to see the situation from the other person's perspective. Openness in communication is one of the most desirable features of a successful leader (Men, 2014), it favors two-way communication, which has a positive effect on employee involvement and shaping a good working atmosphere.

Moreover, good internal communication is the basis of good relations in the company. Most of the employees assessed the relationship with the manager at a good and very good level (46 responses in total) and average (23 responses), and in 5 cases the relationship was poorly assessed. Developing a good relationship is a key aspect of leadership. Employees who have a good, trust-based relationship with the manager show greater commitment at work, are more motivated, achieve better results and are ready to make various sacrifices for the team.

Comparing the answers given by the employees and the manager, it can be concluded that their opinions do not differ significantly. Both parties - participants of the communication process - define it as effective. Information flow takes place in the right form and time, and messages are received in accordance with the intention of the sender and produce the desired effect. Vertical communication in the surveyed enterprise can be described as two-way, the manager shows interest and openness to accepting employees' opinions, uses feedback.

Based on his own observations and anonymous opinions of the team, the manager can pick up signals earlier that require attention and improvement in order to constantly improve the communication process and increase its effectiveness. 


\section{Summary and Conclusions}

Communication is a social process of great importance for the functioning of small and larger organizations. It is a chance for an exchange of views and cooperation. Employees who are kept informed and aware of the current situation, including new challenges and threats to the company, understand their roles better. They feel respected and appreciated by the management, therefore they have a positive and specific approach to the tasks they carry out.

The internal communication process should proceed in such a way that the tasks entrusted by the management staff are performed most effectively. A manager who knows his staff knows how to maximize potential benefits and minimize communication barriers. Therefore, thanks to effective communication, the company is able to achieve success in a faster time, while the lack of formal communication and information flow, as well as ignoring communication dysfunctions can lead to a spectacular failure.

The main purpose of the own research was to analyze and evaluate the effectiveness of the communication process with employees of the Kaufland Polska branch located in the Mazowieckie Voivodeship. A complementary goal was to identify the most important managerial tasks and skills in this area. Research has shown that:

1. The process of internal communication in the enterprise covered by the study is formalized.

2. The employees assessed the current internal communication process very positively.

3. The most effective form of transferring messages used by a manager in the process of internal communication is oral and written (during the transfer of information) and oral (during the transfer of activities).

4. Communication between the manager and employees is two-way and there is feedback, both sides show commitment and show an open attitude to make the process effective.

5. Employees positively evaluate the functions performed by the manager in the process of internal communication and the atmosphere in the company, but they are also able to notice shortcomings related to communication.

6. The most important task of a manager is to listen carefully to employees and to speak to them in an understandable way. It is important that the manager takes care of the quality and continuous improvement of the communication process and selects the appropriate forms of communication. The skills that should be characterized by a manager, which are useful in the process of effective communication, include the ability to understand messages, resolve conflicts and listen carefully. The key features of a manager that are of great importance in the process of effective communication are: personal culture, honesty and empathy. 
Based on the research results obtained, the following recommendations for the manager can be formulated:

1. In order to improve the current process of internal communication, it is worth encouraging employees to express their opinions and suggestions on topics related to their work position, communication in the team or observed problems, e.g. through regular joint meetings and brainstorming sessions (face-to-face meetings and remote sessions using communicators, e.g. MS Teams), "idea boxes", or workshops on communication (including non-verbal communication), which will not only improve the communication process, but also enable integration, especially with new employees.

2. Managing and communicating with a large group of people of different characters and dispositions, having different professional experience, performing their tasks in the presence of clients and under time pressure is a great challenge. It requires many skills from the leader, not only conceptual and decision-making, but also interpersonal, which should be constantly improved so that there are as few communication barriers as possible.

\section{References}

1. Atambo, W.N., and Momanyi, D.K. (2016). Effects of Internal Communication on Employee Performance: A Case Study of Kenya Power and Lighting Company, South Nyanza Region, Kenya. Imperial Journal of Interdisciplinary Research, 2(5), 328-340.

2. Birim, B. (2016). Evaluation of Corporate Social Responsibility and Social Media as Key Source of Strategic Communication. Procedia - Social and Behavioral Sciences, 235(7),70-75. http://doi.org/10.1016/j.sbspro.2016.11.026.

3. Bolesta-Kukułka, K. (2003). Decyzje menedżerskie. Warszawa: PWE.

4. Cornelissen, J. (2012). Corporate communication: A guide to theory and practice. Journal of Communication Management, 16(4), 420-424. https://doi.org/10.1108/ 13632541211279049.

5. Jaworowicz, M., and Jaworowicz, P. (2017). Skuteczna komunikacja w nowoczesnej organizacji. Warszawa: Difin.

6. Kaufland.pl. Available online: https://firma.kaufland.pl/firma/nasze-wartosci.html; https://kariera.kaufland.pl, 07.05.2020.

7. Kożuch, B. (2001). Zarządzanie komunikowaniem się w organizacji. In: B. Kożuch (Ed.), Zarzadzanie: podstawowe zasady (pp. 134-145). Warszawa: Wydawnictwo Akademickie.

8. Kożusznik, B. (2011). Zachowania człowieka w organizacji. Warszawa: PWE.

9. Kozyra, B. (2019). Komunikacja bez barier. Warszawa: MT biznes. 
10. Martinez, A., and Fernandez, R. (2018). Internal Communication Issues in the Firms: Does It Affect the Productivity? Review of European Studies, 10(2), 1-13. https://doi.org/ $10.5539 /$ res.v10n2p1.

11. Men, L.R. (2014). Why leadership matters to internal communication: linking transformational leadership, symmetrical communication, and employee outcomes. Journal of Public Relations Research, 26(3), 256-279. https://doi.org/10.1080/ 1062726x.2014.908719.

12. Meyer, J. (2014). Employee Commitment, Motivation, and Engagement: Exploring the Links. In: M. Gagné (Ed.), The Oxford handbook of work engagement, motivation, and selfdetermination theory (pp. 33-36). Oxford: Oxford University Press.

13. Oleksyn, T. (2001). Sztuka kierowania. Warszawa: Wyższa Szkoła Zarządzania i Przedsiębiorczości im. B. Jańskiego.

14. Penc, J. (2000). Komunikacja i negocjowanie w organizacji. Warszawa: Difin.

15. Penc, J. (2001). Decyzje menedżerskie - o sztuce zarzadzania. Warszawa: C.H. Beck.

16. Pietrzak, A. (2020). Rola kierownika w procesie komunikacji z pracownikami na przykładzie Oddziału Kaufland Polska. Uniwersytet Warmińsko-Mazurski w Olsztynie (maszynopis).

17. Potocki, A., Winkler, R., and Żbikowska, A. (2011). Komunikowanie $w$ organizacjach gospodarczych. Warszawa: Difin.

18. Quirke, B. (2011). Komunikacja wewnętrzna krok po kroku. Warszawa: Wolters Kluwer Polska.

19. Reichheld, F. (2006). Decydujace pytanie: Jak osiagnąć zyski i prawdziwy wzrost? Warszawa: MT Biznes.

20. Robson, P.J., and D. Tourish, (2005). Managing internal communication: an organizational case study. Corporate Communications: An International Journal, 10(3), 213-222. https://doi.org/10.1108/13563280510614474.

21. Ruck, K., Welch, M., and Menara, B. (2017) Employee voice: An antecedent to organisational engagement? Public Relations Review, 43(5), 904-914. https://doi.org/ 10.1016/j.pubrev.2017.04.008.

22. Scandelius, C., and Cohen, G. (2016). Achieving collaboration with diverse stakeholdersThe role of strategic ambiguity in CSR communication. Journal of Business Research, 69(9), pp. 3487-3499. http://doi.org/10.1016/j.jbusres.2016.01.037.

23. Slijepčević, M., Bovan, A., and Radojević, I. (2018). Internal Communications as a Factor of Company's Efficiency. Marketing, 49(2), 124-143. https://doi.org/10.5937/ markt802124s.

24. Smoląg, K., and Ślusarczyk, B. (2018). Komunikacja wewnętrzna - innowacyjny aspekt współczesnego zarządzania organizacją. Studia i Prace Wydziału Nauk Ekonomicznych i Zarzadzania US, 52(2), 203-214. https://doi.org/10.18276/SIP.2018.52/2-15. 
25. Tarnowski, S. Sprawdzone trendy $w$ komunikacji wewnętrznej. Retrieved from: http://www.proto.pl/artykuly/4-sprawdzone-trendy-w-komunikacji-wewnetrznej, 02.12.2019.

26. Tourish, D., and Robson, P. (2006) Sensemaking and the distortion of critical upward communication in organizations. Journal of Management Studies, 43(4), 711-730. https://doi.org/10.1111/j.1467-6486.2006.00608.x.

27. Verčič, A.T., Verčič, D., and Sriramesh, K. (2012). Internal Communication: Definition, Parameters, and the Future. Public Relations Review, 38(2), pp. 223-230. https://doi.org/10.1016/j.pubrev.2011.12.019.

28. Verghese, A.K. (2017) Internal Communication: Practices and Implications. SCMS Journal of Indian Management, 103-113. https://doi.org/10.2139/ssrn.2690026.

29. Waters, R.D., Bortree, D.S., and Tindall, N.T.J. (2013). Can public relations improve the workplace? Measuring the impact of stewardship on the employer-employee relationship. Employee Relations, 35(6), 613-629. https://doi.org/10.1108/er-12-2012-0095.

30. Welch, M., and Jackson P.R. (2007). Rethinking internal communication: a stakeholder approach. Corporate Communications: An International Journal, 12(2)177, 177-198. https://doi.org/10.1108/13563280710744847.

31. Wilkinson, A., Dundon, T., Marchington, M., and Ackers, P. (2004). Changing Patterns of Employee Voice: Case Studies from the UK and the Republic Of Ireland. Journal of Industrial Relations, 46(3), 298-322. https://doi.org/10.1111/j.0022-1856.2004.00143.x.

32. Yeomans, L., and FitzPatrick, L. (2017). Internal Communication. Exploring Public Relations. Pearson Education. Retrieved from: http://eprints.leedsbeckett.ac.uk/3499/3/ Internal\%20Communication.pdf, 1.08.2020. 



\title{
INTERNATIONALIZATION OF POLISH ENTERPRISES. A COMPARATIVE ANALYSIS OF FAMILY AND NON-FAMILY BUSINESSES
}

\author{
Izabella STEINEROWSKA-STREB \\ University of Economics in Katowice, Poland; streb@ue.katowice.pl, ORCID: 0000-0001-5379-5730
}

\begin{abstract}
Purpose: The study aimed to determine whether family businesses in Poland are as involved in international activity as non-family businesses. Moreover, the intention was to identify differences in the forms of foreign expansion employed by family and non-family firms.

Design/methodology/approach: The objectives were pursued based on primary research conducted in 188 family firms and 223 non-family firms operating on the Polish market.

Findings: The analysis of the results indicates that family firms conduct business activity outside the domestic market significantly less frequently than non-family firms. The most common form of internationalization chosen by Polish family firms is export and import. Generally, these firms are not interested in joint ventures with foreign partners. Compared to non-family firms, Polish family firms establish divisions abroad significantly less frequently. However, they engage in non-equity cooperation more often than non-family firms.

Practical implications: Knowledge about the involvement of family and non-family firms in international activity and their preferred forms of internationalization can be used by business environment institutions.

Originality/value: The study results enrich the knowledge on the activity of Polish family firms on foreign markets as compared to similar activity of non-family businesses.
\end{abstract}

Keywords: family firm, non-family firm, internationalization, SME.

Category of the paper: research paper.

\section{Introduction}

Technological development and globalization processes that occurred in the global economy at the turn of the $20^{\text {th }}$ and $21^{\text {st }}$ century caused that expansion into international markets became profitable not only for large corporations, but also for smaller firms (Casillas, and Moreno-Menéndez, 2017). Therefore, in the early $21^{\text {st }}$ century, many firms that had previously focused only on the internal market began to engage in international activity (Camison, and Villar-Lopez, 2010; Lesáková, 2014). Among them there were also family firms. 
They began to perceive international expansion as an opportunity for growth that would ensure employment security for future generations (Pukall, and Calabrò, 2014).

Currently, family businesses successfully compete with non-family businesses on the international arena. However, not all family firms decide to expand their operations outside the country. Many remain in local markets (Mitter et al., 2014), concerned that foreign expansion might lead to a loss of family control over the firm. Casillas et al. (2010) argue that family businesses face two opposing forces. One urges them to grow and expand beyond their traditional markets, while the other encourages them to seek stability and pursue low risk projects in familiar markets.

The internationalization of family businesses has attracted interest of researchers over the recent years (Alayo et al., 2020; Casillas and Moreno-Menéndez, 2017). Nevertheless, to date, research has been inconclusive as to whether family businesses are more involved in international activity than non-family businesses. In general, it is argued that family involvement in business and family ownership have an impact on the internationalization of family businesses (Alayo et al., 2020; Arregle et al., 2012).

In Poland, the issue of internationalization of family businesses is under-researched (Leszczewska and Zaniewska, 2013). The question whether family businesses operating on the Polish market are as active on foreign markets as non-family businesses still remains unanswered. Studies on differences between family and non-family firms in terms of preferred expansion methods are also scarce. The survey discussed in this paper intended to fill this research gap, as it aimed to identify whether family businesses in Poland are as involved in international activity as non-family businesses. Moreover, the study sought to identify differences in foreign expansion methods chosen by family and non-family firms. The objectives of the study were pursued based on primary research.

\section{Literature review}

Enterprises are motivated to launch activity in foreign markets by the opportunity to make better use of economies of scale, access to cheaper production factors, access to know-how in foreign industrial clusters, and potential risk diversification (Pukall, and Calabrò, 2014; Steinerowska-Streb, 2014). Foreign market entry, however, requires every firm to learn a new environment (Casillas et al., 2010) and engage capital resources (Mitter et al., 2014). Thus, foreign expansion contributes to firms' uncertainty and risk (Arregle et al., 2012; LarrazaKintana et al., 2007). Not all firms are willing to take this risk. Enterprises that exercise particular caution are family firms. In principle, they do not want to lose family control over the business and are reluctant to make any decisions that could reduce it (Casillas et al., 2010). 
Low risk-taking propensity of family businesses stems from their concern for future generations. They have a particularly long-term orientation (Muñoz-Bullón et al., 2020) and seek to transfer ownership to their successors. Most often, therefore, they value tradition and are used to operating in local markets known to them (Mitter et al., 2014), where they have developed close ties with local communities (Steinerowska-Streb, 2016). Therefore, compared to non-family firms, many family-owned businesses adopt conservative strategies (Steinerowska-Streb, and Wziątek-Staśko, 2019) and are less inclined to invest in high risk projects, including foreign market expansion (Mitter et al., 2014).

Long-term orientation of family firms and the concern of the family with future generations can also have a positive impact on their internationalization (Alayo et al., 2020). They can perceive expansion beyond the internal market as an opportunity to grow and survive in a changing environment (Pukall, and Calabrò, 2014). Studies carried out in this area provide varied conclusions (Mitter et al., 2014). Some argue that the characteristics of family businesses favor their internationalization (Carr, and Bateman, 2009). Others, on the contrary, point to negative relationships in this respect (Fernández, and Nieto, 2006; Graves, and Thomas, 2004). In their study, Mitter et al. (2014) indicate that family ownership and international entrepreneurship exhibit an inverted U-shaped relationship.

This study assumes that, in Polish market conditions, the fact of being a family business has a negative impact on internationalization. Most family businesses operating on the Polish market are only approaching their first succession or are run by their first successor, and the first generation in a family business usually experience resource constraints that may hinder their foreign expansion. These limitations can be overcome by family members of the second or subsequent generation (Mitter et al., 2014). Therefore, it was considered likely that:

H1: Family businesses in Poland are less involved in international activity than non-family businesses.

To date, relatively few comparative analyses concerning the internationalization of family and non-family firms have been conducted. They generally show that the internationalization process varies in family and non-family businesses (Alayo et al., 2020) and, compared to nonfamily businesses, family businesses expand abroad later, more slowly and avoiding risk (Mitter et al., 2014). Accordingly, the characteristics of family businesses may therefore not only influence their propensity for internationalization, but they may also lead them to choose different internationalization strategies for foreign expansion compared to non-family businesses (Mitter et al., 2014).

Given that family firms mainly finance their operations from family resources (Mandl, 2008) and they do not want to lose family control of the business and are reluctant to make any decisions that might reduce it (Casillas et al., 2010), it can be assumed that family firms prefer less capital-intensive forms of expansion than non-family firms. On the other hand, taking into 
account that family firms tend to recruit employees from among family members (Steinerowska-Streb, and Bernais, 2016), who do not necessarily possess professional knowledge about internationalization strategies (Mitter et al., 2014), it can be proposed that family businesses (i) are less likely to establish their own divisions abroad than non-family firms; (ii) are more likely to pursue non-equity cooperation (license contracts, franchise agreements, management contracts, turnkey investment contracts, supply contracts) than nonfamily firms. Therefore, the study assumed that:

H2: Family firms are significantly less likely to establish divisions abroad than non-family firms.

H3: Family firms are significantly more likely to engage in non-equity cooperation than nonfamily firms.

\section{Methods}

The research hypotheses were verified and the research objectives were achieved based on primary research findings. The study was conducted as part of statutory research carried out by the Department of Entrepreneurship and Management Innovation at the University of Economics in Katowice (project title: Competitiveness of family and non-family firms comparative analysis in selected areas).

A questionnaire was prepared for the purpose of the survey, concerning the broadly defined firm competitiveness and its determinants. It consisted of closed questions, in which the type of scale was adjusted to the examined area. This paper focuses analysis only on the questions about firm internationalization, since its theme is the internationalization of family businesses as compared to non-family businesses. All the questionnaire questions concerning this research area used a nominal scale.

The subject of the study comprised family and non-family firms based in Poland. The research sample was selected by the Center for Research and Knowledge Transfer (CBiTW) from its database of enterprises. The sample was intended to include at least 380 enterprises. Ultimately, the sample size reached 411 firms. During the first half of 2020, CBiTW ran an email survey in order to gather data. 950 invitations to participate in the survey were sent out, 400 were addressed to family businesses and 550 to non-family businesses. 248 family and 229 non-family businesses responded to the invitation. After the questionnaires filled by the respondents were verified, 66 were rejected. All those questionnaires that were incomplete or did not meet the assumptions made upon selection of the research sample were eliminated from further analysis. 
Finally, 188 questionnaires from family businesses and 223 from non-family businesses were analyzed. Ownership and management criteria were used to identify family businesses as these criteria are most commonly used for this purpose (Kontinen, and Ojala, 2010; Kraśnicka, 2017). Serrano-Bedia et al. (2016, p. 498) proposed that a family firm is a firm "in which a family controls the majority of the ordinary voting shares and the family is represented in the firm's management".

Based on the size of family businesses, the systemization revealed $30.3 \%$ of micro firms, $42 \%$ of small businesses, $25 \%$ of medium-sized firms, and $2.1 \%$ of large enterprises. The group of non-family firms comprised $19.4 \%$ of micro firms, $17.9 \%$ of small businesses, 39.5 of medium-sized firms, and $23.3 \%$ of large enterprises. The classification of enterprises in terms of size was conducted according to the number of people employed in full-time positions. The threshold values were adopted from the recommendation of the European Commission (2003) on the definition of micro, small and medium-sized enterprises. According to the recommendation, a microenterprise is as an enterprise which employs no more than 9 workers. A small enterprise employs between 10 and 49 workers, while a medium-sized enterprise between 50 and 249 employees. Large enterprises are those with staff headcount of 250 or more.

The analysis of the data used descriptive statistics and the $\chi^{2}$ significance test. The statistically significant level was established for $p$ to be below 0.05. Moreover, the Bayes Factor $\mathrm{BF}_{10}$ was applied to examine the likelihood of the hypotheses. When $\mathrm{BF}_{10}$ was in the range (i) 1-3, the evidence for the hypothesis was considered to be insufficient; (ii) 3-10 -substantial; (iii) 10-30 - strong; (iii) 30-100 - very strong; (iii) over 100 - extreme (Domurat, and Białek, 2016).

\section{Results}

The analysis of the data revealed that the respondent enterprises were dominated by the firms that are not involved in international activity (67.4\%). Among the enterprises operating on foreign markets, $73.9 \%$ were non-family firms, while the remaining $26.1 \%$ were family firms. Both family and non-family firms were dominated by firms whose operations were limited to the domestic market (Figure 1). 


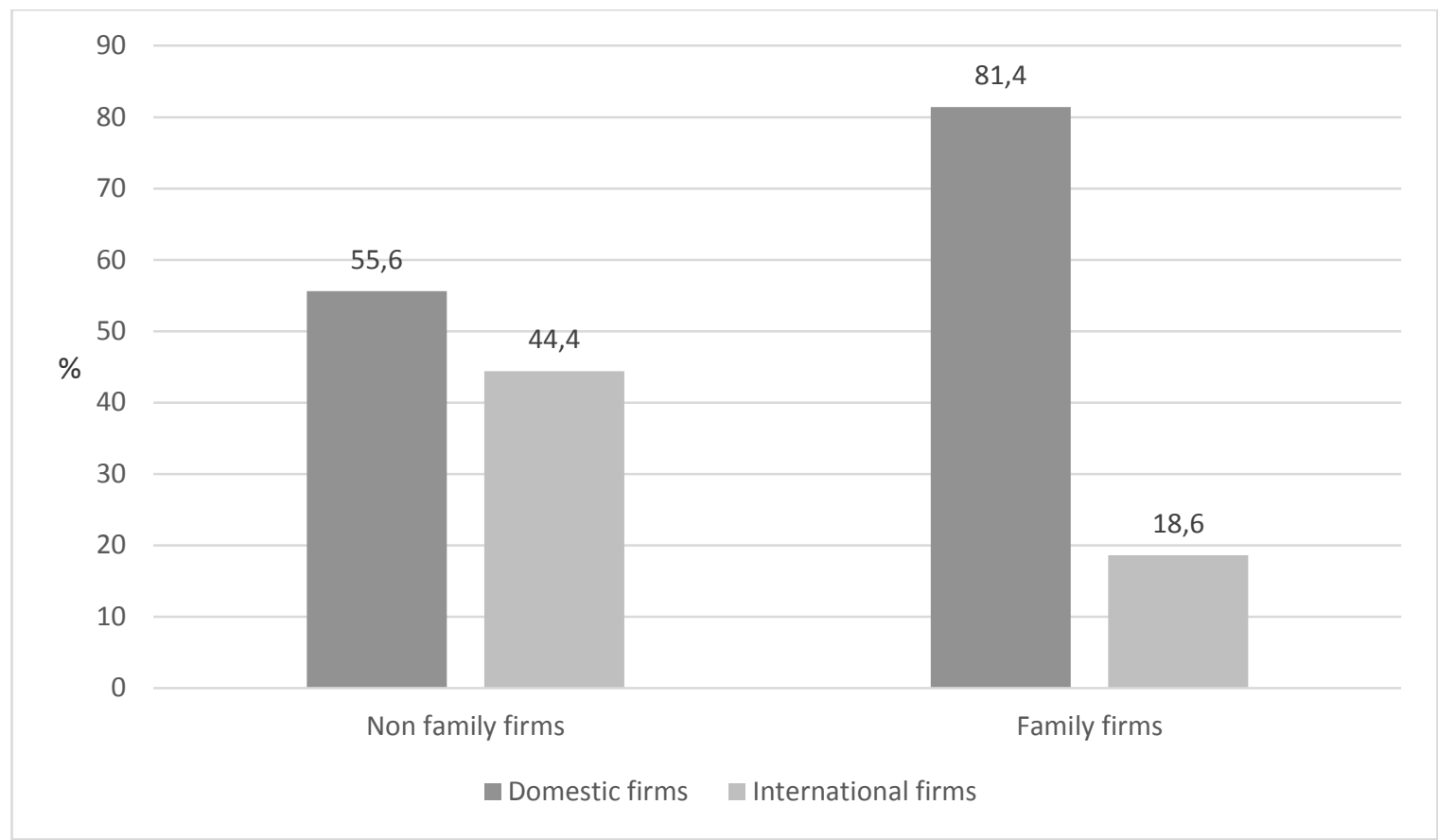

Figure 1. Involvement of family and non-family firms in international activity (\%). Source: Own elaboration.

Medium-sized enterprises dominated among family firms that operated internationally. On the other hand, large enterprises were the most numerous among non-family firms involved in international activity. Both family and non-family micro firms declared conducting international activity. Interestingly, among family firms, as many as every tenth firm (approximately) that conducted international activity was a micro firm. Respectively, micro firms constituted $9.1 \%$ of non-family firms involved in international operations (Figure 2).

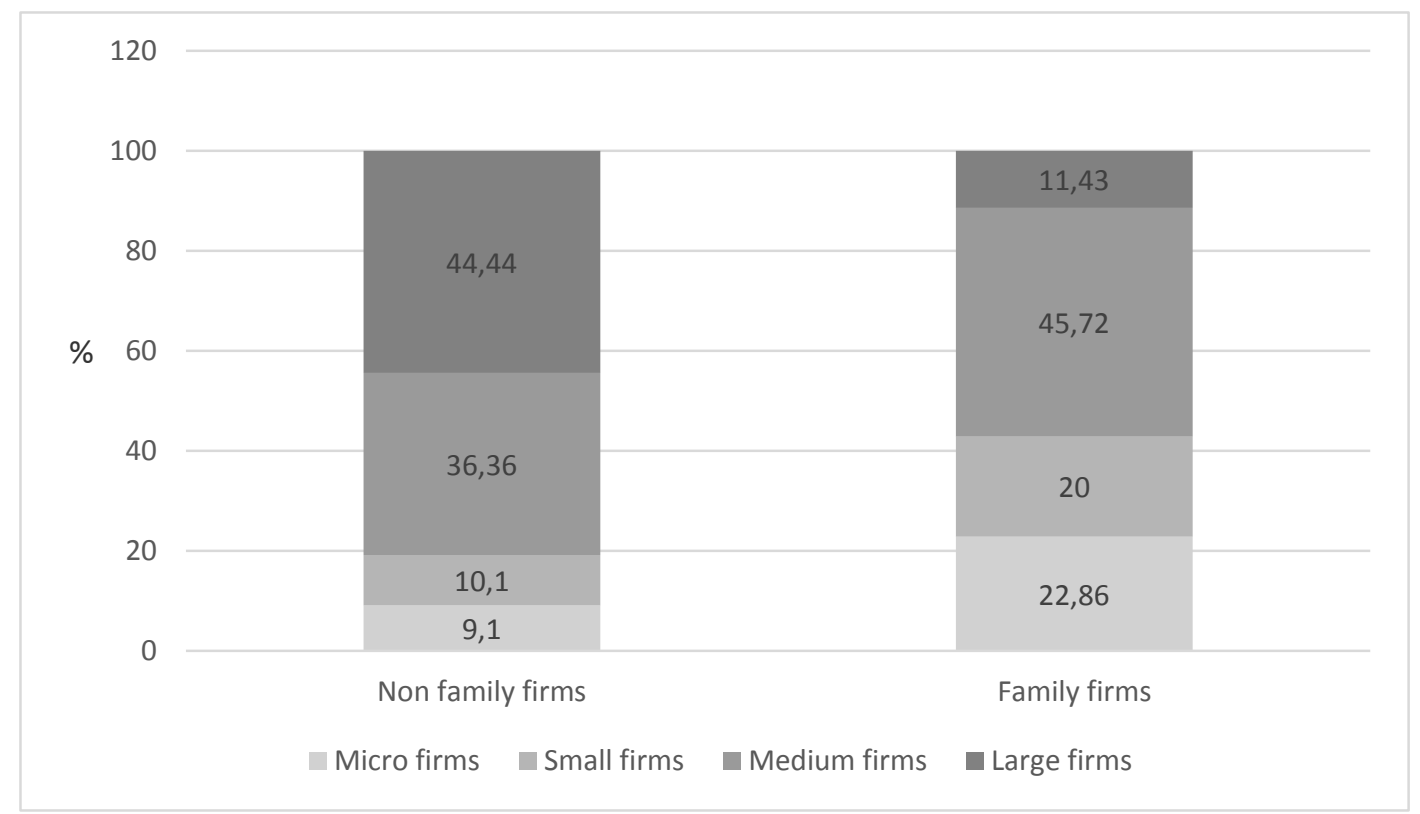

Figure 2. Family and non-family firms not involved in international activity by size (\%). Source: Own elaboration. 
The size-based composition of the respondent firms that did not conduct international operations was slightly different from that of internationalized firms. Among family firms that did not operate internationally, there were no large enterprises, whereas among non-family firms, large enterprises constituted only $6.45 \%$. Small enterprises dominated among non-internationalized family firms, while medium-sized enterprises were the most numerous group among non-family firms (Figure 3).

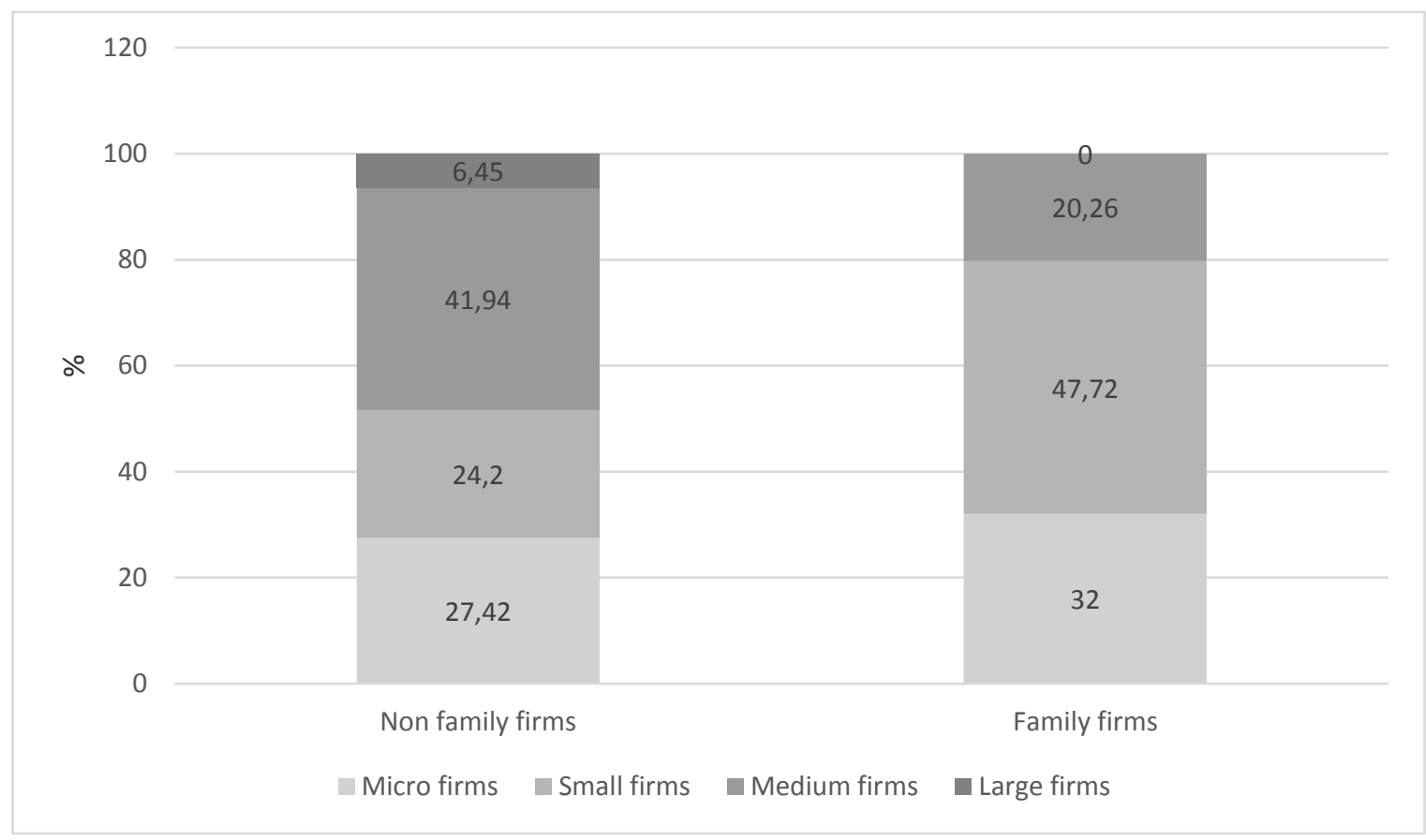

Figure 3. Nieumiędzynarodowione firmy rodzinne i nierodzinne w systematyzacji ze względu na wielkość (\%). Non-internationalized family and non-family firms by size (\%). Source: Own elaboration.

Based on the statistical analysis, it was concluded that family firms conduct business activity outside the domestic market much less frequently than non-family firms $\left(\chi^{2}=30.8\right.$; $\mathrm{p}<0.001)$. This result allowed for the positive verification of the $\mathrm{H} 1$ hypothesis, according to which family firms in Poland are less involved in international activity than non-family firms. The likelihood of this hypothesis was also verified using the Bayes Factor. It assumed a value of $\mathrm{BF}_{10}=1.71 \mathrm{e}+6$ for the variables under examination, which indicates very strong evidence in favor of the H1 hypothesis.

The most popular form of internationalization among the respondent firms was export and import (Figure 3). This form of internationalization is of similar interest to both family and non-family firms $\left(\chi^{2}=1.55 ; \mathrm{p}=0.213\right)$. Strategic alliances with foreign partners also attract similar interest $\left(\chi^{2}=0.26 ; p=0.61\right)$ from both family and non-family firms. Family firms, on the other hand, get involved in non-equity cooperation more frequently than non-family firms $\left(\chi^{2}=8.22 ; \mathrm{p}=0.004\right)$, whereas non-family firms establish their divisions abroad significantly more often than family firms $\left(\chi^{2}=8.22 ; \mathrm{p}=0.002\right)$. Interestingly, neither family nor non-family firms are generally interested in setting up a joint venture with a foreign investor. Among the respondents, only $2 \%$ of non-family firms declared being a shareholder in 
such an entity. In this case, no statistically significant differences between the two groups of firms exist $\left(\chi^{2}=0.718 ; p=3.97\right)$.

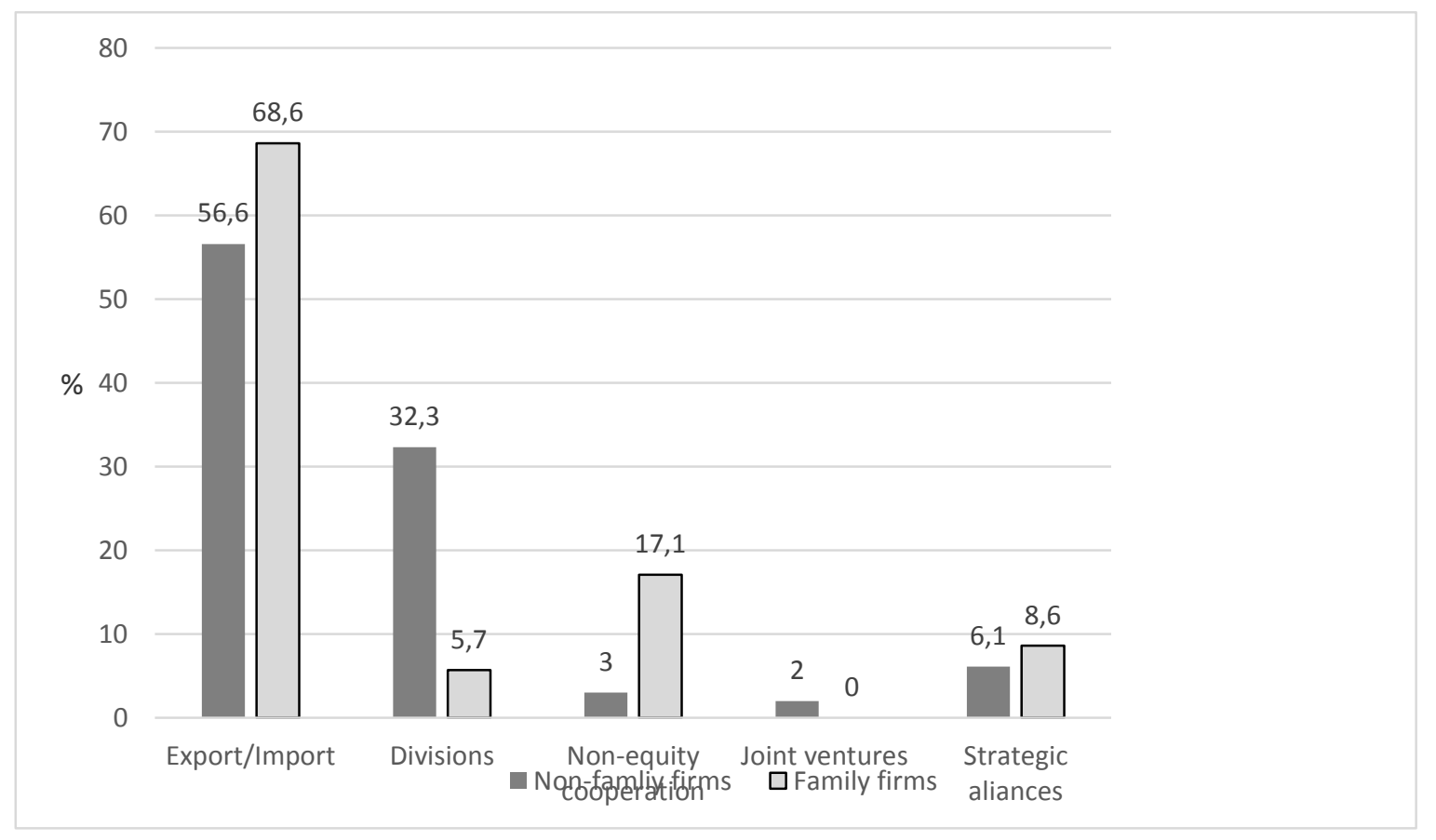

Figure 3. Forms of internationalization in family and non-family respondent forms (\%). Source: Own elaboration.

The statistically significant differences that were identified between family and non-family firms as regards the establishment of foreign divisions and the extent of their involvement in various forms of equity cooperation allow for the positive verification of the hypotheses $\mathrm{H} 2$ (Family firms are significantly less likely to establish divisions abroad than non-family firms) and H3 (Family firms are significantly more likely to engage in non-equity cooperation than non-family firms). The Bayes Factor $\mathrm{BF}_{10}$ proves high likelihood that these hypotheses are correct. In the case of the $\mathrm{H} 2$ hypothesis, the factor is $\mathrm{BF}_{10}=71.10$, while in the case of the $\mathrm{H} 3$ hypothesis, $\mathrm{BF}_{10}=6.59$. The value of the $\mathrm{BF}_{10}$ thus confirms very strong evidence in favor of the $\mathrm{H} 2$ hypothesis and substantial evidence in favor of the $\mathrm{H} 3$ hypothesis.

\section{Discussion}

The analysis of the results indicates that family firms conduct business activity outside the domestic market significantly less frequently than non-family firms. This finding seems to be fully justified taking into account that Polish family firms are relatively young. Most of them were established only after 1989, when the economic and political transformation took place in Poland. Therefore, most Polish family firms are only going through their first generation 
takeover. The founders of these firms, who often still manage them today, had to first learn how to run a firm in a market economy. Then, after Poland's accession to the European Union, they learned how to face intense competition. Many of these firms avoided external partners or shareholders for fear of losing control over their own business and, as a result, experienced capital shortages for years, walking the thin line between profits and losses. In such circumstances, it is difficult to expect them to become involved in international activity, which requires both knowledge and capital expenditure. In the case of Polish non-family firms, foreign expansion was easier because they were not afraid of losing control and did not restrict their sources of funding to their own resources and family capital.

The lower involvement of the respondent family and non-family firms in international activity may be also rooted in the attachment of the majority of these firms to tradition and familiar local markets (Mitter et al., 2014). Bearing in mind that foreign expansion is a high risk undertaking, the fact that family firms in principle avoid making high risk decisions (Casillas et al., 2010) may also have an impact on the results of the survey.

Forms of internationalization chosen by family firms when they decide to pursue international activity also point to their different attitude to risk than that of non-family firms. The results of the survey indicate that those Polish family firms that expand abroad prefer those forms of internationalization that are relatively low risk and do not pose a threat to their control over the ownership of the firm. The data gathered in the survey show that the form of internationalization most frequently adopted by Polish family firms is export and import. Generally, these firms are not interested in establishing joint ventures with foreign partners.

Compared to non-family enterprises, Polish family firms establish their divisions abroad significantly less frequently. On the other hand, they engage in non-equity cooperation much more often than non-family firms. Therefore, it can be inferred that the family firms that expand internationally limit the risk involved by choosing a form of internationalization. Thus, similarly to most family firms operating abroad, Polish family firms avoid high risk decisions that could result in a loss of control over the business.

However, the analysis of the forms of internationalization in the respondent firms clearly revealed that both family and non-family firms favor export and import, which is the most common form of internationalization. It seems possible, therefore, that, according to the Uppsala Model, some of the firms involved in export and import will progress to the subsequent stages of internationalization in the future. Over the next few years, the forms of internationalization of Polish family and non-family firms may, as a result, change. In the case of family firms, such a scenario seems highly likely because most Polish family firms have already gone through the first succession or are preparing for it, and successors are often willing to implement changes in the business (Fernandez, and Nieto, 2005). Moreover, they usually do not experience capital related problems as the generation of founders did (Mitter et al., 2014). 


\section{Conclusions}

Revealing the differences in the involvement of family and non-family firms in international expansion, the survey provides valuable information on the activity of Polish family firms in foreign markets as compared to non-family firms. As the issues related to the internationalization of family firms are under-researched in Poland (Leszczewska, and Zaniewska, 2013), it can be concluded that the results of the survey significantly enrich the knowledge in this area.

The differences identified between family and non-family firms in terms of their involvement in international activity are consistent with most studies comparing the two groups of entities. As Kontinen and Ojala (2010) point out in their literature review on the internationalization of family firms, the studies generally show that family firms are less internationalized than non-family firms.

The results also reinforce the findings of previous surveys showing that family involvement in business and family ownership affect the internationalization of family firms (Alayo et al., 2020; Arregle et al., 2012). In addition, they are in line with the conclusions of other studies, arguing that family firms focus their business primarily on local markets (Mitter et al., 2014).

Additionally, the study provides further support to the categorization of family and non-family firms as separate types of business entities. This division emerged several years ago and since then numerous studies confirm its validity. At present, some researchers even propose to extend this division (Kontinen, and Ojala, 2010).

\section{References}

1. Alayo, M., Iturralde, T., Maseda, A. and Aparicio, G. (2020). Mapping family firm internationalization research: bibliometric and literature review, Rev. Manag. Sci. https://doi.org/10.1007/s11846-020-00404-1.

2. Arregle, J.L, Naldi, L., Nordqvist, M., and Hitt, M.A. (2012). Internationalization of Family-Controlled Firms: A Study of the Effects of External Involvement in Governance. Entrepreneurship Theory And Practice, Vol. 1, pp. 1115-1143. doi: 10.1111/j.15406520.2012.00541.x.

3. Camisón, C., and Villar-López, A. (2010). Effect of Smes' International Experience on Foreign Intensity and Economic Performance: The Mediating Role of Internationally Exploitable Assets and Competitive Strategy. Journal of Small Business Management, Vol. 48(2), pp. 116-151. 
4. Carr, C., and Bateman, S. (2009). International strategy configurations of the world's top family firms: anotherfactor affecting performance. Manag. Int. Rev., Vol. 49(6), pp. 733-758. https://doi.org/10.1007/s11575-009-0018-3.

5. Casillas, J.C., Moreno, A.M., and Acedo, F.J. (2017). Internationalization of Family Businesses: a Theoretical Model Based on International Entrepreneurship Perspective. Global Management Journal, Vol. 2, pp. 18-35.

6. Domurat, A., and Białek, M. (2016). Dowodzenie hipotez za pomocą czynnika bayesowskiego (bayes factor): przykłady użycia w badaniach empirycznych. Decyzje, No. 26, pp. 109-141.

7. European Commission Recommendation of 6 May 2003 concerning the definition of micro, small and medium-sized enterprises. Document number C (2003) 1422, Text with EEA relevance, 2003/361/EC. Official Journal of the European Union, European Commission 2003.

8. Fernández, Z., and Nieto, M. (2006). Impact of ownership on the international involvement of SMEs. Journal of International Business Studies, Vol. 37(3), pp. 340-351. https://doi.org/10.1057/palgrave.jibs.8400196.

9. Fernandez, Z., and Nieto, M.J. (2005). Internationalization strategy of small and medium sized family businesses: Some influential factors. Family Business Review, Vol. 18(1), pp. 77-89. https://doi.org/10.1111/j.1741-6248.2005.00031.x.

10. Graves, C., and Thomas, J. (2004). Internationalisation of the family business: A longitudinal perspective. International Journal of Globalisation and Small Business, Vol. 1(1), pp. 7-27.

11. Kontinen, T., and Ojala, A. (2010). The internationalization of family businesses: A review of extant research. Journal of Family Business Strategy, 1(2), pp. 97-107. https://doi.org/10.1016/j.jfbs.2010.04.001.

12. Kraśnicka, T. (2017). Sukcesja i kondycja ekonomiczno-finansowa firm rodzinnych w Polsce i Czechach. Wyniki badań jakościowych. Zeszyty Naukowe Politechniki Ślaskiej, z. 108, no. 1983, pp. 203-214.

13. Larraza-Kintana, M., Wiseman, R.M., Gomez-Mejia, L.R., and Welbourne, T.M. (2007). Disentangling com-pensation and employment risks using the behavioral agency model, Strategic Management Journal, Vol. 28, pp. 1001-1019. doi: 10.1002/smj.624.

14. Lesáková, L. (2014). Small and medium enterprises in the new world of globalization. Forum Scientiae Oeconomia, Vol. 2(3), pp. 111-122.

15. Leszczewka, and K. Zaniewska, K. (2013). Motywy i formy internacjonalizacji firm rodzinnych, Przedsiębiorczość i Zarzadzanie, Vol. XIV, Issue 6, part I, pp. 261-271.

16. Mandl, I. (2008). Overview of Family Business Relevant Issues, Final Report. KMU Forschung Austria, Vienna: Austrian Institute for SME Research. 
17. Mitter, C., Duller, C., Feldbauer-Durstmüller, B., and Kraus, S. (2014). Internationalization of family firms: the effect of ownership and governance. Rev. Manag. Sci., Vol. 8, pp. 1-28. doi: 10.1007/s11846-012-0093-x.

18. Muñoz-Bullón, F., Sanchez-Bueno, M.J., \& De Massis, A. (2020). Combining Internal and External R\&D: The Effects on Innovation Performance in Family and Nonfamily Firms. Entrepreneurship Theory and Practice, 44(5), 996-1031. https://doi.org/10.1177/ 1042258719879674.

19. Pukall, T.J., and Calabrò, A. (2014). The Internationalization of Family Firms: A Critical Review and Integrative Model. Family Business Review, Vol. 27(2), pp. 103-125. doi: $10.1177 / 0894486513491423$.

20. Sciascia, S., Mazzola, P., Astrachan, J.H., and Pieper, T.M. (2012). The role of family ownership in international entrepreneurship: exploring nonlinear effects. Small Bus Econ, Vol. 38(1), pp. 15-31. https://doi.org/10.1007/s11187-010-9264-9.

21. Steinerowska-Streb, I. (2014). Bariery rozwoju polskich małych i średnich przedsiębiorstw zaangażowanych i niezaangażowanych w działalność międzynarodową. Studia Ekonomiczne Regionu Łódzkiego, Vol. 12, pp. 149-159.

22. Steinerowska-Streb, I., Bernais, J. (2016). Źródła pozyskiwania pracowników w polskich przedsiębiorstwach rodzinnych. Ekonomika i Organizacja Przedsiębiorstwa, Vol. 11, pp. 85-97.

23. Steinerowska-Streb, I. (2016). Wybrane determinanty zatrudniania pracowników w polskich przedsiębiorstwach rodzinnych. Ekonomika i Organizacja Przedsiębiorstwa, Vol. 3(794), pp. 68-78.

24. Steinerowska-Streb, I., and Wziątek-Staśko, A. (2019). Innovations in family firms. A study of owner-managers' knowledge development. Journal of Family Business Management, Vol. 10(3), pp. 247-264. https://doi.org/10.1108/JFBM-09-2019-0058. 


\title{
MANGEMENT OF BLOCKCHAIN BASED DIGITAL ASSETS IN INDUSTRY AND SERVICES
}

\author{
Paweł SZEWCZYK \\ Banking University in Poznan, Faculty in Chorzow; pszewczyk@chorzow.wsb.pl, \\ ORCID: 0000-0003-4240-4532
}

Purpose: The technology industry has become incredibly dynamic and complex, so by utilizing the information technology (IT) framework in the approach to new technology, businesses can avoid confusion around the application of new trends since IT operations can deliver business value.

Design/methodology/approach: An overview of recent literature of some assets digitization concepts was applied. In particular the concept of digital twins was presented. Finally, applying the blockchain technology the security from hackers due to its encryption features may be provided.

Findings: The improvement of digital twins through blockchain technology is set to transform industries such as manufacturing, healthcare and beyond and, companies can work towards building their future business strategies.

Practical and social implications: The impact that digital twins can make is huge. Many are just now in development due to the complexity of their creation, but soon millions of things will have digital twins. And their usefulness and capabilities will continue to evolve. On the other hand blockchain technology has the potential to become the most relevant and capable way to generate and monitor digital twins due to the security and immutability of technology.

Originality/value A jet engine, a human heart, even an entire city can all have a digital twin that mirrors the same physical and biological properties as the real thing enabling three critical drivers: continuous evaluation; faster, cheaper prototyping and innovating at the limits (ethics).

Keywords: blockchain, digital assets, digital twins.

Category of the paper: Viewpoint, General review.

\section{Introduction}

As the world becomes more digital, companies are transforming to use technology more intelligently and more strategically. This transformation in the face of growing complexity is a huge challenge. By utilizing the information technology (IT) framework in the approach to new technology, businesses can avoid confusion around the application of new trends and 
distraction that could lead to inefficiency. The basic foundation of infrastructure, development, security, and data has evolved over time, but it continues to define IT operations that deliver business value (CompTIA.org: A Functional IT Framework, Report 2016). We are living in a digital economy. Every business today can see that technology has become a more critical part of their operations and their future success. In order to remain competitive, companies know they must invest in IT. But that knowledge is not enough; they also must know where those investments should be made. Simply investing more in existing IT tactics is not sufficient. Enterprise technology has gone through a major shift, and understanding that shift is a prerequisite for a winning game plan. Modern IT has expanded to more explicitly serve a dual purpose. Along with the tactical support work that continues to be a requirement, IT now has a role to play in directly driving strategic objectives. Customer acquisition happens on digital platforms. Brand awareness is built through social media. Market share is gained through omnichannel experiences. These initiatives are not achieved simply by building programs on top of technology, but by using technology as the primary mechanism for success. (CompTIA.org: Using Strategic IT for Competitive Advantage, Whitepaper 2018). Emerging technologies have become a key part of the discussion around modern digital organizations. Across the high-tech industry, the term "emerging technology" has become a catch-all descriptor for the futuristic advances that will drive the next wave of innovation, and there is a wealth of resources available for understanding the individual trends that fall under that broad umbrella. From artificial intelligence (AI) to quantum computing, there has been a hunger to find the next big thing. As part of the ongoing evolution towards more strategic thinking, IT leaders of the future will embrace new techniques and responsibilities that will drive greater value into the business (CompTIA.org: The Role of Emerging Technology in Digital Transformation, Whitepaper, 2020).

This general review paper covers those papers which provide an overview of some concepts and techniques concerning digital assets especially in the form of digital twins and presents opinions of different research circles on how, by applying the blockchain technology, the concept of digital twins can be improved. As a basic source of opinions served works of The European Blockchain Observatory and Forum which launched in February 2018, and which is "a European initiative to accelerate blockchain innovation and the development of the blockchain ecosystem within the EU and so help cement Europe's position as a global leader in this transformative new technology" (EU Blockchain Forum WG, 2018). 


\section{Digital assets}

The most basic description of digital assets may be found in the Thematic Report: Digital assets (Blockchain forum.eu: report 2020a, p. 7). "The concept of "digital assets" is not a new one, and does not inherently rely on blockchain. Digital assets, sometimes called tokens ${ }^{1}$, exist in the same way that electronic record-keeping systems do. They can be defined as a string of characters, often stored in a binary format, that represent values or rights that can be exercised within a specific context. For this reason, the term "digital assets" does not necessarily refer to assets issued and transferred on a blockchain, since this is a sub-group within the more generic definition of digital assets. Each digital asset is associated with one blockchain, on which transactions on such assets are stored within blocks. Digital assets can be programmed to serve many different functions. For example, they can represent a resource earned or produced within a sharing economy or environment (such as computing power units), rights (access, voting, etc.), identity or attestations of facts (driving licence, degree, etc.), physical assets (gold, commodities, etc.), securities (shares, debt instruments, etc.), or even property (such as a painting or real estate). Sometimes various functions overlap within the same token, making the asset difficult to place under a single heading". Thanks to blockchain, digital assets can be created by almost anyone with the technical know-how, a process generally referred to as "tokenisation", and can be distributed in a number of innovative ways. The technology also makes them easy to trade on secondary markets, but introduces new concepts and raises new challenges when it comes to asset custody. Thanks to smart contract technology running on blockchain (Blockchain forum.eu: report 2020, Blockchain terminology) digital assets can also be "programmed" - adding new capabilities that are not possible using traditional means of asset issuance and exchange. As such, digital assets can both reflect the traditional world of assets and represent something completely new in the world. This has ignited debate around how to categorise and legally qualify them. While public authorities in many jurisdictions have been examining these issues, today there is no globally recognised, binding taxonomy in use.

In the mentioned above EU Digital assets Thematic Report an informal working consensus has developed around the three basic digital asset categories of:

1. payment/exchange/currency tokens;

2. investment/security tokens; and

3. utility/consumption tokens. Existence of a number of hybrid tokens, which have features spanning more than one of these categories, shows, however, the difficulties that still remain in coming to an agreement on how digital assets should be classified.

\footnotetext{
${ }^{1}$ Tokens are a type of digital asset that can be tracked or transferred on a blockchain. Tokens are often used as a digital representation of assets like commodities, stocks and even physical products.
} 
Don Tapscott, head of the Blockchain Research Institute (BRI) and his co-workers (BRI, 2020) have done significant work defining models for blockchain governance and stewardship, and believe that the most robust form of stewardship is the multi-stakeholder non-state network, consisting of participants from the private sector, government, academia, and civil society at large. For a technology to achieve mass adoption and longevity, such networks must provide stewardship in several areas, such as the development of standards, policy, and knowledge, and the governance of changes to the technology.

In a recent BRI Big Idea White Paper (Tapscott, 2020) Tapscott observes that digital assets, sometimes called tokens, are poorly understood. That may be why they are used to describe a variety of things, some of which are contradictory. In order to help the understanding of the token economy a new standardization framework - the Token Taxonomy Initiative (TTI) was formed by many creators of the enterprise blockchain. It starts with token types and progresses to token properties, with a goal of enabling anyone-technologist, businessperson, or regulator - to understand what is happening and how to take part in token projects. "Standardization requires a commitment to collaborating with competitors, stewarding shared creations faithfully, and developing certification programs that make it easier for users to detect fakes and harder for unscrupulous designers to claim the use of standards while deviating from those standards".

The benefits of shared token standards are many: increased ease of use, improved interoperability, easier communication, and faster and more secure development of the token projects. In conclusion the author states (Tapscott, 2020, p. 21): "Ultimately, there is much work left to be done. The Token Taxonomy Framework is a fantastic base layer, but it won't solve the significant problems that the blockchain community faces overnight. To achieve its full potential, the TTF will require continued adoption, development, and improvement by a wide variety of actors".

Summing up, it is clear that the concept of digital assets is simple. Applying it in practice is harder. The problem with digital assets and blockchain ecosystems is that they are complex. It is not the technology but also all the aspects around it. Questions include: what is the core protocol, the consensus mechanisms, who are the participants, who are the promoters, what are the promises and expectations?

\section{Digital twins}

In January 2020 Purdy, M., Eitel-Porter, R., Krüger, R. and Deblaere, T. published in MIT Sloan Management Review (Purdy et al., 2020) a paper entitled: 'How Digital Twins Are Reinventing Innovation' with a subtitle: From faster and cheaper drug trials to fully "conscious" cities, digital replicas are changing the face and pace of innovation. The authors write that 
a digital twin - a virtual replica of an object, being, or system can be continuously updated with data from its physical counterpart.

Supported by an estimated 25 billion connected global sensors by 2021 (Gartner, 2018) ${ }^{2}$, digital twins will soon exist for millions of things. A jet engine, a human heart, even an entire city can all have a digital twin that mirrors the same physical and biological properties as the real thing. The implications are profound:

- real-time assessments and diagnostics much more precise than currently possible;

- repairs literally executed in the moment; and

- innovation that is faster, cheaper, and more radical.

Digital twins stand to change the innovation game by enabling three critical drivers (Purdy et al., 2020):

1. Continuous evaluation. Traditionally, most complex products could be fully analyzed, piece by piece, only twice during their lifetime - when they were created and when they were broken down at the end of their life cycle. Now that sensors can capture and continuously update the product's digital twin throughout its lifetime, manufacturers have a live window inside the product at all times.

2. Faster, cheaper prototyping. Digital twins can dramatically lessen the need for expensive tests and physical prototypes, reducing the cost and increasing the speed of innovation. The cost of developing new drugs, for example, reaches into the billions, and preclinical testing phases alone take an average of three and a half years.

3. Innovating at the limits. When it comes to solving big human and social problems, the process of innovation becomes that much tougher. It may be unethical to run experimental tests on somebody's heart, for example, and one can't stop traffic in a city's rush hour to experiment with new routing systems.

\subsection{A Digital Twin's Journey}

In a White Paper entitled: 'Gaining Business Intelligence From Your Digital Transformation' the Vertexvis company (Vertexvis, 2019, p. 4) specified the value of a digital twin citing Gartner's opinion that 'digital twin is the top technology trend for the last three years running'.

The White paper contains short descriptions of applications of the concept in practice:

"Digital twins give context and insight into each stage of the product lifecycle, including design, build, and in-the-field usage.

1. Engineering and design teams create a product's design, including requirements and simulation results to understand how a product will perform. This "as-designed" information kicks off the digital twin's journey.

\footnotetext{
${ }^{2}$ Gartner Identifies Top 10 Strategic IoT Technologies and Trends, https://www.gartner.com/en/newsroom/pressreleases/2018-11-07-gartner-identifies-top-10-strategic-iot-technologies-and-trends.
} 
2. As manufacturing teams turn the design into reality, they quickly add any replacements or changes to the digital twin to record "as-built" information.

3. Once a product is in the field, a multitude of sensors gather information about the product's performance. This information streams back into the digital twin to record "as-manufactured" data.

4. Companies take design, build, and performance data to understand what is needed for "as-serviced" information and provide learning and predictive analytics. With the right technology in place, a digital twin can understand information from sensors and relate it to the as-designed and as-built information to gain insight on improving future iterations".

\subsection{Digital Twin Challenges}

In the opinion of experts of many industrial advisory companies efficiency in operations and product design optimization have become strategic imperatives in manufacturing. In addition, pressure from consumers, investors, and regulators to adopt sustainable business practices makes it more difficult for manufacturing companies to maintain their bottom line. Although digital twin technology is often marketed as the silver bullet for manufacturing, offering to increase inefficiencies in operations, facilitate innovative product design, and promote sustainable practices, digital twins are simply a tool. The reality is that obtaining the technology does not guarantee success - companies need to know how to effectively leverage it to achieve their sustainability goals. And successful implementation requires changes at the organizational level (Guidehouse Inc., 2019).

While digital twins have plenty of momentum, significant challenges remain. Technology providers haven't adopted a standard definition of a digital twin, and most describe the set of capabilities in slightly different ways. There's also the issue of data sovereignty — specifically, how to persuade customers and partners to share data collected from assets with manufacturers so they can improve the digital twin to the point it can support preventative maintenance services and optimize future product designs. What's also required is standardization of data management processes and clarity about the available tools to create and manage digital twins. While implementing digital twins doesn't require a whole new toolbox, it does require a new approach for managing and using data.

According to Rafael Go, senior research analyst at Navigant Research (Go, 2020), apart from technology there are also the usual organizational and cultural hurdles. There is still a lot of inertia that prevents manufacturing companies from doing things in different ways. Building organizational comfort and buy-in with the digital twin concept is important. Go considers that "the most important dimension pertaining to the organization is the breadth and depth of the information. The latest applications of digital twin technology require real-time data from a multitude of sources throughout the organization. Enabling timely and proper access and use of this data requires retooling the data sharing, security, and access approaches within the 
organization. Data use protocols and procedures would need to be re-examined and rewritten to break down siloes in data ownership and access while ensuring that sensitive and confidential data is protected. In addition to changing data management practices, companies also need to train their workers to become more data literate. Companies must invest in training and hiring programs that emphasize increasing employee comfort working with data. Taking full advantage of a technology such as the digital twin with organization-wide implication requires an enterprise wide approach".

\section{Blockchain can improve the concept of digital twins}

A digital twin is a concept that refers to the virtual replica of a physical asset, like luxury goods or artworks, in the digital realm, for example on a blockchain. This requires creating a digital identity for such objects, allowing for their digital existence alongside their physical one. The digital identity is generated thanks to traditional authentication solutions (such as near field communication - NFC, radio-frequency identification - RFID, visual recognition, etc.) and is first independent from the distributed ledger. Once created, the digital identity can be associated with a token and managed on a blockchain. This helps track physical assets and integrate them into dematerialised processes to optimise the operation and maintenance of the underlying physical assets. This also encourages innovative solutions that combine both blockchain and Internet of Things - IoT.

\subsection{Examples of case studies}

Case Study 1 (Blockchain forum.eu: report digital assets 2020a, p. 17): LVMH (Louis Vuitton Moët Hennessy) and the AURA platform. "LVMH is developing AURA, a platform that aims to serve the entire luxury industry with product tracking and tracing services on Ethereum $^{3}$. All along the value chain, from production to distribution, LVMH's luxury goods "live" on blockchain. Indeed, once one product is manufactured, a token is minted and affiliated with this product. When the product is sold, the related digital twin is transferred to the acquirer. Consumers can then access the product history and proof of authenticity of any of the items they buy, at any stage of their lifecycle. This is made possible by recording these attributes on the blockchain and attaching a certificate containing all the product information: details on product origin and components, instructions for product care, after-sales and warranty services available. At this stage, even if it is technically feasible, tokens are not traded on secondary markets".

\footnotetext{
${ }^{3}$ Blockchain glossary; https://comptiacdn.azureedge.net/webcontent/docs/default-source/research-reports/07576blockchain-glossary-of-terms-r3.pdf?sfvrsn=7df7462a_0.
} 
Case Study 2 (Blockchain forum.eu: report digital assets 2020a, p. 17): “TEO - The Energy Origin Engie, a French supplier of gas and electricity, and Ledger, a French blockchain startup known globally for its hardware wallets ${ }^{4}$, partnered to create The Energy Origin (TEO) platform. This project is based on several observations. First, climate change and energy transition are now compelling issues for energy suppliers, which are shifting towards more responsible production. Second, citizens have become increasingly concerned by their energy consumption and favour green power sources. However, it is very hard for them to measure the real impact of their efforts on the environment and to know the precise origin of the energy that they use. TEO records in real time both generated and consumed energy volumes thanks to sensors installed on sites. Based on the customer's preferences, TEO's matching engine calculates the volumes of energy exchanged between the renewable assets and the customer's sites as well as the impact in terms of avoided $\mathrm{CO} 2$. This information is registered in tamperproof certificates and accessible on TEO. Tokenising "avoided CO2" enables citizens to value their green commitment. Based on this first layer, further use cases could be imagined, such as a system of rewards or monetisation of energy savings".

\subsection{The future}

By 2020, it is expected that there will be 4.5 billion networked Internet of Things (IoT) devices in Europe, providing digital twins with the data they need (Miskinis, 2018). Blockchain has naturally become the next step in bridging the connection, with the advent of blockchain technology redefining the concept of digital twins. It could be an essential tool to aid the application of digital twins in IoT, transferring the data and value onto the Internet with full transparency. Sectors such as manufacturing and retail are set to benefit from these technologies interlinking, connecting the physical with the digital world. A digital twin built with traditional technologies must need a central intermediary that is dependable in performing analytics and holding data. Perhaps the inability to govern the digital twins and the lack of approval is a reason why digital twins have been slow to gain popularity. Blockchain technology has the potential to become the most relevant and capable way to generate and monitor digital twins due to the security and immutability of technology.

Platform security of the digital twin platform and data is crucial. Blockchain technology enables security from hackers due to its encryption features and provides data history transparency. Digital twins will benefit from these features, as it can transmit data securely. Both small and medium enterprises (SME) and large companies are beginning to utilize blockchain technology to store physical objects, and connecting digital twin technology will soon be the next step. In order for this to succeed, specialized distributed ledger platforms that allow sharing information amongst digital twins are needed. Digital twins on a blockchain will also help with brand protection and counterfeit items. Creating a digital twin of a product on

\footnotetext{
${ }^{4}$ Ibidem.
} 
blockchain would see its transaction records saved, along with information about where it was made, and its previous owners. In addition to this, for the first time in history companies who combine blockchain with virtual simulations will be able to track their product globally with extreme accuracy - this will totally eliminate the number of stolen goods across the globe (Miskinis, 2018). There is a strong belief (Purdy et al., 2020) that impact that digital twins can make is huge. Many are just now in development due to the complexity of their creation, but soon millions of things will have digital twins. And their usefulness and capabilities will continue to evolve. The digital twins of two - or more - of these robots can communicate to figure out how to best work together on a new assembly line.

But it doesn't stop there. Linking the digital twins of completely different types of assets can feed the digital twin of more complex entities. An entire city, for example, will need to connect information from digital twins tied to traffic, weather patterns, pollution, citizens, energy, and other resources. This enables a transformation from smart cities to conscious cities - cities that are aware of assets flowing in and out of their borders. This level of understanding unlocks new ways of innovation (Maxwell, 2018): new forms of urban mobility that are both faster and cheaper, elimination of congestion; reduction of pollution; new ways of emergency planning; and smart tracking of energy and water. A digital twin with all the complexity and detail of a physical city provides a larger and more valuable platform for experiments than has ever been created.

\section{Summary}

Nowadays it is obvious that the blockchain technology is revolutionising just about every industry imaginable. Banking, politics, healthcare... all could technically benefit from the creation of a decentralised digital ledger which tracks and stores information in various places, thus making forgery impossible. Identification is provided through complex calculations, making identity theft virtually impossible, too.

This general review paper provides an overview of some concepts and techniques concerning digital assets especially in the form of digital twins and presents opinions of different research circles on how, by applying the blockchain technology, the concept of digital twins can be improved. As a basic source of opinions served works of The European Blockchain Observatory and Forum which launched in February 2018, and which is a European initiative to accelerate blockchain innovation and the development of the blockchain ecosystem within the EU (EU Blockchain Forum Working Group; 2018). Even though the digital asset phenomenon is well under way, there is still a long way to go and obstacles to overcome before it becomes a real revolution. 
In the opinion of members of the Forum, "the European Union is currently focused more on the risks that arise from digital assets, to the detriment of the great opportunities that they bring. They think authorities should continue their efforts to ensure the healthy growth of digital assets in a safe environment for consumers and established players and take additional measures to help innovative actors progress, experiment and prove their positive potential for the European economy and markets. This starts with providing legal certainty for these actors, which actually means greater clarity for regulators to supervise the digital asset ecosystem" (Blockchain forum.eu: report digital assets 2020a, p. 33).

The final conclusion is the following: impact that digital twins can make is huge. Many are just now in development due to the complexity of their creation, but soon millions of things will have digital twins. And their usefulness and capabilities will continue to evolve. On the other hand, blockchain technology has the potential to become the most relevant and capable way to generate and monitor digital twins due to the security and immutability of technology.

\section{References}

1. Blockchain forum.eu: Blockchain and the future of digital assets, report (2020a). Available online: https://www.eublockchainforum.eu/sites/default/files/report_digital_assets_v1.0. pdf? width $=1024 \&$ height $=800$ \&iframe $=$ true, 3.08.2020.

2. Blockchain forum.eu: Blockchain and the future of digital assets; Blockchain terminology, report (2020b). Available online: https://www.eublockchainforum.eu/sites/default/files/ report_digital_assets_v1.0.pdf?width=1024\&height=800\&iframe=true, 3.08.2020.

3. Blockchain Research Institute (BRI) (2020). Available online: www.blockchainresearchinstitute.org.

4. CompTIA.org: The Role of Emerging Technology in Digital Transformation, Whitepaper 2020. Available online: https://comptiacdn.azureedge.net/webcontent/docs/defaultsource/research-reports/07821-emerging-tech-whitepaper-online.pdf?sfvrsn=a0cbca08_0, 13.08.2020.

5. CompTIA.org: Using Strategic IT for Competitive Advantage, Whitepaper 2018. Available online: https:/comptiacdn.azureedge.net/webcontent/docs/default-source/research-reports/ using-strategic-it-for-competitive-advantage.pdf?sfvrsn=9b963e69_0\%22, 13.08.2020.

6. CompTIA: A Functional IT Framework, Report 2016. Available online: https://comptiacdn.azureedge.net/webcontent/docs/default-source/research-reports/02878it-framework-report-online.pdf?sf, 13.08.2020. 
7. EU Blockchain Forum Working Group; 2018. Available online: https://www.eublockchainforum.eu/news/eu-blockchain-observatory-and-forum-namesmembers-core-working-groups, 3.08.2020.

8. Gaining Business Intelligence From Your Digital Transformation, White Paper (2019, p. 4) Vertexvis company. Available online: https://vertexvis.my.salesforce.com/sfc/p/\#f 4000002c0zl/a/f4000000cKVK/QBbA3.ennNRNidwlbV4CjF7wOOyynxi89Sn2dE8e39o, 10.09.2020.

9. Gartner (2018). Top 10 Strategic IoT Technologies and Trends. Available online: https://www.gartner.com/en/newsroom/press-releases/2018-11-07-gartner-identifies-top10-strategic-iot-technologies-and-trends, 10.09.2020.

10. Go, R. (2020). Organizational Barriers to Harnessing the Digital Twin. Guidehouse Inc. Available online: https:/guidehouseinsights.com/news-and-views/organizational-barriersto-harnessing-the-digital-twin, 10.09.2020.

11. Leveraging Digital Twin Approach for Sustainable Manufacturing. Guidehouse Inc. (2019). Available online: https://guidehouseinsights.com/reports/leveraging-digital-twinapproach-for-sustainable-manufacturing, 10.09.2020.

12. Maxwell, L. (2018). Smart city benefits: How smart cities save governments, businesses and citizens money; Bee Smart City. Available online: https://hub.beesmart.city/en/strategy/ how-smart-cities-save-governments-businesses-citizens-money.

13. Miskinis, C. (2018). How the blockchain can improve the concept of digital twins; Challenge Advisory. Available online: https://www.challenge.org/insights/blockchain-anddigital-twin/, 10.09.2020.

14. Purdy, M., Eitel-Porter, R., Krüger, R. and Deblaere, T. (2020). How Digital Twins Are Reinventing Innovation. MIT Sloan Management Review. Available online: https://sloanreview.mit.edu/article/how-digital-twins-are-reinventing-innovation/ ?gclid=Cj0KCQjw7sz6BRDYARIsAPHzrNKv16P8zykbiuK7JAdESbMiLZln3g_Ly51Xk 7mpfPND2VojPdn9HZoaArLxEALw_wcB, 10.09.2020.

15. Tapscott, D. (2020). Token Taxonomy. The Need for Open-Source Standards Around Digital Assets. Toronto: Blockchain Research Institute. Available online: https://www.blockchainresearchinstitute.org/wp-content/uploads/2020/02/Tapscott_ Token-Economy_Blockchain-Research-Institute.pdf?utm_source=hs_email\&utm_ medium $=$ email\&utm_content $=84603290 \&$ hsenc $=$ p2ANqtz-8_5Yo_tQVzMnAbgg CBV8fxDhF3uSOgs1HpyISLd6FGH0zMTvp6QFnuH_2I376r6WhherbIZWdVj6x6mSFJ TzRe5QWvFg\&_hsmi=84603290, 20.08.2020. 



\title{
IMPROVEMENT OF MAINTENANCE PROCESS IN A COAL MINE - CASE STUDY
}

\author{
Dobrochna SZTAJERSKA ${ }^{1 *}$, Marcin BOGDAŃSKI ${ }^{2}$ \\ ${ }^{1}$ Cavalry Captain Witold Pilecki State University of Malopolska in Oswiecim; \\ dobrochna.sztajerska@dydaktyk.uczelniaoswiecim.edu.pl, ORCID: 0000-0002-8098-282X \\ ${ }^{2}$ Polska Grupa Górnicza S.A., m.bogdanski@pgg.pl \\ * Correspondence author
}

Purpose: identification of possibilities of using quality management methods and tools to improve maintenance processes.

Design/methodology/approach: the tools used were adjusted to the results of cognitive interview and maturity analysis of maintenance process carried out among representatives of various levels of the organization's management, based on an original tool.

Findings: it was found that the level of maturity of the process is in the chaotic phase, despite the fact that the company implemented integrated management systems, quality management methods and tools are not systematically used in the process; it seems, however, the needs in this area are very large.

Research limitations/implications: the study was conducted on the basis of only one process, in one workplace; only on the basis of own observations it can be concluded that other processes in this plant, as well as similar ones, will show similar deficiencies, which should, however, be subjected to a deeper analysis.

Practical implications: it can be assumed that the research results presented in this paper, as well as the proposed practical solutions, may support not only the process under study, but also completely different processes; the study seems to indicate the need of educating the managers in the field of practical skills for improving the processes in the organizations.

Originality/value: the study proposes the use of an original tool for measuring process maturity as an entrance to further steps, it also presents the possibility of using tools, the process of their implementation in an actual process, as well as barriers encountered.

Keywords: process maturity, methods and tools of quality management, process improvement, maintenance.

Category of the paper: research paper, case study. 


\section{Introduction}

It would not be very exploratory to say that the maintenance processes (MP) in large companies are one of the most crucial elements influencing their effectiveness. It seems, however, that there is still an insufficient support for these processes, an understanding of their actual meaning, as well as provision of adequate resources, including knowledge, competences and skills to those managing the maintenance processes. For several years, there have been numerous studies that point out that production plants currently devote a lot of attention to their MP (Zasadzień, 2016; Jasiulewicz-Kaczmarek, 2013; Gajdzik, 2010). However, one should consider what is the attention most often really paid to - investing in the process or looking for the guilty party - if the production does not go according to the plan. Hard coal mines are specific workplaces, according to the author, in many cases with an organizational culture remaining in the previous system and reactive to market needs. However, they provide great potential for the implementation of the quality management tools, because, despite of the implementation of the integrated management systems, the level of using the tools is low, and usually comes down to breaking open doors by process managers. The generation gap causes the mines to suffer from a lack of knowledge and competences among employees, plants collect more and more data that needs to be processed, and the turmoil around the environmental and economic aspects of coal mining makes many people's eyes turn to the mines. Therefore, it seems even more vital to take care for the maturity of the processes, which is manifested, generally speaking, in the degree of "control" (the scope in which the processes are defined, managed, flexible, measured and effective) over the processes taking place in the company (Grajewski, 2007), should be the center of the attention of the coal mining companies. Can a maintenance process maturity assessment help to plan effective and efficient methods and tools for process improvement? Based on the author's previous experience with the study of the maturity of the organization, it could be assumed that it would be an effective tool and, consequently, would allow to diagnose the strengths and weaknesses of the company, as well as to propose tools that could be used, both for organizational and substantive reasons. Therefore, the study was undertaken. Since it was conducted in the idiographic trend on the basis of one case, the formulation of the above research problems seemed to be sufficient to achieve the assumed goal. 


\section{Methods}

The study was divided into two part - introductory - a cognitive interview with the owner of the process, and a main part. The participants in the main part of the study were 53 managers from 4 levels of maintenance management in the mine being under study (level 4 - marked as the lowest level, while level 1 as the highest and represented by one person - the owner of the maintenance process in the examined plant). The most numerous group were level 3 managers $(\Sigma=32)$, then level 2 managers $(\Sigma=14)$ and level 4 managers $(\Sigma=6)$. Due to the specificity of the mining industry, no women took part in the study.

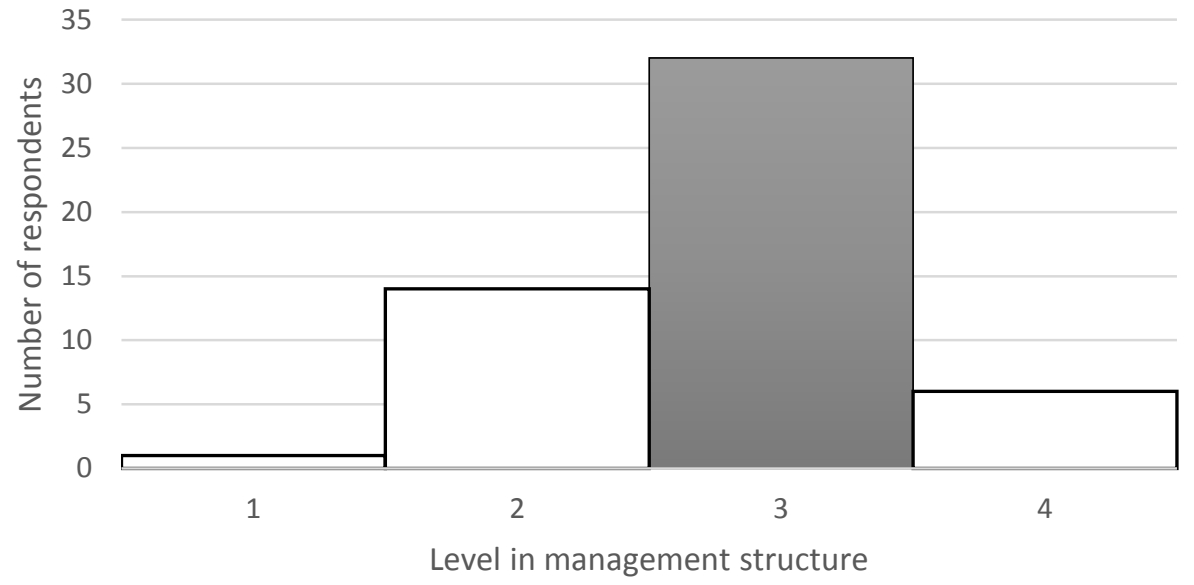

Figure 1. The number of respondents depending on the level of process management.

The researcher was interested in the level of maturity of the maintenance process, according to the managers at various levels. This was to identify strengths and weaknesses in order to propose methods and tools for improving quality management in the examined process.

The study used the proprietary process maturity measurement questionnaire, which consisted of 49 statements divided into 7 areas - customer orientation, leadership, people involvement, process approach, improvement, decision making based on facts and relationship management. The Likert scale in the 5-point variant was used as the answer model, according to the pattern below:

1 - I strongly disagree/the statement is completely inaccurate (M-1);

2 - I disagree/the statement is rather inaccurate (M-2);

3 - I partially agree/the statement is half correct (M-3);

$4-\mathrm{I}$ agree/the statement is rather accurate (M-4);

5 - I strongly agree/the statement is completely accurate (M-5).

The lower the examined person assessed a given statement, the lower the grade on the scale was marked. 
Table 1.

Maturity level scale

\begin{tabular}{|c|c|}
\hline Level & Description \\
\hline M-1 & $\begin{array}{l}\text { For each principle, definitely no or not true (0-19\% compliance). } \\
\text { There is no objective evidence for the implementation of the measures. } \\
\text { Lack of systematic action in the field of: } \\
\text { 1) customer focus of the MP } \\
\text { 2) enterprise leadership focused on managing the MP } \\
\text { 3) involving people in the implementation of the MP } \\
\text { 4) processes implemented to ensure the appropriate level of achieved results } \\
\text { 5) ways to improve the MP } \\
\text { 6) making decisions about the MP on the basis of facts } \\
\text { 7) managing relations with parties interested in the MP }\end{array}$ \\
\hline M-2 & $\begin{array}{l}\text { For each principle, no or false for most activities (20-39\% compliance). } \\
\text { There is little objective evidence for the implementation of the measures } \\
\text { No systematic action in the above-mentioned range }\end{array}$ \\
\hline M-3 & $\begin{array}{l}\text { For each of the principles, no or false for some activities (40-59\% of requirements fulfillment). } \\
\text { There is objective evidence that the measures have been implemented } \\
\text { Systematic operation of selected activities, mainly related to profits }\end{array}$ \\
\hline M-4 & $\begin{array}{l}\text { For each principle, yes or true for most activities }(\mathbf{6 0 - 7 9 \%} \text { compliance). } \\
\text { There is objective evidence that measures have been implemented for almost every activity } \\
\text { Systematic operation in most activities related to the maintenance process }\end{array}$ \\
\hline M-5 & $\begin{array}{l}\text { For each principle, definitely yes or true for most or all of the activities (80-100\% compliance). } \\
\text { There is objective evidence that measures have been implemented for all activities } \\
\text { Systematic action in all activities related to MP }\end{array}$ \\
\hline
\end{tabular}

As a similar tool was previously used, but to study food safety management processes, this time the questionnaire was not tested. It was only consulted with a person familiar with the maintenance process, in order to eliminate such errors as inadequate language of the tool, incorrect knowledge assumption, suggestive statements, blurred concepts, etc.

Cronbach's Alpha was used to assess the reliability of the questionnaire, or the repeatability of the study, for example a situation in which the research carried out with the same tool gives the same result each time. Cronbach's alpha for the total of 49 test items included in the questionnaire was $0.893^{1}$, which means that the questions in the maturity measuring tool are internally correlated - they measure the same construct.

Due to the specifics of the sample - a large group of people working on various shifts and the choice of the questionnaire as a research tool, it was decided to use the CAWI technique. Sending the research tool was always preceded by a telephone or personal conversation with the examined person about the possibility of carrying out the research. This part was carried out by the owner of the maintenance process in the surveyed company. Diagnostic questionnaires were sent to the e-mail address provided by the examined person. The respondents filled in the spreadsheet on their own computer and sent it back via the "send" option. The main introduction of the participants of the study was the cover letter attached to the tool, which included the following content:

\footnotetext{
${ }^{1}$ On a scale from 0 to 1 , the closer to 1 , the higher the consistency of the test items.
} 
1) information about the person conducting the examination and the person supervising it;

2) the purpose of the study;

3) information about anonymity and voluntariness;

4) instruction.

The study was conducted in January 2020. The subjects had 7 days to complete the questionnaire. The adoption of such a time frame gave the opportunity to receive fully valuable questionnaires, and on the other hand, significantly accelerated the obtaining of results, which was important for the process owner. Adopting a longer period could cause the respondents to lose their motivation to complete the questionnaire or, for example, forget to complete it. Additionally, to prevent the above, 5 days after receiving the questionnaire, a reminder e-mail was sent. All of the people who declared participation in the study completed the questionnaire. It should be noted that completing the sheet was voluntary. Although the survey was anonymous for the person conducting the survey, due to the need to monitor the filling of the sheets, the e-mails were collected, but they were only used by the process owner to verify which of the people declaring participation had completed the sheet - both the researcher and the process owner did not compare the content of the questionnaires with those who filled it in.

The purposeful selection of the population itself was dictated by the specifics of the study and the entire project. The study was not a sample of the population of the managers of various levels of the analyzed process, but all of them, it was to enable the identification of special variables influencing the maintenance process, which would be invisible in the study on the sample. The applied research technique, however, has certain drawbacks, which include, first of all, the inability to control whether the person completing the questionnaire devotes himself to it. A control question was used in the study to minimize this problem. Due to the advantages of the technique, taking into account the specificity of the study, for example, the relative ease of reaching all respondents and the relative speed of the study, such a solution was considered the best for this type of project.

Quite complex questionnaires (as in this case) may cause an excessive burden on the respondent. This may lead to the inconsistency with the facts or to the so-called satisficing, that is, giving an answer that is "a satisfactory choice", therefore good enough for the respondent, but not necessarily consistent with the actual state. A preventive measure introduced for this threat was to conduct a cognitive interview with the owner of the maintenance process and to observe the process. 


\section{Results}

\subsection{Introductory information from the study}

As mentioned, the study was conducted in stages, its general outline is presented in the study scheme presented in Figure 2. As also mentioned above, in order to avoid problems with the reliability of the study, in the first phase, an cognitive interview was conducted with the owner of the maintenance process, aimed at drawing attention to the areas in need of improvement. During the interview, the process was also confronted with the model of Crespo Márquez et al. (2009), presented at Figure 4, and areas for improvement were indicated. Then, a study was conducted using the MP process maturity assessment questionnaire, which technical details were described above. On the basis of the study, an analysis and evaluation were made, and conclusions were drawn regarding the maturity of the described process. An action plan was developed and a risk analysis for the planned activities was carried out, which was not included in this study due to its wide scope, making it impossible to be fully and clearly described here.

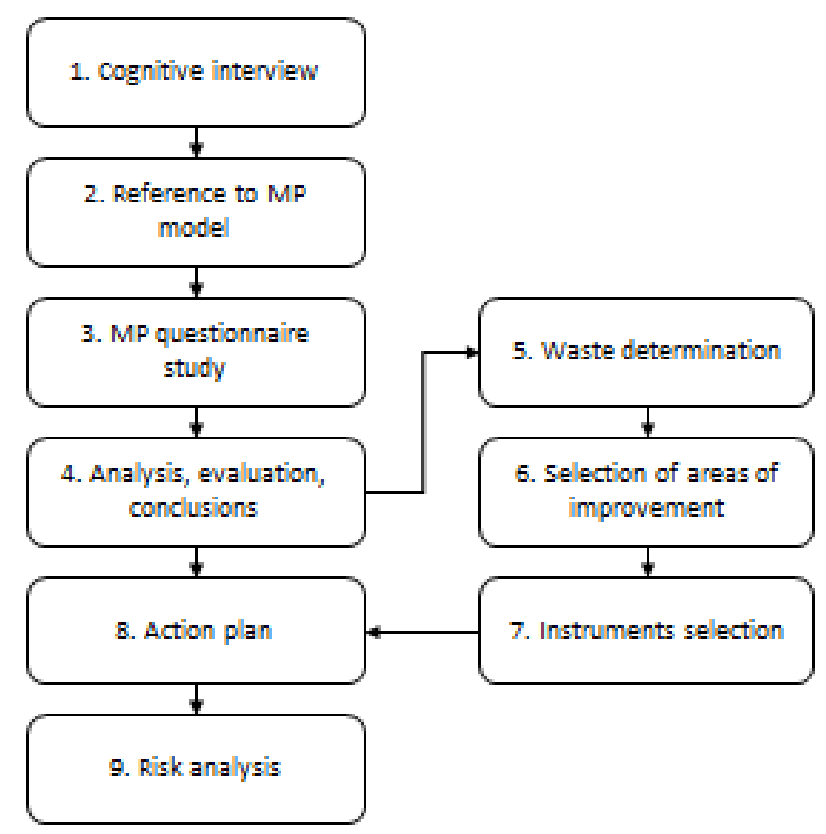

Figure 2. A simplified diagram of the tests performed at the $\mathrm{XYZ}$ coal mine.

For the sake of clarity of this description, the tools will be presented in relation to the identified area of improvement, and not collectively in the tool selection point, therefore regardless of whether the need to implement the tool resulted from the introductory part, the main part of the study, or both. 
The cognitive interview ${ }^{2}$ with the process owner provided, among others, information on difficulties in carrying out tasks resulting from insufficient employee competences or the need to spend time solving problems that should be dealt with by employees of lower levels or other departments. One of the basic themes that emerged from the analysis was also the waste of time in the process. In order to identify the actual duration of activities carried out in practice, it was proposed to implement the Productivity Calculator at the workplace of the owner of the maintenance process (Figure 3). Several main categories were taken into account (apart from those shown in Figure 3, additionally - planned activities and waste ${ }^{3}$ ) and to each of them subcategories identified by the process owner were assigned. Twelve units of measurement (twelve hours) were planned. Within each of them, time was entered in minutes for a given category of activity.

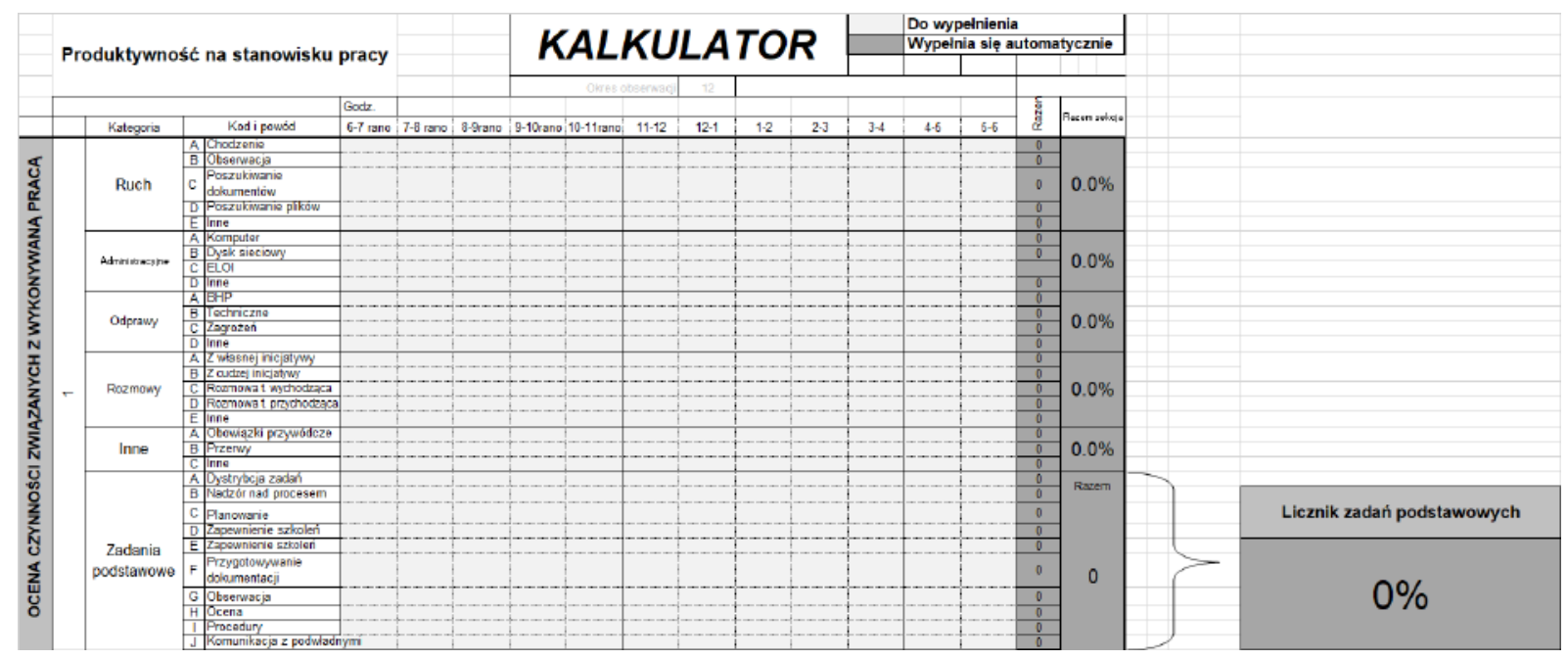

Figure 3. Part of the Workplace Productivity Calculator.

Data was collected for one month and the results were averaged. The measurement showed that the average time devoted to basic tasks was 23.8 pct. of working time, which was the highest value, followed by administrative activities with an average rate of 19.1 pct., the least, because only 1.0 pct. Spent on "other". Waste, on the other hand, was determined at the level of 8.3 pct. and the most important turned out to be the (unused) skills. After the analysis, the scopes of work activities of some employees were changed, which partially solved the problem, another tool for improvement in this area were the competence matrices described below. Interestingly, after the direct supervisor of the process owner returned to work, the waste increased to 20.4 pct. and the highest rate was related to overprocessing. On an hourly basis, it turns out that waste takes one day a month. In similar studies (Zasadzień, 2016), which also measured working time, but of maintenance workers with an unknown position and in a slightly

\footnotetext{
2 The interview was conducted using the paradigm proposed by Saldaña (2009). Information obtained from the process owner was encoded using three types of codes: descriptive, analytical and in vivo.

311 categories of waste were referred to: transportation, inventory, motion, waiting, overprocessing, overproduction, defects, skills, inappropriate use of a computer/telephone, lack of employee involvement, inappropriate indicators.
} 
more general way, it was calculated that ineffective working time is on average 14.6 pct., which would be the average time after adding the before and after the return of the superior of the process owner. An oral request was made to shorten the wasteful activities and to carry some of them out electronically. Unfortunately, even despite documenting the losses in the process, it was not possible to convince the supervisor to change the form of carrying out some of the non-value adding activities (NVA).

As mentioned above, during the interview with the process owner, the studied area was confronted with the maintenance model of Crespo Márquez et al. (2009) (Figure 4). The model consists of eight phases, first three of which relate to the effectiveness of the implemented process, the next two to its efficiency, phases six and seven relate to the evaluation of the maintenance process, and the last phase - to continuous improvement of the process.

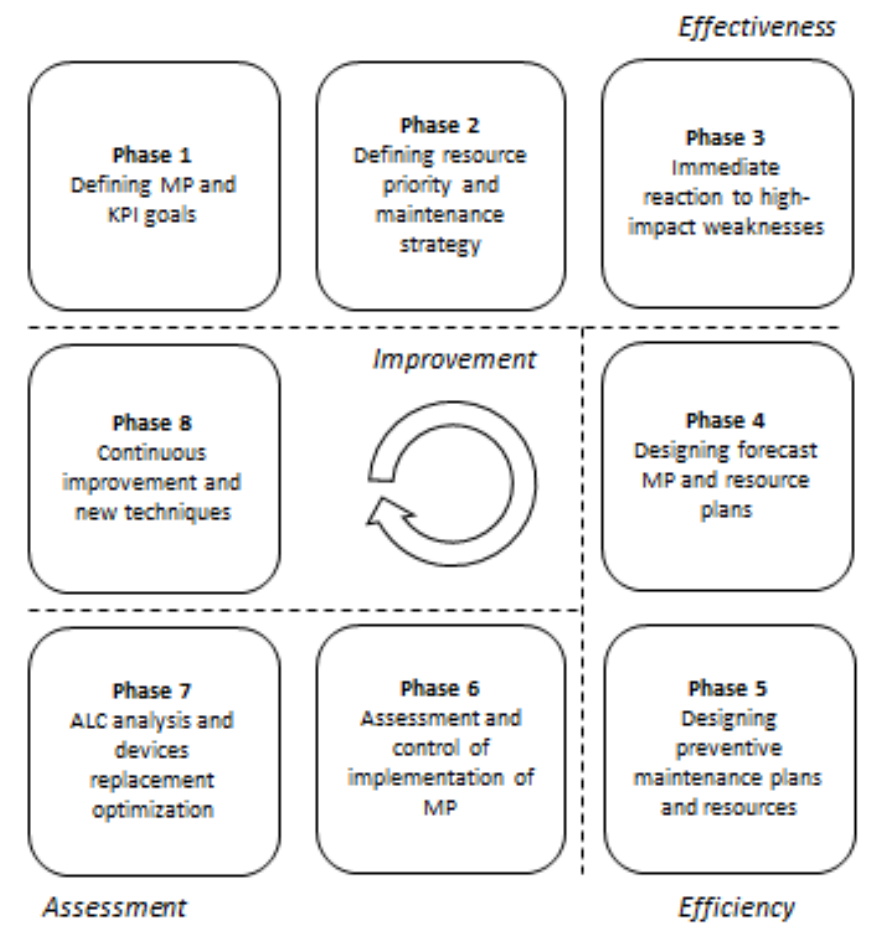

Figure 4. MP model. Adapted from Crespo Márquez et al., 2009.

As it turned out, the examined process does not meet the requirements of the first phase, because at the planning stage, neither the process goals nor the key performance indicators $(\mathrm{KPI})^{4}$ were defined. According to the words of the process owner, its management comes down to extinguishing fires, so it has a reactive dimension, which at the beginning could indicate the low maturity of the examined process. A critical to quality (CTQ) tree, related to the Voice of client (VoC) analysis and the Out of Control Action Plan (OPAC) were used as a process support tool in this area - both shown in Figures 5 and 6.

\footnotetext{
${ }^{4}$ Assuming, as defined in ISO 9000: 2015, that there is no efficiency without effectiveness, then at this stage the comparison of the as is process with the model can be completed.
} 


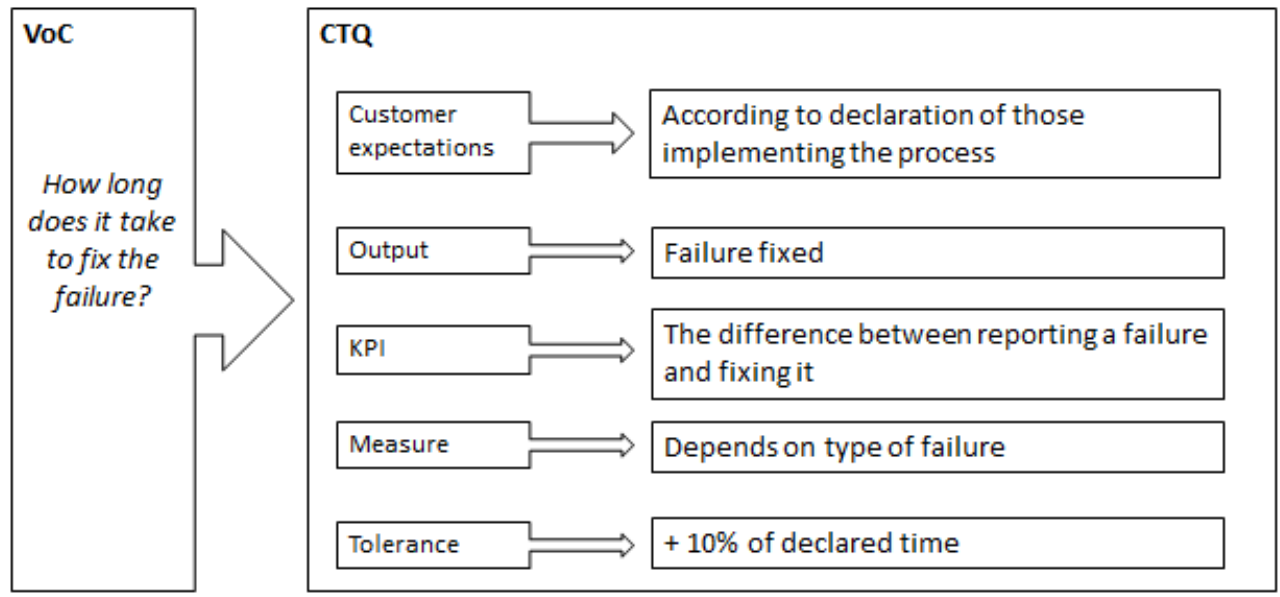

Figure 5. VoC-CTQ analysis example.

Since the organization does not carry out any proactive activities related to the assessment of customer needs, such as, for example, discussion groups, the "customer voice" was determined on the basis of the most frequently reported oral complaints related to the duration of failure removal, etc. In order to alleviate customer concerns, the focus was primarily on the efficient diagnosis of failures, as well as corrective actions. For this purpose, the OPAC and the Non-conformity Card were implemented (Figure 7).

\begin{tabular}{|c|c|c|c|c|c|c|}
\hline Process step & $\begin{array}{c}\text { Measures } \\
\text { (input/output) }\end{array}$ & Value & $\begin{array}{l}\text { Measurement } \\
\text { method }\end{array}$ & $\begin{array}{l}\text { Control } \\
\text { method }\end{array}$ & $\begin{array}{l}\text { Person } \\
\text { responsible }\end{array}$ & Reaction \\
\hline $\begin{array}{l}\text { Receiving } \\
\text { failure report }\end{array}$ & \multirow{2}{*}{$\begin{array}{l}\text { Output } \\
\text { Completeness of } \\
\text { information }\end{array}$} & \multirow{2}{*}{$100 \%$} & \multirow{2}{*}{$\begin{array}{c}\text { Complete answer to checklist } \\
\text { questions }\end{array}$} & \multirow{2}{*}{ checklist } & \multirow{2}{*}{ Shift supervisor } & \multirow{2}{*}{$\begin{array}{l}\text { 1. Train the person } \\
\text { receiving the } \\
\text { information on the data } \\
\text { necessary to implement } \\
\text { the actions } \\
\text { 2. Record in data sheet }\end{array}$} \\
\hline & & & & & & \\
\hline $\begin{array}{l}\text { Organization of } \\
\text { necessary } \\
\text { resources }\end{array}$ & \multirow{2}{*}{$\begin{array}{c}\text { Output } \\
\text { - resource organization } \\
\text { time } \\
\text { - resource completeness }\end{array}$} & \multirow[t]{2}{*}{$\begin{array}{l}515 \mathrm{~min} \\
100 \%\end{array}$} & \multirow[t]{2}{*}{$\begin{array}{l}\text { Time measurement from end } \\
\text { of conversation - application } \\
\text { for sending a brigade }\end{array}$} & \multirow[t]{2}{*}{ check sheet } & \multirow[t]{2}{*}{ Shift supervisor } & \multirow[t]{2}{*}{ Create a decision tree } \\
\hline & & & & & & \\
\hline$\downarrow$ & Input & $100 \%$ & & & & \\
\hline \multirow{2}{*}{ Failure foxing } & $\begin{array}{l}- \text { actual completeness of } \\
\text { resources }\end{array}$ & $100 \%$ & output/input & Failure card & Shift supervisor & \\
\hline & $\begin{array}{l}- \text { actual completeness of } \\
\text { information }\end{array}$ & & measuring time of notification & Shutdown sheet & Person of higher & \\
\hline & - failure procedure time & & & & & \\
\hline
\end{tabular}

Figure 6. An example of an implemented action plan.

The action plan refers to defining actions in the event of an acceptable state being exceeded - "what will we do if ...". It allows to effectively deal with deviations and ensure stability when the conditions change. It also gives a chance to detect impending problems before they become them (Eckes, 2016). In the analyzed organization, high-risk decisions are most often taken, in the case of the analyzed process it is largely associated with financial losses. The cost of the downtime, depending on the technological line, per hour is tens of thousands of zlotys, so it is important to minimize the downtime. In the action plans, a team of higher supervisors built a flow diagram, referred to the indicator and its desired value, the method of measurement and control was determined, and a person responsible for a given step in the process was assigned. The necessary actions were also designed to respond to the threat of failure to complete a given step in the process at the assumed level. 
It is important to take into account not only the effects of problems, but also their causes. Even the best-planned activities related to a potential threat that may occur in the process are subject to error, for example due to the residual risk. Only determining the causes and corrective actions gives a chance to eliminate nonconformities in the future. A major problem in the analysed company was the lack of a formalized system for collecting information on noncompliances and their causes, therefore a Non-conformity Card was introduced, containing information on the situation, its causes, remedial and corrective actions. The Non-conformity Card is presented below (Figure 7) - due to the legibility of the record, the handwritten notes were transferred to the computer version and translated into English.

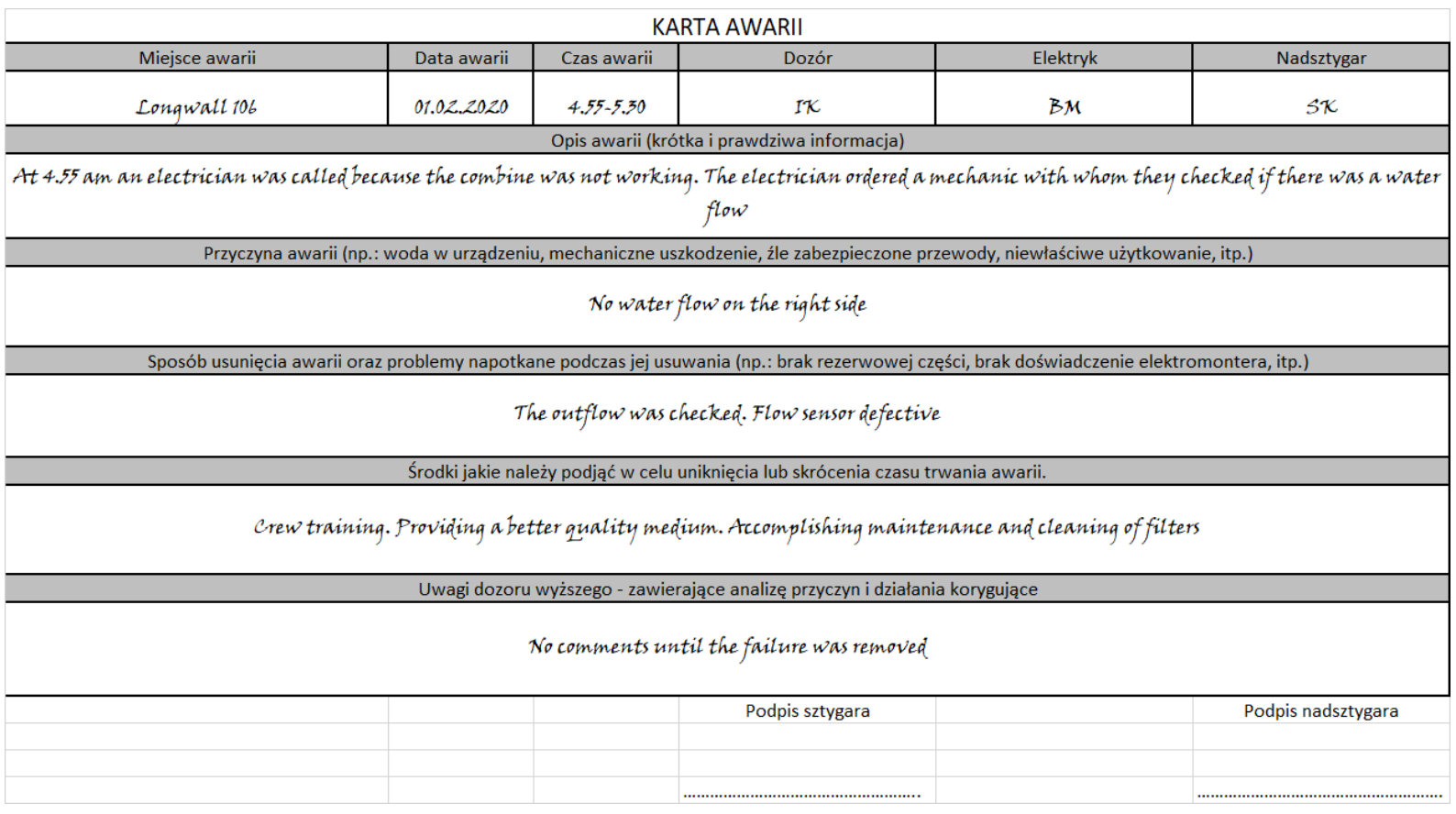

Figure 7. Completed Non-conformity card.

The card is filled in by a supervisory person and verified by a higher supervisory body. As can be seen in Figure 7, the card was not filled in fully in accordance with the requirements, e.g. corrective actions should refer to a deeper analysis (e.g. with a 5-why), carried out in search of the root cause, which, however, was not identified on the card. As it seems, the card also lacks information on the verification of non-compliance after time, and the supervisory remarks contain information on the analysis of causes and corrective actions, which, in principle, to a limited extent, were already described above. The records are also imprecise, there are no dates, employees being responsible, but it was the first tool built on the basis of verbal information on what should be included in the card and since then the card has been modified and enriched with the required information and analyses, which are also introduced into the presented below maintenance process management worksheet (Figure 10).

On the basis of the Non-conformity Card, it is planned to perform an assessment of the root cause analysis. A three-phase analysis will be used for this purpose. 
1. Generating ideas:

a. method 635,

b. Ishikawa diagram.

2. Narrowing down the ideas:

a. prioritizing causes,

b. Pareto-Lorenz analysis.

3. Selection:

a. 5-why,

b. regression analysis.

As these are completely new tools for the process participants and require training, despite their importance in the improvement process, the root cause analysis was not planned to be implemented in the first place. The team is training in its implementation.

\subsection{Results of maturity study of maintenance process}

On the basis of the conducted research, areas requiring improvement were identified by the maturity assessment questionnaire. The assessment of the maturity of each of the seven surveyed areas was based on the weakest point. Figure 8 shows the average score of all respondents with the lowest grade they awarded. This is important because when conducting research on such a large research group, it should be determined whether the lowest grade is adequate to the actual level of the process or results, for example, from specific personality traits of the researched person (e.g. excessively critical, malcontents, etc.), which may possibly be verified by the number of specific, for example lowest, indications of a specific person and compared with the average indications. Of course, low grades may also be the result of the assessor's greater knowledge of specific issues, experience, comparisons with other departments, if known, etc.

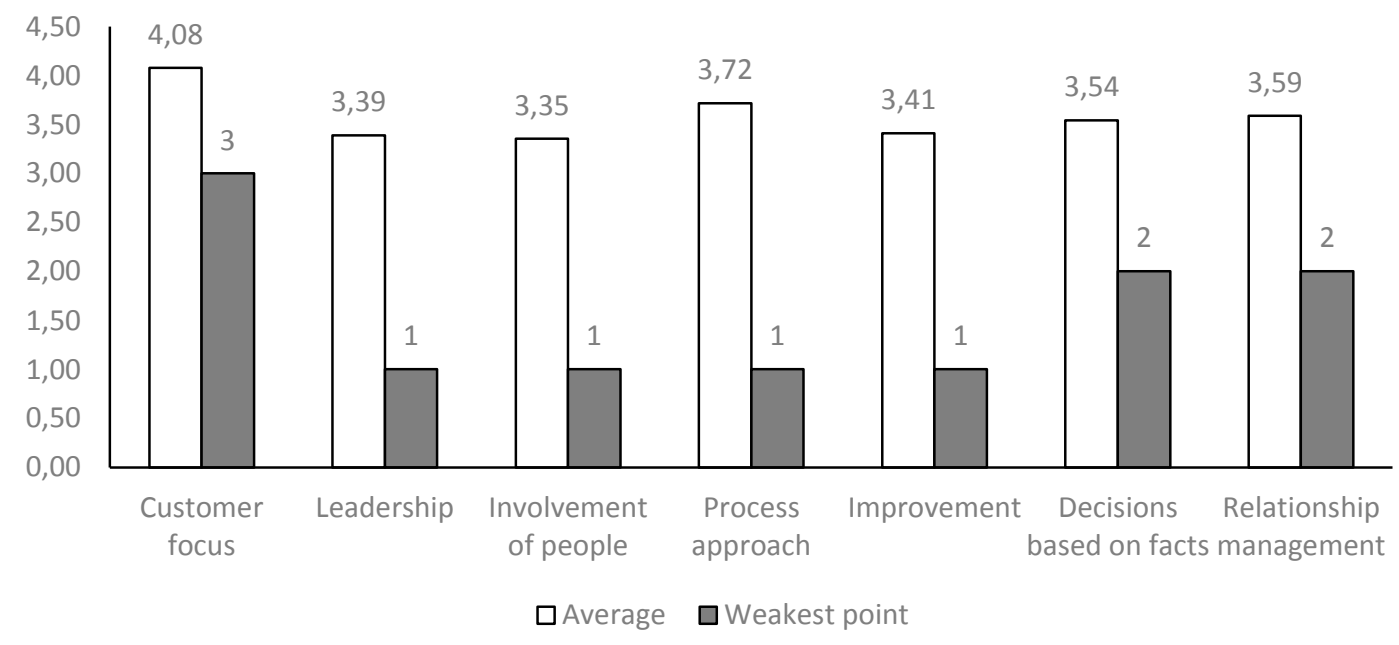

Figure 8. Results of the maintenance process maturity assessment. 
Due to the fact that already in the first phase of the study - during an interview with the process owner - numerous areas for improvement were identified, it was decided that the implementation of the instruments would be justified in each of the areas. In the course of the improvement project, which is still pending, the focus was primarily on the areas with the lowest scores. When selecting the tools to be implemented, the so-called low-hanging fruit strategy was used, so such instruments were selected that would quickly show the effects of their implementation, and would also serve a large group of people. This was primarily to encourage the use of tools, which paradoxically, in the case of a process in which tools are not practically used, does not have to be easy at all, because it requires additional effort and overcoming the typical reluctance to change in the organization. In line with Adamiecki's counteracting principle, it was decided to implement the tools successively on the basis of the improvement plan (Table 2).

\section{Table 2.}

Example of areas and tools within the improvement plan

\begin{tabular}{|c|c|c|}
\hline Improvement area & Instrument & $\begin{array}{l}\text { Implemented } \\
\text { Y/N }\end{array}$ \\
\hline \multicolumn{3}{|l|}{ Customer focus } \\
\hline $\begin{array}{l}\text { I plan, design, develop, } \\
\text { maintenance processes and } \begin{array}{r}\text { support } \\
\text { production to meet } \\
\text { requirements }\end{array}\end{array}$ & CTQ, VoC & $\mathrm{Y}$ \\
\hline \multicolumn{3}{|l|}{ Leadership } \\
\hline $\begin{array}{l}\text { TM creates and maintains common } \\
\text { values, fairness and an ethical model of } \\
\text { behavior at all levels of the organization }\end{array}$ & $\begin{array}{l}\text { Organizational culture analysis - assessment } \\
\text { using a modified organizational culture maturity } \\
\text { assessment form }\end{array}$ & $\mathrm{N}$ \\
\hline \multicolumn{3}{|l|}{ Involvement of people } \\
\hline $\begin{array}{l}\text { In my organization, employee satisfaction } \\
\text { is assessed, the results are presented and } \\
\text { appropriate action is taken }\end{array}$ & Semi-annual employee satisfaction assessment & $\mathrm{N}$ \\
\hline \multicolumn{3}{|l|}{ Process approach } \\
\hline $\begin{array}{l}\text { The MP we carry out is well described } \\
\text { (there are documents, we know what, } \\
\text { when and how to do it, we have resources } \\
\text { for it) and thanks to this we can achieve } \\
\text { the main goal }\end{array}$ & Flow charts & $\mathrm{Y}$ \\
\hline \multicolumn{3}{|l|}{ Improvement } \\
\hline $\begin{array}{l}\text { It is ensured that people are competent to } \\
\text { support and implement improvement } \\
\text { projects }\end{array}$ & Competency matrix & $\mathrm{Y}$ \\
\hline \multicolumn{3}{|l|}{ Decisions based on facts } \\
\hline $\begin{array}{l}\text { KPIs are identified, measured and } \\
\text { monitored as part of the MP (not just } \\
\text { limited to achieving the output level) }\end{array}$ & $\begin{array}{l}\text { MP management worksheet, Kanban board } \\
\text { OEE indicator }\end{array}$ & $\mathrm{Y}$ \\
\hline \multicolumn{3}{|l|}{ Relationship management } \\
\hline $\begin{array}{l}\text { Performance is measured and the } \\
\text { information derived from it is shared with } \\
\text { relevant stakeholders (e.g. suppliers, } \\
\text { partners, customers, employees, etc.) to } \\
\text { support improvement }\end{array}$ & $\begin{array}{l}\text { Presentation of indicators on the visual } \\
\text { management board, e-mails to participants of } \\
\text { other processes with current information on the } \\
\text { effectiveness of the process }\end{array}$ & $\mathrm{N}$ \\
\hline
\end{tabular}


Due to the need for a transparent presentation of the issues, only a part of the improvement plan and examples of the instruments proposed as part of the improvement of individual areas were presented. For the same reason, only some of the implemented process improvement instruments ${ }^{5}$ were presented below.

Another implemented tool was the competency matrix. It was a response to repeatedly communicated problems with the lack of appropriate competencies among employees, also identified as part of the maturity assessment of the "Improvement" area and having a large impact on other areas. The competency matrix is a tool for mapping the required and desired competencies ${ }^{6}$ of a team. It is a grid that visualizes the required and available competencies in the team (Figure 9). First of all, it helps to assess the required competences. Secondly, the competency matrix provides insight into the competences available in the team and indicates the strengths and weaknesses of team members, which in turn gives an opportunity to use the strengths and eliminate weaknesses. In order to successfully implement the matrix, a team consisting of supervisory staff had to review the hard and soft competencies required to successfully complete the work.

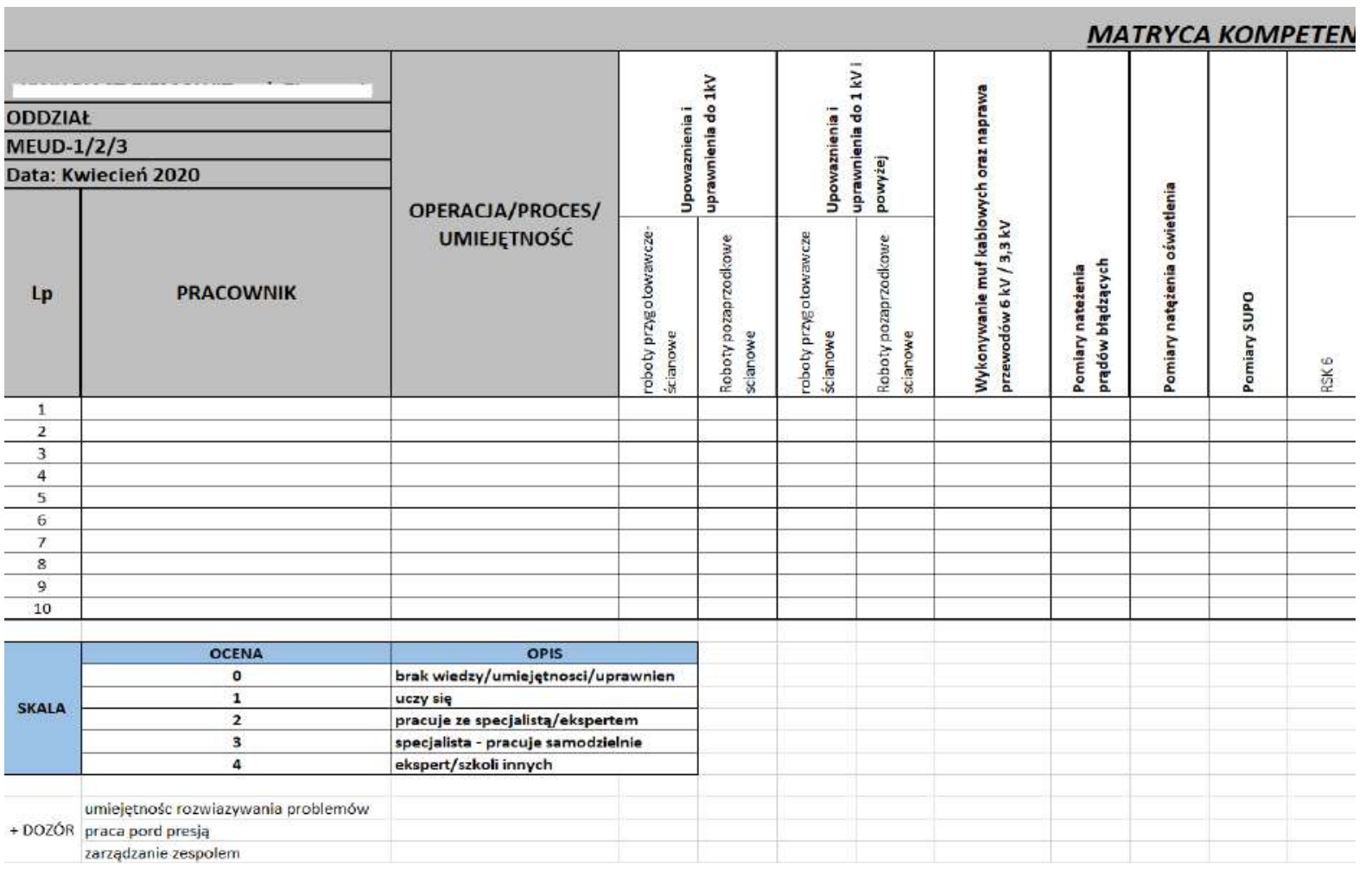

Figure 9. Competency matrix.

\footnotetext{
${ }^{5}$ Broadly understood as tools, methods and techniques that can be used to improve a process.

${ }^{6}$ There are hard and soft competencies. The hard ones include, above all, industry knowledge or the use of specialized computer programs. As part of soft competences, there are personality traits and social skills, such as: conscientiousness, leadership skills, the ability to work under time pressure, teamwork, communication skills, etc.
} 
The competency matrix helps to increase the performance in many ways. This is beneficial not only for the team, but also for the individual, company and internal and external clients, so it also supports the areas of "Customer focus" or "Relationship management". Thanks to the competency matrix, the team obtained a quick overview of both the competences that are present and those that are missing. The missing ones can of course be found by employing people with appropriate competences, but in reality of the surveyed company it is extremely difficult. Therefore, a mentoring system was introduced that allows other employees to train and support people with missing competences. Another important factor is the effective internal training system at the disposal of the organization, as well as the training system with the help of external companies cooperating with the surveyed company. Thanks to the matrix, the team is more aware of its weaknesses and can be especially careful so that the missing competences do not affect the performance. The competency matrix also gave employees individual insight into their own competencies and what they bring to work and what they lack. The process was strengthened by obtaining an overview of available competences and areas for improvement. These are areas where the process can invest its research and development budget in order to function better. In addition, competency matrices can help redistribute internal talent to where it is most needed. Not only is it said that employees lack competences, but you can see exactly which ones and what can be done about it. Customers also benefit from the implementation of the proposed tool, because they have a chance to receive a higher-quality process and it does not matter whether they are internal or external customers.

Fact-based decision making is a systematic process that emphasizes collecting the right data, ensuring its quality, conducting non-judgmental analyzes to isolate insights, jointly weighing up the pros and cons of possible decisions, and selecting business decisions that are supported by analysis results instead of guesswork or just following ones hunch. In the process under study, as in the entire enterprise, many decisions were made in this informal way. In this area, the implementation of the instruments was relatively easy due to the high involvement of the process owner. The first tool that was ever created as part of the implementation of improvement instruments was the maintenance process management worsheet (Figure 10).

The worksheet is constantly being expanded with new and more advanced functions and for the process owner it is the basic instrument for making many decisions, not only regarding the proper workload, but also bonuses or settlements for tasks performed by directly subordinate employees. The tool contains information necessary for the objective management of subordinate employees, including the orders issued and the level of their implementation, along with employee comments. It contains information on absenteeism, training and supervision assessment which translates into the level of bonuses granted. The spreadsheet is an exact answer to the needs of the process owner, and its cost is low as it was created internally using a popular spreadsheet. 


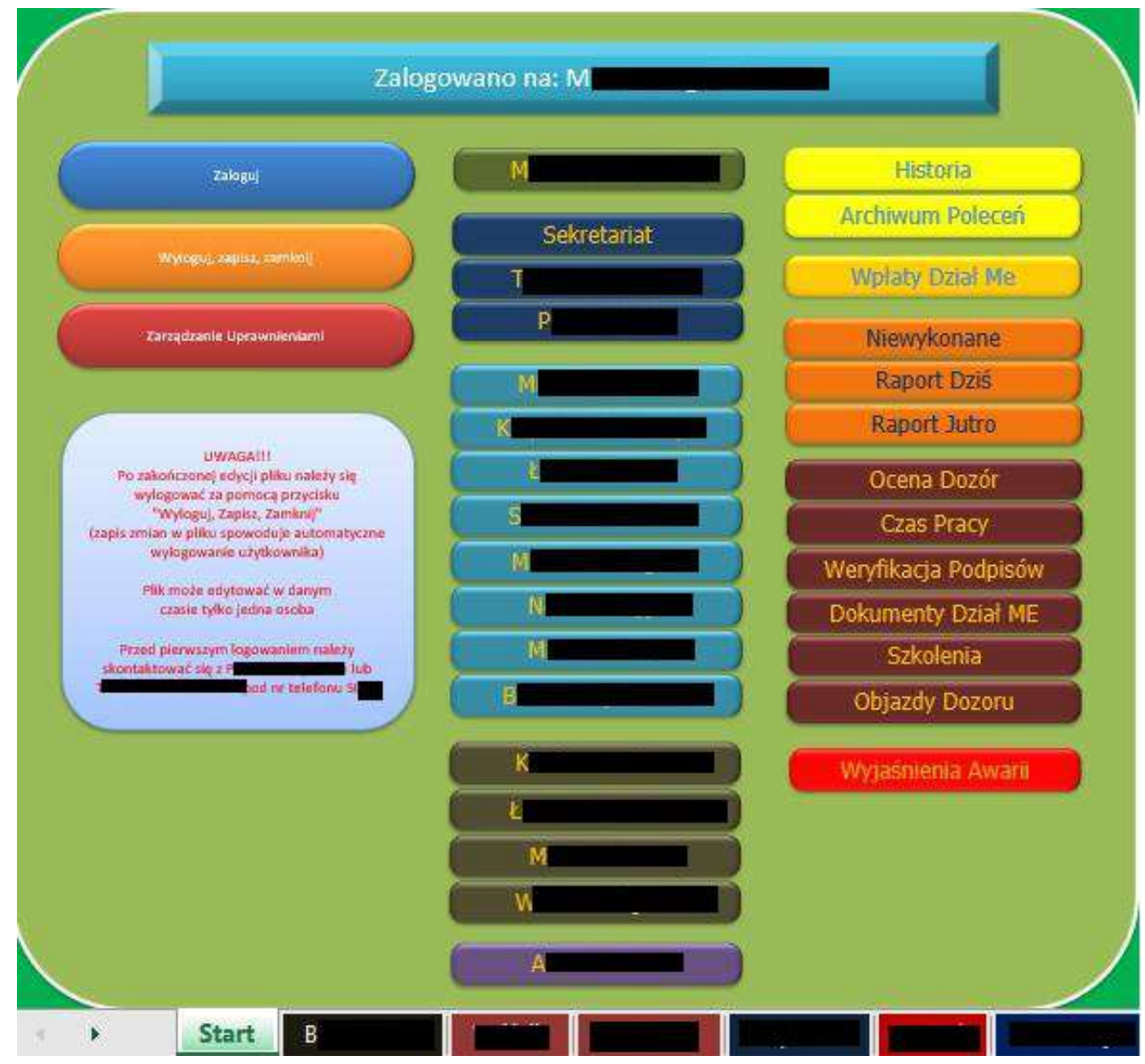

Figure 10. Menu of the MP management worksheet.

Another implemented instrument supporting decision-making based on facts was the Kanban board. This visual management tool is designed to help to visualize ones work, reduce work in progress and maximize efficiency. A simple three-column Kanban board was proposed, consisting of cards whose colors refer to individual employees directly reporting to the process owner and are pasted by them as the tasks and columns progress - "tasks", "in progress", "completed" (Figure 11). Since the employees of higher supervision perform many different activities, the part of them that relates directly to process improvement is included on the board. Kanban can be adapted to many environments, and the type of Kanban often determines whether the board is physical or digital. In this case, for easy tracking the progress of work by all participants of the improvement process and due to the importance of this process, the board was hung in the process owner's office in a place visible to all interested parties. One of the other advantages of a physical board is that it is "always on", easy to set up, easy to show to others, and is often a better way to communicate with specific teams. Additionally, any person entering the process owner's office may realize that there is also improvement as part of the process tasks, which may encourage other people to make a similar effort. Very often, process managers in mining enterprises have extensive knowledge of the practical side of task implementation, but little knowledge in terms of the extensive process management instruments. 


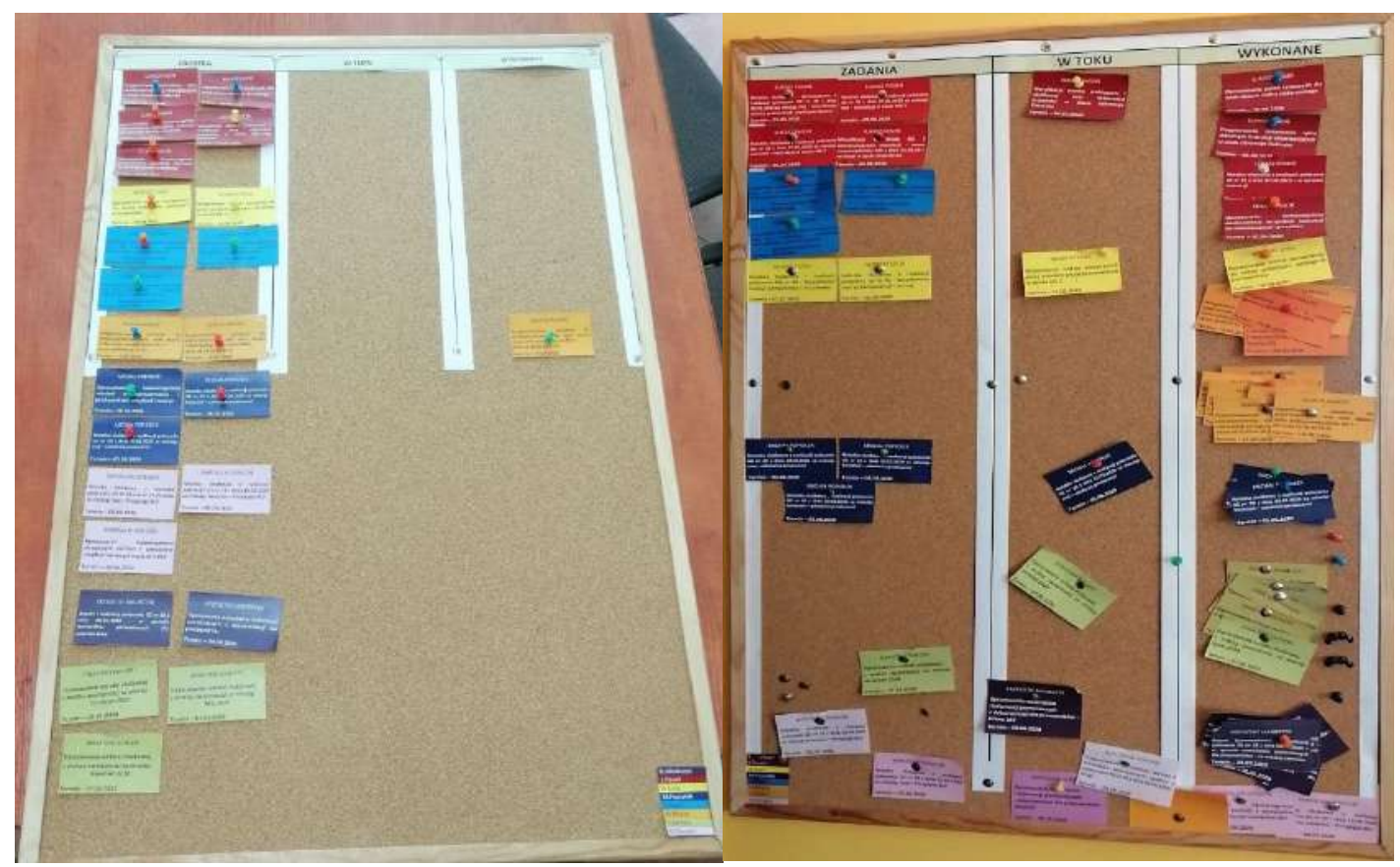

Figure 11. Kanban board while assigning tasks and carrying them out.

As Figure 11 shows, the board perfectly visualizes the workflow and tasks, and provides an overview of the workload. It is also a good tool for visualizing potential problems in the process. It is easy to see which and whose tasks are coming faster than they are leaving, work begins to pile up and the problem becomes visible to the entire team. This could be due to a temporary problem or a bottleneck in the process. Recognition of the problem and implementation of adequate measures gives a chance for the success of the entire maintenance process improvement project.

\section{Discussion}

The maturity level of the examined process was rated at 3.58 on average, which, according to the adopted criteria, should be classified as maturity level 3. This is consistent with other studies carried out in similar enterprises, although with different instruments (Łukasiński, 2016; Brzychczy, Kostka, 2018). However, when referring to the assessment according to the weakest point, the examined processes should be assessed at the first level of process maturity. As it seems, the discrepancy quite often results from the general nature of the research performed using the average, also the most frequently used five-point scale seems to be too general. Quite often, the assessment of maturity is carried out by individual people dealing with management systems in the organization and assessing the process or organization from their own perspective, therefore there is no objectivity, as evidenced by the own research quoted below. Nevertheless, it is of key importance to ensure data integrity through accurate and appropriate analysis of the data obtained. Inappropriate analysis, whether statistical or not, 
distorts scientific findings, misleads the reader and may negatively affect the public perception of research at all (Shepard 2002).

It seems that the implementation of improvement instruments in a mining company is not only possible, but even necessary. This is related, among others, to the large and constantly growing amount of data that should be analyzed and assessed in mining companies. Not without significance is the lack of these instruments, often resulting from the unacquaintance of the instruments, despite the fact that most, if not all, mining companies have integrated management systems, including a quality management system that requires the use of various types of improvement instruments. Especially the latter confirms that without equipping the people managing individual processes, as well as the entire system, with knowledge about modern concepts of process management or, more broadly, of a company, which in some industries or even sectors are mostly Lean Management and Lean Manufacturing, it will not be possible to improve processes.

However, the requirement for introducing changes is taking into account Adamiecki's counteracting principles. Other authors also point to the possibility and necessity of implementing improvement tools, as well as the need for their gradual and rational implementation in mining companies (Jasiński, Jasińska, Janik, 2017; Migza, Bogacz, 2015; Rozmus, 2011). The aforementioned Adamiecki's principle says that the system to which changes are made will tend to return to its original state. This is related to the emotional block in the face of changes, which the members of a company build within themselves in fear that the upcoming change will somehow worsen their current situation (Centkowska, 2015; Eckes, 2016). It is still visible in the surveyed company.

The implemented project indicates a large area to be developed for people dealing with both the theory and practice of process improvement in the mining sector, especially in relation to hard coal mines. It is also related to the organizational culture of these enterprises. As it seems, it remained in the realities of the previous economic system and therefore blocks many improvement activities, which is also supported by the atmosphere around the industry itself, as well as the current market situation, which is definitely not conducive to changes and forces the adoption of rather directive attitudes towards management (Rakowska, 2011; Huczek, 2015). An interesting issue for further research would be the analysis of the organizational culture of mining companies and its impact on the possibility of implementing modern management methods, techniques and tools.

When implementing improvement tools, it is also important to select them in such a way to adequately match them to the examined process, including the competences or personalities of the employees who would use them. As the instrumentation is very rich, it is rarely possible to implement it without cooperation with a person with extensive knowledge of methods, techniques and tools for improvement. During the implementation of the project, it took a lot of time to present the instruments, which also entailed the need for the owner of the process and the supervisors to reach for the literature on the subject. The selected instruments resulted from 
the real needs of people involved in the improvement, which may be of great importance for the sustainability of the improvement project. The research stage - "as is" - and the selection of the appropriate assessment tool are also important. In the case of the implemented project, a proprietary tool was used, which also requires knowledge in the field of tool construction and their evaluation. Even if process managers use ready-made questionnaires, they must have knowledge about their existence, which could be derived from people dealing with management systems in the company, but, as already mentioned, they are rarely actually useful in this area. Own research carried out among 60 employees of various plants with implemented management systems, mainly (66.7 pct.) the quality management system according to ISO 9001, showed that all respondents expect people who carry out tasks within this process to have a more practical approach to the system. Cooperation in the field of quality improvement is expected by 83.3 pct. and 50 pct. of the respondents would like less checking and more improvement, help in the application of tools and introduction of tools based on the needs identified, e.g. during audits. At the same time, one third of the respondents also stated that people who implement and maintain processes related to management systems do not contribute to the organization. Taking into account the already mentioned fact that there is an integrated management system in the examined company, it can be concluded that the ones in charge of it could be described in a similar way, and the process implemented by them could be described as ineffective. It seems interesting to investigate the reasons for such a situation and the possibilities of changing it. Does it result from the lack of proper preparation of people dealing with management systems in the company, a lack of understanding of the ideas of these systems or treating them as a necessary evil related to the image, and not a source of improvement?

As it seems, this study confirms that the assessment of the maturity of the maintenance process can help in planning effective and efficient methods and tools for improving this process, because it was possible to diagnose the strengths, weaknesses of the company, and to propose applicable and content-related instruments.

\section{Summary}

Maturity assessment studies are useful as an input to the improvement process. While maturity models and related assessment methods do not directly address business outcomes and benefits, it is possible to move from one maturity level to the next without having to demonstrate progress. However, they allow to identify the strengths and weaknesses of the company and plan appropriate actions. However, these types of projects are time-consuming, require extensive knowledge in the field of improvement, and the implementation of a management system does not guarantee that the company will use improvement instruments 
on a large scale. A great problem is the employees' resistance to changes, unfamiliarity with improvement instruments or organizational culture that inhibits improvement activities. In the improvement project described in this study, instruments corresponding to the participants of the process with their scope, level of complexity and, above all, adequate to the identified area of improvement were used. The project started in 2019 and how many such ventures has become an integral part of the process under study. At this point, it is a kind of perpetual motion machine, because it is based on the low-hanging fruit strategy and as long as it is possible to use the strategy mechanisms, one can count that the improvement process will not stop. However, it should be noted that at some point it will become necessary to reach for more advanced and innovative improvement projects. Otherwise, it can be expected that the entire improvement process will stop, even though continuous improvement is a prerequisite for supporting quality management in ISO 9001 certification. It does not appear to be an overinterpretation that highly efficient processes and flexible structures are the most important competitiveness factors for an organization. Successful organizations regularly test all processes and procedures. They challenge the status quo, actively search for ineffective activities, and develop unique solutions for more efficient operational processes.

\section{References}

1. Brzychczy, E., Kostka, D. (2018). Assessing Process Maturity of an Underground Mine: a Case Study. Inżynieria Mineralna, 20(2), 55-63.

2. Centkowska, M. (2015). Podstawy teoretyczne oporu wobec zmian w organizacji. Zeszyty Naukowe Politechniki Śląskiej. Organizacja i Zarzadzanie, 77, 9-18.

3. Crespo Márquez, A., Moreu de Léon, P., Gómez Fernándes, J.F, Parra Márquez, C., López Campos, M. (2009). The maintenance management framework: A Practical View to Maintenance Management. Journal of Quality in Maintenance Engineering, 15(2), 167-178.

4. Eckes, G. (2016). Rewolucja Six Sigma. Warszawa: MT Biznes.

5. Gajdzik, B. (2010). Doskonalenie procesu utrzymania ruchu poprzez zaangażowanie pracownicze. Gospodarka Materiałowa i Logistyka, 11, 12-17.

6. Grajewski, P. (2012). Procesowe zarzadzanie organizacja. Warszawa: PWE.

7. Huczek, M. (2015). Zarządzanie kryzysowe w firmie a role i umiejętności menedżerskie, Zarzadzanie, 3, 13-22.

8. ISO/Guide 73:2009 (en). Risk management - Vocabulary. https://www.iso.org/obp/ ui/\#iso:std:iso:guide:73:ed-1:v1:en, 08.07.2020. 
9. Jasiński, M., Jasińska, E., Janik, S. (2017). Proces utrzymania ruchu maszyn dołowych $\mathrm{w}$ aspekcie wykorzystania energii elektrycznej. Wiadomości elektrotechniczne, 85(3), 24-26.

10. Jasiulewicz-Kaczmarek, M. (2013). Klienci i strony zainteresowane utrzymania ruchu. In: R. Knosala (ed.), Innowacje $w$ zarzadzaniu i inżynierii produkcji (pp. 87-98). Opole: Oficyna Wydawnicza Polskiego Towarzystwa Zarządzania Produkcją.

11. Laszczak, M. (2011). Intuicja w zarządzaniu. Zarządzanie. Teoria i Praktyka, 1(3), 77-96.

12. Łukasiński, W. (2016). Zarządzanie jakością w wydobyciu i przetwórstwie kruszyw: ocena dojrzałości procesów. Przegląd Organizacji, 9, 11-17.

13. Migza, M., Bogacz, P. (2015). Możliwość wykorzystania narzędzi Lean Management w przedsiębiorstwach sektora górnictwa podziemnego w Polsce. Przegląd Górniczy, 71(8), 58-61.

14. PN-ISO 31000:2018-08 (en). Zarzadzanie ryzykiem - Wytyczne. Warszawa: PKN.

15. Rakowska, A. (2011). Kryzysowe przywództwo, czyli kompetencje menedżerskie niezbędne w trudnych czasach. Organizacja i Zarzadzanie: Kwartalnik Naukowy, 2(14), 5-18.

16. Rozmus, M., Winkler, T., Jaszczyk, Ł., Michalak, D., Lesisz, R. (2011). Narzędzia wspomagające utrzymanie ruchu maszyn górniczych. Mechanik, 84, 819-827.

17. Saldaña, J. (2009). The coding manual for qualitative researchers. Thousand Oaks: Sage.

18. Shepard, R.J. (2002). Ethics in exercise science research. Sports Med, 32(3), 169-183.

19. Zasadzień, M. (2016). Przykład wykorzystania narzędzi zarządzania jakością w doskonaleniu procesów utrzymania ruchu. Systemy Wspomagania w Inżynierii Produkcji, 4(16), $180-87$. 


\title{
RISK MANAGEMENT IN CONSTRUCTION ENTERPRISES IN ŚLĄSKIE AND MALOPOLSKIE VOIVODSHIPS IN POLAND
}

\author{
Piotr TWOREK ${ }^{1 *}$, Józef MYRCZEK ${ }^{2}$ \\ ${ }^{1}$ University of Economics in Katowice; piotr.tworek@ue.katowice.pl, ORCID: 0000-0002-2871-2902 \\ ${ }^{2}$ University of Bielsko-Biała; jmyrczek@ath.bielsko.pl, ORCID: 0000-0002-9351-1410 \\ * Correspondence author
}

Purpose: The publication is empirical in its character. The key purpose of the paper is to outline and discuss the results of the empirical research into risk in construction activities carried out by the surveyed contractors in Poland. The paper focuses, in particular, on the use of methods, techniques and tools by construction enterprises from Śląskie and Małopolskie voivodships to respond to the risks they encounter.

Design/methodology/approach: The empirical research was conducted in form of a questionnaire interview. The research tools were developed based on in-depth studies of the scholarly literature (theory-cognitive dimension of the research). The paper also uses the methods of synthesis and deduction. In their discussions the authors draw on their own knowledge and experience which they have acquired over many years spent on researching risks faced by a wide range of organisations.

Findings: The presented research findings provide the empirical verification of the theoretical background derived from the literature in the field.

Research limitations/implications: The paper presents only the selected results of the empirical studies. These research findings concern specific categories of construction risk, which is regarded as a scientific and research category.

Practical implications: The paper presents practical knowledge (utilitarian dimension of science) which has been verified empirically in the conducted research. This knowledge is referred to in the scholarly literature as Construction Risk Management (CRM).

Originality/value: The empirical studies present an up-to-date status of the knowledge and awareness as demonstrated by the construction contractors participating in the survey. The research findings are presented for the purpose specified in the paper.

Keywords: Enterprise risk management, risk response, construction risk, construction enterprise, survey research.

Category of the paper: Research paper. 


\section{Introduction}

To come up with the right risk responses individuals responsible for risk management in the construction industry need the right amount of knowledge. The importance of this issue has led to numerous attempts at finding new solutions which could possibly be implemented in this respect. The scholarly literature clearly places an emphasis on that as well. In business practice of major construction companies operating on the Polish market, however, risk management tends to be limited to arranging insurance to cover construction and assembly activities they carry out, as this seems to be the most common method of financing risks in economic activities (Tworek, 2013). Important as this may be, insurance cover is just one of many possible risk responses, which are referred to in the currently available sources of knowledge, such as the concept of Construction Risk Management (CRM) (Palmer et al., 1996; Bunni, 2003). How should construction risks be responded to, then? Which methods, techniques and tools can be used for that? These are the questions the paper attempts to address. The aim of this paper is to outline the problems of risk responses in the field of construction activities carried out by specialised enterprises from Śląskie and Małopolskie voivodships in Poland. The key aim of the publication is, first of all, to outline and discuss the results of the empirical research into risk in construction activities carried out by the surveyed contractors. The empirical studies were conducted in 2016 among part-time students of Construction and Environmental Engineering at Akademia Techniczno-Humanistyczna in Bielsko-Biała (University of BielskoBiała), who were also employed in the companies surveyed. The research covered 31 respondents, who anonymously completed two questionnaires. The paper also provides the results of the research done in 2015 among 29 contractors operating in the selected poviats of Śląskie voivodship (Bielsko-Biała, Żywiec, Czechowice-Dziedzice, Tychy, Jastrzębie Zdrój, Wodzisław Śląski and Rybnik) (Myrczek et al., 2015) and partially draws from the empirical studies conducted among the major construction contractors on the Polish market, including, in particular, companies listed on the stock exchange, in the years of 2010-2012 (Tworek, 2013). Although the paper is empirical in its character its contents are embedded in the theory of risk management in the construction industry. The main research method has been a questionnaire interview. Another technique used in the studies on construction risk has been face-to-face interview. The studies required a prior in-depth review of the literature on the subject. The paper focuses on the methodical aspects of risk management in organisations which specialise in construction and assembly activities.

This publication is a follow-up on the research into risks encountered by Polish construction companies, conducted by the authors (Tworek, 2012, 2013; Myrczek et al., 2015, 2020; Myrczek, and Tworek, 2019; Kosmalski, and Myrczek, 2019). In broad terms, the aim of a series of publications focusing on this topic is an attempt to find an answer to the following question: How should risk be managed by construction contractors operating on the Polish market? 


\section{Responses to risk as an element of risk management process in construction - theoretical approach, survey research}

There are many scientific publications on how to manage risks in the construction industry (Flanagan, and Norman, 1993; Edwards, 1995; Boothroyd, and Emmett, 1996; Godfrey, and Halcrow, 1996; Palmer et al., 1996; Loosemore et al., 2006; Smith et al., 2006; BurtonshawGunn, 2009; Wang, et al., 2004; Serpell et al., 2017; Hoseini et al., 2019). Irrespective of the views expressed by specific authors, however, participants of investment and construction processes are almost invariably required to develop their own individual risk management plans, due to the unique character of construction risks they need to tackle. The development of a risk response plan is a key task within the risk management process as this plan sets out the methods to be used to address potential risk-bearing occurrences (Kosmalski, and Myrczek, 2019). Before construction risk responses may be planned, though, risks need to be clearly identified. A construction contractor's failure to identify and then evaluate risks may lead to the selection of an inappropriate risk response method, technique or tool. Construction risk management as such is a complex process, spanning through the stages of risk identification, quantification and response (Flanagan, and Norman, 1993), which follow in this order. These are the three key phases of risk management but may be supplemented by monitoring and control over the execution of the stages. Whatever the concept of risk management, however, if risks are to be addressed by a construction company, suitable risk prevention methods, techniques and tools must first be chosen. At the same time, risk response itself is a sub-process which is part of the overall risk management process in the construction industry.

Construction enterprises respond to risks in the following ways:

- they eliminate risks by introducing changes and modifications to e.g. a project, technology or delivery etc.,

- they transfer risk, i.e. pass on possible costs of losses, which may arise, to another party to the construction project implementation process,

- they mitigate risk by e.g. arranging construction and assembly insurance,

- they absorb risk, which means that a contractor accepts the risk (Kosecki, and Madyda, 1996).

These are the main ways of responding to construction risks, provided by the scholarly literature (Flanagan, and Norman, 1993; Kosecki, and Madyda, 1996; Godfrey, and Halcrow, 1996; Boothroyd, and Emmett, 1996; Glavinich, 2008; Sawczuk, 2004; Zuo, and Zhang, 2018). According to the studies on modern risk management strategies in organisations a number of risk responses tend to be used simultaneously or even hybrid strategies are devised in order to optimise risk by its mitigation and transfer, while retaining part of it (Edwards, and Bowen, 2005). An extreme way of handling risk in the construction industry is making a decision not to perform high-risk works. The results of the empirical studies from 2016, however, show that 
$47 \%$ of contractors agree to perform even high risk construction projects (Myrczek, and Tworek, 2019; Myrczek et al., 2020). In the research the respondents indicated some reasons for taking up risky construction projects. These included: ensuring healthy cashflow (4 contractors), maintenance of high turnover figures (2 contractors), financial reasons ( 2 contractors), the belief that risk can be eliminated ( 2 contractors), an investment project with a relatively late delivery date (1 contractor), a high value investment project ( 1 contractor), the prestige given by the project - the renovation of Auschwitz ( 1 contractor), the need to perform a given task ( 1 contractor), an investment project with highly filled order portfolio ( 1 contractor), poor market conditions - a small number of tenders (1 contractor), good construction practice ( 1 contractor), a big number of employees ( 1 contractor), more lucrative works ( 1 contractor), the company's position on the market (1 contractor), the investor's insolvency ( 1 contractor), technical documentation (1 contractor). Such arguments allow us to get a better understanding of the motives behind construction contractors' practical decisions, although only $9 \%$ of them agreed to absorb all the risk (Myrczek, and Tworek, 2019; Myrczek et al., 2020). As many as $38 \%$ of the contractors eliminate risks, $34 \%$ of the respondents mitigate risks, while $13 \%$ of them transfer risk onto other participants of investment and construction processes (Myrczek, and Tworek, 2019; Myrczek et al., 2020). For the sake of comparison - no one from among the surveyed major construction and assembly companies operating on the Polish market stated that they absorb risk, while $54 \%$ of them eliminate risks, $11.4 \%$ of the respondents transfer risks and $34.6 \%$ of the biggest contractors limit construction risks (Tworek, 2013). Irrespective of a risk management strategy described in the scholarly literature (Young, and Tippins, 2001) and of specific practices implemented by a given organisation, every contractor must carefully differentiate among methods, techniques and tools which are available for them to handle their construction risks. The key role here is played by the identification of risks which have to be managed.

\section{The use of response methods, techniques and tools in the activity of construction enterprises in the light of the empirical research}

The detailed results of the empirical research concern such sub-categories of construction risks which refer to the measures undertaken by contractors in order to prevent risks related to personnel, construction site documentation, the construction process itself (technological process, technical risk) as well as organisation and management, finance and the environment in which these enterprises operate. What needs to be emphasised here is the fact that such arbitrary division results from the key areas where risks occur in the operations of construction and assembly enterprises, which is yet another argument for the utilitarian dimension of knowledge related to these issues. The general classification of construction risk categories 
given in the theory has a less important role here. When looking at the general theory of economics, where every organisation operates in an environment, exogenous risk, i.e. risk related to the surroundings in which a given contractor conducts its business, should theoretically come first. What measures are then undertaken by the surveyed contractors in order to prevent risks related to their environment? The respective findings are given in Table 1.

\section{Table 1.}

Risks related to the contractor's environment: risk responses

\begin{tabular}{|c|l|c|}
\hline Item & \multicolumn{1}{|c|}{ What measures do you take to counteract risks related to your environment? } & Percentage \\
\hline 1 & Continuous monitoring of your (macro- and micro) environment & $23 \%$ \\
\hline 2 & Additional references from new subcontractors & $42 \%$ \\
\hline 3 & Business intelligence regarding business partners (investors and subcontractors etc.) & $35 \%$ \\
\hline 4 & Engaging reliable designers and subcontractors & $58 \%$ \\
\hline 5 & Keeping up-to-date with legal regulations & $26 \%$ \\
\hline 6 & Maintaining good relations with local authorities (public officials) & $52 \%$ \\
\hline 7 & Defining political risk & $0 \%$ \\
\hline
\end{tabular}

Note. The respondents were permitted to indicate more than one reply, therefore the total may exceed 100\%. Source: based on: Tworek, 2013.

The research shows that the key aspect of risk response is engaging reliable designers and trustworthy subcontractors, as well as maintaining good relations with local authorities (public officials) - over $50 \%$ of the surveyed contractors indicated these items. In practical business these are the elements of the contractors' closest environment. Much less importance was attached to macro- and micro-environment issues ( $23 \%$ of the contractors), including the need to keep up-to-date with legal regulations ( $26 \%$ of the contractors). None of the responding contractors indicated the political risk. How do these results compare with the risk management issues which are easier for construction companies to control? The respective findings are presented in Tables 2-5.

Table 2.

Risks related to the contractor's personnel: risk responses

\begin{tabular}{|c|l|c|}
\hline Item & \multicolumn{1}{|c|}{ What measures do you take to counteract risks related to personnel? } & Percentage \\
\hline 1 & Creating a risk management unit in a company & $6 \%$ \\
\hline 2 & (Continuous) risk management training for company managers & $32 \%$ \\
\hline 3 & Employing in-house risk specialists (risk managers) & $61 \%$ \\
\hline 4 & OHS training for manual workers (compliance with work discipline) & $65 \%$ \\
\hline 5 & Appropriate staff supervision on construction sites & $42 \%$ \\
\hline 6 & $\begin{array}{l}\text { Additional courses and training for manual workers in the area of technical knowledge } \\
\text { for the construction industry }\end{array}$ & $39 \%$ \\
\hline 7 & Additional courses and training for construction site managers (contracts) & $19 \%$ \\
\hline 8 & Delegating risk management tasks to experts & $42 \%$ \\
\hline 9 & $\begin{array}{l}\text { Ensuring appropriate and skilled workforce for the performance of the construction } \\
\text { project }\end{array}$ & $61 \%$ \\
\hline
\end{tabular}

Note. The respondents were permitted to indicate more than one reply, therefore the total may exceed 100\%. Source: based on: Tworek, 2013. 
Table 3.

Risks related to construction site documentation: risk responses

\begin{tabular}{|c|l|c|}
\hline Item & \multicolumn{1}{|c|}{$\begin{array}{c}\text { What measures do you take to counteract risks related to construction site } \\
\text { documentation? }\end{array}$} & Percentage \\
\hline 1 & Entering into cost reimbursement contracts & $26 \%$ \\
\hline 2 & Contractual clauses offering security in case of cost increase & $32 \%$ \\
\hline 3 & Security against exchange rate fluctuations (when cooperating with foreign parties) & $10 \%$ \\
\hline 4 & Security in the case delivery dates for construction projects need to be changed & $29 \%$ \\
\hline 5 & Final delivery date of a construction project & $19 \%$ \\
\hline 6 & Incorporation of special risk clauses & $29 \%$ \\
\hline 7 & Shortest possible guarantee and warranty periods & $48 \%$ \\
\hline 8 & Detailed description of force majeure risk & $13 \%$ \\
\hline 9 & Detailed provisions on liquidated damages & $48 \%$ \\
\hline 10 & Detailed terms for withdrawal from or cancellation of a contract & $32 \%$ \\
\hline 11 & Thorough review of construction site documentation for its completeness & $39 \%$ \\
\hline 12 & Securing construction projects by obtaining central and local government guarantees & $10 \%$ \\
\hline 13 & Transferring risk to subcontractors (within the scope of their operations) & $16 \%$ \\
\hline 14 & $\begin{array}{l}\text { Where risk in its entirety cannot be transferred to an investor, a proposal to equally } \\
\text { share risk between an ordering party (a customer) and a contractor }\end{array}$ & $10 \%$ \\
\hline 15 & $\begin{array}{l}\text { Documenting all irregularities and negative behaviours on the part of other participants } \\
\text { of an investment project }\end{array}$ & $23 \%$ \\
\hline 16 & Submitting a contract for detailed legal review before signing it & $39 \%$ \\
\hline 17 & Creating risk documentation (risk lists, risk sheets) & $0 \%$ \\
\hline
\end{tabular}

Note. The respondents were permitted to indicate more than one reply, therefore the total may exceed 100\%. Source: based on: Tworek, 2013.

Table 4.

Risks related to a construction performance process, including a technological process, and technical risk; risks related to company organisation and management: risk responses

\begin{tabular}{|c|l|c|}
\hline Item & $\begin{array}{l}\text { What measures do you take to counteract risks related to a construction } \\
\text { performance process (technological process, technical risk) and organisation and } \\
\text { management? }\end{array}$ & Percentage \\
\hline 1 & \multicolumn{1}{|c|}{ Using tried and tested technologies } & $61 \%$ \\
\hline 2 & Using premium quality materials which are environmentally friendly & $35 \%$ \\
\hline 3 & Lease of reliable machines and equipment, with required attestations & $35 \%$ \\
\hline 4 & Additional security for force majeure events (e.g. extra wind protection) & $19 \%$ \\
\hline 5 & $\begin{array}{l}\text { Requiring additional expert opinions on subsurface conditions (from an ordering } \\
\text { party) }\end{array}$ & $10 \%$ \\
\hline 6 & $\begin{array}{l}\text { Effective control of a project performance process (regular checks of works } \\
\text { performed, funds spent and delivery time) }\end{array}$ & $32 \%$ \\
\hline 7 & $\begin{array}{l}\text { Including an investor and subcontractors in planning and designing of the scope of } \\
\text { works }\end{array}$ & $29 \%$ \\
\hline 8 & $\begin{array}{l}\text { When performing big investment projects teaming up with other contractors by } \\
\text { establishing shared risk consortia }\end{array}$ & $16 \%$ \\
\hline 9 & Providing and controlling infrastructure around the construction site & $35 \%$ \\
\hline 10 & $\begin{array}{l}\text { Supporting the construction performance process with activities aimed to optimise } \\
\text { project-related processes, combined with the use of appropriate optimisation } \\
\text { techniques (e.g. PERT) }\end{array}$ & $0 \%$ \\
\hline 11 & Implementing an effective logistics system in a company & $23 \%$ \\
\hline 12 & Trying to identify risk factors before starting a project performance process & $23 \%$ \\
\hline 13 & Participating in all 'safe" tenders in the region & $16 \%$ \\
\hline 14 & Using appropriate computer software to support a construction planning process & $23 \%$ \\
\hline 15 & When participating in tenders not offering prices which are below safe levels & $35 \%$ \\
\hline 16 & Ensuring reliable means of transport & $32 \%$ \\
\hline 17 & Collecting risk information (on an ongoing basis) from databases & $10 \%$ \\
\hline 18 & Securing a construction site against vandalism and theft & $35 \%$ \\
\hline & & \multicolumn{1}{|c|}{ and } \\
\hline
\end{tabular}


Cont. table 4.

\begin{tabular}{|c|l|c|}
\hline 19 & $\begin{array}{l}\text { Intensifying such activities as: field inspections, frequent interviews with key project } \\
\text { participants, etc. }\end{array}$ & $19 \%$ \\
\hline 20 & Simulating foreseeable situations and devising risk prevention schemes & $6 \%$ \\
\hline 21 & Implementing schemes, action plans and procedures in case of risk & $10 \%$ \\
\hline 22 & Avoiding high risk investment projects & $16 \%$ \\
\hline 23 & Implementing an ISO quality system in a company & $16 \%$ \\
\hline 24 & Performing a bigger number of construction projects which are less risky & $16 \%$ \\
\hline 25 & Diversification of a company's activities (hotels for workers etc.) & $6 \%$ \\
\hline
\end{tabular}

Note. The respondents were permitted to indicate more than one reply, therefore the total may exceed 100\%. Source: based on: Tworek, 2013.

Table 5.

Risks related to the contractor's finance: risk responses

\begin{tabular}{|c|l|c|}
\hline Item & \multicolumn{1}{|c|}{ What measures do you take to counteract risks related to finance? } & Percentage \\
\hline 1 & Cooperation with a well-established bank (funds provider) & $61 \%$ \\
\hline 2 & Obtaining a payment guarantee from investors & $35 \%$ \\
\hline 3 & Financial monitoring (object- and subject-related) during the project performance & $35 \%$ \\
\hline 4 & Calculating cost-related risk, using such methods as MERA & $19 \%$ \\
\hline 5 & Creating special reserves for risks & $10 \%$ \\
\hline 6 & Cooperating with a successful debt collection company & $32 \%$ \\
\hline 7 & Arranging polices such as CAR and EAR (continuous insurance coverage) & $29 \%$ \\
\hline
\end{tabular}

Note. The respondents were permitted to indicate more than one reply, therefore the total may exceed 100\%. Based on: Tworek, 2013. Source: Myrczek, and Tworek, 2019; Myrczek et al., 2020.

When looking at Tables 2-5 we can see the extent to which specific methods, techniques and tools are used by contractors to respond to the construction risks they encounter. In the vast majority of cases these are the types of risks which may almost entirely be controlled by a given construction company, i.e. they belong to the category of indigenous risks of an organisation. The literature divides risks here into specific ones and systematic ones (Godfrey, and Halcrow, 1996; Boothroyd, and Emmett, 1996; Young, and Tippins, 2001). A risk which remains beyond a contractor's control is a systematic risk (Table 1), while Tables 2-5 concern specific risks which have to be tackled.

The specific character of business conducted by construction and assembly companies makes construction risk management a challenge to deal with. This concerns, first of all, such risk categories as force majeure, the occurrence of which may never be fully predicted. $19 \%$ of the respondents use additional measures to protect themselves against force majeure, e.g. extra wind covers. In addition, construction sites, where construction and assembly companies operate, require risk mitigating measures which differ from the ones undertaken by entities with other business profiles, e.g. other producers or service providers. This can easily be seen when analysing the results given in Tables 3 and 4 . The issues comprised in Tables 1 , 2 and 5, in turn, are a bit more general in their character, as they refer to the theory of economics and management sciences (Drucker, 1964). In business practice it means that the methods, techniques and tools outlined in Tables 1, 2 and 3 may apply to almost any organisation. For instance, the establishment of a risk management unit (Table 2) is an option that may be applicable both to public organisations and private entities. The research done in 2015 shows that as many as $51 \%$ of the companies surveyed have not appointed any specific person to be 
directly responsible for risk management (Myrczek et al., 2015). Nevertheless, during face-toface interviews, when taking a closer look at the risk management issues in the construction industry, the respondents tended to stress the need to change their attitude to practical risk management (Myrczek et al., 2015). For the sake of comparison, a mere 8\% of the largest construction and assembly companies operating in the Polish market have set up risk management units and employed their own risk management specialists (Tworek, 2013). The key reasons behind this, as indicated by the contractors surveyed in 2016, include the belief that the risk they face is not high enough to hire a person (set up a unit) to specifically deal with it ( $25 \%$ of the contractors) and that their peer companies do not employ any specialists in this field either $-31 \%$ of the contractors (Myrczek, and Tworek, 2019; Myrczek et al., 2020). None of the contractors, however, stated that construction risk categories they face cannot be fully identified (Myrczek, and Tworek, 2019; Myrczek et al., 2020).

\section{Conclusion}

The empirical studies the paper refers to may lead to the conclusion that specific risk management methods, techniques and tools vary in terms of their popularity in construction companies. The research conducted in 2016 focused on the selected construction enterprises only and was also limited geographically as it did not cover the entire territory of Poland. In the 2015 studies the respondents admitted that they were acquainted with risk management issues because they dealt with risk management in their own work, rather than studying risk management theories during their education (Myrczek et al., 2015). They often confessed that their understanding of a risk management system was somewhat different to the way the issue used to be presented in the professional literature (Myrczek et al., 2015). Their views are illustrated by the contents of Tables 3 and 4, which are based on highly specialised knowledge. Tables 1, 2 and 5 present the issue from the point of view of a today's engineer - manager who is capable of managing the construction performance process but also managing an organisation, such as a construction business. We can also see that construction risk is a cross-disciplinary research category comprising the elements of technical, business and legal knowledge.

Irrespective of that, the risk management methods, techniques and tools referred to in the paper and used to respond to risks in the operations caried out by construction contractors seem equally important. The review of the literature on the subject shows that risk management methods should be used in a comprehensive and complementary way. Which risk response is selected depends predominantly on the type of a construction project that a company is involved in. A project portfolio that a given construction enterprise has is also important as well as their financial standing and the funds they have available to finance risk. Consequently, 
the contractors surveyed are either ready to retain risk or decide to transfer it to an insurer or another participant of an investment and construction process. In general, contractors in Poland are the stakeholders who tend to bear risk (Tworek, 2013). This is due to the features of the Polish construction and assembly market. Out of all the contractors surveyed from Śląskie and Małopolskie voivodships, as many as $38 \%$ of them bear all the risk, while only $9 \%$ of them transfer most of the risk to investors (Myrczek, and Tworek, 2019; Myrczek et al., 2020).

\section{References}

1. Boothroyd, C., and Emmett, J. (1996). Risk Management: A practical guide for construction professionals. London: Witherby \& Co.

2. Bunni, G.N. (2003). Risk and insurance in construction. London-New York: Spon Press.

3. Burtonshaw-Gunn, S.A. (2009). Risk and Financial Management in Construction. Farnham: Gower Publishing.

4. Drucker, P.F. (1964). Managing for Results: Economic Tasks and Risk-taking Decisions. London: Heinemann.

5. Edwards, J.P., and Bowen, A.P. (2005). Risk Management in Project Organizations. Oxford: Elsevier.

6. Edwards, L. (1995). Practical risk management in the construction industry. London: Thomas Telford.

7. Flanagan, R., and Norman, G. (1993). Risk management in construction. Oxford: Blackwell Publishing.

8. Glavinich, E.T. (2008). Contractor's Guide to Greek Building Construction: Management, Project delivery, documentation and risk reduction. Hoboken: John Wiley \& Sons.

9. Godfrey, S.P., and Halcrow, W. (1996). Control of Risk: A Guide to the Systematic Management of Risk from Construction. London: Construction Industry Research and Information Association.

10. Hoseini, E., Hertogh, M., and Bosh-Rekveldt, M. (2019). Developing a generic risk maturity model (GRMM) for evaluating risk management in construction projects. Journal of Risk Research, 1-21. Retrieved from https://www.tandfonline.com/doi/pdf/ 10.1080/13669877.2019.1646309?needAccess=true, 05.09.2020.

11. Kosecki, A., and Madyda, A. (1996). Kierowanie ryzykiem w przedsiębiorstwie budowlanym. In Technologia w budownictwie - teoria i praktyka. Konferencja NaukowoTechniczna (pp. 76-84). Wrocław-Polanica Zdrój: Instytut Budownictwa Politechniki Wrocławskiej, Towarzystwo Naukowe Inżynierii Procesów Budowlanych.

12. Kosmalski, S., and Myrczek, J. (2019). Zarzadzanie ryzykiem w procesie budowy gazociagu przesyłowego. Warszawa: Difin. 
13. Loosemore, M., Raftery, J., Reilly, Ch., and Higgon, D. (2006). Risk Management in Projects. London-New York: Taylor \& Francis Group.

14. Myrczek, J., and Tworek, P. (2019). From the research on risk management in Polish construction enterprises. In: K. Wilde, M. Niedostatkiewicz (Eds.). 64 Scientific Conference of the Committee for Civil Engineering of the Polish Academy of Sciences and the Science Committee of the Polish Association of Civil Engineers (PZITB) (pp. 1-8). Krynica: MATEC Web of Conferences. doi: https://doi.org/10.1051/matecconf/ 201926207009.

15. Myrczek, J., Juraszek, J., and Tworek, P. (2020). Risk Management Analysis in Construction Enterprises in Selected Regions in Poland. Technical Transactions, 117(1), 1-13. doi: https://doi.org/10.37705/TechTrans/e2020025.

16. Myrczek, J., Sadlik-Lenczewska, M., and Tworek, P. (2015). Wybrane problemy zarządzania ryzykiem w działalności przedsiębiorstw budowlanych. In: M. Szajt (Ed.), Zarządzanie (pp. 127-136). Częstochowa: Politechnika Częstochowska.

17. Palmer, J.W., Maloney, J.M., and Heffron, L.J. (1996). Construction insurance, bonding, and risk management. New York: McGraw-Hill.

18. Sawczuk, B. (2004). Risk Avoidance for the Building Team. London: E \& FN Spon.

19. Serpell, A., Ferrada, X., and Rubio, L.N. (2017). Fostering the effective usage of risk management in construction. Journal of Civil Engineering and Management, 23(7), 858-867. doi: https://doi.org/10.3846/13923730.2017.1321578.

20. Smith, N.J., Merna, T., and Jobling, P. (2006). Managing risk in construction projects. Oxford: Blackwell Publishing.

21. Tworek, P. (2012). Excerpts from the scientific research on risk conducted among the largest Polish contractors. Journal of Management and Finance, 10(1), 113-121.

22. Tworek, P. (2013). Reakcja na ryzyko $w$ działalności przedsiębiorstwa budowlanomontażowego. Warszawa: Difin.

23. Wang, Q.S., Dulaimi, F.M., and Aguria, Y.M. (2004). Risk management framework for construction projects in developing countries. Construction Management and Economics, 22(3), 237-252. doi: https://doi.org/10.1080/0144619032000124689.

24. Young, C.P., and Tippins, C.S. (2001). Managing Business Risk: An Organization-Wide Approach to Risk Management. New York: American Management Association.

25. Zuo, F., and Zhang, K. (2018). Selection of risk response actions with consideration of secondary risks. International Journal of Project Management, 36(2), 241-254. 


\title{
CREATIVITY AS THE MAIN DETERMINANT OF IMPLEMENTING FRUGAL INNOVATIONS IN ENTERPRISES ${ }^{1}$
}

\author{
Roman TYLŻANOWSKI \\ Wydział Ekonomii, Finansów i Zarządzania, Uniwersytet Szczeciński; roman.tylzanowski@usz.edu.pl, \\ ORCID: 0000-0003-3644-1935
}

Purpose: The article aims to define the role that creativity plays in implementing frugal innovations. The article also aims to list examples of innovative, frugal solutions as well as to indicate activities that would stimulate the creativity of employees in enterprises.

Design/methodology/approach: This is an exploratory study that is based on a systematic review of available literature on frugal innovation and creativity. The research was based on both Polish and foreign literature, articles, and internet sources.

Findings: The issue of frugal innovations has recently become "fashionable" in the good sense of the word. Inventive and cheap offers of products and technologies launched on markets are characterised by demonstrable dynamics. The article emphasises, in particular, the role of creativity in creating innovative, frugal solutions.

Research limitations/implications: Although the problem of frugal innovations is known and described, it is also true that publications focussing on and discussing this issue are still lacking. The article, therefore, aims to encourage decision-makers to support the creativity of their employees in order to develop frugal innovations. Nevertheless, the discussed topic requires further research.

Originality/value: The article is based on existing knowledge in the field of creativity and frugal innovations. The added value of the article is a combination of both issues, emphasising the role of employees' creativity in creating frugal innovations, which is illustrated in the form of the proposed model of the innovative process based on creativity.

Keywords: creativity, innovation, frugal innovations, determinants, innovation process.

Category of the paper: Conceptual paper.

\footnotetext{
${ }^{1}$ Project financed under the program of the Minister of Science and Higher Education under the name "Regional Initiative of Excellence" in the years 2019-2022 project number 001/RID/2018/19 funding amount 10684000.00 .
} 


\section{Introduction}

Innovations are invariably one of the most important factors in the development of modern enterprises and the economy as a whole. Their ultimate goal is to create new concepts and to move away from traditional solutions. Initiating, acquiring, and implementing innovations contributes to increasing the competitiveness of enterprises. Companies willing to take innovative actions also strengthen the international position of individual countries.

It seems that innovations have become an inseparable businesses aspect of every enterprise. In order to deal with the dynamic economic changes, to constantly meet market needs, and to achieve and maintain a competitive edge, modern organisations are compelled to implement them. This is also confirmed by the approach "sustainability enterprise" in which one of the paradigms, apart from knowledge, trust, and entrepreneurship combined with organisational culture, is innovation (Grudzewski, Hejduk, Sankowska, Wańtuchowicz, 2010, p. 13). In turn, the innovative activity of enterprises is considered to be one of the most important factors in the development of a modern economy. Terms such as the smart economy (Intelligent Economies..., 2018), sustainable economy (Bontoux, Bengtsson, 2015), knowledge-based economy (OECD, 1999) economy 4.0 (Kaz, Ilina, Medvedev, 2019) describe economic systems that are driven by innovations. Therefore, all considerations concerning innovations as well as their specificity and types, which are characteristic of contemporary economic challenges, constitute an important scientific discourse in the field of management sciences.

Of course, the process of creating and implementing innovations also involves a high risk of failure. This is mainly because this process usually requires high financial outlays, and the obtained results may be noticeable only over a longer time span. For traditionally understood innovations, time is not an ally, therefore, the ability to react to changes continuously and with flexibility in the economy, and to quickly implement innovative solutions, becomes useful. While 30 years ago it took an average of 6 years to develop a new car model, today the process is three times shorter. The Hewlett-Packard company also confirms the crucial role of time in implementing innovations. Currently, most of the company's revenue comes from products that did not exist the previous year (Bencsik, Machová, Tóth, 2016, p. 85). The necessity to react quickly to rapid economic changes, as well as other challenges such as issues related to sustainable development, including environmental protection, force us to search for forms of innovation that will be able to deal with various aspects of the economic reality that surrounds us. Such a group of innovations undoubtedly includes frugal innovations, which are known and described but publications focussing on and discussing this issue are still lacking. 


\section{The importance of frugal innovations in a modern economy}

Due to the increasing pace of changes, the increase in ties with the environment, limited budgets, restricted resources, and growing diversity, enterprises more and more often seek out and decide to introduce innovations that do not absorb significant financial resources. In addition, modern companies do anything to combine their activities with sustainable development. In the field of innovation, the trend that has helped many companies from the East to succeed is playing an increasingly important role (Bencsik, Machová, Tóth, 2016, p. 88); the so-called frugal innovations.

„Frugal innovations refer to products, processes or marketing and organisational methods that aim to minimise the consumption of material and financial resources while meeting or even exceeding predefined criteria of acceptable quality standards" (Tiwari, Herstatt, 2012, p. 4). As indicated by Radjou and Prabhu (2014, p. 12), as opposed to creating completely new or improved products or processes, which is the paramount goal of innovative activity in the traditional sense, the frugal approach involves revising existing solutions in order to provide more business and social value by minimising the use of resources.

These innovations are usually developed with great resource constraints and consist of good quality goods or services that are sold at reasonable prices. As a consequence, even middleclass or lower-class people can afford them. In other words, frugal innovations are „sufficiently good, inexpensive products that meet the needs of resource-constrained consumers" (Zeschky, Widenmayer, Gassmann, 2011, pp. 38-45). Their initial target was countries with a low level of development, but markets in highly developed countries are increasingly opening up to them.

Frugal innovations are becoming a global trend, evoking a new and "healthy" view on the theory and practice of innovative processes. Simultaneously, it turns out that the organisations themselves contain large amounts of savings innovations, supported (stimulated) by a global phenomenon of shrinking resources and catastrophic climate visions. Thanks to frugal innovations, communities in a difficult economic situation are able to raise their standard of living and solve various problems, including those related to health, education, or energy. Thus, frugal innovations have a significant impact on the economy, solving numerous social problems by generating ideas and producing revenue from business (Khan 2016, p. 1). Therefore, the type of innovations under discussion seem to be of key importance for the development of enterprises and the entire economy, and will certainly play a crucial role in the coming years.

The idea of frugal innovations, which consolidate the interests of entrepreneurs and consumers while promoting a simultaneous positive impact on the natural environment, appears as an interesting alternative for purely innovative solutions. Turbulent times, including the ongoing global economic crisis, which has exposed weaknesses even in developed economies, together with the growing social stratification and the spectre of environmental destruction, 
constitute a significant challenge that requires a change in approach to various spheres of our lives, including the sphere of organisation management. Frugal innovations make it possible to face major problems in the global economy, creating economic and social value without harming the environment. For this reason, modern enterprises should consider the implementation of such solutions, and theorists should explore their specificity.

The basic criteria determining frugal innovations include significant cost reduction, focus on key functionalities, and optimised efficiency level. Importantly, the links between these three criteria are crucial. The mere reduction of costs, without revising the functionality of the product or service as well as the level of efficiency, cannot mean that a given change is a frugal innovation. Similarly, the mere improvement of a product, without reducing its function to the necessary functionality, cannot be considered a frugal innovation (Weyrauch, Herstatt, 2016).

The potential of frugal innovations is reflected in many dimensions, such as (A conceptual analysis..., 2016, pp. 11-12):

- local solutions aiming to meet the low demand threshold in less developed markets (e.g. water filter powered by a moped, solar bulb),

- local solutions related to the challenges of sustainable development in less developed markets (e.g. agricultural innovations),

- frugal product engineering and corporate "mass frugality" based on reducing functions and on affordability (e.g. Tata Nano car, costing just $\$ 2,000$ ),

- frugal product-related innovations, based on increasing utility through robustness and sustainability (e.g. Nokia 1100, Jaipur Foot),

- reduction of process costs, based on the use of developing market conditions and intelligent, low-cost production processes (e.g. an uncomplicated dashboard on a Dacia),

- $\quad$ solutions personalised en masse for less developed markets, based on cooperation with local partners (e.g. home appliances),

- standardised frugal solutions for less developed markets, based on the concept of personalised delivery (e.g. solar panel rental models),

- global transformational solutions based on the challenges initially identified in frugal environments (e.g. Skype, mobile banking).

The need to respond to changes in the environment is tested during the global crisis caused by the coronavirus pandemic. The temporary closure of borders and the slowdown in international trade have stimulated local innovativeness in new or even surprising ways. Below are some examples of frugal innovations (most often low-tech ones), which, thanks to the creative approach of their designers, have made it possible, for example, to effectively fight the pandemic (https://includeplatform.net/...): 
- local manufacture of hand sanitisers and soaps using locally available, affordable materials at the grassroots level,

- mechanical and automatic water and soap dispensers in public stations that use pedals or thermal sensors to minimise human contact with sanitisation equipment,

- manufacture of face masks using for instance, kitenge fabric and other locally available materials,

- PumuaIshi 2.0 - portable, robust, compact and economical ventilator that an be used by untrained medical personnel and can operate off grid for up to four hours,

- mobile phone-based e-health applications (e.g. applications that help individuals assess their COVID-19 risk category through a digital triage tool, run interactive COVID-19 FAQs via WhatsApp-based chatbots, and create public awareness through text messaging),

- Kisomo SmartLearn - application that runs a makeshift video recording studio that teachers from the region can use to deliver their content.

These examples show that in times of crisis, innovative undertakings should, above all, be robust, flexible, accessible, and affordable, taking into account the existing constraints and opportunities in terms of resources and infrastructure.

\section{The creativity of employees and its impact on the creation of innovative solutions}

In order to maintain or improve their competitive position in the market, enterprises should constantly strive to maintain the maximum level of informativeness, taking advantage of any new sources for this purpose (Chyba, 2014, p. 230). A number of different factors can affect the implementation of frugal innovations. They are usually dynamic in nature, therefore, their importance, from the point of view of an economic entity, may change over time and may depend on a variety of other conditions. Anything that can generate specific ideas, concepts, and projects, and can contribute to searching for and finding new things, or undertaking ventures as well as implementing and improving them, can be classified as sources of innovation (Penc, 1999, p. 157).

Sources of frugal innovations can be classified in many different ways. At the macroeconomic level, both domestic and foreign sources can be distinguished. This classification takes into account, among others, factors such as economic growth, the structure of unemployment and prices, market situations, fiscal and monetary policy as well as the legal system of a given country. In turn, at the microeconomic level, it is possible to distinguish internal (endogenous) and external (exogenous) conditions; external conditions may be domestic or foreign. The source of innovation is, therefore, everything that can inspire 
a person/enterprise to the process of change. The environment that stimulates changes and allows a reaction to the changing surroundings in a creative way is of key importance (Pomykalski, 2001, p. 34).

The word "creativity" is nowadays used to describe not only people (e.g. "creative attitude"), but also many objects, fields, or phenomena (e.g. "creative product", "creative sales", "creative accounting"). More than half a century ago, people were already pointing out that creativity is a process resulting in innovative and useful products, accepted by large groups of people and which ensures satisfaction from using them during a specific time (Stein, 1953, p. 312). According to Teresa Amabile (1998, pp. 77-78), who has conducted extensive research in this field, creativity is a set of several elements, being knowledge, motivation, competence, creative thinking skills, and organisational culture. It is also emphasised that creativity is the ability of people to create new and valuable creations (Szmidt, 2013, p. 22). Therefore, it is primarily a human trait that determines the generation of ideas, enabling the creation of new and better ones compared to the current solutions. Creativity can also be treated as a human skill that allows for ,a different perception of the world, creating new ideas, expressing knowledge and distinctness" (Szara, 2014, p. 201). Creative thinking is very often also defined as a person's personality disposition, which is distinguished by an unconventional approach to various problems and unusual ideas for solving them as well as a positive approach, learning from mistakes, and determination in taking innovative actions (Kaliszczak, 2013, p. 78). Such unconventional thinking and action are useful especially in difficult and critical moments, independent of the company.

Creativity is, of course, a necessary factor resulting in innovation. According to Kampylis and Berki (2014, p. 6) ,creative thinking should enable all people involved in innovative processes to use their imagination to generate ideas, questions, and hypotheses, experiment with alternatives, and evaluate their own and external ideas, end products, and processes". According to numerous authors from the field of management and quality sciences, creativity should be treated as the first stage of the innovation process, as a source of generating new concepts and ideas.

Two types of creativity can be distinguished: conceptual creativity related to the development of new methods, models, or theories, and operational creativity necessary in practical implementation processes and the verification of conceptual creativity products (Baruk, 2006, p. 90). It cannot be denied that creativity is especially useful when new ideas have a chance to find application in solutions that improve the functioning of a company (e.g. a new process leading to an increase in production capacity), as well as in products offered to its customers and the entire community (e.g. innovative goods and services that can be used by everyone, regardless of their level of wealth). Therefore, creativity should not be considered only in conceptual terms but should be treated primarily as a factor enabling the implementation of new and useful products so, it is imperative that creativity is at the centre of interest for all enterprises, not only those characterised by a high level of innovativeness. Creativity is nothing 
other than necessary when proposing and implementing cost-effective innovations because it is inventive and creative staff who are able to both propose modern, affordable, and sustainable solutions, and achieve them in a quick, efficient, and frugal manner.

\section{A model of the process for creating frugal innovations based on creativity}

Ensuring or maintaining a long-term competitive edge is becoming more and more difficult, which is a result, among other things, of the changing environment and constant competition from other entities. Strengthening the position of business entities is possible primarily thanks to focusing on the originality and uniqueness of the solutions created (products, processes, marketing, or organisational methods). Currently, business entities are looking for a way to continuously improve and develop solutions that will be characterised by high quality (uniqueness), but at the same time will not generate high costs. One of the most important resources that both initiates and leads to obtaining these effects is creative staff. Therefore, the crucial internal source of frugal innovations is creativity. A significant role of creativity in creating the value of an enterprise is seen in particular in entities characterised by a high level of innovativeness, whose products appearing on the market are not the result of incurring significant financial outlays. For such companies, what matters most is the human element, treated as the basic inexhaustible resource in which it is worth investing (Jung, 2010, p. 222), because it leads to a competitive edge for the enterprise.

When assessing the potential of innovations, it is worth quoting the arguments put forward by Radjou and Prabhu (2014). They argue that frugal innovations allow companies to introduce high-quality products to the market cheaper and faster while using a limited amount of resources. They also emphasise that good-quality products can be affordable and sustainable.

In the linear innovation process, based on the classical Schumpeter theory, the creation of innovation is preceded by research and development which consists of 3 phases: basic research, applied research, and development work (Francik, Kosała, 2011, p. 7). It turns out that in the case of frugal innovations, it is not at all necessary to incur high outlays on research and development activities. Entities that offer frugal innovations should pay particular attention to engagement and iteration (Radjou, Prabhu, 2014, pp. 1-18). The smaller role of research and development for this group of innovators results, among others, from the following premises (Radjou, Prabhu, 2014, pp. 1-18):

- Research and development are usually time-consuming and inflexible.

- They focus on the quality of the results itself, rather than the quality of the results in connection with their value to customers. 
- They are complex and costly. Moreover, their complexity is costly, both for the companies producing them and their customers.

- They are not environmentally friendly. For example, the complexity and short life cycle of mobile phones increase waste production.

- The role of customers is rather to approve the product idea/prototype than to co-create solutions.

Therefore, enterprises should work fast, involve end-users, focus on simple solutions, and use external resources, experts, and infrastructure, and reduce bureaucratic restrictions wherever possible. The basic and unlimited resource to which the enterprise has access is the creativity of the employees of the company. The author proposes a model of the process of creating frugal innovations based on creativity (fig. 1).

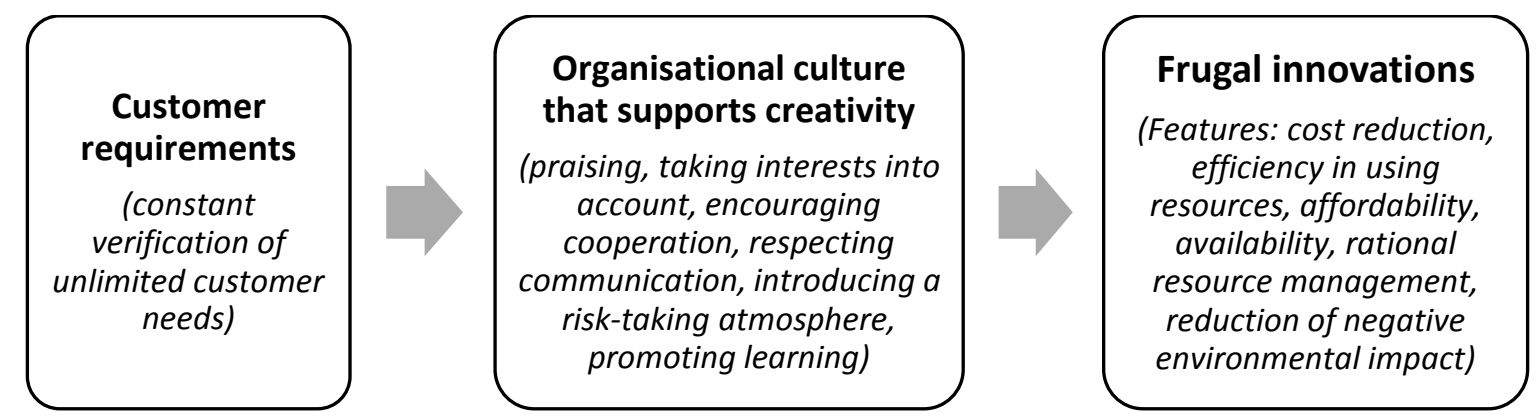

Figure 1. Model of the process of creating frugal innovations based on creativity. Source: Own elaboration.

As in the case of demand models of the innovation process, frugal innovations require, first of all, examining the needs/requirements of recipients. One of the most important sources of frugal innovations is the so-called "street", i.e. people with specific expectations or who are struggling with certain problems. The community can inspire people to develop new, frugal solutions. It should be remembered that innovativeness does not only mean generating creative ideas. We can speak of the effectiveness of innovative processes only when the proposed solutions are commercialised. Innovative products must arouse the interest of a specific group of buyers and be approved by them.

Enterprises differ from each other, e.g. in terms of production volume, assortment offer, level of innovativeness, or the number of employees. Each enterprise, irrespective of the aforementioned differences, should create appropriate conditions within the organisation for stimulating the creativity of its employees. Therefore, the basis for the creative and effective operation of enterprises seems to be an appropriate organisational culture. This constitutes a set of common values, goals, and beliefs of the company that determine the level of commitment as well as the method and quality of the work of all its employees (Armstrong, 1997, p. 115). Creating a favourable organisational culture in a company is not easy; the most important element is that companies implementing innovations (including the frugal ones) should learn from mistakes and draw conclusions for the future. Enterprises should realise that failure must 
be accepted and made to be a factor that strengthens the company, prompting it to seek new, innovative solutions (Bogdanienko, Haffer, Popławski, 2004, pp. 39-40).

The key task of the company's managers is to select the right people for each position, as well as to provide them with opportunities and conditions to use their potential creatively. As a result, employees will be able to find, adapt, implement, and disseminate new solutions that bring benefits, both individual and social (Bal-Woźniak, 2010, p. 258). The tasks of company managers should include ensuring that creativity and innovation are respected by each member of staff and treated as basic cultural norms which are an integral part of the company's strategy.

Providing employees with a creative work environment forces the company management to perform appropriate activities, such as (https://www.roberthalf.com/...):

- Praising people and their work - any employee would like their work to be recognised.

- Taking into account employee interests - employee interests can be a very valuable source of generating new ideas.

- Encouraging cooperation - employees may come up with many interesting ideas during discussions and joint meetings. They only need space for such meetings to be organised.

- Respecting communication - it is important for employees to receive clear and explicit messages from their superiors. Managers should define what they expect, what they are striving for, and provide all necessary information to their co-workers on an ongoing basis.

- Establishing a risk-taking atmosphere - supervisors should allow their employees to take intelligent risks. This may turn out to be one of the most effective ways to achieve market success.

- Supporting innovation - inspiration for new innovative ideas can be anything that surrounds us, not necessarily within a given company. Therefore, employees should be given the opportunity to seek inspiration in a variety of places.

- Promoting learning and teaching - a person who manages staff well is one who allows their employees to attend a variety of training courses and workshops. The effect of this permission will be the acquisition of new knowledge and an increase in the chances to use it, e.g. when proposing and implementing innovative [frugal] solutions.

The above factors emphasise the role of management in stimulating the creativity of their employees. It should be remembered that creativity in an enterprise is usually activated if there is a so-called creative atmosphere. Thanks to greater freedom in action, employees are willing to activate different, out-of-the-box thinking. The system of submitting applications by each employee of the company, which will increase the freedom of choosing and solving problems, may be useful in the efficient introduction of innovations to the enterprise (Bogdanienko, Haffer, Popławski, 2004, p. 43). This way of thinking and acting leads to benefits being acquired not only by the company but also by every employee who is additionally motivated to take further creative actions. 
Creative work becomes active wherever there is a favourable, positive atmosphere. Staff managers must be aware that not all innovation-oriented activities are a success; it is unacceptable to blame and punish entrepreneurial and creative employees for the failures just because they try to introduce changes in the organisation. Relying on a system of penalties for failures definitely weakens the creative atmosphere within the organisation. In turn, rewarding employees should be based not only on the methods used so far but also on the risk taken which was necessary to introduce new solutions. By implementing a mechanism for creating, developing, and promoting new ideas in the enterprise, it is possible to respond more quickly to the market signals and challenges (Strychalska-Rudzewicz, 2009, pp. 1207-1209). The best methods or techniques will not guarantee the intended results in the production or provision of services. The basis for creating innovative and frugal solutions is the commitment of the staff.

\section{Conclusion}

Today, any innovative venture should be based on a frugal mindset. In other words, representatives of businesses, both large and small, must learn to use all the resources that are within their reach. This may involve a recombination of existing materials, knowledge, and skills in a creative way, or adapting existing technologies to deal with a crisis.

In order to better understand and be able to search for opportunities and threats emerging in this environment, as well as to broaden perspectives, the thinking of the staff hired by the company should be creative, inventive, and lateral (including new ways of looking at things). One of the characteristic features of the creative process in the field of frugal innovations, one that makes it so crucial, is that it requires not only knowledge in a specific area but also the proper willingness, the ability to ask questions and to avoid limiting ourselves to the existing, available knowledge. Creativity requires a certain reflection on the essence of the problem, a level of commitment as well as increased trust and responsibility.

Taking into account all the aforementioned arguments, it can be said, again, that creativity is one of the most important sources of frugal innovations. For this reason, it is necessary to invest in staff and create appropriate conditions for them in the company, thanks to which each employee will be able to notice current problems and try to solve them creatively, ultimately leading to the implementation of a number of innovative solutions that benefit the company, the natural environment, and society as a whole. 


\section{References}

1. A conceptual analysis of foundations, trends and relevant potentials in the field of frugal innovation (for Europe) (2016). Interim report for the project "study on frugal innovation and reengineering of traditional techniques" - Study, Directorate-General for Research and Innovation, Fraunhofer ISI, Nesta. European Commission.

2. Amabile, T. (1998). How to kill creativity. Harvard Business Review, 76, no. 5.

3. Armstrong, M. (1997). Jak być lepszym menedżerem. Warszawa: Dom Wydawniczy ABC.

4. Bal-Woźniak, T. (2010). Warunki usprawnienia zarządzania innowacyjnością w kontekście współczesnych wyzwań. In: S. Lachiewicz, A. Zakrzewska-Bielawska (eds.), Zarządzanie wiedza i innowacjami we współczesnych organizacjach. Łódź: Wydawnictwo Politechniki Łódzkiej.

5. Baruk, J. (2006). Zarzadzanie wiedza i innowacjami. Toruń: Wydawnictwo Adam Marszałek.

6. Bencsik, A., Machová, R., Tóth, Z. (2016). Cheap and clever - symbiosis of frugal innovation and knowledge management. Problems and Perspectives in Management, vol. 14(1).

7. Bogdanienko, J., Haffer, M., Popławski, W. (2004). Innowacyjność przedsiębiorstw. Toruń: Wydawnictwo Naukowe Uniwersytetu Mikołaja Kopernika.

8. Bontoux, L., Bengtsson, D. (2015). 2035 Paths towards a sustainable EU economy Sustainable transitions and the potential of eco-innovation for jobs and economic development in EU eco-industries 2035. Publications Office of the European Union.

9. Chyba, Z. (2014). Porównanie wybranych źródeł innowacji w przedsiębiorstwie. Krakowskie Studia Małopolskie, nr 19.

10. Francik, A., Kosała, M. (2011). Teoretyczne aspekty procesów innowacyjnych w organizacjach. Zeszyty Naukowe Uniwersytetu Ekonomicznego w Krakowie, nr 866.

11. Grudzewski, W.M., Hejduk, I.K., Sankowska, A., Wańtuchowicz, M. (2010). Sustainability $w$ biznesie czyli przedsiębiorstwo przyszłości. Zmiany paradygmatow $i$ koncepcji zarzadzania. Warszawa: Poltext.

12. https://includeplatform.net/blog/frugal-innovation-during-the-covid-19-crisis-examplesfrom-east-africa/, 29.08.2020.

13. https://www.roberthalf.com/blog/management-tips/7-elements-of-a-highly-creative-workenvironment, 28.08.2020.

14. Intelligent Economies: AI's transformation of industries and society (2018). A report from The Economist Intelligence Unit. The Economist Intelligence Unit Limited.

15. Jung, B. (2010). Kreatywne gospodarki i „kreatywna klasa”. Otoczenie mediów ery Web 2.0. In: B. Jung (ed.), Wokół mediów ery Web 2.0. Warszawa: Wydawnictwa Akademickie i Profesjonalne. 
16. Kaliszczak, L. (2013). Kreatywność i innowacyjność w kształtowaniu wartości rynkowej oraz przewagi konkurencyjnej przedsiębiorstw. Przedsiębiorstwo i region, $n r$ 5. Rzeszów: Wydawnictwo Uniwersytetu Rzeszowskiego.

17. Kampylis, P., Berki, E. (2014). Nurturing creative thinking. International Academy of Education. UNESCO.

18. Kaz, M., Ilina, T., Medvedev, G.A. (2019). Global Economics and Management: Transition to Economy 4.0 Prospects of Fundamental Science Development International Conference 2018 (PFSD 2018): Economics and Management Session. Springer International Publishing.

19. Khan, R. (2016). How Frugal Innovation Promotes Social Sustainability. Sustainability, vol. $8(10)$.

20. OECD (1999). The Knowledge-Based Economy: A set of facts and figures. Paris.

21. Penc, J. (1999). Innowacje i zmiany w firmie. Warszawa: Agencja Wydawnicza Placet.

22. Pomykalski, A. (2001). Innowacje. Łódź: Politechnika Łódzka.

23. Radjou, N., Prabhu, J. (2014). Frugal Innovation: How to Do More with Less, 1st ed. London: Profile Books Ltd.

24. Stein, M.I. (1953). Creativity and culture. The Journal of Psychology, 36.

25. Strychalska-Rudzewicz, A. (2009). Kulturowe determinanty innowacyjności przedsiębiorstw. In: M. Czerska, H. Czubasiewicz (eds.). Społeczne uwarunkowania sukcesu organizacji. Sopot: Prace i Materiały Wydziału Zarządzania Uniwersytetu Gdańskiego.

26. Szara, K. (2014). Kreatywność a innowacyjność w działalności podkarpackich przedsiębiorców. Zeszyty Naukowe MWSE w Tarnowie, $n r$ 1(24).

27. Szmidt, K.J. (2013). Trening kreatywności. Gliwice: Helion.

28. Tiwari, R., Herstatt, C. (2012). India - A Lead Market for Frugal Innovations? Extending the Lead Market Theory to Emerging Economies. Working Paper No. 67. Institute for Technology and Innovation Management. Hamburg: Hamburg University of Technology.

29. Weyrauch, T., Herstatt, C. (2016). What is frugal innvation? Three defining criteria. Journal of Frugal Innovation, 2(1).

30. Zeschky, M., Widenmayer, B., Gassmann, O. (2011). Frugal Innovation in Emerging Markets: The Case of Mettler Toledo. Research-Technology Management, 54. 


\title{
GLOBAL ENVIRONMENT AS A FACTOR OF CHANGES IN ORGANIZATION AND MODERN MANAGEMENT CONCEPTS
}

\author{
Jerzy WĄCHOL \\ AGH University of Science and Technology, Kraków; jwachol@zarz.agh.edu.pl, ORCID: 0000-0003-0296-0585
}

Purpose: The aim of the study is to present a changing global environment for businesses, to use modern elements of management, IT and telecommunications as necessary elements in the face of the pandemic and global crisis, to sustain the functioning of businesses, organisations, economies and states.

Design/methodology/approach: On the basis of the collected statistical data, own research and surveys, observations and literature, conclusions have been drawn concerning trends of changes in the organisation and the application of modern management concepts and forms of management. The study presents the functioning of enterprises taking into account their further environment, especially economic and social, against the background of the current problems of the EU and the world economy. The study also presents the problems of modern global economy, pandemic and sustainable development.

Findings: Study presents selected elements of governance and trends of change in the organisation. What matters most for companies is marketing, finance, profit, strategies, personnel, innovation, modern methods and forms of organisation, etc. However, elements of IT and modern management methods already have an important and growing position, especially in the face of the pandemic, remote work and the global crisis. Technological and macro-economic changes, new methods of management, shrinking natural resources in the world at the turn of the 20th and 21st century, looking for substitutes, all these set out the directions for the development of companies. In addition, socio-political and epidemiological changes, computerisation and automation, cause changes in the functioning of enterprises, both large and small.

Keywords: Global environment, process organizations, modern management methods, global economy, sustainable development, trends in organization, sustainable development.

\section{Introduction}

With the ongoing SARS-CoV-2 pandemic, the rapid changes in the global environment and the political, social and economic problems of the European Union, businesses and citizens need to adapt quickly in order to earn money and survive. These are not only economic, legal, 
political, technological and IT changes, new methods of management, which are difficult not to follow, but also changes in the socio-cultural environment, the mixing of cultures, and changes in the environment. These changes are being created at global level, at the level of the European Union as a whole and of individual diverse nation states. The challenges for businesses are certainly very great. There are possible next different waves of epidemics, terrorism or states of emergency, which can disturb economic stability, usually so important for companies and their strategic plans (Kapferer, 2012). Especially during the epidemic, it turned out that IT and telecommunications can be used very often, in many cases for remote work in companies, or in organisations such as state government, local government or education (www.computerworld.pl/...). It is possible to hold virtual meetings, teleconferences, do the shopping without leaving home. You can work remotely from home, sending the administrative support items to the headquarters. Similarly, you can perform other commissioned work at home, but here you need couriers. IT and telecommunications are useful on a massive scale for remote medical advice, e-prescriptions, with the possibility of some remote medical examinations. However, the network traffic load was record-breaking (www.komputerswiat.pl/...). It has happened many times that networks as well as local servers and software have failed, due to too many active participants and sophisticated IT processes, also not without significance have hackers been.

The aim of the study is to present a changing global environment for businesses, to use modern elements of management, IT and telecommunications as necessary elements in the face of the pandemic and global crisis, to sustain the functioning of businesses, organisations, economies and states. On the basis of available sources, own research, conclusions were presented concerning the problems of the modern economy, trends in change, during the pandemic and crisis. Emphasis is also placed on technological and environmental changes.

\section{IT, telecommunications and the virtualisation of economic and social processes, and the impact of the epidemic on the economy}

The use of IT and telecommunications is widespread, so if it is cheaper and quicker to do something without leaving home, then it may be worth doing so using IT. The habits of societies acquired during the pandemic of spring 2020 are also an issue, and I believe this will continue to be the case for years to come even without epidemics or similar crisis threats. Provided that, technologically, Internet networks can withstand the growing burden, they are maintained, developed and modernised. However, there are problems and costs. You have to have good computer equipment, servers, Internet and telephone links, radio links, etc. everywhere. And there must also be conditions in the home for remote working, which requires investment outlays. In this case, there are less costs for commuting, but the costs for electricity, computer 
equipment, internet and telecommunication links are rising. Remote working, shopping, education, meetings, medical advice, cashless payments, etc. using IT and telecommunications, are likely to take on even greater significance, even if there are no more pandemics and similar threats (www.pulshr.pl/...).

This is all the more important in view of the next epidemic season in the autumn of 2020 , and the possible next waves of epidemics in the next few years. The SARS-CoV-2 virus is constantly mutating, and more vaccines and medicines will be needed, just as for influenza. The mortality rate of COVID-19 is relatively low for the time being, but the disease is dangerous, severe and very contagious. It affects not only older people, but also younger and younger people, and there are already millions of people infected in the world. Far Eastern societies such as China, North Korea and Japan, which have been accustomed to constant epidemics for many years, are more prepared and disciplined to prevent another wave of the pandemics. In America and Europe, however, this is still a major problem and the pandemic is developing rapidly, even at an exponential rate. It is certainly also a great problem for the global economy.

Scientific and technological achievements gained in one country can be used in industry in a completely different distant country, in the world of a global economy. Skilful use of available knowledge and technology becomes a necessity for the survival of organisations. Once discovered, knowledge, technology and experience usually spread around the world over time thanks to, among other things, IT, and skilful computer-based storage of these achievements also allows for their analysis and transfer (Kasprzak, 2003).

To achieve success, the following are important: assumptions, strategy, good data for the system, storage, selection, processing and analysis of information, for creating currently needed knowledge and technology, on the one hand, and loading currently needed knowledge into the operational area from available archives, knowledge warehouses, on the other hand. So that the IT system is not overloaded with unnecessary data and knowledge, so that it can work quickly and effectively at a given technological level, providing good analysis results, and suggest solutions thanks to artificial intelligence. Effective process management (Kalinowski, 2015) with the use of information technology can be useful here.

Global data indicate that achieving economic success usually goes hand in hand with knowledge, modern technologies and the skilful use of IT and multimedia means; health care and the environment are also important. Moreover, in the future, societies will probably become more accustomed to using these measures wherever possible and wherever this makes sense.

In the 21 st century, it is IT that dominates everywhere, even among other technologies. They apply to the modern economy (mfiles.pl/...), especially in the so-called fourth industrial revolution (Schwab, 2018).

The new century (21st century) is often called the IT and communication era. However, if we analyse more deeply what this IT is supposed to do, we will come to the conclusion that this is consequently a knowledge society, because by analysing information, knowledge is 
created. In such a society, knowledge workers will play a major role, because it is the broad knowledge they possess that will be the main commodity.

The modern use of IT and multimedia in companies and organisations is, of course, very large, important and extensive. It is difficult to imagine how businesses and households might function today in economically developed societies without Internet technologies and multimedia. They have become one of the most important elements of life and functioning of organisations.

Efficient elements of communication, control, automation, information exchange and processing are very important in the computerisation process. As well as elements of training and stable power supply and the high costs associated with this, not only calculated in money for computer hardware, software and electricity, but also ecological costs. The question is, therefore, whether the excessive use of IT is always necessary today, on a large scale? After all, in the past, businesses were also able to operate efficiently without IT. However, the environment in which businesses operate has changed, and this is forcing changes in the direction of digitisation, especially in times of a global pandemic.

\section{The global economic crisis and the pandemic vs. the functioning of IT and modern management methods in a new environment}

The economic crisis, with the current epidemic, is a special time to test and use modern management concepts, crisis management methods and IT systems and telecommunications multimedia means, which is necessary to stop the spread of viruses, bacteria, on the one hand, and to slow down the economic and social crisis, on the other. Thanks to IT systems, it is possible for the economy and the state to function, and the IT industry is growing in strength (cyfrowa.rp.pl/...). Employees in this sector are in demand, unlike many other sectors of the economy, which has resulted in losses and redundancies, particularly in tourism, the hotel and catering industry, and so on.

In highly developed and rich countries, where IT is widely used, and where IT societies make use of computer networks and systems and modern telecommunications connections almost in $100 \%$, it is easier to use these technologies to combat the pandemic, which may limit this phenomenon. However, when it comes to stopping the negative economic phenomena which are leading to the economic crisis, it is much more difficult. There may no longer be the pandemic, but the economic crisis will continue, not only because of the SARS-CoV-2 coronavirus or its mutation, but also because of the accumulation of economic and social problems from previous years, even earlier than the last global economic crisis reported for 2008. 
Table 1 presents selected countries of the world from those more significant in economic terms, and those close to Poland and their GDP growth forecasts, together with unemployment figures for 2020. The forecasts are according to the IMF from May 2020.

Table 1.

The forecasts of GDP growth and unemployment in selected world countries

\begin{tabular}{|c|c|c|c|c|c|}
\hline \multirow[t]{2}{*}{$\begin{array}{l}\text { Country/ } \\
\text { Region }\end{array}$} & \multicolumn{2}{|c|}{$\begin{array}{c}\text { The forecasts of GDP } \\
\text { dynamics for } 2020\end{array}$} & \multirow{2}{*}{$\begin{array}{c}\text { The most likely GDP } \\
\text { dynamics in } \mathbf{2 0 2 0} \\
\%\end{array}$} & \multicolumn{2}{|c|}{ Unemployment/period } \\
\hline & from $\%$ & up to $\%$ & & $\%$ & period \\
\hline Grecja & $\downarrow-10$ & -5 & $-10,0$ & 16,2 & 02.2020 \\
\hline Włochy & -10 & -5 & $-9,1$ & 8,0 & 04.2020 \\
\hline Litwa & -10 & -5 & $-8,1$ & 11,2 & 05.2020 \\
\hline Hiszpania & -10 & -5 & $-8,0$ & 13,8 & 03.2020 \\
\hline Ukraina & -10 & -5 & $-7,7$ & 8,7 & 03.2020 \\
\hline Francja & -10 & -5 & $-7,2$ & 8,1 & 03.2020 \\
\hline Holandia & -10 & -5 & $-7,2$ & 2,9 & 04.2020 \\
\hline Niemcy & -10 & -5 & $-7,0$ & 3,5 & 04.2020 \\
\hline Austria & -10 & -5 & $-7,0$ & 12,8 & 05.2020 \\
\hline Szwecja & -10 & -5 & $-6,8$ & 7,1 & 04.2020 \\
\hline Australia & -10 & -5 & $-6,7$ & 6,2 & 04.2020 \\
\hline Czechy & -10 & -5 & $-6,5$ & 3,7 & 05.2020 \\
\hline Wielka Brytania & -10 & -5 & $-6,5$ & 4,0 & 03.2020 \\
\hline Norwegia & -10 & -5 & $-6,3$ & 3,5 & 03.2020 \\
\hline Słowacja & -10 & -5 & $-6,2$ & 5,2 & 04.2020 \\
\hline Kanada & -10 & -5 & $-6,2$ & 13,0 & 05.2020 \\
\hline USA & -10 & -5 & $-5,9$ & 14,7 & 05.2020 \\
\hline Rosja & -10 & -5 & $-5,5$ & 4,7 & 04.2020 \\
\hline Brazylia & -10 & -5 & $-5,3$ & 12,2 & 04.2020 \\
\hline Japonia & -10 & -5 & $-5,2$ & 2,5 & 04.2020 \\
\hline Turcja & -5 & 0 & $-5,0$ & 13,8 & 02.2020 \\
\hline Polska & -5 & 0 & $-4,6$ & 5,4 & 04.2020 \\
\hline Arabia Saudyjska & 0 & -5 & $-2,3$ & 5,7 & 01.2020 \\
\hline Korea Południowa & 0 & -5 & $-1,2$ & 3,8 & 05.2020 \\
\hline Chiny & 0 & +5 & $+1,2$ & 5,9 & 04.2020 \\
\hline Indie & 0 & +5 & $+1,9$ & 23,5 & 05.2020 \\
\hline
\end{tabular}

Source: Own study based on https://www.forbes.pl/gospodarka/koronawirus-prognozy-gospodarcze$\mathrm{mfw} / \mathrm{d} 742 \mathrm{kyd} \quad 30.05 .2020$, and https://www.obserwatorfinansowy.pl/bez-kategorii/rotator/niewszystkie-gospodarki-wpadna-w-recesje/, 30.05.2020.

The current data and the forecasts are even being tragic for the global economy, which is predicted to contract by $3 \%$ or more of GDP. Many countries will fall into recession and high unemployment, as predicted by, among others, the IMF (International Monetary Fund) (www.forbes.pl/...). According to these predictions, the world is threatened by a global recession, on a large scale, similar to the crisis of 1929-1933, which further ended in the Second World War. According to these forecasts, most of the economically significant countries in the world which have modern technologies, including IT, may have negative GDP dynamics and an increase in unemployment. This does not, however, apply to China, which, after a significant economic slowdown from around 7\%, could achieve still positive GDP growth of $+1.2 \%$ in 2020 , and perhaps India of $+1.9 \%$. The next wave of the pandemic in the autumn of 2020 does not, as yet, affect significantly countries in the Far East, such as China, Japan, South Korea and 
so on. These countries, which have been accustomed to various epidemics for many years, are able to overcome them more easily.

However, the whole of the so-called West, including the countries of Central and Eastern Europe and Russia, have negative GDP growth forecasts for 2020. The question is only how negative they are. According to forecasts, Greece is expected to have the highest negative GDP growth rates, viz. $-10 \%$, and then Italy $-9.1 \%$, Lithuania $-8.1 \%$, Spain -8.5 , Ukraine $-7.7 \%$, France $-7.2 \%$, the Netherlands $-7.2 \%$, Germany $-7.0 \%$ and so on. The recession and the negative forecast of GDP growth will also affect the USA (-5.9\%) with rapidly rising unemployment. Due to the dramatic fall in oil prices in March 2020, caused by falling demand, oil-producing countries such as Russia, Saudi Arabia, Norway, etc. are also experiencing major economic problems and limiting production.

The use of IT and other selected management elements is presented in Table 2.

\section{Table 2.}

The usefulness and application of selected elements in the management

\begin{tabular}{|c|c|c|c|c|c|c|c|c|c|}
\hline & \multirow[t]{2}{*}{$\begin{array}{c}\text { Number of } \\
\text { responses/element } \\
\text { management }\end{array}$} & \multirow[t]{2}{*}{$\begin{array}{l}\text { Weighted average } \\
\text { rating the } \\
\text { suitability of } \\
\text { selected elements in } \\
\text { the management } \\
1 \quad \text { scale } 1-5\end{array}$} & \multicolumn{5}{|c|}{$\begin{array}{l}\text { Number of ratings, scale } \\
\text { of } 1-5 \text { for the suitability of } \\
\text { the selected items in the } \\
\text { management, } \\
(1 \mathrm{~min}, 5 \text { max })\end{array}$} & \multicolumn{2}{|c|}{$\begin{array}{l}\text { The using of these } \\
\text { elements in the } \\
\text { organization, where } \\
\text { respondents work, } \\
\text { by their reviews }\end{array}$} \\
\hline & & & 1 & 2 & 3 & 4 & 5 & Yes & No \\
\hline 1 & Marketing & 4,425 & 0 & 0 & 4 & 15 & 21 & 33 & 7 \\
\hline 2 & Financial management & 4,300 & 0 & 3 & 2 & 15 & 20 & 31 & 9 \\
\hline 3 & Business plan & 4,150 & 1 & 3 & 4 & 13 & 19 & 35 & 5 \\
\hline 4 & HR & 4,050 & 1 & 4 & 7 & 8 & 20 & 31 & 9 \\
\hline 5 & IT & 3,975 & 1 & 1 & 11 & 12 & 15 & 32 & 8 \\
\hline 6 & Outsourcing & 3,675 & 2 & 0 & 12 & 21 & 5 & 30 & 10 \\
\hline 7 & Lean Management & 3,675 & 1 & 1 & 14 & 18 & 6 & 21 & 19 \\
\hline 8 & Ecology & 3,525 & 2 & 4 & 11 & 17 & 6 & 20 & 20 \\
\hline 9 & Virtual organization & 3,500 & 2 & 4 & 13 & 14 & 7 & 22 & 18 \\
\hline
\end{tabular}

Source: Own surveys September 2019 in SME sector, Malopolska and Krakow.

The entrepreneurs of the future are facing new challenges in today's global IT economy and within a changing EU. They are related to the changing environment and the constantly growing processes of globalisation (Borowiecki, 2010), the company's environment is presented in Fig. 1. In the case of advanced, expanding globalisation processes, the area of the global environment is becoming more and more important for further companies in a given country, including Poland. This obviously raises specific problems in the socio-cultural, political and legal, macroeconomic and technological fields. This may concern the natural environment in a given country. This may represent new opportunities and threats for businesses in that country. The economic problems in a changing and undefined environment, which Polish companies face, are very complex. This does not have to mean the complete replacement of the market mechanism by directives from the government or parliament, but only a completely new state interventionism. The authorities' task is, first and foremost, to stimulate and create economic growth, employment and production, protection against threats, and sustainable development. Particularly in times of pandemics and crisis management. 


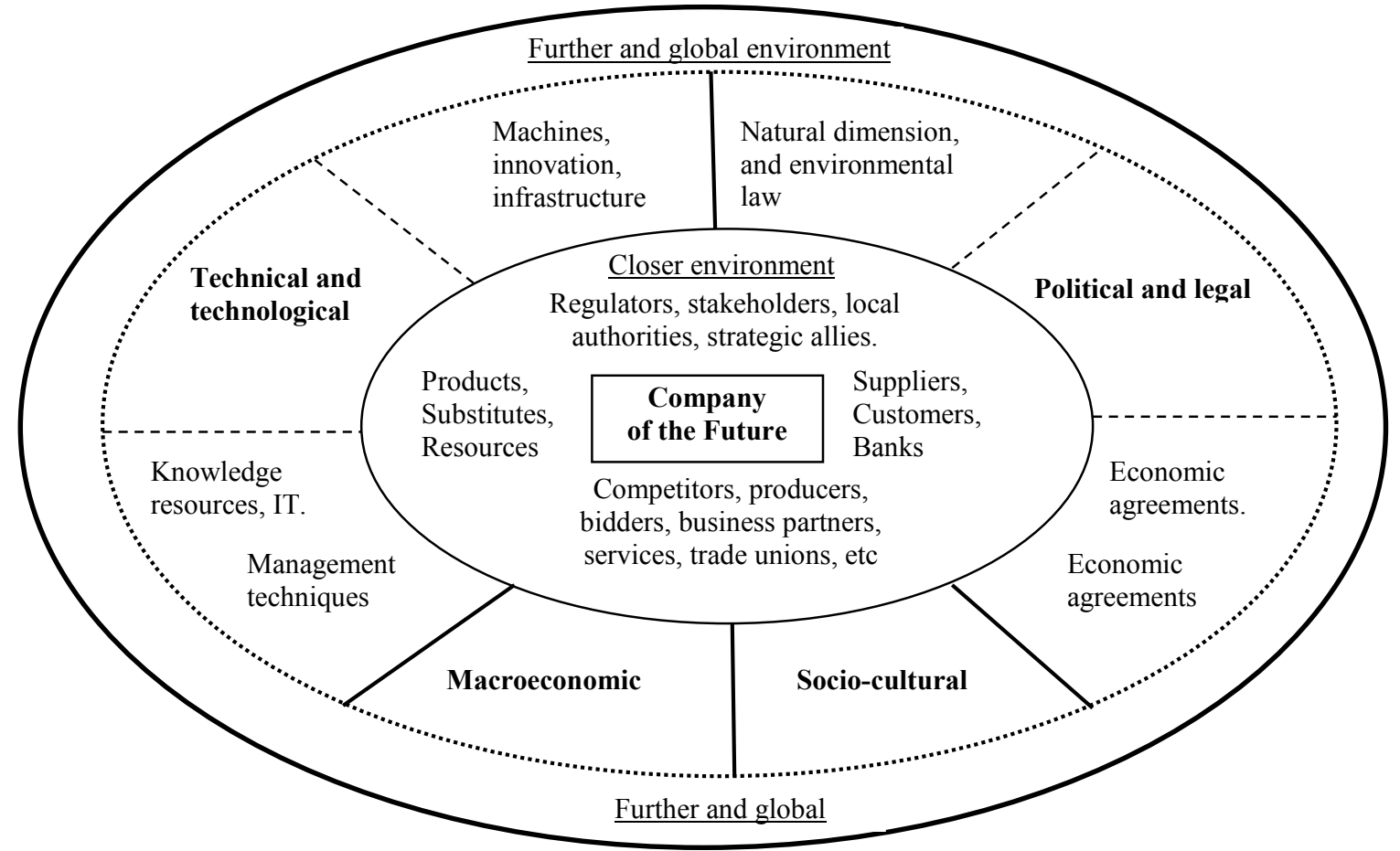

Figure 1. Surroundings of the enterprise of the future. Source: Own study, based on (Griffin, 2010).

Polish enterprises operating under Polish law, even with foreign capital, in future should become a monitored sustainable enterprise, taking into account social and economic factors as well as the elements of the natural environment which make it live (Toczyski, 2004). The literature on the subject also mentions the need for greater social control over the activity of the company and corporation. Moreover, it seems that for the proper course of the globalisation process and for enterprises of the future, continued sustainable development is necessary (Bluszcz, 2017), its education and corporate social responsibility (Pollok, 2015). Too great economic inequalities and concentration of capital in the world are also a problem (Piketty, 2015). Bureaucracy and the distribution of EU money without thinking, and the collection of excessive taxes and fees of any kind, do not really serve the EU as a whole and within the global market. Similarly, environmental protection in the EU, in general, results in a significant increase in production costs, which further reduces the competitiveness of EU enterprises, including Polish enterprises, in comparison to such ones as those from China. However, environmental protection in the EU is important (Muszyńska, Mazur, 2014), as well as the problems of environmental monitoring (Poskrobko, 2012). In Poland, gas and renewable energies should be subsidised more, and coal less, so that there is no smog and health problems associated with this, as well as greater resistance to viruses as part of the epidemic. In fact, Poland's coal mines are becoming deeper and more expensive. Economic development and entrepreneurial optimism are measured mainly by the GDP growth rate in $\%$, but this is not enough, because the whole welfare of people's lives, which is related to health and continued sustainable development, is not taken into account. Preferences concerning various elements of management, economy and life of selected 42 employees of SME enterprises in Małopolska region are presented in Table 3. 
Table 3.

Employees' preferences for the different elements of management, economy and life

\begin{tabular}{|l|l|c|c|c|c|}
\hline \multicolumn{1}{|c|}{ What are the most important elements in management and life yes or no? } \\
\hline Item & Elements: & $\begin{array}{c}\text { Yes } \\
\text { Generally } \\
\text { yes }\end{array}$ & $\begin{array}{c}\text { Generally } \\
\text { no }\end{array}$ & No \\
\hline 1. & Economic and financial (e.g. earnings, prices, investments, costs) & 33 & 7 & 2 & 0 \\
\hline 2. & Family & 33 & 5 & 2 & 2 \\
\hline 3. & Qualifications and experience & 26 & 13 & 3 & 0 \\
\hline 4. & Health and healthy food & 26 & 13 & 3 & 0 \\
\hline 5. & Social (e.g. social, living conditions) & 24 & 16 & 2 & 0 \\
\hline 6. & Leisure & 23 & 15 & 4 & 0 \\
\hline 7. & Ecological (e.g. clean water and air) & 22 & 15 & 3 & 2 \\
\hline 4. & Technology, knowledge, new technologies & 21 & 20 & 1 & 0 \\
\hline 9. & Work & 21 & 18 & 3 & 0 \\
\hline 6. & Legal (e.g. legislation, justice) & 14 & 19 & 9 & 0 \\
\hline 7. & Political (political system, global situation) & 7 & 18 & 17 & 0 \\
\hline
\end{tabular}

Source: Own surveys January-February 2020 in SME sector, Małopolska and Krakow.

Elements of life related to finance, family, health, qualifications, come to the fore here, but also social and ecological aspects, leisure is also very important. Less importance is attached to legal and political aspects at home and abroad. In some cases, respondents point out that technological elements are less important, which may be related to their specific work, rather not innovative, or their beliefs in modern technologies that have flaws and imbalances in the environment.

\section{Conclusion}

The basic condition for the survival of businesses, economies and people is to adapt to the prevailing changing environmental conditions. As a result of the surprise of the pandemic, this environment is changing rapidly. Hence the need to look for modern technologies not only in medicine, but also in terms of management elements, modern management concepts (Bitkowska, Weiss, 2015; McNeil, 2015), crisis management and the use of media in modern enterprise and economy (Nadolna, 2014), as well as better use of IT. The use of broad knowledge and IT to overcome pandemics or similar threats is necessary and gives its positive results for the reduction of adverse phenomena. However, it seems that it is much more difficult to resolve the economic crisis using these technologies, because a crisis or economic slowdown affects all countries of the world. It has accumulated for many years. In addition, this crisis or economic slowdown is strongly affecting precisely those countries which are using IT and modern telecommunications on a massive, widespread scale and want to follow the model of a developed global information society without borders. Important strategic products must be produced in the countries or regions concerned, and everything cannot be transferred to China, for example. 
The IT industry continues to grow, despite the pandemic and the announced adverse economic data. As you can see, there is a high demand for it and for the employees. And the socially learned behaviours of the pandemic will continue to exist even later, building further development for the IT industry. Health, work, family, economic, social and even environmental elements are of great importance to workers, as emerged from questionnaire surveys.

However, the massive use of new technologies has resulted in greater consumption of natural resources, interference with the environment and demand for energy. This causes specific problems and possibly barriers to the further development of a knowledge-based and IT-based society.

Today, companies and organisations need to make rational use of all available innovations (Kraśnicka, 2018), also in the field of IT, telecommunications, management and medicine, of course, in order to overcome the pandemic and economic crisis. It is necessary to apply the so-called modern management methods and techniques, computer-based simulation methods and decision-making in various conditions, using the concepts of research in business and management (Easterby-Smith et al., 2012; Myers, 2013). The organisations of the future will probably follow the needs of humanity in their trends, overcoming epidemics and crises, using innovations, modern technologies including IT and modern management methods. Although there are currently attempts to open economies, because there is a threat of an economic crisis, the situation with a pandemic in the world is still serious. According to data from June 2020 of the Johns Hopkins University, Baltimore, the number of people infected worldwide was over 7.4 million, and a total of 417,000 people died, including 113,000 in the USA (fakty.interia.pl/...). The second wave of the pandemic in the autumn and winter of 2020 will probably bring even more victims, the closure of borders and economies, states of emergency and the deepening of the economic crisis in many countries, especially in America, Europe and Africa. However, the Far East in Asia is already more resistant to pandemics. The next few years may, unfortunately, be similar for people and the economy due to the seasonality of the disease and the generation of successive virus mutations.

\section{Acknowledgements}

Publications and research financed from subsidies to "maintain and develop research potential", thanks to AGH University of Science and Technology, Management Faculty, Krakow, Poland. 


\section{References}

1. Bitkowska, A., Weiss, E. (2015). Wybrane koncepcje zarządzania przedsiębiorstwem. Teoria i praktyka. Warszawa: VIZJA PRESS \& IT.

2. Bluszcz, A. (2017). Metody oceny poziomu zrównoważonego rozwoju. Polska na tle Unii Europejskiej. Zeszyty Naukowe Politechniki Ślaskiej, Organizacja i zarządzanie, z. 118, Nr kol. 1983. Zabrze: Wydawnictwo Politechniki Śląskiej.

3. Borowiecki, R. (2010). Analiza i diagnostyka ekonomiczna w zarządzaniu procesem zmian w przedsiębiorstwie. In: R. Borowiecki, A. Jaki (eds.), Współczesne problemy analizy ekonomicznej. Kraków: Wydawnictwo Uniwersytetu Ekonomicznego.

4. Easterby-Smith, M., Thorpe, R., Jackson, P. (2012). Management research. London: SAGE Publications.

5. Griffin, R.W. (2010). Podstawy zarzadzania organizacjami. Warszawa: PWN.

6. https://cyfrowa.rp.pl/it/47355-firmy-technologiczne-rosna-na-pandemii-kto-zyskujenajwiecej, 30.05.2020

7. https://fakty.interia.pl/raporty/raport-koronawirus-chiny/aktualnosci/news-koronawirusuniwersytet-hopkinsa-ponad-2-mln-zakazen-w-usa,nId,4548705, 10.06.2020.

8. https://mfiles.pl/pl/index.php/Czwarta_rewolucja_przemys\%C5\%82owa, 30.05.2020.

9. https://www.computerworld.pl/news/Informatyka-a-koronawirus-Technologie-w-czasachkryzysu,420082.html, 04.062020.

10. https://www.forbes.pl/gospodarka/koronawirus-prognozy-gospodarcze-mfw/d742kyd, 30.05 .2020

11. https://www.forbes.pl/gospodarka/koronawirus-prognozy-gospodarcze-mfw/d742kyd 30.05.2020.

12. https://www.komputerswiat.pl/aktualnosci/internet/rekordowe-obciazenie-sieci-podczaspandemii-koronawirusa-w-polsce-wzrosty-o-140-proc/8t9sd3s, 30.052020.

13. https://www.obserwatorfinansowy.pl/bez-kategorii/rotator/nie-wszystkie-gospodarkiwpadna-w-recesje/, 30.05.2020.

14. https://www.pulshr.pl/zarzadzanie/kryzys-sie-skonczy-a-branza-it-urosnie-wsile, 72895.html, 05.06.2020.

15. Kalinowski, B. (2015). Wpływ dojrzałości procesowej na efektywność organizacji. Marketing i Rynek, 5. Warszawa: PWE, pp. 1030-1035.

16. Kapferer, J.N. (2012). The new strategic brand management advanced insights and strategic Thinking. Fifth edition. London: Kogan Page.

17. Kasprzak, T. (2003). Biznes i technologie informacyjne. Warszawa: Wyd. Uniwersytetu Warszawskiego.

18. Kraśnicka, T. (2018). Innowacje w zarządzaniu, nowe ujęcie. Warszawa: C.H.Beck. 
19. McNeil, A.J., Frey, R., Embrechts, P. (2015). Quantitative risk management, concepts, techniques and tools. New Jersey: Princeton University Press.

20. Muszyńska, E., Mazur, G. (2014). Unia Europejska 2014. Warszawa: Difin.

21. Myers, M.D. (2013). Quantitative Research in Business \& Management. London: SAGE Publication.

22. Nadolna, M., Skowronek-Mielczarek, A. (2014). Zarzadzanie procesami, a nowoczesne przedsiębiorstwa medialne. Warszawa: CeDeWu.

23. Piketty, T. (2015). Kapitat w XXI wieku. Warszawa: Wydawnictwo Krytyki Politycznej.

24. Pollok, A. (2015). Edukacja dla zrównoważonego i trwałego rozwoju oraz społeczna odpowiedzialność biznesu. Warszawa: Wydawnictwo PTE.

25. Poskrobko, B., Poskrobko, T. (2012). Zarządzanie środowiskiem w Polsce. Warszawa: PWE.

26. Schwab, K. (2018). Czwarta rewolucja przemysłowa. Łódź: Studio Emka.

27. Toczyski, W. (2004). Monitoring rozwoju zrównoważonego i trwałego. Gdańsk: Wydawnictwo Uniwersytetu Gdańskiego. 



\title{
THE IMPACT OF RELATIONS WITH STAKEHOLDERS ON CHANGE MANAGEMENT, INNOVATION AND COMPETITIVENESS OF THE ORGANIZATION ON THE EXAMPLE OF THE CURRENT ECONOMIC SITUATION OF ENTERPRISES IN POLAND
}

\author{
Marta WIĄCEK \\ EMBA INE PAN, CFO; mwiacek3@poczta.onet.pl, ORCID: 0000-0002-1857-3080
}

\begin{abstract}
Purpose: The purpose of this article is to systematize knowledge about organizations' relationships with their stakeholders and to highlight the connection and impact that managing these relationships and functioning in their network can have on them: an organization's capacity for innovation, change management efficiency and competitive advantage.

Design/methodology/approach: Approach to the subject of the paper is theoretical in its first part and in the second one is based on the case study methodology conducted in chosen organization in Poland. On the basis of the literature, the basic variables influencing the accumulation of effects that can be achieved by an organization that effectively uses the synergy of all mentioned phenomena have been analysed. The examples of organizations in Poland applying such activities in the current economic situation were cited.

Findings: Organisations which deal with difficult market situation should flexibly: use support from their stakeholders, take the risk of innovation and using both of the above try to implement and manage necessary changes efficiently and quickly. All these phenomena as well as the way of dealing with them make coping with hard situation easier.

Practical implications: Article's analysis and general view confirmes the significant economic and business impact on maintaining and increasing the competitive advantage of organizations using all mentioned phenomena to deal with difficulties of global market. Mentioned positive practical effects on enterprises prove how high the potential is created as a result of combining management of relations with stakeholders on competitiveness, innovation and the ability to manage organizational change.

Originality/value: The interactions and effects of the impact on the organization of: stakeholders relations, networks and change management - that have already been scientifically described many times were emphasized because only in a few sectors of the economy their' coexistence and its effects on the organization are clearly visible, observable and possible to describe.
\end{abstract}

Keywords: stakeholder relations, networks, change, change management, competitiveness.

Category of the paper: General review; Viewpoint. 


\section{Introduction}

In the primary sources, it is most often emphasized how difficult it is for companies to function in a changeable and highly competitive market environment in the conditions of constantly intensifying competitive struggle. At present, however, we can observe the opposite phenomenon of positive effects of enterprises functioning in the network of various relations with the environment. It spread widely during the viral pandemic. The companies are currently not forced to look for alternative sources of competitive advantage, but as can be observed, they gain it and maximize it through mutual maintenance of relations resulting from mutual cooperation. Thus, we are dealing with the phenomenon of multidimensional, mutual support for organizations from contract stakeholders. Its measurable effect is easier to overcome the difficult market situation and economic crisis caused by the global pandemic. Therefore, cooperation based on building lasting relationships with stakeholders has become an even more important competitive advantage. This article will systematize knowledge in this area.

\section{The Stakeholder Concept - Extract}

There are two approaches to stakeholder definition in management theory. The first, traditional approach, assumes that these are "owners" who have a dominant and direct influence on the functioning of the entity (Downar, Niedzielski, 2006; Freeman, 2013). The second one, on the other hand, assumes a broader perspective on stakeholder issues. It assumes that these are "entities (individuals, communities, institutions, organizations, offices) that can influence and are influenced by the company" (Freeman, Moutchnik, 2013). Thus, they are specific, identifiable entities that constitute the environment of a company, enter into direct or indirect relations with it of various kinds and can facilitate or hinder its functioning (Downar, Niedzielski, 2006). This concept was introduced to the management science by R.E. Freeman using it for the first time in 1979 in his work "Strategic Management: A Stakeholder Approach". (Freeman, 1984) He defined stakeholders as "any individual or group that can influence or be influenced by an organization in pursuit of its goals. An important element of this definition is the impact that exists between stakeholders and the organization. It can be diverse in nature. Stakeholders can influence a particular organization, and an organization can influence its stakeholders. Donaldson's and Preston's definition of a stakeholder is also relevant to this discussion, which means that stakeholders are individuals or groups that have direct or indirect contracts with an organization. If a contract is defined broadly as an informal or formal contract that binds both parties (the organization and its stakeholders), then it can be concluded that a stakeholder can be virtually any element of the organization's proximate and distant 
environment. As a result of such an approach to the definition of an organization's stakeholder, the contractual context in which the relationship is embedded will be important. The provisions of the agreement may limit or inversely impose the type of mutual cooperation, determine mutual interactions and influences. Moreover, it should also be noted here that in the case of contractual relations, the whole organization is not always the subject of interaction with a stakeholder. Very often, in economic practice, it can only be a specific process, a system element or a project limited in time (Civera, Freeman, 2019). However, most often, in the environment of most companies currently operating on the market, classic groups of stakeholders can be distinguished:

- customers, suppliers;

- employees, owners;

- NGOs;

- local communities;

- investors;

- banks, media, state administration.

Depending on the sector of the organization's activity, each of these groups has a different weight for a given entrepreneur. The literature on the subject also lists several other possible ways of classifying the stakeholders and thus making their division into groups according to several criteria. From the point of view of this analysis the most important criterion is the type of relationship existing between the stakeholders and the organization. It allows to classify the stakeholders into:

- Consubstantial stakeholders - these are the entities that co-create the organization and operate within it, such as employees, owners, shareholders.

- Contractual stakeholders - their relations with the organization are based on business, contractual activities, e.g. suppliers, various types of cooperators.

- Contextual stakeholders - they do not have direct contact with the organization, most often they are groups working for the benefit of communities, influencing a positive image and acceptance of the company's activity on the market. Examples are local and social communities or institutions.

The classification presented above is shown in Figure 1.

\begin{tabular}{|l|l|}
\hline Consubstantial stakeholders & $\bullet$ employees \\
& $\bullet$ owners \\
\hline Contractual stakeholders & $\bullet$ recipients \\
& $\bullet$ suppliers \\
& $\bullet$ financial institutions \\
\hline Contextual stakeholders & $\bullet$ competitors \\
& $\bullet$ public administration \\
\hline
\end{tabular}

Figure 1. Stakeholder breakdown by type of relationship with the company. Source: Rodriguez, M.A., Ricar, J.E. (2002). Towards the sustainable business. Revista de Antiquos Alumnos, IESE Universidad Navarra, 86, 30-32. 
Consubstantial stakeholders have a close relationship with the organization. They are strongly connected with the organization and are usually personally involved in its development. Contractual stakeholders are those entities or individuals who, on the basis of ongoing contracts or orders, cooperate with the organization on a more or less long-term basis. These entities are interested in its further welfare. Sometimes, depending on the relationship they have built, they may also be involved in maintaining and developing it. Contextual stakeholders will be more closely associated with the organization if it operates in a strong relationship with local communities. This bond, or relationship, is a two-way impact between cooperating stakeholders and the organization. This relationship can take many forms. Starting from direct market contact, through the relationship resulting from an existing agreement between the entities or other formalized business relationship such as for example: strategic alliance, cluster or consortium. It therefore includes cooperation aimed at achieving the objectives of both parties. It is therefore a phenomenon characterized by bilateralism, voluntariness and active involvement in the existing relationship (Wiatrak, 2014). The multidimensionality and duality of the relationship causes that this type of relationship between entities can be both cooperative and competitive. From the point of view of an organization, it may have more or less value for it. It can be created by material expenditure, i.e., simply real material benefits, investments that have to be made in order to execute this relationship, or non-material investments that have to be incurred in order to actually confirm the existence of a relationship between organizations. In the context of analyzing its value for an organization, in simple terms, this is the difference between the benefits it can derive from it and the expenses it must incur to sustain it (Zeithaml, 1988; Piwoni-Krzeszowska, 2013). The sources of relations should be sought in the following dimensions of the organization:

- $\quad$ economic - gives the possibility to reduce costs or increase revenues;

- $\quad$ product or service - allows to increase the value of the relationship meeting the needs of entities;

- beahavioural - intangible aspects such as maintaining trust, culture of relations, its further development;

- organizational - enables realization of processes between entities in relation to synchronization of standards, information exchange processes, etc.;

- $\quad$ strategic - strengthening of competitive advantage, strengthening key competences, creating market position (Piwoni-Krzeszowska, 2013).

The value of the relationship as many other types of assets owned by the organization can be managed. This enables the organization to build a wide range of relations with other entities from the environment - optimal and useful for it at a given strategic moment. In order to maximize the desired effects, it is necessary to map the sources of relationship value and establish, in a thoughtful way, a strategy for managing the relationship itself. Only such action will allow to generate the benefits expected by the organization in a longer time spectrum (Piwoni-Krzeszowska, 2013). Stakeholder relationship management is a process which - 
to enable the organization to identify, build and maintain relations - should be carried out according to the following stages:

- identification of stakeholders with a distinction between external and internal stakeholders;

- $\quad$ analysis and diagnosis of interests/goals;

- formulation of appropriate strategies;

- $\quad$ implementation of the strategy (Downar Niedzielski, 2006).

Properly conducted diagnosis and stakeholder analysis will lead to the creation of opportunities to manage the relationships arising or already existing between them and the organization. It will also make it possible to establish a hierarchy of their importance, diagnosing the risks associated with their existence. A well-thought-out relationship management strategy can lead to a higher expected added value for the organization. The increase of relationship potential, achieved by appropriate relationship management and its value, can also be maximized. To this end the organization should use the factors influencing the relationship. The following groups are distinguished in the literature:

- relationship factors independent of the organization - they are beyond the possibility of shaping their influence on the company being a party of the relationship;

- relational factors depending on the organization which is a party to the relationship, e.g. satisfactory commercial conditions, readiness to synchronize, improving reputation, recommending to other entities, using informal relations, trust, loyalty, offering discounts, installment sales; informing the market about a joint offer or cooperation.

A consequence of striving for thoughtful relationship management and increase in its value is also the possibility of developing a model of stakeholder relationship management adapted to the specificity of a given company. An exemplary management model is presented in Table 1.

Table 1.

Organisation Relationship Management Model

\begin{tabular}{|l|l|}
\hline 1. Planning & Execution stage \\
\hline Preparatory stage & $\begin{array}{l}\text { - internal and inter-organisational arrangements } \\
\text { - activation of the relationship conditions } \\
\text { - evaluation }\end{array}$ \\
\hline $\begin{array}{l}\text { - reflection on the role of relationships } \\
\text { - analysis of company potential }\end{array}$ & Execution stage \\
\hline 2. Organising & \begin{tabular}{l} 
- coordination in the area of processes, structures, \\
strategies \\
\hline Preparatory stage
\end{tabular} \\
\hline $\begin{array}{l}\text { - selection of entities and forms of cooperation } \\
\text { - collaboration } \\
\text { - design of information and decision making } \\
\text { systems }\end{array}$ & - evaluation \\
\hline
\end{tabular}


Cont. table 1.

\begin{tabular}{|l|l|}
\hline 3. Motivating & Execution stage \\
\hline Preparatory stage & $\begin{array}{l}\text { - exchange of information and experience } \\
\text { - system of values and relational norms } \\
\text { - implementation of the incentive system } \\
\text { - evaluation }\end{array}$ \\
\hline $\begin{array}{l}\text { - developing an incentive system } \\
\text { - identification of motivational incentives }\end{array}$ & Execution stage \\
\hline 4. Control & $\begin{array}{l}\text { - current assessment of the status of relations } \\
\text { - deviation analysis } \\
\text { - expected status of the relationship }\end{array}$ \\
$\begin{array}{l}\text { - ratings } \\
\text { - monitoring }\end{array}$ & $\begin{array}{l}\text { - evaluation } \\
\text { - scenarios of possible events }\end{array}$
\end{tabular}

Source: Own elaboration on the basis of the study: Danielak 2018.

It should be individually adapted to the specificity of the organization itself and the environment in which it operates. The phenomenon of the existence of relations between the organization and its stakeholders has now become one of the most important tools enabling the organization to build and manage not only the relations themselves and their value. The epidemiological situation related to the occurrence of a viral pandemic in the world has highlighted the importance and positive impact that this phenomenon may have on the competitive advantage and perception of the organization on the market. Moreover, as the practice has shown, the difficult economic situation has naturally tightened the existing bonds and deepened them by showing and giving mutual support both material and non-material. Business advantage and benefit have begun to be seen by organizations that cooperate or even compete with each other as providing mutual support for the survival of the stakeholder in a complex situation. What is more, granting various types of support has become one of the factors enabling to build a positive image of the organization and, consequently, an intangible market advantage.

\section{The impact of stakeholder relations on change and innovation management in the organisation}

Modern organizations establish and maintain relationships with other entities because the value they possess makes it easier for them to function in a competitive economy. Moreover, it enables and even facilitates stimulation or achievement of innovation. Therefore, it also has an impact on whether and how the organization manages the broadly understood process of change.

Relations with external entities, as already mentioned, are determined by a wide range of factors, but from the point of view of this article the most important is their value, i.e. the potential of the bond built. It is the one that contributes to stimulating or even initiating and further developing the organization's innovativeness. Thus, it may stimulate its propensity 
to take risks related to generating and implementing broadly understood innovations (Wiącek, 2020; Pichlak, 2012). The entity's potential for such activities is determined mainly by various factors implying changes in the organization, as well as inter-organizational relations with their network value potential (Downar, Niedzielski, 2006; Rzepka, Olak, 2017). Therefore, they usually enable, through more effective, skillful use of intangible resources such as knowledge, technology or experience, to initiate or maintain the innovativeness of the company and the potential for optimal implementation of widely understood changes. The consequence of this combination of influence is most often a significant improvement in the competitive position of such an organization (Smolarek, 2010; Tidd, Bessant, 2013; Wiącek, 2020). However, it should be stressed at this point of consideration that the contemporary understanding of the sources of innovation and change, which differs significantly from the one initially used in the literature, is very important (Smolarek, 2010; Tidd, Bessant, 2013; Wiącek, 2020). It was once believed that innovations arise only inside the organization itself and are the result of its use of various own assets. Nowadays, however, it is believed that the innovativeness of an organization is not only a result of its internal resources, but also, or rather, above all, of the optimal use of external resources coming from cooperation between enterprises (Wiącek, 2020). In order to achieve or maximize such an effect, an organization must establish and maintain relationships (Luecke, 2005; Sankowska, 2009) within the market network of economic relations in which it operates (Czakon, 2007). The organization's membership in various formal and informal business groups, such as the so-called SNA Market Networks in the literature, as well as relationship management has a positive impact on creating and implementing innovation and change (Dewick, Miozzo, 2004; Aarikka-Stenroos, Sandberg, Lehtimäki, 2014; Kim, Lui, 2015). The functioning of an organization in a network of relations, i.e., in the system of relations with other entities with which it cooperates (Czakon, 2017) significantly facilitates the innovativeness of the organization and thus the sharing of knowledge, conducting research or increasing access to resources, especially if they are unique. Such issues as dissemination on the market of information about innovations created by the organization and designed changes, i.e. promoting them, are also important for maintaining the organization's market advantage. It significantly facilitates this process and thus accelerates the benefits of sharing such business information by other entities that are co-workers of the organization and thus the previously described stakeholders. Therefore, in order to maximize the effects of its innovation, also currently called market agility, according to Czakon the organization should:

- create relationships with other organizations operating in its environment;

- ensure that all subjects of the relationship are kept separate so that each of them independently pursues their own goals;

- exchange resources by means of continuous interaction with the entities from the environment. In this way it will naturally create a common knowledge and experience base for itself and its stakeholders. The "exchange platform" that will be created in this 
way will enable synergy of strategic activities undertaken by all organizations participating in the process;

- generate innovation only through active interaction with other entities. This will create a competitive advantage created by the existence and maintenance of ties.

The way, the method by which an organization will make the described interactions is its individual, distinctive model of managing relations, changes and innovations with their potential. These activities are carried out using its unique way of interaction, coordination and effective communication (Czakon, 2017). The modern organization is therefore dependent on effective cooperation with other entities related to it in many aspects affecting its strategic advantage. On the basis of these ties, it can create and develop its own value, increase its competitiveness, and influence the facilitation of its operations in unfavorable market circumstances. Therefore, network structures and relations existing in them positively influence development and innovation. They facilitate and stimulate changes in the organization that are inseparable from innovation. These are phenomena which, as the literature indicates, are interconnected and permeate each other, significantly influencing the construction and maintenance of the strategic advantage of the organization. In the case of the change management phenomenon, a deep connection with the theory of stakeholders needs to be emphasized. Analyzing the causes of change, a common source of both phenomena is easily noticeable. It is enough to analyze the factors determining the organization's propensity to change. They are simply divided into external and internal ones (Zarębska, 2002). The internal ones, which are the result of management decisions, are aimed at further development of the organization, while the external ones are the result of events independent of the organization itself. Such events, which occurred in the environment and caused or even forced the organization to adapt. The changes taking place in the organization's environment affect all areas of its functioning. According to J. Penc, "they force a specific transformation and adjustment to the structure and potential of the environment. They cause the company to often reject what was effective in the past and even "invent" the future, transform itself and create itself anew in order to be able to realize its objectives and better serve its environment and at the same time itself" (Zając, 2006). The most important external factors causing change in the organization are presented in Table 2. Thus, external factors that are a direct source of change force the organization to strive for greater innovation. Relationships with their potential, properly used and managed, can significantly support the functioning of the organization in the situation of implementation of change or reaction to its effects if it comes from outside the organization. Another noticeable implication is the resulting conclusion that the functioning of an organization in a network of relations can contribute quite significantly to such activities. Table 3 presents a summary of a case study conducted by the author of this article in March 2019 on the example of one of the Polish organizations operating in the bottling sector. 
Table 2.

External factors causing change in the organization

\begin{tabular}{|c|c|}
\hline Company environment & Change inducing/shaping factors \\
\hline $\begin{array}{l}\text { International } \\
\text { environment }\end{array}$ & $\begin{array}{l}\text { - } \quad \text { Political changes in Europe and the world } \\
\text { - } \quad \text { Raw material crises } \\
\text { - Integration and disintegration processes }\end{array}$ \\
\hline $\begin{array}{l}\text { International and national } \\
\text { economic situation }\end{array}$ & $\begin{array}{l}\text { - } \quad \text { Globalisation of economies } \\
\text { - } \quad \text { Strket Virtualization } \\
\text { - } \quad \text { Increased customer requirements }\end{array}$ \\
\hline Legal environment & Tax, customs, labor laws that stimulate or inhibit entrepreneurship and job creation \\
\hline Market forces & $\begin{array}{l}\text { - } \text { Globalisation of markets } \\
\text { - } \text { Market Virtualization } \\
\text { - Strong increase in competition } \\
\text { - Increased customer requirements }\end{array}$ \\
\hline Social and cultural trends & $\begin{array}{l}\text { - Demographic phenomena } \\
\text { - Social values } \\
\text { - Lifestyle }\end{array}$ \\
\hline Technological changes & $\begin{array}{l}\text { - } \quad \text { Rapid IT development } \\
\text { - } \quad \text { New solutions for materials, processes and products }\end{array}$ \\
\hline Ownership changes & $\begin{array}{l}\text { - Sale of companies } \\
\text { - Acquisitions, mergers } \\
\text { - Privatisation of companies }\end{array}$ \\
\hline Ecology & $\begin{array}{l}\text { - Changes in the environment } \\
\text { - Environmental legislation } \\
\text { - Eco-movements }\end{array}$ \\
\hline
\end{tabular}

Source: Own elaboration on the basis of study conducted by the author in march.2019 in one of the Polish organisations operating in the bottling sector, Wiącek 2020, Bibliography position no 27.

Table 3.

Existing relationships and their impact on company competitiveness

\begin{tabular}{|c|c|c|c|}
\hline \multicolumn{2}{|l|}{ Type of relationship } & Reasons & Impacts \\
\hline \multirow{6}{*}{ Regional Stakeholders } & \multirow[t]{3}{*}{ Consubstantial } & $\begin{array}{l}\text { availability of cheap labour } \\
\text { directly at the site of the } \\
\text { production plant }\end{array}$ & $\begin{array}{l}\text { the possibility to flexibly } \\
\text { adjust the level of } \\
\text { production and the level of } \\
\text { employment required to } \\
\text { achieve it }\end{array}$ \\
\hline & & $\begin{array}{l}\text { commitment to work - the } \\
\text { only large employer in the } \\
\text { area }\end{array}$ & lower staff turnover \\
\hline & & employment for families & \\
\hline & \multirow{3}{*}{ Contractual } & $\begin{array}{l}\text { reduction of product } \\
\text { manufacturing costs }\end{array}$ & higher final margins \\
\hline & & short delivery time & $\begin{array}{l}\text { - speeded production } \\
\text { - higher turnover of goods } \\
\text { - Speeder and more effective } \\
\text { adaptation of Krynica } \\
\text { Vitamin S.A. to the } \\
\text { changing market situation }\end{array}$ \\
\hline & & $\begin{array}{l}\text { the supplier has a stable and } \\
\text { predictable source of sales } \\
\text { of its products }\end{array}$ & $\begin{array}{l}\text { higher than the market } \\
\text { tendency for flexibility in } \\
\text { commercial cooperation } \\
\text { with the customer Krynica } \\
\text { Vitamin S.A. }\end{array}$ \\
\hline
\end{tabular}

Source: Own elaboration on the basis of study conducted by the author in march.2019 in one of the Polish organisations operating in the bottling sector, Wiącek 2020, Bibliography position no 27. 
The results of this study prove that having relations by an organization not only increases its innovativeness and competitiveness, but also facilitates the management and implementation of changes of different nature. Therefore, it is important for an organization not only to consciously establish relations, but to do so it should have knowledge about what can determine them and how they can successively influence the advantage and innovativeness. A review of the selected scientific views that link building relationships with stakeholders, their determinants and the impact on the competitive advantage of the company is presented in Table 4.

Table 4.

Determinants for strengthening competitiveness and relationship management activities

\begin{tabular}{|c|c|c|}
\hline $\begin{array}{l}\text { Type of } \\
\text { regional } \\
\text { stakeholder }\end{array}$ & $\begin{array}{l}\text { Determinants for strengthening } \\
\text { the competitiveness of the company }\end{array}$ & $\begin{array}{l}\text { Relationship management activities that } \\
\text { can provide a competitive advantage }\end{array}$ \\
\hline \multirow[t]{2}{*}{ Consubstantial } & \multirow{2}{*}{$\begin{array}{l}\text { Economies of scale, reach, increased } \\
\text { flexibility of the organization, building a } \\
\text { positive market reputation, increased } \\
\text { effectiveness of change management }\end{array}$} & $\begin{array}{l}\text { Two-way internal communication, action } \\
\text { consulting }\end{array}$ \\
\hline & & $\begin{array}{l}\text { Building commitment, empowerment in the } \\
\text { decision-making process }\end{array}$ \\
\hline \multirow[t]{2}{*}{ Contractual } & \multirow{2}{*}{$\begin{array}{l}\text { Maximize margin, reduce risk, increase } \\
\text { flexibility, accelerate response to market } \\
\text { changes, economies of scale, facilitate } \\
\text { expansion, build a positive market reputation }\end{array}$} & Creating alliances or business partnerships \\
\hline & & $\begin{array}{l}\text { Joint building of mutually beneficial } \\
\text { conditions for cooperation and development } \\
\text { of partners }\end{array}$ \\
\hline
\end{tabular}

Source: Own elaboration on the basis of study conducted by the author in march.2019 in one of the Polish organisations operating in the bottling sector, Wiącek 2020, Bibliography position no 27.

In the current market and economic situation prevailing in Poland, we can perfectly observe the materialized positive effects of the combination of relationship management with stakeholders, the functioning of enterprises in the network together with innovation and willingness to implement changes. Organizations that had relationships with their stakeholders and the ability to manage them more easily thanks to cooperation with partners coped with the difficulties of the economic situation during the pandemic.

Frequent mutual exchange of experience has led to the dumping of innovative solutions, services or products (nettg.pl, 2020; pb.pl, 2020). As a result, an increase in export dynamics was already recorded in June this year, which, as estimated by economists associated in the Polish Chamber of Commerce, was to be expected much later this year due to the global epidemiological situation (nettg.pl, 2020). Moreover, according to the projection published by the National Bank of Poland, thanks to the flexibility of Polish organizations' ability to react quickly to changes in their environment, the Polish gross domestic product, after the initial decline recorded this year, will gradually increase by $4.9 \%$ in 2021 and $3.7 \%$ in 2022 . It should also be noted that compared to the results of other EU countries, the Polish gross domestic product, which in the second quarter decreased by 8.2 percent year-on-year and 8.9 percent compared to the previous quarter, remains at a very high level (GUS, 2020). Poland recorded one of the lowest declines in the EU. Naturally, this was also influenced by an early and rapid response to the pandemic situation, the introduction of restrictions, but also - or above all - 
it was precisely the flexible, innovative, corporate behavior that made the effects of the crisis caused by the global crisis less severe. A very good example of this type of action were all those companies that started to spill disinfectants (Orlen, bottling industry, cosmetics) or sew protective masks (clothing industry) according to their own technical capabilities. To sum up, therefore, in a situation which was difficult for all market players, it was easier to cope with the survival of those who did:

- they had support from their stakeholders,

- have the inclination and courage to take the risk of innovation,

- thanks to both of the above, they were competent to implement and manage the implementation of the change efficiently and quickly.

All these phenomena as well as the way of dealing with them were a flexible response to factors from the organization's environment and derived from cooperation with stakeholders in the network.

\section{Summary}

1. The correct and accurate identification of stakeholders and the establishment of effective communication with them undoubtedly contributes to increasing the effectiveness of the strategic objectives of the company.

2. Proper management of the relations that arise between them and the organization contributes to the creation of measurable benefits for the company. It undoubtedly increases the organization's propensity for change and innovation. It brings with it the special value that they constitute in the modern economy: effective interorganizational communication, consultation, partnership and dialogue.

3. Relations - optimally maintained and managed nowadays - has a significant positive impact on the continuation of the whole company, increasing and improving its flexibility.

4. The flexible using of combination advantages of all the phenomena mentioned in the article contribute to the easier overcoming of market difficulties by the organization and may contribute to its success at the end. However, it should be emphasized that, in the author's opinion, only combined all together may provide great business success. 


\section{References}

1. Aarikka-Stenroos, L., Sandberg, B., Lehtimäki, T. (2014). Networks for the Commercialization of Innovations: A Review of how Divergent Network Actors Contribute. Industrial Marketing Management, no. 3.

2. Civera, C., Freeman, R.E. (2019). Stakeholder Relationships and Responsibilities: A New Perspective. Symphonya, Emerging Issues in Management (symphonya.unicusano.it), $1,40-58$.

3. Czakon, W. (2017). Sieci w zarządzaniu strategicznym. Warszawa: Oficyna Wydawnicza Wolters Kluwer Business.

4. Danielak, W. (2018). Zarządzanie relacjami z interesariuszami w środowisku projektowym. Wydawnictwo Politechniki Gdańskiej, 24, No. 1, 47-60.

5. Dewick, P., Miozzo, M. (2004). Networks and Innovation: Sustainable Technologies in Scottish Social Housing. R\&D Management, no. 3.

6. Donaldson, T., Preston L.E. (1995) The Stakeholder Theory of the Corporation: Concepts, Evidence, and Implications, Academy of Management Review. 20 (1): 71.

7. Downar W., Niedzielski, P. (2006). Zarządzanie interesariuszami jako instrument wspomagający realizację projektów gospodarczych w transporcie. Zeszyt Naukowy Uniwersytetu Szczecińskiego Współczesne zjawiska i procesy $w$ transporcie. Szczecin: Uniwersytet Szczeciński.

8. Freeman, R.E., Moutchnik, A. (2013). Stakeholder management and CSR: questions and answers. Umwelt Wirtschafts Forum, Vol. 21, No. 1. Springer Verlag.

9. https://nettg.pl/news/169955/polska-gospodarka-niezle-sobie-radzi-z-pandemia, 29.08.2020.

10. https://www.pb.pl/bujak-polska-gospodarka-znosi-relatywnie-dobrze-kryzys-wywolanypandemia-999402, 29.08.2020.

11. Kim, Y., Lui, S. (2015). The impacts of external network and business group on innovation: Do the types of innovation matter? Journal of Business Research, no. 9.

12. Klimas, P. (2014). Sieci innowacji. Implikacja bliskości organizacyjne. EU Publishing House in Katowice.

13. Kodama, M. (2007). Innovation and Knowledge Creation Through Leadership-based Strategic Community: Case Study on High-tech Company in Japan. Technovation, no. 3.

14. Luecke, R. (2005). Zarządzanie kreatywnością i innowacją. Czarnów: MT Biznes.

15. Pichlak, M. (2014). Wpływ otoczenia na generowanie i przyjmowanie innowacji w organizacjach. Przeglad Organizacji, $n r$ 5(892), s. 7-12, Towarzystwo Naukowe Organizacji i Kierownictwa (TNOiK), www.przegladorganizacji.pl.

16. Piwoni-Krzeszowska, E. (2013). Zarzadzanie wartościa relacji przedsiębiorstwa z rynkowymi interesariuszami. Wrocław: Publishing House of the Wrocław University of Economics. 
17. Rodriguez, M.A., Ricar, J.E. (2002). Towards the sustainable business. Revista de Antiquos Alumnos, IESE Universidad Navarra, 86, 30-32.

18. Rzepka, A., Olak, A. (2017). Wpływ relacji międzyorganizacyjnych na pobudzenie innowacyjności przedsiębiorstw. Przedsiębiorczość i Zarządzanie, Vol. XVIII, Book 4, Part I, p. 61-71, Wydawnictwo SAN.

19. Sankowska, A. (2009). Organizacja wirtualna: koncepcja i jej wpływ na innowacyjność. Warszawa: Wydawnictwo Akademickie i Profesjonalne.

20. Smolarek, M. (2010). Znaczenie zmian innowacyjnych w kontekście strategii małych i średnich przedsiębiorstw. In: P. Niedzielski, J. Guliński, K.B. Matusiak (eds.), , Zeszyty Naukowe, Kreatywność - Innowacje - Przedsiębiorczość, no. 579. Wydawnictwo Uniwersytetu Szczecińskiego.

21. Sopińska. A., Jakubowska. W. (2013). Zasoby a konkurencyjność i wyniki przedsiębiorstwa - przegląd wybranych badań. In: R. Bartkowiak, P. Wachowiak (eds.), Wiedza i bogactwo narodów. Kapitał ludzki, globalizacja i regulacja w skali światowej. Warszawa: Oficyna Wydawnicza SGH.

22. Tidd, J., Bessant, J. (2013). Zarządzanie innowacjami: integracja zmian technologicznych, rynkowych i organizacyjnych. Warszawa: Wolters Kluwer Business.

23. Walecka, A., Zakrzewska-Bielawska, A. (2013). Organizacja w procesach zmian w drodze do elastyczności i innowacyjności. In: A. Adamik (eds.), Nauka o organizacji. Ujęcie dynamiczne. Warszawa: Wolters Kluwer Business.

24. Wiącek, M. (2020). Implementation of innovative changes in Polish enterprises outline of perspectives, review of research. Internatinal Journal of Business Management and Economic Review (IJBMER), JAN-FEB, vol. 3 iss. 1, 78-96.

25. Wiącek, M. (2020). Optymalizacja procesów w przedsiębiorstwie produkcyjnym jako skutek implementacji zmiany. Dylematy $i$ wyzwania doskonalenia zarzadzania organizacjami $w$ dobie przemystu 4.0. A., Lemańska-Majdzik, M., Okręglicka, A. Korombel (eds.), cz. III, rozdział 18. Częstochowa: Wydawnictwo Politechniki Częstochowskiej; ISBN 978-83-7193-749-1.

26. Wiącek. M. (2020). Zmiany techniczno-technologiczne na tle specyfiki zjawiska zmian organizacyjnych w przedsiębiorstwach. Inżynieria Zarzadzania. Cyfryzacja Produkcji. Aktualności badawcze 2, issue I; chapter 4. Knosala R. (ed.). PWE, pp. 443-455.

27. Wiatrak, A.P. (2020). Więzi międzyorganizacyjne. Problemy zarządzania, http://pz.wz.uw.edu.pl/pl/numer/wiezi-miedzyorganizacyjne, 21.08.2020.

28. Zając, Cz. (2006). Społeczne i organizacyjne problemy przejęć i fuzji przedsiębiorstw. Wrocław, WAE.

29. Zarębska, A. (2002). Zmiany organizacyjne w przedsiębiorstwie. Warszawa, Difin.

30. Zeithaml, V. (1988). Consumer perceptions of price, quality and value: a means-end model and synthesis of evidence. Journal of Marketing, vol. 52, pp. 2-22. 



\title{
RESEARCH METHODS AND TECHNIQUES APPLIED DURING PREPARATION OF REGIONAL INNOVATION STRATEGIES OF POLISH REGIONS
}

\author{
Dariusz WYRWA \\ Rzeszow University of Technology, The Faculty of Management; dwyrwa@prz.edu.pl, \\ ORCID: 0000-0003-1327-795X
}

Purpose: Review of regional innovation strategies of Polish regions to assess the scope of research methods and techniques applied during their preparation.

Design/methodology/approach: Analysis of regional innovation strategies applicable in all voivodeships with respect to the research methods and techniques used during their preparation. Findings: Polish regions apply diversified methods and techniques that allow them to determine the directions of innovation development, yet in the course of smart strategy identification they encountered limitations with respect to the availability of quantitative aggregated data on the voivodeship or lower levels; therefore, some of them reached to surveys and interviews, as well as the Delphi method which allowed for mitigating the impact of these deficiencies. The regions did not focus exclusively on fulfilling the ex ante condition, but they were intent on proper designation of the priority areas with respect to the aid, which is testified by, among others, reaching to results of foresight type projects and up-dates of the prepared strategies.

Originality/value: A comprehensive review of regional innovation strategies applicable in the Polish regions until 2020 and a concise analysis of methods and techniques applied during their preparation as a starting point for the improvement of processes of preparation of subsequent innovation strategies in voivodeships.

Keywords: regional innovation strategy, smart specialisation.

Category of the paper: research paper.

\section{Introduction}

The first Polish regional innovation strategies (RIS) were prepared as part of the 5th Framework Programme of the European Union thanks to the RIS-NAC (Regional Innovation Strategy Projects in Newly Associated Countries) projects. Five voivodeships (Opolskie, Śląskie, Warmińsko-Mazurskie, Wielkopolskie and Zachodniopomorskie) started to work on them in 2002. Subsequent financial strategies were financed by the Ministry of Science 
and Digitisation and the 6th Framework Programme of the European Union, thanks to which in 2005, 15 out of 16 Polish voivodeships implemented regional innovation strategies (Matusiak, 2005). The last region to adopt the strategy in 2008 was the Mazowieckie voivodeship.

The European Union regions implement regional innovation strategies due to the fact that they may foster innovation of regions, and in consequence their competitiveness, which is essential in the context of functioning in a globalised economy. Development of the concept of smart specialisation requires designation of priority areas as part of which aid is concentrated. Their identification calls for selection and application of proper research methods and techniques.

\section{Innovation Policy of the European Union in Global Economy}

The formation of international economy is greatly impacted by globalisation processes, which started to intensely develop in the second half of the 20th century, and in Europe in particular in the 1980s and 1990s, which may have been affected by the socio-economic transformation in the Central and Eastern Europe (Herodowicz, 2018).

According to A. Stabryła, globalisation in general means "significant and complex processes which take place on a global scale, which constitute a higher, more advanced and complex stage of the process of internationalisation of economic operation and which exert a fundamental impact on the present and future growth of international economy, its directions and nature" (Stabryła, 2009). Some authors define it by taking into account the perspective of its effects as increased flow of goods, services, capital, people and information across borders (Jacoby, and Meunier, 2010). According to G.W. Kołodko, it is related to the liberalisation and the progressing integration of markets operating in a certain separation into a single international market (Kołodko, 2007). As a result of it, national markets are losing their significance, as they are becoming more linked by the exchange of goods and services, along with the flows of capital and technology. Globalisation is a process that encompasses various areas, but usually its economic dimension becomes the basic object of dialogue. It is characterised by increased exchange of products and growth of inter-dependence of national economies (Surugiu, Surugiou, 2015).

Globalisation in the economic approach is perceived as a beneficial process. Elimination of barriers and development of the global market is conducive to the popularisation of modern production technologies and introduction of innovations. Increased competitiveness and international investments activate economies, whereas the developing cooperation integrates people from different cultures. Elimination of barriers is conducive to the free movement of people and goods, which takes place in ever-shortening time (Grzybowska, 2013). Nevertheless, one cannot overlook the dangers that it poses for national economies. As a result 
of globalisation, the global economy is divided into the centre, which comprises well-developed economies with the largest trans-national economies, and the periphery, which is often the outlet market for the products manufactured on the basis of technologies created by entities that make up the centre. Faced with global competition, numerous domestic enterprises turn out to be too weak to export their products and services. Highly qualified employees often emigrate from the peripheral areas in order to find better conditions for pursuing their professional career in the centre (Brożyk, 2006).

Since the onset of intensified globalisation processes, the European Union has been taking action to become a part of them and to accomplish the best possible results in the economic sphere. Benefits which the community derives from it are highlighted. It is estimated that the European Union's share in the global export exceeds $15 \%$, out of which over $80 \%$ is the production of small and medium-sized enterprises. Additionally, in 2017 export outside of the EU supported approx. 35 million jobs in the Union (Facts...). The European Union is striving to maximise benefits resulting from globalisation, simultaneously alleviating its negative effects. Integration as such was already the basis. To this aim, various steps are taken which would allow for the management of globalisation. One of them is creation of new policies and instruments which could allow for using the opportunities which are offered by the global market (Jacoby, and Meunier, 2010). An example may be provided by the continually pursued innovation policy, which is aimed at ensuring growth of competitiveness of the EU economy on the international arena, given the fact that it is essential in the competition with other economies, in particular the USA and Japan.

\section{Regional Innovation Strategies in the European Union}

Issues related to the innovation development process are the object of studies the purpose of which is analysis of its determinants (Conway, and Steward, 2009). For years, politicians and scientists around the world have been focusing on building innovation systems in a mode that allows for proper use of knowledge and learning (Lundvall, 2007). They are meant to reinforce the economy and to increase its competitiveness. Competitiveness of enterprises and economies does not, however, have to be tantamount to their innovation, as there may be other modes of improving it than via development of innovation (de Jong, 2011). Innovation and competitiveness are under the impact of various factors (Siqueira, and Cosh, 2008); nevertheless, the justifiability of creating innovation strategies which could adequately stimulate development of individual entities and entire economies is not questioned (Clark, and Guy, 1998; Bowonder, Dambal et. al., 2010; Weresa, 2012; Moen, Tvedten et al., 2018). However, it should be noted that this requires building of innovation capacity (Nogalski, and Karpacz, 2012). 
Nevertheless, the European Union is characterised by significant diversity in the level of economic development, not only on the level of member states, but also regions. Therefore, the innovation policy is also implemented on the regional level, and its instruments are regional innovation strategies. The first projects aimed at their preparation were launched in Europe between 1993 and 1994 and bore fruit in the drawing up of documents known as the regional technological plans, in order to reach the number of approx. 150 implemented strategies in the regions in the course of the next 15 years (Third report..., 2004).

In 2013, the obligation of preparation of regional innovation strategies by the EU regions was introduced, which constitutes the ex ante condition that allows for the use of the funds of the European Regional Development Fund (ERDF). In line with the regulation, during preparation of a strategy, a SWOT analysis or a similar method is to be applied in order to focus the resources on the limited set of priorities of research and innovations (Regulation..., 2013). An additional requirement allowing for such concentration was inclusion of the so-called smart specialisations (Foray, 2009). Earlier, the created innovation strategies traditionally focused on horizontal activities and policies aimed at improvement of general conditions and possibilities of innovation development, such as the R\&D infrastructure, human capital, reinforcement of scientific centres. Apart from horizontal actions, the new approach to the formation of the innovation policy in the regions based on smart specialisations makes the regions liable for taking into account a more vertical (and previously quite not-neutral) intervention logic, in the formation of which the process of identification and selection of its desired areas was important (based on technology, areas and sub-systems which should be treated as priorities as part of a regional policy) (Foray, and Goenega, 2013). The analysis of the first regional innovation strategies prepared in the European Union showed the limitations and weaknesses in the process of their preparation (Capello, and Kroll, 2016). It was necessary to apply a new approach to identify the priority areas. Initially, the concept of a smart specialisation was not well described and did not have a proper theoretical background, in particular with respect to methodology and methodics; therefore, regions started to individually work out the methods of their selection. Three different approaches were used, i.e. relying on quantitative, qualitative and mixed methods. The procedural nature of the concept of smart specialisation requires application of qualitative analyses; however, these methods are considered less rigorous or offering less objective results for the formation of an innovative policy than quantitative methods. In relation to this, development of the mixed approach is recommended (Fellnhofer, 2017; Griniece, and Panori, 2017). 


\section{Use of Research Methods and Techniques in the Process of Preparation of Regional Innovation Strategies in Poland}

In the study whose aim was the identification of research methods and techniques used for the preparation of regional innovation strategies, the desk research method was used. Current strategies and regional strategic programmes corresponding to them and applicable in Polish voivodeships were analysed. In a breakdown presented in Table 1 only these methods that were indicated in the analysed documents were taken into account. Dates of their adoption or last updates were also subjected to analysis, in order to take the status of knowledge about the applied methods at the time of their preparation into account.

Table 1.

Research methods and techniques applied during the process of preparation of regional innovation strategies in Poland

\begin{tabular}{|c|c|c|}
\hline Strategy/programme & $\begin{array}{l}\text { Date of } \\
\text { adoption }\end{array}$ & Applied methods and techniques \\
\hline $\begin{array}{l}\text { Regional Innovation } \\
\text { Strategy for the } \\
\text { Dolnośląskie } \\
\text { Voivodeship for } \\
\text { 2011-2020 }\end{array}$ & $\begin{array}{l}30 \text { August } 2011 \\
\text { On } 19 \text { August } \\
2015 \text {, } \\
\text { an attachment } \\
\text { Strategic } \\
\text { Framework } \\
\text { for Smart } \\
\text { Specialisations } \\
\text { of Dolny Śląsk } \\
\text { was prepared }\end{array}$ & $\begin{array}{l}\text { Desk research: forecast of global and national development } \\
\text { trends until } 2020 \text { (trends were listed and described), diagnosis } \\
\text { of the condition of the voivodeship in the following areas: } \\
\text { economic and social potential, regional innovation system. } \\
\text { SWOT analysis }\end{array}$ \\
\hline $\begin{array}{l}\text { Regional Innovation } \\
\text { Strategy for the } \\
\text { Kujawsko-Pomorskie } \\
\text { Voivodeship for 2014- } \\
2020\end{array}$ & $\begin{array}{l}\text { 14 January } \\
2015\end{array}$ & $\begin{array}{l}\text { Desk research: up-date of the region's diagnosis in three areas: } \\
\text { school education and higher-level education; science, including } \\
\text { research and development activities, economy. } \\
\text { SWOT analysis (additional opinions on SWOT factors were } \\
\text { procured from an Internet survey among regional stakeholders) } \\
\text { STEEP analysis } \\
\text { Benchmarking }\end{array}$ \\
\hline $\begin{array}{l}\text { Regional Innovation } \\
\text { Strategy of the Lubelskie } \\
\text { Voivodeship until } 2020\end{array}$ & $\begin{array}{l}31 \text { October } \\
2014\end{array}$ & $\begin{array}{l}\text { Desk research: prospective diagnosis in several areas: } \\
\text { environment; natural resources; population; settlement } \\
\text { network; labour market; level of development and economy } \\
\text { structure; education, science, innovation potential; spatial } \\
\text { management; social and institutional capital; culture; hitherto } \\
\text { use of external funds. } \\
\text { SWOT analysis }\end{array}$ \\
\hline $\begin{array}{l}\text { Innovation Development } \\
\text { Programme of Lubuskie } \\
\text { Voivodeship }\end{array}$ & $\begin{array}{l}\text { Update from } \\
30 \text { August } 2018\end{array}$ & $\begin{array}{l}\text { Desk research: diagnosis of the status of innovation in the } \\
\text { voivodeship } \\
\text { SWOT analysis } \\
\text { Key development factors } \\
\text { Problem tree } \\
\text { Benchmarking } \\
\text { Delphi survey } \\
\text { Telephone interviews }\end{array}$ \\
\hline
\end{tabular}


Cont. table 1.

\begin{tabular}{|c|c|c|}
\hline $\begin{array}{l}\text { Regional Innovation } \\
\text { Strategy for the Łódzkie } \\
\text { Voivodeship: "LORIS } \\
\text { 2030" }\end{array}$ & 26 April 2013 & $\begin{array}{l}\text { Desk research: diagnosis of the innovation potential of the } \\
\text { voivodeship } \\
\text { SWOT analysis in areas: knowledge-based economy; science } \\
\text { in the service of innovative development; knowledge-based } \\
\text { society; regional innovation policy; knowledge-based } \\
\text { administration. } \\
\text { IDI, CATI and CAWI interviews } \\
\text { Region development scenarios }\end{array}$ \\
\hline $\begin{array}{l}\text { Strategic Programme } \\
\text { Regional Innovation } \\
\text { Strategy of the } \\
\text { Małopolskie Voivodeship } \\
2020\end{array}$ & 2 October 2018 & $\begin{array}{l}\text { Desk research: key macro-economic data; modern } \\
\text { technologies; infrastructure of the region's knowledge; R\&D } \\
\text { personnel; instruments of the region's knowledge; } \\
\text { entrepreneurship and promotion of entrepreneurship; } \\
\text { infrastructure for information society; implementation of the } \\
\text { Małopolska development policy in the area of innovative } \\
\text { economy. } \\
\text { Forecast of development trends } \\
\text { Surveys } \\
\text { SWOT analysis }\end{array}$ \\
\hline $\begin{array}{l}\text { Regional Innovation } \\
\text { Strategy for Mazowsze } \\
\text { until } 2020\end{array}$ & 16 March 2015 & $\begin{array}{l}\text { Desk research: profile of operation of cluster initiatives, export } \\
\text { structure, concentration of economic activities } \\
\text { Interviews and surveys } \\
\text { SWOT analysis }\end{array}$ \\
\hline $\begin{array}{l}\text { Regional Innovation } \\
\text { Strategy for the Opolskie } \\
\text { Voivodeship until } 2020\end{array}$ & 1 July 2014 & $\begin{array}{l}\text { Desk research: diagnosis of the innovation potential of the } \\
\text { Opolskie voivodeship, industry analyses } \\
\text { Expert consultations } \\
\text { Prospective studies } \\
\text { PEST analysis } \\
\text { SWOT analysis } \\
\text { Trend forecasting } \\
\text { Delphi method } \\
\text { Creative imaging }\end{array}$ \\
\hline $\begin{array}{l}\text { Regional Innovation } \\
\text { Strategy for the } \\
\text { Podkarpackie } \\
\text { Voivodeship for } 2014 \text { - } \\
2020 \text { for the sake of smart } \\
\text { specialisation (RIS3) }\end{array}$ & $\begin{array}{l}\text { Update of } 28 \\
\text { November } \\
2016\end{array}$ & $\begin{array}{l}\text { Desk research: diagnosis of the innovation potential of the } \\
\text { voivodeship } \\
\text { TOWS/ SWOT analysis, surveys and interviews }\end{array}$ \\
\hline $\begin{array}{l}\text { Entrepreneurship } \\
\text { development plan based } \\
\text { on smart specialisations } \\
\text { of the Podlaskie } \\
\text { Voivodeship for } 2015- \\
2020+\text { (RIS3) }\end{array}$ & 1 March 2016 & $\begin{array}{l}\text { Desk research: diagnosis of the innovation potential of the } \\
\text { voivodeship } \\
\text { Detailed SWOT analysis }\end{array}$ \\
\hline $\begin{array}{l}\text { Regional Strategic } \\
\text { Programme in the area of } \\
\text { economic development } \\
\text { Pomeranian Port of } \\
\text { Creativity }\end{array}$ & $\begin{array}{l}\text { Update of } 10 \\
\text { May } 2018\end{array}$ & $\begin{array}{l}\text { Desk research: conclusions from the analysis of situation in the } \\
\text { area of economic development } \\
\text { SWOT analysis }\end{array}$ \\
\hline $\begin{array}{l}\text { Regional Innovation } \\
\text { Strategy for the Śląskie } \\
\text { Voivodeship for 2013- } \\
2020\end{array}$ & $\begin{array}{l}20 \text { December } \\
2012\end{array}$ & $\begin{array}{l}\text { Desk research: among others pertaining to the results of } \\
\text { foresight projects } \\
\text { Benchmarking } \\
\text { SWOT analysis }\end{array}$ \\
\hline $\begin{array}{l}\text { Research and Innovation } \\
\text { Strategy (RIS3) From } \\
\text { Absorption to Results: } \\
\text { How to Stimulate the } \\
\text { Potential of the } \\
\text { Świętokrzyskie } \\
\text { Voivodeship 2014-2020+ }\end{array}$ & $\begin{array}{l}24 \text { February } \\
2014\end{array}$ & $\begin{array}{l}\text { Desk research: potential of the sector of science and } \\
\text { technology, economic specialisations } \\
\text { Gravitational model } \\
\text { Forecasting } \\
\text { SWOT analysis }\end{array}$ \\
\hline
\end{tabular}


Cont. table 1.

\begin{tabular}{|c|c|c|}
\hline $\begin{array}{l}\text { Regional Innovation } \\
\text { Strategy for the } \\
\text { Warmińsko-Mazurskie } \\
\text { Voivodeship until } 2020\end{array}$ & $\begin{array}{l}28 \text { September } \\
2010\end{array}$ & $\begin{array}{l}\text { Desk research: diagnosis of the social capital and innovation } \\
\text { culture, human capital, innovation needs of companies; } \\
\text { research and development potential of the region; innovation } \\
\text { support system. } \\
\text { SWOT analysis }\end{array}$ \\
\hline $\begin{array}{l}\text { Regional Innovation } \\
\text { Strategy for } \\
\text { Wielkopolska for } \\
2015-2020\end{array}$ & $\begin{array}{l}\text { Update of } \\
30 \text { March } 2015\end{array}$ & $\begin{array}{l}\text { Desk research: analysis of competitiveness and innovation of } \\
\text { the region and enterprises; analysis of management on the } \\
\text { regional and local level; analysis of innovation and } \\
\text { competitiveness of enterprises; analysis of the social sub- } \\
\text { system, analysis of intra-regional diversification and } \\
\text { specialisations. } \\
\text { SWOT analysis } \\
\text { Key success factors } \\
\text { Delphi method } \\
\text { In-depth interviews } \\
\text { Innovation benchmarking }\end{array}$ \\
\hline $\begin{array}{l}\text { Regional Innovation } \\
\text { Strategy for the } \\
\text { Zachodniopomorskie } \\
\text { Voivodeship for } 2011 \text { - } \\
2020\end{array}$ & 22 March 2011 & $\begin{array}{l}\text { Desk research: diagnosis of the socio-economic environment } \\
\text { for innovation development } \\
\text { Competition for smart specialisations of the region } \\
\text { SWOT analysis }\end{array}$ \\
\hline
\end{tabular}

Source: Own work based on the strategies review.

The range of methods and techniques used during the preparation of the regional innovation strategies is diversified. The minimum set of methods includes an analysis of the region's profile with the use of the desk research method encompassing primarily the quantitative data pertaining to various areas of the voivodeship's functioning that are important for innovation development. Due to the requirements set by the European Commission, all regions also applied the SWOT analysis method. A significant percentage of the regions used the benchmarking method (25\%). Analysis of documents also indicates that it was prepared as the SWOT/TOWS method only in the Podkarpackie Voivodeship. The Opolskie Voivodeship and the KujawskoPomorskie Voivodeship also applied the strategic analysis method, PEST (in the KujawskoPomorskie Voivodeship, as the STEEP variant). The Delphi method $(18,7 \%)$ and the scenario and forecast methods were also rarely used. As far as the research techniques are concerned, some voivodeships used interviews and surveys (25\%). An interesting approach was used in the Pomorskie Voivodeship, where a competition was announced in order to select smart specialisations.

\section{Conclusions}

Polish regions fulfilled the ex ante requirement in the form of preparation of regional innovation strategies that make use of the SWOT analysis method, which allowed for full use of the European Union funds. Numerous voivodeships used a broader range of research methods and techniques, but the analysis of prepared documents does not always deliver full 
information whether the qualitative methods were commonly applied. However, attention should be drawn to the fact that in the majority of them, regional foresight type projects with extended time horizon were implemented previously, where such methods and techniques were commonly used.

Literature pertaining to best practice in the area of preparation of regional innovation strategies indicates forecasting activities and diagnostic tools which are aimed at determining potential synergies that appear in the analysis of the regional context. Proper assessment of the potential in the area of regional specialisations requires use of diverse qualitative and quantitative data, pertaining primarily to scientific and technical indices, sectoral distribution of employment in the region, indices pertaining to export, road maps or forecasting methods. A certain obstacle with respect to the study of the regional potential was lack of preparation of the public statistics for the aggregation of significant data on the level of the region or lower. The quantitative approach is also mainly aimed at past and current specialisations of the region and limits the possibility of inter-sectoral and inter-technological dimension to indicate new types of activities (Griniece, and Panori, 2017). The information gap resulting from the insufficient quantitative data may be supplemented by the applied qualitative methods that use knowledge and also expert intuition.

Another important finding was also the fact that the Polish regions were not only striving to fulfil the ex ante requirements, but many of them used the foresight type project results implemented earlier, or applied the research methods and techniques typical for them, such as, e.g., the Delphi method, during the preparation of the regional innovation strategies.

\section{References}

1. Bowonder, B., Dambal, A., Kumar, S., and Shirodkar, A. (2010). Innovation Strategies for Creating Competitive Advantage. Journal Research-Technology Management, Vol. 53, Iss. 3, pp. 19-32.

2. Brożyk, P. (2006). Globalizacja: istota, szanse, zagrożenia. Res Humana, nr 5, pp. 16-20.

3. Capello, R., and Kroll, H. (2016). From theory to practice in smart specialization strategy: emerging limits and possible future trajectories. European Planning Studies, No. 24(8), pp. 1393-1406.

4. Clark, J., Guy, K. (1998). Innovation and Competitiveness: A Review. Technology Analysis and Strategic Management, Vol. 10(3), pp. 363-395.

5. Conway, S., Steward, F. (2009). Managing and shaping innovation. Oxford: University Press. 
6. de Jong, J.P.J. (2011). Perceived competition and innovative intentions in Dutch small and medium enterprises. International Journal of Innovation Management, Vol. 15(4), pp. 687-707.

7. Facts: the benefits of economic globalisation in Europe, https://www.europarl.europa.eu/ news/en/headlines/economy/20190603STO53520/facts-the-benefits-of-economicglobalisation-in-europe, 23.09.2020.

8. Fellnhofer, K. (2017). Evidence revisited: Literature on smart specialisation calls for more mixed research designs. International Journal of Knowledge-Based Development, No. 8(3), pp. 229-248.

9. Foray, D., and Goenega, X. (2013). The goals of smart specialization. S3 Policy Brief Series, No. 01/2013 Luxembourg: Publications Office of the European Union.

10. Foray, D., David, PA, and Hall, B. (2009). Smart Specialization - The Concept. Knowledge Economists Policy Brief no. 9, http://ec.europa.eu/invest-in-research/pdf/download_en/ kfg_policy_brief_no9.pdf?11111, 18.08.2020.

11. Griniece, E., Panori, A., Kakderi, C., Komninos, A., Reid, A. (2017). Methodologies for Smart Specialisation Strategies: A view across the EU regions. International Conference for Entrepreneurship, Innovation, and Regional Development (ICEIRD 2017), UniversityIndustry Links: Coproducing Knowledge, Innovation \& Growth, Conference Proceedings, pp. 321-330.

12. Grzybowska, A. (2013), Globalizacja - szanse i zagrożenia, współczesne problemy ekonomiczne. In: G. Wolska (Ed.), Polityka państwa a proces globalizacji. Studia Ekonomiczne, Zeszyty Naukowe Wydziałowe Uniwersytetu Ekonomicznego w Katowicach.

13. Herodowicz, T. (2018). Gospodarczy wymiar globalizacji. Rozwój Regionalny i Polityka Regionalna, $n r$ 41, pp. 13-30.

14. Jacoby, W., Meunier, S. (2010). Europe and the Management of Globalization. Journal of European Public Policy, Vol. 17, Iss. 3, pp. 299-317.

15. Kołodko, G.W. (2007). Polska z globalizacja w tle. Instytucjonalne i polityczne aspekty rozwoju gospodarczego. Toruń: Towarzystwo Naukowe Organizacji i Kierownictwa „Dom Organizatora".

16. Lundvall, B.Å. (2007). National Innovation Systems-Analytical Concept and Development Tool. Journal Industry and Innovation, Vol. 14, Iss. 1, pp. 95-119.

17. Matusiak, K.B. (Ed.) (2005). Innowacje i transfer technologii. Słownik pojęć. Warszawa: Polska Agencja Rozwoju Przedsiębiorczości.

18. Moen, Ø., Tvedten, T., and Wold, A. (2019). Exploring the relationship between competition and innovation in Norwegian SMEs. Journal Cogent Business \& Management, Vol. 5, Iss. 1, pp. 1-15. 
19. Nogalski, B., Karpacz, J. (2012). Zdolność technologiczna jako źródło przewagi konkurencyjnej firm produkcyjnych. Studia Ekonomiczne Regionu Łódzkiego, wyd. specjalne, pp. 173-186.

20. Regulation (EU) No 1303/2013 of the European Parliament and of the Council of 17 December 2013.

21. Siqueira, A.C., Cosh, A.D. (2008). Effects of product innovation and organizational capabilities on competitive advantage: evidence from UK small and medium manaufacturing enterprises. International Journal of Innovation Management, Vol. 12(2), pp. 113-137.

22. Stabryła, A. (Ed.), (2009). Doskonalenie struktur organizacyjnych przedsiębiorstw w gospodarce opartej na wiedzy. Warszawa: Wydawnictwo C.H. Beck.

23. Surugiu, M.R., Surugiu, C. (2015). Interdependence between European Countries: Implications for Businesses and Marketing Framework. Procedia Economics and Finance, No. 32, pp. 131-138.

24. Third report on economic and social cohesion (COM(2004) 107 final).

25. Weresa, M. (2012). Systemy innowacyjne a konkurencyjność w świetle wybranych koncepcji teoretycznych. Prace i materiały Instytutu Gospodarki Światowej SGH, nr 311. Warszawa: SGH. 


\title{
SPATIAL MODELING OF INVESTMENT ACTIVITY OF ENTERPRISES IN SERVICE SECTOR
}

\author{
Katarzyna ZEUG-ŻEBRO \\ University of Economics in Katowice; katarzyna.zeug-zebro@ue.katowice.pl, ORCID: 0000-0001-7786-3478
}

Purpose: Due to the visible disproportions, the problem of innovation is increasingly often perceived regionally. These inequalities result from the concentration of knowledge, resources and the amount of expenditure on innovation in a few regions. The aim of the paper is to study the spatial dependence between Polish voivodships in terms of expenditure on innovative activities in enterprises in the service sector.

Design/methodology/approach: For the selected variable conditioning the innovative activity of the enterprise, a classical econometric model will be built and the necessity to include the spatial factor in the modeling process will be verified. For this purpose, two spatial models will be considered: the spatial error model and spatial lag model.

Findings: During the study, the hypothesis on the legitimacy of introducing spatial relationships to the econometric model describing the shaping of the amount of expenditure on innovative activities in enterprises in the service sector in Polish voivodeships was verified. The hypothesis has been verified positively - there are spatial relationships between the examined objects.

Research limitations/implications: The need to take into account the spatial factor in the econometric model results in taking into account spatial estimation methods. The research used selected spatial models. Due to the limitations resulting from the availability of source data, the analysis was conducted only for voivodships in selected years. The analysis should be further deepened, e.g., by even more precise identification of the models and taking into account other neighborhood matrices - only the first-order neighborhood matrix was included in the study.

Practical implications: Modeling the phenomenon of innovation.

Social implications: An essential condition influencing the innovative activity of enterprises is their environment. It is the regional factors that largely influence innovation and faster development of enterprises.

Originality/value: Introducing spatial relationships to the econometric model of outlays on innovative activities of enterprises in the service sector.

Keywords: spatial modeling, regional innovation, factors shaping innovation.

Category of the papers: research paper. 


\section{Introduction}

The analysis and evaluation of innovative activities of enterprises is complicated and raises many doubts. The innovation process is the result of a number of factors both inside the company and outside. Due to the importance of this topic, many works have been written on the problem of innovation. Most of the time it is international literature. Local analyzes are rare due to the lack of proper data. The set of relevant indicators is available only for voivodships (and not really to the full extent).

The research on the problem of innovation shows increasingly the importance of regions in the innovation process. The processes of learning and knowledge transfer are related to the location in the geographical space. It is at the local level that enterprises have the ability to create knowledge through interactions with other enterprises in the process of mutual learning (Maskell, and Malmberg, 1999). Taking into account the regional nature of innovative activities of enterprises, the aim of the paper is to check whether such relationships exist between the regions studied, i.e., to study the significance of the space factor in modeling outlays on innovative activities.

The analysis of the innovation process in enterprises from the service sector was carried out on the basis of data aggregated to the voivodship level. They were obtained from the Local Data Bank of the Central Statistical Office. Due to the limitations resulting from the availability of source data, the analysis was performed only for selected years (2006, 2010, 2014, and 2017). All calculations were performed with R Cran and Microsoft Excel.

\section{Innovative service enterprises in Poland}

The concept of innovation was introduced into the economic literature in 1911 by J.A. Schumpeter. According to him, innovation is a new combination of means of production and capital in the following cases: introducing a new product, introducing a new production method, opening a new market, acquiring a new source of raw materials or semifinished products, carrying out a new organization of industry (Schumpeter, 1960). On the other hand, according to Haffer's definition, innovations are all changes which, in given spatial and temporal conditions, are perceived as carriers of novelty, concerning products of material and nonmaterial culture as much (Zastempowski, 2010).

Currently, economic growth is largely determined by the development of service enterprises, including those that implement innovation the fastest. This is evidenced by the growing share of services in generating GDP, growth in investments and expenditure on innovation, domestic and foreign trade, and employing a large number of employees (Czubała, 2015). 
In 2017, service companies in Poland spent the most funds in terms of expenditure on innovative activities on research and development activities $-43.4 \%$. On the other hand, the lowest outlays in these enterprises were incurred to introduce new or improved products or business processes. The main source of financing these outlays was own funds, which in 2017 in service enterprises accounted for $85.7 \%$ of all outlays incurred for this purpose (GUS, 2020).

Taking into account the territorial division (Fig. 1), the highest percentage of innovative enterprises in the service sector was recorded in the following voivodships: Lublin $(28.73 \%)$, Swietokrzyskie (26.24\%), Maslovian (25.19\%) in 2006; Masovian (15.56\%), Subcarpathian (13.75\%), Opole (13.67\%) in 2010; in Lublin (17.53\%), Opole (15.73\%), Masovian (15.09\%) in 2014; Masovian (14.17\%), Pomeranian (13.21\%) and Lesser Poland (11.77\%) in 2017. However, the lowest percentage can be observed in the following voivodeships: Lubusz (12.61\%), Kuyavian-Pomeranian (13.53\%), Lodz (14.87\%) in 2006; Podlachian (8.33\%), Warmian-Masurian (8.74\%), Kuyavian-Pomeranian (9.36\%) in 2010; Warmian-Masurian (4.38\%), Lubusz (5.48\%), Greater Poland (7.68\%) in 2014; Opole (2.51\%), Warmian-Masurian $(3.89 \%)$ and Swietokrzyskie (5.15\%). Additionally, it is worth noting a significant decrease in the number of innovative enterprises in 2017 (compared to 2006).

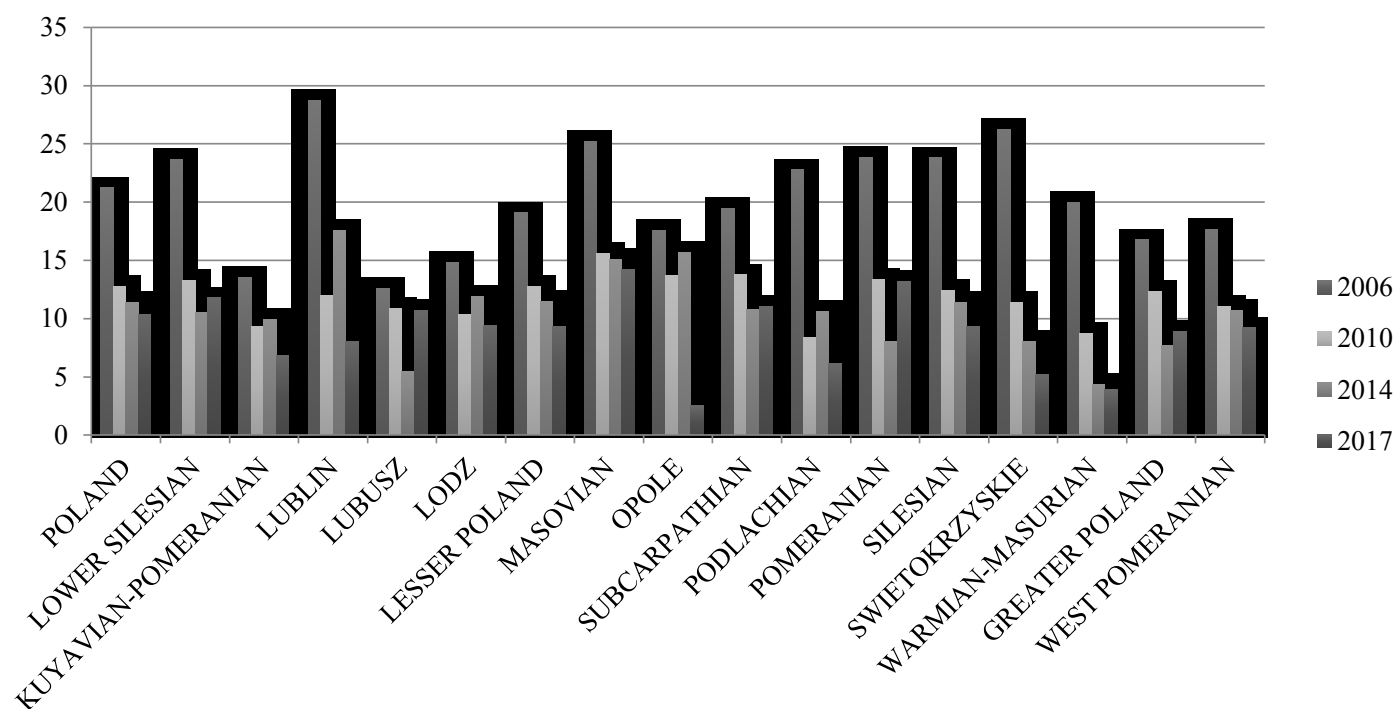

Figure 1. The percentage of innovative enterprises in the service sector in 2006, 2010, 2014 and 2017.

The presentation of the results confirms the regional differentiation in the level of innovation among enterprises. The distance between the highest and the lowest percentage of innovative service enterprises in voivodships was 16.11 percentage points in 2006, 7.23 percentage points in $2010,13.15$ percentage points in 2014 , and 11.6 percentage points in 2017. 

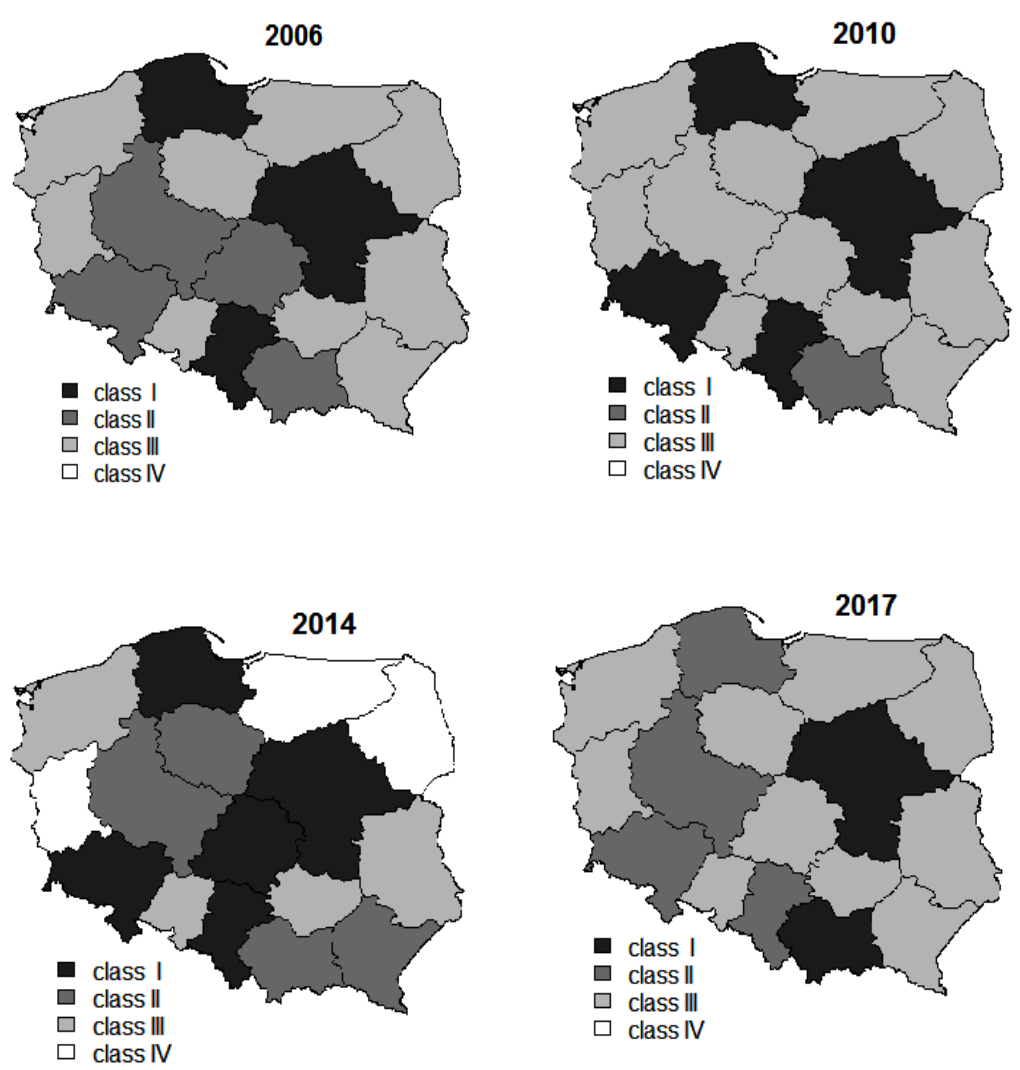

Figure 2. Innovative activity expenditure in enterprises according to the sources of financing innovative activities in 2006, 2010, 2014 and 2017.

This regional differentiation in the level of innovation among enterprises is also confirmed by the analysis of outlays on innovative activities in enterprises according to the sources of financing innovative activities. Figure 2 shows the division into classes depending on the intensity of the studied phenomenon. The first class includes the voivodeships with the highest level of expenditure on innovative activities (Masovian, Silesian and Pomeranian - 2006; Masovian, Silesian, Lower Silesian and Pomeranian - 2010; Masovian, Silesian, Lower Silesian, Pomeranian and Lodz -2014; Masovian and Lesser Poland - 2017). However, in the fourth grade, the voivodeships with the lowest level can be observed (none in 2006, 2010 and 2017; Lubusz, Podlachian and Warmian Masurian in 2014). In 2006, 2010 and 2017, most voivodships belonged to the class with a low level of expenditure on innovative activities.

\section{Spatial modeling}

Observation of social, economic, and natural phenomena almost always allows us to state that each of them is conditioned by the action of other phenomena. Estimating the relationships that occur between the phenomena that are affected and the factors shaping these phenomena 
is performed using regression analysis. In regression modeling using the CLS, it is assumed that the modeled phenomena are independent of their location, so there are no interactions between the examined objects. This assumption does not always apply to the analysis of social and economic phenomena in spatial terms. Therefore, when analyzing and modeling localized data, one should take into account the spatial interactions that may relate to both the dependent variable and the random component (Suchecki, 2010).

The construction of the spatial model is aimed at improving the quality of the econometric model. Inclusion of spatial relationships within a given area as well as within neighboring areas can have a positive influence on the translation of the variability of the features under consideration. The following basic groups of spatial models are distinguished: spatial lag models, spatial error models, cross-regression models and mixed variants. In paper the first two models were considered.

The spatial lag model includes the spatially delayed endogenous variable $\mathbf{W} y$, ie, it is an autoregressive model (the basis of the model is spatial dependence). The general form of this model is described by formula:

$y=\boldsymbol{\beta} \mathbf{X}+\alpha \mathbf{W} y+\varepsilon, \quad \varepsilon \sim N\left(0, \sigma^{2} I\right)$

where:

$\alpha$-spatial autocorrelation coefficient,

$\mathbf{W}$ - spatial weight matrix,

$\boldsymbol{\beta}$ - vector of model coefficients,

$\mathbf{X}$ - matrix of exogenous variables,

$\varepsilon$ - model error.

The model test if $\alpha=0$ is the significance of the dependent variable which is spatially delayed. Spatial delay $\mathbf{W} y$ is interpreted as the level of the dependent variable $y$ in neighboring regions. If this is significant, then the level of $y$ in the $i$-th region can be explained by the level of the phenomena in the neighborhood and other factors represented by the remaining explanatory variables.

The spatial error model contains spatially delayed errors. This model assumes the spatial autocorrelation of the rest of the model. The general form of the model is given by the formula:

$y=\boldsymbol{\beta} \mathbf{X}+\varepsilon$

where:

$\varepsilon=\mu \mathbf{W} \varepsilon+\varphi, \quad \varphi \sim N\left(0, \sigma^{2} I\right)$

$\mu$ - spatial autocorrelation coefficient, other signs as above. 
$\mathbf{W} \varepsilon$ is a spatially delayed error, which should be interpreted as the average error from neighboring locations, and $\varphi$ is an independent error of the model. In the model, we test whether $\mu=0$ ie lack of spatial autocorrelation.

There are different ways to select and specify the model that best describes the issue. One of them is a simple procedure for choosing a spatial regression model, which follows the algorithm (Anselin, 2006; Suchecki, 2010; Kopczewska, 2011):

1. Estimation of the linear model by the classical least squares method (CLS).

2. Study of spatial autocorrelation of model residues (Anselin, and Rey, 1991) - at this stage the Moran test (Moran, 1950) is used for residues, which takes the form:

$$
I=\frac{n}{S_{0}} \cdot \frac{\mathbf{u}^{\mathrm{T}} \mathbf{W} \mathbf{u}}{\mathbf{u}^{\mathrm{T}} \mathbf{u}}
$$

where:

$n$ - number of regions,

u- column vector of residual from the CLS model,

$S_{0}$ - sum of elements of the weights matrix, $S_{0}=\sum_{i=1}^{n} \sum_{j=1}^{n} w_{i j}$,

W - spatial weight matrix degree $n$, defining the structure of the neighborhood,

$w_{i j}$ - element of the weights matrix $\mathbf{W}$.

This test verifies the following hypotheses: $H_{0}$ : no spatial autocorrelation of residues, $H_{1}$ : occurrence of spatial autocorrelation of residues.

The occurrence of autocorrelation of residuals does not necessarily use the need for spatial models, and the residuals of the model (model estimated on the logarithms of variables) can then be analyzed (Cliff, and Ord, 1970).

3. Carry out LM tests (Lagrange Multiplier) to specify a spatial model that better describes the phenomenon (Anselin et al., 1996) - these tests are based on the CLS model residuals. Two basic LM tests are LMerror and LMlag. The LMerror test tests the spatial dependence of the error, and the LMlag tests the significance of the dependent variable which is spatially delayed. LMerror with asymptotic distribution $\chi^{2}(1)$ takes the form:

$$
L M_{E R R O R}=\frac{1}{T_{1}}\left(\frac{\mathbf{u}^{T} \mathbf{W u}}{\hat{\sigma}^{2}}\right)^{2}
$$

where:

$\hat{\sigma}$ - estimated standard error,

$T_{1}=\operatorname{tr}\left[\left(\mathbf{W}^{\mathrm{T}}+\mathbf{W}\right) \mathbf{W}\right]$

other signs as above. 
Using the above statistic, significance of the coefficient $\mu$ is verified.

LMlag with asymptotic distribution $\chi^{2}(1)$ takes the form:

$$
L M_{L A G}=\frac{1}{T_{2}}\left(\frac{\mathbf{u}^{T} \mathbf{W y}}{\hat{\sigma}^{2}}\right)^{2}
$$

where:

$T_{2}=T_{1}+\frac{(\mathbf{W X} \hat{\boldsymbol{\beta}})^{T} \mathbf{M}(\mathbf{W X} \hat{\boldsymbol{\beta}})}{\hat{\sigma}^{2}}$

$\mathbf{M}=\mathbf{I}-\mathbf{X}\left(\mathbf{X}^{T} \mathbf{X}\right)^{-1} \mathbf{X}^{T}$

$\hat{\beta}$ - estimated vector of the coefficients, other signs as above.

Using the above statistic, significance of the coefficient $\alpha$ is verified.

The choice of the spatial model (by hybrid strategy) is determined by the higher (significant) value of the LM statistics (if LMlag > LMerror, then the spatial lag model is determined, otherwise the spatial error model).

4. Carry out additional diagnostic tests: LR test and Wald test and compare the statistic values of these tests with the LM statistic values. Then for:

- the spatial error model: Wald $(\mu) \geq$ LRerror $\geq$ LMerror,

- the spatial lag model: Wald $(\alpha) \geq$ LRlag $\geq$ LMlag.

\section{Empirical analysis - evaluation of models}

The analysis of the innovation process in enterprises from the service sector was carried out on the basis of data aggregated to the voivodeship level. For this purpose, data obtained from the Central Statistical Office for 2006, 2010, 2014, and 2017 were used (www1). The data used is annual data. The study began with the selection of variables on the basis of which three regression models will be estimated. The dependent variable $\mathrm{Y}$ characterizing the innovation process in enterprises from the service sector is the amount of expenditure on innovative activities in enterprises from the service sector from all investment sources (PLN thousand). The set of explanatory variables related to innovation was selected according to the following principles (Cywiński, 2013): the use of advanced production technologies, information technologies, intangible investment, measurement of organizational changes and nontechnological innovations in enterprises, research on society's attitudes towards science and technology. As a result, 14 indicators were selected: 
- $\mathrm{X} 1$ - share of innovative enterprises in the service sector by type of introduced innovation - new, or improved products (\%);

- X2 - share of innovative enterprises in the service sector by type of introduced innovation - new, or improved processes (\%);

- X3 - expenditure on innovative activity of enterprises from the service sector for the purchase of software (PLN thousand);

- X4 - expenditure on innovative activities of enterprises in the service sector on personnel training directly related to the introduction of product or process innovations (PLN thousand);

- X5 - employed in R\&D (FTE);

- X6 - expenditure on innovative activities in enterprises per 1 professionally active person (PLN);

- $\mathrm{X} 7$ - internal expenditure on R\&D (PLN thousand);

- X8 - share of enterprises with computers (\%);

- $\mathrm{X} 9$ - share of enterprises with Internet access (\%);

- $\mathrm{X} 10$ - number of patents granted by the PPO - total;

- X11 - average monthly gross wages and salaries in the enterprise sector (PLN);

- X12 - graduate studies at the master's level;

- X13 - students of postgraduate studies and participants of doctoral studies per 1000 inhabitants (people);

- X14 - expenditure on innovative activities of enterprises from the service sector on marketing related to the introduction of new or significantly improved products (PLN thousand).

In the first stage of the study, three linear econometric models were estimated. The models examined the relationship between the increase in the years: 2006-2017 (Model I), 2010-2017 (Model II), 2014-2017 (Model III), the amount of expenditure on innovative activities in enterprises from the service sector from all investment sources, and the increase in explanatory variables.

Modeling of the global relationships between the dependent variable and the independent variables remaining after the elimination procedure was carried out using the $\mathrm{R}$ program. Assuming a linear relationship between the adopted variables, the multiple regression model was estimated using the Classical Least Squares (CLS) method. As not all parameters of the estimated model showed statistical significance, the posteriori elimination procedure was used, assuming in the next step the removal from the original model (model with all variables) of those variables that have the least significant impact on the dependent variable in a given step. After each elimination step, the model is subjected to statistical verification. The procedure ends when a model is obtained, all the parameters of which show statistical significance (Guzik, 2008). As a result of the applied stepwise elimination procedure, the selected explanatory variables remained in the final version of the model (Table 1). 
Table 1.

Results of estimation of econometric models

\begin{tabular}{|c|c|c|c|}
\hline \multirow{2}{*}{ Variables } & \multicolumn{3}{|c|}{ Value of coefficients } \\
\cline { 2 - 4 } & Model I & Model II & Model III \\
\hline Intercept & 3.0253 & 1.0967 & -1.4242 \\
\hline $\mathrm{X} 1$ & 1.5575 & - & 1.2677 \\
\hline $\mathrm{X} 3$ & - & 1.6462 & 0.7306 \\
\hline $\mathrm{X} 4$ & 0.6563 & - & - \\
\hline $\mathrm{X} 5$ & -0.3839 & - & - \\
\hline $\mathrm{X} 7$ & 0.1041 & -0.1888 & 1.2932 \\
\hline $\mathrm{X} 8$ & - & -60.3745 & 25.4611 \\
\hline $\mathrm{X} 12$ & 4.1538 & - & 6.7403 \\
\hline $\mathrm{X} 14$ & - & - & -0.9709 \\
\hline$R^{2}$ & 0.8082 & 0.7354 & 0.9296 \\
\hline
\end{tabular}

The symbol "-" means that the parameter was statistically insignificant.

The estimated regression coefficients show that part of the variability in the expenditure on innovative activities of enterprises from the service sector from all investment sources was explained by: the share of innovative enterprises from the service sector by the types of innovations introduced - new or improved products (Model I and III), expenditures on innovative activities of enterprises from the service sector for the purchase of software (Model II and III), the expenditure on innovative activities of enterprises from the service sector on training of personnel related directly to the introduction of product or process innovations, employed in R\&D (Model I), internal expenditure on R\&D (Model I, II, III), the share of enterprises using computers (Model II and III), the number of graduates of studies at the master's level (Model I and III), the expenditure on innovative activities of enterprises from the service sector on marketing related to the introduction of new or is totally improved products (Model III). The determination coefficients of all models were relatively high, therefore the fit of the models is good.

In the next step of analysis, the spatial autocorrelation of errors was studied. Results are presented in Table 2.

Table 2.

Moran statistics for the residuals of the model

\begin{tabular}{|c|c|c|c|c|c|}
\hline \multicolumn{2}{|c|}{ Model I } & \multicolumn{2}{c|}{ Model II } & \multicolumn{2}{c|}{ Model III } \\
\hline$I$ & $p$-value & $I$ & $p$-value & $I$ & $p$-value \\
\hline-0.2336 & 0.8940 & -0.1436 & 0.7024 & 0.0413 & 0.2639 \\
\hline
\end{tabular}

Moran's statistic I is statistically insignificant for all estimated models, which suggests the lack of spatial autocorrelation, i.e., a random distribution of the residuals (the distribution does not depend on the location).

In the next step of the study, LM tests were performed for each model to investigate the existence of spatial relationships in linear models. The results of this analysis (indicating which spatial model would be more appropriate) are contained in Table 3. 
Table 3.

Recommended spatial model

\begin{tabular}{|c|c|c|c|c|c|}
\hline \multirow{2}{*}{ Model } & \multicolumn{4}{|c|}{ LM tests } & \multirow{2}{*}{ Type of spatial model } \\
\cline { 2 - 5 } & LMerror & $p$-value & LMlag & $p$-value & spatial error model \\
\hline Model I & 4.6314 & 0.0314 & 2.9375 & 0.0866 & - \\
\hline Model II & 0.7796 & 0.3773 & 0.2338 & 0.3773 & - \\
\hline Model III & 0.1975 & 0.6568 & 0.2330 & 0.6293 & \\
\hline
\end{tabular}

The above results suggest that in the case of Models II and III, estimating spatial models is not advisable, while for Model $\mathrm{I}$ it is best to build a spatial error model. In addition, Table 4 shows the values of the information criteria: Akaike (AIC), Bayesian (BIC), and logLik, to compare the model estimated by CLS with the spatial models (SEM - spatial error model, SLM - spatial lag model). The best model is the one for which the AIC and BIC criteria take the lowest values, while the logLik criterion assumes the highest values.

Table 4.

Values of the information criteria

\begin{tabular}{|c|c|c|c|c|}
\hline \multirow{2}{*}{\multicolumn{2}{|c|}{ Model }} & \multicolumn{3}{|c|}{ Values of criteria } \\
\hline & & \multirow{2}{*}{$\begin{array}{c}\text { AIC } \\
44.0644\end{array}$} & \multirow{2}{*}{$\begin{array}{c}\text { BIC } \\
50.2451\end{array}$} & \multirow{2}{*}{$\begin{array}{c}\text { logLik } \\
-14.0322\end{array}$} \\
\hline \multirow{3}{*}{ I } & SLM & & & \\
\hline & SEM & 32.6687 & 38.8494 & -8.3343 \\
\hline & CLS & 42.1606 & 47.5687 & -14.0803 \\
\hline
\end{tabular}

The values of the information criteria for Model I clearly indicate the spatial error model. For this model, a suggested spatial model has been built; the results of the estimation are given in Table 5. The spatial factor $\mu$ was significant.

Table 5.

Results of estimation of spatial error models

\begin{tabular}{|c|c|}
\hline \multirow{2}{*}{ Variables } & Value of coefficients \\
\cline { 2 - 2 } & Model I \\
\hline Intercept & 4.2209 \\
\hline $\mathrm{X} 1$ & 3.1856 \\
\hline $\mathrm{X} 4$ & 0.6752 \\
\hline $\mathrm{X} 5$ & -0.3684 \\
\hline $\mathrm{X} 7$ & 0.1035 \\
\hline$\mu 12$ & 5.9436 \\
\hline$\mu$ & -1.5620 \\
\hline
\end{tabular}

According to all criteria of information, spatial error models are definitely better than linear models.

The modeling carried out shows that in the analysis of the factors of the size of expenditure on innovative activities in enterprises from the service sector from all investment sources, it is worth taking into account the assumption of the presence of certain spatial spatial relationships, significantly influencing the variability of the intensity of the $\mathrm{Y}$ variable. Omission of this relationship may lead to incorrect model specifications and wrong conclusions. 


\section{Conclusions}

The analysis of the factors influencing the amount of expenditure on innovative activities of enterprises from the service sector from all investment sources, carried out in this study, shows that it depends to the greatest extent on: the share of innovative enterprises in the service sector by the type of introduced innovations (new, or improved products); the expenditure on innovative activities of enterprises in the service sector on personnel training directly related to the introduction of product or process innovations; number of employed in $R \& D$; internal expenditure on R\&D; number of graduates studies at the master's level. These findings are particularly important in the context of current trends related to the concentration of knowledge and resources, the transfer of R\&D employees, and the development of new technologies resulting in an increase in the number of students in the technical faculty. Research has shown that the observed trends are also related to the location in geographical space. The voivodeships characterized by the highest level of expenditure on innovative activities in the analyzed years were: Masovian, Silesian, Pomeranian, Lower Silesian, Lodz and Lesser Poland. Most voivodships belong to the class with a low level of expenditure on innovative activities. The obtained results can be used in the spatial planning process to indicate the appropriate directions for the management of public funds for financing innovative activities.

During the study, the hypothesis about the legitimacy of introducing spatial relationships to the econometric linear model describing the shaping of the amount of investment outlays in industrial enterprises in Polish voivodships was verified. In the light of the obtained results, it was found that spatial effects occur for the data used in Model I (they do not occur in the other two models). This means that if the factors influencing the expenditure on innovative activities in enterprises from the service sector from all investment sources are analyzed, the estimation of regression model parameters using the least squares method changes the properties of the estimators, which may make the results inaccurate. According to the current state of knowledge, an adequate solution in such a situation is the use of spatial regression models. The spatial modeling carried out showed that the spatial error model (for Model 1) gives the highest precision and correctness of the results in the analysis of the amount of expenditure on innovative activities in enterprises from the service sector from all sources of investment. The good specification of the spatial model was confirmed by the values of the relevant statistics. The conducted research has shown that despite the insignificant value of the I Moran statistics, spatial modeling for the discussed issues is justified, although it should be emphasized that the analysis should be further deepened taking into account, for example, a different neighborhood matrix. 


\section{References}

1. Anselin, L. (2006). Spatial Analysis with GeoDa. 4. Spatial Regression. University of Illinois, Urbana-Champaign.

2. Anselin, L., and Rey, S.J. (1991). Properties of tests for spatial dependence in linearregression models. Geographical Analysis, No. 23, pp. 112-131.

3. Anselin, L., and Bera, A.K., and Florax, R., and Yoon, M.J. (1996). Simple diagnostic tests for spatial dependence. Regional science and urban economics, 26, pp. 77-104.

4. Cliff, A., and Ord, J.K. (1970). Spatial Autocorrelation: A Review of Existing and New Measures with Applications. Economic Geography, Vol. 46, pp. 269-292.

5. Cywiński, M. (2013). Próba identyfikacji spójnego systemu oceny działalności innowacyjnej przedsiębiorstw. Zarządzanie i Finanse, Vol. 1, Nr 4, pp. 19-39.

6. Czubała, A. (2015). Innowacje w sektorze usług w Polsce. Zeszyty Naukowe Małopolskiej Wyższej Szkoły Ekonomicznej w Tarnowie, 1(26), pp. 35-45.

7. GUS (2020). Działalność innowacyjna przedsiębiorstw w latach 2016-2018. Warszawa.

8. Guzik, B. (2008). Podstawy ekonometrii. Poznań: Wydawnictwo Akademii Ekonomicznej.

9. Kopczewska, K. (2011). Ekonometria i statystyka przestrzenna z wykorzystaniem programu $R$ Cran. Warszawa: CeDeWu.

10. Maskell, P., and Malmberg, A. (1999). Localized Learning and industrial Competitiveness. Cambridge Journal of Economics, Vol. 23, pp 167-185.

11. Moran, P.A.P. (1950). Notes on Continuous Stochastic Phenomena. Biometrika, 37(1), pp. 17-23.

12. Schumpeter, J.A. (1960). Teoria rozwoju gospodarczego. Warszawa: PWN.

13. Suchecki, B. (ed.) (2010). Ekonometria przestrzenna. Metody i modele analizy danych przestrzennych. Warszawa: C.H. Beck.

14. www1, https://bdl.stat.gov.pl/BDL/dane, 1.09.2020.

15. Zastempowski, M. (2010). Uwarunkowania budowy potencjatu innowacyjnego polskich małych i średnich przedsiębiorstw. Toruń: Wydawnictwo Naukowe Uniwersytetu Mikołaja Kopernika. 


\title{
IMPLEMENTATION OF THE GREEN GOVERNANCE CONCEPT AND GREEN MANAGEMENT PRACTICES IN CORPORATIONS OF EBRD REGIONS - SELECTED ISSUES
}

\author{
Katarzyna ŻAK \\ University of Economics, Katowice; katarzyna.zak@ue.katowice.pl, ORCID: 0000-0002-9212-7206
}

\begin{abstract}
Purpose: The purpose of the paper is to identify the level of involvement of the corporations of the EBRD regions in the implementation of the concept of sustainable development, and to evaluate the applied solutions in the field of green management.

Design/methodology/approach: The research methods used in the paper include the review of Polish and foreign literature, and the analysis of data from secondary sources. The desk research analysis was conducted on the basis of numerical information contained in the publication entitled "Transition Report 2019-20" and presented on the website of The European Bank for Reconstruction and Development (EBRD).
\end{abstract}

Findings: The result of the conducted research include the indication of the corporations in the countries of the EBRD regions that are leaders in the field of green governance and green management, and identification of factors and the extent to which they have an impact on the implementation of sustainable development postulates.

Research limitations/implications: The presented findings encourage further research to determine the causes of drastic differences in the field of green governance and green management in the studied corporations of the EBRD regions and the possibility of limiting them.

Practical implications: The analysis and evaluation of the implementation of the main practices of green management in the corporations of the EBRD regions allow to identify leaders in this area and apply the model of their operation (benchmarking) to improve the position of the organizations that show deficits.

Social implications: The use of the presented data, analyses and conclusions should imply further actions and strategies in enterprises necessary to implement the concept of sustainable development.

Originality/value: The paper synthetically presents the significance of the concept of green governance and the application of green management practices by corporations from the EBRD regions.

Keywords: green governance, green management, environment, sustainable development.

Category of the paper: General review. 


\section{Introduction}

Over the years, the issues of sustainable development of enterprises and corporate governance have been developing separately. The first referred to the expectations and postulates of stakeholders and emphasized the importance of social and environmental dimension of the company's operation. The other focused on shareholders' goals and was based on the paradigm of maximization of the value for shareholders and protection of the interests of investors. In recent years, however, the integration of these two approaches has been observed. It leads to the development and broadening of the perception of the role of enterprises in the economy and society, and integrates the financial, social, and environmental dimensions of its functioning. This resulted in a new approach to the concept of corporate governance and company management. Environmental issues are increasingly more emphasized in both of them.

It should be noted that the integration of the concept of sustainable development, corporate governance and corporate management has specific implications, which mainly include, (Kirkpatrick, 2009):

- Boards (supervisory boards, boards of directors) are expected to incorporate a wider perspective for evaluating company performance and incorporate both shareholder and stakeholder expectations.

- Companies are expected to provide both reporting to shareholders (interested mostly in the financial statements) and at the same time disclosing information of their social and environmental performance. Integrated reporting is supposed to deliver a bigger picture of the company activity and encourage companies to combine the incorporation of shareholder and stakeholder expectations.

- Executive compensation should be structured adequately to combine social, environmental, and financial performance measure to become an incentive for managers to have a more integrated approach to company purpose.

The purpose of the paper is to identify the level of involvement of the corporations of the EBRD regions in the implementation of the concept of sustainable development, and to evaluate the solutions applied in the field of green management.

The paper uses such research methods as the review of Polish and foreign literature and the analysis of data from secondary sources. The desk research analysis was conducted on the basis of the numerical information contained in the publication entitled "Transition Report 2019-20" and presented on the website of The European Bank for Reconstruction and Development (EBRD). 


\section{Environment as the major priority}

Brundtland Commission Report entitled "Our Common Future" that was published in the second half of the 1980s, is often seen as a turning point in the perception of the relationship between human activity and the natural environment. It was then that the term sustainable development appeared. More than 30 years have passed since then, and it seems that there has been a growing awareness of the fact that it is necessary to take both political, economic and social actions, maintaining the natural balance and durability of basic natural processes, in order to guarantee the possibility of satisfying basic needs of individual communities or citizens of both the present generation and future generations (Dz.U. [Journal of Laws], 2019).

The importance of this issue is also proved by the annually published data contained in "The Global Risk Report". Already in 2007, it was indicated that the most important global threats, in terms of the probability of their occurrence and impact, were primarily technological, societal, and economic in nature. As Table 1 shows, environmental threats have also been apparent for some time, but now they completely dominate the list. 2011 was the breakthrough year, when four global threats, i.e. storms and cyclones, flooding, biodiversity loss and climate changes were identified for the first time as the most important to the environment. On the other hand, in 2020, all the top five global threats in terms of the probability of their occurrence concerned the issues related to the environment. In addition, the report identifies three environmental issues among the top five threats that may have the greatest impact if not addressed. The lack of effects in terms of adverse climate changes is the most important of them, but the loss of biodiversity and the occurrence of extreme weather conditions are also mentioned (The Global Risk Report, 2020).

Table 1.

Review of the main global threats in selected years

\begin{tabular}{|c|c|c|c|}
\hline 2007 & 2011 & 2016 & 2020 \\
\hline \multicolumn{4}{|c|}{ Top 5 Global Risks in Terms of Likelihood } \\
\hline Infrastructure breakdown & Storms and cyclones & Involuntary migration & Extreme weather \\
\hline Chronic diseases & Flooding & Extreme Feather & Climate action failure \\
\hline Oil price shock & Corruption & Climate action failure & Natural disasters \\
\hline China hard landing & Biodiversity loss & Interstate conflict & Biodiversity loss \\
\hline Blow up in asset prices & Climate change & Natural catastrophes & $\begin{array}{l}\text { Human-made } \\
\text { environmental } \\
\text { disasters }\end{array}$ \\
\hline \multicolumn{4}{|c|}{ Top 5 Global Risks in Terms of Impact } \\
\hline Blow up in asset prices & Fiscal crises & Climate action failure & $\begin{array}{l}\text { Climate action } \\
\text { failure }\end{array}$ \\
\hline Deglobalization & Climate change & $\begin{array}{l}\text { Weapons of mass } \\
\text { destruction }\end{array}$ & $\begin{array}{l}\text { Weapons of mass } \\
\text { destruction }\end{array}$ \\
\hline Interstate and civil wars & Geopolitical conflict & Water crises & Biodiversity loss \\
\hline Pandemics & Asset price collapse & Involuntary migration & Extreme weather \\
\hline Oil price shock & Energy price volatility & Energy price shock & Water crises \\
\hline
\end{tabular}

Adapted from (The Global Risk Report, 2020). 


\section{From governance and management to green governance and green management}

In view of the presented threats, the need for an appropriate response from various environments, including the business community must occur. Thus, it seems that the concept of sustainable development is most topical and adequate. Many theoretical studies and a number of research works have already been performed on the subject. Generally speaking, the idea of balanced and sustainable development is based on the lasting coexistence of three elements: economy, society, and the environment. One of the definitions says that sustainable development is a process of social, economic and environmental changes that ensures a balance between profits and costs of development, in the perspective of future generations, i.e. it is "a reflection of the policy and strategy of continuous economic and social development with no harm to the environment and natural resources, the quality of which determines the continuation of human activity and further development" (Grudzewski et al., 2010). For an individual company, this means that the basic assumption of its development is the combination of traditional goals of activity, such as development, value growth and long-term profits, with conscious activities aimed at observing the basic economic, social, and environmental principles (Żak, 2015). It should be realised that it is not easy to reconcile such diverse and different priorities. Implementation of the concept of governance is a specific solution that allows to reconcile and balance the selfish goals of the business environment with the requirements of social and ecological circles.

Numerous publications define this concept in various ways, which results both from the adopted cognitive perspective and its context. D. Crowther and S. Seifi (2011) consider the concept of governance from the level of state, and define it as exercising political power and using institutional resources to manage the problems of the society and its affairs. Jones, Hesterly and Borgatti (1997) focus on informal regulatory systems, the so-called network governance. There are no formal rules within it - they are not legally binding. Instead, there are social obligations and governance within the network. In this sense, governance is perceived as a reflective process of self-organization of independent entities involved in complex relations of interdependence for the purpose of implementation of mutually beneficial ventures and proper management of conflicts arising during interactions (Crowther and Seifi, 2011).

The concept of corporate governance (CG) is used in the context of functioning of enterprises. In a general sense it is the system of corporate management and control (BogaczMiętka, 2011). It is worth noting here that in the literature on the subject there are numerous definitions of corporate governance that distinguish its narrow and broad approach. In the first meaning, corporate governance refers to the Anglo-Saxon system, in which its aim is to create solutions so that in the conditions of a dichotomous ownership and control system, the managers act in the interests of shareholders, i.e. the company owners (Shleifer and Vishny, 1997). In a broad approach to this notion, not only managers and owners are noticed, but also other parties interested in the functioning of the corporation, i.e. a wide range of stakeholders. 
Currently, more and more economists and other circles opt for adopting a broad definition of CG (Schwerk, 2008). In this approach, according to OECD (2015) corporate governance involves a set of relationships between a company's management, its board, its shareholders and other stakeholders. Corporate governance also provides the structure through which the objectives of the company are set, and the means of attaining those objectives and monitoring performance are determined. On the other hand, another EU document entitled "Green Paper" (2011) defines corporate governance as the system by which companies are directed and controlled and as a set of relationships between a company's management, its board, its shareholders and its other stakeholders. Li et al. (2016) emphasize that the modern understanding of this notion is characterized by the following features:

- Governance is based on coordination rather than control.

- Governance involves many stakeholders related to each other and representing private and public sectors among others, as well as business organizations.

- Governance emphasizes the balance of interests and goals, as well as participation in decision making.

- Governance is a continuous interaction and aims at maintaining the continuity of the relationships.

The concept of corporate governance is inseparably connected with the notion of corporate management. While corporate governance refers to the rules and procedures implemented to ensure that the company operates in accordance with law and for the optimal benefit of all stakeholders, corporate management refers to the techniques applied by the management to help the company operate and grow. The difference between governance and management is that management takes care of the day to day and is task-oriented. Governance, on the other hand, looks at the bigger picture and is strategy-oriented.

Giving high priority to environmental issues in human activity in a new approach to economy and business management often results in the occurrence of the notion of "green". Green is a symbol of life and the colour of nature that often represents the relationship between humanity and nature. Hence, such terms as green economy, green growth, green corporation, green management, green governance, or other related terms are more and more often used. In the literature on the subject, the concept of green governance is defined as sustainable development. Post et al. (2011) claimed that green governance is a long-term economic, social, and environmental sustainability. On the other hand one of the studies on green management defined this term as practices that produce environmentally-friendly products and minimize the impact on the environment through green production, green research and development, and green marketing $\|$ (Peng and Lin, 2008). On the other hand, Y. Loknath and B.A. Azeem (2017) show that green management is the organization-wide process of applying innovation to achieve sustainability, waste reduction, social responsibility, and a competitive advantage via continuous learning and development and by embracing environmental goals and strategies that are fully integrated with the goals and strategies of the organization. 


\section{Synthetic diagnosis of the application of selected firms' green management practices in the countries of the EBRD regions}

Assessing the implementation of green governance requires access to a number of documents describing the ability of corporations to deal with environmental issues. However, information on the application of such practices by enterprises is often available only for listed companies that declare the implementation of the CSR (corporate social responsibility) policy. Therefore, this gap may be partially filled with the latest data on 7,294 corporations from EBRD regions, i.e. the countries of Central Europe and the Baltic states (Croatia, Estonia, Hungary, Latvia, Lithuania, Poland, Slovak Rep., Slovenia), South - eastern Europe (Albania, Bosnia and Hercegovina, Bulgaria, Cyprus, Greece, Kosovo, Montenegro, North Macedonia, Romania, Serbia), Eastern Europe and the Caucasus (Armenia, Azerbaijan, Belarus, Georgia, Moldavia, Ukraine), Central Asia (Kazakhstan, Kyrgyz Rep., Mongolia, Tajikistan, Turkmenistan, Uzbekistan), Southern and eastern Mediterranean (Egypt, Jordan, Lebanon, Morocco, Tunisia, West Bank Gaza) as well as Russia and Turkey presented by EBRD, the EIB and the World Bank Group (Transition Report 2019-20, 2020).

The average overall rating of firms' green management in the EBRD countries in 2019 was 5.53, but it differed for individual EBRD regions. Central Asia had the lowest value (4.76). Southern and eastern Mediterranean as well as South-eastern Europe were also below the average with the values of 5.17 and 5.42, respectively. On the other hand, the Eastern Europe and the Caucasus region obtained a value identical to the average value for all EBRD countries, and only the Central Europe region and the Baltic states region achieved a value higher than the average, i.e. 6.62. The overall results of firm's green management in individual EBRD countries in 2019 are presented in Fig. 1.

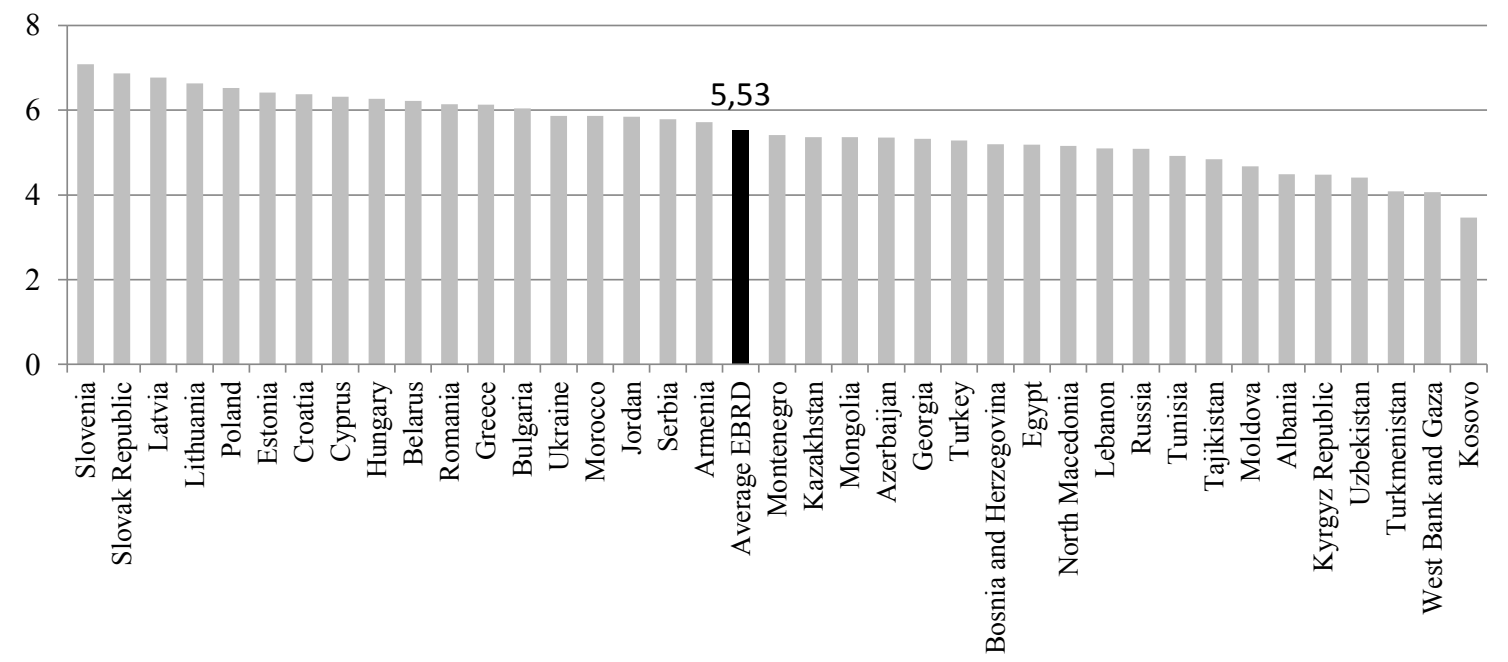

Figure 1. General results of the application of firm's green management in the EBRD countries in 2019. Adapted from (Transition Report 2019-20, 2020, p. 112). 
The intensity with which companies have been paying attention to environmental issues in recent years suggests that there is a clear relationship between the quality of firms' general management and the quality of green management. Meanwhile, the conducted research showed that the average value of the correlation coefficient between them is positive, but quite low and teaches only 0.23 . The leaders for which the correlation coefficient significantly exceeds the value of 0.23 are companies from the countries such as Latvia, Greece, Slovenia, North Macedonia, and Croatia. Corporations from such countries as: Tajikistan, Jordan, Kosovo, Lebanon, Georgia West Bank and Gaza and Turkey perform poorly in this respect (Transition Report 2019-20, 2020). Meanwhile, the conducted research showed that the average value of the correlation coefficient between them is admittedly positive, but quite low, and reaches only 0.23 . The leaders for which the correlation coefficient significantly exceeds the value of 0.23 are companies from such countries as Latvia, Greece, Slovenia, North Macedonia, and Croatia. Corporations from such countries as: Tajikistan, Jordan, Kosovo, Lebanon, Georgia West Bank and Gaza and Turkey rank poorly in this respect (Transition Report 2019-20, 2020).

A detailed analysis of the results of corporations from the above-mentioned regions comprises four main types of green enterprise management practices, i.e.:

- creation and implementation of strategies in the sphere of environment and climate change;

- clear definition of achievable environmental goals;

- hiring a manager with a clear mandate to deal with green issues;

- monitoring energy and water consumption as well as emissions of $\mathrm{CO}_{2}$ and other pollutants.

The obtained calculations confirm that there are clear differences between the EBRD regions not only in terms of overall results, but also within four main practices, i.e. (Transition Report 2019-20, 2020):

- From the point of view of creating and implementing strategies in the field of environment and climate change, companies from the Mediterranean basin, such as Portugal, Italy, Malta, and Spain, as well as from Central Europe and the Baltic countries perform the best - about $20 \%$ of them declare that they have such a strategy. Corporations from Turkey are at the opposite extreme, as only $7 \%$ of them take steps to build such a strategy.

- The situation is similar when it comes to defining achievable environmental goals. On average, around $18.3 \%$ of the surveyed enterprises in the EBRD regions had such goals. In this respect the companies in Central Europe and the Baltic States, as well as Portugal, Italy, Malta, and Spain perform the best. On the other hand, corporations from Turkey and the southern and eastern parts of the Mediterranean (Egypt, Jordan, Lebanon, Morocco) show large deficits in this field.

- Employing a manager responsible for environmental and climate change-related issues in the corporation is another important practice (Martin et al., 2012). On average, only $12.3 \%$ of the surveyed enterprises of the EBRD regions had an employee in such 
a position. Again, there are large discrepancies between corporations in different countries - from only $3 \%$ in Turkey to $28 \%$ in Slovenia. As a region, the countries of Western Europe (formerly EEC) as well as Central Europe and the Baltic states have the best achievements in this respect. In the latter, almost three-quarters of environmental managers in enterprises are directly subordinate to the firm's CEO, its board of directors or its owners, while in Russia only 18\%. Turkish corporations and the economies of the southern and eastern Mediterranean perform the worst in this area.

- In terms of monitoring energy and water consumption, as well as emission of $\mathrm{CO}_{2}$ and other pollutants, companies from Western Europe (France, Germany, Benelux countries, Denmark) are the clear leaders. And once again, Turkish corporations and the economies of the southern and eastern Mediterranean have to do a lot to catch up with others in this respect.

\section{The main drivers of the quality of firms' green management in the countries of EBRD regions}

Exercising effective and efficient governance over the implementation and execution of green corporate governance practices requires identifying the main determinants that shape them. Among many determinants, the most important include (Table 2): the size of the enterprise and the time of business operation on the market, the foreign entities' share in the ownership, the level of internationalization, listing on the stock exchange, customer pressure, own experience of companies related to the effects of extreme weather events or pollution, as well as regulations concerning environment protection, such as energy taxes or levies.

Table 2.

Determinants of the quality of firms' green management

\begin{tabular}{|l|c|c|}
\hline \multicolumn{1}{|c|}{ Drivers } & Correlation coefficient & Standard Error \\
\hline Customer pressure & 0.853 & 0.040 \\
\hline Energy tax/levy & 0.454 & 0.036 \\
\hline Monetary losses due to pollution caused by others & 0.335 & 0.110 \\
\hline 25\% or more foreign-owned & 0.219 & 0.044 \\
\hline Listed & 0.191 & 0.047 \\
\hline Monetary losses due to extreme weather & 0.167 & 0.049 \\
\hline Direct exporter & 0.139 & 0.031 \\
\hline Large old firm & 0.138 & 0.041 \\
\hline Large young firm & 0.074 & 0.113 \\
\hline Old SME & -0.095 & 0.041 \\
\hline
\end{tabular}

Note: Estimated using ordinary least squares. Old firms are at least five years old; large firms have at least 100 employees.

Adapted from (Transition Report 2019-20, 2020, p. 86). 
Comparing the data presented in Table 2, it should be noted that external factors of customer pressure and being subject to an energy tax or levy are the two most important factors influencing the results in the field of ecological management. Customer pressure is a factor that has a major impact on the quality of green management in the enterprise. About one in seven companies operating in the EBRD regions confirm that their customers require environmental certifications or compliance with certain environmental standards as a condition for doing business. In each region, results in the sphere of green management are usually much higher for companies that have experienced such customer pressure than for those that have not experienced it. The strength of this influence is evidenced by estimates showing that the improvement in green management that is associated with facing customer pressure is almost four times the size of that associated with foreign ownership.

Another important external factor is environmental regulations, which can be proxied by energy taxes or levies. Where energy is expensive, firms have an incentive to use less of it. The resulting positive impact on the environment is especially large where energy is generated using fossil fuels. The estimates in table 2 suggest that firms which are subject to an energy tax or levy have substantially better green management practices than firms which are not. That effect is about twice the size of the impact of being under foreign ownership or listed on a stock exchange.

$10.3 \%$ of 7,294 corporations from the above-mentioned EBRD regions declare that they have experienced cash losses due to extreme weather events in the past three years. This concerns Moldova, North Macedonia, and Romania, which faced severe floods in 2016, while Croatia, Poland, Romania and Slovenia experienced severe hailstorms. In many of the analysed countries there were also heat waves and droughts during the summer months, which became almost a permanent phenomenon. It is therefore no surprise that many companies have taken steps to improve their environmental management practices in response to their losses. Corporations from Turkey are an exception. The same is true of the $2.4 \%$ of firms that report having experienced monetary losses as a result of pollution not caused by their own activities.

In general, foreign ownership often improves firm-level productivity by transferring cutting-edge technology, management practices and knowledge to acquired firms and encouraging product and process innovation. Indeed, multinationals tend to use more advanced technology and production methods than their domestic counterparts, which can improve environmental outcomes. At the same time, however, firms in polluting industries may also relocate to "pollution havens" (countries with less stringent environmental regulations) in response to costly regulations in their home countries, increasing pollution levels both in their host countries and globally (Brucal et al., 2019; Cai et al., 2016). Conducted analyses show that in the EBRD regions, enterprises in which foreign investors have a share of $25 \%$ or more, have, on average, higher ecological management results compared to enterprises in which the share is lower. 
Foreign ownership is not the only way in which firms can learn about state-of-the-art green management practices. They can also do so by competing in international markets - firms which export tend to have better green management than firms which do not.

Another factor stimulating green management is the question of whether the company is listed on the stock exchange. Public companies are usually subject to greater control and greater pressure from investors or stakeholders to inform about the issues related to environmental protection activities. It is worth mentioning here that in 2009, the Warsaw Stock Exchange launched the RESPECT index, which was replaced by the WIG-ESG index in 2019. It enables the selection of entities with the highest standards in environment, social and governance areas.

Regardless of the EBRD region, there is a relationship between the quality of green management in a company, its size, and the period of operation on the market. Large companies operating on market for a long time have, on average, better results in environmental management than those with shorter experience and belonging to the sector of small and medium-sized enterprises (SMEs). Meanwhile, the average green management scores of old SMEs are worse than those of young SMEs, and the average green management scores of large young firms are not significantly different from those of young SMEs.

\section{Conclusions}

Managers of enterprises and members of supervisory boards are increasingly more aware of the fact that in order to succeed in conditions of today's global competition, it is not enough to be economically competitive, but it is necessary to become more and more active in the areas that have not been of interest to most societies until recently. Identified requirements of the environment make corporations engage not only in strictly business ventures focused on economic goals, but also actively implement social and environmental projects. Thus, they implement the idea of sustainable development at the enterprise level and become a socially responsible organizations.

The presented data and analyses for the countries of the EBRD regions show that the level of corporate involvement in the concept of sustainable development and environmental issues is remarkably diverse and results from the impact of various stimuli. There are main conclusions:

- The quality of firms' green management, in the countries of the EBRD regions, is positively correlated with the average quality of general management practices (that is to say, firms' general approach to operations, monitoring, targets and incentives). This positive correlation is, however, relatively modest, with a coefficient of 0.23 . 
- The leaders for which the correlation coefficient significantly exceeds the value of 0.23 are companies from the countries such as Latvia, Greece, Slovenia, North Macedonia, and Croatia. Corporations from such countries as: Tajikistan, Jordan, Kosovo, Lebanon, Georgia West Bank and Gaza and Turkey perform poorly in this respect.

- There are several the main determinants that shape of the quality of firms' green management, that is customer pressure, energy tax/levy, monetary losses due to pollution caused by others and monetary losses due to extreme weather. Also foreignowned and listed firms have better green management practices, as do exporters.

- From the point of view of creating and implementing strategies in the field of environment and climate change, companies from the Mediterranean basin, as well as from Central Europe and the Baltic countries perform the best. Corporations from Turkey are at the opposite extreme.

- On average, around $18.3 \%$ of the surveyed enterprises in the EBRD regions had defining environmental goals. In this respect the companies in Central Europe and the Baltic States, as well as Portugal, Italy, Malta, and Spain perform the best. On the other hand, corporations from Turkey, Egypt, Jordan, Lebanon and Morocco show large deficits in this field.

- On average, only $12.3 \%$ of the surveyed enterprises of the EBRD regions had a manager responsible for environmental and climate change-change-related issues. As a region, the countries of Western Europe (formerly EEC) as well as Central Europe and the Baltic states have the best achievements in this respect. Turkish corporations and the economies of the southern and eastern Mediterranean perform the worst in this area.

- In terms of monitoring energy and water consumption, as well as emission of $\mathrm{CO}_{2}$ and other pollutants, companies from Western Europe (France, Germany, Benelux countries, Denmark) are the clear leaders. And once again, Turkish corporations and the economies of the southern and eastern Mediterranean have to do a lot to catch up with others in this respect.

Thus, on the one hand, it is possible to indicate organizations for which the principles of green corporate governance and the practical application of green management solutions are a priority and serve building a positive image and achieving a better competitive position. These corporations mainly come from Central Europe and the Baltic states and usually aspire to the operating standards set by companies from Western Europe. On the other hand, there are corporations with poor results that come from Central Asia (many of which are former USSR republics) and Southern and eastern Mediterranean, in which the concept of sustainable development and environmental issues are not a priority in business culture. 
Finally, it is worth adding that there are many critical opinions towards the new perception of the company. The postulate of taking into account the needs and expectations of various stakeholder groups in the company's operations caused a split among theoreticians and practitioners of management. This is because the question is asked whether creating value for shareholders is still the fundamental goal of the company's operation, or it should rather meet the needs of other interest groups. And if the second option is chosen, where is the limit of the company's responsibility? (Marcinkowska, 2006). While reflecting on the stakeholder approach, K. Kim at el. (2010), formulate another question: how to properly operationalize the company's activity in the new perspectives (social and environmental)? Distracting managers' attention to additional goals that are difficult to measure, often makes them ineffective when trying to serve many "masters" (Kim at el., 2010).

\section{References}

1. Bogacz-Miętka, O. (2011). Kompendium wiedzy o nadzorze $i$ kontroli nad przedsiębiorstwem [Compendium of knowledge about governance and control over a company], Warszawa: CeDeWu, p. 27.

2. Brucal, A., Javorcik, B., Love, I. (2019). Good for the environment, good for business: Foreign acquisitions and energy intensity. Journal of International Economics, vol. 121.

3. Cai, X., Lu, Y., Wu, M., Yu, L. (2016). Does environmental regulation drive away inbound foreign direct investment? Evidence from a quasi-natural experiment in China. Journal of Development Economics, Vol. 123, pp. 73-85.

4. Crowther, D., Seifi, S. (2011). Corporate Governance and International Business. Ventus Publishing Aps., pp. 10-11.

5. Green Paper (2011). The EU corporate governance framework. Brussels, 5.4.2011COM(2011) 164 final. p. 2.

6. Grudzewski, W.M., Hejduk, I.K., Sankowska, A., Wańtuchowicz, M. (2010). Sustainability $w$ biznesie, czyli przedsiębiorstwo przyszłości. Zmiany paradygmatów $i$ koncepcji zarzadzania [Sustainability in business, i.e. a company of the future. Change in paradigms and concepts of management]. Warszawa: Poltex, p. 271 and following.

7. Jones, C., Hesterly, W.S., Borgatti, S.P., General, A. (1997). Theory of Network Governance: Exchange Conditions and Social Mechanism. Academy of Management Review, no. 22, pp. 911-945.

8. Kim, K., Nofsinger, J., Mohr, D. (2010). Corporate Governance. New Jersey: Pearson Hall, p. 173.

9. Kirkpatrick, G. (2009). The Corporate Governance Lessons from the Financial Crisis, OECD, http://www.oecd.org/finance/financial-markets/42229620.pdf, 12.08.2020. 
10. Li, W.A., Li, Y.J., Shi, D. (2016). Theoretical research on supply chain governance: Concept, intention, and normative analysis framework. Nankai Business Review, No. 19, pp. 4-15.

11. Loknath, Y., Azeem, B.A. (2017). Green Management-Concept and Strategies. National Conference on Marketing and Sustainable Development, October 13-14, pp. 692-693.

12. Marcinkowska, M. (2006). Władztwo korporacyjne w kontekście społecznej odpowiedzialności przedsiębiorstwa [Corporate governance in the context of corporate social responsibility]. In: S. Rudolf (ed.), Tendencje zmian $w$ nadzorze korporacyjnym [Trends of changes in corporate governance (pp. 409-428). Łódź: Wydawnictwo UŁ.

13. Martin, R., Muüls, M., de Preux, L., Wagner, U. (2012). Anatomy of a paradox: Management practices, organizational structure and energy efficiency. Journal of Environmental Economics and Management, Vol. 63, pp. 208-223.

14. OECD (2015). G20/OECD Principles of Corporate Governance. Paris: OECD Publishing, p. 9, http://dx.doi.org/10.1787/9789264236882-en, 02.08.2020.

15. Peng, Y., Lin, S. (2008). Local Responsiveness Pressure, Subsidiary Resources, Green Management Adoption, and Subsidiaries‘ Performance: Evidence from Taiwanese Manufacturers. Journal of Business Ethics, 79(1/2), pp. 199-212.

16. Post, C., Rahman, N., Rubow, E. (2011). Green governance: Boards of directors' composition and environmental corporate social responsibility. Business and Society, 50(10), pp. 189-223.

17. Schwerk, A. (2008). Strategisches gesellschaftliches Engagementund gute Corporate Governance. In: H. Backhaus-Maul, Ch. Biedermann, S. Näahrlich, J. Polterauer (eds.), Corporate Citizenship in Deutschland, Bilanz und Perspektiven (pp. 121-145). Wiesbaden: VS Verlag für Sozialwissenschaften, GWV Fachverlage GmbH.

18. Shleifer, A., Vishny, R.W. (1997). A Survey of Corporate Governance. Journal of Finance, vol. 52, no. 2, pp. 737-783.

19. The Act of April 27, 2001, Environmental Protection Law (Dz.U. [Journal of Laws] of 2019, item 1396).

20. The Global Risk Report 2020. Geneva: World Economic Forum.

21. Transition Report 2019-20 (2020). Better Governance, Better Economies. London: European Bank for Reconstruction and Development, 18.08.2020.

22. Żak, K. (2015). Green economy - w drodze do nowego globalnego standardu biznesowego [Green economy - on the way to new, global business standard]. Studia Ekonomiczne, Zeszyty Naukowe Uniwersytetu Ekonomicznego w Katowicach, nr 226, p. 172. 



\section{REVIEWERS}

PhD Michaline GREBSKI, Northampton Community College, USA

Prof. Wiesław GREBSKI, The Pennsylvania State University, USA

Prof. Izabela JONEK-KOWALSKA, Silesia University of Technology, Poland

Prof. Anita KOLNHOFER-DERECSKEI, Obuda University Keleti Faculty of Business and Management, Hungary

Prof. Aleksander LOTKO, Kazimierz Pułaski University of Technology and Humanities in Radom, Poland

Prof. Andrzej PACANA, Rzeszów Technical University, Poland

Prof. Cecilia SZIGETI, Szechenyi University, Hungary

Prof. Radosław WOLNIAK, Silesian University of Technology, Poland 